United Nations University Press is the publishing arm of the United Nations University. UNU Press publishes scholarly and policy-oriented books and periodicals on the issues facing the United Nations and its peoples and member states, with particular emphasis upon international, regional and transboundary policies.

The United Nations University was established as a subsidiary organ of the United Nations by General Assembly resolution 2951 (XXVII) of 11 December 1972. It functions as an international community of scholars engaged in research, postgraduate training and the dissemination of knowledge to address the pressing global problems of human survival, development and welfare that are the concern of the United Nations and its agencies. Its activities are devoted to advancing knowledge for human security and development and are focused on issues of peace and governance and environment and sustainable development. The University operates through a worldwide network of research and training centres and programmes, and its planning and coordinating centre in Tokyo. 
Sexed pistols 



\section{Sexed pistols: The gendered impacts of small arms and light weapons}

Edited by Vanessa Farr, Henri Myrttinen and Albrecht Schnabel

United Nations
University Press

TOKYO • NEW YORK • PARIS 
(C) United Nations University, 2009

The views expressed in this publication are those of the authors and do not necessarily reflect the views of the United Nations University.

United Nations University Press

United Nations University, 53-70, Jingumae 5-chome,

Shibuya-ku, Tokyo 150-8925, Japan

Tel: +81-3-5467-1212 Fax: +81-3-3406-7345

E-mail: sales@unu.edu general enquiries: press@unu.edu

http://www.unu.edu

United Nations University Office at the United Nations, New York

2 United Nations Plaza, Room DC2-2060, New York, NY 10017, USA

Tel: +1-212-963-6387 Fax: +1-212-371-9454

E-mail: unuony@unu.edu

United Nations University Press is the publishing division of the United Nations University.

Cover design by Maria Sese-Paul

Printed in Hong Kong

ISBN 978-92-808-1175-9

Library of Congress Cataloging-in-Publication Data

Sexed pistols : the gendered impacts of small arms and light weapons / edited by Vanessa Farr, Henri Myrttinen and Albrecht Schnabel.

p. $\mathrm{cm}$.

Includes bibliographical references and index.

ISBN 978-9280811759 (pbk.)

1. Firearms - Social aspects. 2. Firearms ownership-Social aspects.

3. Women-Violence against. 4. Violence. 5. Gun control. I. Farr, Vanessa.

II. Myrttinen, Henri. III. Schnabel, Albrecht.

HV7435.S49 2009

$306.4^{\prime} 6-\mathrm{dc} 22$

2009030999 


\section{Contents}

Tables and figures $\ldots \ldots \ldots \ldots \ldots \ldots \ldots \ldots \ldots \ldots \ldots \ldots \ldots \ldots \ldots \ldots \ldots \ldots \ldots \ldots \ldots$

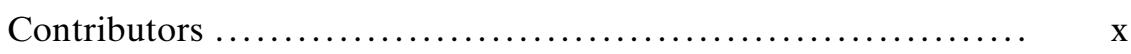

Acknowledgements $\ldots \ldots \ldots \ldots \ldots \ldots \ldots \ldots \ldots \ldots \ldots \ldots \ldots \ldots \ldots \ldots \ldots \ldots \ldots \ldots \ldots \ldots$

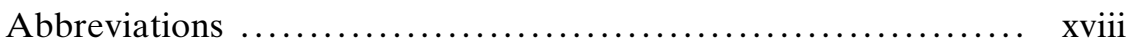

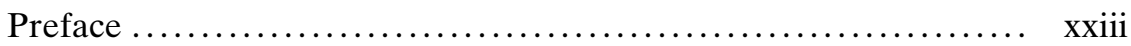

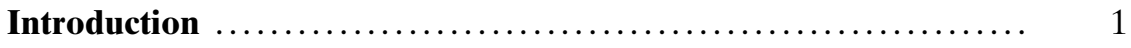

1 Sexing the pistol: The gendered impacts of prolific small arms 3 Vanessa Farr, Henri Myrttinen and Albrecht Schnabel

2 Gender, attitudes and the regulation of small arms:

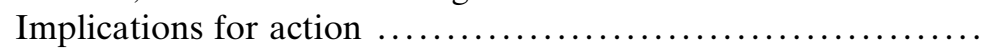
Wendy Cukier and James Cairns

Part I: Sexualized violence, gender and small arms ........... 49

3 Girls and small arms in Sierra Leone: Victimization,

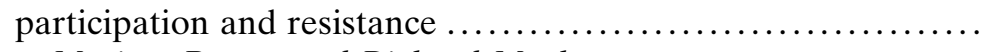
Myriam Denov and Richard Maclure 
4 Small arms and rape as a system of war: A case study of the Democratic Republic of the Congo ........................ Felicity Szesnat

\section{Part II: Gender, small arms and violence in fragmented societies}

5 Haiti: The gendered pattern of small-arms violence against women

Nadine Puechguirbal, Wiza Loutis and Natalie Man

6 State, society and the gender of gun culture in Papua New Guinea ...............................................

7 "Now they have guns, now they feel powerful" - Gender perspectives on small-arms violence in Timor-Leste Saleh Abdullah and Henri Myrttinen

Part III: Militarizing the domestic sphere

8 "That's equality for you, dear": Gender, small arms and the Northern Ireland conflict Miranda Alison

9 The gun on the kitchen table: The sexist subtext of private policing in Israel Rela Mazali

10 Securing private spaces: Gendered labour, violence and democratization in South Africa Jennifer N. Fish and Pumla Mncayi

Part IV: Gender, weapons collection and small-arms control ......

11 Just a matter of practicality: Mapping the role of women in weapons for development projects in Albania, Cambodia

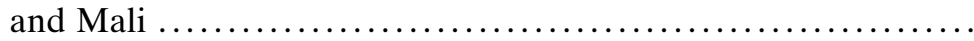

Shukuko Koyama

12 Poems against bullets? The role of Somali women in social gun control 
13 Missing men, lost boys and widowed women: Gender perspectives on small-arms proliferation and disarmament in Karamoja, Uganda ..................................... Christina M. Yeung

Conclusion

14 Conclusions: Recommendations for further research and activism 421 Vanessa Farr, Henri Myrttinen and Albrecht Schnabel

Selected recommended reading $\ldots \ldots \ldots \ldots \ldots \ldots \ldots \ldots \ldots \ldots \ldots, 433$

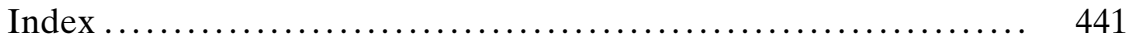




\section{Tables and figures}

\section{Tables}

2.1 Female homicide rates for 25 populous high-income countries, 1994-1999 .............................. 23

5.1 Armed groups and the situation of women ............... 114

6.1 Thefts of military-issue weapons and associated crime ...... 151

7.1 Estimated numbers of SALW supplied to or procured by the Timor-Leste security forces ..................... 182

8.1 Paramilitary weapons estimates (late 1990s) ............. 217

11.1 Roles of women and men in weapons for development projects in Albania ............................... 336

11.2 Roles of women and men in weapons for development projects in Cambodia .............................. $\quad 340$

11.3 Roles of women and men in weapons for development projects in Mali ................................ 343

11.4 Differences between conventional monitoring and evaluation and PM\&E ............................ 351

12.1 Somali views on control of firearms .................. 368

12.2 Perceptions on levels of family violence................ 378

12.3 Security aspects of gun ownership .................... 379

12.4 Age of Somalis with combat experience ............... 380

\section{Figures}

2.1 Annual incidence of weapon injuries during conflict and in post-conflict periods $\ldots \ldots \ldots \ldots \ldots \ldots \ldots \ldots \ldots \ldots \ldots \ldots \ldots, 20$ 
2.2 Rate of homicide of female victims of intimate-partner

homicide by means in Canada ........................ 26

6.1 International comparison of sexual assaults, $1991 \ldots \ldots \ldots \ldots \quad 154$

8.1 Shooting and bombing incidents, 1998/1999 to 2007/2008 _.. 223

10.1 GAP survey on domestic violence in Mannenberg

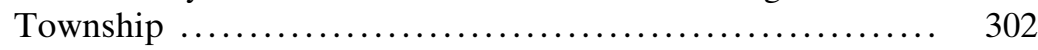




\section{Contributors}

Saleh Abdullah is the executive secretary of the Indonesian Society for Social Transformation, based in Yogyakarta, Indonesia. He has been working extensively on human rights, gender and conflict resolution issues with civil society organizations across Indonesia, including in Aceh, Maluku and Papua as well as in Timor-Leste, for over two decades. He holds a master of philosophy degree from the Indonesian State Institute of Islamic Studies, Jakarta.

Miranda Alison is associate professor of politics and international studies at the University of Warwick, UK. Her main research interests lie in the broad field of gender and war, with a specific focus on ethnonational conflict and political violence, including wartime sexual violence and other gender-based human rights violations. She has fieldwork research experience in Sri Lanka and Northern Ireland. She has published several articles on female combatants and wartime sexual violence, and has written a book entitled Women and Political Violence (Routledge, 2009). She received a $\mathrm{PhD}$ from Queen's University Belfast and an MA Hons from the University of Auckland, New Zealand.

James Cairns is an instructor in the Department of Politics and Public Administration and the Department of Sociology at Ryerson University, Toronto, Canada. He teaches courses on political institutions, consumer culture, media history and methods of social scientific enquiry. Dr Cairns holds a PhD from the Ryerson/York Joint Graduate Programme in Communication and Culture, Toronto (2008). His PhD dissertation, supported by a Canada Graduate Scholarship from the Social Sciences and Humanities Research Council of Canada, analyses the twentieth-century 
evolution of mediated civic ritual. The study maps the rise to dominance of the symbolic performance of rationality in the political sphere. Dr Cairns's argument about the power of interdisciplinary research to shed light on social knowledge about politics has been published in Canadian Parliamentary Review, and his study of transformations in political print advertising will appear in a forthcoming University of Toronto Press anthology on media history. His current research includes a collaborative study of stakeholder discourse on firearms regulation in Canada, and a mediahistory approach to the quickening pace of political time.

Wendy Cukier is a professor at Ryerson University, associate dean of the Ted Rogers School of Management and founder of the Diversity Institute. She has written more than 200 articles on gender, technology and public policy, and worked as a consultant to government and industry. Her last book - The Global Gun Epidemic applies a public health lens to gun violence. She was co-founder of Canada's Coalition for Gun Control and a founding member of the International Action Network on Small Arms (IANSA). She has received many honours for her work, including two honorary doctorates and the Governor General's Meritorious Services Cross, one of Canada's highest civilian honours. Dr Cukier was a YWCA "Woman of Distinction" and has received awards from the Canadian Criminal Justice Association and the Canadian
Public Health Association. She has an MA in history and an MBA from the University of Toronto, and was named one of its "100 alumni who shaped the century". She holds a $\mathrm{PhD}$ in management science from York University. In 2007 she received both Ryerson University's Sarwan Sahota Distinguished Researcher Award and the Stafford Beer Medal for Operations Research.

Myriam Denov is an associate professor in the School of Social Work at McGill University. She holds a PhD from the University of Cambridge, where she was a Commonwealth Scholar. Her research and teaching interests lie in the area of children and youth at risk, with an emphasis on waraffected children. She has published widely in the realms of children and armed conflict, children's rights and gender-based violence and has worked with vulnerable populations internationally, including former child soldiers, victims of sexual violence and people living with HIV/AIDS. She has presented expert evidence on child soldiers and has served as an adviser to government and NGOs on children and armed conflict, and girls in fighting forces. Her upcoming book, The Making and Unmaking of Child Soldiers in Sierra Leone, will be published by Cambridge University Press.

Sinclair Dinnen is a senior fellow with the State Society and Governance and Melanesia Program at the Australian National University. He lectured previously at the University of Papua New Guinea and was a 
senior research fellow at the Papua

New Guinea National Research Institute. His most recent book (edited with Stewart Firth) is Politics and State Building in Solomon Islands (Asia-Pacific Press and ANU E Press, 2008).

Vanessa Farr is a graduate of the Women's Studies Programme at York University, Toronto, where she received her $\mathrm{PhD}$ in 2002. She is currently working for the UNDP as senior social development and gender adviser in the occupied Palestinian Territory. She focuses on how gender impacts on individual experiences of crisis - both natural disasters and violent conflict - and is assisting the UNDP in making its actions in crisis situations more responsive to the different needs of women and men. She has published widely on women, peace and security, including on the demobilization, disarmament and reintegration (DDR) of women and men combatants after war, the impact on women and men of prolific small arms and light weapons (SALW), the gendered implications of security sector reform and women's coalitionbuilding in conflict-torn societies.

Jennifer N. Fish is head of the Department of Women's Studies at Old Dominion University, where she also teaches in the Graduate Program in International Studies and leads annual global studies courses in South Africa. Her research interests centre on postconflict development, with particular emphasis on women's roles in restructuring society. For the past 15 years she has worked on South
Africa's transition from apartheid to democracy through appointments with Nelson Mandela Metropolitan University, the University of Cape Town and the University of the Western Cape, and consultancies with the South African Domestic Service and Allied Workers Union and the Commission for Gender Equality. She is also engaged with research on post-genocide reconciliation in Rwanda through the Rwanda Association of University Women and the National University of Rwanda. Her books include Domestic Democracy: At Home in South Africa (Routledge, 2006) and the co-edited collection Women's Activism in South Africa: Working Across Divides (University of KwaZulu-Natal, 2008). She earned her $\mathrm{PhD}$ in sociology from the American University in Washington, DC, with an emphasis on international studies.

Zeinab Mohamed Hassan is the women's rights coordinator of Action Aid in Hargeisa. Before the war in Somalia she worked as a teacher in primary and secondary schools, and held various posts within the Ministry of Education, including Bay regional coordinator for women's education, director of income-generating programmes in the Women's Education Institute and supervisor of women's incomegenerating programmes in the Institute of Adult Education, Mogadishu. After 1992 she worked as the programme coordinator for the Somaliland Women's Development Association (SOWDA) in Hargeisa, for the Life and Peace Institute and later for GTZ as a gender and health project 
officer. She has written materials on adult education techniques, handsewing, childcare and nutrition and female genital mutilation.

Katrin Kinzelbach is a research fellow at the Ludwig Boltzmann Institute of Human Rights in Vienna, Austria. From 2001 to 2007 she worked for the UN Development Programme (UNDP), where she held various positions focusing on peace and security issues. Before joining the UNDP she worked as an election monitor for the Organization for Security and Co-operation in Europe (OSCE) and as a junior consultant for the UN High Commissioner for Refugees (UNHCR). Katrin Kinzelbach holds an MA in peace and security studies (King's College, London) and a magister/laurea jointly awarded by the Universities of Florence and Bonn. She is a $\mathrm{PhD}$ candidate in political science at the University of Vienna.

Shukuko Koyama joined the ILO in May 2007, working on socioeconomic reintegration of excombatants and economic recovery in crisis-affected communities. From 2002 to 2005 she worked as a project officer at the UN Institute for Disarmament Research (UNIDIR) in Geneva. Prior to coming to Geneva she was a disarmament, demobilization and reintegration (DDR) officer with the UN Mission in the Democratic Republic of the Congo. Her main areas of expertise include socioeconomic reintegration of excombatants, DDR, post-conflict private sector development, weapons collection, participatory monitoring and evaluation, and gender analysis. Shukuko has an MA in conflict resolution from the University of Bradford, and is also a $\mathrm{PhD}$ candidate there. Her doctoral thesis is on security sector reform in the Republic of Georgia.

Wiza Loutis is an assistant professor at the Department of Criminology at the National University in Port-auPrince, Haiti, and has worked as a consultant for the UNDP and MINUSTAH.

Richard Maclure is a professor and former acting dean in the Faculty of Education at the University of Ottawa, where he teaches in the field of comparative and international education. He holds a $\mathrm{PhD}$ in international development education from Stanford University, and has worked as a teacher in Nigeria, a field director for Plan International in Burkina Faso and a programme officer with the International Development Research Centre (IDRC). He has also worked as a consultant with organizations such as CIDA, UNICEF, USAID and the WHO. His research focuses on basic education, civil society organizations and youth rights issues in subSaharan Africa and Latin America. His scholarly publications have appeared in journals such as Comparative Education, Journal of Latin American Studies, Third World Quarterly and Journal of Youth Studies.

Natalie Man currently works as a gender affairs officer with the UN MINUSTAH mission in Haiti. 
Rela Mazali, an author, independent researcher and feminist peace activist from Israel, writes and publishes in both Hebrew and English. She is one of the founders of the New Profile movement to demilitarize Israeli civil society, and has been active since 1980 in efforts to end Israel's occupation of Palestinian territories. A recent article, "Ethnically Constructed Guns and Feminist Anti-Militarism in Israel" (published in Interventions: International Journal of Postcolonial Studies), analyses the role of arms in the construct of Jewish identity prevalent in Israel today. Reviews described Maps of Women's Goings \& Stayings (Stanford University Press, 2001), Mazali's interrogation of women's spatial existence, as one of the best among recent "narratives in space and time, by women about women for women", a "daring departure from the conventions of being, telling, writing, and knowing" and taking "creative leaps in format and content". One of eight women from Israel nominated for the 2005 Nobel Peace Prize by the Swiss-based One-thousand Peacewomen project, Rela also served on the Jury of Conscience at the concluding session of the World Tribunal on Iraq (2005).

Pumla Mncayi is the executive director of the Gender Advocacy Programme (GAP) of South Africa. She has 30 years' experience in the struggle to realize social justice and gender equality in South Africa. After earning her university diploma from Fort Hare University in 1978, she worked in the social service sector with refugees in South
Africa's rural Eastern Cape. In 1989 she became the first black social service supervisor in Cape Town, where she has since led three nongovernmental organizations: Masikhule Children's Home, the Black Sash and GAP. Throughout her work as an activist and NGO leader, a commitment to gender justice, peaceful reconciliation and racial equality remains a central component of her leadership.

Henri Myrttinen is currently a $\mathrm{PhD}$ candidate at the University of KwaZulu-Natal, South Africa, writing his thesis on the intersections between violent conflict and masculinities in TimorLeste. He has worked extensively in Indonesia and Timor-Leste, mostly with various civil society organizations and focusing on issues of gender in post-conflict and postdisaster recovery.

Nadine Puechguirbal has worked as the senior gender adviser for the MINUSTAH mission in Haiti and is also a senior fellow at the University for Peace in Costa Rica.

Albrecht Schnabel is a senior fellow in the Research Division of the Geneva Centre for the Democratic Control of Armed Forces (DCAF). He previously held teaching and research appointments at the Swiss Peace Foundation (swisspeace), the University of Bern, the United Nations University, Aoyama Gakuin University, Central European University and the American University in Bulgaria. He was educated at the University of Munich, the University of Nevada and Queen's University, Canada, where he received his $\mathrm{PhD}$ in 
political studies in 1995 . His

research and publications have focused on ethnic conflict, refugees, human security, security sector reform, conflict prevention and management, peacekeeping and post-conflict peacebuilding. He currently works on the operationalization of human security and engaging armed non-state actors in security sector reform.

Felicity Szesnat is an international human rights lawyer and $\mathrm{PhD}$ candidate at the University of Essex, where her research focuses on the laws of armed conflict; she also lectures in this field. She is currently a senior research officer in the Human Rights Centre at the university, where she is examining the international legal accountability and regulation of private security companies. She has extensive experience working on human rights issues in South Africa (in the antiapartheid movement), Fiji (especially after the 2000 coup d'état) and the UK. Felicity is a member of the research panel for the Matrix Chambers, based in London.

Edwina Thompson has extensive experience in researching situations of armed conflict. Her PhD examined the interplay of state failure, development and human security, and was based on fieldwork conducted in Afghanistan and Pakistan. Her early research investigated the effects of gun violence in Papua New Guinea. She is currently an adviser in the emergency humanitarian aid sector.

Christina M. Yeung has been active in research and advocacy on smallarms issues in East Africa for many years. Previously she worked for the Bonn International Center for Conversion (BICC) in the Horn of Africa. Currently she is a strategic analyst with Defence Research and Development Canada and a fellow of the Walter and Duncan Gordon Foundation. She holds a PhD in international politics from the University of Wales, Aberystwyth. 


\section{Acknowledgements}

This book grew out of a project conceived in 2002 as a research activity of the Peace and Governance Programme of the United Nations University. Albrecht, who worked at the UNU at the time, and Vanessa, who worked at BICC, proposed the project to the UNU and, after approval and successful internal and external fundraising efforts, assembled an international team of gender and small-arms experts. In 2003 Albrecht moved to swisspeace in Bern, while Vanessa began working for the UNIDIR in Geneva. They finalized the project team, which met for the first time in February 2004 in Stellenbosch, South Africa. Preliminary results of the project were presented in a swisspeace working paper entitled "Gender Awareness in Research on Small Arms and Light Weapons", edited by Vanessa, Albrecht and Emily Schroeder, and at a special project panel at the International Studies Association annual meeting in Honolulu in March 2005.

We thank all those who helped us organize our author workshop in Stellenbosch, South Africa. At the outset of the book project, this gathering allowed us to grow together as a team. Many of the contributors in this book were present, along with several other colleagues who offered valuable feedback at that stage of the project. We also thank all participants and speakers at the subsequent public policy symposium, which was entitled "Armed Violence, Weapons Availability, and GenderAware Possibilities for Action" and organized in collaboration with the Center for Humanitarian Dialogue (Geneva) and the Centre for Conflict 
Resolution (Cape Town). Those two meetings were tremendously helpful in reshaping and fine-tuning many of our initial ideas and thoughts.

We gratefully acknowledge financial support from the United Nations University and the Asian Women's Fund, without which this project would not have been possible. We thank Yoshie Sawada at UNU's Peace and Governance Programme for superbly and patiently managing the administrative part of the project.

Vanessa thanks the Government of Norway and Albrecht thanks swisspeace and the Geneva Centre for the Democratic Control of Armed Forces (DCAF) for support during their work on this project. Thanks go to Myriam Bertsch for her help in editing the first full version of the manuscript and Danail Hristov for assistance in preparing the final version.

We are grateful to UNU Press for its encouragement and support, particularly its chief editor, Robert Davis. We thank Cherry Ekins for an outstanding copyediting and proofreading job and Clive Pyne for producing an excellent index. Finally, we are grateful for the very helpful and constructive comments of three anonymous peer reviewers, whose ideas have helped us polish the final version of the manuscript.

Special thanks go to Emily Alexander for her help in recording the results from the Stellenbosch meetings and preparing the working paper, to Cate Buchanan for her constant inspiration and encouragement, and to Cynthia Enloe for contributing such a thoughtful preface.

We hope that the book and its stories will inspire many readers - academics, practitioners and members of the interested and affected public alike - to pay more attention to the gendered implications of small-arms availability and (mis)use.

Together, we can end the scourge of violence that results from such easily available weapons.

Vanessa Farr

Henri Myrttinen

Albrecht Schnabel

Jerusalem, Jakarta, Geneva

February 2009 


\title{
Abbreviations
}

\author{
AAP American Academy of Pediatrics \\ ABRI Angkatan Bersenjata Republik Indonesia \\ AC75 Association of Ex-Combatants 1975 (East Timor) \\ ADF Angolan Defence Force \\ ADFL Alliance des Forces Démocratiques pour la Libération du Congo \\ AI Amnesty International \\ AIDS acquired immune deficiency syndrome \\ AK-47 Avtomat Kalashnikova 1947 (Soviet-made assault rifle) \\ ANC \\ African National Congress (South Africa) \\ APC Armée du Peuple Congolaise \\ APD Academy for Peace and Development (Somalia) \\ ASLLEA Assistance Scheme for Law Enforcement and Legal Agencies \\ ASTU \\ Brimob \\ Anti-Stock Theft Unit (Uganda) \\ CADET \\ Brigade Mobil (Indonesian paramilitary police) \\ CAR-Nord \\ Canadian Assistance to Demobilization in East Timor \\ CAVR Comissão de Acolhimento, Verdade e Reconciliação do Timor- \\ Leste \\ $\mathrm{CBO} \quad$ community-based organization \\ CDF \\ Civil Defence Forces (Sierra Leone) \\ $\begin{array}{ll}\text { CEDAW } & \text { Convention on the Elimination of Discrimination } \\ \text { CGE } & \text { Commission on Gender Equality (South Africa) } \\ \text { CHD } & \text { Centre for Humanitarian Dialogue }\end{array}$ \\ CIRA Continuity IRA \\ CMOC civil-military operation centre
}

xviii 


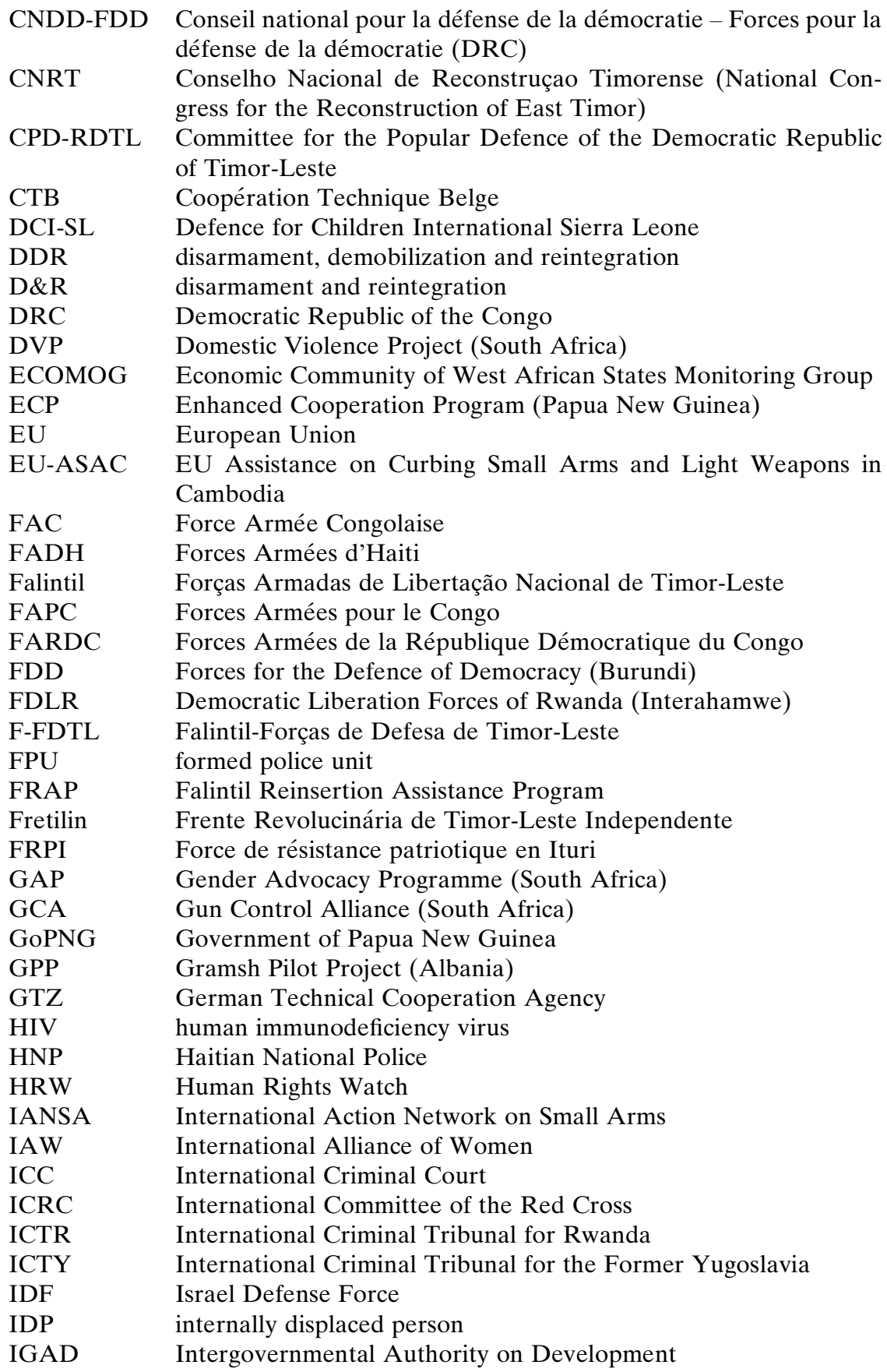




\begin{tabular}{|c|c|}
\hline IICD & $\begin{array}{l}\text { Independent International Commission on Decommissioning } \\
\text { (Northern Ireland) }\end{array}$ \\
\hline INTERFET & International Force for East Timor \\
\hline IOM & International Organization for Migration \\
\hline IRA & Irish Republican Army \\
\hline IRIN & Integrated Regional Information Networks \\
\hline ISF & International Stabilization Force (East Timor) \\
\hline JSAC & $\begin{array}{l}\text { Japan Assistance Team for Small Arms Management in Cam- } \\
\text { bodia }\end{array}$ \\
\hline KAWOGO & Kaabong Women’s Group Organization (Uganda) \\
\hline KWP & Kup Women for Peace (Papua New Guinea) \\
\hline LDU & local defence unit \\
\hline LMG & light machine gun \\
\hline LPV & limited preferential voting \\
\hline LRA & Lord's Resistance Army (Uganda) \\
\hline LVF & Loyalist Volunteer Force \\
\hline MAG & martial arts group \\
\hline MINUSTAH & UN Stabilization Mission in Haiti \\
\hline MK & Umkhonto we Sizwe (South Africa) \\
\hline MLC & Mouvement de Libération du Congo \\
\hline MONUC & Mission de l'Organisation des Nations Unies au Congo \\
\hline MP & member of parliament \\
\hline MRG & Minority Rights Group \\
\hline MSF & Médecins Sans Frontières \\
\hline NACCOF & $\begin{array}{l}\text { National Advisory Council on the Control of Firearms (Somali- } \\
\text { land) }\end{array}$ \\
\hline NAGAAD & women's umbrella organization in Somaliland \\
\hline NCD & National Capital District (Papua New Guinea) \\
\hline NGO & non-governmental organization \\
\hline NOW & National Organization of Women (USA) \\
\hline NRA & National Rifle Association (USA) \\
\hline NRM & National Resistance Movement (Uganda) \\
\hline OAU-IBAR & $\begin{array}{l}\text { Organization for African Unity-InterAfrican Bureau for Animal } \\
\text { Resources }\end{array}$ \\
\hline OECD & Organisation for Economic Co-operation and Development \\
\hline OPMT & Organização Populer da Mulher Timorense \\
\hline OPs & Organisations Politiques (Haiti) \\
\hline PAC & Pan African Congress \\
\hline PDM & People's Democratic Movement (Papua New Guinea) \\
\hline PIF & Pacific Islands Forum \\
\hline PKF & peacekeeping forces \\
\hline PM\&E & participatory monitoring and evaluation \\
\hline PNG & Papua New Guinea \\
\hline PNGDF & Papua New Guinea Defence Force \\
\hline PNTL & Policía Nacional de Timor-Leste \\
\hline POLRI & Kepolisian Negara Republik Indonesia \\
\hline
\end{tabular}




\begin{tabular}{|c|c|}
\hline PRA & participatory rural appraisal \\
\hline PTSD & post-traumatic stress disorder \\
\hline RAG & ritual arts group \\
\hline RCD & Rassemblement des Congolais pour la Démocratie \\
\hline RCD-ML & RCD-Mouvement de Libération \\
\hline RDTL & República Democrática de Timor-Leste \\
\hline RESPECT & $\begin{array}{l}\text { Recovery, Employment and Stability Programme for Ex-Combat- } \\
\text { ants and Communities in East Timor }\end{array}$ \\
\hline RPNGC & Royal Papua New Guinea Constabulary \\
\hline RUC & Royal Ulster Constabulary \\
\hline RUF & Revolutionary United Front (Sierra Leone) \\
\hline SADF & South African Defence Force \\
\hline SALW & small arms and light weapons \\
\hline SALWC & Small Arms and Light Weapons Control project (Albania) \\
\hline SANDF & South African National Defence Force \\
\hline SHP & Southern Highlands Province (Papua New Guinea) \\
\hline SLR & self-loading rifle \\
\hline SMG & submachine gun \\
\hline SNM & Somali National Movement \\
\hline SOWDA & Somali Women's Development Association \\
\hline SPLA & Sudanese People's Liberation Army \\
\hline SSR & security sector reform \\
\hline STD & sexually transmitted disease \\
\hline TEKWIP & Teso-Karamoja Women's Initiative for Peace \\
\hline TFG & Transitional Federal Government (Somalia) \\
\hline TNI & Tentara Nasional Indonesia \\
\hline UDA & Ulster Defence Association \\
\hline UDT & União Democrática Timorense \\
\hline UFF & Ulster Freedom Fighters \\
\hline UHRC & Uganda Human Right Commission \\
\hline UN & United Nations \\
\hline UNAMSIL & UN Mission to Sierra Leone \\
\hline UNDP & UN Development Programme \\
\hline UNESCO & UN Educational, Scientific and Cultural Organization \\
\hline UNICEF & UN Children's Fund \\
\hline UNICRI & UN Interregional Crime and Justice Research Institute \\
\hline UNIDIR & UN Institute for Disarmament Research \\
\hline UNIFEM & UN Development Fund for Women \\
\hline UNMISET & UN Mission of Support in East Timor \\
\hline UNMIT & UN Integrated Mission in Timor-Leste \\
\hline UNOSOM & UN Operation in Somalia \\
\hline UNOTIL & UN Office in Timor-Leste \\
\hline UNPOL & UN Police \\
\hline UNTAET & UN Transitional Administration in East Timor \\
\hline UPC & Union of Congolese Peoples \\
\hline UPDF & Uganda People's Defence Force \\
\hline
\end{tabular}




$\begin{array}{ll}\text { USAID } & \text { US Agency for International Development } \\ \text { UVF } & \text { Ulster Volunteer Force } \\ \text { WED } & \text { Weapons in Exchange for Development programme } \\ \text { WfD } & \text { weapons for development } \\ \text { WHO } & \text { World Health Organization } \\ \text { WID } & \text { Women in Development } \\ \text { WILFP } & \text { Women's International League for Peace and Freedom } \\ \text { WSP } & \text { War-torn Societies Project }\end{array}$




\section{Preface}

Here in my study there is a new rug on the floor. Well, it is new to this floor. It was woven 25 years ago and began its life on the floor of an Afghan home. Woven by Baluchi women of the Afghan province of Herat, the carpet has geometric designs in green and brown on a field of stunning blue. It was a recent birthday gift. I was thrilled. Looking more closely, I began to see that some of the designs, those woven into each corner, looked oddly familiar, yet not what I would have expected to see in a traditional Afghan rug. Stylized fighter planes, abstracted helicopters and geometric but unmistakable AK-47 rifles. During the early 1980s, these Baluchi women had chosen literally to weave into their traditional craft the weapons used to wage the Afghan-Soviet war that was turning their daily lives upside down.

Reading the revealing chapters of Sexed Pistols, I found myself looking with fresh eyes at these stylized woollen AK-47s on my study floor. I wondered anew about where exactly the Baluchi weavers had seen these rifles and the rifles' owners. Did wielding these guns give their owners a reinforced sense of their own occasionally shaky masculinity? And even after the Soviet jet fighters and helicopters were withdrawn in humiliating defeat, did these rifles continue to have localized lives? Each of Vanessa Farr, Henri Myrttinen and Albrecht Schnabel's thoughtful contributors nudges us to question how these AK-47s, so artfully portrayed by the Baluchi weavers, continued to affect the lives of women in Herat and other provinces of Afghanistan. Some women may have felt more secure because their son or husband or father possessed one of these rifles. Other 
women - or perhaps some of these same women months later - might have experienced masculinized intimidation by a man in her household who used this rifle not only to claim his identity as a "warrior" but also to assert his presumed authority as a father or husband in the face of a wife or daughter's apparent insubordination.

I'm still embarrassed that it took me so long to grasp the analytical benefits of developing this kind of feminist curiosity. Now I look back on my early investigations of militaries and armed conflicts (done not long before these Afghan women wove the AK-47s and fighter planes into their rugs) and realize that those analyses of mine were not merely "incomplete", they were naïve and misleading. First, I did not see men as men. I saw them only as conscripts, generals or elected officials, defence strategists and experts. Or I saw those men just as Baluchi, Pashtun, ethnic Russian, Kurd, white American, Malay, Scottish, Indio or Basque. In both instances I left unexplored how - and with what political consequence - each of these sorts of men (those in the élites and in lower ranks, those among the ethnically privileged and the ethnically marginalized) imagined and acted out their own aspirations for appearing, and anxieties about failing to appear, "manly". Simultaneously, I failed to investigate how their militarized masculinities affected the women in their lives - women as wives, mothers, prostitutes, nurses, "our women" and "their women". Nor did I question how potent ideas about femininity shaped men's attitudes towards wielding weapons. Perhaps most glaringly, I adopted an unproblematized assumption that the world of weaponry - from fighter planes to rifles and handguns - was a world of men. I didn't bother to ask "Where are the women?" As the interesting chapters to follow reveal, that means that in the world of small arms and light weapons I missed not simply the diverse women who become the victims of gun violence and intimidation. I also missed women as the hiders and transporters of guns and ammunition, women as disarmament activists and women as international lobbyists.

Once one begins to incorporate a feminist curiosity into one's observations and analytical thinking, one can become quite alarmed by the lacunae gaping in one's previous understandings. Still, as one reads along here, chapter to chapter, it's worth keeping a running list of those gendered dynamics that one has failed, till now, to question. My own resultant list has made me all the more fully appreciative of what being explicit about femininity and masculinity, about women and men, does to deepen and make realistic one's gender-informed reporting on the trade in and wielding of pistols, rifles, grenade launchers, roadside bombs and landmines. After reading these insightful chapters, I don't just see the AK-47s woven into the rug on my peaceful study floor. In my mind's 
eye now I see the Baluchi women who chose to weave them, women shaped by war and attempting to shape the post-war, the next wartime and its post-wartime.

Cynthia Enloe, Research Professor, Clark University, USA 



\section{Introduction}



1 Sexing the pistol: The gendered
impacts of prolific small arms

Vanessa Farr, Henri Myrttinen and Albrecht Schnabel

Every day, small arms and light weapons (SALW) kill, maim, wound and threaten millions of adults and children, whether combatants and civilians in war zones or gangs and communities in degraded "peacetime" environments characterized by large-scale violence. Due to their widespread availability, mobility and ease of use, prolific SALW have become central to maintaining social dislocation, destabilization, insecurity and crime in the build-up to war, in wartime and in the aftermath of violent conflict. Small arms are misused within domestic settings as well as in public spaces, and they impact on everyone in the community without regard to sex or age.

However, although the impacts of these weapons can be vastly different for women and men, girls and boys, a careful consideration of gender and age is rare in the formulation of small-arms policy, planning smallarms collection or control, or even in small-arms research. In our view, one important means to counter their effects is to increase our understanding of the role played by prolific SALW in reinforcing and maintaining gender- and age-specific violence before, during and after conflict. In this book, theorists and practitioners from around the world have collaborated to close existing research and policy gaps by presenting global perspectives on the problem. Sexed Pistols: The Gendered Impacts of Small Arms and Light Weapons collects a wealth of experiences and insights on the nexus of gender, age, violence and small arms in developing and developed countries on five continents.

Sexed pistols: The gendered impacts of small arms and light weapons, Farr, Myrttinen and Schnabel (eds), United Nations University Press, 2009, ISBN 978-92-808-1175-9 


\section{Context}

In the early 1990s, at the beginning of the small-arms policy and research debate, the humanitarian and human rights perspectives of the issue received significant consideration. After 1998, as the debate moved into international forums, this concern was slowly eroded until most of the international and regional documents on small arms - the majority crafted after 1998 - failed to mention humanitarian issues specifically at all. Research and policy on the problem of small-arms (mis)use, and discussions of the human beings responsible for it, were conspicuously absent. As conversations on small arms and light weapons have continued, however, the voices of non-mainstream actors who question the absence of analysis on the people behind the guns have become more audible, assessments of the problem are becoming more descriptive and complex, and more questions are being asked about why civilian demand for such weapons remains so high. ${ }^{1}$ Norms and policies on preventing the proliferation and misuse of small arms have continued to evolve at local, national, regional and international levels, and discussions in academic and policy circles are also becoming more informed and complex - partly because of the impetus from academic and policy debates in the field of human security, a conversation which has arisen, in some measure, to oppose the traditional focus on state/national security. Current work on small arms has begun to look beyond simply "counting the weapons" and is, instead, increasingly focusing on the devastating human impact of their misuse.

Yet a noticeable gap in this discourse has been a discussion of how gender ideologies, which shape and constrain the behaviour of women and men, are influencing people's attitudes to small arms. Remarkably little attention has focused on the fact that gun ownership and misuse are highly gendered phenomena and brutally reinforce unequal social hierarchies that not only give men dominance over women and other men, but also exclude young people from access to social, political and economic power - and they exacerbate race and class tensions in violenceprone communities, as well as often perpetuating the repression of sexual minorities. ${ }^{2}$ Although rates of gender-based violence are universally high, there continues to be a general lack of political interest in the underlying causes of such violence. Rather, there remains a tendency to see "domestic" violence as a problem that can be overlooked because it so often occurs in the private domain, a perspective that frequently provides impunity for its perpetrators. ${ }^{3}$ Gender differences in approaches to and use of small arms have not yet been widely researched, and inadequate data have been collected on how males and females are differently impacted by these prolific weapons. A combination of a lack of political 
interest and will, scarce resources and the sheer difficulty of keeping track of firearms-related injuries in places with poor infrastructure and record-keeping capacities underpins this lack of quantitative sex- and age-disaggregated data and qualitative information on the experiences, views and actions of women and men, girls and boys in gun-prolific societies, both those that are at war and those that are not. As a result, we have little scientific evidence with which to influence the development of gender- and age-responsive programmes to curtail the impacts of small arms and light weapons.

It is not only the domestic impacts of SALW that are ignored - the drafters of international agreements on small arms and light weapons (while they may refer in passing to the "devastating" consequences of armed violence on women) have made little significant effort to align their work with documents such as Security Council Resolution 1325 (2000), which calls for the inclusion of women in all aspects of peacebuilding, including small-arms control. ${ }^{4}$ Indeed, as observed by Vanessa Farr in an early publication on this problem, "[al]though weapons proliferation is often culturally sanctioned and upheld by the manipulation of gender ideologies, gender goes entirely unremarked in all documents which were not explicitly conceived to focus on gender mainstreaming". ${ }^{5}$ The Geneva Declaration on Armed Violence and Development (2006) is, however, an indication that attitudes are slowly changing, with its call to:

promote a comprehensive approach to armed violence reduction issues, recognizing the different situations, needs and resources of men and women, boys and girls, as reflected in the provisions of UN Security Council Resolutions 1325 and $1612 .^{6}$

It is hardly surprising, then, that even in the very new field of research and activism on SALW and their impacts, a paucity of specific research on gender has meant an absence of broadly based surveys and data production from which to draw concrete conclusions. Despite the work of a few feminists in this field, it continues to be difficult to make incontrovertible claims about gender roles. Social stereotypes are shaped to support the use of violence, and no consolidated effort has been made to understand how actors in weapons-prolific contexts are driven by ideals about appropriate behaviour for males and females when it comes to small-arms possession and use.

\section{Structure and contents of the book}

The decision to organize Sexed Pistols by theme rather than geography came about because we were struck by several similarities in the typology 
of the gendered impacts of SALW and how comparable these are across the globe. The chapters in this book cover a range of analyses of how and by whom small arms are used in a range of different societies, from ones still in conflict or moving to a post-conflict phase to those which are considered to be at peace but nevertheless continue to experience high levels of violence. The case studies covered in this book exemplify in a stark manner how it is particularly the ubiquity of SALW which blurs the lines between "conflict" societies and those considered to be "non-conflict" societies but which are not at peace. We believe that this thematic structuring highlights the complexities of dealing with gender and SALW better than the more traditional but somewhat more arbitrary grouping by geographical regions or conflict/non-conflict societies.

The authors of this book come from a range of backgrounds, and the diversity of methodologies used and opinions expressed reflects the complexities of our theme. The chapters combine field experience and academic research, and approach the cases in a transdisciplinary manner. Our book is meant to initiate further debate and analysis as well as to expose a diverse readership to this multifaceted and pressing topic.

After a thematic and methodological introduction to the issues that need to be considered in order to understand better how the misuse of small arms is both shaped by and shapes gender ideologies, the book is divided thematically into four sections. Part I focuses on sexualized violence, gender and small arms, presenting examinations of the lives of girl soldiers in Sierra Leone and the legal framework of examining the systematic use of sexualized violence as a weapon of war in the Democratic Republic of Congo. In Part II, on gender, small arms and violence in fragmented societies, case studies of three violent islands, Haiti, Papua New Guinea and Timor-Leste, are presented, building a comparative study of contexts in which armed gang violence and gender-based violence are seemingly unstoppable by weak state structures unable to provide services or safety to the population. In Part III, case studies of Northern Ireland, Israel and South Africa are used to examine the ways in which violence perpetrated with small arms in these conflict/postconflict societies is militarizing the domestic sphere. The last three case studies, presented in Part IV, leave behind the domestic sphere to consider gender, weapons collection and small-arms control in a comparative study of Albania, Cambodia and Mali; small-arms control in Somalia; and the impacts of small-arms collection programmes in the Karamoja region of northeastern Uganda. Thus we cast light on four important thematic issues linked to gender and SALW: sexualized violence, the role of SALW in fragmented societies, SALW in the domestic sphere and the complexities of weapons collection. 


\section{Thematic introduction}

In Chapter 2, "Gender, attitudes and the regulation of small arms: Implications for action", Wendy Cukier and James Cairns explore small arms and cultures of violence, with particular emphasis on the gender dimensions of these themes. Much of the geographical focus of this chapter is on industrialized countries, in societies generally considered to be "at peace" but nevertheless experiencing high levels of SALW-related violence. Cultural norms are both contributors to and consequences of violence, and small-arms usage and proliferation sometimes figure largely in creating and normalizing cultures of violence because they facilitate violence and contribute to a cycle of violence, fear and further arming. While a wide range of factors fuel this cycle in many regions of the world, "gun culture" and the "culture of violence" are closely connected. Gun culture is also tightly linked to notions of masculinity and expressions of male identity. We see this in the fact that, worldwide, most small-arms owners and users are male. Men dominate the military and the police, but men also dominate domestic firearms ownership. While men die from gun violence in far greater numbers than women, the fact that women represent a very small proportion of gun owners means that they are disproportionately the victims of gun violence, including non-lethal violence.

The role of firearms legislation in promoting the safety of women has been well established. However, the extent to which violence against women is recognized as a crime varies from country to country. Laws of individual countries both shape and reflect social values, and gun control is made all the more complex because it seems to intersect with gender identity and other identities (e.g. national identities). Gender also shapes the formulation of policy regarding firearms. As men dominate political structures in most countries and global institutions such as the United Nations, notions of masculinity can have "invisible" effects on the ways in which policy debates and research are constructed. At the same time, gender has shaped the development of advocacy efforts for and against gun control as well as community-based initiatives in response to gun violence.

Cukier and Cairns argue that political decision-making (including donor behaviour) is shaped by national firearms cultures and reinforced by male-dominated institutions, policies and processes. Weak impact on policy processes has been a consequence of (but also causes) weak impact on research and policy formation on small-arms control. Cukier and Cairns find that it is still a challenge for women's voices (and men's gendered voices) to be heard in formal peace negotiations and SALW policy development. 


\section{Sexualized violence, gender and small arms}

In Chapter 3, "Girls and small arms in Sierra Leone: Victimization, participation and resistance", Myriam Denov and Richard Maclure's study of girls in fighting forces is part of a larger research project that explores the experiences and perspectives of war-affected boys and girls in Sierra Leone. Once on the margins of violent conflict, the availability and easy use of small arms have now put children at the very heart of it. It is believed that tens of thousands of children in Sierra Leone actively participated in the armed conflict in that country. Traditionally, the term "child soldier" has evoked the image of a small boy with a gun, yet in Sierra Leone up to 30 per cent of child soldiers were girls - whose perspectives and experiences, both as victims and as combatants, have been largely ignored. While the women and girls of Sierra Leone were not invisible to the Revolutionary United Front (RUF), as they were seen as assets and resources to be exploited, they were invisible to the government and the international community when it came to devising the disarmament, demobilization and reintegration (DDR) process and were thus once more victimized.

Girls' initiation into the violence came about largely through forced recruitment - they were abducted by the RUF, often at a very young age, through extreme coercion and the force of the gun. They suffered not only from the violence of conflict, but also from displacement and separation from their families. Once abducted, girls fulfilled various roles in the armed groups, according to age, physical strength and the circumstances of the group they were forced to join. The culture of violence was apparent in the girls' experiences of victimization and perpetration. Often, for survival's sake, any command given would be obeyed: if the children did not do what they were ordered, they could be killed. The transition from victim to perpetrator and back was not, however, linear, as the girls continually drifted between perpetration of violence, including with small arms, and victimization by those same arms. Moreover, perhaps as a result of their lack of status in Sierra Leonean society, girls reported a sense of empowerment through the use of weapons and the supremacy they conferred over others, including civilians of both sexes who were not similarly armed.

In Chapter 4, "Small arms and rape as a system of war: A case study of the Democratic Republic of Congo", Felicity Szesnat examines several case studies, the national and international legal frameworks and the international community's response to the widespread use of sexual violence in the two Congo wars of 1996-1997 and 1998-2003, respectively, and the continuing violence in many parts of the country. As Szesnat points out, armed conflict in the DRC has been fought mostly with small 
arms. All of the nine states directly involved in the conflict, as well as the non-state armed groups, have been primarily armed with small arms. There are an estimated 500,000 illegal weapons in the DRC; in addition, many civilians in the DRC keep small arms at home.

It has also been mainly small arms which have been used systematically to perpetrate tens if not hundreds of thousands of cases of sexualized violence in the DRC, including various kinds of rape, sexual slavery, mutilation and other forms of gender-based brutality, against both women and men. Szesnat analyses the role of the international community in the post-conflict phase, especially in the context of the UN MONUC mission, which has failed to stem the widespread occurrence of sexualized violence. In fact, even members of the MONUC mission have been involved in cases of sexual exploitation.

Szesnat concludes that, based on her research on the DRC, there is strong evidence that rape has been used by all sides in the conflict as a system of war, and that small arms have played a vital role in the scale of violence, including men's use of small arms to threaten and intimidate women into submitting to rape; using small arms themselves to penetrate women's bodies; and using small arms to kill or injure women either before, during or after raping them. Szesnat concludes that the use of small arms in committing systematic rape should be further studied and documented. Based on her research, she draws a range of recommendations for the national authorities in the DRC, the MONUC mission and other international actors to address the widespread use of sexual violence as a system of war.

\section{Gender, small arms and violence in fragmented societies}

In Chapter 5, "Haiti: The gendered pattern of small-arms violence against women", Nadine Puechguirbal, Wiza Loutis and Natalie Man examine the role of women as both victims and perpetrators of smallarms-related violence in the country. As the authors point out, while efforts have been made to disarm and reintegrate various armed elements in Haiti, until recently little was known about whether women are involved in armed violence other than as victims and, if so, about their motivations for association. In order to get a better understanding about their association and how women are affected by violence, the authors look into the varying behaviour of Haiti's armed gangs. Despite the fact that contemporary Haitian women have often proved themselves capable of armed violence, a stereotype of the gentle and benevolent Haitian woman remains quite strongly in place today, thus hiding women's participation in armed violence and complicating responses to such violence. 
The authors analyse attitudes of various armed groups towards women and women's participation in such groups, against the backdrop of Haiti's history, political situation and socio-economic framework. They explore gender and class differences, and how these impact upon attitudes to SALW in communities, the perception of security and the different gender norms that appear to motivate the use of SALW in perpetrating violence. In their conclusions, the authors urge both national and international actors, such as the UN MINUSTAH mission in Haiti, to go beyond stereotyped notions of gender and violence in order to find more realistic approaches to problems of small arms and violence, including sexualized violence, in the country.

In Chapter 6, "State, society and the gender of gun culture in Papua New Guinea", Sinclair Dinnen and Edwina Thompson explore important gender differences in perceptions of security and the gendered nature of gun ownership and violence. Situating the proliferation of small arms in the context of culture, power and security in Papua New Guinea (PNG), Dinnen and Thompson's study considers how the social and political history of PNG has been impacted by a changing pattern of conflict and violence, in particular after the influx of firearms and the cultural, political and economic changes which have affected traditional gender relations. The prevalent gun culture of the past 10 to 15 years can be described as creating an enduring situation of disorder, rather than one of outright conflict; and gender-based violence in PNG is also widespread. Continued low levels of violence, expressed through "raskolism" (gangsterism), tribal fighting and election-related violence, have a day-to-day impact on the population. Today, PNG as a "state" is still largely a fiction, and the government is profoundly weak or absent in large parts of the country. Much of the oral evidence indicates that the various communities have always engaged in cycles of warfare and peacemaking - a practice which has, however, become increasingly lethal and difficult to pacify since the advent and proliferation of small arms.

Although fatalities have increased because of gun-related violence, it is not only gun misuse that characterizes the kinds of violence people are experiencing on a daily level. In addition to raskolism, tribal fighting and election-related violence, the authors point out that other forms of aggression, such as gang rape, are growing rapidly. Moreover, both men and women experience sexual violence: in a fairly new development, sexual violence against men and boys is particularly widespread in prisons. However, Dinnen and Thompson found that, while it is considered shameful for sexual violence to occur against men, it is not considered shameful for such violence to be directed against women. Disputes in which a woman is raped are still settled by the affected families themselves without recourse to the state. Official responses (or lack thereof) 
are part of the problem, and new solutions, using local resources and knowledge, must urgently be found.

In Chapter 7, " 'Now they have guns, now they feel powerful' - Gender perspectives on small-arms violence in Timor-Leste", Saleh Abdullah and Henri Myrttinen examine gender, violence and small arms in the context of this nation's history and its current social, economic and political situation. They analyse the impact of small arms, gendered violence and the role of ex-combatants after the East Timorese conflict - issues that have become serious concerns for the country's security. Their study examines how gender roles and expectations are being affected in the post-conflict moment. It looks at gendered notions of security in East Timorese society, which has experienced a dramatic upsurge in reported post-conflict gendered violence, continued political instability and gang violence.

After a bitter and bloody 24-year armed struggle against Indonesian military occupation and two years under UN administration, Timor-Leste gained its independence in 2002. Socio-economic and political instability has, however, dogged the nation, with events coming to a head in a violent implosion of state structures in 2006, followed by two more years of constant crisis, culminating in a coup attempt in 2008. Much of the instability and insecurity in the new nation can be linked to gangs, organizations formed by disgruntled veterans of the struggle and problems in the security sector. In short, violent expressions of masculinity, facilitated by prolific small arms, lie at the heart of the nation's security problems. Participation in violence-prone organizations has become both a socioculturally acceptable way for men to address legitimate socio-economic and political concerns and a key means for young men to build their identities. At the same time, women's space in society has been reduced and the country continues to suffer from very high levels of gender-based violence.

As Abdullah and Myrttinen point out, the international community has played a central role in Timor-Leste in the post-conflict years, and thus needs to refine its stabilization policies further, especially with regard to the way in which the DDR and security sector reform (SSR) programmes have been carried out, paying special attention to the needs of both men and women in these processes.

\section{Militarizing the domestic sphere}

In Chapter 8, “'That's equality for you, dear': Gender, small arms and the Northern Ireland conflict", Miranda Alison examines a specific feature of the Northern Ireland conflict: the involvement of women in paramilitary activities and paramilitary violence. Like male combatants, 
female combatants in nationalist conflicts view themselves as fighting to protect the political, cultural, economic and military security of their nation, community or family. It is clear, however, that women have been more centrally and directly involved in paramilitary violence in republican organizations than in loyalist ones. Republicanism has constructed itself as a revolutionary movement while loyalism has been concerned with bulwarking the status quo, which includes the maintenance of patriarchal social systems and "traditional" gender roles. However, even in the Irish Republican Army (IRA) some male paramilitary members were not comfortable with female comrades in arms. Moreover, as well as occasionally refusing to go out on an operation with female "volunteers" (the IRA's term for its combatants), they seem to have maintained or developed conceptualizations of their masculinity that entail status associated with guns.

Within both loyalist and republican paramilitaries it is women who have had the primary responsibility for hiding and transporting small arms - indeed, in loyalist paramilitaries this has been one of their most significant roles. Although for loyalist paramilitaries this role for women came about in part due to the sexual division of labour within these organizations along stereotypical gender lines, for both loyalist and republican groups it has also been a strategic tactic because broadly accepted social stereotypes of women as "peaceful" meant that they were rarely subjected to the same scrutiny as men.

A further issue explored by Alison is the question of the sexualization of violence and proliferation of weapons from a women's perspective. Here she takes up a contradictory pattern: while there were many cases of members of the security forces sexually harassing or molesting women and girls both during street searches and during arrest and interrogation, women nonetheless participated in non-traditional ways in furthering the violence. Alison challenges the fact that, although much is made of men's violence in militarized societies, feminists have been more reluctant to address the question of women who are attracted to and support such violence, and what this says about constructed femininity.

In Chapter 9, "The gun on the kitchen table: The sexist subtext of private policing in Israel", Rela Mazali focuses on the highly accelerated proliferation of privately owned and operated security companies in Israel in the past decade. She argues that the spread and growth of such companies deepen Israeli militarization in a variety of ways, including through the domestication of small-arms proliferation. While she observes that prolific small arms intensify already existing gender discrimination and violence against women, analyses of race and class are also important because a large part of the private security sector consists of exploited and unorganized workers who are often from socially and eco- 
nomically marginalized sections of society, with few other job prospects on the horizon.

As private security companies are loosely regulated and efforts to organize themselves as a segment of the labour market are not very advanced, there is little transparency and weak enforcement of equal opportunity laws. In a depressed job market, the private security sector was the only site of growth for some years. Women's own perception of employment in private policing as inappropriate for females is a significant obstacle to their participation in this growing sector, as many women do not associate themselves with guns or guarding. As stereotyped gender roles are prevalent in Israeli society, this has resulted in selfexclusion: most women do not apply for jobs in this sector.

Mazali notes, furthermore, that broader army and police cultures have been incorporated into the private policing sector. Among other things, this has led to higher levels of sexual harassment. There has, however, been little public monitoring of harassment in private companies. Moreover, unlike the police and the army, which have preventive policies in place, private security companies are not required to address the problem of sexual harassment.

These conditions contribute to generally high levels of insecurity for women in Israeli society. In recent years there has been an increase in gun use in murders of women by intimate partners, with a significant percentage shot with guns signed out to private security guards. Ironically, security guards are perceived to be protective agents who are supposed to avert danger. Yet for many women in Israel the private policing industry brings discrimination and danger into their private lives - their families and homes.

In Chapter 10, "Securing private spaces: Gendered labour, violence and democratization in South Africa", Jennifer Fish and Pumla Mncayi offer an in-depth analysis of domestic labour in South Africa - a nation that continues its struggle to realize a non-violent, non-racist democracy. They explore the linkages between individual/personal security, the proliferation of small arms and light weapons and the heavily gendered institution of paid household labour. Like Mazali, they show how the particular relationship between gender and personal security is played out in the supposedly most private and protected domain, the household.

With its emphasis on the existence of divisions among women according to their race, class and location, the institution of domestic labour is often referred to in South Africa as "the last bastion of apartheid". Domestic work embodies a striking polarity in relation to perceptions of safety in post-apartheid South Africa. For example, domestic workers are often aware of and threatened by the presence of guns inside the private households where they are employed. Moreover, as Fish and Mncayi 
argue, workers' fears tend to increase when they are unaware of the specific location of such weapons. Yet an assumed expectation of this particular occupation is the protection of employers' private households from outside threats. Non-compliance with these assumed security roles often results in immediate job loss. Thus workers are required to risk their own safety to maintain employment, whereas employers consider the presence of domestic workers to be a strong enhancement of their own security through the human barrier created between "outside" threats and the interior private household space.

In South Africa's current transitional phase - characterized by extremely high rates of both small-arms and gender-based violence - domestic workers provide a critical service that is rarely acknowledged as part of the formal labour contract. Their economic privilege allows employers to buy a certain "peace of mind" from the threat of the severe proliferation of small arms and violence in South African society. Domestic workers thus become in essence unarmed security guards whose bodies mediate the threat of violence in their employers' private households while reifying the race and class divides of the apartheid era.

\section{Gender, weapons collection and small-arms control}

In Chapter 11, "Just a matter of practicality: Mapping the role of women in weapons for development projects in Albania, Cambodia and Mali", Shukuko Koyama argues that the capacities of women as actors in such programmes are not fully recognized nor utilized by relevant stakeholders, and that women have much more potential to contribute to such projects. Koyama's study focuses on weapons collection programmes that have been linked to development initiatives. These voluntary approaches to disarmament are increasingly attracting attention from donors and implementing agencies. Those encouraged to hand over their weapons are usually civilian community members, and not ex-combatants. The case studies demonstrate that women tend to contribute to weapons collection projects because they want to remove weapons from their communities. They motivate male family members to give up weapons and are major supporters of formal disarmament programmes.

Koyama concludes that while the implementers of weapons collection programmes may have the political will to include women's participation, they are not well equipped to do so. In addition, approaches other than that of ensuring participation will need to be developed. For example, she believes that it is not adequate merely to hold, as is often done, a women's participatory workshop, as this approach is too simplistic: the international assistance community needs to be aware of women's actual and potential capabilities as agents of arms control, and to underpin its 
assistance policies with instruments to utilize these capabilities as much as possible.

Equal participation in weapons collection programmes should be promoted across all social groups and divisions, and include men, women, youth and elders. Yet while the challenge of promoting women's role without excluding other social actors is real, Koyama warns that it is important to note that many men are also excluded from weaponscollection processes due to differences in social status.

In Chapter 12, "Poems against bullets? The role of Somali women in social gun control", Katrin Kinzelbach and Zeinab Mohamed Hassan explore the roles of women's oral poetry and political activism in Somalia and how they relate to small-arms control. Although data on this subject are limited, they produce a gender-sensitive quantitative analysis of the small-arms problem in Somalia. They also provide an analysis of the socio-political and security context in which women's disarmament poems are created and recited. The aim of their approach is to generate analysis that is relevant to the work on gender and small arms, while recognizing that women who have been excluded from most small-armsrelated surveys find their known ways to convey the messages they wish to communicate.

In the context of the civil war, Somali women have used their poems to communicate with highly militarized men. Through their poetry, women comment on power relations in society. Although some of their poems continue to encourage raids and fights, as is traditional, many appeal for peace. They often confront men directly in exhortations such as "you men, lay down your arms". Women's aspirations, such as political empowerment, are also reflected in the poetry.

The emotional power of women's poems is linked to the personal experience of loss and the struggle for life. Women are empowered through their poetry and are often able to appeal to the emotions of men, some of whom have laid down their arms in response. Through poetry, women remind men of the horrors of war and ask why they are still fighting. The authors believe that mobilization of women, whether as fighters or as peace promoters, has policy implications. By paying attention to the tradition of debate through the recitation of poetry, women can be supported to use their voices publicly and in a positive and effective way. Their practice highlights the importance of attending to customary forms of debate when undertaking consciousness-raising work.

In Chapter 13, "Missing men, lost boys and widowed women: Gender perspectives on small-arms proliferation and disarmament in Karamoja, Uganda", Christina M. Yeung examines the gendered effects of weapons proliferation in this agro-pastoralist region in northeastern Uganda. She explores how the demand for small arms is underpinned by gender 
ideologies and how, in turn, gender identities and relations are shaped and impacted by violence and the use of firearms. Particular attention is paid to the experiences of male youth and women, both married and unmarried. Yeung discusses the 2001-2002 weapons collection programme in Karamoja, examining whether certain social groups were marginalized or ignored in the process. She asks how successful the weapons collection programme was at fully disarming households, to what extent women were involved in the decision to disarm or retain firearms and whether the experience and perception of (in)security of men and women differed as a result of the decommissioning of weapons. Finally, her study explores whether and how practical disarmament affected the demand factor for small arms, for example whether cultural valuations of traditional expressions of masculinity and femininity have changed, whether socioeconomic deprivation in the Karamoja cluster has become more clearly gendered and whether the weapons collection programme has made any positive or negative contributions to the long-term social, economic and political empowerment of women and men in the subregion.

Yeung suggests that we are still a long way away from micro-disarmament initiatives that are truly situated in a demand-side logic. During the conception of the 2001-2002 Karamoja programme, as in many other disarmament programmes, there was little attempt to address the material and security needs of the various stakeholders in a sustained manner, including both the gun users and the more vulnerable sections of society, such as rural women and orphans. Disarmament benefits went to élite groups, and there was very little impact on those who actually needed the benefits. In addition, men experienced emasculation through the disarmament programme, in that the men who gave up weapons were called "women". Yeung identifies this as part of a "crisis of masculinity" in the community, as fewer men are able to reach traditional markers of adulthood.

\section{Conclusion}

From the Beijing Platform of Action in 1995 to the Windhoek Declaration in 1999, and the passing of Security Council Resolution 1325 in 2000 to the Geneva Declaration of 2006, we have found increasing ways in which to hold governments and international agencies responsible for the gender-based violence that small arms underpin. ${ }^{7}$ All of these resources allow analysts and policy-makers to focus on identifying how ideologies of masculinity and femininity are constructed to support the misuse of small arms in societies that are war-afflicted or suffering from elevated levels of social violence and/or severe underdevelopment - or which are 
merely highly tolerant of the presence of individually owned firearms. To further the effectiveness of such work, in the concluding chapter the editors tie together a number of the findings from the various case studies and draw out a number of recommendations for future policy formulation, programme implementation and research designed to illuminate more fully and counteract the "sexed pistol" that is so often fired.

\section{Notes}

1. The Small Arms Survey estimates that nearly 60 per cent of weapons are in private hands. See Small Arms Survey (2002) Small Arms Survey 2002: Counting the Human Cost, Oxford: Oxford University Press.

2. See Schroeder, Emily and Lauren Newhouse (2004) Gender and Small Arms: Moving Into the Mainstream, ISS Monograph 104, October, Institute for Security Studies, Pretoria, for a discussion of the lack of analysis of gender in small-arms-related UN discussions even up to the 2003 Biennial Meeting of States on the Programme of Action.

3. Several accounts of violence against women with guns that has gone unpunished are recorded in Control Arms Coalition of Amnesty International, IANSA and Oxfam (2005) The Impact of Guns on Women's Lives, Oxford: Alden Press; see also www.controlarms. org.

4. Available at www.un.org/events/res_1325e.pdf.

5. Farr, Vanessa (2002) "A Gendered Analysis of International Agreements on Small Arms and Light Weapons", in Gender Perspectives on Small Arms and Light Weapons: Regional and International Concerns, Brief 24, Bonn International Center for Conversion, Bonn, p. 17.

6. Available at www.genevadeclaration.org/geneva-declaration.html.

7. Available at www.undp.org/fwcw/plat.htm; www.reliefweb.int/library/GHARkit/ FilesFeb2001/windhoek_declaration.htm. 


\section{Gender, attitudes and the regulation of small arms: Implications for action}

Wendy Cukier and James Cairns

In North America, as worldwide, men dominate the military and the police. Men also dominate domestic firearms ownership. In the United States a study in 1997 estimated that 42 per cent of men compared to only 9 per cent of women owned guns. ${ }^{1}$ In Canada, data collected in 2002 show that 88 per cent of gun owners are male. ${ }^{2}$ These facts suggest that in order to develop effective strategies to stem the misuse and proliferation of small arms, we must understand the ways in which concepts of masculinity affect the demand for these weapons.

Women represent a very small proportion of gun owners, but are a disproportionate number of gun-violence victims. This imbalance has been one of the arguments advanced for positioning the debate on small-arms control in the context of human rights and equity. ${ }^{3}$ Small arms affect women differently to men, and this shapes the solutions needed to address the problem. While men represent the majority of small-arms victims, they are also the majority of small-arms users. Women, in contrast, represent a higher percentage of victims of small arms than of users. In addition, while women are victimized by combatants and criminals, they are also at risk of being victimized by their intimate partners. Statistics show that the number of small arms in civilian possession is far greater than those in the possession of states and police. ${ }^{4}$ The evidence is clear: civilian-owned small arms represent a particular threat to women. In addition, as most women are victimized in their homes, distinctions between "legal" and "illegal" small arms are not particularly meaningful for women. It is necessary to explore these gendered differences in the effects of small arms and the contexts of victimization in order to develop different

Sexed pistols: The gendered impacts of small arms and light weapons, Farr, Myrttinen and Schnabel (eds), United Nations University Press, 2009, ISBN 978-92-808-1175-9 
approaches and strategies to counter the misuse and proliferation of small arms. For example, a focus on the safety of women produces different interventions to a simple focus on "crime" or "conflict". There are also pronounced differences in the attitudes of men and women to small arms, created and recreated by a wide range of cultural carriers including cultural practices, media and even laws themselves. This, in turn, shapes the demand for small arms, the demand for controls on small arms and political processes. It also affects the way in which violence reduction strategies are implemented.

In this chapter we will offer a gendered perspective on, firstly, gender and the effects of small arms. Women are at risk from intimate partners as well as from "criminals" or combatants armed with guns, a phenomenon seen in both industrialized and developing countries, while the rates at which women are killed with small arms tend to be linked to the prevalence of small arms in a particular context.

Second, domestic violence and the regulation of civilian possession: the ways in which policy and legislation address (or neglect) the issue of violence against women using small arms.

Third, gender and the demand for small arms: the link between "guns" and "masculinity" is (re)produced in many ways through cultural practices, including songs, celebrations and the media. Recognizing this is important in understanding the demand for guns and ways to address this demand.

Fourth, gender and attitudes: the link between "small arms" and concepts of "masculinity". There is strong evidence of a gender gap in attitudes to firearms; however, while women may be more likely than men in their community to support stronger controls on firearms, cultural splits between entire communities (men and women) are greater than those between individuals. Furthermore, in some cultures the normalization of weapons possession is higher than in others. Consequently, to understand the demand for small arms we must understand multiple identities.

Fifth, policy development processes: gender shapes the formulation of policy regarding firearms. As men dominate political structures in most countries and global institutions such as the United Nations, notions of masculinity can have "invisible" effects on the ways in which policy debates and research are constructed. At the same time, gender has shaped the development of advocacy efforts for and against gun control as well as community-based initiatives in response to gun violence.

\section{Gender and the effects of small arms}

Conflicts fought with small arms affect women differently to men. And the evidence is clear - if arms remain in circulation, the level of violence 
continues even after conflict formally ceases. Thus women are often as much at risk from small arms during "peace" as they are in "conflict", and are as often killed and threatened with legal small arms as they are with illegal ones. This has great significance for the discussion of the small-arms problem and potential solutions.

Conflict has different impacts on men and women because of their social roles, and it has been suggested that women in conflict often have more in common with women from opposing sides than with the men in their own societies. In Kashmir, for example, one female respondent noted: "Both sides have guns, they shoot each other, they both die. But the problem remains." 5

Men account for the majority of users of small arms as well as direct casualties of conflict. Although little gendered analysis is available, a study by the ICRC concluded that a minimum of 35 per cent of casualties during conflict are civilians. In this study, civilians were defined as all females, males under 16 and males aged 50 and over. ${ }^{6}$ There is strong evidence that the unrestrained availability of small arms is directly linked to levels of lethal violence in both conflict and non-conflict contexts. ${ }^{7}$ If small arms are not removed following the cessation of conflict, interpersonal violence substitutes for violence between warring factions. One study which compared levels of injury during and after conflict in the Kandahar region of Afghanistan revealed that levels of small-arms injury declined only 30 per cent following the cessation of conflict (Figure 2.1). ${ }^{8}$

Sexual assault, often aggravated with weapons, is another crime in which women represent a disproportionate number of victims, whether in conflict or in peace. Women are strategic targets in conflict. Rape and sexual abuse have been used as intimidation strategies in conflicts in $\mathrm{Yu}$ goslavia, Afghanistan, Sudan and elsewhere. ${ }^{9}$ A study in Sierra Leone,



Figure 2.1 Annual incidence of weapon injuries during conflict and in postconflict periods

Source: Meddings, David R. (2001) "Weapons Injuries During and After Periods of Conflict", in Human Rights Watch, Women's Human Rights: Women in Conflict and Refugees, available at www.hrw.org/wr2k1/women/women3.html. 
which surveyed 991 households, revealed high levels of sexual violence. While 91 per cent of the women surveyed indicated that they were quite or extremely worried about future sexual violence to themselves or their family members by "combatants", a substantial proportion (39 per cent) indicated that they were quite or extremely worried about future sexual violence to themselves or family members by "non-combatants", again reinforcing the fact that risks to women are not confined to war. ${ }^{10}$ Victimization surveys indicate that the rate of sexual assaults reported by women is high in developing as well as industrialized countries. For example, 20 per cent of women in Colombia reported being assaulted compared to 28 per cent in the United States. ${ }^{11}$ Many of the assaults are conducted by individuals known to the victim. Where guns are available, they are used extensively in armed sexual assaults on women, as evidenced by the high levels of armed rape and sexual assault in South Africa. ${ }^{12}$

However, as stated above, the majority of victims of most crimes with small arms are men. According to the World Health Organization (WHO), of 115,593 small-arms deaths reported, women accounted for 11,110 , including roughly 10 per cent of homicides. ${ }^{13}$ It is significant that the nature of violence directed at women is different: worldwide, women are more at risk from violence at the hands of intimate partners in the private sphere of the home, while men are more at risk from male acquaintances in public spaces. Women account for the majority of victims in domestic violence worldwide, and a number of studies have suggested that the risk of being murdered by an intimate partner increases with the availability of firearms. In many countries considered to be at peace, the number of women killed with small arms is significant - female casualties in the United States average more than 10 per day. ${ }^{14}$ Data on this issue are uneven, however, for a variety of reasons, including the fact that many countries view domestic violence, particularly against women, as a private issue rather than a crime.

Women worldwide are victimized by guns in the possession of their intimate partners. Research in South Africa suggests that more women are shot at home in domestic-violence situations than are shot by strangers on the streets or by intruders. ${ }^{15}$ In Brazil more than 40 per cent of women killed by their husbands were shot. ${ }^{16}$ In Canada firearms accounted for approximately 40 per cent of femicides in 1989, but now account for under 15 per cent. ${ }^{17}$ The vast majority of female murder victims in Canada (85 per cent) are killed by their intimate partners. Similarly, women account for the majority ( 80 per cent) of intimate-partner homicides in Australia. ${ }^{18}$ In a 10 -year period in the United States, 71 per cent of spousal homicides carried out by husbands or ex-husbands involved firearms, and guns were used in 47 per cent of all murders committed by 
boyfriends. ${ }^{19}$ American women are far more at risk from intimate partners than from strangers: among female homicide victims, murders by spouses, ex-spouses and intimate acquaintances were nearly seven times more prevalent than murders by strangers. In fact, for every female killed by a stranger, four women were murdered by intimate partners using guns. ${ }^{20}$ A study of femicide in 25 developed countries showed a strong relationship between the rates of women killed and the availability of firearms ${ }^{21}$ (see Table 2.1). These statistics suggest that while violence against women is endemic, rates of death are higher in contexts where guns are prevalent because guns increase the lethality or risk of death in violence.

The patterns persist in both developing and industrialized countries. For instance, a Cambodian study reported that in areas with high frequencies of weapons possession, youth threaten people with guns over trivial matters and women fear that males in the house, especially if intoxicated, will use a gun on a family member. ${ }^{22}$ Similarly, in Turkey, where official reports are uneven, the patterns reported in "official" statistics on women killed with firearms are highly unusual. Women account for only 12 per cent of firearm homicide victims but an unprecedented 41.7 per cent of reported firearm suicide victims and 35.7 per cent of the victims of reported "accidental" shootings. ${ }^{23}$ It seems quite possible that in Turkey, as in other countries, murders of women by their husbands are often misreported as suicides and accidents. Physicians have queried the accuracy of the reporting of these incidents. ${ }^{24}$

A study of the Oslo (Norway) and Copenhagen (Denmark) areas examined firearm homicides in 1985-1994, and showed that 58 per cent of victims were male while 42 per cent were female. Female victims were typically shot in their own domicile by their spouse with a shotgun, mostly because of jealousy or a family argument, whereas male victims were shot in different locations, predominantly with a handgun, for many different reasons. ${ }^{25}$ A study of homicides and suicides in the Paris region showed that the phenomenon was most often associated with domestic violence. In 45 events ( 80 per cent), the offenders used a gun for both the homicide and the suicide. Typically it was precipitated by marital break-up and a woman leaving her husband. Women (wives and intimate partners), their children and even pets were killed. The killings most often occurred in the home. ${ }^{26}$ The patterns of violence against women with firearms are consistent across many nations.

The presence of firearms is a particular risk factor for domestic homicide. One early study showed that family and intimate assaults involving firearms were 12 times more likely to result in death than intimate assaults that did not involve firearms. ${ }^{27} \mathrm{~A}$ study of women physically abused by current or former intimate partners in the United States re- 
Table 2.1 Female homicide rates for 25 populous high-income countries, 1994-1999

\begin{tabular}{|c|c|c|c|c|c|c|c|c|c|}
\hline \multirow[b]{2}{*}{ Country } & \multirow[b]{2}{*}{ Year } & \multirow{2}{*}{$\begin{array}{l}\text { Female } \\
\text { population } \\
\text { (millions) }\end{array}$} & \multicolumn{2}{|c|}{ Total homicides } & \multicolumn{2}{|c|}{ Gun homicides } & \multicolumn{2}{|c|}{ Non-gun homicides } & \multirow{2}{*}{$\begin{array}{l}\text { Gun } \\
\text { suicides as } \\
\% \text { of total }\end{array}$} \\
\hline & & & No. & Rate & No. & Rate & No. & Rate & \\
\hline Australia & 1997 & 9.3 & 106 & $(1.14)$ & 25 & $(0.27)$ & 81 & $(0.87)$ & 11.3 \\
\hline Austria & 1999 & 4.2 & 36 & $(0.86)$ & 8 & $(0.19)$ & 28 & $(0.67)$ & 17.5 \\
\hline Belgium & 1995 & 5.2 & 69 & $(1.33)$ & 22 & $(0.42)$ & 47 & $(0.91)$ & 13.4 \\
\hline Canada & 1997 & 15.1 & 146 & $(0.96)$ & 44 & $(0.29)$ & 102 & $(0.67)$ & 22.2 \\
\hline Denmark & 1996 & 2.7 & 23 & $(0.86)$ & 4 & $(0.15)$ & 19 & $(0.71)$ & 9.0 \\
\hline England and Wales & 1997 & 26.5 & 106 & $(0.40)$ & 6 & $(0.02)$ & 100 & $(0.38)$ & 2.9 \\
\hline Finland & 1996 & 2.6 & 51 & $(1.94)$ & 10 & $(0.38)$ & 41 & $(1.56)$ & 22.3 \\
\hline France & 1997 & 30.0 & 216 & $(0.72)$ & 84 & $(0.28)$ & 132 & $(0.44)$ & 22.9 \\
\hline Germany & 1998 & 42.0 & 278 & $(0.66)$ & 47 & $(0.11)$ & 231 & $(0.55)$ & 7.8 \\
\hline Greece & 1997 & 5.3 & 32 & $(0.60)$ & 12 & $(0.23)$ & 20 & $(0.38)$ & 20.1 \\
\hline Hong Kong & 1996 & 3.2 & 24 & $(0.76)$ & 1 & $(0.03)$ & 23 & $(0.73)$ & 0.5 \\
\hline Ireland & 1996 & 1.8 & 14 & $(0.77)$ & 2 & $(0.11)$ & 12 & $(0.66)$ & 9.1 \\
\hline Israel & 1997 & 3.0 & 6 & $(0.20)$ & 1 & $(0.03)$ & 5 & $(0.17)$ & 19.3 \\
\hline Italy & 1997 & 29.6 & 159 & $(0.54)$ & 52 & $(0.18)$ & 107 & $(0.36)$ & 13.3 \\
\hline Japan & 1997 & 63.7 & 284 & $(0.45)$ & 4 & $(0.01)$ & 280 & $(0.44)$ & 0.2 \\
\hline Netherlands & 1997 & 7.9 & 63 & $(0.80)$ & 11 & $(0.14)$ & 52 & $(0.66)$ & 3.2 \\
\hline New Zealand & 1998 & 1.9 & 25 & $(1.30)$ & 1 & $(0.05)$ & 24 & $(1.25)$ & 12.5 \\
\hline Norway & 1997 & 2.2 & 13 & $(0.58)$ & 5 & $(0.22)$ & 8 & $(0.36)$ & 23.8 \\
\hline Portugal & 1998 & 5.2 & 33 & $(0.64)$ & 17 & $(0.33)$ & 16 & $(0.31)$ & 9.0 \\
\hline Scotland & 1999 & 2.6 & 20 & $(0.76)$ & 1 & $(0.04)$ & 19 & $(0.72)$ & 2.2 \\
\hline Singapore & 1997 & 1.5 & 16 & $(1.04)$ & 0 & $(0.00)$ & 16 & $(1.04)$ & 1.3 \\
\hline Spain & 1997 & 20.1 & 99 & $(0.49)$ & 22 & $(0.11)$ & 77 & $(0.38)$ & 6.6 \\
\hline Sweden & 1996 & 4.5 & 36 & $(0.80)$ & 2 & $(0.04)$ & 34 & $(0.76)$ & 13.0 \\
\hline Switzerland & 1994 & 3.6 & 48 & $(1.34)$ & 22 & $(0.61)$ & 26 & $(0.72)$ & 26.4 \\
\hline United States & 1997 & 136.6 & 4,384 & $(3.21)$ & 2,106 & $(1.54)$ & 2,278 & $(1.67)$ & 57.6 \\
\hline Total & & 430.5 & 6,287 & $(1.46)$ & 2,509 & $(0.58)$ & 3,778 & $(0.88)$ & \\
\hline $\begin{array}{l}\text { Total excluding } \\
\text { United States }\end{array}$ & & 293.9 & 1,903 & $(0.65)$ & 403 & $(0.14)$ & 1,500 & $(0.51)$ & \\
\hline
\end{tabular}

Source: Hemenway, David, Tomoko Shinoda-Tagawa and Matthew Miller (2002) "Firearm Availability and Female Homicide Victimization Rates Across 25 Populous High-Income Countries", Journal of the American Medical Women's Association 57, pp. 100-104. 
vealed a fivefold increased risk of the partner murdering the woman when he owned a firearm. ${ }^{28}$ More recent work reinforces the fact that access to firearms is also one of the top five risk factors associated with domestic femicide in Canada. ${ }^{29}$

Often homicides are not random acts of violence and the guns used to murder women are not smuggled or illegally owned. In Canada, for example, the majority of firearms used to kill women were legally owned rifles and shotguns. Thus distinctions between "law-abiding citizens" and "criminals" in the context of domestic violence have little meaning.

In addition, the statistics on death and injury do not capture the full extent of the problems faced by women when they are dominated by men with guns. For every woman who is killed or injured with a small arm, many more are threatened: "Even when a gun is not fired, it has the power to inflict serious psychological damage on the people threatened with shooting." ${ }^{30}$ When it is difficult for women to report such behaviour, it largely goes unrecorded. For example, in a small study of non-fatal shootings of women in South Africa, eight (57.1 per cent) of the 14 women in the study said they knew the person who shot them, but only four reported the shooting to the police. ${ }^{31}$ The patterns of threatening are astonishingly similar across cultures. According to the Australian Women's Services Network submission on model domestic violence laws, ${ }^{32}$ many women live in fear of their partners because they know they are capable of serious violence even though they have not experienced a direct attack. As an example of circumstances giving rise to such a fear, a woman living in rural Australia reported that she is made to watch her husband cleaning his gun and muttering about how easily the gun might go off and hurt someone accidentally and no one would ever know what really happened. The threat is veiled: he has not actually assaulted her, but she is fearful, isolated and vulnerable. Another example is the not uncommon practice of perpetrators who terrorize family members by gross illtreatment of their pets. Studies of abused women in different areas of the world - South Africa ${ }^{33}$ and Canada ${ }^{34}$ - report remarkable similarities in the behaviour of abusers, including those who rely on a gun to underpin their violence.

Freedom from fear is a fundamental human right and women in most societies express more fear about violence than men, which has secondary effects on their mental health. The psychological trauma associated with small arms, as well as their actual disruption of social cohesion and family safety, often impacts on women much more profoundly than on men. ${ }^{35}$ The fact that prolific weapons so often present a thinly veiled threat to women may explain their heightened fear of firearms: while statistically men are more likely to be victims of gun violence, women often express more fear of being injured by firearms. For example, a Canadian 
study revealed that only 36 per cent of males compared to 59 per cent of females feared that "you or someone in your household would be threatened or injured with a firearm". ${ }^{36}$ The psychological trauma of firearms, in addition to the actual disruption of social cohesion and family safety caused by firearms, often impacts on women in different ways than on men, given their roles in society and the family and women's often limited access to policing and judicial services.

The role of firearms legislation in protecting women has been acknowledged in some international circles for over a decade. The UN Commission on Crime Prevention and Criminal Justice also recognized that strong controls over firearms were needed to protect women from violence, and explicitly recognized the need to strengthen regulations on firearms in order to address violence against women. Its resolution of 1997, sponsored by 33 countries, "requests the Secretary-General to promote, within existing resources, technical co-operation projects that recognize the relevance of firearm regulation in addressing violence against women, in promoting justice for victims of crime and in addressing the problem of children and youth as victims and perpetrators of crime and in re-establishing or strengthening the rule of law in post-conflict peacekeeping projects". ${ }^{37}$ The resolution outlined the key elements to effective legislation, including licensing, registration and safe storage. Licensing is intended to reduce the chances that those who present a risk have access to firearms. Registration is intended to reduce the chances of diversion from legal to illegal markets and to reinforce licensing. Safe storage also reduces the risk of using guns impulsively. These measures are in place in the majority of countries worldwide, although violence against women is still not a priority in many countries. ${ }^{38}$

Some countries have introduced provisions which address violence against women in their regimes to control firearms. Given the particular role of legally owned guns in the murder, injury and intimidation of women and children in the home, several countries have instituted screening mechanisms to prevent gun acquisition by those with a history of violence, whether or not it resulted in a criminal conviction. South Africa and Australia now have specific prohibitions on issuing licences to those with a history of violence to women and children. ${ }^{39}$ In Canada, several high-profile inquiries into domestic-violence cases drew attention to the role of guns in violence against women and stressed the importance of licensing gun owners and registering firearms. Canadian law, for example, requires current and former spouses to be notified before a gun licence may be issued, and continuous eligibility checking ensures that gun owners subject to complaints or charges will have their licences reviewed and may have their guns temporarily or permanently confiscated. ${ }^{40}$ Even in the United States, federal law makes it a criminal offence to possess a 
gun while subject to an intimate-partner violence restraining order. Eleven American states have laws that prevent individuals with convictions from purchasing or possessing a firearm. Some states have implemented screening processes to check for restraining orders before issuing gun permits, although the quality of implementation varies. For example, one study shows that although California law prohibits the purchase or possession of a firearm by persons against whom a restraining order is issued, 9.2 per cent of the orders documented no firearm restrictions. ${ }^{41}$ At the same time, many industrialized countries such as Switzerland and Finland have relatively weak firearms legislation in spite of relatively high rates of firearm femicide. ${ }^{42}$

Laws, of course, are merely words on paper, and their effectiveness is highly dependent on their implementation. Extensive training for police and community-based education are critical to ensure that the risks associated with legal firearms in the home are understood, that the possible interventions are known and that actors (whether police, crisis workers, physicians or friends) take appropriate action. ${ }^{43}$

To date there is considerable evidence that strengthening firearms legislation is often of particular value to women: in Australia, the United Kingdom and Canada, stronger firearms laws were accompanied by greater decreases in femicide than in male homicide. In Canada, for example, homicides of women using firearms dropped by over 75 per cent with progressive strengthening of laws (1989-2003), while murders of women by other means (stabbing, beating etc.) declined by only 30 per cent $^{44}$ (see Figure 2.2). This is largely because women are more often

\section{Female victims}



Figure 2.2 Rate of homicide of female victims of intimate-partner homicide by means in Canada

Source: Bunge, Valerie Pottie (2002) "National Trends in Intimate Partner Homicides, 1974-2000", Juristat 22(5), p. 5. 
victimized in their homes with legally owned weapons, and measures aimed at improving controls over legally owned weapons have the greatest impact on violence against women, suicides and "accidents".

\section{Implications}

The nature of violence against women using small arms reinforces a number of issues. First, women are threatened with small arms in both conflict and non-conflict zones, with both legal and illegal weapons. A comprehensive approach is needed to protect women from small-arms violence. Second, most (60 per cent) of the small arms worldwide are in the possession of civilians, and the evidence is clear that these weapons represent a particular threat to women, who are often killed or threatened by guns in the hands of their intimate partners. And third, a focus on proper controls on civilian possession of small arms is therefore critical to preventing lethal violence against women, and has been shown to be effective.

\section{International norms in the regulation of civilian possession of small arms}

Recently released statistics show that the number of small arms in civilian possession far outnumber those in the possession of states and police. Increasingly, efforts to regulate civilian possession of firearms are being justified in terms of women's rights and, more broadly, in terms of human rights. The UN special rapporteur on violence against women and the special rapporteur on small arms and human rights have both maintained that states have a responsibility to protect their citizens, particularly women, from the violence associated with small arms. They have also maintained that states failing to regulate civilian possession of small arms adequately may be failing to meet their obligations under international law. ${ }^{45}$

While rights to legitimate national security, self-determination and national sovereignty have been reaffirmed several times, there is no evidence of a general right to unrestricted civilian access to arms under any international human rights instrument. Even within the United States, where constitutional claims of the civilian right to bear arms are often invoked, courts have maintained repeatedly and unanimously that the American Constitution does not guarantee individuals the right to possess or carry guns. Furthermore, the Second Amendment protects only the right of the states to maintain organized military forces. It does not impede local, state or national legislatures from enacting or enforcing gun-control laws. ${ }^{46}$ Many other jurisdictions, including South Africa, the 
United Kingdom, New Zealand, Canada and the Philippines, have explicitly rejected the notion that a right to bear arms exists at all, arguing instead that the right to life, liberty and security of the person under Article 3 of the Universal Declaration of Human Rights supports efforts to reduce access to arms. Indeed, in 2002 the United Nations issued a working paper on small arms which reinforces the responsibility of states under international human rights law to address the problems associated with misuse of firearms by civilians generally, as well as particularly from the perspective of the rights of women. This report, by the special rapporteur on human rights and small arms, adds further impetus to international efforts to develop norms around civilian possession of small arms:

Under international human rights law, the State is responsible for violations committed with small arms by private persons who, because they are operating with the express or implicit permission of authorities, are considered to be State agents. Under this theory, the State would be responsible for failing to prevent, investigate or prosecute vigilante groups or private militias that carry out ethnic or religious massacres, or "social cleansing" of street children. There is also growing pressure to hold States accountable for patterns of abuses, such as the State's failure to establish reasonable regulation regarding the private ownership of small arms that are likely to be used in homicides, suicides and accidents; [including] its failure to protect individuals from a pattern of domestic violence. ${ }^{47}$

In other words, it is argued that under international law states have an obligation to protect their citizens from firearm violence and to regulate firearms appropriately. The discourse is shifting from "the right to bear arms" to "the right to be protected from those who bear arms". ${ }^{48}$

In spite of this, the establishment of international standards for the regulation of civilian possession of firearms has been blocked at many critical stages. The UN Commission on Crime Prevention and Criminal Justice, for example, shifted its focus to the Convention on Transnational Organized Crime. While it included a firearms protocol, the focus was entirely on import and export controls, marking and tracing; references to regulating civilian possession or use through licensing, registration and safe storage were dropped. Although initial drafts of the programme of action developed at the 2001 UN Conference on the Illicit Trade in Firearms in All Its Aspects included references to state responsibilities to regulate possession and use of firearms, all references to controls on civilian possession were dropped, largely in response to pressure from the United States and the American gun lobby. ${ }^{49}$ As a result, the programme of action has significantly lost value and relevance in addressing the global problem of violence against women. 
Nonetheless, at the national level progress continues. In spite of the removal of references to the regulation of civilian possession of firearms, many states reported on their progress during the review conferences in 2003 and 2005, implicitly recognizing that the regulation of civilian possession must be part of a comprehensive strategy. While one country (the United States) relaxed its firearms controls in the years covered by the reviews, more than 50 countries have strengthened them. The importance of adequate controls on civilian possession of small arms has been recognized at the international level as a matter of both women's rights and human rights. However, special interests have effectively blocked progress at the global level. In spite of this, countries are making progress at the regional and national levels.

\section{Gender and the demand for small arms}

Many theorists and activists stress the importance of understanding the factors affecting the "demand" for small arms that fuel conflict and violence. They discuss disparity in social and economic status, lack of basic needs (work, shelter), lack of protection from threats, lack of effective policing, lack of access to influence, lack of prestige goods; ${ }^{50}$ but they do not explain why the response to these forces is often very different for men and for women. Most of the existing work exploring the demand for small arms is silent on one of the factors most consistently found across nations, in times of both war and peace: most of those who use and misuse small arms are male. Understanding the (re)production of notions of masculinity is critical to understanding the demand for small arms, but it is an often-neglected area of research. Few mainstream researchers raise the issue of gender in this context. To date, most discussions of the role of gender are relegated to "gender studies" rather than addressed in the dominant literatures. There is an acute need to examine notions of masculinity and the roles that guns play in male culture, and to develop ways to decouple these.

In this vein, some criminologists, such as Gartner, have argued that empirical evidence supports the notion that cultural factors are stronger predictors of violence than economic factors. ${ }^{51}$ She notes that societies frequently at war consistently have higher rates of interpersonal and intra-group violence. In addition, homicide rates have consistently increased after wars within participant nations, whether they won or lost. Similarly, societies with violent sports and corporal and capital punishment tend to have higher levels of interpersonal violence. The socialization of males is critical in these contexts. Gartner notes that in such societies male children are typically socialized for aggression, in part to 
equip them for adult roles as warriors and soldiers. Cultural norms are both contributors to and consequences of violence, and small arms figure in this culture. ${ }^{52}$ Small arms facilitate and contribute to a cycle of violence, fear and further arming. While a wide range of factors fuel this cycle in many regions of the world, "gun culture" and "the culture of violence" are tightly coupled, and also tightly linked to notions of masculinity and male identity. ${ }^{53}$

Conventional notions of masculinity ascribe the role of protector and defender to men. In many cultures this role has become symbolized by the possession of a gun. Gun ownership has become a symbol of masculine power and status. A report by Oxfam and Amnesty International highlights the ways in which small arms are linked to male identity in a variety of contexts. ${ }^{54}$ In countries as diverse as Albania, Afghanistan, Somalia, Papua New Guinea and Iraq, guns are strongly associated with masculinity.

Nowhere is the association of guns and masculinity stronger than in US culture. Guns are essential equipment for cowboys and soldiers. The symbolic significance of guns and their connection to male sexual dominance has been made explicit in many ways, ${ }^{55}$ from Mae West's "Is that a gun in your pocket or are you just glad to see me?" to the marine in Full Metal Jacket who explains: "This is my rifle [military weapon]. This is my gun [grabs crotch]. One is for shooting and one is for fun." Rituals and cultural practices are important "carriers" of these cultures of masculinity. In Western industrialized societies, the media are one of the principal conduits of culture. The American media, in particular, tend to portray heroes using violence as a justified means of resolving conflict and prevailing over others. ${ }^{56}$ There is ample work suggesting that a link between gender, media violence and individual violent behaviour exists, although the definitions, analysis and explanatory frameworks of these connections differ. Research has tended to focus on exposure; for example, content analyses focused on violent acts or depictions of heroes connect the exposure to violence in media with a variety of physical and mental health problems in children and adolescents, including aggressive behaviour, desensitization to violence and fear. It has been noted that "titillating violence in sexual contexts and comic violence are particularly dangerous, because they associate positive feelings with hurting others". ${ }^{57}$ Studies have considered the effects of violent entertainment as well as video games. The American Academy of Pediatrics (AAP) has concluded that: "The murder rate of young blacks rose 300 percent during the three decades after television's introduction in the [United States]. Although exposure to media violence is not the sole factor contributing to aggression, anti-social attitudes, and violence among children and adolescents, it is an important health risk factor." ${ }^{58}$ As a result, the 
AAP has made a variety of recommendations regarding measures to regulate media content and media exposure. Similar studies have been conducted across different cultures, including Australia, Poland, Finland ${ }^{59}$ and South Africa. ${ }^{60}$

Lynch et al. found that exposure to video-game violence was positively correlated with hostile attitudes, arguments and fights, and negatively correlated with school performance. ${ }^{61}$ Sherry suggested that the effect of video games on aggression is smaller than the effects of television. ${ }^{62}$ Von Feilitzen and Carlsson conducted a broad-based study for the UN Educational, Scientific and Cultural Organization (UNESCO), and concluded that there were no simple causal relations but broader effects on psychology and behaviour. ${ }^{63}$ The analysis of empirical studies must be carefully nuanced. For example, some researchers frame their analysis in terms of gender stereotypes and role models, as it is clear that exposure to violence affects girls and boys in different ways. Others suggest that extensive exposure to violent media is symptomatic of other problems, such as a lack of parental care and supervision, while still others examine it in terms of violent media's contribution to a broader "culture of violence". Those perspectives which focus on "cultures of violence" rather than simple cause and effect appear to be the most promising, ${ }^{64}$ and underpin a wide range of media literacy and anti-violence campaigns such as CCAVE in Canada and Media Watch in the United Kingdom.

In exploring the media-culture-violence link, it is critical to understand that it is only one factor among many. It should not be used to minimize other factors such as socio-economic disparity, inequity or, more recently, access to small arms. For example, following the Columbine school shootings in the United States, then National Rifle Association (NRA) president Charlton Heston maintained that it was not the availability of guns that was an issue, but rather violent video games. This thesis has been advanced by some researchers who explicitly oppose gun control, ${ }^{65}$ and even in Michael Moore's (2002) documentary Bowling for Columbine, which suggested simply that the US culture of violence was the principal differentiator between gun use in the United States and Canada, downplaying the different availability of guns in each country.

Studies of American television and film have illuminated the relationship between guns, firearms and masculinity in the United States, as revealed in Hollywood action films. Scholars have discussed the rise of white, violent men as cinematic heroes (Sylvester Stallone, Arnold Schwarzenegger, Bruce Willis), for whom guns are iconic. It has been suggested that the appeal of these stereotypes is particularly strong with disempowered white working-class men. ${ }^{66}$ Furthermore, it has been noted that the depiction of gun use in films (particularly the use of guns for self-protection) is very much at odds with the reality of gun use by 
American men. The masculine discourse of self-protection thus remains pervasive, even though it flies in the face of reality. Related to this argument are the studies of the "mythic" constructions of gunplay in American movies. ${ }^{67}$

The power of advertising is well understood, and in relation to small arms unmistakably feeds into the gun culture of the United States. Studies have explored the ways in which gun manufacturers exploit traditional notions of masculinity in their advertisements by invoking the need for self-protection, "awesome power beyond belief" and occasionally relying on the scantily clad female models that populate car advertisements. ${ }^{68} \mathrm{~A}$ visual analysis of gun advertisements shows a number of common elements that are designed to invoke the mythic cowboy-cumRambo popularized by Hollywood. For example, in a single issue of Guns and Ammo magazine (2003), there are 15 advertisements which evoke popular action movies.

There have also been studies of the NRA's discourse and the advertising which pervades its magazines. O'Neill argues that the NRA's production of a "faceless and nameless threat, one which terrorizes us in our most intimate spaces... is not intended exclusively to demonstrate that Americans must have the right to keep and bear arms. Instead, the NRA also uses the 'Armed Citizen' to manufacture its own politically potent mode of masculinity by way of a strategically constructed threat." 69 The manufacture of hegemonic masculinity - best symbolized by Charlton Heston, with rifle raised and proclaiming "Out of my cold dead hands" - also links images of masculine heroes with the defence of "gun rights". The framing of NRA discourse includes extensive invocation of history (the founding fathers and the constitution), family values, honour and self-reliance. This linking of heroic myth to the struggles of the gun lobby pervades the lobby's discourse in many countries.

Studies of the construction of violent white masculinity in advertising also reinforce the cultural links between men and guns. For example, the creation of modern masculine archetypes such as the Marlboro Man and the ways in which "guns are an important signifier of virility and power... and hence are an important part of the way violent masculinity is constructed and then sold to audiences. In fact, the presence of guns in magazine and newspaper ads is crucial to communicating the extent of a movie's violent content... images of gun-toting macho males pervade the visual landscape." 70

Gun makers have also attempted to play on gender differences in appealing to notions of "femininity" and women's fear of violence in their efforts to fuel demand. The Canadian National Firearms Association, for example, published the "Lioness Method of Rape Prevention" with graphic details of violence, rape, AIDS etc. in an effort to encourage 
women to turn to guns for self-protection. ${ }^{71}$ Groups specifically claiming women's rights to defend themselves with guns have sprung up in several countries and some have tried to appropriate feminist discourse, dubbed "power feminism" by MS. Magazine, in an effort to encourage women to arm for self-protection. It is a strategy that mainstream feminism has soundly rejected. ${ }^{72}$

The NRA developed a column specifically aimed at women in an effort to persuade them to purchase guns, and even elected a woman as its president. A number of "feminists" have maintained that access to guns is part of the appropriation of male power. Armed and Female (1993), for example, was one in a series of books maintaining that "until women learn to use the weapons of men to defend themselves, they will continue to be the victims of men". ${ }^{73}$ Advertising campaigns, aimed at playing on women's fears, pictured women cowering in the corner from an intruder and mocked the notion of dialling "911" rather than packing a gun. Provocateurs such as Camille Paglia ridiculed the pro-control Million Mom March, saying, "I venerate the armed woman as a transcendent symbol of independent female power - from ancient goddesses like the Venus Armata or the knife-wielding Hindu Kali to the pistol-packing babes of 'Charlie's Angels'."'74

Research suggests that arming for self-protection increases the risks to women. ${ }^{75}$ Indeed, one study suggests that women with a gun in their home are three times more likely to be shot and killed than those in homes without guns. ${ }^{76}$ In spite of the aggressive efforts of the gun lobby, and contrary to fears of the emergence of "firearms feminism", there is little empirical evidence to support claims that rates of firearm ownership among women have increased in response to these persistent marketing campaigns - in the United States rates have remained relatively constant. ${ }^{77}$ Meanwhile, the most progressive women's organizations nationally $^{78}$ and globally ${ }^{79}$ support stronger controls on firearms as part of a strategy to prevent lethal violence against women.

The role of legislation in reducing the risk to women from gun violence has been discussed above. From a theoretical perspective, legislation to control the availability of small arms is generally understood in the context of "supply-side" strategies. ${ }^{80}$ However, there is an important interaction between the supply of and demand for small arms. In contexts where small arms are readily available, levels of violence tend to be rising, fuelling fear and the demand (primarily among men) for small arms. Legislation which makes access to small arms more difficult in effect raises the "price" of weapons and so limits demand. However, legislation can play a more significant role in shaping values and norms. We know, for example, that attitudes and legislation related to violence against women are significant in both reflecting and shaping values. And indeed, 
the extent to which violence against women is recognized as a crime varies from country to country.

Empirical research into attitudes towards killing in various contexts also reveals a strong link between laws and a culture of violence. There is a strong association between attitudes such as willingness to kill to protect property or avenge the rape of a child, lending support for capital punishment and homicide rates and attitudes to gun ownership. ${ }^{81}$ In general, countries and regions with high scores on the "culture of violence" scale also have high rates of particular types of interpersonal violence. These countries and regions tend to be resistant to laws that impose controls on firearms. This suggests that the relationships between laws, rates of gun ownership and values are potentially complex and mutually influencing. Society shapes laws and laws shape societies. ${ }^{82}$

Studies in the United States, for example, show distinct differences in attitudes to guns in regions characterized by the "frontier mentality" of the west and the south. These regions also boast what has been termed "a culture of honour". Southerners and westerners are likely to voice stronger support than northerners for honour-related violence (similar to what is seen in many southern countries). ${ }^{83}$ The same study shows states in the south were less likely to address domestic violence in the first place, for example through mandatory arrest. ${ }^{84}$ The role of conceptions of "honour" as a precipitant to violence has been explored in other cultures as well. For example, in certain gang cultures "disrespecting someone" can be punished by death. While Cohen shows huge differences in the approval of symbolic violence in the south and west of the United States, this did not correlate with rates of all types of actual violence. It did, however, correlate with homicides committed in the course of an argument (as opposed to those committed during the course of another crime). In Canada, resistance to gun control tends to parallel gun ownership rates, which, in turn, parallel rates of gun deaths and injury, especially domestic homicide rates. Thus it is evident that more work needs to be done to unpack these issues and, in particular, to understand cultures where notions of masculinity are not linked to guns.

Cultural differences in attitudes to firearms have often been explored as an excuse for resisting the development of international norms over weapons controls. For example, gun apologist David Kopel, in The Samurai, the Mountie and the Cowboy, maintains that history and culture in places like Japan and Canada are so distinct from the history and culture of the United States that their experience with gun control is not transferable. ${ }^{85}$ Others, of course, have maintained that while history and culture are useful explanatory frameworks, they are not excuses for inaction. After all, slavery was part of the history and culture of the United States, but that does not make it acceptable or ethical. The adoption of 
stronger gun laws is often linked explicitly to rejecting American culture. For example, in Great Britain, former cabinet minister David Mellor said: "What I want to see taken out are the Clint Eastwood-type guns which are an American accretion on our way of life. If we want to import the American way of life, we've got to come to terms with the American way of death." 86

The media play a critical role in shaping discussions of the role of guns in society and the need for controls on guns. A review of articles published in different countries shows a striking similarity in the framing and argumentation of the stories. With regard to coverage of gun crime, significant attention was given to gun-related incidents in the media, with little attention to the overall trend of gun violence; for example, evidence that gun-related violence is actually declining in the United States. Furthermore, random violence is featured more prominently than domestic violence, spurring a reaction of fear and dread in the general public.

The media's framing arguments about restrictions on small arms are also worth careful consideration. In Australia, Simon Chapman discusses framing of the gun-lobby debate in the media. ${ }^{87} \mathrm{He}$ points out that gun laws are framed as being both unjust and dangerous. The majority of gun owners, for example, are law abiding, therefore the "gun grab" was overkill and "besmirched the character of law abiding shooters by implying they were not to be trusted with these guns". The gun lobby spent much money on creatively demonstrating that gun deaths were uncommon compared to dozens of other preventable causes that claimed far more lives.

We see similar patterns in both South Africa and the United States. For example, in South Africa ${ }^{88}$ the gun lobby's argument parallels that of the NRA and gun-lobby groups in Canada, Australia and elsewhere. The main arguments of the gun lobby are that:

- legislation will not take one illegal firearm out of the hands of criminals

- money would be better spent putting police officers on the street

- restricting legal ownership of firearms is disarming the victims

- guns don't kill, people kill: "the true problem are those people who set out in the morning to murder, rape and pillage".

Resistance to including discussions of national firearms regulation in campaigns against small arms has been driven in large part by American opposition, which in turn has been driven by the NRA. ${ }^{89}$ As discussed above, resistance to gun control is steeped in traditional notions of masculinity, individualism and patriotism. Opponents of gun control try to frame it as "emotional, irrational", even emasculated, and to marginalize the supporters of gun control. For example, one study by a prominent gun collector argued that students who were pro-gun control were also pro-homosexual, pro-censorship of pornography and not experienced with guns. He implied that men who favour gun control are emasculated 
and tend to have "politically correct" attitudes. Women who support gun control do so in the context of controlling male violence and sexuality. Gun control is thus a symbolic attack on masculinity. ${ }^{90}$

Studies of gun-control movements in industrialized countries have demonstrated the critical role the media can play in promoting or undermining efforts, ${ }^{91}$ as well as the subtle ways in which women involved in the discussion are often marginalized. Those supporting gun control are seldom "experts" but often "anti-gun advocates". Women speaking on the issue are "a small but strident group of misguided people who lack a basic comprehension of how guns work" ${ }^{92}$ Expertise is often defined in terms of knowledge of and experience with guns rather than knowledge and experience with crime or violence prevention.

Summing up this section's discussion, the following points can be made. First, firearms ownership and use are primarily male practices closely linked to notions of masculinity. Second, powerful and often taken-for-granted cultural practices reinforce the link between guns and masculinity. Third, while cultural determinants are important, they are not deterministic. Many countries have made conscious decisions to reject cultures of violence by strengthening gun laws. And fourth, the media play an important role in shaping attitudes to guns and to the regulation of small arms.

\section{Gender and attitudes to small arms and regulation}

Given the different experiences of men and women with small arms, as well as the pervasive gendering of guns in society and even in the debates over controls, it is not surprising to see significant gender splits in attitudes to small-arms ownership and their regulation. Although men are more likely to be victims of gun violence, they are also more likely to be aggressors. Women are more likely to fear guns than are men, and gendered attitudes to guns are important in definitions of human security and human rights.

In a study of three high-crime communities in South Africa, for example, 34.4 per cent of women wanted to own firearms compared to 44.9 per cent of men. ${ }^{93}$ Another survey showed that only 38 per cent of South African women felt anyone should be allowed to carry a firearm compared to 46 per cent of men. ${ }^{94}$ Similarly, a survey conducted in Phnom Penh, Cambodia, an area with high rates of firearm injuries, indicates that 43 per cent of men would own a gun if it were legal compared to 31 per cent of women. ${ }^{95}$

While the United States has some of the least restrictive gun laws in the industrialized world, there is a clear gender split surrounding the 
gun-control issue. An Associated Press poll found that 66 per cent of American women supported stricter gun laws, compared with 45 per cent of men. While more than half of Americans indicated that recent shootings in the news had made them worry about their own safety, almost two-thirds of women said they were likely to feel that way. ${ }^{96}$ Indeed, there have been efforts, largely unsuccessful, to exploit this fear in marketing guns to women.

Women generally have more negative attitudes towards weapons than men, and are generally more committed to measures to reduce their misuse and proliferation. This is an important factor in terms of mobilization and resistance for policy change. Polls conducted in Canada illustrate a significant gender split in attitudes towards firearms. In one poll, 84 per cent of women and 65 per cent of men favoured restricting access to ammunition; support for mandatory firearm registration showed a much wider gap between men and women. ${ }^{97}$ While a poll in Mali showed 50 per cent of gun owners opposed gun-control legislation, 77 per cent of people living with gun owners supported it. ${ }^{98}$ The fact that women represent a very small proportion of gun owners, but tend to be victims of gun violence in greater proportions, indicates an imbalance that has been the basis for positioning this debate in the context of human rights and equity. ${ }^{99}$

Gender splits are observed in the voting behaviour of elected politicians. The final vote on the US Brady Bill highlighted this phenomenon. In the House of Representatives, 51 per cent of men voted for passage, compared to 81 per cent of women. In the Senate, the split was 60 per cent of men and 100 per cent of women in favour. ${ }^{100}$ Indeed, women have played a critical role worldwide in movements for stricter regulation. ${ }^{101}$

Gendered attitudes towards firearms also play into the intense and emotional arguments that emerge among opponents of regulatory measures that are aimed at controlling small arms. Few people object to the regulatory schemes in place to control cars, dangerous products or even pets with the intensity that they oppose regulations on firearms. ${ }^{3}$ Rational debate and the introduction of reasonable controls have been blocked in large part because of the politicization of the debate and the marginalization of women's concerns and perspectives.

Any discussion of the role of gender and attitudes to small arms must take into account the fact that differences in attitudes between cultural groups are much greater than gender differences within those cultures. While it is absolutely true that the vast majority of those who misuse small arms worldwide are men, we find that on many of the dimensions explored in this chapter, particularly attitudes to weapons and regulation of weapons, the cultural splits, even within the same region, are greater 
than the gender differences. For example, as noted above, a survey of South Africans' attitudes to firearms showed a gender split -46 per cent of men compared to 38 per cent of women believed "any adult should be allowed to own a gun". However, the gap between whites and blacks was far greater: 62 per cent of whites believed anyone should be allowed to own a gun compared to only 29 per cent of black Africans and 29 per cent of Indian South Africans. ${ }^{102}$ While class may be an issue, the differences in attitudes based on culture are much greater than the differences based on gender. A similar phenomenon is found in the contrasting the gender split and the cultural split between French and English Canadians. While 82 per cent of women support gun control, compared to 65 per cent of men nationwide, support in Quebec, the dominantly French province, is consistently around 90 per cent compared to support in Saskatchewan, a rural Anglophone province, at around 45 per cent. ${ }^{103}$ In Quebec, support even among gun owners is high. Moreover, there are often rural/urban splits and regional differences which are greater than the differences between men and women.

In sum, we find that, first, there are significant differences between the attitudes of women and men to firearms; second, cultural differences are, however, often even more pronounced; and third, understanding the differences between male and female attitudes to small arms is important to efforts aimed at reducing their proliferation and misuse.

\section{Gender and political processes}

Women have often taken the lead in disarmament and weapons collection programmes as well as campaigns to strengthen gun laws. In the Democratic Republic of Congo, various women's groups have called for disarmament as the first step towards solving any of their problems. Similarly, "Women in Liberia demanded disarmament before elections because elections taking place under militarized conditions are not free nor fair." 104 Various women's groups in that country have promoted a culture of peace by holding conflict-prevention workshops, implementing micro-disarmament projects and acting as bridge between various social adversaries. ${ }^{105}$ Moreover, the African Women's Anti-War Coalition and Women Waging Peace are initiatives connecting women addressing conflicts worldwide, and the latter acts as a forum for various peacebuilding projects. ${ }^{106}$ These movements tend to adopt holistic, broad-based approaches, and small-arms/gun control is usually an important component of their message.

Gender has played a role in shaping the evolution of policy regarding small arms worldwide. Not surprisingly, groups opposing regulation are 
dominated by men. On the other hand, many of the groups which are active in promoting the regulation of small arms worldwide are led or dominated by women. The Coalition for Gun Control in Australia and Canada, the Snowdrop Petition and Gun Control Network in Great Britain, Waffen-Weg in Austria and Gun Free South Africa are all led by women. ${ }^{107}$ Women's organizations have also been active in all of these countries. The US Million Mom March is a significant indication of the potential power of women to effect change. In Israel, Mothers Against Military Might played an active role dealing with the peace process in Lebanon. In Mali, women played a major role in the weapons collection programme. ${ }^{108}$ This holds true for many other peace movements worldwide. However, as most political institutions at all levels remain maledominated, there is a systemic bias against the introduction of more rigorous controls on small arms.

In Canada, the murder of 14 young women at an engineering school by a man who shouted "you are all a bunch of feminists" ensured a strong link between gun control and violence against women. The anniversary of the infamous "Montreal Massacre" of 6 December 1989 is a national day of mourning for the victims of violence against women. Legislation which was developed in 1991 and 1995 explicitly included provisions aimed at reducing access to guns among those with a history of violence against women. The 1995 legislation included a provision requiring current and former spouses to be notified when a person applies for a firearm, and continuous monitoring of firearm licensees is intended to ensure that licence eligibility is immediately reviewed when there is a domestic-violence incident. The online licensing and registration system also provides police with round-the-clock access to information about the presence of legal firearms when they answer domestic-violence calls. Murders of women with firearms have plummeted - by more than 60 per cent in the last decade alone - in part due to the stricter controls on firearms. ${ }^{109}$ Women led this movement, women's organizations were part of the Coalition for Gun Control (along with police, public health bodies and faith-based and other community groups) and women politicians played pivotal roles in ensuring the law passed, some voting against their party to support the law. ${ }^{110}$ Before the 2004 federal election, more than 70 leading women's organizations in Canada wrote to political leaders reaffirming their support for the legislation. The gender dimensions of the debate are also reflected in the ways in which the gun lobby targeted the leaders of the gun-control movement in Canada; not only did they receive death threats and hate mail, but also violent pornography, white supremacist rants and materials which clearly reflected the misogynistic undercurrents of the extremist opponents of the law. 
Similarly, in Australia women's groups played a key role in the debate leading up to the passage of national standards for gun control following the Port Arthur massacre in 1996. They challenged gun-lobby arguments, maintaining that the largest category of homicide among women occurs within the domestic context. Registration of firearms was presented as key to allowing police to remove firearms in situations of domestic violence and enforce prohibition orders. The issue of officer safety also came into play, following some specific incidents where police were killed while responding to domestic calls. It was argued that if they had known guns were present, they could have approached the situation differently. ${ }^{111}$ During inquiries and reviews of gun control held by some states, women's groups appeared as expert witnesses. On one occasion, when some states indicated they would pull out of making prohibitions compulsory for domestic-violence offenders, they were embarrassed nationally by women's groups. Women's groups also obtained a five-year minimum prohibition on owning guns for those who have restraining orders or have been convicted of any violent offence. In some states, prohibitions of up to 10 years are being issued. In various states, consultation committees have been set up to monitor implementation of the law, and women's groups are continuing to play a key role in that process. Similar to the Canadian context, the gun lobby also targeted women and "feminists" as the enemies of gun ownership and accused pro-control politicians of "trying to get the women's vote".

In the United Kingdom, organized women's groups played a more indirect role in the campaign to ban handguns which followed the murder of 16 primary school children and their teachers in Dunblane, Scotland. Gill Marshall-Andrews, for example, was one of the founders of the Gun Control Network, but she was acting as a concerned citizen who happened to be a woman. The Dunblane victims' families played an important role. Mothers and fathers gave interviews. While individual women made significant contributions, with the role of the victims' parents in the process and the speed with which the legislative changes were implemented, one would have to conclude this was not a gender-based campaign. While gun violence in the United Kingdom has continued to be fuelled with illegal guns, murders of women with guns have declined significantly since the ban. ${ }^{112}$

Some groups in the United States are specifically concerned about a gender perspective. The group Women Against Guns was founded in 1993 in response to efforts by the gun industry to market firearms to women. They rejected the notion that women could only be equal to men if they owned guns. They brought together 100 organizations to bring women into the debate over gun laws because they see themselves as responsible for the safety of their families. Efforts to use women to 
mobilize women on the issue are also evident. Among a range of progun-control articles in popular magazines, Mademoiselle, a magazine aimed at young women, ran an article which asked "Does Your Boyfriend Own a Gun?" 113 As noted above, the National Organization of Women (NOW) was a supporter of the Million Mom March in 2000.

In South Africa, the Domestic Violence Act (1998) was an attempt to prevent the occurrence of spousal violence involving firearms. Women historically were at the forefront of the gun-control movement in South Africa, and women's groups play an important role in Gun Free South Africa and the Gun Control Alliance (GCA). The GCA is a network of organizations and individuals calling for stricter control of firearms in South Africa. Currently, over 200 diverse national, regional and local organizations support the Charter for Gun Control, including business, health, religious, women's and youth organizations. These include Black Sash, Business Against Crime, Child Accident Prevention Foundation of South Africa, Disabled People of South Africa, the Human Rights Committee, Human Rights Institute of South Africa, People Opposing Women Abuse, Quaker Peace Centre, South African Association of Youth Clubs, South African NGO Coalition, South African Society of Physiotherapy and Red Cross Children's Hospital. Once again, leaders of the movement were targeted in particularly vicious ways because of their gender.

The use of firearms in violence against women in Brazil has been a significant focus of campaigning in that country. There have also been efforts to appeal to traditional notions of gender in efforts to counter gun violence, for example in the campaign of Viva Rio. The Viva Rio initiative looks to reduce the availability and use of firearms, notably in the poor areas of Rio de Janeiro, which has some of the highest rates of firearms deaths in the world. One of its approaches has urged, "Choose gunfree: It's your weapon or me!" The slogan seeks to mobilize the female population to refuse weapons and deconstruct the myth that firearms equate protection. ${ }^{114}$ Dealing with the culture of violence, and in particular attitudes towards guns, is an essential part of a strategy to counter violence, whether in the context of conflict, gang warfare or family violence.

International groups such as the Women's International League for Peace and Freedom (WILFP) and the International Alliance of Women (IAW) have also taken up the issue of firearms control at the United Nations, arguing that guns in the home pose a threat to women and children. The International Action Network on Small Arms (IANSA) has a women's caucus aimed at ensuring a gender perspective and voice. More recently, as part of their Control Arms Campaign, IANSA, Amnesty International and Oxfam have drawn attention to the use of guns in 
violence against women and the need for action. ${ }^{115}$ Ironically, however, while the global Control Arms Campaign invokes violence against women as part of its raison d'être, it pays little attention to the importance of national firearms legislation, one of the key measures proven to improve the safety of women.

Despite their role in promoting solutions, women are still often excluded from decision-making and policy. "Quite often, since men dominate the activities of war and violence, there is a tendency to assume that men should be the ones responsible for solving these problems, leaving women on the outside, capable as NGOs in helping forge the peace, but unable to address the serious issues once it is time to negotiate the future." 116 Women may be seen as "actors", but not necessarily as "experts". This discrimination is found in the small-arms debate as well. Expertise, particularly in the early stages, was defined in terms of knowledge of weapons (consider the composition of the UN Small Arms Expert Panel, for example). The way in which expertise is defined (e.g. technical knowledge of the weapons themselves rather than knowledge of violence or conflict prevention) also shapes the way in which the issue is addressed. Further, most political institutions at all levels remain maledominated, so there is a systemic bias against the introduction of more rigorous controls on small arms. As Canadian Senator Janice Johnson said, "If there were more women in parliament, we would not even be having this debate." 117

In sum, one can thus conclude that, first, given their different experience of and attitudes to small arms, women have often been at the forefront of efforts to improve gun controls. Second, political processes tend to define expertise in terms as knowledge of small arms rather than violence prevention, and women are often excluded from the processes. And third, while gender is not the only determinant of attitudes to small arms, the domination by men in the processes and the exclusion of women tend to impede the development of solutions

\section{Conclusions}

This chapter has shown that women have a very different relationship to weapons than men and are more likely to support legislation that severely limits access to weapons. Their exclusion from many of the diplomatic processes aimed at addressing the problem of small arms has, therefore, contributed to the lack of action on this problem, particularly where domestic regulation is concerned. While more exploration of the implications of the gendered nature of gun culture is needed, it is clear that understanding the ways in which culture shapes values is important 
in understanding the demand for small arms and official attitudes and policy, and in reshaping them. Meidzian maintains that while certain notions of masculinity were pervasive and biological tendencies to violence may exist, cultural norms can prove a strong antidote, as shown in her studies of adolescents in Amish communities. ${ }^{118}$ Culture, then, may be an explanation; it is, however, not an excuse for inaction.

There are several important conclusions that emerge from this discussion on small arms, culture and gender. First, it should be noted that guns are an essential part of the constructed concept of masculinity in many different cultures. Second, this chapter has argued that the media play a large role in (re)producing this notion of masculinity in industrialized countries. Through news, entertainment and advertising, it is clear that representations of gun culture in the media work to reinforce notions of heroes with guns. Gun manufacturers, playing on the mythic status of the gun and its role in the construction of masculinity, invoke it for purposes of advertising.

Furthermore, it has been established that women account for a higher percentage of victims of gun violence than of users of small arms and light weapons; therefore, they generally express greater negative attitudes towards weapons than men. They also tend to be more committed to measures created to reduce the misuse and proliferation of guns and gun violence. For these reasons, women have exerted significant influence in many of the movements aimed at reducing the proliferation and misuse of weapons. However, women have also been under-represented in the formal decision-making processes that affect the deployment of weapons as well as their use and control at local, national and international levels. Finally, it must be recognized that new perspectives which focus on human security will highlight governments' obligations to protect civilians from small-arms violence. This is something that may give added impetus to the people's right to regulate arms.

\section{Notes}

1. Cook, Philip J. and Jens Ludwig (1997) "Guns in America: National Survey on Private Ownership and Use of Firearms", Research in Brief, National Institute of Justice, May.

2. GPC Research (2002) "Fall 2001 Estimate of Firearms in Canada: Report on Findings", Public Policy Forum, Ottawa.

3. Cukier, Wendy (1991) Ceasefire: Guns and Violence against Women, Ottawa: Canadian Advisory Council on the Status of Women; Alberta Court of Appeal, Reference on the Canadian Firearms Act, 128 C.C.C. (3d) 225, at 339, Alberta, 1998.

4. Small Arms Survey (2002) Small Arms Survey 2002: Counting the Human Cost, Oxford: Oxford University Press, 2002.

5. Naraghi-Anderlini, Sanam, Rita Manchanda and Shereen Karmali, eds (1999) Women, Violent Conflict and Peacebuilding: Global Perspectives, London: International Alert. 
6. Cited in Meddings, David R. and Stephanie M. O'Connor (1999) "Circumstances Around Weapon Injury in Cambodia After Departure of a Peacekeeping Force: Prospective Cohort Study”, British Medical Journal 319, pp. 412-415.

7. Cukier, Wendy and Victor W. Sidel (2006) Global Small Arms Epidemic: From Saturday Night Specials to AK-47s, New York: Praeger.

8. Meddings, David R. (1999) "Weapons Injuries During and After Periods of Conflict: Retrospective Analysis", British Medical Journal 315, pp. 1417-1420.

9. Human Rights Watch (2001) "Women's Human Rights: Women in Conflict and Refugees", available at www.hrw.org/wr2k1/women/women3.html.

10. Reis, Chen, Kristina Hare Lyons, Beth Vann, Lynn L. Amowitz, Vincent Iacopino, Binta Mansaray, Adyinka M. Akinsulure-Smith and Louise Taylor (2002) "The Prevalence of War-Related Sexual Violence and Other Human Rights Abuses Among Internally Displaced Persons in Sierra Leone", paper presented at conference on The Role of Public Health in the Prevention of War-Related Injuries, Montreal, 9-11 May.

11. Krug, Etienne G., Linda L. Dahlberg, James A. Mercy, Anthony B. Zwi and Rafael Lozano (2002) World Report on Violence and Health, Geneva: WHO, available at www.who.int/violence_injury_prevention/violence/world_report/en/full_en.pdf/.

12. Cock, Jacklyn (1997) "Fixing Our Sights: A Sociological Perspective on Gun Violence in Contemporary South Africa", Society in Transition 1(4), pp. 70-81; Mathews, Shanaaz, Naeemah Abrahams, Lorna J. Martin, Lisa Vetten, Lize van der Merwe and Rachel Jewkes (2004) "Every Six Hours a Woman Is Killed By Her Intimate Partner: A National Study of Female Homicide in South Africa", MRC Policy Brief, South African Medical Research Council, Cape Town, pp. 1-4; World Health Organization (2001) Small Arms and Global Health, Geneva: WHO.

13. World Health Organization, ibid.

14. Hemenway, David, Tomoko Shinoda-Tagawa and Matthew Miller (2002) "Firearm Availability and Female Homicide Victimization Rates Across 25 Populous HighIncome Countries", Journal of the American Medical Women's Association 57, pp. $100-104$.

15. Ryan, E. (1998) "South African Women Speak Out", Gun Free South Africa, Johannesburg, June.

16. Fernandez, Rubem Cézar, Benjamin Lessing, Carolina Iootty, Julio Cézar Purcena, Luciana Phebo, Marcelo de Souza Nascimento, Pablo Dreyfus and Patricia Rivero (2005) Brazil: The Arms and the Victims, Rio de Janeiro: ISER.

17. Hung, Kwing (2005) "Firearms Statistics: Updated Tables", Department of Justice, Research and Statistics Division, Ottawa, January.

18. Carcach, Carlos and Marianne James (1998) "Homicide between Intimate Partners in Australia", Trends and Issues in Crime and Criminal Justice 90, July, pp. 1-6.

19. Violence Policy Center (2002) When Men Murder Women: An Analysis of 2000 Homicide Data, Washington, DC: VPC.

20. Ibid.

21. Hemenway, Shinoda-Tagawa and Miller, note 14 above.

22. STAR Kampuchea (1998) "Possibilities to Reduce the Number of Weapons and the Practice of Using Weapons to Solve Problems in Cambodia", STAR Kampuchea, Phnom Penh, 23 July.

23. Suleyman Goren, Mehmet, Yasar Tirasci and Serdar Kemaloglu (2002) "FirearmRelated Mortality: A Review of Four Hundred Forty Four Deaths in Diyarbakir, Turkey Between 1996 and 2001”, Tohoku Journal of Experimental Medicine 201, pp. 139145.

24. Ozcebe, Hilal (2002) "Firearm Deaths in Turkey", paper presented at conference on The Role of Public Health in the Prevention of War-Related Injuries, Montreal, 9-11 May. 
25. Hougen, Hans, Sidsel Rogde and Klaus Poulsen (2000) "Homicide by Firearms in Two Scandinavian Capitals", American Journal of Forensic Medicine \& Pathology 21(3), pp. 281-286.

26. Lecomte, Dominique and Paul Fornes (1998) "Homicide Followed by Suicide: Paris and Its Suburbs, 1991-1996", Journal of Forensic Science 43(4), pp. 760-764.

27. Saltzman, Linda E., James A. Mercy, Patrick W. O'Carroll, Mark L. Rosenberg and Philip H. Rhodes (1992) "Weapon Involvement and Injury Outcomes in Family and Intimate Assaults", Journal of the American Medical Association 267, pp. 3043-3047.

28. Campbell, Jacquelyn, Daniel Webster, Jane Koziol-McLain, Carolyn Block, Doris W. Campbell, F. Gary, J. McFarlane, C. Sachs, P. Sharpe, Y. Ulrich, S. Wilt, J. Manganello, X. Xu, J. Schollenberger and V. A. Frye (2003) "Risk Factors for Femicide Within Physically Abusive Intimate Relationships: Results from a Multi-site Case Control Study", American Journal of Public Health 93, pp. 1089-1097.

29. Ontario Office of the Chief Coroner (2002), quoted in Toronto Star (2004), 1 April, p. A8.

30. Chapman, Simon (1998) Over Our Dead Bodies: Port Arthur and Australia's Fight for Gun Control, Annandale: Pluto.

31. Sapnas, Kathryn G. (2004) "The Context of Violence in Women Hospitalized for Gunshot Wounds in Cape Town, South Africa", Journal of Multicultural Nursing \& Health 10(1), pp. 34-41.

32. Women's Services Network (WESNET) (1998) “Australian Women's Services Network Submission on Model Domestic Violence Laws", available at www.nwjc.org.au/ current/wesnetdv.htm.

33. Mathews et al., note 12 above.

34. Dansys Consultants Inc. (1992) Domestic Homicides Involving the Use of Firearms, Ottawa: Department of Justice.

35. World Health Organization, note 12 above.

36. Angus Reid Group (1993) "Gun Control: Public Support for Regulating Firearm Ownership in Canada", The Reid Report 8(9).

37. UN Commission on Crime Prevention and Criminal Justice (Sixth Session) (1997) "Criminal Justice Reform and Strengthening of Legal Institutions Measures to Regulate Firearms", Resolution L.19 E/CN.15/1997/L.19/Rev.1.

38. Cukier and Sidel, note 7 above.

39. Ibid.

40. Department of Justice Canada (1995) "Canada Firearms Act", Ottawa: Department of Justice Canada, available at http://lois.justice.gc.ca/en/F-11.6/239507.html and www. guncontrol.ca/Content/New/VictimsRightsAdvocatesAlarmed.pdf.

41. Vigdor, Elizabeth Richardson and James Mercy (2003) "Disarming Batterers: The Impact of Domestic Violence Firearm Laws", in Jens Ludwig and Philip J. Cook, eds, Evaluating Gun Policy: Effects on Crime and Violence, Washington, DC: Brookings Institution Press, pp. 157-216.

42. Cukier and Sidel, note 7 above.

43. Cukier, Wendy (2006) "A Pilot Project of a Community Based Approach to Implementing Firearms Legislation: Results of an Action-based Research Project in Québec", paper presented at Pre-conference on Reducing Firearm-Related Mortality and Morbidity: Data to Action, Durban, South Africa, 31 March-1 April.

44. Bunge, Valerie Pottie (2002) "National Trends in Intimate Partner Homicides, 1974 2000", Juristat 22(5), p. 5.

45. Frey, Barbara (2002) "The Question of the Trade, Carrying and Use of Small Arms and Light Weapons in the Context of Human Rights and Humanitarian Norms", Economic and Social Council Doc. E/CN.4/Sub.2/2002/39, 30 May, United Nations, New York. 
46. Cukier, Wendy, Tania Sarkar and Tim Quigley (2000) "Firearm Regulation: International Law and Jurisprudence", Canadian Criminal Law Review 6(1), pp. 99-123.

47. Frey, note 45 above

48. Cukier, Sarkar and Quigley, note 46 above

49. Laurance, Edward and Rachel Stohl (2002) "Making Global Public Policy: The Case of Small Arms and Light Weapons", Occasional Paper No. 7, International Alert, London.

50. Atwood, David and Cate Buchanan (2002) Curbing the Demand for Small Arms: Focus on Southeast Asia, Geneva: Centre for Humanitarian Dialogue; Krug et al., note 11 above.

51. Gartner, Rosemary (2000) "Cross-cultural Aspects of Interpersonal Violence: A Review of the International Empirical Evidence", paper presented at International Conference on Crime and Violence: Causes and Policy Responses, World Bank, Washington, DC, May.

52. Cock, note 12 above.

53. Cukier, note 3 above; Myrttinen, Henri (2003) "Disarming Masculinities", in Disarmament Forum: Women, Men, Peace and Security, Geneva: UNIDIR, available at www. unidir.org/pdf/Gender/6\%20myrttinen.pdf; Hillier, Debbie and Brian Wood (2003) "Shattered Lives", Oxfam and Amnesty International report, available at www. controlarms.org.

54. Hillier and Wood, ibid.

55. Goldstein, Joshua S. (2001) War and Gender: How Gender Shapes the War System and Vice Versa, Cambridge: Cambridge University Press.

56. American Academy of Pediatrics, Committee on Public Education (1995) "Media Violence", Pediatrics 96(6), pp. 949-951.

57. Ibid.

58. Ibid.

59. Huesmann, L. Rowell and Leonard D. Eron (1986) Television and the Aggressive Child: A Cross-National Comparison, Hillsdale, NJ: Lawrence Erlbaum.

60. Centerwall, Brandon S. (1992) "Television Violence: The Scale of the Problem and Where We Go From Here", Journal of the American Medical Association 267, pp. 3059-3063.

61. Lynch, Paul J., Douglas A. Gentile, Abbie A. Olson and Tara M. van Brederode (2001) "The Effects of Violent Video Game Habits on Adolescent Aggressive Attitudes and Behaviors", paper presented at Biennial Conference of the Society for Research in Child Development, Minneapolis, April.

62. Sherry, John L. (2001) "The Effects of Violent Video Games on Aggression: A MetaAnalysis", Human Communication Research 27(3), pp. 409-431.

63. Von Feilitzen, Cecilia and Ulla Carlsson (2000) Children in the New Media Landscape: Games, Pornography, Perceptions, Göteborg: UNESCO/Nordicom.

64. Gerbner, George and Larry Gross (1980) "Living with Television: The Violence Profile", Journal of Communication 30(3), pp. 10-29.

65. Centerwall, note 60 above; Grossman, Dave (1996) On Killing: The Psychological Costs of Learning to Kill in War and Society, Boston, MA: Little, Brown.

66. Katz, Jackson (2003) "Advertising and the Construction of Violent White Masculinity: From Eminem to Clinique For Men”, in Gail Dines and Jean McMahon Humez, eds, Gender, Race and Class in Media: A Text Reader, 2nd edn, Thousand Oaks, CA: Sage Publications, pp. 349-358.

67. Arjet, Robert (2002) "Gunplay: Men, Guns and Action Films in the United States", doctoral dissertation, Emory University, December.

68. Cukier, note 3 above.

69. O'Neill, Kevin Lewis (2003) 'I Need a Hero: Gender and the Rhetorical Dimension 
of the NRA's Use of Media", paper presented at Critical Themes in Media Studies Conference, New York, 11 October, available at http://beard.dialnsa.edu/ treis/pdf/ NRA \%20use \%20of\%20Media.pdf.

70. Katz, note 66 above.

71. Canadian National Firearms Association (undated) "Lioness Method of Rape Prevention", available at www.nfa.ca/publications/lioness.pdf.

72. Jones, Ann (1994) "Is This Power Feminism? - The Push to Get Women Hooked on Guns", Ms. Magazine 41.

73. Quigley, Paxton (1993) Armed and Female: Twelve Million American Women Own Guns, Should You? New York: St Martin's Press.

74. Paglia, Camille (2000) "The Million Mom March: What a Crock!", available at www. salon.com/people/col/pagl/2000/05/17/cpmillionmom.

75. Hemenway, Shinoda-Tagawa and Miller, note 14 above.

76. Wiebe, Douglas J. (2003) "Homicide and Suicide Risks Associated with Firearms in the Home: A National Case-control Study", Annals of Emergency Medicine 41, pp. 771-782.

77. Smith, Tom W. and Robert J. Smith (1995) "Changes in Firearm Ownership Among Women, 1980-1994”, Journal of Criminal Law \& Criminology 86, pp. 133-143; Cook and Ludwig, note 1 above.

78. National Organization for Women (2000) "NOW Activists to Join the Million Mom March", 12 May, available at www.now.org/issues/global/alerts/05-12-00.html.

79. Women's International League for Peace and Freedom, available at http://wilpf.org.

80. Cukier and Sidel, note 7 above.

81. McAlister, Alfred (2001) "Homicide Rates and Attitudes Towards Killing in Fifteen Nations", paper presented at Aiming for Prevention conference, Helsinki, 28-30 October.

82. Cohen, Dov (1996) "Law, Social Policy, and Violence: The Impact of Regional Cultures", Journal of Personality and Social Psychology 70(5), pp. 961-978.

83. Cohen, Dov (1998) "Culture, Social Organization, and Patterns of Violence", Journal of Personality and Social Psychology 75(2), pp. 408-419.

84. Ibid.

85. Kopel, David (1992) The Samurai, the Mountie and the Cowboy: Should America Adopt the Gun Controls of Other Democracies?, Buffalo, NY: Prometheus.

86. Quoted in McLeod, A. (1996) "A Shot in the Dark? Antigun Lobby in Britain Aims for Ban on Organization", Christian Science Monitor, 5 August.

87. Chapman, Simon (2001) "Advocacy in Public Health: Roles and Challenges", International Journal of Epidemiology 30, pp. 1226-1232.

88. Dempster, Carolyn (2000) "SA Targets Guns", available at http://news.bbc.co.uk/1/hi/ world/africa/969369.stm.

89. Laurance and Stohl, note 49 above.

90. Buckner, Taylor (1994) "Sex and Guns: Is Gun Control Male Control?", paper presented at American Sociological Association Annual Meeting, Los Angeles, 5 August.

91. Cukier, Wendy and Fred Fletcher (1999) "Media and Advocacy: The Gun Control Story", paper presented Canadian Communications Association Conference, Sherbrooke, May; Cukier, Wendy and N. Thomlinson (2004) "The Age of Missing Information: Canadian Media, Politics and the Construction/Deconstruction of the 'Billion Dollar Registry',", paper presented at Canadian Communications Association Annual Conference, Winnipeg, 3-5 June.

92. Gruenfeld, G. (1991) "Gun Control Lobby Small But Strident Group of Misguided People", Montreal Gazette, 25 January. 
93. Jefferson, Clare (2001) "Attitudes to Firearms: The Case of Kwa Mashu, TsoloQumbo and Lekoa-Vaal", July, ISS, Pretoria.

94. Gun Free South Africa (2000) "South Africans Support Civilian Gun Ban", available at www.gca.org.za/pressreleases/releases/gfsa20011023.htm.

95. Kappell, D., Y. C. Lin and S. O. Yem (2002) "Risk Factors for Wanting a Gun in Phnom Penh, Cambodia", paper presented at conference on The Role of Public Health in the Prevention of War-Related Injuries, Montreal, 9-11 May.

96. Associated Press (1999) "Women, Men Differ on Gun Control", Associated Press, 7 September.

97. Angus Reid Group, note 36 above.

98. International Committee of the Red Cross (1996) Mali: The Women and the War, Geneva: ICRC, available at www.icrc.org/Web/fre/sitefre0.nsf/iwpList153/ 596E0A67FAEF7068C1256C7500418ED3.

99. Cukier, note 3 above.

100. Jones, note 72 above.

101. Cukier and Sidel, note 7 above; Jones, note 72 above.

102. Gun Free South Africa, note 94 above.

103. Environics Research Group (2003) "Majority Support for Gun Control; Majority Support Continuation of National Firearms Registry", Queens University, Kingston, ON, available at www.queensu.ca/cora/polls/2003/February21-Support_for_Gun_Control.pdf.

104. Hill, Felicity (2001) "Statement", in Gender Perspectives on Disarmament, Geneva: United Nations, available at http://disarmament.un.org:8080/gender/14marilpf.htm.

105. Association des Femmes Pour les Initiatives de Paix (AFIP), available at www.grip. org/rafal/membres/afip.html; International Committee of the Red Cross, note 98 above.

106. Women Waging Peace, available at www.womenwagingpeace.net.

107. Cukier, Wendy (2000) "Women and Firearms in the International Context", International Peace Update 65(3).

108. Maiga, Mariam Jibrilla (1999) "Joining Hands in Collecting Small Arms: The Mali Experience", in Sanam Naraghi-Anderlini, Rita Manchanda and Shereen Karmali, eds, Women, Violent Conflict and Peacebuilding: Global Perspectives, London: International Alert.

109. Bunge, note 44 above.

110. Breton, C. (1999) "The Role of Women's Organizations in the Gun Control Movement in Canada", paper presented at American Criminology Society Annual Conference, Toronto, 17-20 November.

111. Ibid.

112. Cukier and Sidel, note 7 above.

113. Baumgardner, Jennifer (2002) "Does Your Boyfriend Own a Gun?”, Mademoiselle 106, August, pp. 81-83.

114. Fernandes, Rubem, Luciana Phebo and Pablo Dreyfus (2002) "Viva Rio", paper presented at conference on The Role of Public Health in the Prevention of War-Related Injuries, Montreal, 9-11 May.

115. Amnesty International, International Action Network on Small Arms and Oxfam (2005) The Impact of Guns on Women's Lives, Oxford: Amnesty International.

116. Mazurana, Dyan and Susan McKay (1999) Women and Peacebuilding, Montreal: International Centre for Human Rights and Democratic Development.

117. Cukier, Wendy (2001) "Gender and Illicit Trafficking of Small Arms", paper presented at International Women's Day Conference on Disarmament, Women's International League for Peace and Freedom Conference, Geneva, 7 March.

118. Meidzian, Myriam (1991) Boys Will Be Boys: Breaking the Link between Masculinity and Violence, New York: Doubleday. 


\section{Part I \\ Sexualized violence, gender and small arms}



3

\section{Girls and small arms in Sierra Leone: Victimization, participation and resistance}

Myriam Denov and Richard Maclure

Small arms and the antecedents of Sierra Leone's civil war

The structural antecedents of Sierra Leone's decade-long civil war (1991-2002) are complex and multifaceted, and intimately connected to a weakened state, institutional collapse, structural violence, growing mass disillusionment and small-arms proliferation. Like much of subSaharan Africa, Sierra Leone was integrated into the world system in a way that marginalized its traditional social systems and left its economy colonized by international enterprises and a kleptocratic governing élite. Over time, the long-standing institutional fragility of what has been referred to as Sierra Leone's oligarchic "shadow state" ${ }^{1}$ was undermined by the very corruption that sustained it. Inevitably, with poor governance and a weak economy, educational and occupational opportunities for young people were consistently thwarted. Within the context of widespread government corruption, mismanagement and institutional collapse, and with more than half the population of Sierra Leone under the age of 18, disillusion and anger among young people - especially young males in towns and cities - were infectious and volatile. ${ }^{2}$ Drawing upon this growing disillusionment, former Sierra Leonean Army corporal Foday Sankoh (backed by Liberian warlord Charles Taylor) formed the rebel Revolutionary United Front of Sierra Leone (RUF). Relying on the emancipatory rhetoric of "freedom, justice and democracy to all Sierra Leoneans", ${ }^{3}$ Sankoh systematically recruited largely uneducated, unemployed and

Sexed pistols: The gendered impacts of small arms and light weapons, Farr, Myrttinen and Schnabel (eds), United Nations University Press, 2009, ISBN 978-92-808-1175-9 
unemployable male youths to join a "movement" against the government. In circumstances of mounting insurgence, traditional institutions were gradually replaced by militarized structures that were sustained by an ethos of extraordinary violence. When Sankoh's message of political revolution failed to attract popular support, the RUF's aim of broad social "emancipation" was sidelined by the goals of wealth, power and control of the country's diamond mines. Marked as one of the most unrestrained fighting forces in recent history, the RUF invaded Sierra Leone from Liberia in 1991 and embarked on a decade-long campaign of terror characterized by indiscriminate violence and brutality against women, children and entire communities.

As in other civil conflicts, cheap and efficient small arms and light weapons, often purchased through illicit diamond sales, were widespread throughout the war in Sierra Leone. ${ }^{4}$ In taking control of many of the country's diamond mines, the RUF is reputed to have earned anywhere between US $\$ 30$ million and US\$125 million a year from illicit diamond sales. ${ }^{5}$ Most of this trade went through Liberia and was controlled directly by Charles Taylor. ${ }^{6}$ Indeed, at the height of Sierra Leone's civil war Taylor played the role of banker, trainer and mentor to the RUF by providing them with outlets for diamond exports in return for weapons and military training. Light and unmarked aircraft were used to transport arms to remote areas. ${ }^{7}$ Yet Taylor was not the only supplier of small arms to the RUF. The UN Security Council has indicated that, alongside Liberia, there is conclusive evidence to show that other West African countries - Burkina Faso, Niger, Gambia and Guinea - were also conduits for the supply of arms to the RUF. ${ }^{8}$ There is likewise evidence that profiteers in Belgium, the Netherlands, Kenya, Ukraine, Israel, South Africa, Tajikistan, Russia and the United States were involved in illegal transactions that fuelled the war in Sierra Leone. ${ }^{9}$ In addition to the trafficking of foreign-produced small arms, hand-made guns and other traditional arms were used as weapons of war by auxiliary forces, such as the local hunters known as Kamajors, who were drawn into the Sierra Leonean conflict. Despite a formal UN arms embargo from 1997 onwards (amended in June 1998 to exclude the Sierra Leonean government) and a 1998 regional moratorium on the production, procurement and sale of small arms, ${ }^{10}$ there is little indication that such efforts had any tangible effect on the smuggling of arms into Sierra Leone. ${ }^{11}$

As has been documented elsewhere, the negative social and economic effects of small arms on human development are considerable, involving fatal and non-fatal injuries, the treatment and rehabilitation of firearm casualties and the costs of long-term disability and lost productivity. ${ }^{12}$ Equally disturbing are the indirect and less visible costs of gun violence. While small arms in and of themselves do not cause war, ethnic and reli- 
gious strife or political instability, their proliferation fuels these conditions in no small measure. ${ }^{13}$ As is noted in other chapters in this book, small arms can prolong the duration and intensity of conflict, undermine peacebuilding efforts, threaten economic development and social cohesion and increase the culture of violence. ${ }^{14} \mathrm{~A}$ particularly disturbing result of global small-arms proliferation has been the rise of child soldiery throughout the developing world. ${ }^{15}$ Until recently weaponry was either too expensive or too heavy for children to handle. ${ }^{16}$ With the development of lightweight automatic weapons, however, particularly the AK47 and the M16, as well as the increased availability of inexpensive light weapons that have become largely redundant in Northern countries following the end of the Cold War, children have moved from the margins of war into the very heart of modern conflicts.

During Sierra Leone's decade-long civil war, an estimated 20,000 Sierra Leonean children were actively engaged as combatants fighting for the RUF and for government and civil defence forces. ${ }^{17}$ The involvement of children in this horrific conflict was rooted not only in the proliferation of small arms, which children could easily manipulate, but also in Sierra Leone's above-noted history of structural violence. With the stability of tradition diminished and frameworks of cultural continuity eroded, and with aspirations for education and meaningful work denied to most children and youths, young people were vulnerable to the influence of emergent "warlordism" in the country. While some children joined the RUF willingly, the majority of them were abducted and press-ganged into armed conflict. ${ }^{18}$ Paradoxically, through a combination of indoctrination and brutal coercion, most of these children came to regard the RUF as a source of survival, protection and family-like solidarity. ${ }^{19}$ For many as well, the power of the gun came to be regarded as an effective means of altering their status of indigence and despair, ${ }^{20}$ and thus led them to become perpetrators of extraordinary violence.

\section{Girl combatants in Sierra Leone: Under-reported and misunderstood}

While there is ample descriptive evidence of the conditions and factors underlying the rise of child soldiery and the proliferation of small arms in Sierra Leone and elsewhere in the developing world, most of the literature has portrayed child soldiery as a uniquely male phenomenon and has failed to include gender perspectives on conflict and small arms. Given women's and girls' low status within Sierra Leonean society and their exclusion from social, political and economic power and influence, ${ }^{21}$ it is perhaps not surprising that there have been very few accounts of 
girls' involvement in the conflict. Nonetheless, the impact of Sierra Leone's conflict on girls has been significant. The direct effects have included victimization through acts of murder, torture and rape, while the indirect effects have included displacement, loss of home or property, family separation, poverty and illness. ${ }^{22}$ Girls also participated directly in hostilities; approximately 30 per cent of the child soldiers in rebel forces were females. ${ }^{23}$ Yet so far there has been little empirical information that distinguishes the experiences of girls as child soldiers from those of boys. ${ }^{24}$ In this chapter, therefore, drawing from a study undertaken by a Canadian research team in conjunction with Defence for Children International Sierra Leone (DCI-SL), a national NGO, we trace the perspectives and experiences of girls in the RUF's fighting forces in Sierra Leone. ${ }^{25}$ In particular, we examine the factors that propelled girls into the world of armed conflict and use of small arms, and their experiences as victims and as perpetrators of violence. In so doing, we explore the dialectic between girls' victimization in the context of a savage conflict that had profound structural antecedents and their innate capacity for reasoning and independent choice during the conflict, whether through active participation or through resistance. It is this juxtaposition of structure and agency that frames our case study of girls, small arms and armed conflict in Sierra Leone and provides insights into the challenges of the rehabilitation and reintegration of girls in post-conflict circumstances.

\section{The case study}

This study employed a qualitative approach, using interviews and focus groups as the main instruments of data collection. A qualitative approach, which emphasizes depth and detail rather than representativeness, is particularly suitable for uncovering girls' harrowing experiences as victims and participants in armed conflict and the effects of those experiences. A significant aspect of the study has been its attempt to gain a "thick description" of the mental and experiential world of girls in fighting forces, and the transitions into and out of violent conflict that have been inherent to this world. ${ }^{26}$

In-depth semi-structured interviews focusing on the experiences and perspectives of girls in fighting forces were undertaken over an eightmonth period between May and February 2004 with 40 girls living in the north, south, east and west of Sierra Leone. The girl respondents, all of whom had been under the age of 18 years at the end of the conflict, were identified and invited to participate in the study with the assistance of Sierra Leonean research partners whose existing ties and established trust in respondents' communities facilitated the process. Participants 
were between the ages of 14 and 21 at the time of the interview. All of the girls had been abducted by the RUF and had remained under rebel control for periods ranging from a few months to seven years.

The majority of participants were interviewed twice - first by a Sierra Leonean researcher in the child's native language (Krio, Mende, Temne or Limba), and a second time, several months later, by Denov with the assistance of an interpreter. All interviews were audio-taped and later transcribed and translated into English.

Focus groups with girls served as the second means of primary data gathering. The same girls who participated in in-depth interviews were invited to participate in focus groups designed to ascertain the psychosocial needs of girls in fighting forces. To benefit from their unique knowledge and experience, six girls who had been part of the RUF during the conflict were invited to lead focus groups comprised of three to four girls who had been involved in hostilities as either victims or combatants, or both. Focus-group leaders were selected by the research team on the basis of their interest in the project and their maturity, and were provided with extensive research training prior to undertaking the focus groups. It was hoped that inviting girls who were former combatants to play a lead role in focus-group interaction would not only enhance the richness of the discussion and therefore the quality of the data, but would provide purposeful activity and structure that would be educational and empowering, and thus enhance their self-esteem. In the following thematic examination of the experiences and perspectives of these former girl soldiers, we rely extensively on excerpts from their own voices to highlight the uniqueness and the frightfulness of their experiences in the world of armed conflict.

\section{Girls' initiation into the use of small arms and the world of armed conflict}

Girls' introduction into the world of armed conflict was an intense experience that involved a process of conscription, role allocation and training. Here we outline the ways in which girls were recruited into armed conflict, the varied roles that they were required to perform and the combat training they received that cumulatively facilitated their initiation into the rebel armed forces.

\section{Recruitment}

While other accounts of child soldiery in Sierra Leone indicate that some children willingly joined the rebels, all of the girls who were interviewed 
for this study stated quite clearly that they were abducted by the RUF under circumstances of extreme coercion, violence and fear. In most cases, the beginning of their initiation into the world of conflict and small arms was under the threat of a gun:

During the night, men came into our village and began to fire shots... There were shouts of "get them, catch them" from all directions. My brother and I ran into a bedroom, locked the door and hid under the bed. But they kicked the door in... they found us and threatened us at gunpoint... They took all of [the family's] valuables and told my brother and I to carry them on our backs. I was carrying a huge load, including a mattress and it was too heavy for me I couldn't even walk... I was 12 years old when captured and was with the [rebels] for five years.

The experience of being captured at gunpoint eerily anticipated the world into which they were being coerced when their captors, and those who threatened them with death, were children of their own age bearing lethal weapons.

[I was] captured by a young boy who was armed. He said that he had been sent by his commando in the RUF.

All the girls interviewed for this study spoke of their intense fear when they were forcibly separated from their loved ones.

I felt so horrible. I was scared to death. I was trembling and even had to urinate on myself.

I was seven years old at the time and we had already been separated from our parents ... I didn't want to leave my older sister's side. The woman rebel told me if I didn't come, she was going to kill me. I was so afraid and I was crying. Then she dragged me away.

\section{The multiple roles of girls in the RUF}

Once captured, girls were required to perform an array of tasks to support rebel activities. In most cases, girls had multiple roles and were not assigned to any one task. Their duties often varied according to their age, physical strength and the circumstances of the armed group. Younger girls, and those who were newly captured, tended to be relegated to a wide variety of domestic tasks that contributed to the overall functioning of rebel activities. Such responsibilities included cooking, washing dishes, fetching water and firewood, laundering and taking care of younger children. Others were required to carry heavy loads of small arms, ammu- 
nition and looted goods. For many girls the work was difficult and strenuous.

We were ordered to beat the rice. We had to do it for hours and hours. My hands were bleeding and they would not let us stop. I was tired of the whole thing and in so much pain.

Failing to perform one's domestic duties in a timely or efficient manner often led to harsh punishment, and even death.

If one of the commandos told you to fetch water and you were slow at performing the task, you would be beaten... Their wives would utter obscenities against your mother. Sometimes, as punishment, you would be starved.

If you refused or failed to do what you were told, they would put you in a guardroom or tie you up. In some cases, one of [the commanders] might pass a command saying "Kill that person for not taking orders."

Despite their peremptory treatment and the arduous nature of the work, many girls saw it as a preferable option to fighting and thus strove to perform their domestic duties well in order to avoid combat.

I was responsible for cooking and I always did it well because I did not want to leave the [domestic duties] for jobs like combat which were more deadly.

Also included as a "duty" for most girls was the provision of sexual services to the men and boys in their group. Indeed, all but two girls interviewed for this study reported being subjected to repeated sexual violence. Gang rape and sexual assault by single individuals were common. This accords with estimates that between 215,000 and 257,000 women and girls in Sierra Leone were raped during the conflict. ${ }^{27}$

I had no relationships [during my time in the bush]. I was a mere sex machine. They used me anytime they wanted.

We were used as sex slaves. Whenever they wanted to have sexual intercourse with us, they took us away forcefully and brought us back when they finished with us. Sometimes, other officers took us up as soon as we were being finished with and subsequent ones were particularly painful... I don't even know who might have been the father of my child.

While sexual violence was widespread and brought debilitating physical and psychological after-effects, many girls were forced to "marry" individual rebels. Euphemistically referred to as "bush marriages" or 
"AK-47 marriages", this was tantamount to sexual slavery whereby girls were deemed to be the (sexual) "property" of specific RUF males. Yet as explained by the respondents for this study, once "married" to a male commander who held a senior rank, girls could actually benefit by access to more food, a higher social status within the group and a degree of protection from other males.

The girls who were serving as wives were treated better, and according to the rank and status of their husbands... At the beginning, I was raped daily. At least one person would come to me for sex... I was every man's wife. But later, one of them, an officer, had a special interest in me. He then protected me against others and never allowed others to use me. He continued to [rape me] alone and less frequently.

Combat activities were a significant part of the duties of many girls. Some reported that when first captured, they initially held only domestic roles. However, later on they became part of the fighting forces. One girl explains:

Initially, I used to carry heavy loads and do domestic work but later I became part of the fighting force, to attack and defend.

Other girls were forced to carry arms only in situations where there was a lack of military power on the side of the fighting forces:

[The girls] were just there mainly to prepare the stolen food the [fighters] came with. We were cooks and they slept with us whenever they wanted... But sometimes we would need all the manpower we had. The girls would then, under instructions and directions, do some fighting.

However, for several of the participants, combat activities formed the crux of their involvement in the conflict. As this former combatant explained:

Our only motive to exist was killing. That is the only thing that we thought about ... I burnt houses, captured people, I carried looted properties. I was responsible for tying people, and killing. I was not too good at shooting, but I was an expert in burning houses. This was less risky. We could just enter the house after the enemy had left the area and set it on fire with kerosene or petrol.

\section{Training in small arms and combat}

All of the respondents in this study reported some form of physical and technical military training as part of their initiation into the RUF. Yet the 
content and quality of the training varied significantly. Some girls recounted their discomfort with the entire training exercise.

We were trained by a commander's wife - Mariatu. I felt very uncomfortable during the training. I was very nervous about it and I was trembling. But Mariatu was encouraging us and each time we practised firing the gun, she would tell us that we could do it. She said that she was a woman too, and that if she could do it, we could do it.

For some girls training was cursory, especially when the RUF was engaged in protracted conflict and enemy attack was imminent. For others, however, training was more intense and lengthy. In all cases, it was designed to harden the girls so that they could fight fearlessly and be immune to killing.

When we were captured... they took us to their base and trained us. They trained us to shoot guns, to run, escape and to fight... They taught us how to load our magazines, press the trigger, put it in rapid firing. Some forms of physical training [were involved] like jogging... They also showed us how to set an ambush, how to attack and defend... It was strenuous... After the training with the guns, they would bring someone for us to kill. Each one of us was forced to kill.

I was given training on how to kill... I learned to kill, to cut somebody's throat... They trained us to use a gun. We were taken for training early in the morning to load the gun and fire ... and to dismantle a gun quickly ... Basically, we were told to fire on people above the waist. This would ensure that they would die. If we just wanted to intimidate people and not kill them, we were trained to point the gun in the air. This was important because we were told not to waste any cartridges or ammunition...

The RUF's campaign of terror also included the systematic maiming of civilians. In response to the 1996 Sierra Leonean presidential election campaign, and particularly the campaign slogan of "let's put our hands together to create a new future", the RUF embarked on mass amputations to terrorize the population and punish them for voting. There were special RUF units deployed to cut off hands whose members received a promotion when they returned with a bag of hands. ${ }^{28}$ Amputations, which continued to be a terror tactic used by both the rebels and the Sierra Leonean Army during the conflict, were often part of the duties of our girl respondents. When asked if they were trained to carry out amputations, one respondent explained:

Not really. One would learn from experience. We were told to cut either at the wrist or at the elbow. We were told to tie them up before we began to cut. 
Several girls reported that to enable them to train and fight more effectively, they were given alcohol and injected with drugs. Rarely did they know what they were being injected with. ${ }^{29}$ Invariably, however, the drugs were effective - they engendered feelings of strength and a readiness to pick up their weapons and kill.

When they saw how nervous and uncomfortable we were, they gave us drugs... Before the injection [in the arm], I was nervous, afraid and unsure of myself. Later, after the injection, I felt more confident.

Sometimes we were given drugs. When we took those drugs we grew strong at heart. Many of us would never have had the nerve to attempt to kill otherwise... The drugs were helpful to accomplish our assignments.

The abundance of illicit drugs greatly facilitated the recruitment and training of children, and, importantly, the transmogrification of disoriented and highly impressionable youngsters into ruthless combatants.

In addition to these forms of physical and technical training, the effectiveness of girl fighters was increased through indoctrination. It was essential that they develop a strong belief in, and affiliation with, the RUF cause of overthrowing Sierra Leone's government. Researchers who have explored the hidden world of professional torturers have observed that, as a part of their training, former civilian identities are broken down in an attempt to build up a new identity based upon an identification with the torturer's group subculture, ideology and worldview. ${ }^{30}$ Sierra Leonean girls reported examples of similar ideological training by their captors which, in their view, made them more receptive to the cause of the rebels and thus more willing to fight:

When we were recruited there was a meeting held with all the recruits. At the meeting they were preaching that those in power were not giving all people equal access to benefits and that [the rebels] needed to get control... I was convinced by this meeting and it pushed me and motivated me to go to war.

I did not willingly go and join them, but when I was abducted and my consciousness was raised about the movement, I became willing to fight.

A factor which facilitated both the weapons training and the indoctrination of girls was that they were constantly exposed to violence, which eventually rendered it routine. Their experiences resonate with Kelman's observation about the normalization of violence. ${ }^{31}$ When individuals perpetrate acts of violence and torture, over time they tend to see themselves as performing a routine, even professional, job. ${ }^{32}$ This sense of the routinization of violence was expressed by a number of the respond- 
ents in our study. As the war dragged on, many girls came to view participation in killing as simply a normative act, whose senselessness they had learned not to question:

Killing was just part of the normal activities of the RUF... Overcoming the enemy was part of our job... Once you were part of the fighting force, you should be seen killing someone even without a reason. This shows that you were committed and ready to work with them.

Children amid the RUF were viewed as resources to be exploited, particularly given their obedience to adult authority and their malleability and effectiveness as fighters. Taking full advantage of their vulnerability and dependency, the RUF deliberately invoked strategies designed to desensitize children to violence and turn them into proficient fighters. As an example, when committing a violent act, children were forbidden to show any remorse, sadness or shame. Instead, following brutal acts of torture and violence, they were encouraged and even coerced into participating in acts of celebration.

[Whenever we engaged in violence] you were not permitted to show [negative] emotions. Everyone always had to show happiness and laughter... Sometimes we sang, shouted and danced for doing or seeing what we had done to peo-

ple... This was to train the children... All of this mayhem and celebrating was part of the culture of the RUF.

As the girls clearly articulated, a key characteristic of life among the rebels was the culture of violence that pervaded every aspect of their daily routines and activities. In the next section we further examine this culture of violence, particularly as it pertains to girls' experiences of victimization and perpetration of violent acts during the Sierra Leonean conflict.

\section{Girls in the RUF: Drifting between victimization and perpetration of violence}

The limited available literature on the experiences of girls within the context of armed conflict has underscored their ongoing experiences of brutal victimization. ${ }^{33}$ The accounts of our girl respondents support such findings. During their life with the RUF, violence was an integral feature of daily interaction and ranged along a continuum from verbal abuse to outrageous acts of wanton cruelty, consistently under the peril of a gun. At one end of the continuum, interviewees spoke of those with power, almost always male, exercising their authority by shouting commands 
and threatening girls with rape or death if they did not comply. An aura of terror, repeatedly articulated, was a key factor in ensuring cohesion and obedience within the group. Such terror is reflected in this statement by an ex-combatant who was branded with the letters "RUF" and "AFRC" on her breast to prevent her from fleeing the group:

[People] cried while they were waiting to be branded. I didn't cry openly but I cried in my heart. If you cried openly they would ask you: "Do you want us to wash you or to brand you?" "Washing" us meant killing. After they branded me I just cried and cried.

Further along the continuum, most girls who were attached to rebel groups reported being subjected to regular physical assaults, through either beatings or rape:

I was beaten several times and they used electric cables [to beat me] for not finishing cooking food in time... I was tied to a tree and starved.

The more senior men had the power to say "this [girl] is mine, this one is mine". After they captured women, they would rape them. I was raped the moment they captured me at 12 years old... and I bled and bled... I could not walk. The man who raped me later carried me on his back.

While most of the worst excesses of violence on girls and women appear to have been perpetrated by boys and young men, particularly the recurrent sexual assaults, physical violence was a currency of interaction and authority among females as well:

[One] woman found out that a girl was impregnated by her husband and she told her to come to see her. The girl went to see her and the woman tried to strangle and kill her. Later on in her pregnancy, the woman would try to punch the girl in the abdomen and was trying to kill the baby.

In the face of persistent violence or threats of assault, mutilation and death, a primary compulsion was to survive. This generally meant obeying whatever command was issued. Invariably, therefore, the line between being a victim of assault and a perpetrator of violence was blurred:

[The] colonel gave me a gun and instructed me to fire a shot. I told him I didn't want to hold a gun. He threatened me to do whatever he commanded otherwise he was going to kill me. I then did as he commanded and fired my very first shot in the air nervously. 
That girls were victims of harsh violence, often under the threat of a gun, is obvious. Yet a singular focus on situations of female victimization tends to oversimplify the layers of complexity that surrounded girls' experiences with the RUF. For in fact, many girls who were victimized by their commanders often went on to become their unwitting soldiers and allies. As time wore on, the "enemy" was transformed from those individuals who captured and coerced them into those who fought against their captors. This transition from victim to perpetrator was often a gradual one:

I didn't have the mind to kill someone initially... but later on I enjoyed the wicked acts... I was responsible for killing anybody that was assigned to die. I was so happy and vigilant in carrying out this command.

As they began to identify more with their abductors, many girls were actively involved in perpetrating acts of violence, and became adept at using weapons as a means of attaining power and status. Actions that were initially alien and frightening eventually became synonymous with expressing their new group identity, and perversely were seen as a source of recreation, excitement and skill.

By then I felt good, especially when I was with my colleagues... I was an expert in burning houses... The flames form large chunks of fire like those in the movies. They were very exciting.

I enjoyed firing guns without killing people. I would let off several rounds in the empty bush when we were just having fun.

Significantly, many respondents recounted these experiences to interviewers with a sense of pride, accomplishment and even nostalgia. Given that many female and male youths have come to associate the post-war period in Sierra Leone with their current low status and sense of powerlessness, it was not entirely surprising that some of our participants appeared to yearn for the excitement and sense of self-importance that they had experienced as fighters during the war.

It is important to note, however, that the transition from "victim" to "perpetrator" was not a linear one; nor is it true that all - or even most - girl recruits experienced the full transition from victim to hardened combatant. Instead, many girl combatants continually drifted between committing acts of violence and being victims of violence perpetrated by others. For some girls, the complexity of this situation and the feelings it evoked often brought about much shame and confusion. Most of those 
who fought with small arms appear to have maintained a substantial degree of sensitivity and abhorrence to the social situations and actions in which they were caught, but over which they felt they had no control:

[The combatants] were very nervous and wept bitterly when out of sight of the rebels. Some even fainted at the sight of dead bodies.

Yes, the [combatants] felt bad, lonely and always kept to themselves. They cried secretly.

While most former girl combatants expressed sadness and guilt about their part in the war, a few quite candidly revealed that carrying and using light weapons gave them a sense of power and control which at the time they relished. This thrill in handling weapons may have been tantamount to experiencing a form of emancipation from previous relations of gender dependency and subservience.

I felt powerful when I had a gun. As long as you are holding a gun, you have power over those who don't. It gave me more status and power.

On the whole, the structure of the RUF mirrored the traditional patriarchal hierarchies of the region, which relegated girls to lower social standing than that of most boys. Yet the occasion to use a gun elicited for some girls a sense of personal power over others, and feelings of elation emanating from such power. Although carrying weapons did not alter their relatively low status within the rebel group, it did provide them with an opportunity to achieve power outside the group, particularly over civilians. It also generated increased pride, self-confidence and a sense of belonging:

I was not very powerful in my own group, but I had a lot of power over civilians. The commander would give us each a civilian - he would say "this one is yours, this one is yours" and you would kill the one that was given to you. I was quite enthusiastic about it - I was proud and confident. I felt good - that was one way of building confidence in me that I am just like them.

The discovery of power through the use of guns in many respects was intoxicating for girls. This was exemplified in the account of one interviewee who described her experience of demobilization at the end of the conflict. Although no longer able to exercise control and domination through the brandishing of a weapon, she was nonetheless able to continue to exercise power over other children after being elected "head girl" in the demobilization camp: 
When I was in the demobilization camp, I was elected by the others as head girl... I was very glad. This way, I could control the others and not do any work myself. I would delegate who would do what chore and they had to listen to me. If they disobeyed me I would punish them ... I would starve them for a day... I was powerful in this camp... I liked it... I miss being in the camp. I had more power in the camp than I did in the bush.

As the narratives of these girls attest, their experiences with the RUF were by no means one-sided. All of them were subjected to brutal victimization by their captors. Yet to characterize them solely as victims is to present a skewed picture of the lived realities of these girls, and especially to dodge the question of their potential to perpetrate violence in the fragile post-war period. As we have seen, many girls became active combatants, perpetrating acts of violence and cruelty themselves and experiencing a commonly described rush of power in holding and using weapons of war.

\section{Female resistance and solidarity}

While recent studies of the RUF have emphasized the culture of violence as a basis for maintaining its militarized solidarity, ${ }^{34}$ there has been very little assessment of either gender differentiation within the RUF or modes of resistance within what was essentially a totalitarian social environment. As we discerned from our interviews, however, numerous girls explained that despite their subservience and victimization they nonetheless strove to counter the RUF's culture of violence by resisting authority structures in subtle and resourceful ways and forming peer relationships that helped them to fend off complete desensitization to the fear and cruelty surrounding them. For many girls, a critical aim of resistance was to thwart the potential of sexual assault. Pretending to menstruate was one tactic: one respondent described how, to avoid being raped, "I would fix a pad as if I was observing menstruation." Other respondents surreptitiously ignored orders to kill during battle:

While on patrol if we came across [unknown] people they would order us to kill them. But I was not really interested in killing people... [I] would normally fire, intentionally not aiming well. [I] would then report that the mission was completed without really killing the people.

My first time in combat I was just firing sporadically. I was not really aiming at anything at all. I wasn't interested in harming anyone. 
Some particularly courageous girls recounted collective efforts to escape the RUF, all the while being fully aware of the consequences of violence or death if they were discovered.

I was about 10 years old at the time... Several of us small children sat together and planned our escape... We decided that when and if we are attacked by the $\mathrm{CDF},{ }^{35}$ we will not go with the rebel group, but we will go with the CDF. Everyone knew about the plan so when the CDF did attack, we ran away.

I was tired and in so much pain - that's what motivated me to try to escape. When I went to fetch water, I tried to escape. I wanted to use the opportunity to cross the river. But when I ran into the bush there was a commander who [saw me]. He ran after me.

Although most respondents were unsuccessful in their attempts to escape, it was clear that they demonstrated a capacity to organize and to act collectively with extraordinary courage. Indeed, for many girls the formation of close relationships and a sense of solidarity with other girls and women proved to be an effective way of reducing their fear and warding off the threat of violence. Fostering supportive female relationships not only brought a degree of solace, comfort and solidarity, but also created a unique physical and emotional "space" where males were inherently excluded. For example, one girl explained the importance of talking to other girls about her experience of rape and sharing it with them:

One day a girl was brutally raped and she bled so badly she died... I had heard about it and was so affected by it, but I was afraid to discuss it... Two girls began discussing it and I overheard them. We all sat down and started sharing our stories [of rape]... I felt much better after this because I thought that I was the only one to have this happen.

Another girl, who became pregnant as a result of rape at the age of 12 , spoke of the reliance of the younger and inexperienced girls on the older women for knowledge and mentorship, and on the unique sense of community that often developed among girls and women.

I heard from the older women in the bush that if you didn't menstruate for two months, you were pregnant. I didn't menstruate for more than two months, so I went to an older woman and told her. She told me that I was pregnant... I really didn't believe it and I began to cry. So after the woman told me that I was pregnant, I continued to go to other women in the group and tell them the same thing. I kept hoping that they would tell me something different. They all said the same thing and I was devastated. 
While pregnant, this participant reported enduring ongoing verbal abuse by the boy soldiers. When this occurred, however, the older women offered her protection and validation.

[The boys] would come around and taunt me and say "Out of all the girls here, only you are pregnant." They made fun of me and kept repeating and pointing at me: "Pregnant woman! Pregnant woman!" I was so humiliated. [But] when the boys did this I would swear at them and all the women in the group would also come around and swear at them and abuse them back.

This sense of female solidarity in a male-dominated environment was further revealed by this same girl in her description of the eventual delivery of her child:

The delivery happened in the bush... The men stayed away ... The older women helped me. They knew what to do.

As these interview narratives reveal, numerous girls who were drawn into the conflict demonstrated a spirit of volition and a capacity for independence that belies a deterministic explanation of girls as either wholly indoctrinated killers or supine victims with no capacity to resist the circumstances imposed upon them. Instead, there appeared to be an interactive and dynamic relationship between structural constraints and individual agency. In the context of crude patriarchal authority and wanton abuse of small arms, girls often exercised forms of resistance and demonstrated female solidarity that helped to diminish the effects of outright cruelty and preserve a "space" for compassion. Caught up in a vortex of often unspeakable cruelty, they could nonetheless sometimes attain a measure of comfort and support from one another.

\section{Girls' struggle to survive: The duality of structure and agency}

In considering the plight of girls who were attached to the RUF during the Sierra Leonean conflict, it is necessary to appreciate fully the powerful structural forces that shaped and influenced their struggle to survive. Particularly important was the steady demise of the state and the collapse of social services in Sierra Leone, the wide socio-economic gap between wealthy urban élites and the urban poor, and the corresponding impoverishment of rural regions that had been exacerbated by poorly conceived and executed structural adjustment policies of the 1980s. Out of the turmoil of a collapsed state and growing civil unrest arose a revolutionary 
ferment that quickly degenerated into the emergence of militarized structures that were sustained through extraordinary violence. These forces of armed conflict were also in many respects extensions of conventional patriarchal structures in which girls and women had long been regarded as subservient to male authority. Indeed, Sierra Leonean societal arrangements have historically been shaped by patriarchal relations that legitimized the economic, socio-cultural and sexual dominance of males over females. Yet when civil conflict expanded in Sierra Leone, girls were swept up by forces of violence over which they had little control, and the deep-seated gender differentiation that shaped their realities became even more pronounced within the context of "militarized masculinity" induced by the civil war.

As the narratives of our female respondents revealed, once they were absorbed into the ranks of the RUF, often after the trauma of witnessing unspeakably brutal acts and the shattering of their natural centres of social support, sheer survival necessitated adhering to the dictates of the rebel community into which they had been drawn. That some eventually participated in violent actions themselves was largely the result of the militarization process whereby girls were controlled by, dependent on and derived their value from militaristic criteria. ${ }^{36}$ Militarized masculinity thus became the dominant force in controlling not only gender relations but also the acts of ordinary citizens. The combined effects of the spate of small arms and hallucinatory drugs that inundated Sierra Leone before and during the conflict likewise further acted to diminish and constrain young people's capacity for rational thought, action and decisionmaking. Indeed, children's ready accessibility to drugs and small arms was indicative of the predatory warlordism that had overcome Sierra Leone's weak state and came to dominate the vestiges of civil society. Overwhelmed by patriarchal, militarized structures of violence on all sides, girls were easily socialized into the norms and behaviours that helped to reinforce these structures.

In acknowledging the predominance of powerful social forces that clearly affected the circumstances and behaviours of girls and women, especially those ensnared by the RUF, we are nonetheless averse to a reductionist cul de sac implying that girl soldiers in Sierra Leone were little more than automatons who were recruited, equipped, trained and conditioned to kill and maim. As Machel ${ }^{37}$ has cautioned, it is important not to regard child soldiers solely as victims of war, and thereby to dismiss the capacity of children to exercise autonomy, resilience and the ability to make choices. As several of our female respondents attested, although they were coerced into joining the RUF, the occasion to kill and maim ultimately gave some of them a sense of personal power over others. For many of these girls, the feelings of pride and satisfaction gen- 
erated from these acts of cruelty were akin to expressions of exhilaration at no longer being objects of terror and abuse themselves. Having undergone a cruel process of "initiation", some girls who perpetrated acts of violence on others were aware of the pain that they were inflicting, and appeared to relish the corresponding power and strength of identity that derived from their cruelty. Such self-serving rationality cannot be simply explained away as a function of larger social forces or intensive indoctrination. At the same time, however, it is evident that many girls did not entirely succumb to the RUF's totalist system of militarized masculinity. Some resisted, on occasion at grave risk to their safety, while others sought a "feminist" space with other girls and women that provided a modicum of temporary solace. These differences in actions were indicative of the variability of girls' responses to their abduction and coercion by the RUF. Despite the powerful structural forces that affected them all, girl child soldiers demonstrated diversity in their capacity to exercise agency and make independent choices.

But here too one must be cautious about being drawn too far down the path of rationalist conjecture. As female dependants in entrenched patriarchal systems of authority that essentially became militarized during the Sierra Leonean conflict, girls were caught up in a maelstrom of violent social forces that they had no real capacity to control or even fully comprehend. Their experiences were thus a reflection of the duality of structure and agency. Girls' actions within the RUF were shaped and constrained by broad historical and social forces, and by the militarized masculinity that dominated the ethos of the RUF. In turn, their actions served to reinforce, but sometimes also to contest, these forces. As the narratives of our female respondents revealed, despite overwhelmingly dominant and oppressive structural influences, they coped with these influences in differentiated and individualized ways.

\section{Aftermath of conflict: The continuing marginalization of girl ex-combatants}

Given the major humanitarian disaster that engulfed Sierra Leone, an understandable element of urgency has led to the rapid conceptualization and implementation of post-war development assistance projects and programmes, particularly for children. Much attention has been directed towards the demobilization of child combatants, the reunification of families, the reconstruction and expansion of the national educational system and the integration of young people into productive community life. ${ }^{38}$ To date, however, there are clear indications that girls who were formerly attached to fighting forces continue to be marginalized and stigmatized 
within such programming, as well as in the context of daily life in Sierra Leone. This section explores girls' experiences in the aftermath of conflict, focusing particularly on their unique perspectives on disarmament, demobilization and reintegration programmes, as well as on the diverse challenges they face in post-conflict Sierra Leone. In tracing girls' postconflict experiences, the tangled realities of victimization, participation and resistance once again become apparent.

\section{Experiences with disarmament, demobilization and reintegration}

Although women and girls are largely responsible for rebuilding families and communities in the aftermath of conflict, research has consistently demonstrated that females have generally been excluded from leadership positions in formal peace talks, within political parties and in formal reconstruction and peacebuilding initiatives. ${ }^{39}$ The disarmament, demobilization and reintegration (DDR) programme in Sierra Leone provides a salient example of post-conflict gendered exclusion.

The Sierra Leonean government and international partners, which included the Economic Community of West African States Monitoring Group (ECOMOG) and the UN Mission to Sierra Leone (UNAMSIL), conducted a formal DDR programme in three phases between 1998 and $2002 .{ }^{40}$ To qualify for entry to the programme, each former combatant was required to present a weapon at any of the official reception centres across the country in order to "disarm" and receive financial and educational benefits. As a prerequisite for participation in the programme, every candidate was required to respond to questions and to disassemble and reassemble a gun, normally an AK- $47 .{ }^{41}$ By January 2002, when hostilities were officially declared at an end, 48,000 combatants had been disarmed and a total of 42,300 weapons and 1.2 million rounds of ammunition had been collected. The end of the DDR programme in January 2002 was marked by the symbolic burning of several thousand weapons. ${ }^{42}$

Although the DDR programme in Sierra Leone has officially been touted as having greatly increased the country's security and is widely seen as a model upon which other DDR processes could be based, ${ }^{43}$ the number of female combatants was grossly underestimated by those responsible for planning and conducting the DDR programme. Indeed, in the early phases of the programme they were considered to be ineligible by programme planners. According to demobilization figures, 6,787 children were formally demobilized $-6,281$ boys and a mere 506 girls. ${ }^{44}$ The very small proportion of demobilized girls stems in part from their inability to benefit from the initial "cash-for-weapons" approach to DDR, which was highly exclusionary. In phases I and II of the programme the 
"wives" of male combatants, as well as their dependants, were not eligible for entry. Many girls reported being ordered to hand in their weapons prior to demobilization, and were left behind as their male colleagues were transported to assembly centres. ${ }^{45}$ Other girls indicated that their guns were taken away by their commanders and given to male fighters, or in some cases sold to civilians who then reaped the financial benefits of the DDR programme. On other occasions, girls used small arms that were provided "communally" and thus did not possess their "own" weapons and were simply not deemed to be "primary fighters". Sadly, therefore, instead of being formally demobilized and sharing in the putative benefits of the process, the vast majority of female combatants experienced demobilization as a struggle to fend for themselves and their children. Many of them simply drifted to camps for the internally displaced in search of alternative forms of support. By downplaying the role of female combatants during the war, the DDR programme had the effect of extending gender-based power differentiation into the postconflict era.

Aside from these deliberately exclusionary practices, many girls intentionally avoided the entire DDR process. Among our interviewees, girls reported fear of stigmatization and criminal prosecution as their main reasons for avoidance:

No, I didn't go through DDR. I was too afraid. I was afraid that people would be able to identify me and single me out as one of the bad people of the war. I didn't want anyone to learn that I was in the bush. I didn't want my name advertised - I'm ashamed of that and very afraid.

I didn't go through DDR. My aunt who came to find me after I came out of the bush told me that if I went, my name would go on a computer and they would use it later to prosecute me. If I went through DDR they would know that I was a combatant and I don't want anyone to know.

Exclusion, fear of stigmatization and a lack of information (or the spread of misinformation) combined to ensure that relatively few girls and women were formally demobilized. Among the girls who were interviewed for this study, many were convinced that participating in DDR programming would have hindered their chances for reintegration into their communities. Girls feared that public acknowledgement of their role as "fighters" via DDR, a role which counters accepted traditional norms for females, would increase the likelihood of being cast out of their families, stripped of their social standing and losing their potential marriageability. As one girl observed: "I am afraid I won't get a husband to marry me because of my past activities with the rebels." 
For Sierra Leonean females, marriage is often their best option for long-term socio-economic security. Women and girls who are stripped of their social standing may lose their access to an agricultural livelihood in rural societies, thus suffering enormous economic consequences. For many girls, the risks of participating in DDR, and exposing their former roles as fighters, far outweighed the potential benefits.

Yet even those who did go through the programme expressed their disillusion with a process they felt did not meet their needs and was undermined by corruption, mismanagement and false promises. This led many to drift away from the programme without acquiring any of the proposed skills or financial benefits:

I liked the idea of learning, but there were constant delays in the process - and the people were very crooked... They were not teaching us well and we were not paid on time or we were not given our allowances at all. As a result, we had no materials to use to continue with the programme - there were no sewing materials. So I drifted from the programme.

I did not like the DDR programming. At first, I was given training to do garatye dying. I really liked this and wanted to continue with it, but they told me that programme was closing and that I should take on something else. They were trying to get me to do salon-type training. I didn't like this as much, not nearly as much.

For some, the ongoing security issues and threats of sexual violence that continued in the demobilization camps impelled them to leave the programme, even if the alternative meant living on the streets of Freetown:

The [demobilization] centre became chaotic and disorganized... there was no order... The officers [at the camp] who were on night duty were not able to control the boys [former combatants], so the boys were coming over to [the girls] and harassing us for sex. I didn't feel safe and my friend and I decided to leave and go to Freetown because of that. Since we came to Freetown I have been living in the street.

Unfortunately, even among those girls and women who eventually completed DDR programming and found it to be a positive experience, many ultimately felt betrayed by the process. As one of our interviewees recounted, in one instance of frustration girls organized an attack against the DDR programmers. Significantly, to prepare for the attack and to build courage and strength, a group of girls organized themselves to purchase and take drugs - the same technique that they were taught as RUF fighters: 
The ex-combatants in the [demobilization] camp would get together and plan... We would take drugs and then go as a group to physically attack the DDR programmers for not giving us our money. We were very angry about not getting our money.

The short-term nature of the programme and its lack of sustainability were particularly problematic. Once the programme ended, children, both boys and girls, who had no support systems or families were often left to fend for themselves.

While both sexes have been affected by such realities, post-conflict vulnerability has been more acutely felt by girls due to their peripheral social status as females and the continuing risk of sexual assault. ${ }^{46}$ The ongoing predicament of girls and women in post-conflict Sierra Leone is reflected in this brief story recounted to us by a 16-year-old former RUF girl combatant. Soon after the end of the conflict, with no place to live and no money, she had accepted an invitation to live with an NGO worker who ended up sexually abusing her and abandoning her once she became pregnant with his child:

At the beginning, the DDR programme provided me with a place to stay. Then suddenly they told me that the programme was closing and I had to find a new place to live. I had nowhere to go! There was this man - an NGO worker at the DDR camp. He was always kind to me and I felt that he was trying to court me even though he had a wife at home. He invited me to come live at his house. I didn't want to go to live with him. I didn't fully trust him, but I had no alternative. After a while he began to make advances on me... I became pregnant. When I found out I was pregnant, I thought that he would assist me in getting an abortion, because he wouldn't want his wife to find out. He didn't... he told me to leave the house. He will not support this new baby... I have no place to go and I now have two babies to take care of.

Left to care for her two children, both less than three years old at the time of the interview, this girl was selling chewing-gum and relying on hand-outs from strangers to pay for food and shelter. That similar conditions are experienced by many other former girl combatants is suggestive that the end of civil war has not meant the end of gender-induced suffering in Sierra Leone.

\section{Marginalization and survival in post-war Sierra Leone}

The marginalization and discrimination that so many girls experienced during the conflict continued throughout the DDR process and remains extant today. As many girls we interviewed feared, their status as excombatants had put them at risk of social stigmatization and ostracism, 
and thus had impeded their own efforts and those of supportive civil society institutions to reintegrate them into their communities:

People are rejecting me, so this is proving a very difficult aspect in my life. Most of them do not encourage me. They always remind me of joining the rebels. I want them to accept me, to forgive me and allow me to be part of the community.

Since I came back, I have not been one year with my people, but there have just been problems, problems, problems... You know, they don't love me anymore. They don't love me anymore... They despise me now.

Significantly, the marginalization of girls and women has an economic as well as a social dimension. Following a decade of war, Sierra Leone is plagued with economic stagnation, high unemployment, lack of educational opportunities and a weak civil society. With so few structural supports, most girls in Sierra Leone are living in impoverished circumstances and have few viable alternatives beond being household dependants. At the time of the main part of the field research in 2005, most of our female respondents were continuing to live in poverty with no educational, financial or familial assistance. Separated from their families through death, displacement or rejection, these girls were relying on other child ex-combatants for comfort and support. While a few have been able to attend school through the support of local NGOs which provide them with school fees and uniforms, the majority of our respondents were surviving on the fringes of society with minimal or no opportunities for education or remunerative work beyond informal petty trading. In these circumstances, there is a natural inclination among some girls and women to regard peace in Sierra Leone as disappointing - in many ways just as dispiriting as the period of war.

Yes, I feel depressed most of the time. I sometimes feel there is no hope for me because of the horrible things I have done. I just think of ending my life.

I am depressed, I have a child and am pregnant but there is nobody to support me.

I feel tormented and I sometimes cry ... I live in the street... people don't treat me with respect... The war has left me in the street as a prostitute and drug addict. I have no family and no future.

In response to continued social and economic marginalization, some have turned to prostitution, petty crime and drug use in order to cope and survive. 
I now live on prostitution... I live in the street exposed to all kinds of danger and I am tired of living in the street. To cope, I take drugs; either cocaine or brown-brown [crack]. [When I take the drugs] I feel relieved and I don't think of any problems, no bad memories of the war, and no sadness.

For others, under immense pressure to support themselves and their families, resort to violence is a way to express their frustration and anger, often towards those closest to them:

Sometimes, I just feel so angry and I want to beat my two children.

Yes, I am angry and I often grow angrier. I [find myself] getting into trouble with my family.

I weep at times - especially if I am isolated. Sometimes, I become very aggressive to my husband and he beats me.

While it is often former boy combatants who are typically viewed as "security risks" in post-conflict situations, the reality of female anger and violence cannot be ignored. Although girls have not traditionally been perceived as presenting the same potential threat as disaffected young men, our interviews clearly highlight girls' mounting dissatisfaction and frustration, as well as their potential for continued aggression in the private and public spheres in the aftermath of the civil war. Within the current climate of uncertainty and continued economic stagnation in Sierra Leone, many former girl combatants are raising a new generation of children whose experiences are likely to inure them to violence. As a response to ongoing marginalization, outbursts of aggression reveal girls' capacity for agency and resistance, but when expressed in violent form it probably exacerbates their alienation from the communities into which they must be successfully reintegrated if the prospect of long-term peacebuilding is ever to be realized in Sierra Leone. Failing to provide for the needs of these girls and their children after the war is not only shortsighted but potentially dangerous.

\section{Conclusion: Implications of girls' experiences as combatants for post-conflict demobilization and reintegration}

This analysis has uncovered the intricacies of girls' experiences in relation to the violence and widespread use of small arms that characterized life in the RUF. It has illustrated the multifaceted world girls were forced to contend with during the Sierra Leonean conflict and their ongoing 
plight in the post-war period. Their world has included situations of victimization, of the perpetration of violence and of resistance, often experienced in a shifting and dialectical fashion. Focusing on the complex sets of realities that confronted many female combatants has compelled us to move beyond a simplistic depiction of all girl child soldiers as merely passive victims. Instead, we contend that they must be seen as individual agents who participated in planning and carrying out acts of violence, who at times also sought power and who in other instances resisted authority. Throughout both the war and the uneasy peace which has followed, their capacity for agency and resilience has been apparent.

While the data clearly illustrate girls' visibility within the RUF and their role as assets and "resources" to be perversely exploited, ironically the complex roles of girls as child soldiers have largely been discounted or misunderstood by the international community. Despite recent calls for "gender mainstreaming" in policies and practices related to armed conflict, and the creation of resolutions such as the UN Security Council Resolution $1325,{ }^{47}$ the marginalization of women and girls continues in post-conflict Sierra Leone. The failure to incorporate the views and perspectives of girls fully in demobilization and peacebuilding efforts, including disarmament activities which continue to focus on reducing the impact of the plethora of small arms in Sierra Leone and elsewhere in West Africa, not only raises questions about the efficacy of such initiatives, but also concerns about the implications of this neglect for longterm social reconstruction - especially the goal of establishing democratic institutions adhering to fundamental human rights. To ignore the voices and needs of girls and women, whether in the form of decision-making or in action, denies them the right to participate actively and be accounted for in the key realms of human security, development and reconstruction efforts which could have a profound impact on social stability. As noted earlier in the chapter, some girls actually wax nostalgic for their remembered experiences of conflict, particularly for the power they held when they brandished weapons. Given that this sense of power for the most part has not been replicated in post-conflict circumstances, there are clearly risks for social stability. As our interviews with girls have revealed, continuing marginalization of vast numbers of young people - female as well as male - may engender a resurgence of anger and violence; precisely the same forces that sparked the bloody conflict of the 1990s.

While it is hoped that interventions can help to transform erstwhile structures of violence, those foundations are deeply rooted in political, economic and ideological forces that are highly gendered and dominate both the political landscape of Sierra Leone and, it must be said, in the regional and international communities that have sought to intervene in 
its conflicts. The connection between societal reconstruction and the satisfaction of the psycho-social needs of former girl combatants in a context of a fragile political economy remains fraught with uncertainty and complexity, particularly when there remain understandable currents of resentment against those who committed unspeakable atrocities during the war. While undoubtedly justice must be served and the perpetrators of the worst forms of violence must be held accountable for their actions, it is also necessary to recall that many of those involved in the conflict were children, for whom the line between victim and perpetrator of violence was extraordinarily ambiguous. From both a moral and a legal standpoint, as outlined by the UN Convention on the Rights of the Child, the vulnerability of children is such that they must be accorded special rights and be regarded as subjects of actions undertaken on their behalf. That is to say, rather than being considered as passive recipients (objects) of interventions that are formulated and implemented entirely by an adult population, as far as possible children and youth must be actively engaged in decisions and actions that affect them.

In Sierra Leone, however, the apparent gender "neutrality" of the DDR and the continuing plight of many girls and women suggest a situation of plus ça change, plus c'est la même chose. If peacebuilding efforts are to be truly effective, then the process of societal reconstruction in Sierra Leone must be more responsive to girls' distinctive experiences and needs, regardless of their former status within armed groups. There is a need for a gender-sensitization element in all peacebuilding programmes - one that ensures widespread dissemination of information for girls and women, ${ }^{48}$ and is derived not from the notion of state security but from a broad-based understanding of security as a right for all. ${ }^{49}$ It is crucial to examine not only how gender identities, relations and inequalities have shaped past policy and decision-making, but also how a gendered analysis can be integrated into future policy and programming. Only by considering the experiences of all who have been involved in combat, including their differentiated roles and power relations, can the challenges and opportunities for disarmament be fully met.

In our view, genuine societal reconstruction in Sierra Leone must strive to redress continued female marginalization and subservience, and in so doing tap into the capacity of girls and women to exercise agency and resistance. Programmes of disarmament and social renewal in areas such as health, HIV/AIDS prevention and mitigation, civic and land rights, education and employment must be expressly attuned to gender differentiation and the ongoing marginalization of girls and women. To this extent, and reflecting a more rights-based approach, policies and programmes for former girl combatants should be developed in a way that 
heeds women's voices and encourages a stronger female role in public decision-making. A gender-differentiated approach to social interventions is nothing new in Sierra Leone or in Africa as a whole: conventional development strategies have long adhered to the ideals of the Women in Development (WID) movement that was prominent during the 1970s and 1980s. In our view, a similar gender-oriented approach must now be adopted in working with former female child combatants who were largely entrapped as victims of war. By facilitating girls' demonstrable capacity for independence of thought and action, we believe that collectively many former female combatants will be in a position to resist further outbreaks of armed conflict in Sierra Leone.

\section{Notes}

1. Reno, William (1995) Corruption and State Politics in Sierra Leone, Cambridge: Cambridge University Press.

2. Kresch, Robert and Richard Maclure (2003) "Education and Human Security in Sierra Leone: Discourses of Failure and Reconstruction", in Wayne Nelles, ed., Comparative Education, Terrorism and Human Security: From Critical Pedagogy to Peacebuilding, New York: Palgrave Macmillan.

3. RUF/SL (1995) Footpaths to Democracy: Toward a New Sierra Leone, Revolutionary United Front of Sierra Leone.

4. It has been estimated that 75,000 people died as a result of the illicit arms trade in Sierra Leone. Partnership Africa Canada (2000) The Heart of the Matter: Sierra Leone, Diamonds and Human Security, Ottawa: Partnership Africa Canada.

5. Ibid.

6. Berman, Eric (2000) Re-Armament in Sierra Leone: One Year After the Lome Peace Agreement, Geneva: Small Arms Survey.

7. Ndumbe, J. Anyu (2001) "Diamonds, Ethnicity and Power: The Case of Sierra Leone", Social Justice 27(4), pp. 24-31.

8. UN Security Council (2000) "Report of the Panel of Experts Appointed Pursuant to Security Council Resolution 1306”, 23, 193.

9. Ibid.

10. This moratorium was extended in 2001.

11. Berman, note 6 above.

12. Small Arms Survey (2003) Small Arms Survey 2003, Geneva: Small Arms Survey.

13. Atanga, Lucien Mufor (2003) Tackling Small Arms in Central Africa, Bonn: Bonn International Center for Conversion.

14. Klare, Michael (1997) "The New Arms Race: Light Weapons and International Security", Current History 96(609), pp. 173-178.

15. Brett, Rachel and Margaret McCallin (1998) Children: The Invisible Soldiers, Stockholm: Radda Barnen; Freedson, Julia (2002) "The Impact of Conflict on Children: The Role of Small Arms", Disarmament Forum 3, pp. 37-44; Singer, Peter (2005) Children at War, New York: Pantheon.

16. For this study we adopt the definition of a child set out in the UN Convention on the Rights of the Child, as being "every human being below eighteen years" (Article 1).

17. Women's Commission for Refugee Women and Children (2002) Precious Resources: 
Adolescents in the Reconstruction of Sierra Leone, Freetown: Women's Commission for Refugee Women and Children.

18. Peters, Krijn (2004) "Re-examining Voluntarism: Youth Combatants in Sierra Leone", Monograph 100, Institute for Security Studies, Pretoria.

19. Maclure, Richard and Myriam Denov (2006) “'I Didn't Want to Die So I Joined Them': Structuration and the Process of Becoming Boy Soldiers in Sierra Leone", Journal of Terrorism and Political Violence 18(1), pp. 119-135; Peters, Krijn and Paul Richards (1998) "Why We Fight: Voices of Youth Combatants in Sierra Leone", Africa 68(2), pp. 183-199.

20. Skinner, Elliott (1999) "Child Soldiers in Africa: A Disaster for Future Families”, International Journal on World Peace 16(2), pp. 7-23.

21. Human Rights Watch (2003) We'll Kill You If You Cry: Sexual Violence in the Sierra Leone Conflict, Vol. 15, No. 1(A), New York: Human Rights Watch.

22. Denov, Myriam (2006) "Wartime Sexual Violence: Assessing a Human Security Response to War-affected Girls in Sierra Leone", Security Dialogue 37(3), pp. 319-342; Denov, Myriam and Richard Maclure (2006) "Engaging the Voices of Girls in the Aftermath of Sierra Leone's Conflict: Experiences and Perspectives in a Culture of Violence", Anthropologica 48(1), pp. 73-85.

23. Mazurana, Dyan, Susan McKay, Khristopher Carlson and Janel Kasper (2002) "Girls in Fighting Forces and Groups: Their Recruitment, Participation, Demobilization and Reintegration", Peace and Conflict 8(2), pp. 97-123.

24. There is an emerging literature examining the role of female fighters in Sierra Leone. Among others, see Coulter, Chris, Mariam Persson and Mats Utas (2008) "Young Female Fighters in African Wars: Conflict and Its Consequences", NAI Policy Dialogue, NAI, Uppsala; McKay, Susan and Dyan Mazurana (2004) Where Are the Girls? Girls in Fighting Forces in Northern Uganda, Sierra Leone, and Mozambique: Their Lives During and After War, Montreal: International Centre for Human Rights and Democratic Development; Schroeven, Anita (2008) Women after War: Gender Mainstreaming and the Social Construction of Identity in Contemporary Sierra Leone, Berlin: LIT Verlag.

25. In this chapter, the term "girls in fighting forces" includes not only girls who are carrying or have carried arms, but also girls who act as cooks, porters and messengers, and those accompanying such groups. Importantly, this definition includes girls who are recruited for sexual purposes and forced marriage.

26. Kvale, Steiner (1996) InterViews, London: Sage; Atkinson, Robert (1998) The Life Story Interview, London: Sage.

27. Amowitz, Lynn, Chen Reiss, Kristina Lyons, Beth Vann, Binta Mansaray, Adyinka Akinsulure-Smith, Louise Taylor and Vincent Iacopino (2002) "Prevalence of Warrelated Sexual Violence and Other Human Rights Abuses among Internally Displaced Persons in Sierra Leone", Journal of the American Medical Association 287(4), pp. 513-521.

28. Women's Commission for Refugee Women and Children, note 17 above.

29. Reports indicate that children were systematically injected with cocaine. Clapham, Christopher (2003) Sierra Leone: The Political Economy of Internal Conflict, The Hague: Netherlands Institute of International Relations, Conflict Research Unit.

30. Crelinsten, Ronald (1995) "In Their Own Words: The World of the Torturer", in Ronald Crelinsten and Alex Schmid, eds, The Politics of Pain: Torturers and Their Masters, Oxford: Westview Press.

31. Kelman, Herbert (1995) "The Social Context of Torture: Policy Process and Authority Structure", in Ronald Crelinsten and Alex Schmid, eds, The Politics of Pain: Torturers and Their Masters, Oxford: Westview Press. 
32. Ibid.

33. Denov, Myriam and Christine Gervais (2007) "Negotiating (In)Security: Agency, Resistance and the Experiences of Girls Formerly Associated with Sierra Leone's Revolutionary United Front", Signs: Journal of Women in Culture and Society 32(4), pp. 857910; McKay and Mazurana, note 24 above.

34. Abdullah, Ibrahim (1998) "Bush Path to Destruction: The Origin and Character of the Revolutionary United Front/Sierra Leone", Journal of Modern African Studies 36(2), pp. 203-235; Keen, David (1997) "A Rational Kind of Madness", Oxford Development Studies 25(1), pp. 67-75.

35. Civil defence forces.

36. Enloe, Cynthia (2000) Maneuvers: The International Politics of Militarizing Women's Lives, Berkeley, CA: University of California Press.

37. Machel, Graca (1996) The Impact of War on Children, New York: United Nations.

38. Women's Commission for Refugee Women and Children, note 16 above.

39. Gardam, Judith and Hilary Charlesworth (2000) "Protection of Women in Armed Conflict", Human Rights Quarterly 22, pp. 148-166; Meintjes, Shiela, Anu Pilay and Meredith Turshen (2002) "There is No Aftermath for Women", in Shiela Meintjes, Anu Pilay and Meredith Turshen, eds, The Aftermath: Women in Post-conflict Transformation, London: Zed Books.

40. Programmes of reintegration continued after 2002.

41. The one-person, one-weapon approach was later changed and group disarmament was instituted, where groups would disarm together and weapons would be turned in jointly.

42. Bah, Alhaji (2004) "Implementing the ECOWAS Small Arms Moratorium in Post-war Sierra Leone", Ploughshares Working Paper 04-1, Project Ploughshares, Waterloo, Ontario.

43. Women's Commission for Refugee Women and Children, note 17 above.

44. Mazurana, Dyan and Khristopher Carlson (2004) From Combat to Community: Women and Girls of Sierra Leone, Washington, DC: Hunt Alternatives Fund.

45. Mazurana and Carlson, note 43 above.

46. Denov, note 22 above.

47. Resolution 1325, passed on 31 October 2000, declares that women and girls' visibility, both in national and regional instruments and in multilateral organizations, is crucial. The resolution calls for gender awareness and women and girls' active participation in all aspects of peacekeeping and security initiatives and disarmament exercises. It also insists on women and girls' right to carry out their post-conflict reconstruction activities in an environment free from violence and threats.

48. This would mean placing greater emphasis on transmitting programme information in marketplaces, healthcare clinics, churches and mosques, women's associations and other areas frequented by women and girls.

49. Department for Disarmament Affairs (2003) Gender Mainstreaming Action Plan, New York: United Nations. 
4 Small arms and rape as a system
of war: A case study of the
Democratic Republic of the Congo

Felicity Szesnat

Rape as a system of war has been perpetrated by armies throughout history, but because of its overwhelmingly gender-specific character it has remained largely hidden. However, it has been exposed in recent years through research done by human rights and women's activists into conflicts such as those in the former Yugoslavia, Kashmir, Somalia and Rwanda. ${ }^{1}$

More recently, rape as a system of war has been alleged on a massive scale during the armed conflict in the Democratic Republic of the Congo (DRC). ${ }^{2}$ In researching this issue, it has become apparent that many, if not most, of these rapes were, and are, committed by male fighters carrying small arms. While there is research into rape when used as a system of war, and also separately into the impact of small arms on women's lives generally, there appears to be little research into the role small arms play in committing rape as a system of war. Because rape was so widespread in the DRC, and because it has been well documented, the DRC conflict will be used as a case study to highlight this issue. It should be noted that, in spite of the peace accord signed in December $2002,{ }^{3}$ it is reported that mass rapes by soldiers and armed groups are continuing at the time of writing, particularly in the Ituri and Kivu regions. ${ }^{4}$

This study begins by providing a legal framework for considering systematic rape in both international and non-international armed conflicts. The framework is then applied to the situation in the DRC to show that there is evidence that rape has been used as a system of war by most, if not all, warring parties. Next, attention is focused on small arms in the

Sexed pistols: The gendered impacts of small arms and light weapons, Farr, Myrttinen and Schnabel (eds), United Nations University Press, 2009, ISBN 978-92-808-1175-9 
DRC: firstly, an attempt will be made to trace who is using small arms in the conflict, and where these weapons are coming from; secondly, the issues of what is being done to control arms imports (both legal and illegal) to the DRC and to decommission weapons already in the DRC will be considered; and finally, the issues of small arms and rape as a system of war will be drawn together.

Experience and empirical data both clearly suggest that the proliferation of small arms does not impact upon women and men the same way; however, the gender dimensions of the difference in impact are poorly researched. ${ }^{5}$ Arguably, rape as a system of war, when perpetrated with small arms, is one of the most extreme examples of this gendered impact. In spite of this, there has been little or no research conducted to date to track how small arms are used to facilitate systematic rape. Such an investigation will further our understanding of the ways in which these weapons maintain and strengthen gender-specific violence in societies caught up in violent conflict. This study concludes with recommendations for further research in this area, as well as reflecting on how the issue of systematic rape including the use of small arms should be dealt with, both in the DRC and internationally, at the level of law and policy.

\section{Research methodology}

This chapter was compiled in the main through reading reports on the situation in the DRC written by different organs of the United Nations, particularly the UN Security Council, and by many non-governmental organizations (NGOs). Numerous online newspaper articles regarding rape and the use of small arms were consulted. A study was also made of the DRC's domestic law on rape, which was then compared and contrasted with its international legal obligations to protect women against rape. In this regard, international case law was also examined. Most of these materials are available through the internet.

\section{Background to the conflict}

The recent DRC conflict is rooted in the 1994 Rwandan genocide, after which many Interahamwe Hutu fighters responsible for the genocide fled into eastern Zaire. ${ }^{6}$ The first Congo war began in 1996 when the Rwandan army entered Zaire to capture those fighters. Soon after this, Rwanda and Burundi began to support Laurent Kabila's armed group, the Alliance des Forces Démocratiques pour la Libération du Congo (ADFL), which was fighting against President Mobuto and the Force 
Armée Congolaise (FAC), by giving them money and weapons. In 1997 Kabila unseated Mobuto, took power and renamed Zaire the DRC. ${ }^{7}$

In 1998 the ethnically Tutsi Banyamulenge members of the DRC armed forces mutinied, believing that the DRC was taking the side of the Hutus, and were immediately offered assistance by Rwanda and Uganda, under whose sponsorship the armed group Rassemblement des Congolais pour la Démocratie (RCD) was formed. The RCD took control over towns in the Kivu region, while the Ugandan, Burundian and Rwandan armed forces invaded the DRC, occupying northeastern DRC. ${ }^{8}$ These states set up further armed groups to fight alongside their armies, such as the Mouvement de Libération du Congo (MLC). Kabila appealed for international assistance, and Namibia, Zimbabwe and Angola responded quickly. Other nations also allied themselves later to Kabila and his government, such as Chad, Libya and Sudan. Thus began the second Congo war, which has been the widest inter-state war in modern African history, involving nine African nations at its height. It also gave rise to a non-international conflict involving more than 20 armed groups. ${ }^{9}$

In August 1999 the UN Security Council authorized a mission to the DRC - Mission de l'Organisation des Nations Unies au Congo (MONUC) - under a Chapter VI mandate. ${ }^{10}$ This was upgraded to a Chapter VII mandate in July 2003. ${ }^{11}$ MONUC has responsibility for the protection of civilians "under imminent threat of violence"; implementing the disarmament, demobilization and reintegration (DDR) campaign; enforcing an arms embargo intended to prevent weapons from being supplied to armed groups in eastern DRC (the embargo was established by the UN Security Council in July 2003); ${ }^{12}$ and collecting and disposing of arms and related materiel found in the DRC in violation of this embargo. ${ }^{13}$

As will be seen later in this chapter, the arms embargo has not been successful. In January 2005 the United Nations reported that Uganda and Rwanda were in violation of the embargo. ${ }^{14}$ In their letter to the UN Security Council in July 2005, the Group of Experts on the Democratic Republic of the Congo stated that although it has not "collected irrefutable evidence of new violations of the arms embargo", mainly (it seems) due to time constraints, it "continues to receive reports of ongoing weapons flows and illegal armed group activities in the Democratic Republic of the Congo and neighbouring States". ${ }^{15}$

There have been many attempts at peace negotiations, none entirely successful, although the Global and All-Inclusive Agreement, signed in December 2002, formed the basis for holding multi-party elections in July 2006, the first such elections since independence. ${ }^{16}$ As there was no outright winner in the first round of elections, a second round was held on 29 October 2006, which was won by the incumbent president, Joseph 
Kabila. These elections led to violence in the capital Kinshasa between Kabila's supporters and those of his rival, Jean-Pierre Bemba. ${ }^{17}$ This violence was contained and short-lived, unlike the conflict which continues in the Ituri and Kivu regions.

Fierce fighting has continued in Ituri and North and South Kivu between government forces and about 20 different armed groups. The largest and most powerful of these groups, the RCD, is led by General Laurent Nkunda. Although the RCD joined the transitional government in 2003, it was not until 2007 that General Nkunda agreed to it being assimilated or "brassaged" into the DRC's national army, the Forces Armées de la République Démocratique du Congo (FARDC). ${ }^{18}$ However, the assimilation never took place, and General Nkunda currently controls a large portion of North Kivu along the Rwandan and Ugandan borders. ${ }^{19}$ It is believed by some UN officials that General Nkunda is being supplied with ammunition and other matériel by Rwanda, which views Nkunda and his troops as the only force willing to take on the Democratic Liberation Forces of Rwanda (FDLR) or Interahamwe, as the group is more commonly known; this is the armed group led by Hutus blamed for the genocide in Rwanda. There has been fierce fighting between the FARDC and General Nkunda, and hopes that a cease-fire signed on 23 January 2008 between the DRC government, General Nkunda and about 20 other smaller armed groups may hold are not high. ${ }^{20}$

The road to peace has been complicated by the fact that many of the states and armed groups involved in the conflict are exploiting the mineral wealth of the DRC. This has increased their reluctance to end the fighting, as the mineral exploitation is immensely profitable. ${ }^{21}$

Currently, the situation in the DRC remains fraught. The UN Security Council has extended the mandate of MONUC until 31 December 2008. The Security Council used this opportunity to express "grave concern at the continued presence of foreign and Congolese armed groups and militias in the eastern part of the Democratic Republic of the Congo", and to condemn the continuing "sexual violence perpetrated by militias and armed groups". The Council urgently called on the government of the DRC, "in cooperation with MONUC and other relevant actors, to end such violence and bring the perpetrators, as well as the senior commanders under whom they serve, to justice". ${ }^{22}$

\section{Legal framework}

Rape is prohibited in the domestic laws of the DRC. However, until very recently the definition was very problematic. The act of rape was only 
deemed to have occurred if a man's penis was inserted into a woman's vagina. If an object, such as a gun, was used instead of a penis, or the penis was inserted into any part of the woman's body other than the vagina, the act did not qualify as "rape", but instead as indecent assault. The penal code called for the "use of violence" during rape, but the interpretation of this phrase was also problematic. International Alert used the following example: "if a man forcibly removes a woman's clothes, tears her clothes and underwear and knocks her to the ground, but the woman then yields to him voluntarily, there is no possibility of him being prosecuted for rape". ${ }^{23}$ In other words, the code could be interpreted as requiring that the woman must physically struggle with her attacker throughout the rape in order for the act to qualify as "rape". This may have made prosecuting a man who holds a gun to a woman's head to force her to submit to being raped difficult, as legally this may not have amounted to the "use of violence".

In spite of the fact that, at the time, the DRC's domestic law did not appear to recognize rape during armed conflict as a war crime, and the international treaties to which the DRC is party had not yet been incorporated into domestic law, ${ }^{24}$ in April 2006 a military garrison court in Songo Mboyo found seven soldiers guilty of crimes against humanity, including the mass rape of at least 119 women in the northwestern province of Equateur. ${ }^{25}$ This has set a welcome precedent for further prosecutions in respect of rape committed during the DRC armed conflict, albeit one which has not been followed much since then.

This situation - regarding the definition of rape - has changed with the promulgation, and entry into effect on 20 July 2006, of Loi no. 06/018, which amended the Decree of 30 January 1940 of the Congolese Penal Code. ${ }^{26}$ This amendment recognizes that both men and women may commit rape, and that both men and women may be raped. Secondly, it recognizes that rape may be committed by the perpetrator inserting any part of his or her body, or any "unspecified object", into the vagina, mouth or anus of the victim. Finally, the law no longer requires actual physical violence to accompany the rape: it now states that the threat of violence is sufficient. This need not be overt: taking the victim by surprise, using psychological pressure or a "coercive environment" are currently recognized as elements of rape. In addition, where a rape is committed by obtaining the acquiescence of the victim through threatening him or her with a gun, the judge may impose double the minimum sentence. ${ }^{27}$

These changes are extremely welcome; however, it is yet to be seen whether or not they are put into practice, and are properly enforced. ${ }^{28}$ Given that this change in law is fairly recent, and (as far as can be ascertained at the time of writing) that rape still does not appear to be 
recognized in domestic law as a war crime, it is necessary to turn to international law to provide a framework for considering whether rape, and more particularly rape as a system of war, has been perpetrated in the DRC.

The DRC succeeded to all the Hague and Geneva Conventions on the laws of war on independence in $1960 .{ }^{29}$ It also ratified Additional Protocols I and II to the Geneva Conventions in 1982 and 2002 respectively. ${ }^{30}$ International armed conflict is regulated by the 1907 Hague Convention IV and its Annexed Regulations, the Geneva Conventions of 1949 and Additional Protocol I. Non-international armed conflict is regulated by Common Article 3 of the Geneva Conventions and Additional Protocol II. There is a prohibition on directing attacks against civilians in both international and non-international armed conflicts. ${ }^{31}$ For the purposes of international armed conflict, civilians are defined as those persons who are not members of the armed forces. ${ }^{32}$ However, there is no definition of civilians for the purposes of non-international armed conflicts. ${ }^{33}$

Rape is prohibited in international armed conflict: Geneva Convention IV states that "Women shall be especially protected against any attack on their honour, in particular against rape." ${ }^{34}$ Additional Protocol I states that "Women shall be the object of special respect and shall be protected in a particular manner against rape." ${ }^{35}$ It further prohibits "outrages upon personal dignity"; this is held to cover "humiliating and degrading treatment, enforced prostitution and any form of indecent assault". ${ }^{36}$

Rape is also prohibited in non-international armed conflict. Although it does not specifically list rape, Common Article 3 prohibits attacks on those taking no active part in hostilities, including "Violence to life and person... mutilation, cruel treatment and torture." Common Article 3 applies to "each party to the conflict", indicating that armed groups are also bound. Additional Protocol II prohibits rape in Article 4(2), which forbids "outrages upon personal dignity"; while Article 4(1) implicitly forbids it, by requiring that all persons are entitled to respect for their person and honour. Hague Convention IV also implicitly prohibits rape by providing for the protection of family honour and rights in Article 46.

The International Committee of the Red Cross (ICRC) has stated that the prohibition on rape and other forms of sexual violence constitutes a rule of customary international law in both international and noninternational armed conflicts. ${ }^{37}$ The International Criminal Court (ICC) Statute states that committing rape, or any other form of sexual violence constituting a grave breach or a serious violation of Common Article 3 of the Geneva Conventions, constitutes a war crime in both international and non-international armed conflicts. ${ }^{38}$ This is regardless of whether it 
is practised systematically by a party to the conflict or not. However, when rape is conducted on a mass scale, it may be classified and prosecuted as a crime against humanity.

The International Criminal Tribunal for the Former Yugoslavia (ICTY) held in the Delalic case that rape could constitute torture when specific conditions were fulfilled, ${ }^{39}$ while the International Criminal Tribunal for Rwanda (ICTR) found, in the cases of Akayesu and Musema, that rape and sexual violence could constitute genocide if they fulfilled the specific conditions of the crime of genocide. ${ }^{40}$

Since rape is not defined in any international instrument, the definition which will be used in this study to ascertain whether rape has been committed systematically in the DRC is that provided by the ICC, as the DRC ratified the Rome Statute in July 2002. ${ }^{41}$ The definition is to be found in the ICC's "Elements of Crime" document; it incorporates those laid down by the ICTY in the case of Furundzija, ${ }^{42}$ and those recommended by the special rapporteur on the issue of systematic rape and sexual slavery practices in armed conflict. ${ }^{43}$ It should be noted that the definition is broad enough to encompass both female and male rape, although this research focuses solely on female rape.

Rape is defined as having occurred when

the perpetrator invaded the body of a person by conduct resulting in penetration, however slight, of any part of the body of the victim or of the perpetrator with a sexual organ, or of the anal or genital opening of the victim with any object or any other part of the body. ${ }^{44}$

This definition denotes an important step forward for the protection of women's rights during armed conflicts. There are two specific points to be made for the purposes of this study: firstly, on the issue of whether the woman raped consented to the act or not, it acknowledges that the "manifestly coercive circumstances that exist in all armed conflict situations establish a presumption of non-consent and negates the need for the prosecution to establish a lack of consent as an element of the crime". ${ }^{45}$ Secondly, this definition includes as rape those instances where objects other than a sexual organ have been used to penetrate a woman's body. This covers the many instances where small arms have been used by fighters to commit rape.

The term "systematic" rape is used in this study as it was by the special rapporteur, "as an adjective to describe certain forms of rapes, not to denote the invention of a new crime or a new burden of proof that must be established to prosecute an act of rape". The ICTY, in the Tadic case, held that 
it is now well established that the requirement that the acts be directed against a civilian "population" can be fulfilled if the acts occur on either a widespread basis or in a systematic manner. Either one of these is sufficient to exclude isolated or random acts. ${ }^{46}$

Some jurists have concluded that "Proof of policy, plan or design is generally considered to be a necessary element of a prosecution for crimes against humanity"; ${ }^{47}$ however, the special rapporteur argues that "failure to take action to address widespread or systematic attacks against a civilian population can be sufficient to establish the requisite element of policy, plan or design". ${ }^{48}$

Systematic rape may therefore be prosecuted as a war crime, torture, a crime against humanity or genocide, depending on the nature of the evidence that is collected.

\section{Systematic rape as a system of war in the DRC}

Turning to the evidence presented by various organizations working on the issue of rape in the DRC, it is immediately apparent that rape has been (and in some areas continues to be) one of the most prevalent forms of human rights violations perpetrated in the armed conflict. Médecins Sans Frontières (MSF) Holland reports that it has treated thousands of civilians, female and male, who have been raped during the armed conflict in the DRC. ${ }^{49}$ The organization has also dealt with numerous cases of women reporting being "gang raped" on different occasions over several years. ${ }^{50}$

Human Rights Watch (HRW) states that "tens of thousands" of people have been raped. ${ }^{51}$ The World Health Organization (WHO) made a study of two DRC provinces and found that at least 40,000 women had been raped in those areas alone. ${ }^{52}$ The US Agency for International Development (USAID) cites figures of more than 51,000 people as having been raped in South Kivu province, Maniema province, Goma and Kalemie between 1998 and 2003. ${ }^{53}$ These organizations all issue disclaimers stating that, given the stigma of rape, it is highly likely to be underreported, meaning that many thousands more rapes most likely have gone uncounted.

MSF-Holland has written up many accounts of rape; the following are two examples, which have been selected for their specific references to the ways in which small arms were used to terrorize and subjugate the victims. 
That night, there was an attack on our village. Five armed men entered our house. I was there with my husband and children, but they caught me and took me to the bush. They made me lie on the ground and spread my legs. Then, the five of them climbed onto me and raped me, until their needs were satisfied. When they were done with me, they carried me back to the village. My house had been burnt in the attack and my children had fled. My husband was not there anymore and later we found his body in the bush.

That night, I was at home with my husband and my four children. Suddenly, there was an attack on our village. My husband managed to escape, but I was eight months pregnant. I had no strength to run and my children were with me. I had to protect them and so I couldn't escape. Three armed men entered our house and tore off my clothes... They hit me with the butt of their guns and then raped me - all three of them, in front of my children. ${ }^{54}$

It appears from media and NGO reports that most, if not all, armed forces and armed groups active in the DRC have committed rape against the civilian population. ${ }^{55} \mathrm{HRW}$ has noted that in the eastern DRC, the RCD-Goma, its Rwandan allies, its adversaries the Mai-Mai rebels ${ }^{56}$ and the Rwandan Hutu and Burundian armed groups are particularly responsible. The organization states that in the Ituri region it is mainly the RCD-Mouvement de Libération (RCD-ML), the MLC, the Union of Congolese Peoples (UPC) and the Front for National Integration (FNI) which have committed rape. HRW also names FAC and its successor, the FARDC, as committing rape against the civilian population. ${ }^{57}$ USAID further identifies the Interahamwe (FDLR) ${ }^{58}$ the Forces for the Defence of Democracy (FDD), ${ }^{59}$ the Angolan Defence Force (ADF) and members of local police forces as perpetrating systematic rape. USAID stated that "Many women treated at health centres have testified that they were raped by military commanders." 60

Most organizations working on this issue agree that rape has been used as a system of war by all sides. MSF-Holland stated that

All armed groups have been involved in the widespread sexual violence. The intent to terrorize, punish, and humiliate communities seen as supportive to the opposing side made rape a weapon of war. Sexual violence has been so clearly linked to the military strategy of warring parties and has occurred in such a systematic way that it is wrong to think of it as a side effect of war. ${ }^{61}$

HRW noted that "On occasion military commanders and the heads of armed groups seem to have encouraged the use of sexual violence as a way to terrorize civilians." 62 USAID wrote, "According to a doctor at Panzi Hospital in Bukavu, many victims in that area reported that 
attackers would encircle villages and rape the women publicly and collectively, including children and the elderly." ${ }^{63}$ The Integrated Regional Information Networks (IRIN) quotes the German Technical Cooperation Agency (GTZ) as stating that

The army dissidents also carried out atrocities during their occupation of $\mathrm{Bu}-$ kavu... They would choose a neighbourhood and go from house to house, raping from one year old babies to women as old as 80 . The dissidents broke into medical distribution centres, stole Viagra that had been stored there, and distributed it to their comrades... ${ }^{64}$

In July 2004 the Minority Rights Group (MRG) handed a dossier to the ICC, alleging a campaign of genocide and systematic rape against the Batwa people ("Pygmies"). They cited the leader of the campaign as being Jean-Pierre Bemba, the former leader of the MLC, who was elected to the Senate of the DRC in January 2007. A 14-year-old Pygmy survivor reported: "The leader ordered the mass rape. The attack lasted hours. I was called a "dirty Pygmy'." Another survivor told the MRG: "They asked my husband several times to sleep with my mother. They beat him but he refused to do it... then they raped my mother and me, one after the other, each by two of them." 65

A report by MONUC cites numerous allegations and accounts of systematic rape committed by both DRC and Burundian security forces, as well as armed groups, in the Ituri and South Kivu regions, the province of Equateur and the cities of Bunia and Goma, among others. ${ }^{66}$ In its annual report of 2007, Amnesty International (AI) confirmed that rape during the conflict had not abated: "Rape of women and girls by government security forces or armed groups remained widespread in all areas of the DRC." ${ }^{67}$ IRIN News reported in early 2008 that "rape and other forms of sexual violence remain prevalent in northeastern DRC". ${ }^{68}$

Some reasons given by soldiers or fighters for employing systematic rape as a system of war include punishment for sympathizing with or supporting opposing armed groups; demoralizing the opposition; subjugating local populations in order to gain control of resources such as minerals and cattle; and the belief that sex with young or older women can protect fighters. ${ }^{69}$

From the evidence presented above, it can be seen that there has been, and continues to be in some areas, widespread or systematic rape of civilians in the DRC by all sides which have been involved in the conflict, in breach of the DRC's obligations under the Hague and Geneva Conventions, and under customary international law. It appears that there have been instructions given by those in command of both soldiers and fighters to use rape as a system of war, indicating an organizational policy in this 
regard. Even if there is insufficient explicit evidence of such a policy, it is submitted that the position of the special rapporteur is correct: failure to prevent systematic rape may itself be taken to constitute the existence of such a policy.

The ICC is currently investigating the situation in the DRC - according to its own definition of rape, there appear to be strong grounds for the court to charge those involved in the rapes, particularly the commanders of armed groups who have issued orders to rape or have failed to prevent rape, with war crimes, crimes against humanity and, at least in relation to the rapes of the Pygmy population, genocide. ${ }^{70}$ In February 2006 the ICC issued its first warrant of arrest in respect of war crimes committed during the armed conflict in DRC for Thomas Dyilo, alleged to be the president of the UPC. He has been arrested and charged with enlisting and conscripting children under 15 years, and using these children to participate in active hostilities. ${ }^{71}$ However, two years on there has still been no mention by the ICC of the systematic rapes alleged to have been committed by the UPC; it is imperative that the ICC investigates these allegations and considers bringing charges of rape against Dyilo.

On 2 July 2007 the ICC issued a warrant of arrest for Germain Katanga, as the highest-ranking Force de résistance patriotique en Ituri (FRPI) commander, charging him with, among other things, sexual slavery as both a crime against humanity and a war crime. ${ }^{72} \mathrm{He}$ surrendered to the ICC on 17 October 2007. It is hoped that this case will set a precedent for holding individuals to account for crimes of a sexual nature committed in the DRC.

\section{Small arms in the $\mathrm{DRC}^{73}$}

The armed conflict in the DRC has been fought mostly with small arms. ${ }^{74}$ All the states involved in the conflict, as well as the non-state armed groups, have been primarily armed with small arms. There are estimated to be 500,000 illegal weapons in the DRC: ${ }^{75}$ in addition, many civilians in the DRC keep small arms at home. ${ }^{76}$

Most NGO reports state that it is impossible to know how many people have been killed or injured by small arms. Many deaths and injuries go unreported and undocumented because the victims are treated at home or hospitals and health centres have been targeted in the fighting and destroyed. ${ }^{77}$

Until the imposition of an arms embargo by the United Nations (see below), the United States of America, which is one of the biggest arms suppliers to African states, had supplied the armies of Chad, Namibia, Uganda and Zimbabwe, all of which have been engaged in fighting in 
the DRC. ${ }^{78}$ Because of the involvement of so many of the countries in the region in the DRC conflict, arms supplied to these countries frequently find their way into the DRC. For example, Uganda People's Defence Force (UPDF) soldiers brought numerous small arms into the Ituri and North Kivu regions when Uganda invaded the DRC in $1996 .{ }^{79}$ Many of these weapons were later sold, given away, lost or stolen. Uganda itself has been supplied with weapons by North Korea and South Africa ${ }^{80}$ At various stages in the conflict there have been allegations of arms supplies to Uganda from Russia or Ukraine. ${ }^{81}$

The UPDF has supplied small arms directly to the Armée du Peuple Congolaise (APC). When militia groups broke away from the APC, they took their weapons with them. Other rebel groups were reported to be supplied with weapons indirectly through the UPDF and the DRC government. Militia groups have also been recorded as buying guns from Ugandan soldiers. ${ }^{82}$

The DRC has received arms from Angola, Namibia, Chad and Zimbabwe; ${ }^{83}$ Zimbabwe obtained some of these weapons from Slovakia and Bulgaria. ${ }^{84}$ In 1999 allegations were made that Zimbabwe had funded the Conseil national pour la défense de la démocratie - Forces pour la défense de la démocratie (CNDD-FDD) and other militia groups, and provided them with weapons in order to support their fight against the DRC army. ${ }^{85}$

In the Ituri region, the Forces Armées pour le Congo (FAPC) purchased weapons from the Sudanese People's Liberation Army (SPLA) and from Ugandan sources. It raised money for this purpose by taxes imposed on people living in Aru and Mahagi territories. The FAPC then sold these weapons to the FNI, which paid for them with gold mined in Mongbwalu. Numerous other small armed groups have also bought weapons from Ugandan sources, while the UPC bought its weapons from Rwandan sources. ${ }^{86}$ Rwanda, in turn, has imported "millions of rounds of small arms ammunition, grenades and rocket launchers from surplus stocks in Albania and... has recently been ordering even more supplies of such equipment from surplus stocks in Bosnia". Although these transactions were not in themselves in breach of the arms embargo, they would have significantly increased the arms flow in a region already awash with weapons. AI reports that Rwanda continued to arm groups which are known to have committed grave human rights violations even after the imposition of the arms embargo by the UN Security Council. ${ }^{87}$

Even though an arms embargo on the DRC has been in place since July 2003, there is still no end to the weapons and ammunition reaching the country. For example, the UN Panel of Experts reported in October 2003 that small arms and light weapons originating in Jordan had been received by DRC transitional government forces. The panel further re- 
ported in July 2004 that substantial quantities of arms and ammunition had reached the DRC by air. It stated that one of the planes was Libyan, registered in Equatorial Guinea but based in the United Arab Emirates and crewed by Romanians. ${ }^{88}$

These are just some examples of the convoluted ways in which small arms have reached those who are party to the fighting in the DRC conflict. The fact that nine states and approximately 20 armed groups have been involved in the conflict at one time or another, as well as the lengthy duration of the conflict, the size of the DRC and its very porous borders with the nine other states, has meant that the trade in weapons is well established, extremely lucrative, highly complex and very difficult to stop.

\section{Arms embargo on the DRC}

The UN Security Council has attempted to deal with the issue of weapons in the DRC, albeit unsuccessfully thus far. ${ }^{89}$ Acting under Chapter VII of the UN Charter, the Security Council passed a resolution in July 2003 establishing an arms embargo - initially for a 12-month period - by calling on all states to

prevent the direct or indirect supply, sale or transfer, from their territories or by their nationals, or using their flag vessels or aircraft, of arms and any related matériel, and the provision of any assistance, advice or training related to military activities, to all foreign and Congolese armed groups and militias operating in the territory of North and South Kivu and of Ituri, and to groups not party to the Global and All-inclusive agreement, in the Democratic Republic of the Congo. ${ }^{90}$

While this embargo did cover all weapons mentioned above in the definition of small arms, it was problematic, as it was initially limited to the Ituri and Kivu regions only. ${ }^{91}$ It took the UN Security Council two years to rectify this situation - during which time weapons could be transferred lawfully from the rest of the DRC to the eastern regions - by extending the embargo to the whole of the DRC. ${ }^{92}$ Initially the embargo applied to all armed groups in the Ituri and Kivu regions, as well as those not party to the Global and All-Inclusive Agreement, and anyone found to be violating it would be subject to a travel ban and have their assets frozen. ${ }^{93}$ Later, in April 2005, after the DDR process had been under way for some time, the embargo was altered to cover all armed groups not integrated into the national army or police. ${ }^{94}$ Additional pressure was placed on political and military leaders to adhere to the arms embargo: the UN Security Council decided that the leaders of foreign armed groups which 
operate in the DRC and which impede the DDR and repatriation processes, as well as leaders of DRC groups which receive support from outside the country and which impede the DDR process, would also be subject to a travel ban and have their assets frozen. ${ }^{95}$

In spite of the fact that many of the countries neighbouring the DRC had been involved in the regional armed conflicts, and that weapons were still being transferred to the DRC through some of these countries, the arms embargo applied only to the territory of the DRC. ${ }^{96}$ In 2005, in recognition of this problem, the UN Security Council demanded that "the Governments of Uganda, Rwanda, as well as the DRC put a stop to the use of their respective territories in support of violations of the arms embargo". ${ }^{97}$ Nevertheless, the Security Council was still calling for these countries, as well as Burundi, to "prevent" their territories from being used to violate the arms embargo more than two years later - an indication of the ineffectiveness of the embargo. ${ }^{98}$ In August 2007 the UN Security Council, in extending the arms embargo until 15 February 2008 , continued to condemn the "continuing illicit flow of weapons within and into the Democratic Republic of Congo". ${ }^{99}$

The UN Security Council has monitored the arms embargo in two ways: firstly, through establishing a Committee of the Security Council and a Group of Experts to assist the committee in its work, and secondly, through MONUC. The committee's task is to ensure that states are taking all necessary measures to abide by the embargo, while the Group of Experts was established to collect and analyse information relating to "flows of arms", and to report those found to be violating the embargo to the committee. ${ }^{100}$ The Group of Experts has issued several reports, which include accounts of numerous violations by armed groups in the DRC as well as violations of the embargo by Uganda, Rwanda, Armenia and South Africa. It was this group which recommended, among other things, that the arms embargo be extended to cover the whole of the DRC. ${ }^{101}$ In January 2006, in recognition that the arms embargo continued to be violated, the UN Security Council extended the group's mandate until February 2008. ${ }^{102}$ However, in spite of the many allegations of violations of the arms embargo, currently there is no evidence available that anyone has been charged or prosecuted in connection with these alleged violations.

MONUC was mandated to monitor and enforce the arms embargo, including by "inspecting, as it deems it necessary and without notice, the cargo of aircraft and of any transport vehicle using the ports, airports, airfields, military bases and border crossings in North and South Kivu and in Ituri". MONUC was further mandated to "seize or collect, as appropriate, arms and any related matériel" in the DRC in violation of the arms embargo, and to dispose of this matériel. ${ }^{103}$ MONUC stated that be- 
tween 2003 and 2005 it had collected 17,371 weapons from fighters entering the DDR process. It also said that it had retrieved approximately 10,000 weapons in Ituri alone. ${ }^{104}$ The Commission Nationale de Désarmement claimed that "at least 100,000 arms, including Kalashnikov guns, have been recovered since the programme started". ${ }^{105}$ Given that estimates for the total number of weapons in the DRC are placed conservatively around $500,000, \mathrm{AI}$ is right to claim that the number of weapons still in circulation in the DRC is "alarming". ${ }^{106}$

In conclusion, in spite of the arms embargo being in place for nearly five years, it is still not being strictly adhered to. States other than the DRC are not covered by the embargo and continue to acquire weapons, some of which then find their way into the DRC. It is very easy to violate the embargo as the DRC has a lengthy and porous border with its nine neighbouring states. This makes it extremely difficult for MONUC to monitor and enforce the arms embargo, particularly given the size of the DRC and the under-staffing and under-resourcing of the mission. ${ }^{107} \mathrm{It}$ also does not appear that the seizure and decommissioning of weapons have been particularly successful.

\section{Small arms and rape as a system of war in the DRC}

Systematic rape has often been accompanied by other violence, such as killings, beatings and assaults with weapons - mostly small arms. USAID has reported that "Attacks have comprised individual rapes, sexual abuse, gang rapes, mutilation of genitalia, and rape-shooting or rapestabbing combinations." 108 The Centre for Humanitarian Dialogue (CHD) noted that "Small arms are principal tools used to facilitate gender-specific atrocities such as the rape and sexual abuse of women." 109

MSF-Holland reported how a woman was raped in the fields, and then forced to watch while her child was beaten up, raped by three men and then shot in her leg, breaking it. ${ }^{110}$ Another woman described how two armed men appeared in front of her: "They hit me on the face with the butt of their gun. I threw the wood at them and started to run. But I fell on the ground and they took off all my clothes. One was holding me, sticking his knife on my throat, and the other one raped me."111

HRW stated that six armed men, in uniform but wearing masks, forcibly entered a home in Bukavu and attacked the father with machetes. The soldiers raped the 15-year-old daughter for an hour, and when she began crying, stuck the barrel of a gun in her mouth. ${ }^{112}$ Another young woman was kidnapped by an RCD official and held hostage for eight days. She was raped several times and threatened at gunpoint. On two occasions a revolver was held at her throat, and she was forced to phone 
her mother and lie about where she was. ${ }^{113}$ HRW reported a nursecounsellor as explaining, "Most [perpetrators] say they are going to kill them [the victims]. They say 'how much does it cost to kill you - one bullet, one dollar.' The girls say they then give in."114

HRW spoke to numerous witnesses about rapes including the use of small arms: one such witness spoke of a woman in Kambumbe who was raped by seven Banyamulenge soldiers. Afterwards, one of the soldiers inserted his gun into the woman's vagina and shot her. She died shortly afterwards. In two other cases in Kambumbe at around the same time, RCD soldiers also shot the women in their vaginas. Yet another woman, who was raped by an RCD soldier and shot in the genitals three times, survived the attack, spending several months in hospital and undergoing numerous operations. ${ }^{115}$

Recently, Professor Yakin Ertürk, special rapporteur of the UN Human Rights Commission on Violence against Women, made a country visit to the DRC. She subsequently described the situation in the Kivus as "the worst crisis I have encountered so far", saying that women continue to be "brutally gang raped, often in front of their families and communities. In numerous cases, male relatives are forced at gun point to rape their own daughters, mothers or sisters. Frequently women are shot or stabbed in their genital organs, after they are raped."116

The reports of these types of rape may appear relatively rare when contrasted with the majority of rapes carried out by men bearing small arms, but there is a dearth of research which could reveal whether or not this is the case.

Small arms have not just been used to coerce women into being raped, but in other ways too. International Alert reports that 12.4 per cent of rape survivors whom it had interviewed had had objects inserted into their genitals, including small arms. Its report stated that "some women also said how, sometimes, during these gang rapes, after one man had finished raping the victim, the attackers would insert the end of a rifle, wrapped in a cloth soaked in water, into the woman's vagina, so as to 'clean' her ready for the next attacker". ${ }^{117}$

Women are not only raped at gunpoint, but are often abducted by fighters and soldiers, and kept as slaves by these groups to provide "sexual, domestic and agricultural services... they have to cook, wash and mend the men's clothes, cultivate small patches of land in the forest, gather firewood, fetch water and carry weapons and ammunition or other items". ${ }^{118}$ It is argued that keeping women physically captive may be easier if the captors are armed with small arms, as opposed to knives or other weapons which, by their nature, require closer physical proximity for the threat of using them to be wholly effective.

These are but a few examples of the hundreds of accounts of rape us- 
ing small arms cited in media and NGO reports. However, there do not appear to be any reliable statistics showing how many women are injured or killed with small arms during rape. It is very common for rapes to be committed by men carrying small arms which are used to threaten and intimidate women into submitting to being raped. This is not to say that systematic rape would not occur but for easy access to small arms, but these weapons do seem to make systematic rape easier to carry out. In addition, the injuries sustained through the use of small arms during rape appear, at first glance, to be more serious and frequently more deadly, as opposed to rapes carried out without the involvement of small arms. However, further research into, and documentation of, systematic rape are needed to confirm these observations.

\section{MONUC and the protection of women from systematic rape $^{119}$}

MONUC was established by UN Security Council Resolution 1278 on 30 November 1999. Its mandate included assisting in the protection of human rights, but nothing more specific than that in relation to the protection of women. Resolution 1291 added to MONUC's mandate, authorizing it to act under Chapter VII of the UN Charter, including protecting "civilians under imminent threat of physical violence". Yet again, nothing more specific on protection of women was included. ${ }^{120}$ This changed with Resolution 1493, which recognized the importance of gender perspectives in peacekeeping operations in accordance with Resolution $1325,{ }^{121}$ and recalled "the need to address violence against women and girls as a tool of warfare, and in this respect encourag[ed] MONUC to continue to actively address this issue; and call[ed] on MONUC to increase the deployment of women as military observers as well as in other capacities". ${ }^{22}$

In line with Resolution 1325, the MONUC Gender Office was established in March 2002. It has a twofold approach to gender issues: firstly, it focuses internally on training those involved in MONUC, and secondly, it focuses on "governmental institutions, civil society associations, companies, trade unions and professional associations". ${ }^{123}$ In respect of its work with governmental institutions, it aims to reform the security sector "to ensure the daily safety of women", and as such is involved in training of police officers in "gender relations". ${ }^{124}$

MONUC also provides training for FARDC soldiers, addressing "the causes and consequences of sexual violence", and introduces soldiers to the concept of women's rights in international human rights law. In addition, MONUC works with military magistrates to promote awareness of 
the laws on sexual violence, as these laws are rarely applied. Furthermore, MONUC reports that it "conducts inquests into all reported rape cases involving agents of the State (police, military, FARDC) and takes the perpetrators to court". ${ }^{125}$

However, it is a little worrying that different organs of the United Nations have different perspectives on rape in the DRC: recently, MONUC's human rights division claimed that there has been a "decline in the number of state agents committing rape", while the UN SecretaryGeneral has stated that "Sexual and gender-based violence remains endemic throughout the Democratic Republic of the Congo, with security services among the worst offenders." 126

It should be noted, though, that MONUC may only act within its mandate, which is set by its political masters - states as represented in the United Nations. It is argued that MONUC has been mandated to do too little, too late, in respect of protecting women from systematic rape. Rape as a system of war has been used in many conflicts before, and it was widely known before MONUC was established that rape was used by all sides in the DRC conflict. MONUC's mandate should have included action on this issue much earlier on. In addition to lacking a proper mandate in respect of the protection of women, the fact that MONUC has been under strength and under-resourced from the beginning means it is not surprising that it struggles to fulfil even its current mandate.

More worryingly, MONUC troops themselves have been accused of "sexual exploitation" on numerous occasions, ${ }^{127}$ the impact of these accusations on the legitimacy of the mission and its efforts to deal with systematic rape in the DRC cannot be overestimated. ${ }^{128}$ Finally, it could be argued that failures within the DDR process may also have had a negative impact on the ongoing rapes committed by armed groups and the FARDC.

\section{Conclusion and recommendations}

It is clear from researching the DRC as a case study that there is strong evidence that rape has been used by all sides to the conflict as a system of war, and that small arms have played a vital role in perpetrating systematic rape. This includes using small arms to threaten and intimidate women into submitting to rape; using small arms themselves to penetrate women's bodies; and using small arms to kill or injure women either before, during or after raping them. It is submitted that the use of small arms in committing systematic rape should be further studied and documented, including considering the following questions. What proportion of documented rapes are perpetrated using small arms? How were small 
arms used during these rapes; that is, were they used to threaten women, to rape them with or to kill or injure them? What injuries do women sustain as a result of being raped using small arms? What are the short- and long-term implications for women's health as a result? Do rapes committed with the use of small arms differ from rapes carried out using other weapons, such as knives? If so, how do they differ? Are women raped at gunpoint more likely to be killed or injured than if other weapons, or no weapons at all, are involved in the rape? Does the use of small arms by fighters make widespread or systematic rape easier for these fighters to perpetrate? Does the power conferred on rapists by small arms make prosecution more difficult and increase impunity?

Such research will increase our understanding of the impact of small arms in the maintenance of gender-specific expressions of violence in the lead-up to conflict, as well as during and after conflict. This research could assist in informing responses to the conflict in the DRC, as well as other ongoing and possible future conflicts. Aside from calling for research into the link between systematic rape and small arms, this chapter recommends the following steps.

Firstly, the role of small arms in systematic rape needs to be publicized to put further pressure on states to consider committing themselves to adhering to the terms contained in the Draft Framework Convention on International Arms Transfers ${ }^{129}$ and other initiatives to control arms, such as the recommendation that states ensure that licensed arms manufacturers mark each small arm produced, in order for it to be traceable. ${ }^{130}$

Secondly, arms embargoes put in place by the United Nations need to be strengthened. ${ }^{131}$ This includes providing sufficient resources to monitor and enforce the embargoes, and prosecuting those against whom there is evidence of violating the embargoes. In the case of the DRC, MONUC is still under strength, making its task of monitoring and enforcing the embargo much more difficult.

Thirdly, more effort needs to be put into DDR processes generally by the United Nations, to remove the illegal weapons already in use from the conflict arena. It is of little use to prevent new weapons from entering a conflict-ridden country if existing weapons are not taken out of commission simultaneously. In respect of the DRC, this again would entail expanding the MONUC mission, and resourcing it properly.

Fourthly, assistance should be given to, and pressure brought to bear on, the DRC to implement and enforce fully its amended criminal law on rape, and to bring to justice those responsible for using rape as a system of war. If rape committed during an armed conflict is not yet recognized as a war crime, the DRC should be called upon to amend its domestic legislation accordingly. All other countries whose domestic 
laws do not yet reflect the ICC definition of rape should also face international pressure to amend their laws accordingly, and to recognize that rape in conflict is a war crime.

And, finally, it is essential that the issue of systematic rape be taken as seriously by the ICC as the other "grave crimes" that the court is required to investigate when situations are referred to it. In the case of the DRC, as discussed previously in this chapter, it is essential that the ICC brings charges against those for whom there is evidence of responsibility for systematic rape. In particular, it is argued that the ICC should consider systematic rape as a crime against humanity, and even genocide, especially when investigating the rapes of Pygmies in the DRC.

\section{Notes}

1. Human Rights Watch (1995) Rape as a Weapon of War and a Tool of Political Repression, New York: Human Rights Watch, available at www.hrw.org/about/projects/ womrep/General-21.htm\#P426_39439.

2. MSF-Holland (2004) "I Have No Joy, No Peace of Mind": Medical, Psychosocial, and Socio-economic Consequences of Sexual Violence in Eastern DRC, Amsterdam: MSFHolland, available at www.msf.org/source/countries/africa/drc/2004/drcreport-nojoy. pdf, p. 10.

3. Global and All-Inclusive Agreement (2002) "Dialogue Intercongolais negociations politiques sur le processus de paix et sur la transition en RDC accord global et inclusif sur la transition en Republique Democratique du Congo, Signé à Pretoria (République d'Afrique du Sud) le 16 Décembre 2002", available at www.monuc.org/downloads/ accord_de_Pretoria.pdf.

4. Médecins Sans Frontières (2007) "Ituri Civilians Still the First Victims: Permanence of Sexual Violence and Impact of Military Operations", MSF, Geneva, October, available at www.doctorswithoutborders.org/publications/reports/2007/Ituri-Civilians-Still-theFirst-Victims.pdf, p. 4. See also IRIN News (2007) "DRC: Rape Cases Up by 60 Percent in North Kivu - UNHCR", 12 October, available at www.irinnews.org/Report. aspx?ReportId $=74767$.

5. See for example, Amnesty International, the International Action Network on Small Arms (IANSA) and Oxfam (2005) The Impact of Guns on Women's Lives, London: Oxfam, available at www.oxfam.org.uk/what_we_do/issues/conflict_disasters/women_ guns.htm.

6. Oxfam (2001) Under Fire: The Human Cost of Small Arms in North-east Democratic Republic of the Congo, London: Oxfam, available at www.oxfam.org.uk/what_we_do/ issues/conflict_disasters/downloads/drc_underfire.pdf, p. 8.

7. Global Security (2005) Military: Congo Civil War, available at www.globalsecurity.org/ military/world/war/congo.htm.

8. Oxfam, note 6 above, p. 7.

9. Amnesty International (2004) Democratic Republic of Congo: Mass Rape Leaves a Public Health Crisis, 26 October, Index AFR 62/021/2004, London: Amnesty International, available at www.amnesty.org/en/alfresco_asset/80db86b7-a3b9-11dc-9d08f145a8145d2b/afr620212004en.html. 
10. The Charter of the United Nations from 26 June 1945, entered into force on 24 October 1945. Chapter VI provides for the "Pacific Settlement of Disputes".

11. Chapter VII of the UN Charter provides for "Action With Respect to Threats to the Peace, Breaches of the Peace, and Acts of Aggression".

12. UN Security Council Resolution 1493, S/RES/1493, 28 July 2003.

13. MONUC (2008) Democratic Republic of Congo: MONUC Mission Mandate, available at www.un.org/Depts/dpko/missions/monuc/mandate.html.

14. Amnesty International (2005) Democratic Republic of Congo: Arming the East, 5 July, Index AFR 62/006/2005, London: Amnesty International, available at http://web. amnesty.org/library/index/engafr620062005, p. 9.

15. Letter from the Chairman of the Security Council Committee established pursuant to Resolution 1533 (2004) concerning the Democratic Republic of the Congo addressed to the President of the Security Council, 26 July 2006, S/2005/436, p. 5, available at www.securitycouncilreport.org/atf/cf/\%7B65BFCF9B-6D27-4E9C-8CD3CF6E4FF96FF9\%7D/DRC\%20S2005436.pdf.

16. Global and All-Inclusive Agreement, note 3 above.

17. US Department of State (2008) Background Note: The Democratic Republic of Congo, Washington, DC: US Department of State, available at www.state.gov/r/pa/ei/bgn/ 2823.htm.

18. The DDR process is referred to as brassage in the DRC: it is a French word meaning to "brew, mix or stir", and began in September 2003. The process is meant to integrate the various troops of all armed groups in order to build a new national army (the FARDC). All fighters are to be "mixed" together so that groups no longer form along ethnic, political or regional affiliations. They are then sent as integrated brigades to parts of the DRC from which they did not originate. For further information see the MONUC website at www.monuc.org/news.aspx?newsID=15719.

19. BBC News (2007) "Profile: General Laurent Nkunda", 4 September, available at http://news.bbc.co.uk/1/hi/world/africa/3786883.stm.

20. BBC News (2008) "Eastern Congo Peace Deal Signed", 23 January, available at http:/ news.bbc.co.uk/1/hi/world/africa/7204898.stm.

21. Report by the UN Panel of Experts (2003) The Illegal Exploitation of Natural Resources and Other Forms of Wealth of the Democratic Republic of Congo, 23 October, $\mathrm{S} / 2003 / 1027$, p. 14 , available at www.natural-resources.org/minerals/CD/docs/other/ N0262179.pdf.

22. UN Security Council Resolution 1794, S/RES/1794, 21 December 2007.

23. See the Decree of 27 June 1960 and Edict No. 78-015 of 4 July 1978 relating to Article 170 of the Congolese Penal Code. International Alert (2005) Women's Bodies as a Battleground: Sexual Violence Against Women and Girls During the War in the Democratic Republic of Congo. South Kivu (1996-2003), London: International Alert, available at www.internationalalert.org/pdfs/sexual_violence_congo_english.pdf, p. 53.

24. International Alert, ibid., p. 27.

25. IRIN News (2006) "DRC: Soldiers Jailed for Mass Rape", 14 April, available at www.irinnews.org/report.asp?ReportID=52801.

26. Journal Officiel de la Republique Democratique du Congo 47(15), Kinshasa, 1 August 2006: Loi no. 06/018 du 20 juillet 2006 modifiant et completant le Decret du 30 janvier 1940 portant Code penal congolais, available at www.glin.gov/view.do?documentID= 182501 (hereinafter Loi no. 06/018). There is insufficient information available in the public domain for the author to undertake a proper analysis of its theoretical or practical impact.

27. Loi no. 06/018, ibid. See in particular the amendments to "Section II: Des Infractions de Violences Sexuelles", Article 170: du Viol. 
28. The UN Secretary-General has stated that "Rape and other forms of sexual violence remain prevalent, with few perpetrators reaching the justice system. Many of those accused are released on bail with no subsequent appearance... Police and military commanders, as well as local authorities, continue to encourage families of rape victims to settle out of court." UN Secretary-General (2007) Twenty-fourth Report of the Secretary-General on the United Nations Organization Mission in the Democratic Republic of the Congo, 14 November, S/2007/671, para. 40, available at www.un.org/ Docs/sc/sgrep07.htm.

29. 1907 Hague Convention IV Respecting the Laws and Customs of War on Land and Annexed Regulations, 18 October 1907. Entered into force on 26 January 1910. For full text see Roberts, Adam and Richard Guelff, eds (2000) Documents on the Laws of War, 3rd edn, Oxford: Oxford University Press, pp. 67-84. 1949 Geneva Convention I for the Amelioration of the Condition of the Wounded and Sick in Armed Forces in the Field, 12 August 1949. Entered into force on 21 October 1950. 75 UNTS (1950) 31-83 (hereinafter Geneva Convention I). 1949 Geneva Convention II for the Amelioration of the Condition of the Wounded, Sick and Shipwrecked Members of Armed Forces at Sea, 12 August 1949. Entered into force on 21 October 1950. 75 UNTS (1950) 85-133 (hereinafter Geneva Convention II). 1949 Geneva Convention III Relative to the Treatment of Prisoners of War, 12 August 1949. Entered into force on 21 October 1950. 75 UNTS (1950) 135-285 (hereinafter Geneva Convention III). 1949 Geneva Convention IV Relative to the Protection of Civilian Persons in Time of War, 12 August 1949. Entered into force on 21 October 1950. 75 UNTS (1950) 287-417 (hereinafter Geneva Convention IV).

30. 1977 Geneva Protocol I Additional to the Geneva Conventions of 12 August 1949, and Relating to the Protection of Victims of International Armed Conflicts, 8 June 1977. Entered into force on 7 December 1978. 1125 UNTS (1979) 3-608 (hereinafter Additional Protocol I). 1977 Geneva Protocol II Additional to the Geneva Conventions of 12 August 1949, and Relating to the Protection of Victims of Non-International Armed Conflicts, 8 June 1977. Entered into force on 7 December 1978, 1125 UNTS (1979) 609-699 (hereinafter Additional Protocol II).

31. Additional Protocol I, ibid., Articles 48, 51(2) and 52(2); Additional Protocol II, ibid., Article 13(2).

32. Additional Protocol I, note 30 above, Article 50.

33. ICRC (2005) Customary International Humanitarian Law, Vol. 1, Cambridge: Cambridge University Press, Rule 6, p. 19.

34. Article 27 of Geneva Convention IV, note 29 above.

35. Article 76 of Additional Protocol I, note 30 above.

36. Article 75(2) of Additional Protocol I, note 30 above.

37. ICRC, note 33 above, Rule 93, p. 323.

38. Articles 8(2)(b)(xii) and 8(e)(vi) of the Rome Statute of the International Criminal Court, 17 July 1998. Entered into force on 1 July 2002. 2187 UNTS 90 (hereinafter Rome Statute).

39. The Prosecutor v Zejnil Delalic, Zdravko Mucic, Hazim Delic and Esad Landzo, Judgment, Case No. IT-96-21, November 1998. For conditions see para. 494, available at www.un.org/icty/celebici/trialc2/judgement/index.htm.

40. The Prosecutor v Jean-Paul Akayesu, Judgment, Case No. ICTR 96-4-T, 1996; The Prosecutor v Alfred Musema, Judgment, Case No. ICTR 96-13-A, January 2000.

41. Of the African countries mentioned in this chapter, Angola, Burundi, Chad, Libya, Rwanda, South Africa, Sudan and Zimbabwe all became parties to the 1949 Geneva Conventions before 1994; see www.icrc.org/Web/Eng/siteeng0.nsf/iwpList103/ 6C6481C326D8DC31C1256E35004D53AB. Again, of the African countries mentioned 
in this chapter, only Burundi, Chad, the DRC, Liberia, Namibia, South Africa and Uganda are currently parties to the Rome Statute; see www.icc-cpi.int/region\&id= 3.html.

42. The Prosecutor v Anto Furundzija, Judgment, IT-95-17/1-T, December 1998. The court (at para. 185) held the objective elements of rape to be "the sexual penetration, however slight: (a) of the vagina or anus of the victim by the penis of the perpetrator or any other object used by the perpetrator; or (b) of the mouth of the victim by the penis of the perpetrator; (ii) by coercion or force or threat of force against the victim or a third person".

43. UN Special Rapporteur (1998) Systematic Rape, Sexual Slavery and Slavery-like Practices during Armed Conflict, Final Report to the Commission on Human Rights, E/ CN.4/Sub.2/1998/13, 22 June. At para. 24, rape is defined as being "the insertion, under conditions of force, coercion or duress, of any object, including but not limited to a penis, into a victim's vagina or anus; or the insertion, under conditions of force, coercion or duress, of a penis into the mouth of the victim"; see www.unhchr.ch/Huridocda/ Huridoca.nsf/0/3d25270b5fa3ea998025665f0032f220? OpenDocument.

44. Article 7(1)(g)-1 of ICC Elements of Crime, adopted and entered into force on 9 September 2002, available at www.icc-cpi.int/NR/rdonlyres/9CAEE830-38CF-41D6AB0B-68E5F9082543/0/Element_of_Crimes_English.pdf.

45. UN Special Rapporteur, note 43 above, para. 25.

46. The Prosecutor v Tadic, Judgment, Case No. IT-94-1, 7 May 1997, para. 646.

47. Meron, Theodor (1993) "Rape as a Crime Under International Humanitarian Law", American Journal of International Law 87(3), p. 428.

48. UN Special Rapporteur, note 43 above, para. 39.

49. Unless otherwise indicated, the term "armed conflict" denotes both international and non-international armed conflicts in the DRC during the past few years.

50. MSF-Holland, note 2 above, p. 16.

51. Human Rights Watch (2005) Seeking Justice: The Prosecution of Sexual Violence in the Congo War, Vol. 17, No. 1(A), New York: Human Rights Watch, March, available at http://hrw.org/reports/2005/drc0305/, p. 7.

52. IRIN News (2004) "DRC: Focus on Rampant Rape, Despite End of War", 8 March. It was concluded that there were about 25,000 victims in South Kivu province, 11,350 in Maniema province, 1,625 in Goma and 3,250 in Kalémie; see www.reliefweb.int/w/ rwb.nsf/0/253bfc93b573d42885256e51006c20e4?OpenDocument.

53. USAID/DCHA (2004) "Sexual Terrorism: Rape as a Weapon of War in Eastern Democratic Republic of Congo. An Assessment of Programmatic Responses to Sexual Violence in North Kivu, South Kivu, Maniema, and Orientale Provinces", Assessment Report, available at www.peacewomen.org/resources/DRC/USAIDDCHADRC.pdf, p. 11.

54. MSF-Holland, note 2 above, p. 12.

55. Human Rights Watch (2002) The War within the War: Sexual Violence against Women and Girls in Eastern Congo, New York: Human Rights Watch, June, available at www.hrw.org/reports/2002/drc/Congo0602.pdf, p. 1.

56. Traditional militias in the eastern provinces.

57. Human Rights Watch, note 51 above, p. 7.

58. Literally "those who work together"; later translated as "those who kill together", according to Rwandans who fled the genocide of 1994.

59. A Burundian organization.

60. USAID/DCHA, note 53 above, p. 9.

61. MSF-Holland, note 2 above, p. 16.

62. Human Rights Watch, note 51 above, p. 7. 
63. USAID/DCHA, note 53 above, p. 7.

64. IRIN News (2004) "Our Bodies - Their Battle Ground: Gender-based Violence in Conflict Zones", web special on violence against women and girls during and after conflict, available at www.irinnews.org/webspecials/GBV/default.asp.

65. Afrol News (2004) "Congo Vice-President Charged with 'Pygmies' Extermination', 6 July, available at www.afrol.com/articles/13564.

66. MONUC Human Rights Division (2006) The Human Rights Situation in the Democratic Republic of Congo (DRC) During the Period of January to June 2006, July, available at www.unhcr.org/cgi-bin/texis/vtx/refworld/rwmain?page=publisherdocid= 46caaafe0skip $=$ publisher $=$ MONUC.

67. Amnesty International (2007) Annual Report 2007, London: Amnesty International, available at www.amnesty.org/en/region/africa/central-africa/dr-congo, p. 102.

68. IRIN News (2008) "The Rapists Roam the Streets", 21 January, available at www. irinnews.org/Report.aspx?ReportId=76338.

69. USAID/DCHA, note 53 above, p. 10.

70. The terms "war crimes", "crimes against humanity" and "genocide" are used in this chapter as defined in the Rome Statute, note 38 above, Articles 8, 7 and 6.

71. International Criminal Court Warrant of Arrest in Relation to the Situation in the Democratic Republic of Congo: Prosecutor v Thomas Lubanga Dyilo, Case No. ICC01/04-01/06, available at www.icc-cpi.int/library/cases/ICC-01-04-01-06-2_tEnglish.pdf.

72. International Criminal Court Warrant of Arrest in Relation to the Situation in the Democratic Republic of Congo: Prosecutor v Germain Katanga, Case No. ICC-01/0401/07, available at www.icc-cpi.int/library/cases/ICC-01-04-01-07-1_tEnglish.pdf.

73. This section attempts to indicate the complexity of the issue of small arms in the DRC, particularly the routes by which these arms end up in the hands of parties to the conflict. However, a detailed discussion of the issue is outside the scope of this chapter. See Report by the Panel of Governmental Experts on Small Arms to the UN General Assembly, A/52/298, 1997, available at www.un.org/sc/committees/sanctions/a52298. pdf; Amnesty International, note 14 above.

74. Oxfam, note 6 above, p. 9.

75. Inter Press Service (2005) "Politics: Africa Awash With Small Arms, Misery", 19 April, available at http://allafrica.com/stories/200504190608.html.

76. Oxfam, note 6 above, p. 12.

77. Ibid., pp. 10 and 29.

78. Ibid., p. 12.

79. Ibid.

80. Ibid.

81. Amnesty International (2000) DRC: Killing Human Decency, Index AFR 62/007/2000, London: Amnesty International, 31 May, available at http://web.amnesty.org/library/ Index/engAFR620072000, p. 23.

82. Oxfam, note 6 above, p. 13 .

83. Amnesty International, note 81 above, p. 22.

84. Ibid.

85. Ibid.

86. International Crisis Group (2004) Maintaining Momentum in the Congo: The Ituri Problem, Brussels: International Crisis Group, available at http://129.194.252.80/ catfiles/3227.pdf, p. 13.

87. Amnesty International, note 14 above, p. 9.

88. Ibid., p. 18.

89. Control Arms (2006) "UN Arms Embargoes: An Overview of the Last Ten Years", London, 16 March, available at www.globalpolicy.org/security/smallarms/2006/ 0316embargoes.pdf. 
90. UN Security Council Resolution 1493 , note 12 above.

91. Ibid. This resolution imposed an arms embargo on "all foreign and Congolese armed groups and militias operating in the territory of North and South Kivu and of Ituri, and to groups not party to the Global and All-inclusive agreement", para. 20.

92. UN Security Council Resolution 1596, S/RES/1596, 18 April 2005.

93. Ibid. For a list of the parties to the Global and All-Inclusive Agreement, signed on 17 December 2002, see Kamwimbi, Theodore Kasongo (2006) "The DRC Elections, Reconciliation, and Justice", International Centre for Transitional Justice, 27 July, available at www.ictj.org/en/news/coverage/article/986.html.

94. UN Security Council Resolution 1649, S/RES/1649, 21 December 2005.

95. UN Security Council Resolution 1596, note 92 above.

96. UN Security Council Resolution 1493, note 12 above.

97. UN Security Council Resolution 1592, S/RES/1592, 30 March 2005.

98. UN Security Council Resolution 1756, S/RES/1756, 15 May 2007, para. 18.

99. UN Security Council Resolution 1771, S/RES/1771, 10 August 2007.

100. UN Security Council Resolution 1533, S/RES/1533, 12 March 2004, para. 8.

101. Report from the Group of Experts on the Democratic Republic of Congo to the Chairperson of the UN Security Council Committee established pursuant to Resolution 1533, 25 January 2005. In April 2005 the UN Security Council took up this recommendation, exempting only "units" of the FARDC and the DRC police force, and the MONUC mission. See www.grip.org/bdg/pdf/g4259.pdf.

102. UN Security Council Resolution 1771, note 99 above.

103. UN Security Council Resolution 1565, S/RES/1565, 1 October 2004.

104. MONUC (2006) "Small Arms Remain a Major Threat in DRC", 12 July, available at www.monuc.org/news.aspx?newsID=11723.

105. IRIN News (2007) “Weapons Destroyed as Disarmament Picks Up in Ituri”, 22 May, available at www.irinnews.org/Report.aspx?ReportId=72289.

106. Amnesty International (2007) DDR and Reform of the Army, Index AFR 62/001/2007, London: Amnesty International, January, available at www.amnesty.org/en/report/ info/AFR62/001/2007, p. 28.

107. The UN Secretary-General had recommended that MONUC should consist of 23,900 troops in order to carry out its mandate. However, as of November 2007 MONUC consisted of 17,386 troops only. UN Secretary-General (2004) Troisième rapport spécial $d u$ Secrétaire général sur la Mission de l'Organisation des Nations Unies en République démocratique du Congo, 16 August, S/2004/650, available at http://daccessdds.un. org/doc/UNDOC/GEN/N04/457/43/IMG/N0445743.pdf?OpenElement. See also UN Secretary-General, note 28 above.

108. USAID/DCHA, note 53 above, p. 6.

109. Centre for Humanitarian Dialogue (2003) "Small Arms and Human Security: A Snapshot of the Humanitarian Impacts", Briefing Paper, Centre for Humanitarian Dialogue, Geneva, available at www.hdcentre.org/files/RXbriefing.pdf, p. 6.

110. MSF-Holland, note 2 above, p. 16.

111. Ibid., p. 19.

112. Human Rights Watch, note 55 above, p. 59.

113. Ibid., p. 60.

114. Ibid., p. 76.

115. Ibid., pp. $54-55$.

116. MONUC (2007) "South Kivu: 4,500 Sexual Violence Cases in the First Six Months of This Year Alone", 27 July, available at www.monuc.org/news.aspx?newsID=15065.

117. International Alert, note 23 above, p. 34.

118. Ibid., p. 46.

119. It is impossible within the scope of this chapter to evaluate properly how successful 
MONUC's work has been in this area; this section is merely intended to highlight some of the issues around protecting women from systematic rape.

120. UN Security Council Resolution 1291, S/RES/1291, 24 February 2000.

121. UN Security Council Resolution 1325 on Women, Peace and Security, S/RES/1325, 31 October 2000.

122. UN Security Council Resolution 1493 , note 12 above.

123. MONUC website, "Gender: Activities"; see www.monuc.org/news.aspx?newsID=728.

124. MONUC website, "Gender: Women and Security"; see www.monuc.org/news.aspx? newsID=732.

125. IRIN News, note 68 above.

126. UN Secretary-General, note 28 above, para. 43.

127. United Nations (2005) Investigation by the Office of Internal Oversight Services into Allegations of Sexual Exploitation and Abuse in the United Nations Organization Mission in the Democratic Republic of the Congo, 5 January, A/59/661, available at www. monuc.org/downloads/0520055E.pdf.

128. See e.g. UN Security Council Resolution 1565, note 103 above; also Holt, Kate and Sarah Hughes (2004) "Peacekeepers Accused of Rape", The Star, 12 July, available at www.thestar.co.za/index.php?fSectionId=129\&fArticleId=2146949.

129. Draft Framework Convention on International Arms Transfers (2004) Working Draft, 25 May, available at www.iansa.org/documents/2004/att_0504.pdf.

130. Part II, Article 7 of the Programme of Action to Prevent, Combat and Eradicate the Illicit Trade in Small Arms and Light Weapons in All its Aspects, July 2001, A/ CONF.192/15, available at http://disarmament.un.org:8080/cab/poa.html.

131. For further recommendations on strengthening arms embargoes, see Control Arms (2006) "UN Arms Embargoes: An Overview of the Last Ten Years", Briefing Note, 16 March, available at www.globalpolicy.org/security/smallarms/2006/0316embargoes. pdf. 
Part II

Gender, small arms and violence in fragmented societies 

5

\title{
Haiti: The gendered pattern of small-arms violence against women
}

\author{
Nadine Puechguirbal, Wiza Loutis and Natalie Man
}

While efforts have been made to disarm and reintegrate various armed elements in Haiti, until recently little was known about whether women are involved in armed violence other than as victims, and, if so, about their motivations for association. With the aim of gaining a better understanding about their association and how women are affected by violence, this chapter looks into the phenomenon of armed violence in Haiti and the varying behaviour of the armed groups. Despite the fact that contemporary Haitian women have often proved themselves capable of armed violence, a stereotype of the gentle and benevolent Haitian woman remains quite strongly in place today, thus hiding women's participation in armed violence.

Furthermore, in order to evaluate how armed violence and domestic violence intertwine to maintain women's subordinate status, this chapter analyses gender relations in Haitian society and their impact on women's access to political and economic spheres, the situation of women associated with and as victims of armed groups and the misuse of small arms in juvenile delinquency. In particular, it will ask what kind of coping mechanisms women develop to deal with daily violence.

\section{Background to the Haitian conflict}

The departure of President Aristide in April 2004, and the subsequent eruption of armed violence in Haiti, resulted in the deployment in June

Sexed pistols: The gendered impacts of small arms and light weapons, Farr, Myrttinen and Schnabel (eds), United Nations University Press, 2009, ISBN 978-92-808-1175-9 
2004 of MINUSTAH (the UN Stabilization Mission in Haiti) ${ }^{1}$ under Chapter VII of the Charter of the United Nations (1945). Under the extension of MINUSTAH's mandate in August 2006, the Security Council "requests MINUSTAH to reorient its disarmament, demobilization and reintegration efforts towards a comprehensive community violence reduction programme adapted to local conditions, including assistance for initiatives to strengthen local governance and the rule of law and to provide employment opportunities to former gang members, and at-risk youth", and makes specific reference to gender by:

reaffirming the importance of appropriate expertise on issues relating to gender and peacekeeping operations and post-conflict peace-building in accordance with resolution 1325 (2000) and the need to address violence against women and children. ${ }^{2}$

Article 1 of the UN Declaration on the Elimination of Violence against Women (1993) defines "violence against women" as:

Any act of gender-based violence that results in, or is likely to result in physical, sexual or psychological harm or suffering to women, including threats of such acts, coercion or arbitrary deprivation of liberty, whether occurring in public or in private life.

Furthermore, the Inter-American Convention on the Prevention, Punishment and Eradication of Violence against Women, "Convention of Belem Do Para" (1994), adds that:

Violence against women shall be understood to include physical, sexual and psychological violence that is perpetrated or condoned by the state or its agents regardless of where it occurs.

This definition is extremely important in the Haitian context, where agents of the state, such as the police, are renowned for their participation in acts of violence against women in a climate of impunity that has been prevailing in the country for the past few years. As the sociologist Laënnec Hurbon writes:

The paradigm under which one usually tries to tackle the problem of insecurity is impunity. The more an individual is provided with impunity, the more he is encouraged to commit a crime. [...] As a result, if someone is shot dead by bandits or police officers right in the street, this will not automatically lead to legal proceedings or complaints against persons unknown, nor investigations. ${ }^{3}$ 
Although Haiti has been party to the Convention on the Elimination of Discrimination against Women (CEDAW) since $1981^{4}$ and ratified the Inter-American Convention on the Prevention, Punishment and Eradication of Violence against Women in 1996, there has been little implementation by the government. The UN special rapporteur on violence against women visited Haiti in $1999 .{ }^{5}$ Her documented observations and concerns from that date remain unchanged - women's rights violations continue to take place at the structural level, legislation which would normally protect and empower women is lacking and her recommendations on action to eliminate violence against women have not been implemented. Furthermore, the high level of corruption within the security and justice sectors, as well as the lack of capacity and resources within these sectors, has resulted in impunity and a lack of reporting of women's rights violations. Additionally, apart from the work carried out by women's organizations in an effort to promote the principles of Security Council Resolution 1325 (2000) on women, peace and security, there has been little political will in the government relating to the empowerment of women and their inclusion in the peacebuilding process. However, since its deployment in June 2004 MINUSTAH has established a fully staffed Gender Unit that is working on the development of a sustainable process targeting the reduction of violence for women in collaboration with the MINUSTAH/UNDP DDR Unit and national partners.

Furthermore, the UN independent expert on the situation of human rights in Haiti, Louis Joinet, emphasizes in his 2005 report the deterioration of the situation of violence against women. As he writes:

This development is particularly alarming because a number of hitherto relatively marginal practices have been spreading, such as group rape, a "specialty" of certain gangs, and even repeated rapes over time, practiced as a way of blackmailing the victim or her family. ${ }^{6}$

The 1995 Beijing Platform for Action identified violence against women as one of its 12 critical areas. Violence against women is deeply rooted in the social construction of gender roles, in what is acceptable behaviour for a man and for a woman. This type of violence is frequently an accepted norm which is not properly sanctioned and continues to take place in a large number of societies within a climate of impunity. As a result, any strategy used to fight violence against women should also involve boys and men, as recommended in a UN report on "The Role of Men and Boys in Achieving Gender Equality". This report concludes that: 
A gender equal society is one that is free of gender-based violence. Involving men and boys is a strategy for creating a non-violent and gender equal society. Men and boys are important agents for changing attitudes, behaviour and the wider power relations which sustain gender-based violence. Programmes for men against gender-based violence aim at positively influencing both men who oppose violence and those who do not. ${ }^{7}$

Boys should therefore be socialized through male role models who respect women and condemn violence, thus demonstrating that one does not need to be violent to be a man.

Yet this objective is difficult to achieve when stereotypical notions that males are the main support of a family are persistent, even as social realities change dramatically. In post-conflict or socio-political crisis situations, such as that found in Haiti, violence is perpetuated in part because of a change in gender roles which profoundly questions the status of the man as the breadwinner. The decline in Haiti's economy means that men are increasingly unable to find paid work in legitimate income-generating activities, whereas women have been struggling throughout the crisis to keep extended families alive, thus taking on more responsibilities - including that of earning a small income outside the household.

In Haiti today, violence against women is not confined to the domestic realm; it is perpetuated through patriarchal institutions such as the school, the family, the church and the state which condone psychological, physical and symbolic violence by maintaining stereotypical views of what a woman is supposed to be and how she is supposed to behave. According to the French sociologist Pierre Bourdieu, symbolic violence is based on the production of beliefs that society teaches individuals through the socialization process so that they will be made to behave and think according to socially constructed norms and perceptions. ${ }^{8}$ As Myriam Merlet, the director of the Haitian women's organization ENFOFANM,${ }^{9}$ writes:

Gender stereotypes, which have striking psychological and cultural connotations, are at the base of violence against women. Power relationships become entrenched in a definite hierarchical order. On the basis of social differences between men and women in roles, behaviour, and mental and emotional structures, women find themselves at the bottom of the hierarchy. ${ }^{10}$

\section{Typology of armed groups in Haiti}

To complicate women's lives further, in Haiti armed violence also exacerbates exclusionary race and class hierarchies and disrupts development 
so that the country's poorest are caught in an increasingly vicious cycle of poverty and violence. While efforts have been made to disarm and "reintegrate" various armed elements, until recently little was known about whether women are involved in armed violence other than as victims, and if so about their motivations for association. To gain a better understanding of their association and how women are affected, and to define appropriate strategies to enable the women to exit the violence, the MINUSTAH Gender Unit and the MINUSTAH-UNDP DDR Unit commissioned an anthropological six-month study to examine the phenomenon of armed violence in Haiti, specifically in relation to women, titled "The situation of women in the context of armed violence in Haiti". This study identified how women become associated with armed groups, how they become victims of armed violence and the varying behaviour of the armed groups, as reflected in Table 5.1. ${ }^{11}$

As the table demonstrates, women are generally members of all types of armed groups, except the Organisations Politiques (unless of course they establish their own female "armies" within a locality controlled by an OP - particular to Gonaïves), the zenglendo (particular to Gonaïves) and vagabonds. Women are members of the brigades de vigilance and brigades de quartier, very often because they are single heads of household and are obliged to pick up arms to defend their family, property and honour due to the lack of presence of the national police force. However, those women who are members of the groupes de bandits carry out criminal activities such as kidnappings in order to earn a living.

The OPs originally developed as "Organisations Populaires", i.e. poor socio-economic groups composed of young people and adults of both sexes supporting President Artistide's Lavalas party, established upon his return to Haiti in 1994. OPs were provided with small arms and funds in order to impose Aristide's new rule(s) in the suburban areas of the principal towns. Their activities included "cleansing" these areas of local "bandits" (Group Zero tolerans). Later, under Aristide's second term in office (between 2001 and 2004), these OPs became known as the Organisations Politiques because they were utilized by different political parties (e.g. Convergence Démocratique, Lavalas, etc.). They were provided with light weapons and small arms in order to achieve each party's individual goals.

Older male children and young men below the age of 25 years are principally members of groupes de bandits, vagabonds or zenglendo which terrorize their local neighbourhoods. In Les Cayes they use light weapons to carry out punitive gang rapes as well as banditry. In Gonaïves, light weapons are used by young men to rob homes; in these crimes, women and girls are systematically raped. In Port-au-Prince the older male children and young men use light weapons to control areas of 
Table 5.1 Armed groups and the situation of women

\begin{tabular}{|c|c|c|c|}
\hline Category & Primary motivations & Description & Position of women \\
\hline $\begin{array}{l}\text { Organisations } \\
\text { Politiques (OPs) }\end{array}$ & $\begin{array}{l}\text { Political } \\
\text { Position is contingent and } \\
\text { depends on how leader can } \\
\text { make personal gains }\end{array}$ & $\begin{array}{l}\text { Oscillate between acting as } \\
\text { OPs, groupes de bandits or } \\
\text { milices populaires, depending } \\
\text { upon advantages of each role } \\
\text { Armed with weapons }\end{array}$ & $\begin{array}{l}\text { Do not target women and girls } \\
\text { Women and girls are not } \\
\text { immediate members } \\
\text { Women can also organize } \\
\text { themselves into an armée as } \\
\text { in Gonaïves }\end{array}$ \\
\hline $\begin{array}{l}\text { Milices populaires } \\
\quad \text { (local militias, } \\
\text { found only in } \\
\text { Port-au-Prince) }\end{array}$ & $\begin{array}{l}\text { Carry out "cleansing", operations } \\
\text { to rid immediate/neighbouring } \\
\text { areas of criminals }\end{array}$ & $\begin{array}{l}\text { High in numbers; exist with } \\
\text { certain amount of legitimacy } \\
\text { due to being supported by } \\
\text { various members of the police }\end{array}$ & $\begin{array}{l}\text { Target all members of the } \\
\text { community, including } \\
\text { women and children } \\
\text { Women fight alongside men } \\
\text { and children }\end{array}$ \\
\hline $\begin{array}{l}\text { Brigades de vigilance } \\
\quad \text { (vigilantes) }\end{array}$ & $\begin{array}{l}\text { Temporary response to } \\
\text { defending own immediate } \\
\text { community from criminality } \\
\text { (composed of neighbouring } \\
\text { households) }\end{array}$ & $\begin{array}{l}\text { Composed of members of } \\
\text { households in immediate } \\
\text { locality }\end{array}$ & $\begin{array}{l}\text { Target bandits/zenglendo } \\
\text { (male) who try to force } \\
\text { entry into homes } \\
\text { Women fight alongside men } \\
\text { and children }\end{array}$ \\
\hline $\begin{array}{l}\text { Brigades de quartier } \\
\quad \text { (self-defence groups) }\end{array}$ & $\begin{array}{l}\text { Appear in periods of political } \\
\text { strife to defend own immediate } \\
\text { community from criminality or } \\
\text { political violence }\end{array}$ & $\begin{array}{l}\text { Composed of members of } \\
\text { households in local } \\
\text { neighbourhood }\end{array}$ & $\begin{array}{l}\text { Defend neighbourhood from } \\
\text { political adversaries } \\
\text { Women fight alongside men } \\
\text { and children }\end{array}$ \\
\hline $\begin{array}{l}\text { Groupes de bandits } \\
\quad \text { (groups of bandits) }\end{array}$ & $\begin{array}{l}\text { Control zone through criminal } \\
\text { acts } \\
\text { Motivated by cash and power }\end{array}$ & $\begin{array}{l}\text { Generally strangers to the zone } \\
\text { which they control } \\
\text { Acts of violence include rape, } \\
\text { kidnappings, murder, } \\
\text { extortion etc. } \\
\text { Generally composed of young }\end{array}$ & $\begin{array}{l}\text { Target entire communities } \\
\text { Groups composed solely of } \\
\text { women exist in the capital } \\
\text { and only target girls and } \\
\text { young women }\end{array}$ \\
\hline
\end{tabular}

Generally composed of young people 
Bandes de zenglendo (groups of bandits; found only in

Gonaïves)

Vagabonds (delinquents)
Diffuse terror through criminal acts

Imposition of macho values upon young, single, childless girls and women within the community in order to control their behaviour
Generally composed of young men aged $18-25$ years

Majority arrived in Gonaïves after a hurricane in

September 2004

Composed of male children and young men

Generally not armed but borrow weapons in order to carry out gang rape
Target homes where they rape women and girls, and extort money from female market stall-holders

No women present within these bandes

Only target young, single, childless girls and women who do not respect the community's macho values Girls and women are not members 
refuge which lack the presence and security of the police. In these types of situations, the local population are taken hostage and girls and women are specifically targeted so that these boys and men can assert their power.

As the table shows, from the perspective of traditional demobilization, disarmament and reintegration (DDR), there can be no "demobilization" process in the strict sense since armed groups in Haiti have not been formally mobilized. The process has rather more to do with members' "disassociation" from their involvement with the armed groups and armed violence, which needs to be simultaneously accompanied by a far-reaching arms control programme embedded in a philosophy of community security and the establishment of a police presence in areas affected by armed violence. It is, however, not possible to ask the brigades de vigilance and brigades de quartier to lay down their arms if a police presence has not been established beforehand. Most importantly, it is imperative that the local communities trust the police presence which is in place. Furthermore, because armed individuals in Haiti are already members of their local communities, they do not need to pass through a "reintegration process" as in other countries. Instead, they require a process of "rehabilitation". Programming for these individuals must emphasize the reduction of violence at the community level and the respect of human rights, the identification and development of leadership training programmes (for community leaders/peer educators) and legitimate economic opportunities, where necessary.

\section{Social and political context}

The Haitian situation does not correspond to traditional conflicts since there is no armed conflict in the legal sense. However, various quarters in many towns are so severely affected by urban violence and criminality that the consequences are similar to that of a civil war, such as displacement and/or migration, a lack of presence of the national security forces within the specific areas or lack of access for humanitarian activities. Armed groups in Haiti are currently more like gangs and bandits, and they are involved in criminal activities. Acts of violence include kidnapping, murder, rape and gang rape, armed robbery and the destruction of property. While political violence is minimal, it is mobilized to manipulate the perpetrators of urban violence. The situation is further worsened by the fact that, in order to protect communities from this criminal violence, other types of armed groups have appeared, such as local militias, self-defence groups and vigilantes.

One of the principal reasons for the surge of armed groups in Haiti is the fact that the Haitian National Police is not present within the urban 
areas most affected by poverty and armed violence. This is partly a result of the policy of zero tolerans which was established under Aristide's rule in 1994, providing for the existence of Organisations Populaires groups in the most poverty-stricken areas. Composed of young people, these Organisations Populaires were supplied with small arms by the Aristide government (power in place) and were responsible for "cleansing" the capital and the principal towns of criminals. Consequently there was little need for the security and justice sectors to be present or to carry out their duties in these areas.

It is within the most impoverished urban areas of the country, where the living conditions are inhumane, that this urban violence is experienced most intensely. It is an additional burden to the daily violence experienced by Haiti's poorest citizens (characterized by, among other problems, hunger, poverty, illness, unsanitary and crowded living conditions and an absence of public services and infrastructure). ${ }^{12}$ But while the violence remains localized in the country's principal towns (Port-auPrince, Les Cayes, Gonaïves, Cap Haitien etc.), the ensuing terror is diffused throughout the entire country, bringing the economy to a halt and even further degrading the precarious economic situation of the majority of the population.

The highest level of violence takes place in the poorest areas because of the presence of diverse armed groups, which operate for different reasons and with diverse motivations. The Haitian state is proving unable to assume its responsibilities to control this armed violence, and MINUSTAH faces difficulties in disarming these groups because the justice and security sectors are unable to fulfil their functions and the mission's mandate does not provide for a forced disarmament. An additional contributing factor to the continued proliferation of arms is the small number of state security personnel, which currently stand at approximately 7,000 police officers in a population of 8 million. As a result of these failings at the highest levels, civil and daily violence has become the status quo for many of these poverty-stricken areas.

\section{The gendered aspects of armed violence}

A number of Haitian historians have pointed to the presence of women alongside men during the battles against Napoleon's troops for the island's independence at the start of the nineteenth century. ${ }^{13}$ Systematically presented as parents or girlfriends of the distinguished Haitian heroes, these women in reality occupied the positions of combatants, supporters or informers. Women are equally present in almost all of the revolts which have shaken the country throughout its history after independence in 1804. Historians report that during this period the 
parliamentarians never ceased to emphasize that their female supporters were not only violent but above all more determined and vindictive than the men, which resulted in a call for more severe sentencing for women involved in armed resistance to the colonial power. ${ }^{14}$

Despite this history and the fact that contemporary Haitian women have often proved themselves capable of armed violence, a stereotype of the gentle and benevolent Haitian woman remains quite strongly in place today, thus hiding women's participation in armed violence. It is important to recognize, however, that women are not just victims but also real actors in armed violence - a fact which shocked many Haitians during a conference on the situation of women in the context of armed violence in Haiti. ${ }^{15}$ Participants' reactions, when presented with concrete anthropological evidence that women may perpetrate armed violence, was caused by their firm belief in the stereotypical images of roles which women are expected to fulfil. Also, the general understanding holds that, since armed violence in Haiti is politically motivated and women are largely excluded from the political landscape, only men can be associated with armed groups.

In reality, women have played a significant role as direct actors in armed violence alongside men, young people and children associated with armed groups. The women interviewed for the study revealed that the state's neglect of the local population (i.e. the lack of infrastructure such as water, electricity, healthcare, education, justice, etc. $)^{16}$ and their abandonment by their children's fathers were the most severe types of violence experienced. Those women associated with the armed groups represented themselves as being obliged to join the groups for various reasons, including the protection of the household, family and community, and the need to seek financial security (through the conduct of criminal activities such as kidnappings).

Like men, women also appear to be motivated by greed. Since 2004 a phenomenon has been developing whereby young women aged 18-23 years, lured by the US dollar, actively participate in lucrative kidnapping operations. These women possess small-calibre weapons, such as pistols, which they use in the same manner as their male counterparts. Unfortunately, however, when it comes to disarmament and reintegration programmes, they are very often left aside and not recognized as actors in armed violence. Nonetheless, they clearly occupy a very complex position: while they are perpetrators of violence such as in kidnappings, they are partners to men who refuse to participate in these criminal activities. There exists a gendered distinction between the weapons used by men and women, resulting in perceptions that "masculine" and "feminine" armed violence differs according to whether it takes place in the towns (capital versus provincial towns), in a particular type of armed group or 
in discrete places of origin. In general, women do not utilize firearms but use work tools, such as machetes, and objects which can be thrown, such as conch shells, stones and glass bottles. Men, however, generally use firearms in addition to machetes, batons and stones.

\section{A pattern of violence against women}

In order to analyse how armed violence and domestic violence intertwine to maintain women's subordinate status, this section analyses gender relations in Haitian society and their impact on women's access to political and economic spheres, the situation of women associated with, and victims of, armed groups and the (mis)use of small arms in juvenile delinquency. In particular, we ask what kind of coping mechanisms women develop to deal with daily violence. We observe that women are not only victims of violence; they are also actors who will try, by any means possible - even through the use of force - to carve out for themselves an acceptable life in a society that treats them as second-class citizens. Without access to their political rights, they will never be able to play a major role in the public sphere where political decisions are taken by men, or fully enjoy their citizenship. The reason why these three topics have been identified for discussion is that, for the first time in Haiti's modern history, the country is now confronted by urban violence, which radically differs from the political violence traditionally associated with the country's political instability. Far from solely targeting political opponents, this violence unpredictably and randomly affects all categories of people, without discrimination as to sex, age, race or social status.

As Robert Muggah writes in his study of small-arms violence in Haiti:

While the country has a longstanding tradition of repressive politics and militia inspired violence, widespread firearms use has increased substantially since the late 1980 s... Determining the absolute number of small arms circulating in Haiti, including firearms held by civilians, is exceedingly difficult. This is largely because there is no up-to-date registry of firearms in the country. The HNP [Haitian National Police] is alleged to have registered 20,379 "legal" firearms among civilians in 2001. But the registration system collapsed and despite the suspension of new licenses, no records currently exist. It is clear that the absolute number of legal and illegal arms available to civilians and armed groups is in fact much higher than was officially reported... The distribution of these firearms can be disaggregated according to non-state armed groups, civilians, and international and state-based actors. ${ }^{17}$

Muggah's study finds, for example, that there are comparatively fewer small arms held by non-state armed groups - whether OPs or revolution- 
ary groups - than previously believed: fewer than 13,000 . The study observes, however, that "Haitian civilians and homeowners own by far the majority of the estimated national stockpile: up to 170,000 weapons. It is generally believed that most middle and upper class households own several handguns, many of them procured legally in the United States and subsequently imported into Haiti. It is assumed that the majority of these owners are not in fact either baz or members of military forces."

In general, violence contributes to the exclusion of women from the public sphere, thus preventing them from taking an active part in the political life of their country and reducing their ability to make decisions, especially in the male-dominated territory of security. In its report "Beyond Victimhood: Women's Peacebuilding in Sudan, Congo and Uganda", the International Crisis Group emphasizes that the long-lasting effects of the impact of sexual violence against women should be taken into consideration if more women want to take part in peacebuilding activities. Violence against women leads to the destruction of the social fabric of society. The report explains: "Strategies to prevent violence against women during war are simultaneously strategies to protect women's participation in reconstruction and democracy-building in the aftermath." 18

Women are prevented from playing an active part in the political life of their country, peacebuilding or reconstruction efforts because of the prevalent state of insecurity that is entrenched in society. As the Haitian feminist Danièle Magloire writes: "Violence against women, or even the threat of violence, maintains women in a state of fear or constant vulnerability and limits their movements (particularly in the evening or at night), their access to public spaces where they would feel safe, their social participation, their autonomy. Their access to a full citizenship is denied." ${ }^{19}$ She further explains that the condition of the Haitian woman is reflected in her state of subordination to male power. This subordination is translated into the depreciation of women (women are undervalued in all aspects of their life, at work, in society, etc.) as well as their exclusion (women are excluded from the public sphere and relegated to specific activities with limited decision-making power); most of all, this subordination increases women's vulnerability to violence while simultaneously denying them a voice in decisions that could be made to enhance human security.

\section{The historical background of violence against women in Haiti}

From an overview of the scattered evidence available, it appears that an increasing number of young women are becoming victims of violence in Haiti. There is clearly a deterioration of the social safeguards that were previously used to regulate society and prevent young women from being 
exposed to violence in the past. However, it is still easier to report a case of violence committed against a girl than against an adult woman, because the latter is very often exposed to shame and reprobation (many Haitians argue that a young girl, after all, is only an innocent victim, whereas an adult woman may somehow be held responsible for what happened to her). But even this view is more of a stereotype than a reality: a young girl victim of gang rape is highly likely to be rejected not only by her family but by the entire community.

Danièle Magloire explains that the attitude of Haitian society regarding sexual violence, and in particular rape, varies according to the context. For example, protests would easily be ignited if the rape had been committed by bandits or, in the past, by the armed forces. It is, however, important to stress that the so-called protests tend to focus more on condemning a situation of insecurity and the underlying impunity attached to the ensuing acts of violence as opposed to the violation of women's rights. She further explains: "When assaults are not committed within the framework of what is seen as a general attack against populations, therefore when rape is committed by an average citizen, protests against it are few and are not as vehemently accusing." 20

The situation of women in Haiti has deteriorated over the years in all sectors of the society. Women are the main victims of violence due to a combination of factors, which include:

- women continue to fear for their lives in the current context of violence with gangs using rape as a weapon to terrorize populations and conquer territory where they can assert their power

- the feminization of poverty has made women and girls more vulnerable to sexual exploitation and abuses

- the perpetuation of a structural form of violence such as domestic violence is culturally accepted ${ }^{21}$

- a lack of adequate legislation to sanction violence against women contributes to the perpetuation of a climate of impunity. ${ }^{22}$

Over the past years, as the crisis in Haiti has deepened, women have been victims of rape used as a weapon for political motives. In 1991 a military coup overthrew the government, and violations of human rights were committed with impunity on a wide scale. As Myriam Merlet writes:

Violence against women, particularly gang rape and forced rape by a close relative, were among the weapons used systematically by the putschists. Popular resistance, by women in particular, matched in intensity the atrocities committed. ${ }^{23}$

Violence against women during the coup did not target women exclusively, but was also used to instil fear in people for better control. 
Atrocities committed against women were aimed at keeping them away from political activities as well as targeting the men who were suspected of political activism. The putschists used women's bodies to send a message to the men that they were unable to protect their women, thus undermining the masculinity of the men, who are seen as first and foremost the protectors of women and children in society. Since women are seen as the guardians of the honour of the family and the bearers of the national culture, a raped woman is not immediately considered as a violated individual but rather a disgraced representative of the vanquished group, due to this symbolic power. The victim as a human being is not a cause of concern in Haiti. Instead, concern is focused on the social impact of a rape on the family and community.

\section{The exclusion of women from political life}

The traditional sexual division of labour in Haiti limits women's opportunities to participate in public life. This division is rooted in the gender hierarchy that imposes a separation of tasks and physical space between men and women. In Haiti, as in most societies in the world, women are associated with the home, caring for children and domestic chores, mainly defined in their roles as a good mother and a good wife. This reality is further reinforced by the widely shared view that only men are competent to deal with the public sphere where decisions are taken (at the economic and political levels, and especially on issues relating to security). As the former Senator Mirlande Manigat writes:

One can't think that she [the woman] can organize her timetable to be able to participate in political life and if she does so, one makes her feel guilty - and she also blames herself - because one thinks that this would be time stolen from the family that is her natural and sole environment as well as her main responsibility within the society. ${ }^{24}$

Because women have been placed on a pedestal as keepers of the morality of society, and because Haitian politics is characterized by such high levels of corruption, there is a strongly held expectation in the country that women should remain outside the political realm so that they will not become contaminated by their contact with power, corruption and violence. By defining society through referring to norms that are acceptable as "traditionally masculine", Haitians have isolated women in a separate category that excludes them from politics, and especially the most male-dominated sphere, that of security. However, as the American feminist Ann Tickner stresses: "But if the implication of this view [that women are first and foremost caring and nurturing mothers] was that 
women were disqualified from participating in the corrupt world of political and economic power by virtue of their moral superiority, the result could only be the perpetuation of male dominance."25

Women's organizations have identified four main obstacles to the participation of women in the political process, namely:

- lack of time - women in general, and female single heads of household in particular, have too many responsibilities in the household to be available for political gatherings and campaigns

- traditionally women have less financial resources than men for conducting political activities and networking because they don't have access to sponsors $^{26}$

- politics is linked to corruption and violence and therefore is not considered a suitable environment for women

- some women do not want to commit themselves to political activities for fear of becoming "like the men", i.e. being seen as stepping out of their socially defined roles and responsibilities.

Because women cannot participate fully in the political life of their country, they cannot fully enjoy their citizenship and, as a result, they remain at the periphery of the public arena where political decisions are taken by men on women's behalf and on behalf of the whole society. Politics is seen as a dangerous environment for both men and women where intolerance and violence are intertwined. In the case of women, the idea of violence will certainly prevent them from entering politics since they fear for their lives, and the lives of those they have to care for. In Haiti it is estimated that more than 40 per cent of women are single heads of household. There is an obvious link between the social structure of the country, the prevalence of single-parent households, the feminization of poverty and the level of political participation of women. Interestingly enough, the man is still defined by society as the head of household even when he is absent and does not financially contribute to the household. Stereotypical notions of how society should be organized make a woman believe that she cannot manage her responsibilities without a man, although she is the main economic pillar of the community. In Haiti, the household is built around the mother and her children (biological children and those she is taking care of), as well as another woman or several women (more or less close relatives) who also have children. The absence of men from the domestic realm reinforces the differences in conceptions of security between men and women. And the belief that a woman cannot cope without a man reinforces her vulnerability because she is led to convince herself that she has no status within society, thus exposing herself to abuses by other male relatives or neighbours.

Very few women in Haiti have previously been elected into politics. Consequently, women who are currently seeking office lack experience, 
expertise, required skills and competencies in the political arena, as well as exposure to the daily political management of society. Men are not better than women in politics, but they have been active and visible in the public sphere for so long that they have gained a so-called "natural" legitimacy that nobody dares to question. Available figures are thin, but demonstrate that in 1999 women represented only 3.5 per cent of elected members of parliament, ${ }^{27} 0$ per cent of senators and 4.5 per cent of mayors. In addition, women only occupied 14 per cent of government posts. It must be noted that none of these positions was prominent.

Out of a total of 102 women who entered the first round of the 2006 legislatives elections, only 19 women made it through to the second round, which was disappointing but not surprising in the current precarious environment (as we have demonstrated, it is a well-known fact that fewer women than men run for electoral positions due to traditional obstacles and recurrent violence). Out of these 19 candidates, six women from a variety of political parties were elected as senators and deputies. There are currently only two women ministers (Ministry for the Status of Women and Ministry for Trade).

\section{Perception of the issue of security for women}

Issues of violence against women cannot be properly addressed as long as there is a perception that women's experiences of security are not entirely different to those of men. This is one of the consequences of a lack of sex-disaggregated data: specific needs for the protection of women are not identified. Because sex-disaggregated data make gender inequalities visible, without such data a society does not need to deal with the problem or take special measures to protect women. In such circumstances, no real case can be made to divert resources that are seen as necessary for security and military issues as defined by male stakeholders.

For example, following the hurricane that devastated the city of Gonaïves in Haiti in 2004, a lack of gendered analysis relating to the needs of women and girls left them destitute and even more vulnerable: female teenagers could be seen bathing naked in the open in the compound of the so-called shelters where men, women, boys and girls were living in very close quarters, thus exposing women and girls to sexual violence.

In addition, a system was put in place to have women as direct beneficiaries of assistance, thus avoiding mismanagement of food items by local men belonging to the main armed gangs (this measure had been implemented after watching young men take control of the food during the first distributions). A lack of adequate consultation and coordination between the main partners involved in the humanitarian operation resulted 
in delays in food distribution, with women and girls waiting for hours under the scorching sun. Women who lost everything in the hurricane, and who were now also in charge of cleaning, rebuilding and feeding their communities, should not have had to go through this ordeal. In addition, a few women were reportedly attacked on their way home after they had left the distribution spots secured by the UN peacekeepers. Although it was an apparently good initiative to organize the food distribution through the women, its effect was to stress them even more when they were already bearing the brunt of the crisis. Neither the national nor the international community properly tackled the need for specific protection for women and girls in this dysfunctional environment. Women should have been consulted in the management of food distribution, health centres and shelters so that they could find a new human dignity. Instead, they were forced to bear the brunt of decisions made without their input which not only added to their insecurity but exacerbated stereotypical ideas that women cannot take the lead in a crisis. This series of events is a strikingly accurate summation of the precariousness of women's security in a community in which small arms are so prolific, and impunity for their misuse so widespread, that their presence decides the fate of the community even in the face of a natural disaster.

This example illustrates clearly what the American feminist Cynthia Enloe writes about the perpetuation of violence from war to peace:

Women peace activists have found that the sorts of insecurity many women experience in the midst of openly armed conflict are surprisingly akin to the forms of insecurity that women experience when the guns are silent: the lack of resources that can be used to ensure their own physical integrity. ${ }^{28}$

Enloe further talks about the "silent assumptions" that are made to trivialize security issues for women, and asks the following question: what keeps people from thinking that security is important for women? She explains that:

For many women, the home and neighbourhood (and temporary "home", a refugee camp) can be as insecure as a battlefield. In fact, a home or a neighbourhood street can be a battlefield. When post-war local and international authorities treat violence against women as a non-priority, as an issue to be put off until "later", as a matter not falling within their own mandate, those same authorities perpetuate a crucial dynamic of militarization in a time of alleged peace. $^{29}$

In a post-conflict/crisis environment there is often a shared view that any intimidation of women will stop once other forms of insecurity are taken care of; in Haiti, the belief is that once male militia or gangs have 
been dealt with, the problem of violence against women will also disappear. By denying the specificity of violence against women and refusing to recognize it as a product of an unequal system, society never has to face up to the need for profound change through a specific and detailed reform programme that addresses gender inequality. Furthermore, there is a perception that women are always dependent upon a male gang member and simultaneously protected by that male, thus denying these women their own agency as independent individuals with rights. This perception overlooks the truth that the majority of women have little choice but to be locked into violent relationships, although they do not find protection through this manner. For the men in power, insecurity created by violence by men against other men is understood to be more detrimental to political stability and stable governance than insecurity created by violence perpetuated by men against women. Accordingly, violence by men against men is where they prioritize spending their resources, including developing new policies to combat such violence.

Women have redefined the term "security" by envisioning it as the absence of any kind of violence, i.e. economic, sexual, political or military, in any sphere, i.e. both within and outside the home. A genuine security will be possible only with the elimination of unequal gender relations and the abolition of the hegemonic masculinity associated with violence. As Ann Tickner writes about the development of a feminist discourse on security:

The term structural violence was used to denote the economic insecurity of individuals whose life expectancy was reduced, not by the direct violence of war but by domestic and international structures of political and economic oppression. Peace researchers began to define security in terms of "positive peace", a peace that included economic security as well as physical safety. ${ }^{30}$

When discussing security, one needs to emphasize that women occupy diverse positions and multiple functions within armed groups in Haiti today. As previously explained, their association depends upon their motivations and needs. Their inclusion is unsurprising given that all armed groups are dependent upon a community base. These women are simultaneously perpetrators of armed violence and dependants and/or supporters of those men with whom they fight. ${ }^{31}$ Some women who have been gang raped by members of armed groups are stigmatized and singled out by their community or family. These women eventually find themselves associated with their former aggressors because they have no alternative financial possibility for survival. Other women, categorized as "girlfriends/partners" of certain armed members, have been forced to become sex slaves - lacking any possibility to exit their captivity, they are hostages. 


\section{Characteristics of female armed violence}

\section{The status of women in armed groups}

While women are generally associated with the majority of armed groups in Haiti, it is important to emphasize the fact that women are not full members of the OPs - and cannot directly become members. There is not one OP in existence with a female leader because, traditionally, the political sphere excluded women for reasons relating to social and cultural expectations of their traditional role within society. As we have discussed, society's position was that women were supposed to manage the children and the household, i.e. the private sphere. This traditional stereotype underpins their political exclusion, but is compounded by the fact that the OPs use heavy-calibre weapons such as Galil, M14s and M1s. These are considered to be "male" weapons, and therefore not appropriate for women. The OPs are mainly active in the capital, Port-auPrince. Although women have no space/membership in these OPs, they support the men within the organization in the hope that their actions will improve their living conditions, as well as those of unemployed young men. They are only associated with the OPs as the "dependants" of their male partner, father, etc., but would for example support the OP if it was to be attacked. They predominantly support the OPs as mothers, wives or sisters of men who are members of the organization, as opposed to being active and autonomous participants.

\section{Women's motivations and weapons used}

While men always handle heavy-calibre weapons, the weapons used by women differ according to the type of armed group with which they are associated. If they are part of les groupes d'autodéfense mixtes and their personal social structure is matrifocal, they are the heads of household (as single women) and are unable to rely on the security and justice systems to uphold the law. These groupes d'autodéfense, and the milices populaires (local militias), have been in existence since 2004 and are a specific and short-term response to the widespread civil violence in the principal towns.

As défenseurs of their homes and local community, women are present within the brigades de vigilance (vigilantes) and brigades de quartier ${ }^{32}$ (neighbourhood brigades) in the capital and provinces. These groupes d'autodéfense are composed of men, women and children. Their only objective is to protect their immediate space - which includes their belongings and their own personal honour as well as that of their family - from external attacks carried out by individuals possessing firearms. In these 
types of circumstances the women use armes de jet (conch shells, stones, glass bottles), blunt objects (batons) and above all armes blanches (machetes). These women will not hesitate to drive back aggressors through arresting, injuring or killing. Furthermore, Haitian legislation does not criminalize those who injure or kill in the name of self-defence within their own homes.

As justicières (righters of wrongs), women are present in the milices populaires, a social phenomenon which only exists in the capital. These milices populaires (local militias) exist in order to "cleanse" their environment of bandits through attacking those areas which harbour/shelter them. This is a continuation of the policy and tradition of zero tolerans previously practised by the Organisations Populaires Lavalas. During raids, any individuals living within the area, whether or not they are acquaintances, neighbours or related to the bandits - are targeted, since the milices populaires presume the community to be collectively responsible for wrongdoing. The women are armed with batons and machetes alongside the men and young people - the latter (men and youth) are armed with small- and heavy-calibre weapons. The women participate actively in the attacks, injuring and killing men, women and children with impunity. It is important to highlight that many witnesses state that the police (those in and those no longer in service) are present in these milices populaires. These police/ex-officers provide the armed groups with weapons and a carte blanche to carry out their "cleansing" operations.

Women associated with the groupes de bandits mixtes work with the men, and are motivated and lured by the US dollar in exchange for hostages. They principally participate in the kidnapping of children and adults, commit physical violence against these very same people and are known to rape their hostages (both sexes). They also act as informers. To carry out these activities, the women are armed with small-calibre weapons which they use without hesitation. The youngest, aged 18-23 years, participate in these crimes since their male partners refuse to be involved in criminal activities. However, women justify their participation by citing poverty and the need to provide for their families. It is important to emphasize that this practice is limited to Port-au-Prince.

\section{Profile of the women and the armed groups}

Each armed group is known and named after the weapons it favours using, a characteristic trait or the group's motivations. Therefore, in the capital, armed groups composed solely of women using small-calibre weapons are known as Fanm Boss (female bosses) and Fanm Pye Poro (women with green feet). Another group of women, who are in samesex relationships within their group, are known as Baz Madivin (group 
of lesbians). In Gonaïves, two armed groups composed of women are called Lame Boutey (army using glass bottles) and Lame Polanbi (army using conch shells). There are no armed groups composed specifically of women or groups where the women play a major role in Les Cayes. Women are also very present in the milices populaires, which are extremely violent in the capital. These milices populaires are known as Lame ti machete (army of small machetes), Baz Pilat (Base Pilate) and Brigad Machet (brigade of machetes).

The Fanm Boss and Fanm Pye Poro are members of criminally motivated armed groups which principally carry out kidnapping operations in the capital. The title Fanm Boss projects the image of determined women who can direct a kidnapping operation - in the absence of men. They do not fear breaking the law, and above all do not fear the police, MINUSTAH or the Ex-FADH. ${ }^{33}$ While carrying out the study, it was reported that one of these women, owning a gun, injured a former FADH during an exchange of gunfire in 2004. The title Fanm Pye Poro above all emphasizes the objectives of the group, the principal motivation being the US dollar. It is the green colour of the notes which provides the group's title.

The title Baz Madivin refers to two characteristics which are known by the local and surrounding population. The first is the organization of these women around a "base", or more precisely a fixed meeting place. The second characteristic is this group's sexual orientation, since they are known as "lesbians", madivin. In addition, it is important to note that this group is headed by a female leader. Although there is no proof that these women are armed with firearms, they are known to work in collaboration with the armed male groupes de bandits within their area. The women kidnap young girls who are gang raped before being transferred by the very same women to the local groupes de bandits. These girls are then once again raped by the young men or adolescents. ${ }^{34}$ It is important to highlight that there is no financial motivation attached to these kidnappings or transfers of hostages.

In Gonaïves, Lame Boutey and Lame Polanbi are two neighbouring rival armed groups, respectively armed with glass bottles and conch shells. These two "armies" have a tendency to be confused with the brigades de quartier since they are composed of women living in adjoining rival areas which are renowned for their Organisations Politiques. One of these two areas is systematically attacked and abused by its neighbour. When the tension grows between the two communities, the fighting takes place firstly among the women, followed by the children from the same communities, who are also organized into "armies". ${ }^{35}$ Occasionally some men participate in the fighting to support the women, children and their community. The men will never use their firearms in these clashes, which 
are considered to be "feminine" due to the type of weapon used, i.e. glass bottles, stones and conch shells. "Masculine" violence takes place outside these areas, within neutral territory, using small arms and light weapons - weapons which are considered to be "masculine". It is important to note that the distinction between "masculine" and "feminine" weapons is solely applicable to Gonaïves.

Any type of programme established to enable women to disassociate themselves from armed violence must foremost take into consideration the women's primary motives for association. Three principal yet different types of motivation include:

- acting as "defenders" of their immediate environment in order to protect their own homes and communities from criminally related activities (through association with the brigades de vigilance and brigades de quartier)

- acting as "righters of wrongs" and "cleansing" neighbouring communities of criminals/bandits (through association with the milices populaires)

- acting as criminals/bandits in order to earn a living.

As previously mentioned, for those women associated with the brigades de vigilance and brigades de quartier, unless a functioning police presence in which the local community trusts is established well in advance, it is not possible to request that these groups be dissolved, since they have been established by the local community for its own protection. Programming to target the women in these armed groups should therefore take place only once the community feels secure.

For all three categories, a gendered approach to violence reduction programming should focus on numerous activities, including:

- leadership training programmes to provide the capacity to aspiring/ local leaders to become peer educators and inform and sensitize members of their community

- the reconstruction of social and community ties through the establishment of various support groups for those individuals who are victims of violence and those who are the perpetrators - this is imperative given the lack of a functioning judicial system

- civic education (human rights, responsibilities and obligations, gender relations, etc.) and establishing discussions to address the problem and impact of armed violence.

For those women acting as "righters of wrongs", it is imperative that a violence reduction programme be established with the support and inclusion of the police. This programme should target all members of the community, thus ensuring that members of the milices populaires do not become marginalized during the process.

Those women who are associated with armed violence for economic 
gain require income-generating activities as well as a civic educational programmes focusing on violence reduction. Once again, it is imperative that, while the government has not addressed the issue of justice in relation to the serious crimes committed by the armed groups, those women wishing to disassociate themselves from a life based on crime have access without being exposed and marginalized. Therefore, any type of programming must be community based and incorporate a larger target group.

\section{Gang rape within the context of armed violence}

\section{Rape: Young childless girls/women targeted}

It is important to emphasize that violence against women is rooted in relations of domination over women by men in patriarchal societies. These relations are socially constructed, and educate women and men to accept women's subordination. It is enforced through exclusion and violence which become accepted cultural norms. Violence is not only sexual but also physical, economic, social, political and symbolic, i.e. embedded in the social fabric in its traditions and norms. It becomes especially egregious when the fabric of society breaks down as a result of prolonged armed conflict. As Tina Sideris writes in an article about rape in war and peace: "Unequal relations of power between men and women suggest a set of social practices, beliefs, ideas, values and speech that promote male domination and superiority and female subordination." 36

In Haiti it is very difficult to find reliable data on violence against women because there is no systematic data collection system. However, statistics compiled in November 2005 by the Concertation Nationale pour la Prévention contre les Violences Spécifiques faites aux Femmes et leur Prise en Charge, ${ }^{37}$ taken from four institutions working with women and girls exposed to violence, demonstrate that of the documented cases:

- approximately half of the women affected by rape are minors

- a large number of rapes are carried out under the intimidation of weapons and by strangers (according to one institution)

- the high percentage of gang rapes is of particular concern

- conjugal violence is widely reported by at least two of the institutions

- three of the institutions are receiving an increasing number of women and girls who have been exposed to violence - possibly a result of people being more informed of the services available.

On 11 August 2005 a government decree was published that modified a few articles of the Haitian Penal Code. Rape is no longer defined as an "indecent assault", and is heavily penalized by a 10-year prison sentence 
or even life imprisonment. According to the same decree, a husband who kills his wife and her partner in a case of adultery is no longer excused. It remains to be seen if this new decree will be stronger that the customary law that prevails in Haiti.

\section{The current situation of sexual violence in areas affected by armed violence}

In Les Cayes, girls and single, young, childless women are targeted for gang rape. They are labelled by the community's malicious gossip as "deviant", which includes the fact that the girls may be in conflict with the parental authority within the home, are sexually active at a young age, may go out late at night alone or with male friends, or may even have an older sister who was previously a victim of gang rape. In Les Cayes and one specific area within Port-au-Prince, these gang rapes are punitive acts which aim at imposing a behavioural code upon girls and women whose behaviour is "different" from the socially imposed "norm". Those responsible ${ }^{38}$ for the acts are from within the community, and inform the family and community about what they have perpetrated by publicly calling their victim kante $^{39}$ instead of using her real name. Alternatively, they may request that the local groupe de rara (traditional band which moves throughout the local area) diffuses the information through song. The term vagabond is used by the girl victims of sexual violence to describe those who attack them, and according to them differentiates these young rapists from the "bandits" who are permanently armed and principally carry out other criminal activities.

Although the younger victims do not link being gang raped to their own behaviour, the older victims may be aware of this correlation. A case was presented to the research team in which a young, single, childless woman recounted that her neighbours had come to her defence when two brothers (minors) had forced entry into her home in an effort to kidnap her for gang rape. Her neighbours had explained to the brothers that they had mistaken the identity of this woman, who was recognized as leading a correct lifestyle. Consequently, the two boys left the young woman's household. It is worth noting that this woman was living with another single young woman who had a child. This second woman was not vulnerable to the gang rape since she was a mother, but her housemate, a single woman who had left her own home to live elsewhere without any children, was.

Another example illustrates the position of the community regarding the behaviour of young, single and childless girls and women in one specific area within Port-au-Prince. When single childless girls and women identified as leading a "deviant" life were gang raped, their cases were 
not reported by the community. The community therefore became complicit with the rapists, and thereby approved the macho values these bandits imposed. However, when the gang rapes within the same area escalated and started to take place randomly, affecting any category of women/girls, the community reported these cases. We conclude that the community's complicity is a means of consolidating the macho values imposed by the bandits and vagabonds, and confers on rapists the power to regulate the social behaviour of young, single, childless women/girls, men and boys at the community level.

However, communities which implicitly condone such behaviour do not seem to understand that their silence creates an environment in which violence against women and girls can only keep escalating. It is by no means an acceptable form of control over "deviant" females, but a breeding ground for ever-increasing aggression that tears apart the very fabric of society. In the end, the entire local community suffers the consequences of a gang rape since it "pollutes" all the members of the victim's household, as well as her immediate neighbours. As previously mentioned, the macho values established by the young people and condoned by the community may increase the probability that the victims' younger sisters will also become victims of gang rape, although their behaviour might be considered exemplary. Once the household has been "polluted", the victim's parents enter a conflictual relationship with the families of those responsible for the rape - who are often friends, neighbours or local acquaintances - depending upon the position adopted by each of these persons. Furthermore, it is not rare for the victim's immediate neighbours to send their own daughters to live in another area in order to avoid all "contamination", convinced that their daughters' vulnerability to gang rape is increased due to their physical proximity to victims of sexual violence.

Consequently, the victims who receive no support from their families especially from the father - are stigmatized within their own family and community. In this type of situation, the only alternatives for these girls are:

- to leave their area quickly and settle down as far away as possible from the town for a period of one to two years, in an effort to give the community and perpetrators sufficient time to forget the incident

- to remain in spite of everything, enduring the disdain and hurtful remarks of their immediate entourage

- to enter into commercial sex work because of the loss of their economic power (as a consequence of marginalization) in order to survive, thereby becoming a dependant of their aggressors or other armed elements. Needless to say, it is extremely difficult for the girl/woman to establish a family life following this event. 
In Gonaïves and various areas within Port-au-Prince, the situation is very different. While some young single women and girls are targeted for gang rape due to "inappropriate" behaviour and consequently are treated the same way as women and girls in Les Cayes, the majority of the perpetrators of rape and gang rape are known to the community as "criminals". Consequently, their victims are neither stigmatized nor marginalized. Furthermore, as they are considered to be "real" victims, they receive the support of their families, neighbours and friends.

\section{Characteristics of juvenile armed violence}

The phenomenon of armed violence in Haiti is not restricted to adults, but involves children and young people between the ages of 15 and 24 years old. In certain poverty-stricken areas it is possible that children as young as eight are implicated, since children aged eight to 10 years are often used as watchmen, messengers, informers and porters of ammunition (lame limye, l'armée Lumière or army of light). In order to carry out these activities, these children carry small arms. They are also active during specific fights in which they operate as an armed group (lame timoun, l'armée des enfants or army of children - particular to Gonaïves). Because education in Haiti is mainly private ( 80 per cent of primary schools) and expensive to attend, a large number of children do not have access to primary or secondary education. ${ }^{40}$ Consequently, children are left to their own devices and are often sent out by their families to earn a living. With few legal economic alternatives, they quickly become drawn into armed violence. Moreover, women interviewed for the study recognized that a principal factor in the association of children with armed violence is the absence of sports and educational activities. ${ }^{41}$

Male juvenile violence is distinguishable from the armed violence carried out by women through the choice of weapons utilized, namely small arms, and the fact that these weapons are principally used in order to control a specific territory, control the behaviour of girls and young women in their local area and take part in criminal activities.

\section{Morphology and motivation of the armed groups}

Young people are principally members of the groupes de bandits in Portau-Prince and Les Cayes, the bands of zenglendo in Gonaïves and vagabonds in Les Cayes. Although these three groups differ according to their various morphologies, dynamics and motivations, they do share one common denominator: operating in spaces where there is no police presence. Contrary to the idea that all young people are armed, however, the re- 
search highlighted that, in reality, only a few individuals possess firearms. These armed young people who are members of groupes de bandits or zenglendo are always in possession of small-calibre weapons, and are thus known as chef. It is the possession of a firearm which gives the status of chef to its owner within the group, as opposed to age. One can therefore be a chef and a minor. It is important to note that there is not one girl or young woman who is a cheffe of a juvenile armed group.

While few members of armed groups are permanently armed, a fluid group of young, unemployed people gravitate around these armed members, for whom they carry out petty services through acting as informers, watchmen, messengers and so on. Since a strong solidarity unites the non-armed elements and those who are armed, financial exchange is not a prerequisite for the work provided by the non-armed youth. What matters is that belonging to an armed group gives the unarmed young people the feeling that they can commit their crimes - both sexual and economic (racketeering) - with complete impunity, knowing that they have the approval of the local chefs.

\section{Firearms as a symbol of power}

The principal occupations of the groupes de bandits can be summarized as acting as hitmen (professional killers) or drug or arms traffickers; imposing their power within their community through targeting and arbitrarily raping girls and young single women; and extorting market stallholders (male and female), who are ultimately forced to pay them a "tax". These acts of violence always take place with the intimidation of a firearm, which is sometimes even used to lethal effect. The daily exhibition and occasional use of a firearm terrorizes the community and gives the "bandit" a feeling of power. The absence of the police on the ground and the failure of the justice system only feed into the problem of impunity, providing members of the groupes de bandits with additional feelings of self-confidence and invulnerability. This ultimately enhances their control over the local area.

The bandes de zenglendo in Gonaïves also operate using small arms. Their principal activities are the illegal acquisition of items through burglaries or attacking market stall-holders at night. The use of firearms enables them to neutralize men and young people in their homes by forcing entry and raping the girls and women within the household while the men and children, powerless to respond, are obliged to watch. These groups appear to be rather more concerned with marking "their territory" throughout Gonaïves (apart from one specific area) through spreading terror by committing these criminal acts. In the long term their ultimate objective is to be recognized as chefs. However, the strong 
communal solidarity does not allow these groups to impose themselves upon the local population.

The power represented by the possession of a firearm limits the number of children and adolescents who have one. This strategy locally regulates the number of chefs. However, it is possible for a chef to lend out his firearm in order for a crime to be committed. This is the case within the peripheries of Les Cayes, where the vagabonds, who are never normally armed, occasionally borrow a firearm expressly for the purposes of committing gang rape: the firearm is used to subjugate the victim(s) during this premeditated act.

\section{Young people and disarmament and reintegration $(D \& R)$}

The problem of unpunished gang rapes and various criminal acts gives an indication of the high levels of juvenile delinquency in Haiti. The disarmament and disassociation of these young people and their social rehabilitation must take into account various factors.

- The morphology of the groups. As previously mentioned, only a few are armed but they are surrounded by a fluid group of unarmed young people. It is important to establish a programme of disassociation for all armed and non-armed children and young people, which includes a preventive aspect for those children who are vulnerable to association with the armed groups. This should be carried out, where possible, at the community level through programmes aimed at the reduction of violence.

- The motivation of the children and young people. As discussed, the motivations are the control of a territory; the control of the behaviour of girls and single young women; and participation in criminal activities. Programming should therefore include psycho-social activities and counselling for those children who have committed serious crimes; psycho-social activities for children who are vulnerable to association; and a civic educational programme targeting children, parents and the entire community. This civic education should provide the parents with the ability to reassume their responsibilities and authority in relation to their children (since many of the children and young people only respect and recognize the authority of the chefs), in addition to ensuring that the children learn about responsibilities and respect within their family, at the community level and as Haitian citizens. Furthermore, this educational programme should sensitize and inform the entire community about respect for others so that harmonized social relations between men and women are established.

- Poverty (lack of educational and professional opportunities). All children and young people (male and female), including those who are vul- 
nerable to association, should be provided with access to education (formal/professional), cultural activities and sports. Access to these activities will give them not only the possibility to re-establish their own personal sense of self-worth and goals, but also a space in which they can reassert their own identity as part of a group within structured educational activities.

- Single-headed matrifocal households. Given the fact that the majority of households in the poverty-stricken areas affected by armed violence are headed by single women, ${ }^{42}$ it is important to enable these women to access income-generating activities and projects to alleviate the poverty in which they are immured, and ensure that they can provide for their children in the future. At the political level, daily violence must be addressed through the rehabilitation of public facilities.

The macho values upheld by society only serve to increase the vulnerability of young girls and childless single women to gang rape. Within the macho context of Haitian society, a woman only acquires her own identity through becoming a mother or a partner. Socially, therefore, a woman is forced to establish her own household and have children before the age of 30 years. As a result, she is expected to conform to a stereotypical attitude and behaviour, which is always subject to the approval or disapproval of the community (men and women alike).

Women are very vulnerable as a consequence - any woman who enters a relationship will always be questioning her status in relation to her sexual partner: ${ }^{43}$ "Am I his 'partner for life' or simply a 'sexual partner'?" she will be forced to ask. If a single childless girl/young woman decides to have multiple sexual partners without any concern as to what others may think, this is negatively perceived by the community (men and women alike). She may even be compared to the local commercial sex workers and singled out by her entire community for disapproval. It is within this context that punitive gang rapes are carried out under the subjugation and intimidation of a firearm. This macho attitude is nothing more than a manifestation of the power relations which govern the social relations between the sexes in Haiti.

\section{Conclusion}

Women, men and children should be considered as equal actors within armed violence in Haiti - without consideration being given to the types of weapons utilized. The weapon most commonly used by women is the machete as opposed to firearms, although today young women aged 1823 years no longer hesitate to use small-calibre weapons while carrying out their criminal activities in the capital. 
The disarmament of women presents two major problems. First, it is impossible to remove from circulation tools used for work, such as machetes, or to control the use of stones, glass bottles and conch shells. Secondly, young women who own firearms and are implicated as collaborators in kidnapping operations are sought by the police as criminals. It is therefore unlikely that they will divulge their identity in order to enter a D\&R programme. Civil society seeks justice against those who have committed serious crimes such as murder, rape, kidnapping and the destruction of houses. This firm position presents an additional social and political factor, which increases the delicacy and sensitivity of carrying out a D\&R operation. While women might very well accept disarming and participating in a D\&R programme, civil society would immediately identify such women as having previously acted as armed elements, and ask that they be brought before the justice system for their previous crimes.

The MINUSTAH/UNDP DDR programme has been facing the significant challenge of being bound by stereotypical gender ideas; consequently, until the UNDP/MINUSTAH study on the situation of women in the context of armed violence in Haiti was conducted in 2006, women were not recognized to be perpetrators of armed violence or associated with the armed groups in any other capacity than as dependants or victims. Furthermore, urban violence in Haiti is understood to be, above all, a typically "masculine" phenomenon, since previously, within the framework of political violence, women were generally invisible. This is the reason why, to date, armed women have not been acknowledged by the international community as either spokespersons for D\&R programming in Haiti or participants in such programmes. Women are only ever questioned as victims of sexual violence or as agents of change in order to bring about peace. The UN's own limited vision of how women both participate in and are impacted by community violence is harmful and limiting. It does not recognize the extent to which women could contribute to disarmament programmes, for example as mothers of armed children or adolescents. It is important to remember that the majority of poverty-stricken families are largely single-parented and matrifocal. With support, women are therefore in a better position to persuade young people to disarm.

To this end, as highlighted by Vanessa Farr, ${ }^{44}$ it is essential that women are provided with knowledge and information about disarmament and conflict management, and given the economic tools and support they need to manage the reintegration of their children. Since women are extremely sensitive to questions relating to insecurity, and experience insecurity in a different manner to men, improving their knowledge of the D\&R process would allow them to collaborate better with MINUSTAH 
to help identify young armed people in their communities, so that their weapons might be taken out of circulation. The women could even bring the weapons into the disarmament process on behalf of their children ${ }^{45}$ in order to ensure that their children remain protected and unexposed. Sensitization and educational programmes need to be carried out at the community level, targeting all members of the community, including the children. However, as previously mentioned, whether or not the D\&R process will be a success is still not known. We are therefore obliged to monitor closely the involvement of women in this dangerous exercise, which could expose them as participants in a process that could harm them if expectations are created among the beneficiaries that cannot be fulfilled or sustained.

\section{Notes}

1. MINUSTAH S/RES/1542 (2004) - UN Security Council Resolution to establish the UN Stabilization Mission in Haiti (MINUSTAH), available at http://daccessdds.un.org/doc/ UNDOC/GEN/N04/332/98/PDF/N0433298.pdf?OpenElement.

2. MINUSTAH S/RES/1702 (2006) - UN Security Council Resolution to extend MINUSTAH's mandate, available at http://daccessdds.un.org/doc/UNDOC/GEN/N06/ 468/77/PDF/N0646877.pdf?OpenElement.

3. Hurbon, Laënnec (2004) "Violence et raison en Haïti", De la Violence, Chemins Critiques, Revue Haïtianno-Caraïbéenne $\mathrm{V}(2)$, October, p. 10. Original: "Le paradigme sous lequel on essaie d'habitude d'appréhender la problème de l'insécurité en Haïti est l'impunité. Plus un individu est assuré de l'impunité, plus il est encouragé au crime. [...] Effectivement, si quelqu'un est abattu par des bandits ou par des policiers en pleine rue, cela n'entraîne pas automatiquement des poursuites ou plaintes contre X; ni même des enquêtes."

4. Since the ratification of CEDAW, Haiti has never submitted a country report to the Committee on the Elimination of Discrimination against Women.

5. UN Special Rapporteur (2000) E/CN.4/2000/68/Add.3, 27 January.

6. Joinet, Louis (2005) "Situation of Human Rights in Haiti", Economic and Social Council Commission on Human Rights, E/CN.4/2005/123, 24 January, p. 8.

7. UN Division for the Advancement of Women (2003) "The Role of Men and Boys in Achieving Gender Equality", Report of the Expert Group Meeting, Brasilia, 21-24 October, available at www.un.org/womenwatch/daw/egm/men-boys2003/Connell-bp.pdf, p. 32 .

8. Bourdieu, Pierre (1994) Raisons pratiques, sur la théorie de l'action, Paris: Editions du Seuil, p. 188.

9. Organization for the Defense of Women's Rights.

10. Merlet, Myriam (2001) "Between Love, Anger and Madness, Building Peace in Haiti", in Sheila Meintjes, Anu Pillay and Meredeth Turshen, eds, The Aftermath, Women in Post-Conflict Transformation, London and New York: Zed Books, p. 168.

11. One international consultant and six national researchers carried out focus-group discussions, individual interviews, the documentation of individuals' experiences and observations, and observation activities in specific areas affected by armed violence within the capital, Port-au-Prince, and the provincial towns of Gonaïves and Les Cayes 
between January and June 2006. Wiza Loutis, a co-author of this chapter, was lead researcher on this study.

12. Corten, André (2004) "Paroxysme haïtien: violence et droit par le bas", De la Violence, Chemins Critiques, Revue Haïtianno-Caraibéenne V(2), October, pp. 19-33.

13. See Manigat, Mirlande (2002) "Au panthéon de l'histoire: les femmes dans la mémoire collective", in Etre femme en Haïti hier et aujourd'hui. Le regard des constitutions, des lois et de la société, Port-au-Prince: Université Quisqueya, pp. 59-74; Boisvert, Jayne (2001) "Colonial Hell and Female Slave Resistance in Saint-Domingue", Journal of Haitian Studies 7(1), pp. 61-76.

14. Boisvert, ibid.

15. The results of the study, "Women in the context of armed violence in Haiti", were presented to the international community, government and civil society during a conference held on 29-30 June 2006 in Port-au-Prince, Haiti.

16. Thirty-two per cent of urban households suffer from food insecurity on a daily basis, and 26 per cent are often food insecure: UNICEF (undated) "At a Glance: Haiti”, available at www.unicef.org/infobycountry/haiti.html?q=printme. In Haiti, 8.5 per cent of households are connected to water, 82.3 per cent use gas lamps and 5 per cent have toilets; see Ministère de l'Economie et des Finances (2003) Information, 4ieme RGPH, Resultats Definitifs, IV Recensement General de la Population et de l'Habitat, Port-au-Prince: Institut Haitien de Statistique et d'Information.

17. Muggah, Robert (2005) Securing Haiti's Transition: Reviewing Human Insecurity and the Prospects for Disarmament, Demobilization, and Reintegration, independent study commissioned by DFAE, Geneva: Small Arms Survey, p. 13.

18. International Crisis Group (2006) "Beyond Victimhood: Women's Peacebuilding in Sudan, Congo and Uganda", Africa Report 112, 28 June, p. 17.

19. Magloire, Danièle (2004) "La violence à l'égard des femmes: une violation constante des droits des femmes", De la Violence, Chemins Critiques, Revue Haïtianno-Caraïbéenne V(2), October, p. 102. Original: "La violence envers les femmes, ou même la menace de la violence, a principalement comme conséquences de maintenir les femmes dans un état de peur ou de vulnérabilité constante et de limiter leurs déplacements (particulièrement le soir ou la nuit), leur accès à des espaces publics o1 elles se sentent en sécurité, leur participation sociale, leur autonomie. Les femmes se voient ainsi dénier l'accès à une citoyenneté pleine et entière."

20. Ibid. p. 93. Original: "Par contre, lorsque les agressions ne s'inscrivent pas dans le cadre de ce qui est considéré comme une attaque contre les populations, donc lorsque le viol est le fait d'un citoyen ordinaire, les protestations se font rares et n'accusent généralement pas avec la même vehemence."

21. On Saturday 24 December 2005 Ms Ginou Mondésir, a famous host of a Haitian TV show, was beaten to death by her boyfriend with a car jack following a heated argument. The wounds on the victim's body showed the intensity of the violence that was used. A few days later, as young people marched in the streets of the Haitian capital dancing and singing songs in preparation for the upcoming carnival, some men (and women) were heard singing songs encouraging men to rape women. The songs were celebrating Ginou Mondésir's killer as a hero, thus reminding the local population of the power that Haitian men can use against women in a society where violence against women is so culturally entrenched.

22. See UN Special Rapporteur on Violence Against Women (2000) E/CN.4/2000/68/ Add.3, 27 January.

23. Merlet, note 10 above, p. 161.

24. Manigat, note 13 above, p. 318. Original: "On ne pense pas qu'elle puisse organiser son emploi du temps et participer aux choses politiques et, si elle le fait, on la culpabilise - 
et elle aussi se culpabilise - car l'on croit que c'est du temps volé à la famille qui est son cadre naturel et exclusif et sa responsabilité principale dans la société."

25. Tickner, Ann (1992) Gender in International Relations, Feminist Perspectives on Achieving Global Security, New York: Columbia University Press, p. 59.

26. In 2005 the Network of Women Candidates for Winning the Elections organized a fundraising event, which was poorly attended. If a similar event had been organized by and for men in politics, it would have been extremely well attended by men seeking political support and an opportunity to network.

27. However, the parliament was dissolved in the years following the 2000 elections that were mired with fraud.

28. Enloe, Cynthia (2004) "Demilitarization - Or More of the Same? Feminist Questions to Ask in the Postwar Moment", in Cynthia Enloe The Curious Feminist, Searching for Women in a New Age of Empire, Berkeley, CA: University of California Press, p. 225.

29. Enloe, Cynthia (2002) "Demilitarization - Or More of the Same? Feminist Questions to Ask in the Postwar Moment", in Cynthia Cockburn and Dubravka Zarkov, eds, The Postwar Moment, Militaries, Masculinities and International Peacekeeping, London: Lawrence \& Wishart, p. 26.

30. Tickner, note 25 above, p. 69.

31. Women assuming multiple functions is widely documented. See Schroeder, Emily, Vanessa Farr and Albrecht Schnabel (2005) "Gender Awareness in Research on Small Arms and Light Weapons: A Preliminary Report", Working Paper 1/2005, Swiss Peace Foundation, Geneva, p. 4.

32. The brigades de vigilance appear intermittently during periods of increased criminal activities within the local area or neighbouring areas. The brigades de quartier, however, appear spontaneously whenever political unrest targets certain areas because of their political disposition. Although members of the community may not all share the same political position, the community will unite when attacked.

33. The Ex-FADH (Forces Armées d'Haiti) are the former military armed forces for Haiti. Although they were dissolved in 1994 by President Aristide, they were never disarmed. According to the local population, between 2003 and 2004 some members of the ExFADH were used by various members of the Haitian National Police to carry out SWAT operations in Gonaïves and Port-au-Prince. These men were known as les Hommes en Noir (men in black) or Assaillants (assailants).

34. This practice echoes the procedure established by the de facto authorities, i.e. the military, between 1991 and 1994. Women who were arrested either for involvement in political activities or on behalf of a male family member likewise involved were often raped by the military, only then to be delivered to male detainees at the national prison in order to be gang raped. They were therefore raped twice over. See Magloire, note 19 above.

35. Lame timoun: literally l'armée des enfants (children's army).

36. Sideris, Tina (2001) "Rape in War and Peace, Social Context, Gender, Power and Identity", in Sheila Meintjes, Anu Pillay and Meredeth Turshen, eds, The Aftermath, Women in Post-conflict Transformation, London and New York: Zed Books, p. 143.

37. National coordination body combating violence against women, composed of the Ministry for the Status of Women, UN agencies and international and national NGOs and associations.

38. The "lover" of the victim may participate in the crime through instigating the rape.

39. Kantè simultaneously means boats of people who are escaping the country and crowded buses leaving the capital for the provinces, particularly recognizable by the number of persons sitting on the roof of the bus. The term therefore comes from the image of promiscuity and many "passing" men abusing the same body. 
40. Sixty-one per cent of the country's population (aged 10 years + ) are literate (63.8 per cent male; 58.3 per cent female). Between 2001 and 200245.9 per cent of the population between ages six and 24 years attended an educational establishment ( 46.6 per cent boys; 45.3 per cent girls). See Ministère de l'Economie et des Finances, note 16 above.

41. Haitian legislation allows for children to enter professional training at the age of 14 . Therefore some professional schools, state-run as well as private, exist in Port-au-Prince and some provincial cities.

42. Women represent 52 per cent of the population (aged 10 years + ); single people aged 10 years + represent 50.8 per cent of the population; and 38.5 per cent of the country's households are headed by women (45.7 per cent urban; 33.8 per cent rural). See Ministère de l'Economie et des Finances, note 16 above.

43. For additional information see Loutis, Wiza (2005) Obstacles socioculturels à l'utilisation du préservatif masculin en Haïti. Représentations du corps et Rapports de genre, Port-auPrince: UNFPA/PSI.

44. Farr, Vanessa (2003) "The Importance of a Gender Perspective to Successful Disarmament, Demobilization and Reintegration Process", paper presented at UNIDIR Disarmament Forum 04/2003, available at www.unidir.org/pdf/articles/pdf-art1995.pdf.

45. For discussions as to how women may contribute towards disarmament programming see Schroeder, Farr and Schnabel, note 31 above, p. 4. 
6

\title{
State, society and the gender of gun culture in Papua New Guinea
}

\author{
Sinclair Dinnen and Edwina Thompson
}

Recent international and state-reforming measures to curb the effects of small arms and light weapons have not adequately addressed the issue on the ground. As this chapter will show, the limitations of this approach are particularly vivid in a country such as Papua New Guinea (PNG), where the capacity and reach of the modern state are extremely circumscribed. Both multilateral negotiations and the existing academic literature on small-arms proliferation tend to focus on international aspects of the problem, rather than on direct local causes and impacts of the proliferation of small arms. As a result, questions of specific legislation and regulatory policies directed at the small-arms trade have in some places tended to override investigations into the underlying reasons why individuals, even those not in active conflict zones, choose to own and misuse weapons to such an extensive degree. We argue that a proper understanding of small-arms proliferation at a local level and the cultural, economic and political impetus for arms misuse would allow policy-makers to shape more effective mechanisms for arms control at national and subnational levels. In order to achieve such an understanding, gender difference must be recognized as a central force shaping individual identity, capacity and choices; and as such, knowledge of gender must be seen as essential for successful disarmament. In PNG, as we elaborate below, this gender difference is largely manifest through the impact of illegal weapons in reinforcing and perpetuating traditions of militarized masculinity and tolerance of gender-based violence.

Growing acknowledgement of the need for gender mainstreaming in

Sexed pistols: The gendered impacts of small arms and light weapons, Farr, Myrttinen and Schnabel (eds), United Nations University Press, 2009, ISBN 978-92-808-1175-9 
the international discourse on small arms has had little practical impact in PNG. While successive governments, international donors, non-governmental organizations (NGOs) and civil society groups have been engaged in various ways with the serious problem of violence against women in PNG, it is only relatively recently that government authorities have acknowledged the distinct issue of gun violence in the country and the need to develop effective strategies of prevention and control. ${ }^{1}$ Existing legislative controls have had only a nominal impact on those directly affected by gun violence in PNG. An important reason for this failure, we contend, is that from a local perspective the international community and, more significantly, the PNG state constitute a remote presence in the daily lives of most citizens. As the hold of precarious state structures continues to loosen, a burgeoning gun culture has contributed to high levels of personal insecurity in many parts of the country, particularly among women and children, as well as serving as a major disincentive to investment and economic development. While addressing the weak capacity of PNG's state institutions has been the traditional focus of years of international development assistance, including assistance to the police and other agencies of law and justice, the present configuration of statesociety relations in PNG requires a much greater focus on identifying and assisting community-based mechanisms capable of addressing some of the problems underlying the proliferation of guns and rising levels of societal violence. Indeed, PNG offers an excellent example of why arms control processes need to derive from a wider perspective than that of simply reforming the state apparatus: they should include a broader consideration of why people procure weapons in the first place and which people are most drawn to owning guns; and they must incorporate the work of community-based organizations in meeting the challenges presented by prolific and unregulated weapons.

Evidence offered by media, anecdotal and hitherto unpublished sources suggests that violence resulting from small arms in PNG is distinctly gendered. While it is important to recognize the differential impact of conflict and post-conflict situations on men and women, it is instructive to go further and examine the different experiences of men and women in the context of the "gun culture" that has developed in recent years. Our primary research gathered from recent fieldwork in PNG uncovers both important gender differences in perceptions of security and the gendered nature of gun violence. By situating the proliferation of small arms in the context of culture, power and security in PNG, our contribution is grounded in a social and political history of PNG, with an account of the changing pattern of conflict and violence, gender relations and, in particular, the role of firearms. Our investigation proceeds through a discussion of the three broad and overlapping settings in which the gun culture has 
emerged: raskolism, ${ }^{2}$ tribal fighting and election-related violence. The analysis then moves to an overview of the gender of violence in PNG, and concludes with a discussion of the alternative responses of the state and community-based organizations to violence and conflict. A number of policy implications follow.

Original fieldwork for this chapter was undertaken by Edwina Thompson, who spent two weeks visiting the capital, Port Moresby, and parts of the Highlands in early 2004, where she interviewed a range of informants. Her co-author, Sinclair Dinnen, has been studying conflict and violence in PNG for over 20 years and was formerly head of crime studies at the PNG government's National Research Institute.

\section{Papua New Guinea - Background}

Because of its unique diversity, PNG offers an interesting case study for an analysis of the gendered impacts of readily available small arms. Of particular relevance to the problem is the country's heterogeneous national setting. With over 850 different languages spoken among a population of approximately 6.1 million people, PNG is arguably the most sociolinguistically diverse country in the world. While English is the official language of government, most people communicate in local vernaculars or Melanesian pidgin. Thirty years after its establishment as an independent nation-state, there is still little sense of shared national identity and, for most people, allegiance to tribes, clans and subclans remains significantly stronger than loyalty to abstracted notions of nation and citizenship.

Because the formal institutions of the modern state were introduced late in the colonial period, little time was left to prepare the human resources and infrastructure necessary for modern statehood when the country was granted independence in 1975. The fragile post-colonial state's most tangible source of legitimacy is that provided by the "outside world" through PNG's membership of international and regional organizations, as well as the provision of development assistance and loans. ${ }^{3}$ In reality, the state suffers from limited capacity and an uneven presence in many parts of the country. This reflects, in part, the uneven spread of the administrative frontier. Although some coastal and island communities had experienced over 100 years of contact by the time of independence, parts of the densely populated Highlands region had less than 20 years of external influence and central administration. It is hardly surprising, then, that indigenous Melanesian institutions, as these have adapted to change, continue to exert such a strong influence in the daily lives of most Papua New Guineans today. 
"Traditional" societies in what is now PNG were essentially "stateless" in so far as they lacked a centralized political or administrative organization equivalent to a modern state. Leadership was dominated by prominent men and, while subject to considerable variation, was more usually achieved than inherited. Melanesian bigmen acquired their standing in various ways, including through prowess in warfare, organizing trade or ceremonial exchanges. Some modern critics claim that today's politicians have corrupted these "traditional" politics and use cultural traits such as bigmanship as legitimating strategies for the pursuit of personal and political gain. Certainly, chronic political instability and corruption have become growing problems over the past two decades. Financial mismanagement, combined with external economic shocks, has adversely affected the capacity of successive governments to deliver essential services to the rural population. ${ }^{4}$ In the absence of a formal welfare state, the extended family and the wantok ${ }^{5}$ system provide a critical informal safety net for many citizens, again reinforcing the importance of kinship ties as the primary site of social organization and identity.

In recent years rising levels of rural poverty and the pull of "the bright lights of town" have contributed to rapid migration to the major urban centres, particularly the national capital, Port Moresby, and the next two largest towns, Lae and Mount Hagen. However, less than 10 per cent of the total population are employed in the urban-based formal sector. Approximately 50,000 young people enter the labour market each year and, of these, only 20,000 find employment. This continual build-up of unemployed and underemployed youth, particularly in urban areas, has contributed to the growth of criminal gangs. A 1995 survey found that almost 70 per cent of males in Port Moresby who considered themselves "unemployed" were earning a living through criminal activities. ${ }^{6}$ This amounts to almost 19 per cent of the entire male urban workforce, and suggests that crime has become the largest occupational category in the informal urban economy. Rising levels of rural poverty have contributed to the spread of gangs and other forms of criminality to many rural areas.

Although traditional cultures have inevitably been affected by rapid modernization, many of the older beliefs remain deeply ingrained in social institutions and continue to manifest themselves in contemporary practices. As in many parts of the world, women have generally been viewed as inferior to men, and in some areas relations between the sexes continue to be characterized by deep-seated antagonism. This is most marked in Highlands societies, where traditionally women were often viewed as polluting of male power. Much contemporary violence is still predicated on the belief that men have both the power and the right to inflict harm on women by virtue of prevailing beliefs about male rights and the inferiority of women. ${ }^{7}$ The introduction of modern weapons 
into society has reinforced and perpetuated traditions of militarized masculinity and tolerance of gender-based violence, while the lethality of the violence has greatly increased.

Official social and economic indicators suggest a reversal of earlier advances, particularly in the areas of health and education. PNG now has many of the characteristics of the world's poorest nations. ${ }^{8}$ HIV/AIDS is a major and growing challenge. Following sub-Saharan African patterns, the virus has moved beyond high-risk groups and now constitutes a generalized epidemic. ${ }^{9}$ High levels of rape, child abuse, family violence, poverty and prostitution have contributed to the spread of the epidemic. ${ }^{10}$

It is against this background that PNG has been experiencing serious law and order problems. ${ }^{11}$ The availability and use of firearms are an integral part of this larger predicament. Its principal manifestations include raskol gangs in urban centres; armed hold-ups and banditry along major highways; land disputes; ethnic tensions; outbreaks of protracted inter-group fighting in parts of the Highlands and increasingly in urban areas; ${ }^{12}$ sexual assaults; election-related violence; and the growing incidence of corruption, fraud and other white-collar crimes. Violence against women is prevalent throughout the country. These phenomena contribute to the depressing images of endemic lawlessness that dominate local and international media accounts. Such a generalized picture can, however, be misleading. Significant differences exist between urban, rural and different regional contexts, as well as within them, and these differences must be carefully assessed as part of the process of developing and implementing violence-prevention measures appropriate to PNG's diverse problems. The growing levels of interpersonal violence and social conflict present a profound challenge and there are no quick or easy fixes.

\section{Firearms regulation}

\section{Legislation}

There has been a belated acknowledgement of the problem of escalating gun violence at government level and tentative attempts to reassert a commitment to arms control. In January 2004 the then minister for internal security asserted that a "ban on firearm licenses and the supply of ammunition is still in effect and will be maintained until further notice". ${ }^{13}$ On closer inspection of PNG's Firearms (Amendment) Act 1998, however, it becomes clear that this is only a "qualified" ban on pistols and high-powered weapons. Although some members of parliament support more effective gun control, there is insufficient political will to implement stronger legislation, as well as a serious lack of capacity to 
enforce such measures. Earlier attempts to strengthen gun control laws have not fared well.

The current legislation is problematic in that existing licence holders can procure weapons for private sales and transfers. This allows licensed guns to fall into the wrong hands. Proper background checks on gun owners are also lacking, particularly in the renewal of licences. Even when individuals acquire licences for their own self-defence, ${ }^{14}$ there is a risk that the gun owner is not properly trained to handle a weapon. There have been several instances of alleged self-defence going badly wrong. In September 2003, when four men attempted to hijack a car outside a Port Moresby restaurant, an expatriate man got out of a nearby parked car and fired shots at the criminals. He failed to hit his target and instead fatally wounded a toddler who was sitting with his sister in the back of his parents' vehicle. ${ }^{15}$ This example illustrates a distinct dynamic within PNG's emerging gun culture. While the numbers of guns are relatively low compared to many other parts of the world, the culture of fear and insecurity generated by the absence of adequate state protection is such that people are increasingly choosing to arm themselves. Accidental shootings, such as the one illustrated above, contribute to a growing cycle of violence and insecurity, which in turn leads to more individual decisions to take up arms.

While there is clearly room for improving the current legislative framework for the regulation of firearms, the more fundamental challenge in PNG in this, as in many other areas of policy, is to enforce the law. Failure to enforce existing law has been a major and recurring problem. Law reform on its own is unlikely to change this situation. As Alpers notes, "no amount of legislative improvement can substitute for effective enforcement of existing laws, which in many cases are already close to world standards. Nor can writing new laws improve the population's willingness to comply, in the absence of respect for those laws, and for the justice system which administers them."16

\section{Weapons trade and availability}

The number of weapons smuggled illegally into PNG is relatively small in relation to the total number of weapons used in criminal incidents or politically motivated violence, as well as compared to the size of the illegal weapons market in South and Southeast Asia. ${ }^{17}$ Trading high-quality PNG marijuana for Australian guns through the Torres Strait islands appears to involve relatively low numbers. ${ }^{18}$ There have also been reports of arms crossing the largely unmarked PNG/West Papuan (Irian Jaya) border, with shipping containers delivering the weapons from Asia via mining and logging companies. Again, the numbers involved do not appear to be very large. Despite sporadic and protracted periods of conflict 
in West Papua, Bougainville and the Solomon Islands, recent studies suggest that the illicit arms trade has not made any significant inroads into the Pacific region. McFarlane ${ }^{19}$ suggests several reasons for this:

- without external sponsorship, neither criminal nor insurgent groups have the resources to purchase significant numbers of small arms or light weapons from external sources

- given the level of criminality and conflict, there is probably no need for higher-calibre weapons for the groups involved to maintain their current activities

- shortage of imported weapons is not a serious problem for criminal and insurgent groups due to relatively easy access to police and military firearms, surplus weapons from the Second World War, home-made guns and traditional weapons.

There is no doubt that ample firearms are available for use in criminal incidents and tribal fighting. ${ }^{20}$ Yet ultimately, while the numbers of arms trafficked into the country may be low, the precarious nature of the PNG state and its lack of control over wider society are such that even small numbers of unsophisticated weapons can shift the balance of power and further destabilize the state once they have fallen into the wrong hands.

Statistics reported in the local press suggest that there is one licensed gun for every 180 people in PNG. ${ }^{21}$ This figure neither reflects nor takes into account the number of illegal guns circulating in the country or the number held in police and defence armouries. During parliamentary debates on proposed amendments to the Firearms Act in June 1996, it was noted that a total of 69,000 firearms $(55,000$ shotguns, 10,000 rifles and 4,000 pistols) were registered for private protection. ${ }^{22}$ Conservative estimates placed the number of illegal firearms at around 10,000. This number, however, appears to have increased significantly over the past seven years.

Most of the illicit weapons in circulation are domestically generated and made up of:

- borrowed, hired or stolen small arms and light weapons from the Papua New Guinea Defence Force (PNGDF) or Royal Papua New Guinea Constabulary (RPNGC) armouries

- registered or unregistered fire

- arms procured through robberies

- arms from the Bougainville conflict

- old weapons recovered and refurbished from Second World War arms dumps

- home-made guns.

Many Highlands villages boast of owning several high-powered weapons, while according to some villagers "every house has a home-made gun of some sort for their protection". ${ }^{23}$ In the view of one seasoned local observer, "the morgue is constantly full" because of the intrusion of 
guns into people's everyday lives. ${ }^{24}$ John Wakon, a former police commissioner, has claimed that "there are more guns in the Highlands than in the PNG Defence Force". ${ }^{25}$

\section{Leakage from legal stocks}

While some high-powered guns are imported from overseas, most of these weapons and the required ammunition originate from poorly secured military and police arsenals. On the basis of results from audits at the time, a 2004 Small Arms Survey report reveals that 30 per cent of police small arms were unaccounted for, amounting to a total of 1,440 weapons; while 16 per cent of PNGDF small arms were missing, totalling some 1,501 weapons including 907 assault rifles and 102 machine guns. ${ }^{26}$ Table 6.1 contains some examples of the use of military-issue weapons by criminals. As stated recently by National Court judge Justice Kirriwom, "It is common knowledge that... high-powered weapons [lost] from the army, police and prisons through criminal acts committed from within end up in the wrong hands outside and therefore those who supply these deadly weapons that bring much damage, loss and grief must be held accountable for their part in bringing about such disastrous consequences." 27 The Australian government has committed over AU\$8 million to the construction of new armouries over recent years. In order to access the armouries, up to seven combinations are now required with an equivalent number of people holding each combination. Despite these measures, guns still go missing from defence stocks. Armouries are, after all, only as secure as those who hold the key.

As Table 6.1 illustrates, there are critical problems with security force discipline and control that demand urgent attention, especially in relation to the guarding of police and military armouries. Substantial evidence exists of the negative consequences of inadequately secured armouries. For example, around 100 soldiers entered the armoury at Port Moresby's Murray Barracks in March 2001 and seized a large number of M16 A2 rifles, plus thousands of rounds of ammunition, ostensibly in protest against a proposal to reduce the size of the PNGDF. Two days later, Commander Carl Marlpo was asked by a journalist why guards at the armoury had not stopped the robbery: "What guards?" he replied. "There are no guards there. You just lock the place and go home. What breakin? There was no break-in. Soldiers just walked in." 28 A number of armouries have since been made secure. However, there continues to be a lack of discipline and professionalism in the security forces, which serves to exacerbate PNG's burgeoning gun culture.

The apparent involvement of members of the political élite in gunrelated incidents is another source of concern. In blatant disregard of the law they are elected to uphold, several high-profile people have 
Table 6.1 Thefts of military-issue weapons and associated crime

\begin{tabular}{|c|c|c|}
\hline Date & Incident & Weaponry involved \\
\hline November 1996 & $\begin{array}{c}\text { Robbery at Westpac Bank, } \\
\text { Waigani, Port Moresby }\end{array}$ & $\begin{array}{l}\text { M16 assault rifle, grenades, a } \\
\text { grenade launcher }\end{array}$ \\
\hline May 1999 & $\begin{array}{l}\text { Armoured vehicle robbery } \\
\text { at Gerehu, Port } \\
\text { Moresby }\end{array}$ & $\begin{array}{l}\text { M16 and A15 rifles, and a } \\
\text { pump-action shotgun }\end{array}$ \\
\hline December 1999 & $\begin{array}{l}\text { "Millennium" bank raid, } \\
\text { Port Moresby }\end{array}$ & $\begin{array}{l}\text { Military automatic rifles and } \\
\text { hand grenades }\end{array}$ \\
\hline 31 May 2000 & $\begin{array}{l}\text { Group of armed men raid } \\
\text { South Pacific Bank in } \\
\text { Port Moresby }\end{array}$ & $\begin{array}{l}\text { Two pistols and a hand } \\
\text { grenade }\end{array}$ \\
\hline October 2000 & Drunken fight, four killed & Hand grenade \\
\hline November 2000 & $\begin{array}{l}\text { Hijackers seize an aircraft } \\
\text { carrying gold from } \\
\text { Wau-Bulolo goldfields } \\
\text { to Port Moresby }\end{array}$ & Rifles and a hand grenade \\
\hline February 2002 & $\begin{array}{l}\text { Looting; weapons not } \\
\text { recovered }\end{array}$ & $\begin{array}{l}\text { Two M16 A1 machine guns, a } \\
\text { grenade launcher and two } \\
\text { carbine machine guns still } \\
\text { missing from PNGDF stores }\end{array}$ \\
\hline June 2002 & $\begin{array}{l}\text { Looting by officers who } \\
\text { were later sentenced to } \\
12 \text { months in prison }\end{array}$ & $\begin{array}{l}\text { Three officers from Igam } \\
\text { Barracks in Lae stole and } \\
\text { sold an M16 carbine to } \\
\text { buyers in Kainantu for } \\
\text { K4,500 (US\$1,178.10) }\end{array}$ \\
\hline January 2003 & $\begin{array}{l}\text { Looting; weapons not } \\
\text { recovered }\end{array}$ & $\begin{array}{l}\text { Three high-powered weapons } \\
\text { stolen at change of guard } \\
\text { duty in a defence barracks; } \\
\text { the weapons were simply } \\
\text { left unattended in a cage } \\
\text { with a padlock }\end{array}$ \\
\hline November 2003 & $\begin{array}{l}\text { Looting; weapon not } \\
\text { recovered }\end{array}$ & $\begin{array}{l}\text { One M16 went missing from } \\
\text { quarter store at Murray } \\
\text { Barracks }\end{array}$ \\
\hline January 2004 & $\begin{array}{l}\text { Legally issued weapons } \\
\text { not recovered; guns } \\
\text { were never returned to } \\
\text { Murray Barracks (Port } \\
\text { Moresby) following an } \\
\text { Independence Day } \\
\text { parade }\end{array}$ & $\begin{array}{l}\text { Six SLR, a } 9 \mathrm{~mm} \text { pistol and } \\
1,800 \text { rounds of ammunition }\end{array}$ \\
\hline
\end{tabular}

Note: This table builds on and updates a chart that appears in Capie, David (2003) Under the Gun: The Small Arms Challenge in the Pacific, Wellington: Victoria University Press in association with Peace and Disarmament Education Trust. His data cover the period up to 2000. 
been implicated in gun-related incidents in recent years. Former tourism minister Alois King allegedly threatened a university lecturer at gunpoint at a Port Moresby rugby club. Ex-minister Philemon Embel was reported to have pulled a gun out at the Holiday Inn in the national capital, while another provincial governor drew his pistol at the city's five-star Crowne Plaza. Former governor of Oro Province, Sylvanius Siembo, went to court after he allegedly shot a youth whom he claimed had tried to rob him. Anderson Agiru, former governor of Southern Highlands, was ousted by a leadership tribunal after he drew a pistol at the Port Moresby Golf Club. Agiru had also been photographed with an automatic weapon inside an airport. ${ }^{29}$

At the beginning of 2004 Air Niugini cargo handlers at Port Moresby airport discovered a shipment of six stolen PNGDF guns, a 9mm pistol and 1,800 rounds of ammunition addressed to the headmaster of Pangia High School. As a result of this incident, a number of corrective measures were reported to have been initiated by the defence minister. These included:

- replacement of all officers in the defence supply system at Murray Barracks

- changing of all armoury combinations

- replacement of all armoury staff

- stocktake of all weapons and ammunition in all units

- recall of all weapons issued to officers and soldiers

- restrictions placed on access to the holding bay and ammunition depot at the Goldie River Barracks outside Port Moresby. ${ }^{30}$

In an effort to reduce the potential risk posed by surplus weapons, the Australia-Papua New Guinea Defence Cooperation Program oversaw the successful destruction of roughly 4,000 weapons within the first six months of 2003. These included mainly high-powered weapons and rocket-propelled grenades left over from the Sandline affair in Bougainville, ${ }^{31}$ and surplus police and defence stocks. These weapons were disabled, cemented inside 44-gallon drums and disposed of at sea. ${ }^{32}$ Despite these measures, Defence Force commander Brigadier-General Peter Ilau has claimed that at least 300 military weapons, mostly from the Bougainville crisis, were still unaccounted for. ${ }^{33}$

Firearms seized from the public and subsequently destroyed have included sophisticated weapons such as MAG 58 machine guns. Due to the value placed on gun ownership in PNG, the surrender of such weapons is probably an indication of the difficulty in procuring the requisite ammunition to operate them. For example, the MAG 58 requires 7.62 $\mathrm{mm}$ cartridges, which are scarce in PNG. Shortage of ammunition for high-powered weapons also influences the frequency of their use in tribal fighting, which provides one of the main contexts of small-arms usage in PNG. 


\section{Principal contexts of firearms use}

\section{Raskolism}

The raskol gang is the most potent symbol of PNG's so-called law and order problems. From its relatively benign origins as a vehicle for enhancing self-esteem among young male migrants in Port Moresby in the $1960 \mathrm{~s},{ }^{34}$ raskolism has evolved into the most menacing face of contemporary lawlessness and has gradually spread to other towns, as well as to many rural districts. ${ }^{35}$ Gangs of predominantly young males engage in criminal activities ranging from minor assaults, car-jacking, housebreaking and highway hold-ups to armed robberies, gang rapes and murder.

Gang networks now operate on a nationwide basis. Larger gangs in Port Moresby have affiliated organizations in other towns and some rural areas. These networks allow criminals who are being pursued by authorities in a particular town or area to move elsewhere. In the process, they also allow the dissemination of criminal knowledge and organization and have contributed to the spread of raskol crime. Evidence also exists of a growing nexus between raskol elements and political and business figures that employ criminal "muscle" for electoral, commercial or security reasons. In late 1997 the Australian Broadcasting Corporation screened remarkable footage from a concealed video in which the then PNG prime minister, Bill Skate, was heard boasting that he was "the godfather" of all PNG's gangs and had participated in an earlier gang killing. Mr Skate claimed subsequently that he was drunk at the time of the recording. ${ }^{36}$

Although raskols are by no means the sole, or even the main, perpetrators of violence against women, they have become closely associated with the practice of gang rape involving multiple assailants. ${ }^{37}$ In addition to premeditated rapes, many sexual assaults are opportunist. An example would be where a group of young men come across a woman in an isolated location. Women and girls encountered in the course of a housebreaking, robbery or car-jacking are routinely subjected to sexual assaults, almost as incidental to the "main" crime. A crime victimization survey was undertaken in PNG's urban centres in 1991 as part of an international survey by the UN Interregional Crime and Justice Research Institute (UNICRI). ${ }^{38}$ The results revealed that PNG's major towns fared worst among the surveyed cities, a trend that was most marked in the serious crime category. PNG also had by far the highest incidence of sexual assault (Figure 6.1). Nearly 12 per cent of women aged 16 years and over had been victims of sexual assault at least once in the preceding year and more than 32 per cent had been victims in the preceding five years. Around one-quarter of the sexual assault cases were classified as rape. Available criminal justice data suggest a further increase since the 


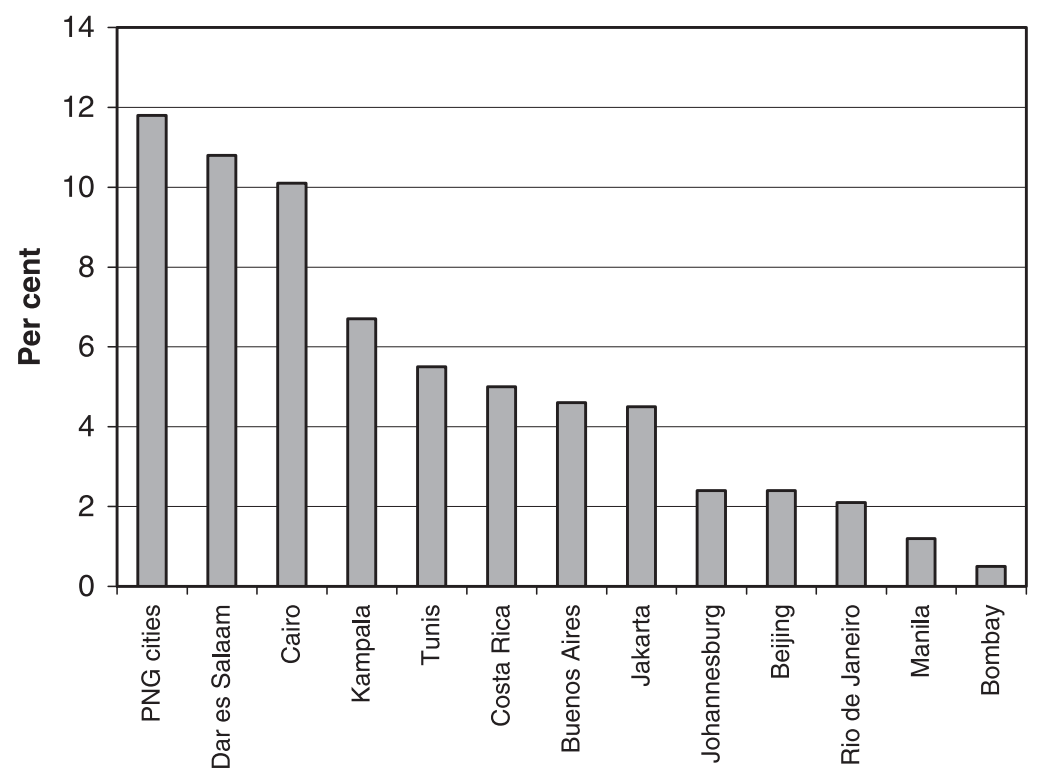

Figure 6.1 International comparison of sexual assaults, 1991

Note: This figure compares victimization rates among females aged 16 and over. The results of the UNICRI international victimization survey also found that rates of assaults and robberies were higher in PNG's urban centres than in other surveyed cities.

Source: Constructed from survey data in Zvekic, Ugljesa and Anna Alvazzi del Frate (1995) Criminal Victimization in the Developing World, New York: Interregional Crime and Justice Research Institute. Reproduced in Levantis, Theodore (2000) "Crime Catastrophe - Reviewing Papua New Guinea's Most Serious Social and Economic Problem", Pacific Economic Bulletin 15(2), pp. 130-142, at p. 132.

UN survey was conducted: there appears to have been a significant growth in crime in past years, with a 65 per cent increase in the number of serious offences reported to the police during the course of the 1990s alone. ${ }^{39}$ Port Moresby accounts for the highest proportion of reported serious crimes and has been described as one of the most dangerous cities in the world. ${ }^{40}$

Victimization surveys in the National Capital District (NCD) and Southern Highlands province (SHP) for the 2006 Small Arms Survey confirmed the high levels of sexual assault. More than 8 per cent of responding households in SHP and 3 per cent in the NCD reported that a member of their household had been the victim of sexual assault or rape in the six months to May 2005. The survey also revealed that victimization events were clustered in particular areas and typically involved the use of weapons, especially firearms and bush knives. ${ }^{41}$ 
The organization and modus operandi of criminal groups vary from place to place. Rural raskols are more likely to speak the same local language and will often come from the same village or group of villages. Banditry is commonplace, typically involving the armed hold-up of vehicles travelling slowly along poorly maintained roads. Rural crime of this kind tends to be episodic and is likely to peak during the harvesting of cash crops, such as coffee. Towns and other areas of concentrated development, such as mining and petroleum projects, provide the most lucrative criminal opportunities. Well-organized urban gangs target payrolls, banks, business premises, affluent residences and cash in transit. Criminal groups operating in town are more likely to be ethnically heterogeneous, reflecting the composition of the overall urban population.

The availability and use of firearms have added greatly to the menace of raskolism. Home-made weapons began to appear in the 1970s. Today, weapons include high-powered automatic and semi-automatic rifles as well as assorted home-made guns and rifles. There have even been reports of raskol groups armed with grenades. ${ }^{42}$ While usually carried to intimidate victims, weapons will be used in the case of resistance by victims or pursuit by police. As mentioned earlier, the growing threat of criminal violence has encouraged non-criminals to acquire firearms for self-defence. There have been many instances of alleged criminals being shot by their intended victims. In 1995 a foreign businessman shot dead four criminals during the course of a robbery at a Port Moresby restaurant. ${ }^{43}$ Guns are also taken off victims and used against them and others. Such actions belie arguments about the effectiveness of guns as a means of self-defence against criminal violence. The brazenness of criminal operations has also become increasingly pronounced. Shoot-outs between criminals and police are reported regularly. The most spectacular attempted robbery in recent years was the so-called "Millennium heist" in Port Moresby in December 1999. After months of planning, five members of a professional gang hijacked a commercial helicopter they had hired legally to transport rice. The helicopter was used to land on the roof of a major bank in downtown Port Moresby. Unknown to the robbers, however, undercover police were waiting for the gang, who were armed with military rifles and grenades. The helicopter was disabled as it tried to take off and crash-landed on a busy street. In controversial circumstances, four of the robbers were shot dead by police on the spot, while the fifth died in hospital.

From its inception, the raskol gang has been a predominantly male preserve. Gangs have become an important vehicle for the initiation of young, disenchanted, urban men into the ambivalent space of PNG's rapidly expanding towns. As well as drawing on older Melanesian models of masculinity, they draw increasingly on models provided by global culture. 
Prominent among these are the macho heroes of the action videos that are watched avidly in settlements, villages and private homes. The violent masculinity of Rambo and his many imitators is reflected in the popular culture of urban youth. Militaristic clothing is highly valued, as are dreadlocks or shaven heads, and the ubiquitous dark shades. Media images from distant conflicts, including the "war on terror", are scrutinized with great interest and used selectively to replenish a vibrant street style. In late 2002 Osama Bin Laden t-shirts became the latest accoutrement of young male fashion in Port Moresby. ${ }^{44}$ There is little evidence of female gangs or gang members in Papua New Guinea, which is hardly surprising given the overall state of gender relations. While girlfriends and female relatives might benefit indirectly from the acquisitive crimes of gang members, there is no evidence of young women playing an actively "supportive" role to this kind of male youth culture, unlike in many other countries. Melanesian women have a long history as peacemakers at local levels, and are more likely to participate in low-key resistance to raskol subculture in affected communities.

\section{Tribal fighting}

Tribal warfare, which was common to many Papua New Guinean societies in pre-colonial times, was effectively suppressed by colonial authorities. However, it reappeared in parts of the Highlands in the years immediately preceding independence in 1975 . Fighting was triggered by both old and new issues, in some places over land and in others over earlier killings or unpaid compensation arising from previous disputes. ${ }^{45}$ It was exacerbated by excessive alcohol consumption that often led to brawls and fatal traffic accidents. The revival of fighting prompted the establishment of a government committee to investigate tribal fighting. It found that the limited availability and effectiveness of introduced procedures for dispute settlement had facilitated a reversion among certain groups to older and violent forms of self-help strategies. ${ }^{46}$ The final report of the committee comprised an interesting mix of conventional deterrent and innovative recommendations. Although most were never implemented, the Inter-Group Fighting Act 1977 provided for the declaration of "fighting zones" and a reversal of the onus of proof in certain criminal proceedings. ${ }^{47}$ Over the past two decades tribal fighting has become an increasingly debilitating problem in many Highlands areas, particularly Southern Highlands, Enga, Western Highlands and Simbu provinces. As documented in the 2006 Small Arms Survey, it has also become a major problem in the larger urban centres, notably Port Moresby. The NCD victimization survey conducted in 2005 revealed that in the previous six months 18 per cent of respondent households had been 
victims of inter-group fighting, 27 per cent included someone who had been involved in inter-group fighting as a combatant and 15 per cent included someone who had changed residence due to inter-group fighting. ${ }^{48}$

Fighting results in numerous fatalities and injuries, cycles of "payback" killings, extensive damage to property and serious disruption to government services and commercial activities. Between 1988 and 1996 fights in the Tsak-Wapenamanda area of Enga province reportedly claimed more than 300 lives. ${ }^{49}$ In 1999 more than 35 people were killed in two fights in the Okapa and Kainantu districts of the Eastern Highlands province. ${ }^{50}$ Fighting between the Unjumap and Wogia tribes in the Southern Highlands in late 2001 and early 2002 was estimated to have killed as many as 120 people. According to a senior police officer, weapons used in that fight included M60 light machine guns, M16, SLR and AR15 (modified) assault rifles, L40 and Mark 47 Second World War rifles, pump-action and single-shot shotguns, pistols and assorted home-made guns, as well as bush knives and axes. ${ }^{51}$ The same officer claimed that the illicit gun trade had become an increasingly profitable business for those who hire weapons to combatants for substantial sums of money. Nine people were reportedly killed in a tribal fight between two warring clans in Enga in late 2002. ${ }^{52}$ The fight erupted near an international high school following the death of a man from one of the clans. High-powered weapons were used by both sides and, in order to evade police, a lot of the fighting took place at night. The death toll from all recent conflicts in the Southern Highlands was estimated in the hundreds (May 2004). In 2001 it was reported that some 1,000 people had been killed as a result of fighting in Enga province over the previous four years. There have also been many reports of rapes occurring in the context of fights. The destruction of schools, aid posts, houses, gardens and business premises has disastrous long-term effects upon development in the areas concerned. Government services are likely to be seriously disrupted as teachers, health workers and other public servants are forced to flee for their own safety.

The account below, by a grade 12 schoolgirl in Enga Masemana, indicates the devastating effects of the tribal fighting on the local community. ${ }^{53}$

We were just a typical group of Papua New Guinean teenagers who were enjoying a Wednesday afternoon in the sun, playing an interesting game of soccer and were unsuspecting of the world around us, even though we were aware of the tension that existed. The tribal war that took place right outside the school fence had already taken its toll. Our main building in the school which included five classrooms, a computer lab, a library, and the main office was burnt down while the students were on holidays. That particular Wednesday afternoon is one I will never forget. The grade eleven and twelve class of Highland 
Lutheran International School were busy playing soccer on the open field when suddenly we heard huge explosions that sounded like grenades. There was pandemonium everywhere. Some students leapt to the lawn and laid flat while others were running but couldn't decide which route to take because the explosions were so loud and sounded so close it felt like guns were being fired from all directions. The tribal fight brought the most smoke I had ever seen or breathed in my entire life. It brought the regretful sound of crying voices, which I put up with every other day. But most of all, it brought a fear that never allowed me to sleep peacefully at night.

The likelihood of prolonged cycles of retaliatory violence has been increased significantly as warriors blend older methods of dealing with inter-group conflict with modern technology, notably the use of modern firearms. Traditionally, tribal warfare was conducted at close quarters with bows, arrows, axes and spears. It was often highly ritualized and fatalities generally remained low. ${ }^{54}$ Shotguns used for hunting game were not used in tribal fights. Although the first reported use of a gun in a tribal fight occurred in the 1970s, it is only since the mid-1980s that shotguns have become commonplace. ${ }^{55}$ High-powered rifles, some with telescopic sights, began appearing in the early 1990s, and this served to make traditional fighting techniques increasingly redundant, with a corresponding increase in fatalities. ${ }^{56}$

The first shotguns used in tribal fights were home-made. In his study of warfare methods in the Highlands, Burton points to the sophistication of home-made guns and the manner in which they transformed tribal fighting. In his view, "these weapons have swept the bowmen off the battlefield as surely as the Panzers brushed aside the valiant Polish cavalrymen on the North European Plain in September 1939". ${ }^{57}$ They are inexpensive, and an experienced gun maker can produce one within a week. Locally produced weapons also coexist alongside more sophisticated, imported small arms. According to a villager from Nipa in the Southern Highlands, "there are roughly five high-powered weapons in the village, including M16s, SLRs, pump-action shotguns", in addition to the large number of home-made shotguns and pistols available. Although each gun reportedly has two full magazines, "if we run out of ammunition in a fight, we travel to the next village and buy more ammunition from them. They are guaranteed to have some, so we can buy." 58 According to another villager, "the same fights would not occur without modern weapons" because the young men no longer know how to use bows and arrows. ${ }^{59}$

Those in search of weapons have devised numerous, often ingenious, ways of acquiring them and concealing them from unwanted attention. A possibly apocryphal tale concerns an unusual funeral party from the Western Highlands. Aware of roadblocks at provincial borders, the 
"mourning party" "ran down to Lae in their Dyna, loaded up the 'coffin' with guns and ammunition, rubbed retpela graun [red clay used by grieving relatives] over themselves, the coffin and the truck, and then went free back to Hagen with their haul". ${ }^{60}$

Guns have become a major topic of everyday discussions in many rural villages, and all members of the community - men and women alike who are able are likely to contribute to the purchase of weapons and ammunition. Money spent on guns diminishes a community's ability to pay school fees and meet medical and other essential costs. Guns acquired in this context are highly valued and often left in the custody of young men for safekeeping and maintenance. As the following story illustrates, the acquisition, disposition and use of the guns are governed by gender-specific rules which are derived from older beliefs and practices that separate the sexes and exclude women from decision-making on matters of security. ${ }^{61}$

Dora Kegemo is a married mother of two young children. She is a community leader and sits in village court hearings as a mediator and adviser after attending a number of police-run community policing meetings and conflict resolution training.

Dora recalls the time when guns arrived in her village. All the strong and young men gathered in a house where all the guns were stored. After oiling and decorating the guns these men called in all the village leaders, counsellors, village court magistrates and church pastors to come and see the guns. Then a speaker among the group addressed the leaders and said, "Your lives are in these things. We will now bury these and will not touch them unless we have a tribal fight." The guns were put in a coffin box and buried. On top of the "grave" a haus man was built where only men and young boys can enter. No woman is allowed to go anywhere near the house.

An alarming recent development has been the growth in gunmen who hire out their services as "hitmen", personal security to political leaders, or as mercenaries in tribal fights. These "hire-men", as they are known, have become entrenched as a new tier of leadership in many Highlands communities. They have accentuated already high levels of social dislocation in many villages and have effectively undermined the role of older, traditional male leaders. Young men with access to guns are also a constant threat to local women and are blamed for rising levels of rape and other forms of violent assault.

The account below illustrates the way in which women become inadvertently caught up in the fighting. ${ }^{62}$

Maria Tombename lives in the Tsak valley in the Enga province of PNG. Fifteen years ago, much of the valley was reduced to ugly ashes due to devastating tribal warfare in which over a hundred people died. 
Women are seldom targets in Eastern Enga tribal warfare, so Maria would go close to the fighting in order to harvest food from her garden. While talking to a young man near the parish church a shot rang out and the young man fell mortally wounded. She then heard someone from the enemy clan identify her as the wife of a fight leader. Another shot rang out. She didn't feel anything at first and reached down into her pocket to find her rosary beads. Instead of her beads she felt blood. She tried to run away but couldn't as the shot had shattered her leg bone. So, dragging her injured leg behind her, she crawled to where she could hide until sunset. With nightfall she was able to attract attention and her clan rescued her and took her to hospital where her leg was amputated at the hip. Maria does not bear a grudge against her assailants. She says that she can get around as well as women with two legs and she is glad to be alive. "Many others are in a box with grass growing over them."

In another disturbing trend, young women have become a form of currency for paying mercenaries and purchasing guns. Women may also be offered until sufficient funds are raised to make cash payments. One man from the Berepka tribe in the Western Highlands claimed that his sisters had been transacted for guns in 1995-1996. ${ }^{63}$ Towards the end of a fight between groups in Akom and Pina in Enga province in 2003, a girl was designated to "pay the hand" of one of the mercenaries (e.g. the hand that wielded the gun, and the hand by which the man will marry). She was decorated in traditional attire and stood in the back of an open utility vehicle. People from the enemy group shot her and she died instantly. ${ }^{64}$ The immediate purpose of the shooting was to prevent the delivery of the mercenary's payment. Other common forms of payment for the services of "hire-men" in the Highlands include pigs and money. ${ }^{65}$

The commoditization of women in the context of this growing gun culture demonstrates a tragic new degeneration in PNG social customs. While violence against women did occur in the course of raids and in some places women were exchanged as part of traditional peacemaking ceremonies, there were usually significant constraints on such practices. In many places it was unacceptable to kill women and children. Today, however, such constraints have largely disappeared and women and children often find themselves in grave danger. Women can also become the victims of tribal "payback" killings. In 2003 a young Engan woman, Dorothy Ambo, was fatally shot while waiting for a bus. Her assassins mistakenly thought she was from Sirunki and killed her in retaliation for a murder committed by a Sirunki man on a member of their tribe. ${ }^{66}$

Not only have guns greatly increased the casualty rate, but their acquisition, maintenance and use also require financial resources beyond the normal capacity of most local communities. ${ }^{67}$ In addition, they allow non-combatants to play a lucrative and lethal role in tribal fights by supplying guns and ammunition without having to participate in the actual 
fight. Gun ownership generates prestige, as well as fuelling competition between communities to acquire more weapons. Rumours that a particular community possesses a certain number of weapons are likely to induce anxieties among neighbouring villages and prompt efforts to match these numbers. This contributed to a mini arms race in parts of the Highlands founded on growing levels of insecurity and local efforts to build defensive capacities.

Some church leaders speak of a growing phenomenon that resonates with the Cold War notion of "mutual assured destruction". On 31 January 2004 Bishop Douglas Young was involved in a peace and reconciliation ceremony in Mount Hagen, where the two sides wanted peace because they believed they were both too heavily armed and feared "mutual destruction". Although there was no surrendering of arms in the process, it was their growing stockpiles of arms, and the potential threat they posed, that brought the tribes together in an effort to settle their differences. These kinds of ceremonies are a positive step towards peaceful resolution of conflict. According to Bishop Young, "small acts of reconciliation are much more important than simply giving arms back", because they feed into a more enduring process of peacemaking between warring communities. ${ }^{68}$

\section{Election-related violence}

National elections, which are held every five years, have become another major context of violence and increasingly involve the threat and use of firearms, particularly in the Highlands. They are often the catalyst for the revival of dormant tribal disputes and generation of new ones. Although there is no evidence that the incidence of election-related violence in PNG matches that in many other parts of the world, it is definitely on the increase. In the Highlands, modern electoral contests have been grafted on to highly competitive and unstable local political cultures, and almost inevitably exacerbate existing tensions.

As early as 1977 (two years after independence), election observer Bill Standish recalls that firearms were being used to impress local voters and intimidate rival candidates and their supporters in Simbu province. Twenty years later, Standish notes that gun violence during the 1997 elections resulted in the deaths of 35 Simbu people and displaced 1,000 others from their land. Guns also played a significant role in Simbu in the 2002 elections. ${ }^{69}$ Politicians and the security services continue to be implicated in the supply of illicit weapons to areas where they aim to solicit support. ${ }^{70}$ Guns are also used in acts of retributive violence directed against individuals and communities believed to have voted for rival candidates. Sir Mekere Morauta, incumbent prime minister during the 2002 
elections, conceded that members of his own People's Democratic Movement (PDM) were involved in some smuggling operations. ${ }^{71}$ It is widely recognized that candidates stockpile weapons and use them to intimidate voters. In one incident, four Southern Highlands MPs allegedly organized a helicopter shipment of 20 semi-automatic rifles and machine guns. On the eve of the 2002 elections, Southern Highlands leaders called for the deployment of the PNGDF to maintain order in the troubled province, which a former senior commander described as "totally out of control". ${ }^{72}$ The district administrator for Koroba/Kopiago in the Southern Highlands released a warning to various airline companies in the country that any aircraft flying into his area were at serious risk of being shot down. This was because 19 local candidates had stockpiled high-powered firearms, from AK-47s and M16s to 303s, which they intended to use during the election period. ${ }^{73}$ The extraordinary levels of violence and disruption experienced in the Southern Highlands in 2002 led to "failed elections" being declared in six of the province's nine electorates.

By mid-2002 the election-fuelled arms race had resulted in at least 20 killings. ${ }^{74}$ This figure had risen to over 30 deaths by early August. In the single most spectacular incident of election-related violence in 2002, an armed gang of about 30 men took control of Enga's provincial police headquarters in Wabag and, using drums of aviation fuel, blew up two shipping containers, destroying at least 30,000 ballot papers. ${ }^{75}$

On a more hopeful note, the conduct of the 2007 general elections was remarkably peaceful. While detailed assessments are yet to appear, the view among informed observers is that significant legislative and administrative changes contributed to this outcome. ${ }^{76}$ These included a switch from a first-past-the-post voting system to the adoption of a limited preferential voting (LPV) system. This has served to ameliorate the tensions arising from previous vote-splitting practices that divided many communities and, in the process, generated conflict. The well-organized and coordinated security campaign in 2007 involving the PNGDF, RPNGC and electoral officials has also been credited with reducing election-related conflict.

\section{The gender of violence in PNG}

The prevalence of domestic violence in PNG was documented by the Law Reform Commission in a series of studies undertaken in the 1980s. ${ }^{77}$ This research found that, on average, two-thirds of wives had been hit by their husbands. The frequency and severity of violence are greater in the urban environment. Considerable variation exists across the country, with figures of close to 100 per cent from some Highlands 
areas, and half that level in some communities in Oro and New Ireland provinces. In rural settings, perceived causes of domestic violence were listed as sexual jealousy, the wife's failure to fulfil her duties and dislike of the spouse. In urban areas, the main perceived causes were alcohol, sexual jealousy and money problems. At the level of underlying causes is the widespread acceptance of domestic violence, particularly wifebeating, as a part of normal life. This naturalization of gender-based violence is the most widespread iteration of the marked inequality between men and women in both "neo-traditional" and "modern" sectors.

Other underlying causes of domestic violence identified in the LRC research related to the stress caused by rapid socio-economic change; lack of communication between husbands and wives; and the high background level of violence and aggression in many of the traditional cultures, as reinforced by the media, tribal fighting and civil war. Growing poverty was an important aspect of "stress caused by rapid socio-economic change". The decline in the value of the local currency has dramatically affected purchasing power, and the effects of this are most apparent in the highly monetized urban centres. However, even in rural areas people need money for school fees, clothing, transport, kerosene, medical treatment, soap and other basic household items. Growing levels of poverty are increasing the vulnerability of women to violence and crime. As one report puts it:

Poverty pushes people past the limits of their patience. The effects of this are seen not only in the climbing crime statistics (and the flourishing security industry) but also in the high levels of violence against the most vulnerable, and the rising numbers of women and girls turning to prostitution for a living. ${ }^{78}$

As elsewhere, most sexual violence against women and girls is perpetrated by men known to the victims, including family members and the women's own husbands.

Another study concluded that "The pervasiveness of gang rape as a form of criminal activity has become a major threat to social stability and the security of women and families throughout Papua New Guinea." 79 National crime summaries compiled by the police for 2000 state that an average of 5.6 rapes are reported daily throughout the country. ${ }^{80}$ Within a seven-day sample period, 22 rapes were counted, and 18 gang rapes were reported with as many as 20 assailants per case.

Armed conflict and emergency situations increase women's risk of rape and sexual assault. Sister Gaudentia Meier reported that in January 2001 alone she had examined 17 young girls and older women for rape during tribal fighting in Mendi, Southern Highlands province. ${ }^{81}$ A common theme linking past and present patterns of sexual violence in PNG is 
women's low socio-economic status, which makes them vulnerable to coercion, along with attitudes which support men's sense of entitlement over women and their bodies. High levels of sexual violence contribute to STD rates and the rapid spread of HIV/AIDS. The latter, in particular, is likely to have a major impact on the growth of poverty. Frank Kasahya, the pathologist at Tari Hospital, disclosed in an interview that he receives at least two new HIV patients each week. ${ }^{82}$

Another universal theme linking patterns of violence against women and children in PNG is polygamy. Traditionally, the acquisition of multiple wives was an expression of bigman status. Among other things, polygamy was a means of forging strategic alliances between different clans and tribal groups. Many of these older social dimensions have disappeared, and today many wealthy and powerful men simply use their resources to acquire young brides. This often leads to the neglect of the first wife and her children. School teachers at Tari primary school claimed that their most disruptive students were often children abandoned by fathers who had entered into polygamous relationships. ${ }^{83}$ The first wife occasionally receives visits from her husband when he demands sex. If she refuses, she is likely to be beaten. ${ }^{84}$ Polygamy places enormous strain on women who are fighting to maintain their dignity at the same time as providing for their children. Polygamy also provides the main context of violence between women in PNG. Nurses in hospitals from Port Moresby to Mount Hagen stated that a high proportion of their female patients suffering from stab wounds were victims of other women in domestic disputes. ${ }^{85} \mathrm{~A}$ female prison officer in Ialibu confirmed that the majority of women inmates are imprisoned because of violence perpetrated against their husbands' other wives, or against the husbands themselves. ${ }^{86}$

When a first wife is sent to prison, her children are often left to fend for themselves. This was the case with a woman in Mendi, whose children were eventually rescued from starvation and destitution by a group of Franciscan sisters. ${ }^{87}$ By contrast, men are rarely imprisoned for the sexual abuse and murder of their wives. In the rare cases that reach the courts, sentences are often light. When a woman is raped or killed, usually one of her male blood-relatives demands "compensation" from the assailant's tribe, and once this has been paid the crime is effectively absolved. Sister Gaudentia Meier illustrates the problem: ${ }^{88}$

One day a husband returned home and proceeded to beat and kick his young wife while their three children were looking on. The unconscious woman was brought to the Health Centre. Tragically, she died of a ruptured spleen on the way to the Mendi Base Hospital. We continued to Mendi as I wanted a post mortem done to bring justice to the case. Nothing was done. The body was taken home and quietly burned and buried within a day. Compensation was paid, but there was no court case and the husband went free. 
In addition to the growing number of women imprisoned for crimes arising from polygamous relationships, there is evidence of rising levels of child abuse in PNG. A GoPNG/UNICEF report concluded that "the increasing incidence of child abuse can be viewed as a direct consequence of the rapidly changing conditions that characterize PNG's transitional society". ${ }^{89}$ Tari Hospital admissions records document rape cases of children as young as two years old. ${ }^{90}$ The 2003 surgical admissions book for Mount Hagen Hospital recorded five cases of scrotal lacerations to young boys and a number of deep penetrating wounds to the vaginas of fiveyear-old girls. ${ }^{91}$ Child prostitution is an increasing phenomenon in towns, as well as in rural areas in the vicinity of mining and other large-scale resource-extraction projects. Poverty and the expense of urban living render children especially vulnerable to violence, sexual exploitation and neglect. In the absence of any organized state welfare provisions, growing numbers of women, including those deserted by their husbands, are forced to look for any opportunities for earning money to support their families. Children have to look after themselves or are left in the care of underemployed youths or relatives. While church groups and other voluntary associations might provide some temporary relief, poverty levels are growing in both rural and urban areas.

\section{State responses to violence and conflict}

Papua New Guinea's formal criminal justice system has been progressively overwhelmed by the growth of violent crime and tribal conflict. It remains an urban-based system and has only a limited presence in many parts of the country. For the 85 per cent of the population who live in rural areas, crimes and disputes are more likely to be dealt with informally rather than through the formal justice system. Even in the towns, lack of confidence in state policing is demonstrated in the preference for informal approaches and the massive growth in private security. ${ }^{92}$ The institutional weaknesses of the formal agencies, notably the police, have been the subject of numerous reviews as well as substantial capacity-building projects funded by the Australian government. A 2004 police review commissioned by the PNG government echoed the widely held sentiment that "policing was close to total collapse". ${ }^{93}$ This state of affairs was attributed to a lack of support and direction; ineffective leadership; inadequate resources, including salaries, allowances and other entitlements; lack of discipline, accountability and self-respect; and an absence of community trust and respect.

Lack of adequate government support for state police has been a major constraint. The current number of police, approximately 5,500 
officers, has not increased significantly since independence in 1975 despite the population having more than trebled and the exponential growth in serious crime and disorder. Most of the annual police budget is spent on wages. Funds for petrol, airfares, office equipment and other necessities are scarce and officers-in-charge are forced to seek external assistance, often from local businesses. Police stations and accommodation are regularly condemned as unfit for human habitation by health authorities. These conditions, including extremely low wages, have contributed to morale problems and growing levels of corruption. In the field, police are often outgunned by better-equipped criminals and tribal warriors. This has sometimes led to political leaders donating firearms to local police in acts of questionable legality. For example, on the eve of the 1992 elections the premier of Simbu province presented his provincial police commander with 24 weapons (shotguns and pistols) plus ammunition after learning that the police only had two shotguns. ${ }^{94}$

Reactive policing strategies have not only failed to stem existing levels of crime but, in many cases, have contributed to further disorder. Fear and distrust of police are the prevailing sentiments in many communities. Speaking of the impact of police on tribal fights, Mapusia claims that "police interventions have been counter-productive. They have prolonged fights, increased fatalities, and obstructed negotiations and settlements. Essentially the police have made matters worse." 95 The excessive use of force has contributed to increasing levels of litigation in recent years. Claims cover matters such as illegal police raids, false imprisonment, wrongful arrest, assault and police killings. Over 50 per cent of all litigation against the state arises from actions against the police. ${ }^{96}$

Violent encounters with police provide a recurring theme in the legitimating rhetoric of raskols and constitute an important aspect of induction into urban gang life. Police violence in the course of arrest or questioning is depicted as routine by criminal informants. There have been numerous reports of suspects being shot "while committing an offence", "while resisting arrest" or "while trying to escape". Police killings contribute to an escalating cycle of retributive violence between police and criminals, fuelled by the abundant supply of sophisticated weapons. Relatively few cases are followed up with coronial inquiries.

The Bougainville war (1988-1997) served to reinforce the militarization of state responses to conflict. Heavy-handed policing by mobile squads contributed significantly to the initial escalation of that conflict. In addition, mobile squads returning to the mainland brought back many of the techniques and attitudes derived from their experience in war-torn Bougainville and applied them in daily policing practice. Special equipment issued for the Bougainville context, including black uniforms and face camouflage, continued to be used by some of these units upon 
their redeployment. ${ }^{97}$ The working culture of the mobile squads, particularly in the Highlands, entails an unbridled machismo and a predisposition towards Rambo-like solutions to problems. Intimidation and violence on the part of the police, including high levels of sexual violence against women and children, ${ }^{98}$ are a regular response to localized outbreaks of disorder. A Human Rights Watch report in 2004 alleged that brutal beatings, rape and torture were routine practices among the PNG police, drawing particular attention to the abuse of children, women and sex workers by members of the force..$^{99}$

The institutional culture of the RPNGC is singularly masculine. Women officers comprise a mere 5.4 per cent of uniformed personnel. Interviews with women police confirm the overwhelming masculinity of police culture, with a strong emphasis on the use of physical force as the appropriate remedy for resolving problems. ${ }^{100}$ They also confirm that male officers rarely treat seriously complaints of domestic violence from members of the public and that, moreover, domestic violence is pervasive inside police barracks.

\section{Community-based initiatives directed against tribal fighting and gun culture}

In light of limited government capacity, a number of local communities have taken steps to try to address the growing problem of guns and violence in their areas. These initiatives reflect the absence or inadequacy of state responses to violence, as well as demonstrating a willingness on the part of some local groups to take back responsibility for maintaining security in their own communities. The methods employed vary, but generally entail strategies that draw on local knowledge and cultural resources.

Women's groups and churches have been particularly active in the area of peacemaking and conflict resolution. However, local "success stories" in different parts of the country are often not well known beyond the immediate vicinity owing to communications and transport problems and, as a result, do not contribute to the growth of a PNG-wide women's or peace movement. They tend to take place in rural areas far from the eyes of the urban-based media and policy community. Alan Rumsey tells the remarkable story of the Kulka Women's Group (KWG) and its successful intervention to end a long-standing tribal conflict in the $\mathrm{Ne}$ bilyer Valley of Western Highlands province. ${ }^{101}$ The KWG developed a strategy that appealed to both modern conceptions of state law and development and more traditional notions of peacemaking. The women concerned, wearing t-shirts bearing PNG's national emblem, marched in between rival groups of warriors and exhorted them to lay down their 
arms and go home. After planting the national flag in the middle of the battlefield, they distributed food and other gifts to the warriors, who accepted these and subsequently disbanded. There are also many examples of innovative and courageous peacemaking initiatives led by women's groups in war-torn Bougainville. ${ }^{102}$ These have been integral to the success of community-based reconciliation processes on that island.

Sarah Garap, a women's leader and community activist from the Highlands province of Simbu, is a co-founder of a local NGO called Kup Women for Peace (KWP), which has made significant inroads in restoring peace to a formerly conflict-ridden area. ${ }^{103}$

Kup subdistrict comprises approximately 25,000 people divided into 12 distinct tribal groupings living in a relatively undeveloped part of rural Simbu. Intermittent fighting between different tribal groups has occurred since the early 1970s. Fights have often been triggered by relatively minor disputes including adultery and drunken brawls, but also by rapes, murders and election-related disputes. The use of high-powered firearms has resulted in many deaths and injuries. There has been extensive criminal activity unrelated to the fighting but also involving guns.

KWP was established by a group of local activists in March 2000 with the aim of restoring peace and promoting sustainable livelihoods. KWP has received support from local leaders and others tired of living with constant fear, insecurity, violence and lack of development. Educated leaders have formed the Kup Restoration and Development Authority to help direct the rebuilding work and ensure a sustainable peace. People are now able to move around beyond their own tribal land without fear of attack. Communities have reconciled and are slowly beginning to regenerate. Displaced families are returning. Government officials have started visiting the area after many years of absence to prepare for the restoration of services. As the larger community has begun to mobilize, KWP has continued to work with women on health issues, food production, education and human rights. In August $2003 \mathrm{KWP}$ organized the first of a planned series of surrender ceremonies where local criminals surrender themselves and their weapons before a large audience, including representatives from the provincial government, police and magistracy. There has been no major resurgence of fighting since KWP began its campaign.

There are also various ad hoc community-based initiatives aimed at persuading raskol gangs to disband and assisting former criminals to reintegrate back into the community. Criminal gang surrenders have occurred periodically in different parts of PNG over the years. ${ }^{104} \mathrm{Com}$ munity and church groups often act as brokers, engaging in protracted negotiations with leaders of local gangs. Gang leaders negotiate the conditions of their surrender and abandonment of crime. These are likely to include pleas for leniency in the event of subsequent prosecutions, as well 
as access to vocational training and legitimate income-generating opportunities. A formal surrender agreement is often drawn up and signed by gang members, community representatives, local government officials and the police. The success of such informal strategies is to a large extent dependent on the follow-up support provided.

\section{Policy implications and conclusions}

Efforts to improve the formal justice sector are currently in place, particularly in the area of security sector reform. For instance, overcoming the institutional deficiencies of the police was a major objective of the recent Australian-supported Enhanced Cooperation Program (ECP). The ECP was to entail the deployment of over 200 Australian Federal Police into PNG, as well as significant levels of assistance designed to strengthen other law and justice agencies. However, a decision by the PNG Supreme Court invalidated the immunity provisions applying to Australian police and they were hastily withdrawn. ${ }^{105}$ The Defence Cooperation Program between Australia and PNG has also been working to improve the management of security force armouries. It should be stressed that it is no small task to persuade renegade police and military personnel to forsake their lucrative trade in arms and ammunition under their current working and living conditions.

At this stage in PNG, the most promising prospect for change lies in the informal sector. Formal systems of governance have less reach than the existing alternative forms of governance, due in part to their relatively late arrival into the country. As a consequence, there are many opportunities to tap into the energy and innovation that can be found at the community level, which is largely invisible from the centre and yet manages many of the outstanding problems without any assistance from the state. ${ }^{106}$ Community-based groups tend to deal with problems associated with tribal fighting and gun culture in a more holistic way. Outside efforts should therefore aim to build on the local knowledge and cultural resources available to the groups so that lasting solutions can be reached.

At some level, there needs to be coordination between the state and communities in order to bring together all the stakeholders involved in the process. Below are some brief recommendations for both the formal and informal sectors.

- Destruction of seized weapons. Some weapons confiscated, seized or collected by the police remain in poor storage facilities. Instead of lying loose inside the armoury, police should aim to destroy the firearms to eliminate the risk of recycling them into the wrong hands.

- National legislation reform. Stricter weapons control should be en- 
forced through legislation to regulate the production and proliferation of small arms. Conditions for possessing a licence should be reviewed, and high-powered weapons should be prohibited.

- Ammunition controls. Firearms owners should only be permitted to buy ammunition for the type of firearm attached to the licence. The amount of ammunition should not exceed the established legal limit per year.

- Imported weapons restriction. Imports should require a licence, while exports or shipments within or through the country should require the written authority of the police commissioner.

- Regional cooperation. Cooperative enforcement within the Pacific, under the auspices of the Pacific Islands Forum (PIF), is necessary for the successful reduction of illegal arms trading. Various initiatives have been offered to curb regional security problems, including the issue of small arms, such as the PIF's 1992 Honiara Declaration on Law Enforcement Cooperation, the 2002 Nasonini Declaration on regional security and the 1998 establishment of the Assistance Scheme for Law Enforcement and Legal Agencies (ASLLEA). ${ }^{107}$ These options should be explored thoroughly.

- Alternatives to a buy-back scheme. It is widely known that excombatants choose to cache their best arms for future use, while simultaneously benefiting from the peace dividend. The money can be used to replace their inferior weapons with better-quality guns. Alternative methods of disarmament should be explored, such as an exchange of weapons for a community development project, or the creation of niche industries in the community which can engage young men on return to their villages.

- Improved public awareness and information. Both the state and community-based organizations should raise public awareness of small-arms-related problems, and of any voluntary weapons-surrender programmes that may be available to communities.

Success at this stage in Papua New Guinea cannot be measured by actual numbers of weapons collected in any kind of state-sponsored disarmament programme. It is essential to appreciate the complexity of PNG's gun culture first in order to develop effective strategies which reduce the impact of gun violence. A Peace Monitoring Group commander in Bougainville commented that "weapons disposal is not so much about collecting guns, but about building trust". ${ }^{108}$ Disarmament efforts must therefore be considered as part of a broader commitment to peace and reconciliation, which takes time and patience, as in "untangling or mending a fishing net". ${ }^{109}$ For all their destructiveness, people will continue to resort to the use of arms as long as they are made to feel insecure in the absence of adequate state protection. 


\section{Notes}

1. The former government of Sir Michael Somare (2002-2007) hosted the first National Gun Summit in mid-2005. This was the first representative consultative forum to discuss this issue with a view to developing appropriate national and regional policies. The summit report contained over 200 detailed recommendations and, almost three years later, is still awaiting consideration by the PNG Cabinet. Somare was re-elected in 2007 and remains prime minister.

2. Raskolism is the term commonly used to describe the organization and activities of criminal gangs made up predominantly of teenage boys and young men. These gangs are concentrated in the main urban centres but have also spread to many rural areas.

3. Migdal, Joel (1998) “Why Do So Many States Stay Intact?", in Peter Dauvergne, ed., Weak and Strong States in Asia-Pacific Societies, Sydney: Allen \& Unwin, pp. $11-37$.

4. Approximately 85 per cent of PNG's population continue to live in rural villages, surviving on a combination of subsistence agriculture, fishing and cash cropping.

5. The pidgin term wantok connotes one who speaks the same language (literally, "one talk") and, in popular usage, describes the relations of obligations binding together relatives and members of the same clan, tribal or language grouping.

6. Levantis, Theodore (1997) "Urban Unemployment in Papua New Guinea: It's Criminal", Pacific Economic Bulletin 12(2), pp. 73-84.

7. MacIntyre, Martha (2000) "Major Issues of Law and Order Affecting Women and Children", Discussion Paper, Royal Papua New Guinea Constabulary Development Project Phase III, pp. 1-25.

8. PNG has the lowest human development index and highest human poverty index of 12 Pacific island countries reviewed by the UN Development Programme. See UNDP (1999) Pacific Human Development Report 1999 - Creating Opportunities, Suva: UNDP. In the most recent global Human Development Report, PNG is ranked towards the bottom of the "medium development" category, at 145 out of a total of 177 countries. See UNDP (2007) Human Development Report 2007/8 - Fighting Climate Change: Human Solidarity in a Divided World, New York: UNDP.

9. The 2006 Report on the Global Aids Epidemic states that the epidemic in PNG is growing at a dismaying pace, with HIV diagnoses increasing by about 30 per cent since 1997. An estimated 60,000 Papua New Guineans were living with HIV in 2005, with HIV prevalence estimated at 1.8 per cent nationally. See UNAIDS (2006) 2006 Report on the Global Aids Epidemic, Geneva: UNAIDS, available at www.unaids.org/en/ KnowledgeCentre/HIVData/GlobalReport/Default.asp.

10. Bradley, Christine (2001) "Family and Sexual Violence in PNG: An Integrated LongTerm Strategy. Report to the Family Violence Action Committee of the Consultative Implementation and Monitoring Council", Discussion Paper No. 84, Consultative Implementation and Monitoring Council and Institute of National Affairs, Port Moresby, pp. 1-117.

11. Dinnen, Sinclair (2001) Law and Order in a Weak State: Crime and Politics in Papua New Guinea, Honolulu: University of Hawai'i Press.

12. The alarming spread of inter-group fighting from the rural Highlands to urban centres was one of the most significant findings in the PNG study undertaken as part of the 2006 Small Arms Survey. See Haley, Nicole and Robert Muggah (2006) "Jumping the Gun - Armed Violence in Papua New Guinea", in Small Arms Survey 2006 - Unfinished Business, Geneva and Oxford: Oxford University Press, pp. 165-187.

13. PNG Gossip Newsletter, 16 January 2004, available at www.pnggossip.com/. 
14. PNG and the French territories are the only Pacific states that explicitly recognize selfdefence as a genuine reason for gun ownership. See Small Arms Survey (2003) Small Arms Survey 2003: Development Denied, Oxford: Oxford University Press.

15. From personal accounts in February 2004 and PNG Gossip Newsletter, 6 October 2003, available at www.pnggossip.com/.

16. Alpers, Philip (2004) Gunrunning in Papua New Guinea: From Arrows to Assault Weapons, special report by AusAID and Small Arms Survey, first draft, 12 October, p. 90.

17. McFarlane, John (2001) Ka ho te rangatahi: A Pacific Way to Disarmament, unpublished paper, p. 18.

18. Ibid., p. 19. See also Alpers, note 16 above, pp. 32-34.

19. McFarlane, ibid., p. 24.

20. Ibid., p. 19.

21. Post-Courier (2003) "One Gun for 180", Post-Courier, 23 June.

22. "Policy Information Paper on Gun Control", addressed to Chief Secretary Robert Igara, 15 August 2000.

23. Interview with Philip Moya, provincial administrator, Southern Highlands, 9 February 2004.

24. Interview with Lawrence Stephens, Catholic Bishops Conference of Papua New Guinea and Solomon Islands, 5 February 2004.

25. John Wakon, quoted in Time Pacific 14, 9 April 2001.

26. Alpers, note 16 above.

27. Post-Courier, 16 July 2002.

28. Capie, David (2003) Under the Gun: The Small Arms Challenge in the Pacific, Wellington: Victoria University Press in association with Peace and Disarmament Education Trust, p. 101.

29. "Calls to Disarm PNG Politicians", available at www.news.com.au/common/story page/ $0,4057,5606613 \% 255 \mathrm{E} 401,00 . \mathrm{html}$

30. The National (2004) "Army Weapons Sold to Public, Says Yarka", The National, 12 February.

31. The Sandline affair involved an attempt by Prime Minister Sir Julius Chan in 1997 to defeat Bougainville secessionist rebels by employing mercenaries supplied by a UKbased private military contractor. For details see Dinnen, Sinclair, Ron May and Anthony J. Regan, eds (1997) Challenging the State: The Sandline Affair in Papua New Guinea, Canberra: National Centre for Development Studies, Research School of Pacific and Asian Studies, Australian National University.

32. We are grateful to Colonel Dougal McMillan, Australian Defence Force, and John ToGuata, former assistant commissioner of police, chief of operations in the Ombudsman's Office, for these details.

33. Post-Courier, note 21 above.

34. Harris, Bruce M. (1988) "The Rise of Rascalism: Action and Reaction in the Evolution of Rascal Gangs", Discussion Paper No. 54, Institute of Applied Social and Economic Research, Port Moresby, pp. 1-52.

35. The PNG study for the 2006 Small Arms Survey notes the spread of criminal (gang) violence to rural areas. Just as inter-group fighting has moved to the towns, gang crime has moved to many rural parts. See Small Arms Survey (2006) Small Arms Survey 2006 - Unfinished Business, Geneva and Oxford: Oxford University Press.

36. Post-Courier, 1 December 1997.

37. Dinnen, Sinclair (1993) "Big Men, Small Men and Invisible Women: Urban Crime and Inequality in Papua New Guinea", Australian and New Zealand Journal of Criminology 26, March, pp. 19-34. 
38. Zvekic, Ugljesa and Anna Alvazzi del Frate (1995) Criminal Victimization in the Developing World, New York: Interregional Crime and Justice Research Institute; Zvekic, Ugljesa and Donald J. Weatherburn (1995) Crime and Criminal Justice Information in Papua New Guinea, New York: Interregional Crime and Justice Research Institute.

39. World Bank (1999) Papua New Guinea - Improving Governance and Performance, Washington, DC: World Bank, p. 108.

40. Zvekic and Alvazzi, note 38 above.

41. Small Arms Survey, note 35 above, pp. 174-175.

42. Post-Courier, 22 August 1996.

43. The Bulletin, 21 November 1995.

44. Post-Courier, 23 October 2002.

45. Strathern, Andrew (1977) "Contemporary Warfare in the New Guinea Highlands: Revival or Breakdown?", Yagl-Ambu 4(3), pp. 135-146.

46. Paney, Philip (1973) Report of the Committee Investigating Tribal Fighting in the Highlands (Paney Report), Port Moresby: Territory of Papua New Guinea, Government Printer.

47. The provision reversing the onus was subsequently declared unconstitutional by the Supreme Court in Constitutional Reference No. 3 of 1978. See Papua New Guinea Law Reports, 1978.

48. Small Arms Survey, note 35 above, pp. 172-174.

49. National, 23 January 1997.

50. Capie, note 28 above, p. 92.

51. Post-Courier, 16 January 2002.

52. Post-Courier, 27 November 2002.

53. Extract from Reto, Irene (2003) "The Law and Order Problem in the Enga Province", paper presented at Enga Law and Order Summit, September.

54. Evidence from genealogies suggests that casualty rates were considerably higher where the purpose was to drive people off their land.

55. Dorney, Sean (2000) Papua New Guinea: People, Politics and History Since 1975, Sydney: ABC Books for the Australian Broadcasting Corporation, p. 318.

56. Muke, John D. (1992) "The Wahgi Opo Kumbo: An Account of Warfare in the Central Highlands of New Guinea", PhD thesis, University of Cambridge, p. 255.

57. Burton, John E. (1990) "Tribal Fighting - The Scandal of Inaction", Research in Melanesia 14 , pp. $35-36$.

58. Interview with man from Suma village, Nipa, Southern Highlands province, February 2004.

59. Interview conducted in Suma village, Nipa, Southern Highlands province, February 2004.

60. Burton, note 57 above, p. 37.

61. Garap, Sarah (2004) "Kup Women for Peace: Women Taking Action to Build Peace and Influence Community Decision-Making", State Society and Governance in Melanesia Project Discussion Paper 2004/4, Australian National University, Canberra, pp. 1-16; see also Hinton, Rachael, Michelle Kopi, Angela Apa, Agnes Sil, Mary Kini, Gerry Kai, Yanny Guman and Daniell Cowley (2008) "The Kup Women for Peace Approach to Peacebuilding: Taking the Lead in the Papua New Guinea National Elections", Gender \& Development 16(3), pp. 523-533.

62. Gibbs, Phillip (2003-2004) "A Tale of Two Women: Faith and Destruction", Divine Word Missionaries Magazine, Winter, pp. 2-5.

63. Private communication with an anonymous source, February 2004.

64. Interview with Father Phillip Gibbs, Melanesian Institute, Goroka, February 2004. 
65. Yala, Charles (2002) "Aspects of Conflict in the Contemporary Papua New Guinea Highlands", State Society and Governance in Melanesia Project Discussion Paper 2002/4, Australian National University, Canberra, p. 10.

66. Interview with Father Phillip Gibbs, Melanesian Institute, Goroka, February 2004.

67. Strathern, Andrew (1993) Voices of Conflict, Ethnology Monographs No. 14, Pittsburgh, PA: University of Pittsburgh, Department of Anthropology; Young, Douglas W. (1995) "Resolving Conflict for Gutpela Sindaun: An Analysis and Evaluation of Traditional and Modern Methods of Achieving Peaceful Intergroup Relations among the Enga of Papua New Guinea", PhD thesis, Centre for Conflict Resolution, Macquarie University.

68. Interview with Bishop Douglas Young, Catholic Church, Mount Hagen, February 2004.

69. Standish, Bill (2002) "Electoral Governance in Papua New Guinea: Chimbu Poll Diary", June, available at www.anu.edu.au/melanesia/pngresourcepage.htm; PostCourier, 22 July 2002.

70. Post-Courier (2002) "Gun Terror in Chimbu", Post-Courier, 25 July.

71. The National (2002) "Premier Appeals for Halt to PNG Arms Smuggling", The National, 28 February.

72. May, Ron J. (2006) "Papua New Guinea: Disorderly Democracy or Dysfunctional State?", in Dennis Rumley, Vivian Louis Forbes and Christopher Griffin, eds, Australia's Arc of Instability: The Political and Cultural Dynamics of Regional Security, Dordrecht: Springer, pp. 151-171.

73. Post-Courier (2002) "Aircraft Warned of No-go Area", Post-Courier, 14 June.

74. Forbes, Mark (2002) "PNG Politicians Smuggle Guns", The Age, 20 July.

75. Ibid.

76. These views were expressed by participants at the Papua New Guinea Election 2007 Workshop at the Australian National University, Canberra, 5-7 February 2008.

77. Toft, Susan, ed. (1985) Domestic Violence in Papua New Guinea, Monograph 3, Port Moresby: Law Reform Commission; Toft, Susan, ed. (1986) Domestic Violence in Urban Papua New Guinea, Occasional Paper No. 19, Port Moresby: Law Reform Commission; Toft, Susan, ed. (1986) Marriage in Papua New Guinea, Monograph 4, Port Moresby: Law Reform Commission; Toft, Susan and Susanne Bonnell, eds (1985) Marriage and Domestic Violence in Rural Papua New Guinea, Occasional Paper No. 18, Port Moresby: Law Reform Commission.

78. Bradley, note 10 above, p. 11.

79. Government of Papua New Guinea and UNICEF (1998) Children, Women and Families in Papua New Guinea: A Situational Analysis, Port Moresby: GoPNG and UNICEF, p. 144.

80. Royal Papua New Guinea Police Constabulary (2000) National Crime Summary, January-March.

81. Meier, Sr Gaudentia (2003) Report on Family and Sexual Violence in the SHP, Port Moresby: PNG Family and Sexual Violence Action Committee.

82. Interview with Frank Kasahya, Tari Hospital, 11 February 2004.

83. Interview with schoolteacher, Tari primary school, February 2004.

84. Personal accounts of women in the Southern Highlands and Port Moresby, February 2004.

85. Various interviews conducted at hospitals in February 2004.

86. Interview with prison officer, Ialibu Prison, Southern Highlands, February 2004.

87. Interview with Sr Gaudentia Meier, Mendi, February 2004.

88. Meier, note 81 above.

89. Government of Papua New Guinea and UNICEF, note 79 above, p. 140. 
90. The authors thank David Kane, senior medical clerk at Tari Hospital, for access to these records (February 2004).

91. The authors thank Dr James Kintwa, CEO, Hagen Hospital, for access to these records (February 2004).

92. National Research Institute and Justice Advisory Group (2005) The Port Moresby Community Crime Survey, Port Moresby: NRI and JAG.

93. Royal Papua New Guinea Constabulary, Administrative Review Committee (2004) "Draft Report", p. 40.

94. Standish, Bill (1994) "Papua New Guinea: The Search for Security in a Weak State", in Alan Thompson, ed., Papua New Guinea: Issues for Australian Security Planners, Canberra: Australian Defence Studies Centre, Australian Defence Studies Academy, p. 70.

95. Mapusia, Mike (1986) "Police Policy towards Tribal Fighting in the Highlands", in Louise Morauta, ed., Law and Order in a Changing Society, Monograph 6, Canberra: Department of Political and Social Change, Australian National University, p. 65.

96. Papua New Guinea Department of Attorney General (1999) Brief to the Minister for Justice, Honourable Kilroy K. Genia, M.P., Port Moresby: Department of Attorney General, p. 26.

97. Standish, note 94 above, p. 80.

98. Human Rights Watch (2004) Making Their Own Rules: Police Beatings, Rape, Torture of Children in Papua New Guinea, New York: Human Rights Watch.

99. Ibid. A follow-up report was published in 2006: Human Rights Watch (2006) Still Making Their Own Rules: Ongoing Impunity for Police Beatings, Rape, and Torture in Papua New Guinea. New York: Human Rights Watch, available at http://hrw.org/reports/ 2006/png1006/png1006webcover.pdf.

100. McLeod, Abby (2003) Gender Analysis of Law and Justice Sector Agencies, Port Moresby: Law and Justice Sector Program.

101. Rumsey, Alan (2000) "Women as Peacemakers - A Case from the Nebilyer Valley, Western Highlands, Papua New Guinea", in Sinclair Dinnen and Allison Ley, eds, $R e-$ flections on Violence in Melanesia, Sydney: Hawkins Press and Asia Pacific Press, pp. $139-155$.

102. Garasu, Sr Lorraine (2003) "The Role of Women in Promoting Peace and Reconciliation", in Andy Carl and Sr Lorraine Garasu, eds, Weaving Consensus: The Papua New Guinea-Bougainville Peace Process, London: Conciliation Resources, also published in Accord 12, 2002, pp. 28-31; Savoana-Spriggs, Ruth (2003) "Bougainville Women's Role in Conflict Resolution in the Bougainville Peace Process", in Sinclair Dinnen, Anita Jowitt and Tess Newton Cain, eds, A Kind of Mending - Restorative Justice in the Pacific Islands, Canberra: Pandanus Books, pp. 195-213.

103. Summarized from Garap, Sarah (2004) "Kup Women for Peace: Women Taking Action to Build Peace and Influence Community Decision-Making", State Society and Governance in Melanesia Project Discussion Paper 2004/4, Australian National University, Canberra, pp. 1-16.

104. Dinnen, Sinclair (1995) "Praise the Lord and Pass the Ammunition - Criminal Group Surrender in Papua New Guinea", Oceania 66(2), pp. 103-118.

105. See McLeod, Abby and Sinclair Dinnen (2007) "New Directions in Australian Regional Policing", in Andrew Goldsmith and James Sheptycki, eds, Crafting Transnational Policing - Police Capacity-Building and Global Policing Reform, Oxford and Portland: Hart Publishing, pp. 295-328.

106. Hegarty, David and Pamela Thomas, eds (2005) "Effective Development in Papua New Guinea", Development Bulletin 67, April, pp. 1-129, available at http://devnet. anu.edu.au. 
107. Details can be viewed on the PIF website at www.forumsec.org/_resources/article/files/ ASLLEA_GUIDELINES_2006.pdf.

108. Cited in Small Arms Survey, note 14 above, p. 100.

109. Pirie, Barbara (2000) "The Complexity of Ethnic Conflict in Fiji: Finding Effective Interventions", Development Bulletin 53, October, pp. 53-57. 


\title{
"Now they have guns, now they feel powerful" - Gender perspectives on small-arms violence in Timor-Leste
}

\author{
Saleh Abdullah and Henri Myrttinen
}

On the surface of things, it looked like a replay of the bad days of September 1999: smoke rising from burning homes; tens of thousands of men and women, children and elderly, huddling under makeshift tents in IDP (internally displaced persons) camps; bands of armed young men roaming the streets; international peacekeepers doing little more than securing the international airport for evacuations; the constant pop-poppop of small-arms fire echoing around the capital Dili and in the surrounding hills. In late May 2006 Timor-Leste, the "success story" of the international community's nation-building efforts, was on the brink of imploding. Yet there was one important difference from 1999: this time it was not militias acting as the proxies of the occupying Indonesian armed forces that were terrorizing the population. This time it was local gangs and members of the disintegrated East Timorese security forces who were wreaking havoc. At the time of writing, almost two years later, despite the arrival of the new International Stabilization Force (ISF) and additional UN Police (UNPOL), gang-related violence is still a daily occurrence and the country remains politically unstable, with mutinying soldiers in February 2008 shooting and critically wounding President José Ramos Horta and only surrendering after a two-and-a-half-month manhunt. What had gone wrong?

This chapter is based on a review of existing literature and the study of relevant documents from East Timorese, Indonesian and UN sources, security force reports, reports by human rights and other non-governmental organizations (NGOs) and interviews and impressions collected by

Sexed pistols: The gendered impacts of small arms and light weapons, Farr, Myrttinen and Schnabel (eds), United Nations University Press, 2009, ISBN 978-92-808-1175-9 
the authors during numerous visits to West Timor and Timor-Leste between 1999 and 2008. Both authors have also been actively engaged with East Timorese civil society actors since the 1990s and draw in part on these experiences.

Gender, violence, power and the role of small arms and light weapons (SALW) have come together in a violent, tragic way, threatening to undermine the efforts of the Timorese to build a stable, equitable society in Timor-Leste after decades of war.

From 1975 to 1999 Timor-Leste was engulfed in an exceptionally bloody war of independence, one in which an estimated third of the population of the territory lost their lives. Aside from shelling by Indonesian navy ships and bombing runs by the Indonesian air force, the conflict was carried out almost exclusively with SALW. The main parties involved in the conflict were the East Timorese pro-independence Falintil (Forças Armadas de Libertação Nacional de Timor-Leste) guerrillas; the Indonesian armed forces ABRI (Angkatan Bersenjata Republik Indonesia), which were renamed TNI (Tentara Nasional Indonesia) in 1999 when the police force and armed forces were separated; and pro-Indonesian militias established from approximately mid-1998 onwards and acting as proxies of the Indonesian armed forces. Following the militia violence in the run-up to, during and in the aftermath of the referendum on independence in 1999, the territory came under the administration of the United Nations. It (re)gained its independence in May 2002 as the Democratic Republic of Timor-Leste (República Democrática de Timor-Leste - RDTL).

\section{Historical background}

When Timor-Leste (re)gained its independence at midnight on 20 May 2002 , the citizens of what was then the world's newest nation took a moment to commemorate the violent path to national independence dating back to the Portuguese "Carnation Revolution" in 1974. Following the ousting of the fascist dictatorship of Salazar and Caetano by left-wing officers, Portugal began a rapid, even hasty, decolonization process. TimorLeste, which had been - mais ou menos - under Portuguese control since the sixteenth century, did not experience a sustained armed struggle for independence like that in Portugal's African colonies, although the nascent independence movement was influenced politically by its counterparts in Angola, Guinea-Bissau and Mozambique.

But, as was the case in Portugal's former African colonies, Timor-Leste was ill prepared for independence and found itself quickly caught up in the web of Cold War superpower politics. During the short period of de- 
colonization, fractures emerged within the East Timorese political landscape which eventually led to a brief civil war between the left-leaning Fretilin (Frente Revolucinária de Timor-Leste Independente) and the more conservative UDT (União Democrática Timorense). Fretilin and its armed wing, the Falintil, emerged victorious. Indonesia played a destabilizing role in this period.

Fearing an impending Indonesian invasion, Fretilin declared the territory independent on 28 November 1975. Nine days later, on 7 December, Indonesian paratroopers landed in Timor-Leste after receiving a green light from the visiting US President Ford and Secretary of State Kissinger. Australia also indicated its preference for an integration of the territory into Indonesia. One of the driving forces behind this invasion was a fear in Washington, Canberra and Jakarta of a new, leftist "domino" falling in Southeast Asia.

The Indonesian armed forces, ABRI, met with resistance from the $\mathrm{Fa}$ lintil. The initial phase of the fighting, which lasted until 1979, was the bloodiest. Estimates on the number of Timorese killed vary, but the conservative estimate of the East Timorese Truth and Reconciliation Commission is that around 108,000 Timorese were killed in this phase. ${ }^{1}$ The guerrilla war of the Falintil and the atrocities of the ABRI continued at varying levels of intensity until 1999 . Sexualized violence against female and male civilians was a common feature of the conflict, the perpetrators being mainly members of the Indonesian security forces, although there were also Timorese perpetrators.

Following the downfall of the Suharto dictatorship in 1998, the Indonesian government announced that a UN-supervised referendum on the future of Timor-Leste was to be held in 1999, with the Timorese people given the choice between special autonomy as a part of Indonesia or full independence. The run-up to the referendum on independence saw a new quality of violence, with the Indonesian armed forces, now renamed TNI, setting up and arming Timorese pro-Indonesian militias as proxies. These militia groups were established across the territory and enjoyed the overt and covert support of the Indonesian administrative structures as well as of the security forces. According to the 5 May 1999 agreement that outlined the way the referendum would be carried out, the Indonesian security forces were tasked with ensuring that the ballot could take place in a peaceful environment. While the Falintil voluntarily withdrew to cantonment areas and did not engage in the fighting, the Indonesian security forces showed little inclination to stop the numerous massacres, individual killings, rapes, burnings and lootings carried out by the militias in the run-up to the referendum.

Immediately after the announcement of the result of the ballot - in which 78.8 per cent voted in favour of independence - the militias, sup- 
ported by the TNI and the paramilitary mobile brigade of the Indonesian police (Brigade Mobil - Brimob), began an unprecedented rampage. A common conservative estimate is that around 1,500 unarmed civilians died in this phase. Utilizing a "scorched earth" policy, the infrastructure was systematically destroyed. An estimated 70 per cent of buildings and houses in the territory were razed. ${ }^{2}$

Over a third of the population, around 250,000 people, were forcibly deported, mainly to militia-run camps in West Timor. There have been persistent reports of serious human rights abuses, in particular sexualized violence, in these camps. In addition to rapes, young women have been forced into sexual slavery and/or marriage with militia members. Some of these women have not returned to their communities. ${ }^{3}$

The international outcry over the violence after the August 1999 referendum led to the deployment of an Australian-led UN peacekeeping force (International Force for East Timor - INTERFET) in September 1999 and the establishment of a temporary UN administration (UN Transitional Administration in East Timor - UNTAET). UNTAET administered the territory until its independence in 2002. The follow-up mission, the UN Mission of Support in East Timor (UNMISET), ended on 20 May 2005. This was followed by a much-reduced mission, the UN Office in Timor-Leste - UNOTIL. After the flaring up of violence in April/May 2006, a further UN mission was agreed upon, the UN Integrated Mission in Timor-Leste (UNMIT).

The years immediately following independence were marked by economic and social instability as well as a growing political crisis. Events came to a head in March 2006, when the government sacked 600 members of the country's armed forces who had been protesting against their working conditions, alleging discrimination based on their geographical origin. After the sacking, firefights erupted between the rebellious troops and pro-government forces, between police and army units and between police units and armed gangs. A key role was played by the renegade Major Alfredo Reinado, who was subsequently arrested but escaped from prison before being put on trial. The most detailed examination of these events was by a UN Commission of Inquiry in late $2006 .{ }^{4}$

One defining feature of the wave of violence in 2006 was the emergence of an east-west divide, between East Timorese of loro mono or kaladi (western ${ }^{5}$ ) and loro sa'e or firaku (eastern) descent. This division will be examined in more detail below.

Australian-led international peacekeeping forces (ISF) arrived in Timor-Leste in late May 2006 followed by additional UNPOL, including Malaysian, Pakistani and Portuguese formed police units (FPU). Units of the ISF and FPU have been involved in fighting armed gangs and mutineer soldiers. 
On 11 February 2008 one of the leaders of the disgruntled soldiers, Major Alfredo Reinado, possibly attempted a coup d'état. Major Reinado and one of his supporters were killed, while President Ramos Horta was seriously wounded in circumstances which at the time of writing remain unclear. The remaining mutineers fled to the mountainous west of the country, surrendering on 30 April 2008 after a two-an-a-half-month manhunt.

\section{SALW in Timor-Leste}

During the struggle for independence, both the Falintil and the militias used SALW exclusively. More advanced weapons systems were only used by the ABRI/TNI and later by INTERFET and the ISF. The Indonesian forces engaged in aerial bombings of the territory and shelling it from the sea, especially during the initial years of the conflict.

The majority of Falintil's SALW came from old Portuguese stocks taken over during the 1975 civil war, weapons captured from ABRI/TNI and weapons purchased from members of the Indonesian security forces. Falintil weapons purchases were conducted mainly by the underground civilian resistance, who on occasion used minors as buyers and couriers of the purchased arms. Pinto and Jardine quote prices of around US $\$ 0.80$ per round of ammunition and around US\$12 for a hand grenade. ${ }^{6}$ The militias were mainly armed with machetes, katana swords, spears and rakitan at first, but higher-powered SALW (mainly M16, SKS and AK-47 assault rifles) were handed to them by members of the Indonesian security forces closer to the date of the referendum and in the post-referendum wave of violence. The authors did not come across reports of female militia members who used arms; most were employed as administrative or support staff.

The newly formed national armed forces, the F-FDTL (Falintil-Forças de Defesa de Timor-Leste), are also equipped solely with SALW, with the exception of two small patrol boats. The national police force, PNTL (Policía Nacional de Timor-Leste), is equipped with handguns and riot gear (Table 7.1).

An assessment of the new Timorese security forces on behalf of the United Nations by a team from Amnesty International found serious deficiencies in the way the force members are trained to use weapons, how the weapons are stored and handled and what the rules are for their use, especially in the case of crowd-control situations. Both the F-FDTL and PNTL have used firearms to disperse demonstrators, resulting in civilian deaths. An indication of the lack of transparency and control can be seen in the fact that the exact number of SALW supplied to the security forces 
Table 7.1 Estimated numbers of SALW supplied to or procured by the TimorLeste security forces

\begin{tabular}{|c|c|c|c|c|}
\hline Type of weapon & $\begin{array}{l}\text { Number of } \\
\text { weapons } \\
\text { supplied }\end{array}$ & Produced in & Supplied by & Supplied to \\
\hline M16A2 & 1,200 & USA & USA & F-FDTL \\
\hline M203 & 75 & USA & USA & F-FDTL \\
\hline $\begin{array}{c}.45 \text { calibre Colt } \\
\text { handguns }\end{array}$ & 50 & USA & USA & F-FDTL \\
\hline Minimi & 75 & Belgium & Belgium & F-FDTL \\
\hline $\begin{array}{l}\text { FN Herstal "light } \\
\text { machine guns" }\end{array}$ & 129 & Belgium & Belgium & F-FDTL \\
\hline Glock pistols & $3,500-4,000$ & Austria & $\mathrm{N} / \mathrm{A}$ & PNTL \\
\hline Steyr assault rifles & 180,200 or 400 & Austria & Malaysia & PNTL \\
\hline $\begin{array}{l}\text { Heckler \& Koch } \\
\text { HK33 }\end{array}$ & 200 & Germany & N/A & PNTL \\
\hline FNC assault rifles & 88 or 200 & Belgium & Belgium & PNTL \\
\hline F-2000 & 7 or 20 & Belgium & Belgium & PNTL \\
\hline Mossberg shotguns & 200 & USA & USA & PNTL \\
\hline
\end{tabular}

is not known. Thus the figures in Table 7.1, based on various sources, are not precise.

No statistics on civilian SALW ownership exist, yet based on interviews carried out by the researchers it would seem that the majority of East Timorese households do not have handguns. However, what are classified as "offensive weapons" by UNTAET Regulation $2001 / 5,{ }^{7}$ the key regulation on SALW later also adopted by the RDTL government, such as machetes, spears and swords, are widespread, especially in rural areas. Most handguns are either home-made rakitan or ceremonial weapons, such as old colonial-era rifles. Given the relatively high price of modern SALW compared to the low average income, most modern weapons will either have been "taken home" by ex-combatants and off-duty members of the security forces or acquired illegally. Apart from "dual-use" offensive weapons such as machetes, which are mainly used as everyday tools, the handling of weapons has traditionally been viewed as a male prerogative. The handling of weapons by female Falintil fighters was generally seen as an abnormal situation caused by the exceptional conditions of an all-out war.

\section{Violence and the socially constructed meanings of SALW}

SALW are viewed very differently by those wielding them and those whose lives and livelihoods are threatened by persons bearing arms. We 
embarked on this research with the expectation that attitudes would vary greatly between combatants and non-combatants, males and females, urban and rural dwellers, across age groups, and depending on the social and political backgrounds of individuals.

From the point of view of an unarmed victim, whether female or male, the display and threat of small arms underscores their subjugated position and lack of power vis-à-vis the armed perpetrator. This display of power and powerlessness is at its starkest when SALW are used in conjunction with sexualized violence against women. In Timor-Leste, as elsewhere, sexualized violence not only exploits power differences between gun users and their victims but also erodes the power of those who, according to tradition, are supposed to protect women, i.e. the village community, the family, husband, mother, father or brother.

In the Timorese conflict it has been mainly the ABRI/TNI and the militias who have been misusing SALW for purposes of intimidating the local population, although as of late disgruntled ex-Falintil and other groups have begun using SALW for social, economic or political gains. This need not involve the actual display or use of weapons: the insinuation that these groups might conceivably have weapons stashed away is enough to give them the necessary leverage over unarmed civilians.

East Timorese combatants, whether they were warriors of the precolonial and colonial eras, Falintil, militia or members of the various violence-prone gangs, have had the tradition of carrying amulets said to be lulik (sacred or possessing magical powers) which give the bearer supernatural powers and protection. Older traditional weapons do at times fall under this category. Similar phenomena can be observed in Java, where ancient weapons might be seen as containing supernatural powers, and in the eastern islands of Indonesia, where cannons and firearms have gained ritual importance. Modern weapons, however, do not seem to have been invested with any special significance above and beyond the "bond" created between the combatant and the weapon, which is fostered in the vast majority of armed forces, be they state or non-state actors. This bond often takes on gendered and overtly sexualized connotations. ${ }^{8}$

\section{Post-conflict violence and SALW}

The numbers of violent incidents involving firearms in Timor-Leste fell dramatically between the arrival of the INTERFET forces in 1999 and the beginning of the crisis of April/May 2006. In the post-conflict situation it has been more common for non-firearm offensive weapons to be used, with the machete and slingshot-fired steel arrows (rama ambon) being the weapons of choice. When firearms are used, they tend to be 
rakitan. No reliable statistics are available, but a sizeable majority of these acts of violence would seem to be intimate femicide, domestic and/ or sexualized violence. ${ }^{9}$

The initial situation in the West Timorese IDP camps was somewhat different. Having initially retained their firearms, the militias used them for murder, rape, theft and intimidation. A number of clashes between militias and UN peacekeepers took place on the border, resulting in several deaths. In the most serious case, a militia-led mob in Atambua in 2000 killed three UNHCR workers, who, in a cruel twist of irony, had been supplying humanitarian aid to these very same East Timorese IDPs.

An important aspect of SALW and insecurity in the Timorese postconflict situation is the implicit threat conveyed by their display or the assumption of their presence rather than their active use. ${ }^{10}$ The implied, potential violence of a gun is usually enough to force the victim to succumb to the will of the perpetrator in a society that has been deeply traumatized by three decades of violence and where rumour is often the main source of information. It should be noted that not only SALW are used as a tool of power projection and intimidation but that also paramilitary dress and martial gestures (e.g. quasi-military parades) are used to this effect.

In the aftermath of the 2006 breakdown of the Timorese security forces, several thousand of the newly purchased firearms and almost all the ammunition from the PNTL stocks went missing. According to a UN inquiry report six months after the outbreak of violence:

219 PNTL weapons remain outside PNTL custody and control. These weapons comprise 190 Glock $9 \mathrm{~mm}$ pistols, 13 Steyr semi-automatic assault rifles, 10 HK33 semi-automatic assault rifles, 2 FN-FNC semi-automatic assault rifles and 4 12-gauge shotguns [...] additionally 45 M16 weapons, three FN-FNC semi-automatic rifles, three SKS semi-automatic rifles and two Uzi weapons previously within the custody and control of F-FDTL are missing. ${ }^{11}$

An undisclosed number of SALW have since been recovered by UNPOL and the ISF, with unofficial UNMIT estimates placing the number of unaccounted SALW at the end of 2007 at several dozen, including those in the hands of the late Major Reinado and his supporters. At least some of these weapons have ended up in the hands of the gangs, though they prefer to use "traditional" offensive weapons which are not fully banned by the UNTAET (2001) firearms regulation. However, given the fact that the East Timorese security forces have been heavily infiltrated by gang members, the gangs continue to have access to SALW which are officially under the control of the security forces. Thus the threat of 
gun violence and the instability and insecurity it brings, especially to women, will remain a major problem for Timor-Leste for years to come. The spectre of the disenchanted young men becoming PNG-style raskols looms large (see also Chapter 6).

\section{Disarmament and weapons control}

The disarmament and demobilization of the militia groups that fled to West Timor were the responsibility of the Indonesian security forces. They have not displayed much enthusiasm in carrying out this task, and armed militia members who have been caught in Timor-Leste have instead been disarmed by international peacekeepers.

The ownership, import, export, display and use of firearms, ammunition, explosives and offensive weapons (such as swords, machetes, knives and spears) in Timor-Leste are regulated by legislation (UNTAET Regulation 2001/5) which was introduced by UNTAET in 2001. These regulations have been taken over by the RDTL government. Although the Falintil was for the most part disarmed by INTERFET, is very likely that stockpiles of SALW and ammunition set up by the guerrillas during the 24-year campaign still remain spread out over the country, and that these may be used by rogue groups. Rumours of these stockpiles abound, but according to UN sources the peacekeeping forces (PKF) and UNPOL which have been called in to investigate have not been able to find any major caches. This of course does not mean that weapons are not being stored, a fact acknowledged by the authorities. The same applied to rumours of weapons being smuggled into Timor-Leste from West Timor. Home-made rakitan are still relatively common. ${ }^{12}$

A new phenomenon in post-conflict Timor-Leste has been the proliferation of replica handguns, which has been the cause of some alarm among UNPOL and the PKF as well as the local population. They look real enough to have been perceived as a threat by communities, which have repeatedly called in UNPOL and the PKF for help. The presence of smuggled replicas attests to the ease of smuggling across the porous border. As a PKF officer pointed out, "If replica weapons can be smuggled in, why not real ones?"13 One constraining factor in new weapons purchases by individuals is the lack of capital in Timor-Leste in general. Unfortunately the authors are unable provide any data on collected arms previous to the 2006 violence - despite repeated requests for such data to East Timorese and UN authorities. This may be due to a lack of shared data, from INTERFET to UNTAET and on to subsequent UN missions and the relevant East Timorese authorities, or may even attest to a total lack of these data. 


\section{Social constructions of gender in Timor-Leste}

\section{Gender ideologies in East Timorese society}

Both Timorese and outside observers have tended to characterize traditional Timorese society as being patriarchal. Undoubtedly men do take a privileged place in society, but the important positions taken by women in society should not be overlooked. Although most East Timorese communities are traditionally patrilinear in terms of kinship, there have also been strong matrifocal traditions and some communities follow matrilinear kinship and ownership patterns. ${ }^{14}$ Thus, while especially in the public sphere society is male-dominated, the influence of women, especially in the private sphere, should not be overlooked. Using a simplistic notion of patriarchy obscures the various and complex roles played by women and men in various positions of social, political and economic power in either promoting or discouraging violence.

Traditional Timorese society and its views on gender roles have not been left untouched by the past 30 years. Portuguese and Catholic influences, the ideals of equality inspired by socialism and espoused by Fretilin, Indonesia's modernization programme, increasing urbanization, the influences of globalized Western and Indonesian popular cultures brought in by the media, returning exiles, the UN and international NGO community and students studying in Indonesia, and above all the cataclysmic violence of the war have all combined to challenge, modify, erode or reinforce through backlash traditional notions of genderappropriate behaviour.

Arguably, the greatest impact has been the Indonesian occupation, which was the formative period in the lives of most East Timorese. Indonesian occupation brought with it oppression and resistance, but also compulsory education, a new common language and an opening up of the territory to the impacts of globalization. Ironically, given the prominent role of the Catholic Church in the resistance movement, it was also the Indonesian authorities with their insistence on the need to belong to an officially recognized religion which brought the Timorese en masse into the arms of the Catholic Church.

Given the conflicting and powerful outside influences of the past three decades, many traditional notions have been diluted or disappeared altogether, while others have proven more resistant to change. In traditional East Timorese society ${ }^{15}$ during the long Portuguese colonial period, gender roles were strictly circumscribed, with men given more political, economic and social clout than women. A "sense of ownership of women" by men was and in part still is also reinforced by the bride price or dowry (barlaki) system which is still being followed by many East Timorese 
communities. The price system is differentiated geographically and along class lines, with women from certain regions (e.g. Los Palos) and from certain families (e.g. liurai families) seen as necessitating a higher bride price. Especially in the early years of the struggle, when much of the territory and population was under their control, the Falintil initially sought to promote gender equality based on socialist ideals. This involved campaigning, among other things, against polygamy and the barlaki system. As the armed resistance came under increased military pressure from the Indonesian armed forces, these educational campaigns ended. Women fighting in the Falintil ranks have pointed out that there was also a gap between the theoretical promulgations of gender equality and the actual practice in the field. ${ }^{16}$

While women fought in the ranks of the Falintil and supported them logistically, the heroes and icons of Timorese resistance were male. These were both local, such as Nicolau Lobato, Sahe and Xanana Gusmão, and imported, such as Che Guevara, Bob Marley and Nelson Mandela. They were idolized in street graffiti and on banners, with the idolization of imported icons acting as a way of showing clandestine support to the resistance. Bob Marley, for example, was likened to the Falintil guerrillas, who also often had long, "natty" hair. The late Major Reinado successfully drew on this imagery, becoming at least for a while a kind of youth idol.

Both the transitional UN administration and the government of the Democratic Republic of Timor-Leste have made sustained efforts at gender mainstreaming, supported by the presence of local and international NGOs. Together with the UNMIK mission in Kosovo, the UNTAET mission was the first to have a Gender Affairs Unit and a gender mainstreaming policy. In spite of these efforts and the general perception as having been exceptional in terms of gender mainstreaming, the actual impacts of the UN missions were relatively modest. ${ }^{17}$

Together with the new Timorese administration and civil society organizations, the UN missions and international NGOs have created new economic, social and political spaces for East Timorese women, who had been marginalized in the public sphere. Although these spaces are still relatively small - e.g. in spite of the gender mainstreaming efforts 74 per cent of the newly elected parliament members and 87 per cent of local staff of the UNMISET mission were men - there was a general feeling in Timor-Leste that the immediate post-conflict situation benefited women more than men. Unfortunately, in a climate of un- or under-employment, this led to increased tensions between women workers and their husbands, who are jealous of the non-traditional role of a female breadwinner or feel threatened in their masculinity if they are not able to fulfil their perceived duties as men. 
The international presence has also had an unintended "collateral" effect in gender relations, and particularly in freedom of sexual expression. A nascent gay, lesbian, bi- and transsexual scene has developed, although still keeping a low profile.

The more liberal post-occupation atmosphere and the support of foreign funding agencies also allowed new women's and men's movements to emerge. These have taken up themes previously not discussed in society, such as rights of sexual minorities, gender-based sexual violence or trafficking, and worked with marginalized groups such as sex workers. Some of these, such as Alola, Fokupers and ETWave, Rede Feto and Asociação Mane Contra Violencia (Association of Men Against Violence), seek to redefine prevalent notions of gender roles.

\section{Masculinity and violence}

In many of our interviews with both Timorese and international observers, the issue of violence, especially domestic violence, perpetrated by Timorese men was characterized as being part of a "Timorese culture of violence". Although cultural factors undoubtedly shape both a society's and an individual's views on the legitimacy of the use of violence, placing the blame for violence solely on culture is an unsatisfactory, albeit easy, way out. On the one hand, it leaves out other factors, such as power and class relations. On the other hand, it also presupposes a monolithic culture, one which "prescribes that [people] would behave in a certain way because of their culture, rather than seeing culture as offering a vast repertoire of actions". ${ }^{18}$

Traditionally, expressions of masculinity in Timorese society have been tied to men's potential to use violence, if only at a symbolic level. At puberty, attaining a fighting cock has traditionally been seen as a rite of passage to manhood. It is, however, worth remembering that, as in other cultures in the region, conflict resolution or avoidance rather than violent and public settling of disputes has been an important part of Timorese culture. According to Hicks, ${ }^{19}$ rape was traditionally not seen as primarily a crime against the female victim but rather against her husband or, in the case of unmarried women, against her father or brother. Rape of males is not mentioned. Indeed, the issue of male-to-male sexual violence is still very much a taboo topic in East Timorese society.

Both Timorese and Indonesian observers have argued that the militarization of society, and especially of males, during the Suharto dictatorship, through both state indoctrination and the 25 years of war, has created generations of men who feel that violence is the only tool at their disposal to confront and attempt to solve problems, whether of a personal, social or political nature. 
The social, economic and personal dimensions of male violence echo experiences from other countries, such as the examples of Haiti, Uganda and Papua New Guinea outlined in this book, where young males resort to violence in order to gain the prestige or status that they do not seem to be able to gain through other means. This can be seen as a kind of violent "protest" masculinity, to borrow a term from Connell. ${ }^{20}$ Many men, especially the young and the unemployed - the average age in Timor-Leste is 18 years and unemployment levels are high - have been drawn to violent enactments of masculinity in the absence of other, less destructive, alternatives.

One very visible manifestation of this phenomenon prior to the 2006 violence could be seen in the martial arts groups (MAGs) and ritual arts groups (RAGs) which mushroomed around the country in the immediate post-independence period. The difference between the two categories of groups is that the MAGs draw their inspiration from "imported" martial arts such as silat, karate or kung fu while the RAGs draw on Timorese rituals and traditions. These groups seemed to embody all that is uncertain in the lives of young East Timorese males: a PKF officer described them as displaying a mixture of "naivité and Machiavellianism". ${ }^{21}$ These groups have been a source of repeated instability, with riots erupting in conjunction with their gatherings well before the 2006 crisis. Rumours circulated of MAGs and RAGs being manipulated by one political group or another, and of their having been involved in the large-scale riots in Dili in December 2002 and in subsequent acts of possibly politically orientated violence, perhaps in collusion with discontented ex-Falintil such as the Sagrada Familia.

In addition to MAGs and the RAGs, the spring of 2004 saw a return of an old phenomenon, the "ninjas". The "original" ninjas were death squads organized by the Indonesian special forces, Kopassus, who, dressed in black, would go after suspected independence activists in urban areas in the mid-1990s. ${ }^{22}$ "Ninja" violence has also taken place in other parts of Indonesia, such as in East Java. The term is used for murders and acts of violence committed by phantom perpetrators who move stealthily at night and are often rumoured to be linked to the security forces. The 2004 ninja phenomenon started with several burglaries and "ninja sightings" in the border area close to West Timor. Fear of ninjas quickly spread to Dili, where in May/June 2004 roadblocks were set up at night and paramilitary police together with Portuguese PKF carried out extra nocturnal patrols. ${ }^{23}$ Rumours abounded as to who was behind the ninjas - ordinary criminals, militias from West Timor, ex-Falintil, ex-Kopassus or perhaps the security forces themselves, who may be stirring fear in an attempt to create a task for themselves. The ninja scare disappeared, however, as quickly as it emerged, leaving behind a lingering feeling of insecurity in society. 
In the light of these developments, the emergence of gangs of armed, young, angry men burning and looting in Dili in May 2006 and rumours of their links to one political group or another did not come as a complete surprise.

An initial defining feature of the meltdown of the security forces and the communal violence which followed was that regional allegiance with origins in either the east (loro sa'e) or the west (loro mono) became the dividing line. The conflicting allegations between "easterners" and "westerners" accusing each other of having gained more from the postindependence situation at the expense of the other group took place in a situation where the already poor state of the country's economy had become gradually worse, as testified by the UNDP annual report in $2006 .{ }^{24}$ The contest for limited jobs, such as those in the security forces, was intense and was seen as a "zero-sum" game. Large sections of East Timorese society were and are living below the "dollar-a-day" poverty limit. Especially those living in the peri-urban areas around Dili, in Becora, Comoro, Delta or Bairo Pite, who have left their traditional villages in the countryside to seek - but not find - a better life in the capital city, feel marginalized. Not surprisingly, it has been these areas which have been the breeding ground for the youth gangs, where frustrated and marginalized young men vent their anger at each other, claiming that the "others", hailing from another part of the country, have had the better deal. The east/west divide became an easy identity marker for these gangs. This divide, however, melted into the background almost as quickly as it emerged, with new political and economic "justifications" being given for the continued violence. While much of the violence has been perpetrated by marginalized young men, it should be kept in mind that many of the gang leaders are actually members of the small middle and upper classes, and that the gangs do enjoy a considerable degree of political backing from the élite. ${ }^{25}$

The common denominator between all of these groups is the fact that the perpetrators are males who are ready to resort to violence - which is to a varying degree organized - to reach whatever economic, social or political gain they may be seeking.

\section{Gender politics within the Falintil}

Over the years, the Falintil developed an autochthonous "warrior ethos", blending socialism, Portuguese and Catholic influences and traditional Timorese concepts. While the combatants were overwhelmingly male, some women were also armed. The majority of the women, however, supported the fighters in non-combatant duties. These included roles such as acquiring and transporting supplies and ammunition, cooking, 
cleaning and supplying medical services. Women also acted as estafetas or couriers, conveying messages between the Falintil fighters and the civilian "clandestine front" which was active in the urban areas.

Women in the Falintil formed their own organization, the OPMT (Organização Populer da Mulher Timorense), and have their own veterans' organization. Falintil is also known to have used under-age volunteers in the early years of its campaign. There is no evidence of minors being forced to join. In spite of the existence of the OPMT and women's participation at all levels of military and civilian resistance, the role of women in the resistance has been publicly subordinated to that of men. Women's role in the armed struggle has not been properly acknowledged either by the new Timorese authorities or by the international community. This phenomenon is comparable to post-conflict situations in other countries. As Siapno points out, however, concentrating on women's participation (or lack thereof) in modern, organized and armed political movements such as the CNRT (Conselho Nacional de Reconstruçao Timorense) or OPMT might mean that we are missing out on other strategies employed by women in the conflict situation, as well as their reasons for deliberately choosing not to participate as actively in the nationalist movements' structures as the males. ${ }^{26}$ In part, this has meant a retreat into the private sphere or, in the public sphere, seeking out other channels to express their concerns, such as civil society organizations outside of the nationalist movement.

\section{Gender ideologies within the pro-Indonesian militia groups}

The pro-Indonesian militias were very much male-dominated, although female staff did work in administrative duties. Teenage males were also recruited into their ranks. It needs to be noted that not all militia members were violent or acted according to their beliefs or even voluntarily, as coercion and threat of violence were a major "recruitment tool". Economic reasons also prevailed - joining the militia meant a steady income in an impoverished area, and doubtlessly some were motivated by legitimate political goals, i.e. they wished to see Timor-Leste remain a part of Indonesia. But for others the chance to gain notoriety, personal power and economic, social or sexual rewards was the motivating factor.

The dress style and mannerisms of the militias have, as elsewhere, been influenced by popular culture, such as video games and action movies, and also by media coverage of other conflicts. The main role models for the violent masculinity displayed by the militias are, however, to be found in Indonesia. As they were set up, trained, armed, run and partially manned by the Indonesian security forces, the militias adopted much of the militarized masculinity of the ABRI/TNI. As in all armed 
forces, the Indonesian military cultivates a very narrow, hegemonic form of violent, militarized masculinity. At least during the Suharto era, the ABRI/TNI subculture included a very high readiness to use physical violence, a high degree of disdain for civilians and a sense of impunity.

The existence of this set of common norms and accepted ways of behaviour in the security forces and the militias meant that it was not necessary to give an explicit order for the violent militia rampage. The insinuation that violence would achieve the militia's goals was enough. The epitome of this militarized, "manly" subculture is to be found, as the name implies, in the "élite" troops of a security force. In the Indonesian/Timorese case it was the Kopassus who epitomized this violent militarism, and it was they who played a key role in the training of the militias.

Two other violent Indonesian male role models who have had a visible influence on the East Timorese militia are the pemuda activist (a glorified young, reckless political activist) and the preman (a glorified street-tough thug). Similar patterns of male behaviour are visible in violent conflicts in other parts of post-Suharto Indonesia. ${ }^{27}$ The roots of the pemuda youth culture can be traced back to the armed youth groups established by the Japanese Imperial Army in Indonesia during the Second World War, which then formed the nuclei of the armed pemuda groups of the Indonesian war of independence. These groups adopted the violent, authoritarian masculinity at the centre of the worldview of the imperial Japanese military as their own. ${ }^{28}$ The pemuda activist of Indonesian historiography, as depicted in official history and monuments, bears a striking similarity to the images of maleness manifest in East Timorese militias: young men, dressed casually, often with a bandana on their heads, brandishing swords, spears or handguns, in poses of martial aggressiveness.

The second role model of violent masculinity which has been evoked is the preman, or neighbourhood toughs, who are often involved in smalltime criminal activities and extort money - but also provide an informal "security service" for the neighbourhood. Observers have for the past decade referred to a premanization or premanisasi of Indonesian politics. ${ }^{29}$ Not only are preman recruited into the "security services" (satgas) of the political parties, but criminal gangs from Java have also been used as proxies by members of the security forces in conflicts such as in the Moluccas. ${ }^{30}$ Key militia figures, such as the overall military commander of the militias, Eurico Guterres, had been involved in semi-legal or illegal activities. The TNI itself has admitted to using funds from illegal gambling ventures to pay for the Timorese militias in 1999. ${ }^{31}$

In Indonesia, where the security forces are widely regarded as violent and corrupt and the provision of security has been largely "privatized", ${ }^{32}$ the provision of community security is often seen as a necessary, quasi- 
legitimate and even lesser evil, along the lines of "at least it's 'our neighbourhood boys" " extorting money for protection - often in collusion with the police and/or private security companies. ${ }^{33}$ In Timor-Leste today, the preman system is a further legacy of the Indonesian period. The armed youth groups at the centre of the violence in Dili's outer bairos from May/June 2006 onwards also to an extent fall into this ambiguous category: on the one hand, they can be seen as semi-spontaneous "selfdefence" groups defending their neighbourhood against incursions by other gangs; on the other hand, they become perpetrators of violence when attacking other neighbourhoods.

\section{The post-conflict DDR process in brief}

In analysing what went wrong in the post-independence period in TimorLeste in the lead-up the violence in 2006, one issue which needs to be carefully scrutinized is the disarmament, demobilization and reintegration (DDR) process which led to the new East Timorese police forces and army. The disintegration of both of these did, however, not come as a surprise. Numerous commentators from inside and outside Timor-Leste had long pointed at problems in the security sector. Intermittently, these problems erupted for all to see in open firefights between the police and armed forces. An indication of how strained the relations had become was the killing in cold blood of nine PNTL officers and the wounding of 27 (including two UNOTIL staff) by F-FDTL members at the Dili police headquarters on 25 May 2006. Nota bene, these were police officers and soldiers who were supposedly on the same, pro-government, side combating the rebel factions.

The UNTAET mission oversaw the DDR process of the Falintil while the Indonesian authorities were, at least in theory, responsible for disarming the pro-Indonesian militias which crossed over into West Timor. At the end of the conflict around 2,000 Falintil guerrillas, both women and men, were in the cantonment areas. Estimates on the number of militia ranged from 8,000 to 12,000 people, although not all of them could be considered active militia members.

\section{Falintil-DDR process and build-up of new security forces}

The Falintil guerrillas were voluntarily cantoned in 1999 in the run-up to the referendum and, for the most part, remained in the cantonment areas in spite of attacks by the militias and Indonesian security forces. Their containment led to strains within the movement but was more or less enforced, as any move on their side to fight the militias would have given 
credence to the Indonesian claim that Timor-Leste was engulfed in a civil war.

Security Council Resolution 1272 (1999), upon which the UNTAET mission was based, did not make specific reference to a DDR process. The DDR programme which came about, named the Falintil Reinsertion Assistance Program (FRAP), was run by the International Organization for Migration (IOM) and funded by Japan, the US Agency for International Development (USAID) and the World Bank. Funding also came from the Canadian government through Canadian Assistance to Demobilization in East Timor (CADET).

Following the end of FRAP, the UN Development Programme (UNDP) started up its RESPECT (Recovery, Employment and Stability Programme for Ex-Combatants and Communities in East Timor) programme. Although originally conceived as a reintegration programme for ex-combatants only, the ongoing political debate about who falls into this category led the UNDP to extend it to all "vulnerable sections of society". These included actual fighters, supporting personnel, widows, orphans and also groups such as the elderly and the disabled. The activities carried out have included agricultural, reforestation and bridgerehabilitation projects, the latter of which were carried out in conjunction with the Japanese PKF component. The programme was strictly a technical assistance project and has not actively sought to incorporate a gender perspective, although the participation of women's groups was encouraged. The programme's failure to empower local women has been criticized by Timorese civil society organizations. ${ }^{34}$

\section{Integration of ex-combatants into the new security forces}

Some of the former Falintil fighters were integrated into the newly formed PNTL police force and into the new national F-FDTL armed forces. The planned strengths of the police force and the armed forces are 1,500 and 3,000, respectively. Both include women and men. Approximately 650 former Falintil were incorporated into the F-FDTL and around 150 into the PNTL. The blueprint for the new armed forces was drawn up by King's College, London, with minimal input from East Timorese civil society. ${ }^{35}$ The establishment of the armed forces went against an earlier pledge by independence leader Xanana Gusmão that the new state would not have any military forces, which was retracted following the wave of militia violence in 1999.

The DDR process itself was not smooth. Only a fraction of the former fighters were integrated into the newly formed national security forces, while a large part of the former guerrillas had difficulties in finding their place in the new East Timorese society. This is partially due to a lack of 
employment opportunities in Asia's poorest country, but also due to difficulties in adapting to civilian life after spending years - if not decades as part of an armed struggle. The adaptation problems faced by the former guerrillas and the problems of civilian society in reintegrating the fighters are similar to those experienced by ex-combatants in other postconflict countries.

Despite the common view that UNTAET was one of the most "gender-aware" missions of the United Nations to date, in spite of the debate on gender and conflict throughout the 1990s and in spite of UN Security Council Resolution 1325 which was passed during the UNTAET mandate, the DDR process failed to recognize the contribution of women to the armed struggle and has not taken into account the needs of female members of the armed resistance. As Rehn and Sirleaf state:

Male Falintil fighters were offered the option of joining the new Timor-Leste Defence Force; those who chose not to, received the equivalent of \$US100 along with language and computer training. Nothing comparable was offered to the women who had occupied support functions throughout the struggle. ${ }^{36}$

Thus female ex-combatants were marginalized socially, economically and politically in the DDR process. Furthermore, the process has been seen as being politicized by some former Falintil, such as those in the Sagrada Familia group, who claim that preferential treatment has been given to those ex-combatants with close links to President Xanana Gusmão. Others, including the rebel faction led by Australian-trained Major Alfredo Reinado which triggered the 2006 crisis, claimed, somewhat contrarily, that it was ex-combatants from the eastern parts of the country who had been given preferential treatment.

A presidential commission set up to determine who falls under the categories of "ex-combatant" and "veteran" was long mired in controversy, and dissatisfied ex-combatants came to be seen as one of the most significant threats to Timor-Leste's fragile democracy. Those who feel that they have been slighted include the Sagrada Familia group of Commander Ely Foho Rai Bo'ot (also known as Elle Sete or L7) and the Committee for the Popular Defence of the Democratic Republic of Timor-Leste (CPD-RDTL). These groups also operate under the umbrella of the Association of Ex-Combatants 1975 (AC75).

In the post-independence years, the veterans' organizations became increasingly vociferous in demanding social, economic and political privileges. Their discontent fuelled sporadic rioting with the security forces. Part of the security forces, however, seemed to be in support of the veterans' demands. The former combatants' increasingly open and public display of military uniforms and weapons, involvement in criminal and 
violent activities and participation in the MAGs and RAGs were seen as intimidating and destabilizing by the local population.

The DDR process can thus be argued to have created a new marginalized and discontented underclass in the territory, one which is potentially ready to use violence in an attempt to address its legitimate economic, social and political goals. The problems are compounded by the fact that UNTAET failed to disarm fully former Falintil fighters. Thus small arms - including home-made arms and outdated weapons but also highpowered weapons captured from or supplied by the Indonesian armed forces - were to be found in the hands of disgruntled ex-combatants.

On the other hand, those integrated into the security forces, i.e. those seen as the "winners" of the DDR process, were also disappointed by their working conditions and jealousies between the two branches as well as between people hailing from different parts of the country. In addition, the security forces were heavily armed, even over-armed, both by the international community and by the rival Interior and Defence Ministries, while control of the SALW in the security forces was not up to par. ${ }^{37}$

\section{Security sector problems}

A further point of discontent has been the inclusion of around 350 former Timorese members of the Indonesian police force POLRI (Kepolisian Negara Republik Indonesia) into the PNTL, which some former Falintil see as an affront. Already, prior to the meltdown of the security sector institutions, feelings of mistrust and inter-service rivalry between FFDTL and the PNTL ran dangerously high, leading to violent confrontations. The two forces became highly politicized, and, as Rees noted in 2004, an "adequate and appropriate civilian oversight [of the security sector] does not exist". ${ }^{38}$

The East Timorese political and security élite are primarily to blame for the current situation, as they have manipulated the security sector reform process for political ends. But part of the blame must also be placed at the door of the international agencies, for the process was conceived and implemented by them, with minimal input from and the inadequate understanding of East Timorese society. ${ }^{39}$ It should also be remembered that it was precisely those nations which played a central role in the 2006 peacekeeping force - Australia, Malaysia and Portugal - which played central roles in training and arming the very same F-FDTL and PNTL units they now came to disarm and retrain.

The militia groups in West Timor have not been comprehensively disarmed or reintegrated by the Indonesian authorities. Most have "faded back" into society, some have returned to Timor-Leste, some remain 
armed in West Timor while yet others are putting their "expertise" to new use. Former militia leader Eurico Guterres has, for example, been active in West Papua in putting up similar militias as in Timor-Leste, such as Laskar Merah Putih (Red-White Warriors). The armed forces have also established similar militias in Aceh, which is currently going through a fragile post-conflict period. ${ }^{40}$

The remaining armed Timorese militia groups are a continuing threat to stability in both West Timor and Timor-Leste, though their influence is waning. The possible involvement of former militia members in the current gang violence in Timor-Leste remains unclear, with many rumours and little in the way of hard information abounding.

\section{Gender mainstreaming and the new security forces}

The new security forces are still in a process of defining themselves and their role in society. The relationship between the only two officially armed East Timorese groups was very strained throughout the immediate post-independence period. Public trust eroded, corruption increased and, as one Timorese observer noted, members of the new security forces were "now feeling powerful" with their guns ${ }^{41}$ which was a worrying development as far as democratic control of these forces was concerned. These fears were to be confirmed in 2006.

\section{Women in the new security forces}

The challenges faced in the process of integrating female professionals into the security forces, which are not only traditionally male-dominated but are based on a very exclusive view of militarized masculinity, are of course not unique to Timor-Leste but are echoed across the globe. The professionalism of women is questioned, as is their physical and mental capacity to be "up to the task". Arming of women and admission to higher echelons of power usually only come after years or decades of the opening up of the force. In Timor-Leste this process is only at its very beginning. Before the 2006 disintegration the F-FDTL had 70 female members, equalling 6 per cent of the total force, while the PNTL had approximately 20 per cent female staff, but with only one female inspector. According to outside observers, both Timorese and international, the women were "not on an equal footing" with their male colleagues. A particular issue with policewomen that one international observer (male) felt obliged to comment upon ${ }^{42}$ was the impression that their careers tended to end relatively quickly in pregnancy. 
In Timor-Leste the presence of uniformed and armed female security forces - in F-FDTL, PNTL or PKF uniforms - has come as a "culture shock" to East Timorese society, as the Indonesian occupation forces did not include women other than in administrative duties and armed female Falintil fighters were a very small minority - and would not have been seen by the urban population in any case. ${ }^{43}$ The Indonesian police forces did employ some women, but they were unarmed and not Timorese. Apart from the "growing pains" of transforming a former guerrilla army into a regular national defence force, the problems associated with building up new national institutions and the obstructions encountered by women entering traditionally masculine realms such as the police and military, a worrying development throughout the post-independence period has been the lack of interest on the side of the law enforcement officials in investigating cases of sexualized and/or domestic violence as well as cases of alleged sexual harassment and rape by PNTL officers. The most publicized case is the alleged gang rape of a young Timorese woman by six PNTL officers, which caused a storm in June/July 2004 after around 300 PNTL staged a "show of support" for the suspected rapists in front of the court in Dili. There have been cases of sexual harassment within the PNTL and incidents of sexual harassment of suspected sex workers. ${ }^{44}$

In addition, respect for human rights and constitutional rights of detainees has been found to be lacking. Amnesty International in 2005 found police brutality still existed, and suspected members of dissident groups having been targeted "on uncertain legal grounds". These developments came in spite of extensive - and expensive - training of the PNTL and F-FDTL by UN agencies on issues of gender sensitivity and human rights. The training courses would not have been able to root out deep-seated notions and modus operandi, for example concerning the acceptability of excessive use of force against detainees, as was the norm during both the Portuguese and Indonesian occupations, or that genderbased sexual violence is primarily a domestic matter. As several UN staff members, who wished to remain anonymous, pointed out in interviews, part of the problem also lay with the trainers. If the UNPOL in question come from countries where police brutality is common (and this was the case for a number of the contributing countries) or where attitudes towards gender-based sexual violence are rather laissez faire, the training given may well be suboptimal.

An interesting footnote perhaps is that in the 2006 violence, as far as the authors were able to tell, no female members of the PNTL or FFDTL took up arms. Aggressive display and violent use of SALW looks to have once more become an exclusively male domain. 


\section{Sexualized violence during and after the conflict}

Sexualized violence during the 1975-1999 conflict took a range of forms, from sexual harassment to rape, sexual slavery, forced marriages, forced abortions, sexualized torture and the sexual mutilation and display of corpses, in which for example a man has been castrated and his penis placed in his mouth. Despite such examples, sexualized violence was aimed primarily at women, especially those suspected of being part of the resistance, of harbouring pro-independence sentiments or of being wives or relatives of male pro-independence activists. ${ }^{45}$ A more indirect form of sexual domination was practised through the Indonesian government's family planning programmes, which included forced abortions and sterilizations carried out with the support of the Indonesian military.

While a considerable amount of work has been done to document the experiences of women, gathering information about sexualized violence against males has proven more difficult. This situation has arisen for two reasons. Firstly, it results from the immense stigma attached to sexualized violence against males, which is manifest in their inability to admit to having been raped. Secondly, it might be argued that, unlike what women have created for themselves by speaking out against sexualized violence, there is neither a cultural nor a political space in which men can safely address the ways in which they have been traumatized. The report of the Truth and Reconciliation Commission (CAVR) ${ }^{46}$ documents several cases, but the actual number of male victims of sexualized violence is in all probability much higher.

SALW played a central role in these cases of sexualized violence. The role of small arms in perpetrating sexualized violence was threefold they acted as an instrument of coercion to force the victims to choose between succumbing to the will of the armed perpetrator or dying; they were used as objects of torture to penetrate both vaginas and anuses; and lastly they were, in many cases, used to kill the victim. Many of the forms of sexualized violence bear a striking resemblance to methods used in Central American and other Southeast Asian counterinsurgency operations. This diffusion of methods of violence may well be due to the fact that some of the key figures behind the violence in both Indonesia and Central America studied at the same institutions in the United States, e.g. at Fort Benning and Fort Bragg. In all cases the perpetrators also received political and financial backing from the United States and other Western countries and used US/Western SALW. ${ }^{47}$

These methods included the sexualized torture of men and women (including inflicting pain on the genitals, rape and castration), mutilation and public display of castrated corpses, sexual slavery of civilian women 
and widescale use of rape of women as a weapon of war. Other gendered strategies of domination included the specific targeting of men for interrogation and extra-judicial killings, and forced sterilization and birth control programmes which were implemented with the aid of the security forces, as mentioned above. ${ }^{48}$ Other methods employed in the military operations included the setting up of and forcible relocation of the civilian population to "strategic hamlets" and setting up of locally recruited death squads or militias which operated in close collaboration with members of the security forces. In some cases, the methods utilized were identical to methods used in other violent conflicts in the region and other parts of the world - be it the use of local superstitions as a tactic for terrorizing the local population in the Philippines, the "strategic hamlets" in Viet Nam, the methods of sexual exploitation and sexual slavery in Guatemala or mobilization of pro-government mobs-for-hire as in Thailand.

\section{The post-conflict era}

The post-conflict era has seen a number of changes in gender relations. As in other post-conflict zones, there has been a dramatic increase in reported sexualized and domestic violence. In statistics collected during the UNTAET administration, up to 40 per cent of recorded crimes fell into this category. ${ }^{49}$ This figure needs to be treated with some caution, however: it may not indicate an increased level of violence but an increased level of reporting, as East Timorese women would have been very reluctant to report these crimes to the Indonesian occupation forces. ${ }^{50}$

On the other hand, the crime statistics may reveal some underreporting, as both UN and Timorese police staff may have recorded cases of, say, intimate homicide under "murder" and not sexualized violence. ${ }^{51}$ Furthermore, East Timorese women may still be very reluctant to report sexualized violence to the authorities for fear of social stigmatization, lack of interest and concern by the law enforcement officials and fear of losing their livelihood - as the husband still is overwhelmingly the breadwinner, especially in the rural areas. The police force's and judiciary's reluctance to address cases of gender-based violence, especially in rural areas, is a major problem, as Amnesty International points out in its 2005 annual report:

Widespread sexual and domestic violence constituted a significant proportion of reported crimes but was largely perceived as a matter to be resolved privately or through "traditional" justice mechanisms, where women were at particular risk of discrimination. Although improvements were noted, the relatively few cases brought to court were subject to delays and were sometimes dealt with insensitively. ${ }^{52}$ 
The main weapon used in cases of domestic and sexualized violence in Timor-Leste is the machete, with firearms being more uncommon. Unfortunately, no statistics could be procured from either the PNTL or UNPOL. Nevertheless, based on anecdotal evidence, the quality of violence has changed in the post-conflict situation, with the wounds inflicted on the victims of domestic violence being more severe, e.g. the cutting off of nipples with a machete. Domestic violence in Timor-Leste is mostly directed by the husband against the wife or the children, but also includes violence against the elderly, which is somewhat of an anomaly in Southeast Asian societies.

Sexual harassment and violence have unfortunately also been a problem for the peacekeeping force. Rapes are documented as having been committed, at least by members of the Jordanian and Pakistani contingents, sexual harassment charges have been raised against Australian soldiers and Portuguese soldiers have fathered children in cases where it is doubtful whether the sex was consensual or not. Prostitution, including both male and female sex workers, many of whom are under 18, has also been on the rise with the arrival of the internationals. Although peacekeepers have gained the most attention, UN civilian staff, NGO workers, journalists, contractors and businesspeople, both locals and foreigners, are among those who exploit sex workers. ${ }^{53}$

Timor-Leste has also seen an occasionally violent gender-conservative backlash, especially in 2000/2001, when there were several cases of women being physically assaulted, including being pelted with stones in the Dili central market and on the city's beaches for wearing clothing deemed inappropriate. This is not a phenomenon restricted to TimorLeste, but one that is often visible in post-conflict societies: a conservative backlash seeks to close social and political spaces opened by women during the conflict and return to a mythical, pre-conflict era "when men were men and knew what that meant" and women were relegated to the sidelines. ${ }^{54}$ The sexual violence against East Timorese women by the Indonesian security forces has been discussed and acknowledged publicly by society in the post-conflict situation, but this has unfortunately not translated into a deeper understanding of, resistance to or commitment to provide redress for sexual violence. That sexual violence has occurred tends to be seen only in the context of the conflict, and is often depicted as an "ugly sacrifice"; but its continuation in the post-conflict moment has not led to reflections about sexual violence in Timorese society itself.

No data are yet available on cases of sexual harassment or sexual abuse during the current outbreak of violence beginning in April/May 2006, but unfortunately we must assume that these cases have occurred, especially given the precarious conditions of the IDP camps. 


\section{Conclusions}

This study of the Timor-Leste conflict and the post-conflict situation in the country shows the centrality of both SALW and gender issues to the security of the Timorese people - a point which was made brutally and tragically clear by the events following the crisis of April/May 2006. The 24-year conflict which left approximately 200,000-300,000 East Timorese dead was fought almost exclusively with SALW, with that category needing to be expanded to cover what were classified in Timor-Leste as "offensive weapons" by UNTAET, i.e. machetes, spears, knives and swords. In the volatile post-conflict situation, the two greatest threats to security are linked to SALW. Weapons, especially machetes, continue to be used in cases of gender-based sexual violence, which is the most common crime in the country. Furthermore, the uncertainty about the exact number of SALW from the conflict still in circulation - to which one must add the PNTL and F-FDTL weapons "unaccounted for" after the security sector meltdown in 2006 - and whether or not they can be accessed by disgruntled ex-combatants or others adds to an atmosphere of instability.

Both threats are also intricately linked to issues of gender, of men using violence or the threat of violence backed up by weapons to assert their power over others. The inadequate responses of the newly formed security forces, while they still existed, to these threats are also based on masculinist views of the world: gender-based sexual violence is seen as a "domestic" issue and members of the security forces who themselves have committed these crimes can count on the support of their col-

leagues. The reply to the challenge posed by dissident groups was one of countering violence by violence. The gender awareness and human rights training given by the UN missions obviously did not have the hoped-for impact on the conduct of the forces. Furthermore, civilian control of the security sector was not up to par, with several key figures, such as the Interior and Defence ministers, manipulating the respective forces for their own gain.

The two UN missions in the country have made an effort to address gender issues and the security threat posed by SALW. However, the two have not been properly considered in combination with each other. This was visible in the DDR and SSR processes, which had originally not been part of the UNTAET mandate. These processes, planned by outside agencies with minimal Timorese civil society input, sidelined female ex-combatants as well as leaving numerous male ex-combatants disaffected.

Apart from the need to be more gender-aware and participatory, we argue that DDR and SSR processes should be more holistic undertakings. Disarmament needs to be as complete as possible, taking into ac- 
count not only the number of weapons collected but the cultural, social, economic and gendered meaning attached to the ownership of a weapon. Demobilization must take all ex-combatants into account, but should also be seen as a deeper process than merely turning in weapons and uniforms. Some mistakes were made at the outset of the DDR process, and some problems have not been properly addressed during the process, either by the international agencies and the East Timorese authorities or by the Indonesian government. To summarize:

- DDR was not a part of the original UNTAET mandate

- the planners of the DDR process were seemingly not aware of the social standing of and the political tensions inside the security sector institutions and Timorese society, thus leading to a politicization of the process

- the areas of responsibility between the police and armed forces were not clearly delineated

- infighting and turf wars bred mistrust between the security forces, and insecurity and lack of trust in the population

- the security forces themselves became politicized, breaking down first along political, then regional, lines of allegiance

- the gender sensitivity training given to the security forces has had no apparent impact

- there is lack of transparency in the purchase of arms for the security forces, leading them to have weapons in excess of what would have been necessary for performing their normal functions

- lax control of the arms in the security forces has led to their dissipation

- reform, recovery and reconstruction programmes have not been based on the needs of the recipients but more on the desires of the donor community.

What is perhaps most surprising is the lack of a gender perspective in the whole process of transition, in spite of Security Council Resolution 1325, which was passed during UNTAET and before UNMISET, and the relatively high priority given to gender issues as part of UN missions. Despite the debates surrounding women and conflict, despite the knowledge in Timor-Leste and outside of the contribution of women to the struggle, they were mostly forgotten in the DDR process and beyond. The UNDP's RESPECT programme has, by default rather than by design, as the presidential commission was unable to define "ex-combatants" and "veterans", had a more comprehensive outlook than regular DDR processes. Instead of concentrating on the disputed group of excombatants, the focus group has been vulnerable people in the communities, including ex-combatants, widows and widowers, orphans, the elderly and so on. Unfortunately, according to informal information from Timorese and UN sources, the programme was plagued by problems of 
implementation due to pressures within the UN system, and it was strictly focused on technical assistance and thus did not take other needs of society into account. Above all, it did not have a comprehensive gender perspective above and beyond involving women's groups where possible.

In the aftermath of the 2006 violence there has been a lively debate regarding the question of whether the international community left too soon or too late. We believe that this discourse misses the mark, to a point. The question should not be merely about the duration of the UN mission, but about the aims and contents of its work in Timor-Leste. Others have argued that the UN mission did not have a realistic view of the situation in Timorese society and was more interested in achieving "visible" results, such as holding elections, without considering - or understanding - the local context in which these processes were happening. We would argue that the same goes for the post-conflict DDR process and the setting up of the new security forces. What is also striking is how many observers both in Timor-Leste and on the outside had been warning about the tensions and potential for violence in the country. Did these warnings perhaps go unheeded because of the need for the international community to see Timor-Leste as a "success story"?

The breakdown of the security forces and the ensuing communal violence need also to be seen in the context of the country's dire socioeconomic situation. Joining the security forces was one of the few employment opportunities available, thus competition was intense. The gangs which have been going on the rampage are composed mostly of young men from the marginalized parts of Dili, though not without connections into the political and social élite, as well as into the security forces. Without improving the socio-economic situation, there is little hope of integrating these youths. Improving the socio-economic situation, in turn, is also dependent on the policies of the international community, which have not always prioritized the needs of Timorese society in their policies towards the country.

While firearms are clearly linked to militia violence in West Timor, the impact of firearms (as opposed to traditional offensive weapons) tended initially to be more a "phantom" one in Timor-Leste, though it has now, post-2006 crisis, become very real. However, given the level of trauma in East Timorese society, even the possibility or the mere rumour of any one group having access to SALW is a potent source of power. Rumours of arms caches, smuggled arms and shadowy groups such as the "ninjas" and the flashing of replica guns all contributed to creating a climate of fear and instability prior to the 2006 outbreak of violence. In a fragile post-conflict setting, these can be enough to coerce the civilian population into accepting the need to be ready for more violence and convince them of the potential violent power of one group or the other. The 
"phantom menace" of possible SALW was used by groups such as the MAGs, ex-Falintil or others as a form of leverage over society. Now, unfortunately, the disappearance of the weapons from the security force stores has taken this to a new level.

What is needed now is for the international community, the RDTL government and Timorese civil society to address urgently the issue of "demobilizing" militarized concepts of masculinity prevalent in society, giving men other tools than violence to address their needs and problems, and finding other outlets than organized violence as a way for men to gain societal respect.

The build-up of the new national security forces, in spite of efforts, was not able to create democratically accountable, professional, gendersensitive police and armed forces which fully respect human rights and national legislation. At the core of this problem lies the lack of a broader understanding of issues of gender and violence, of why certain sections of society revert to violence in order to gain power over others and what the implications of this are. More work needs to be done in this field, by Timorese civil society itself, by the RDTL government, within the UN system and by the research community, to allow the people of TimorLeste to build a peaceful, more prosperous society.

\section{Notes}

1. CAVR (2006) Chega! Relatório da Comissão de Acolhimento, Verdade e Reconcilição de Timor Leste, Dili: CAVR.

2. Ibid.; SCU (2003) Brief in Support of the Application for the Issuance of an Arrest Warrant for Wiranto - Case No. \#5/2003 Deputy General Prosecutor vs. Wiranto and Others, Dili: Serious Crimes Unit, available at www.etan.org/etanpdf/pdf2/wirantobrief2.pdf.

3. For accounts see CAVR, note 1 above; Cristalis, Irene (2002) Bitter Dawn-East Timor: A People's Story, London: Zed Books.

4. UN Special Commission (2006) Report of the United Nations Independent Special Commission of Inquiry for Timor-Leste, Geneva: United Nations.

5. The western East Timorese should not be confused, as has occasionally happened in the international media, with the West Timorese. West Timor remains part of Indonesia.

6. At the time, US $\$ 0.80$ would have equalled several packs of cigarettes and US $\$ 12$ would equal a pig or a goat; see Pinto, Constancio and Matthew Jardine (1997) East Timor's Unfinished Struggle - Inside the Timorese Resistance, Boston, MA: South End Press.

7. UNTAET (2001) "Regulation No 2001/5 on Firearms, Ammunition, Explosives and Other Offensive Weapons in East Timor", UN Transitional Administration in East Timor, Dili, 23 April, available at www.un.org/peace/etimor/untaet/reg00105E.pdf.

8. Donatus Marut, interview at Indonesian Society for Social Transformation, 20 March 2004; Myrttinen, Henri (2003) "Disarming Masculinities", in Women, Men, Peace and Security, Disarmament Forum 4/2003, Geneva: UN Institute for Disarmament Research; Myrttinen, Henri (2007) "Up in Flames - Impoverishment and Instability in PostIndependence Timor Leste”, Kepa Working Papers No. 11, Finnish Service Centre for Development Cooperation, Helsinki; Scambary, James, Hipolito da Gama and Joao 
Barreto (2006) A Survey of Gangs and Youth Groups in Dili, Timor-Leste, Dili: AusAid Timor-Leste.

9. John White, interview at UNPOL headquarters, Dili, 3 May 2004.

10. See also AustCare and Small Arms Survey (2008) Dealing with the Kilat, Camperdown and Geneva: Austcare/Small Arms Survey.

11. UN Special Commission, note 4 above.

12. Lt-Col R. Bradford, interview at UNMISET PKF headquarters, Dili, 26 April 2004; Myrttinen (2007), note 8 above.

13. Bradford, ibid.

14. Siapno, Jacqueline (2001) "Gender, Nationalism, and the Ambiguity of Female Agency in Aceh, Indonesia, and East Timor", in Marguerite Waller and Jennifer Rycenga, eds, Frontline Feminisms - Women, War and Resistance, London: Routledge.

15. As described, for example, in Hicks, David (2004) Tetum Ghosts and Kin - Fertility and Gender in East Timor, Long Grove, IL: Waveland Press.

16. Cristalis, Irene and Catherine Scott (2005) Independent Women - The Story of Women's Activism in East Timor, London: CIIR; Hill, Helen (2002) Stirrings of Nationalism, Fretilin 1974-1978 - The Origins, Ideologies and Strategies of a Nationalist Movement, Sydney: Otford Press.

17. For a more comprehensive analysis of the gendered impacts of the UNTAET and UNMISET missions, see Koyama, Shukuko and Henri Myrttinen (2007) "Unintended Effects of Peace Operations on Timor-Leste from a Gender Perspective", in Aoi Chiyuki, Cedric de Coning and Ramesh Thakur, eds, Unintended Consequences of Peacekeeping Operations, Tokyo: United Nations University Press.

18. Cribb, Robert (2002) "From Total People's Defence to Massacre - Explaining Indonesian Military Violence in East Timor", in Freek Colombijn and Thomas Lindblad, eds, Roots of Violence in Indonesia, Singapore: Institute of Southeast Asian Studies.

19. Hicks, note 15 above; Luis Akara, interview with Asociação Mane Contra Violencia (Association of Men Against Violence), Dili, 28 April 2004; Ubalda Alves, interview at Fokupers, Dili, 6 May 2004.

20. Connell, Raewyn (2000) The Men and the Boys, London: Polity Press.

21. Bradford, note 12 above; Scambary, da Gama and Barreto, note 8 above.

22. Aditjondro, George (2000) "Ninjas, Nanggalas, Monuments and Mossad Manuals - An Anthropology of Indonesian State Terror in East Timor", in Jeffrey A. Sluka, ed., Death Squad: The Anthropology of State Terror, Philadelphia, PA: University of Pennsylvania Press.

23. Authors' observations.

24. UNDP (2006) National Human Development Report 2006, Dili: UNDP, available at www.undp.east-timor.org/documentsreports/nhdr/index.html; Prüller, Vanessa (2008) "The 2006 Crisis in East Timor - An Ethnic Conflict?" MA thesis, University of Passau.

25. Myrttinen (2007), note 8 above.

26. Siapno, note 14 above.

27. Aditjondro, George (2001) "Guns, Pamphlets and Handie-Talkies - How the Military Exploited Local Ethno-religious Tensions in Maluku to Preserve Their Political and Economic Advantages", in Ingrid Wessel and Georgia Wimhöfer, eds, Violence in Indonesia, Hamburg: Abera; Colombijn, Freek (2001) "What Is So Indonesian About Violence?", in Ingrid Wessel and Georgia Wimhoefer, eds, Violence in Indonesia, Hamburg: Abera; Nordholt, Henk Schulte (2002) "A Genealogy of Violence", in Freek Colombijn and Thomas Lindblad, eds, Roots of Violence in Indonesia, Singapore: Institute of Southeast Asian Studies.

28. Anderson, Benedict (1972) Java in a Time of Revolution: Occupation and Resistance 1944-1946, Ithaca, NY: Cornell University Press. 
29. Nordholt, note 27 above.

30. Aditjondro, note 27 above; TAPOL (2003) "Kopassus and the Maluku Crisis", TAPOL Bulletin 169/170, Thornton Heath: TAPOL Indonesia Human Rights Campaign.

31. O'Shea, David (1999) Dateline, Special Broadcasting Service (SBS) Network, 18 August, Australia.

32. Myrttinen, Henri (2003) “Alte 'neue' Kriege - Die Privatisierung der Gewalt in Indonesien", in Dario Azzelini and Boris Kanzleiter, eds, Das Unternehmen Krieg - Paramilitärs, Warlords und Privatarmeen als Akteure der Neuen Kriegsordnung, Berlin: Assoziation A.

33. Authors' observations.

34. La'o Hamutuk (2004) "Observations Regarding the RESPECT Program in East Timor", La'o Hamutuk Bulletin 5(5-6), Dili: La'o Hamutuk East Timor Institute for Reconstruction Monitoring and Analysis.

35. King's College London (2000) Independent Study on Security Force Options and Security Sector Reform for East Timor, London: Centre for Defence Studies, King's College London.

36. Rehn, Elisabeth and Ellen J. Sirleaf (2002) Women, War and Peace: The Independent Experts' Assessment on the Impact of Armed Conflict on Women and Women's Role in Peace-building, New York: UNIFEM.

37. Amnesty International (2003) Timor Leste: Briefing to Security Council Members on Policing and Security in Timor Leste, AI Index ASA 57/001/2003, 6 March, London: Amnesty International.

38. Rees, Edward (2004) Under Pressure - Three Decades of Defence Force Development in Timor Leste 1975-2004, Geneva: Geneva Centre for the Democratic Control of Armed Forces.

39. For a thorough analysis and critique of this issue see Rees, ibid.

40. Jakarta Post (2004) "Concern Heightens About Militia Groups in Aceh", Jakarta Post, 21 April; TAPOL (2003) "Danger of Violent Instability in West Papua Increases as Rights Abusers Take on Key Roles", press release, 4 December, available at http:/ tapol.gn.apc.org/pr031204.htm.

41. Alves, note 19 above.

42. Interview with UNPOL officer, UNPOL headquarters, Dili, 6 May 2004

43. Alves, note 19 above.

44. Alola Foundation (2004) Trafficking and Prostitution in Timor Leste, Dili: Alola Foundation.

45. These acts of violence are documented in detail in Aditjondro, note 22 above; Carey, Peter (2001) "Dimensions of Domination - Institutionalised Violence against Women During the Indonesian Occupation of East Timor (1975-1999)", in Ingrid Wessel and Georgia Wimhoefer, eds, Violence in Indonesia, Hamburg: Abera; CAVR, note 1 above.

46. CAVR, note 1 above.

47. Aditjondro, note 22 above; Carr, Barry and Elaine McKay, eds (1989) Low Intensity Conflict - Theory and Practice in Central America and South East Asia, Monash: La Trobe University Institute of Latin American Studies/Monash University Centre of Southeast Asian Studies; CAVR, note 1 above; Gonzales, Maria (2003) "Nachhaltig zum Schweigen gebracht - Paramilitarismus, Gewalt und Geschlecht in Guatemala", in Dario Azzelini and Boris Kanzleiter, eds, Das Unternehmen Krieg - Paramilitärs, Warlords und Privatarmeen als Akteure der Neuen Kriegsordnung, Berlin: Assoziation A; MacDonald, Hamish, Desmond Ball, James Dunn, Gerry van Klinken, David Bourchier, Douglas Kammen and Richard Tanter (2002) "Masters of Terror - Indonesia's Military and Violence in East Timor in 1999", Canberra Paper 145, Strategic and 


\section{ABDULLAH AND MYRTTINEN}

Defence Studies Centre, Australian National University, Canberra, available at http:// yayasanhak.minihub.org/mot/booktoc.htm.

48. Aditjondro, note 22 above; Carey, note 45 above; CAVR, note 1 above; Conboy, Ken (2002) Kopassus - Inside the Indonesian Special Forces, Sydney: Equinox.

49. UNTAET (2002) "Gender Equality Programme", UNTAET Fact Sheet 11, UN Transitional Administration in East Timor, Dili, available at www.un.org/peace/etimor/fact/ fs11.pdf.

50. Alves, note 19 above.

51. White, note 9 above.

52. Amnesty International (2005) Annual Report 2005, London: Amnesty International.

53. Alola Foundation, note 44 above; Koyama and Myrttinen, note 17 above.

54. Farr, Vanessa (2002) “Gendering Demilitarisation as a Peace Building Tool”, Paper 20, Bonn International Center for Conversion, Bonn. 


\section{Part III \\ Militarizing the domestic sphere}



8

\title{
"That's equality for you, dear": Gender, small arms and the Northern Ireland conflict
}

\author{
Miranda Alison
}

The academic fields studying women, gender, armed conflict, small arms and light weapons are still relatively new. Thus far, research has tended to focus on women as victims of armed conflict, which is of course extremely important. There has been a corresponding emphasis on constructing women as somehow inherently or "naturally" more peaceful and peaceloving and less violent than men, which has meant that the issue of women as the perpetrators of violence has been very much neglected. As Vanessa Farr notes, women are often "referenced for their capability to make peace as a supposed organic by-product of their ability to mother and nurture. These lines of discourse have tended to promote a simple women=peace:men=war dichotomy." Farr goes on to contend that we "have to question the idea that women are always and only victims and men always and only perpetrators of violence". ${ }^{1}$ However, Cynthia Enloe suggests that analysis of "Women in the military has never been an easy topic." Challengingly, she describes how "gradually I began to realize that paying attention only to women as soldiers was simply too confining... To invest one's curiosity solely in women as soldiers is to treat the militarization of so many other women as normal. If I slipped into that naive presumption, I probably would be allowing my own curiosity to become militarized."2

These are thought-provoking comments, and I do not wish to suggest that stark binary categories of women warriors versus women victimpeacemakers are the only forms of agency or activism available to women in war; clearly this is not the case. I also do not wish to suggest

Sexed pistols: The gendered impacts of small arms and light weapons, Farr, Myrttinen and Schnabel (eds), United Nations University Press, 2009, ISBN 978-92-808-1175-9 
that combat is the only role that women have fulfilled in war or that their other, more common, auxiliary support roles are less significant. Indeed, war centrally relies on both men and women in a variety of support roles. As Farr notes, one form of women's participation in the proliferation and normalization of guns in the context of armed conflict is their role in smuggling and hiding weapons and/or their bearers, ${ }^{3}$ and this is one of the topics covered by this chapter. Linda Grant de Pauw comments in her history of women in war that "Although some women in war appear in conventional combat roles, most do not. The reality of women's experience is distorted by focusing exclusively on exceptional females, but it is also distorted by focusing only on the most typical." 4 It remains the case that women who engage in organized violence have been consistently under-examined, and that they fundamentally challenge our enduring image of women as natural peacemakers.

Research on female combatants and women involved in other ways with political violence is necessary for various reasons. In contrast to conventional wars, many contemporary conflicts "privatize violence", with more civilians being drawn into conflicts and the separation of (male) belligerents and civilians breaking down. Concomitantly, the stereotype of aggressive men and pacifist women is disrupted; particularly in civil wars and wars of liberation, women are also combatants and serve in a variety of other functions in both the military and armed groups. ${ }^{5}$ The breakdown of the home front/war front boundary in contemporary conflicts seems to be significant in resulting in increased numbers of female combatants. The increasing availability, portability and ease of use of small arms and light weapons are also contributing to this phenomenon. ${ }^{6}$ Nothing could be further from the truth than Martin van Creveld's claim that in contemporary intra-state "low-intensity" wars women are staying away from combat roles. ${ }^{7}$ Significantly, if we see women as only victims of, not also as perpetrators of, violence and perpetuators of conflict, we are considering only part of the story. Simona Sharoni argues that "the prevalent view of women as victims of conflict... tends to overlook, explicitly or implicitly, women's power and agency". 8 As Ronit Lentin points out, "Viewing women as homogeneously powerless and as implicit victims, does not allow us to theorize women as the benefactors of oppression, or the perpetrators of catastrophes." 9 This prevents us from addressing and responding to the effects of women's violence (even if this is only expressed through condoning or encouraging male violence) alongside men's violence, and makes attempts at peacemaking, peacebuilding or post-conflict reconstruction less effective. A greater acknowledgement and understanding of women's participation in political violence is needed as part of an overall struggle towards peace. As Farr maintains, "Frames of reference that fail to interrogate the complex roles played 
by women, children, and non-combatant men in times of war show an incomplete picture of violent conflict. This leads to an equally incomplete understanding of how peacemaking should work; as a result, all too many reconstruction and peacebuilding efforts result in lamentable failure." 10

As part of the project to complete our picture of how armed conflict draws in different social actors, this chapter primarily addresses the issue of women's involvement with paramilitary organizations, ${ }^{11}$ both republican and loyalist, in the Northern Ireland conflict. ${ }^{12}$ The chapter draws on fieldwork I carried out in Ireland in 2003 as part of wider doctoral research on female combatants, utilizing in-depth semi-structured qualitative interviews with 11 female former republican paramilitary members, two female former loyalist paramilitary members and seven others involved to varying degrees with loyalist paramilitary activities. The approach of the research was to take women's narrations of and reflections about their lives and experiences as primary documents deserving attention. The majority of interviews were obtained through ex-prisoner organizations, with some accessed through other community groups.

The chapter begins with a very brief outline of the Northern Ireland conflict, and then looks at two significant issues pertaining to small arms and light weapons in Northern Ireland: the contentious issue of disarmament/decommissioning of paramilitary weapons and the problem of postconflict patterns of violence. It moves on to examine women's role in the concealment and transport of arms during the "Troubles", then addresses gender relations in both republican and loyalist paramilitary organizations. It ends with two more speculative sections, on the sexual appeal of arms and paramilitarism and visual representations of paramilitary women.

\section{The Northern Ireland conflict}

From the outbreak of the violence in Northern Ireland in 1969 until the 1994 cease-fires, around 3,400 people were killed and over 20,000 injured. ${ }^{13}$ The current population is almost 1.7 million, of whom around 53 per cent are of Protestant background and almost 44 per cent are of Catholic background. ${ }^{14}$ In the course of the struggle there have been deaths and injuries in Great Britain, the Republic of Ireland and continental Europe, but people in Northern Ireland have been the primary victims. Nearly half the population (80 per cent in some areas) know someone injured or killed in the conflict, ${ }^{15}$ which has been over the constitutional status of Northern Ireland; that is, whether it should remain part of the United Kingdom of Great Britain and Northern Ireland or 
become part of a united Ireland. Political conflict has, broadly, taken place between British unionists and Irish nationalists. People of Catholic background are primarily associated with the republican/nationalist movement and people of Protestant origins are mainly unionists/loyalists. The primary armed parties to the conflict have been republican paramilitaries, a variant of Irish nationalists who desire Northern Ireland to become part of an island-wide Irish republic; loyalist paramilitaries, a variant of British unionists who want Northern Ireland to remain part of the United Kingdom; and the British military forces. Although the absolute number of fatalities appears small when compared with other violent conflicts, when one considers it in light of the tiny population of Northern Ireland as well as in terms of its long duration, this armed conflict certainly qualifies as a war. Calling this period the "Troubles", as locals do, is at best a euphemism. Although there has been a cease-fire of the major militant groups since 1994 (on and off), and a political settlement was reached in 1998 with the Belfast Agreement, ${ }^{16}$ there is no guarantee that the foundation for a lasting peace has been laid. The peace process has been strained and precarious since it began, and in 2002 the Northern Ireland Assembly (the devolved government established with the Agreement) and the wider peace process became severely deadlocked over, among other things, the issue of Irish Republican Army (IRA) weapons decommissioning. The British government suspended the Assembly in October 2002 and direct rule from London was reintroduced. Further political strife ensued. However, following the IRA's final act of decommissioning in September 2005, negotiations between the political parties of Northern Ireland and the British and Irish governments at St Andrews in October 2006 and subsequent political progress, the devolved Northern Ireland Assembly was restored in May 2007 and has been in operation since that time.

Women have participated in both republican and loyalist paramilitaries in Northern Ireland in a variety of roles, but have been more active in republican groups than in loyalist ones. Women have also been present in the Royal Ulster Constabulary (RUC), the Ulster Defence Regiment and the British military. However, the focus of this chapter is on non-state military groupings; accordingly, women's roles in the various state security forces are not addressed here. ${ }^{17}$

The experience of community resistance in the 1970s helped to politicize many nationalist women and bring them into community activity. Women in nationalist areas have played an active role in community protests since the civil rights movement and are still, on the whole, more active in political and community groups than most Protestant women. Some female republican combatants active in the Troubles, such as Mairead Farrell and the Price sisters, came to be internationally known. Re- 
publicans view themselves as being part of an unbroken political tradition going back to the 1798 United Irishmen rebellion (although this is highly contestable), and women have been significantly involved in all uprisings including and since that of 1798, though not in a direct military capacity in all of them. It has only been during the Troubles that women have been allowed into the IRA itself as "volunteers" (the organization's term for combatants). Margaret Ward suggests that this shift came about as a result of both women demanding this change and men recognizing the need to have some militarily trained women. ${ }^{18}$ In the late 1960 s younger women joining Cumann na mBan (a women's auxiliary organization set up to support and fundraise for the IRA, including providing first aid and hiding weapons) began expressing disillusionment with their subsidiary role and strongly argued for their integration into the IRA itself. Sympathetic male IRA officers eventually provided them with military training, but apparently this was at first carried out without the knowledge of the older Cumann na mBan women. When the Provisional IRA movement formed it maintained Cumann na mBan but allowed women to be seconded into the IRA, where they were militarily active but did not have the status of full members. With the later restructuring of the organization into cells, women were finally accepted into the IRA on an equal basis with men.

While the active involvement of women in republican paramilitaries has been comparatively well known, Rosemary Sales notes that "Much less is known about loyalist women paramilitaries... who appear to have had less prominence [and independence] within the movement." 19 Elisabeth Porter suggests that "the nominal claim to socialist credentials in republicanism provides an ideological space for egalitarianism. The conservative leanings in much [of] loyalism stultify gender equality." 20 Loyalist women's activities have primarily been in the realms of "welfare work" (support for male prisoners and their families), first aid and cleaning, and moving and hiding weapons. Nevertheless, a minority of women have been involved in loyalist paramilitaries in more directly combative roles. The scale and extent of women's presence and involvement in loyalist paramilitaries are very hard to gauge, and I found it extremely difficult to gain access to women willing to talk about their involvement. A community worker told me that in the rural mid-Ulster area, of around 300 ex-paramilitary members with whom she has contact, she knows only one woman who was directly involved. A male worker at the same organization told me of two more. The proportion is likely to have been slightly higher in urban Belfast, but I have no reliable figures to support this hypothesis.

Nira Yuval-Davis suggests that incorporating women into militaries in national liberation movements conveys the message that women are 
(symbolically) equal members of the collectivity, and that all members of the collectivity are symbolically incorporated into the military. ${ }^{21}$ This ideology is significant in respect to Northern Ireland, where republicanism has constructed itself as a national liberation movement in a way that loyalism, concerned with bulwarking the British state and the political and social status quo against the republican threat, has not. In an interview, Peter, ${ }^{22}$ a loyalist ex-prisoner and community worker, made the point that loyalists and republicans were "fighting two different wars". Republicans viewed the conflict as being a revolutionary war of resistance against the state, so there was a role for many people to play, including women. In contrast, in Peter's words:

Loyalist paramilitaries were never about buildin' a revolutionary movement. They were... involved in a low-intensity counter-terrorist war against republicans. Now, what role is there for women to play in that? [Further,] if you are buildin' a revolutionary movement then you have to be fightin' that revolution on all fronts, and one of them is on that gender front - I mean you've gotta link your revolutions, you've gotta be all embracin' and you link yourself to human rights issues and to gender issues... which the republicans have done. Loyalists didn't need to.

Peter also pointed out that "loyalists would define themselves [by] what they're not, so you look at your enemy and everything he's for, you're against. So if republicans are embracing women's rights, then again ... [loyalists would] move against that." The implications of Peter's comments are that loyalism, being less of a cohesive movement than republicanism and not being a revolutionary movement, has not had the same perceived strategic or ideological need for women's involvement that republicanism has had.

\section{Small arms and light weapons in Northern Ireland}

\section{Disarmament/decommissioning of paramilitary weapons}

As previously noted, one of the most significant factors in the 2002 suspension of the Northern Ireland Assembly was the issue of IRA disarmament, though the suspension was finally triggered amid allegations of IRA intelligence-gathering in Stormont, the Assembly building. However, disarmament has been a contentious part of the peace process since even before the 1994 cease-fires. Republicans have viewed disarmament as a matter to be resolved as part of the peace process rather than as a condition of entry to it, as unionists have. ${ }^{23}$ In September 1997 the Inde- 
Table 8.1 Paramilitary weapons estimates (late 1990s)

Irish Republican Army

- 2.6 tonnes of Semtex explosive

- 588 AKM assault rifles

- 400 other assorted rifles

- 10 general-purpose machine guns

- 17 DSHK heavy machine guns

- 30.50 calibre heavy machine guns

- 9 Sam-7 missiles

- 46 RPG-7 missiles

- 11 RPG-7 launchers

- 7 flame-throwers

- 115 hand grenades

- 600 handguns

- 40 submachine guns

- 31 shotguns

- 1.5 million rounds of ammunition

This list does not take into account the IRA's capacity to manufacture its own explosives or other ordnance.
Loyalist paramilitary groups: Ulster Volunteer Force and Ulster Defence Association/Ulster Freedom Fighters

- 74 VZ58 assault rifles

- 674 handguns

- 20 RPG-7 grenades

- 185 RGD grenades

- 80 submachine guns (including home made)

- 33 shotguns

- Unknown quantities of Powergel commercial explosive

A report in the Irish Times (May 1998) stated that sometime between 1996 and 1998 the UVF and UDA smuggled hundreds of assault rifles, submachine guns and pistols into Northern Ireland. The report estimated that the UDA and UVF each had 200 assault rifles/ submachine guns.
The breakaway Real IRA

has a small number of rifles, handguns, machine guns, unknown quantities of Semtex, detonators and homemade mortars. The Continuity IRA has small quantities of rifles and pistols and a small amount of Semtex. It has recently acquired an M79 grenade launcher. Both the Continuity IRA and the Real IRA have the ability to manufacture their own explosives.

The Irish National Liberation Army has dozens of automatic weapons and pistols. It has circa 100 kilos of commercial explosives.

The Loyalist Volunteer Force has only a small number of rifles and handguns, and a limited amount of commercial explosives.

Sources: Magill, June 1998; Irish Times, 14 May 1998; Guardian, 8 May 2000.

Source: Brown, Kris and Corinna Hauswedell (2002) Burying the Hatchet: The Decommissioning of Paramilitary Arms in Northern Ireland, Brief 22, Bonn: Bonn International Center for Conversion, p. 44.

pendent International Commission on Decommissioning (IICD) came into existence by a treaty between the British and Irish governments. The IICD, chaired by General John de Chastelain, monitors and reports on acts of decommissioning. The 1998 Belfast Agreement committed all participants to the total disarmament of all paramilitary organizations (see Table 8.1 for estimates of paramilitary weapons stores from around that time). Initially it was intended that full decommissioning would be achieved within two years of the May 1998 referendum supporting the 
Agreement, but this proved to be unrealistic. Before the Northern Ireland Assembly even began functioning, the question of decommissioning threatened to unravel the whole process. Unionists demanded that the IRA disarm before the new Assembly opened, as a test of republicanism's commitment to peaceful means ("no guns, no government"); republicans refused, since they viewed prior decommissioning as an attempt to isolate Sinn Féin (the political party of the Provisional republican movement) and create dissention among republicans. They also saw such preconditions as unhelpful and self-defeating. For republicans, decommissioning has been "not simply a strategic difficulty within the peace process but also an historical impossibility", since their view has been that "there was no precedent in Irish history for disarmament by insurgents either voluntarily or under pressure". They have also pointed out that their own decommissioning should be viewed in the context of a wider demilitarization of Northern Ireland, also including loyalist paramilitary groups, the security forces and "the thousands of legally held firearms in Northern Ireland which were mostly in Unionist hands". ${ }^{24}$ However, after many false starts, governing powers were transferred to the Assembly in December 1999 (though the Assembly would go on to be suspended a number of times).

To date there have been five acts of decommissioning witnessed by the IICD: four acts by the IRA in October 2001, April 2002, October 2003 and September 2005 and one act by the Loyalist Volunteer Force (LVF) in December $1998 .{ }^{25}$ The quantity of arms decommissioned by the LVF was very small and there have been no other official, witnessed acts of decommissioning by loyalist paramilitaries. ${ }^{26}$ In January 2004 the Independent Monitoring Commission came into effect, established by an international agreement between the British and Irish governments. For its own part, the British government is committed to the normalization of security arrangements and practices, and has worked towards the removal of security installations and a serious reduction in the number and role of British forces in Northern Ireland. Indeed, by summer 2007 there remained no more than 5,000 soldiers in 11 locations in Northern Ireland (commensurate with other areas of the UK, for deployment around the world), as opposed to 27,000 soldiers in over 100 locations at the height of the Troubles. Operation Banner, the name for the British Army's 38-year operation in Northern Ireland, officially came to an end in August 2007.

Unionist political leaders have been extremely reluctant to accept the IRA's steps towards decommissioning as clear evidence of a lasting commitment to non-violent political means, and expressed vocal disbelief that the IRA's final act of decommissioning in September 2005 really represented the sum total of its outstanding stock of weapons. Part of the issue for unionists has been the lack of transparency in regard to decom- 
missioning. As is its right according to the terms of the decommissioning scheme, the IRA has refused to specify how many weapons, ammunition and explosives have been "put beyond use" in each act, and therefore the IICD has been very restricted in terms of the details it can provide. Nevertheless, the IICD stated that the IRA's third act of decommissioning involved a larger amount of weapons than the previous acts and included light, medium and heavy ordnance and associated munitions as well as automatic weapons, ammunition, explosives and explosive material, ${ }^{27}$ and has expressed the conviction that the fourth and final act did represent all the arms under the control of the IRA leadership. ${ }^{28}$ The IICD has an inventory of the arms concerned, but will not publicly disclose it without IRA agreement.

Kris Brown and Corinna Hauswedell argue that although disarmament of warring groups in the context of attempts to end conflicts has been crucial, sometimes as part of demobilization and reintegration programmes, "the heightened status it has received in Northern Ireland, where it became the core issue of dispute between rival sectarian groups during an eight-year period, is virtually unprecedented". The highly politicized nature of debates on disarmament has been unfortunate and unhelpful for the building of a stable peace, yet has served the strategic interests of both unionists and republicans at various points. Unionists have used the issue to apply pressure on republicans and "compensate for political setbacks and failures incurred on other issues", while republicans have used it as a bargaining chip to push for desired political concessions. ${ }^{29}$ As the UN Development Programme (UNDP) has highlighted, disarmament (and demobilization and reintegration) often has "a symbolic and political importance beyond the sum of its parts". ${ }^{30}$ This has certainly been the case in Northern Ireland, where "the symbolic value of guns surpasses their inherent military potential" and "the issue of paramilitary arms... serv[ed] as the political foundation upon which both conflicting parties anchored their positions". ${ }^{31}$ For republicans, "the symbolic importance of retaining weaponry served as political ballast, its purpose being to steady the Republican movement while it jettisoned much of its traditional ideology". ${ }^{32}$ Arms, then, became a symbol of continuity during a highly uncertain period of great change. Nevertheless, the eventual efforts of republicans at decommissioning have been spurred by their commitment to the survival of the new political institutions. For loyalists, the traditional construction of the purpose of their paramilitarism as being the provision of defence for the loyalist community, as part of their oft-mentioned "siege mentality", has reinforced their determination to refuse to decommission weapons in the context of their weaker and less consistent commitment to the new political order, a crisis of identity and perception of deepening political and socio-economic exclusion. ${ }^{33}$

Despite the participation of women in Northern Ireland in the trans- 
port, concealment and even usage of arms during the Troubles (discussed in a later section), a masculinist identity associated with paramilitarist gun possession and usage is as visible there as in other countries. As Wendy Cukier emphasizes, although "violence is not an exclusively male practice, it is linked to masculine identity and guns are a part of the dominant masculine code in many different cultures". ${ }^{34}$ However, this does not mean that those women who have had a more intimate relationship with small arms than other women, through their paramilitary activities, are more likely than men to be in favour of disarmament in the context of "peace". In fact, women on both sides of the politicomilitary divide who were interviewed for this study tended to see disarmament as a political red herring, a distraction from "more important" issues such as poverty, education and the broader constitutional question. Republican women, in true republican fashion, tended to view decommissioning as a ploy on the part of unionists to continue to block nationalist access to political power, while loyalist women tended to view it as an irrelevant issue since the IRA could easily procure more weapons and manufacture more explosives if it went back to war, even if its entire existing stock were to be put beyond use (which loyalists do not believe would ever happen). The recurring refrain essentially was "so long as the guns are silent, it doesn't matter if they still exist". This, however, is a problematic attitude in light of post-conflict patterns of violence in Northern Ireland (as elsewhere), which are discussed in the next section.

\section{New forms of violence}

The UNDP has noted that demobilization of armed groups "is only possible when there is some measure of disarmament. Similarly, the success of demobilization efforts is contingent upon effective rehabilitation of the former combatants and their integration into civilian life or a restructured army." 35 However, as Brown and Hauswedell point out, "the decommissioning debate [in Northern Ireland] occurred in the absence of any concept or programme of demobilization or ex-combatant reintegration". In fact, "no comprehensive approach towards alternative civilian options for members of paramilitary groups has been developed in Northern Ireland". ${ }^{36}$ This may have contributed to the fact that in the context of attempts to emerge from the protracted conflict and consolidate peace, violence in Northern Ireland has continued and at times increased, with new forms of violence emerging and increased rates of "ordinary", non-conflict-related crime. As the UNDP argues:

Small arms and light weapons facilitate the creation of cycles of violence. At the local level, these cycles of violence distort attitudes and behaviour in 
a given society. In the most benign form, cultures of violence entail the normalization and glorification of war, weaponry, military force and violence in popular media, sport and recreation. At worst, cultures of violence celebrate armed violence and privilege violent solutions to peaceful ones in which individuals seek recourse to physical protection rather than dialogue and reconciliation. ${ }^{37}$

Caroline Moser contends that reducing one type of violence (political, economic and social violence are her three categories) does not necessarily reduce other types - in fact, it may lead to an increase in instances of other expressions of violence. She points out that after El Salvador's peace accords and the subsequent reduction in political violence, rates of murder and economic crime increased. ${ }^{38}$ Similar patterns may be occurring in Northern Ireland. It is a common complaint of locals in Belfast that "ordinary" street crime (economic crime and apparently motiveless violence) has increased rapidly since the easing of political tensions and violence. Reports of racially motivated attacks have also significantly increased since the signing of the Belfast Agreement; so as sectarian and political violence has decreased with the cease-fires, racism and racist violence (social violence) appear to have increased. ${ }^{39}$

Evidence from other contexts also suggests that the wartime proliferation of small arms and light weapons contributes to a rise in levels of domestic violence against women involving small arms; political violence encouraged or supported in the context of war is transformed into interpersonal violence, particularly in the "post-conflict period". ${ }^{40}$ More research in this area is vitally needed: there appears to be a lack of data despite domestic violence being a widespread problem in Northern Ireland. Available statistics on domestic violence from the Police Service of Northern Ireland are beginning to improve, but do not disaggregate incidents of domestic violence into those involving weapons and those not involving weapons. Feminist and domestic violence activists, however, have carried out independent investigations that suggest that throughout the conflict and beyond:

The interaction of militarism and masculinity in Northern Ireland means that there is a much wider tendency [than in the rest of the United Kingdom or the Republic of Ireland] to use, or to threaten to use, guns in the control and abuse of women within the context of domestic violence. For a proportion of women within these households, the availability of guns has provided the additional fear that they or their children could be shot in conflicts involving domestic violence. $^{41}$

The increased availability of guns in Northern Ireland has meant that particularly dangerous forms of violence have been used against women 
domestically. Monica McWilliams reports that a "significant feature of the incidents in which guns had been used in homicide or assault cases was that the majority of victims have been married to members of the security forces", who are entitled to apply for "personal protection weapons" to keep at home. Other men who do not keep weapons in the house, mostly members of paramilitary organizations, have threatened their partners with believable suggestions that they could get access to guns easily. ${ }^{42}$

One of the most significant and threatening developments since the signing of the Belfast Agreement has been the deepening intra-loyalist violence. In the summer of 2000 a violent feud erupted between the U1ster Defence Association (UDA)/Ulster Freedom Fighters (UFF) and the Ulster Volunteer Force (UVF), centred on the Shankill district of Belfast, which left dozens of families and hundreds of individuals homeless. Internecine conflict between different paramilitary groups on the same side of the divide is by no means historically unknown in Northern Ireland, but the bitterness and violence associated with the feud between the UDA/UFF and the UVF in 2000 were unprecedented within loyalism and have left a legacy of suspicion and hatred. Brown and Hauswedell note that in 2001 this violence also spilled over into threats and attacks on nearby Catholic homes and there was a significant rise in paramilitary attacks. ${ }^{43}$ This outbreak was closely followed in 2002 by intra-UDA/UFF violence. Since then there has been a long and vicious internal feud within the UDA/UFF between different local leaders over the drugs trade, territory and power, originally centred on "C" Company leader Johnny Adair's struggle for ascendancy (at times even while behind bars). ${ }^{44}$ In early 2003 this feud resulted in the expulsion of a number of families from their homes in Adair's territory in the lower Shankill, and their flight to Scotland and England. Possibly because of the fragmented and haphazard nature of their origins, internal rivalry and competition between different areas have always been a significant problem for the UDA/UFF. ${ }^{45}$ However, again this feud was unusual in the intensity of its violence. In the two years after the 1994 cease-fires the number of paramilitary-style shooting casualties was very low, then rose to annual rates of 72-73 in 1997 through 1999. In 2000, however, the number of such shooting casualties rose sharply to 136 and peaked at 186 in 2001, subsequently subsiding to a low of six in $2007 .{ }^{46}$ Significantly, between 1995 and the end of 2006 loyalists were responsible for over twice the number of paramilitary shooting casualties as republicans (764 versus 364). ${ }^{47}$ Since 2007, however, the balance of armed paramilitary violence appears to have shifted towards republicans as so-called "dissident republican groups" have targeted police and military personnel, though as of early 2009 the casualty figures remain low. The total number of shooting inci- 


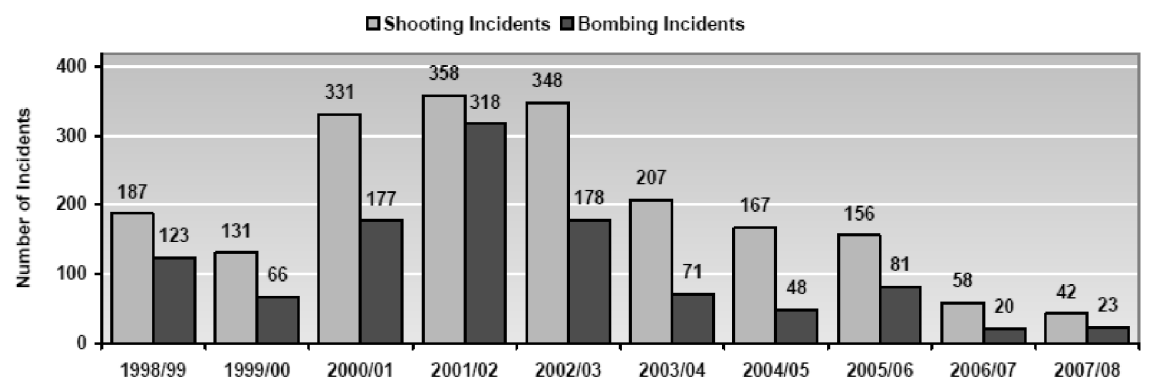

Figure 8.1 Shooting and bombing incidents, 1998/1999 to 2007/2008

Source: Police Service of Northern Ireland statistics, available at www.psni.police. uk/5._statistics_relating_to_the_security_situation_2007-08.pdf.

dents is actually much higher than just the paramilitary shooting casualties - see Figure 8.1, which includes paramilitary-style shots fired, shots fired by the state security forces, shots heard and later confirmed, and other violent incidents involving shots fired (such as armed robbery), as well as bombing incidents. These figures are not disaggregated by sex, but judging by Northern Ireland patterns they are likely to represent largely (though not exclusively) male-on-male violence. Nevertheless, if women are less frequently the direct victims of shooting incidents outside of domestic violence, they are frequently indirect victims as partners or family members of those killed or injured.

Edward Laurance and Sarah Meek point out that "the post-Cold War period has found many countries experiencing an increase in common crimes that can be directly traced to the availability of weapons", and note that this problem is often related to weapons left over from wars and not destroyed. "Crime does not occur in a vacuum, and the poverty and relative deprivation of the populations explains a great deal of this crime wave. However, the use of military-style weapons has emboldened the disaffected and has added to the level of damage and insecurity in the communities involved." 48 A significant feature of the recent phase of Northern Ireland's history is the transformation of loyalist paramilitarism and violence away from motivation by politics and towards "ordinary decent crime", particularly drug smuggling and dealing. Brown and Hauswedell state that there has been a 500-1,000 per cent rise in drug usage within Protestant working-class areas since the mid-1990s. ${ }^{49}$ Turf wars over drugs, racketeering, extortion and prostitution were a significant factor in the internal splintering of the UDA/UFF.

This transformation of loyalist violence and purpose was a theme that emerged repeatedly in my interviews with loyalist women. All were concerned at the implications of this shift for their communities, particularly 
for the lives of young women. Those who had participated in political violence in the earlier days of the Troubles were scathing and dismissive of drug-dealing loyalist paramilitaries, whom they viewed as bringing loyalism into disrepute. According to Alison, "When money comes in, loyalty goes out the window... The generation these days are only loyal to themselves and their own pockets." She further said that "in the late $60 \mathrm{~s}$ and the early $70 \mathrm{~s} . .$. they were there fightin' a cause. I think a lot of them joins now for a cause for themselves; it's not the same, it's completely different. And the drugs situation has a lot to do with that." 50

\section{Women's role in the concealment and transport of arms}

In both republican and loyalist paramilitaries it was women who had primary responsibility for hiding and transporting small arms and explosive materials, as the gender ideologies of Northern Ireland meant that women were perceived, at least initially, as less dangerous than men. They have been consistently less likely to be stopped and searched than men. Members of the British military previously stationed in Northern Ireland to whom I have spoken informally maintained that they knew women engaged in such activities, but that there was a significant risk of negative publicity associated with searching women's bodies. Presumably having female military members or police officers carry out body searches of women made this less problematic, but given their lower numbers this was not always an available option. Being searched or interviewed by women rather than by men was not, however, necessarily less problematic for the women being searched. Numerous accounts report physical and sexual molestation or harassment, and implicit or explicit threats of sexual violence, being meted out by male members of the security forces with the complicity of female colleagues, or by female members themselves. ${ }^{51}$ Forcible and often violent strip-searching of female prisoners by female prison officers has also been an extremely significant gendered aspect of the prison experience for republican women, and on numerous occasions it has clearly been used deliberately as a gendered tactic of intimidation. Many prisoners have experienced this as being psychologically akin to rape. Nevertheless, in Northern Ireland the politics of gender did give women greater freedom (though not without considerable risk) to carry out paramilitary roles, as can be seen in the following personal accounts.

Niamh $^{52}$ joined Cumann na mBan as a teenager in the early 1970s, having belonged to a junior organization before that. She transported weapons and performed other supportive tasks, and was involved with Cumann na mBan for a number of years, being "active" from the 1980s. 
She stated that in the earlier years of the conflict "it was very much a case where men fired the guns and women generally carried the guns", though this later changed for republican women.

For Maria, ${ }^{53}$ concealing weapons resulted in major life changes. After the Troubles began she and her husband allowed their house to be used by the IRA for meetings and to hide weapons, explosive materials and money from bank robberies. This led to the arrest of herself and her husband in the early 1970s, when items were found in the house during a raid. When she was allowed out on bail she took her children and went on the run in the Irish Republic for a few years before returning north under an assumed name, after leaving her abusive husband. She lived a very "quiet life" in Belfast until the early 1980s, when she began disguising IRA operatives. Later she rejoined the IRA and went on "active service" until her imprisonment for her part in an attempted bombing.

Maria is an example of the fact that, contrary to the maternalist feminist position, which claims a special relationship between women and peace on the basis of women's biological or social role as mothers, ${ }^{54}$ motherhood can be as much a basis for militarism as for pacifism. ${ }^{55} \mathrm{~A}$ factor in her decision to rejoin was that one of her sons wanted to enlist in the IRA after he reached the end of his endurance when his girlfriend was sexually harassed by British soldiers. Maria was totally opposed to any of her children being involved, and conceptualizes her own participation as being in large part trying to create a better life for them:

I said "I am not gonna go and visit you in prison. I am not gonna bury you with a tricolour over you. I'll do anything that has to be done, I will not see any of you doin' anything. When I first joined the IRA in 1970 it was with the view that my kids would never go through or suffer the indignities that we had to suffer, and I am stickin' to that." And I went and I joined the IRA again.

While in the case of republican women the concealment and transport of weapons was often one paramilitary role among many others, including more "active" roles, for many loyalist women it was their sole or primary role. All the loyalists I interviewed (both female and male) who had been personally involved in some way with paramilitary organizations stated that, notwithstanding the few women who took more directly combative roles, there was a clear gendered division of labour in loyalist groups, with women being involved in support roles such as carrying weapons and first aid, rather than close-quarter killing or planting bombs. Tracey, ${ }^{56}$ an ex-UVF member, cleaned, stored and moved guns and drove on operations. She also admitted, though not in detail, to a more active involvement. She went to prison in the 1970s for weapons possession, after an initial murder charge was dropped, and served five years in 
Armagh prison. She explained to me that, although she was willing to work with small arms in other ways, when she joined the UVF she informed the organization that there was no way she would ever be involved in armed robberies (one of the fundraising activities of paramilitary groups on both sides of the divide), since she viewed that as morally wrong. "You earn your money and I believe you're entitled to it, and I earn mine. I go out to work, earn my money and that's mine. I wouldn't lift a gun and take money off you. That is not up my street at all."

Two other loyalist women I interviewed, Ann ${ }^{57}$ and Alison, ${ }^{58}$ also engaged in the concealment and transport of weapons as well as activities not involving the use of arms, such as first aid and fundraising. On numerous occasions Ann took weapons away for male UVF members after they had been on an operation, as it was too risky for men to carry guns in case they were searched. She went out with men who were going on an operation, to carry the weapons to and from the job, and said that if women were caught with guns the men would say that they forced them to carry them. "Many's the time a fella just walked past you, you just opened your bag [for the weapon] and walked on, you know?" She also went to inform young women that their paramilitary husbands had been killed and took away any weapons left in the house, before the RUC arrived. Ann initially became involved with the UVF through her husband's membership of the organization and, like many militant women in Northern Ireland and other similar contexts, strategically utilized existing gender stereotypes to pursue her military objectives:

Well, my husband was involved and they couldn't be involved without you knowin' some things, and you were used just. Didn't have to be, if you didn't want to do it you didn't do it but, you know, you used to go up the road with your pram, the child sittin' in it, and "hello" to the soldiers and they didn't know what you had under the pram! [That is, concealed weapons.]

As I discussed earlier, local gendered ideologies combined with British military gendered expectations and concerns about publicity to provide women like Ann with a certain space in which to operate. On the other hand, as I have asserted elsewhere, the known actions of militant women may also in some cases contribute to the physical insecurity of other women, who could potentially be subject to unjust harassment as a consequence of this. ${ }^{59}$

Later, Ann was asked actually to join the UVF, which she did. "Nobody forced me. It wasn't all wives was in it but I think it was just like a chosen few at that time was asked. Well I mean you were doin' the things anyway so why not, you know?" After joining the UVF she had weapons, physical exercise and drill training and did "certain things" but was 
"never involved the way the men were". In one incident she had to dispose of a gun, with a soldier standing nearby, in the middle of a fraught situation where her female companion had been shot in the back when their car got caught in crossfire between the IRA and the British Army. Her narrative of this incident suggests that, as was implied earlier, even when the British military knew women were involved in such activities they were not always clear about how to respond to this - perhaps particularly when dealing with Protestant women, given the at least tenuous (though inconsistent) relationship of mutual support between the state security forces and loyalist paramilitaries. The soldier witnessed Ann run past him as she shouted "we're Protestants, leave us alone!", concealing the gun under a coat until she threw it over a wall. She reported that the soldier appeared shocked and seemingly didn't know what to do, but he later testified against her in court. However, Ann told the judge she had been forced to carry the weapon and, in another example of gender ideologies at work in terms of differential treatment of men and women, the judge in her case dismissed the charges, telling her to go home and look after her children.

Alison's father was imprisoned with a lengthy sentence for paramilitary offences when she was a child, and she and her sister worked in part-time jobs to help support the family. She married at 17 and, like Ann, became involved in paramilitary activities through her husband. She never officially joined the Red Hand Commandos (her husband's organization) or the UVF (her father's organization), but was actively involved in support roles, primarily moving weapons. She makes a connection between loyalist women's involvement and their need to protect their families - again, implicitly challenging the maternalist feminist argument - stating "I would be a person who would fight tooth and nail for my family. And if I thought anyone was gonna harm them in any shape or form, I wouldn't care what measures I had to go to, I would do it." She suggested that for many women, the reason they became involved was that the conflict began touching the lives of their families:

It was affectin' their families, it was affectin' their husbands, it was affectin' their kids. They were defendin' their families and that's why they did it. Because probably the man, in my opinion, they joined for to defend their country. Women would've joined to defend their families. Within the loyalist side, yeah, they would've joined because they were defendin' their families and their homes.

Alison feels that "the women were the backbone of the paramilitaries, years ago; the men couldna done it without the women. You know, moving guns and things - the men didn't do that, the women done that, so 
they did." A number of times she went to Liverpool on the ferry from Belfast and came back with grip-bags full of guns. She remembers one occasion when there was "trouble" going on at the Springmartin estate in Belfast and she and other loyalist women hid rifles up under their long coats and pushed their way through the army to get them to a safe house. "It was easier for the women to do. But not only that, it took a dedicated woman to do it, it wasn't every wife that would've supported their husbands in that affair. It took you to believe in it yourself."

This idea of loyalist women engaging in paramilitary activity from motivations of protecting their families and homes and loyalist men enlisting to "defend their country" (a more directly and abstractly political goal) is intriguing. The editors of Arms to Fight, Arms to Protect, the result of an extensive oral history project on women in conflict situations around the world, suggest from their interviews that even when women strongly identify with a cause or community, they usually still participate in war as combatants only when their families or homes come under attack. ${ }^{60}$ This mirrors Turshen's point, discussed earlier, about contemporary conflicts breaking down the boundary between (male) combatants and (female) civilians. Relatedly, Robert Miller's discussion of gender in societal transition periods is also relevant. Miller refers to Michelle Saint-Germain's claim in regard to the Argentinean group Madres de la Plaza de Mayo that "Ironically, it was in many cases the invasion of the private sphere by government authorities that provoked women to enter... the public sphere." 61 On the other hand, to what extent this holds true as a generalization about women who engage in political violence remains open for discussion. Even in the Northern Ireland context this deserves further investigation in regard to both loyalist and republican paramilitary women. Whether the different ideologies of loyalism and republicanism are significant in terms of defence of family having greater or lesser importance as a motivating factor is also an interesting question, given that loyalism places great importance on "traditional" gender roles and women's family concerns while republicanism is, in principle, more open to challenges to the status quo. As reported earlier, women such as Maria explicitly became involved with the IRA as a way, in their view, of protecting their children and creating a better life for them. On the other hand, it is worth noting that a male ex-IRA member turned community worker whom I spoke to suggested that there were many male IRA members over the years, particularly during periods of intense IRA activity, who joined the organization because it was the general social expectation in their communities at the time and their friends and peers were doing so, rather than because of a deeply held political belief. In contrast, he asserted, there was not the same community expectation of 
women and most of the female members he knew were more educated about the struggle, "more political", in his words, and joined from these motivations.

\section{Gender relations in paramilitary organizations}

\section{Republicans}

Like many others, Yuval-Davis notes that women have not easily been integrated into most state militaries and argues that "womanhood" is not easily incorporated within the imagery and experience of the military, which supposedly makes "boys" into "men". Woman-hating and homophobia are generally part of the training of male recruits, and rape and sexual harassment of female soldiers are common. In contrast, she asserts that in national liberation armies, with less formal hierarchical and organizational frameworks, "a strong common ideological stance might help to transcend some of these tensions". ${ }^{62}$ This certainly seems to have some validity in many cases, particularly in contexts where liberation movements have drawn from socialist ideology, but the evidence from Northern Ireland is somewhat mixed. My interviewees' experiences of gender relations within the IRA varied, primarily according to the time of their involvement. It seems that there was a significant change in attitude on the part of the organization and the male members over time. On the whole the younger women I interviewed, who were active in the 1980s and 1990s, did not report experiencing sexism or a lack of respect from male colleagues, nor any gendered division of labour (apart from the fact, as previously noted, that it was usually women who carried weapons away). In contrast, women who were involved in the early 1970s were more likely to report various incidents of sexism that excluded them in some way or another from the struggle, or inhibited their participation.

In the early 1970s women had to fight hard to be allowed into the IRA itself rather than into Cumann na mBan. A male ex-prisoner told me that "in the early days they [women] were treated as just a wee bit more than coffee makers". When Teresa ${ }^{63}$ joined there were almost no other female volunteers anywhere in the country.

When you first approached the movement you're told go and join Cumann na mBan and you said "no, I don't want to join Cumann na mBan, I want to be a volunteer", and you basically had to fight your way. Of course it depended on who you approached - if you approached the right man and you kind of sussed out somebody who was a bit more forward lookin' than some of the older men. 
However, she reported that although she had to struggle to get in, once she was in "I must say I had a wonderful experience with the men that I worked with. They accepted me totally. I was treated just as another volunteer." However, she concedes that "in many ways, lookin' back I know they spoiled me in many ways [by being over-protective]". Like most of the women I interviewed, Teresa also stressed that her own experience should not necessarily be taken as representative of that of others. "Now there would've been other people in the Army [the IRA] who would've been very dismissive of women bein' in the Army... I had a very positive experience in the Army but that's not to say that there weren't men there who were Neanderthals, you know, thought 'what's a girl doin' in the Army?" "She believes that "once we broke the ice it was easier, you know, once we had actually joined and the precedent had been set, it then became easier for women to become volunteers".

Mary, ${ }^{64}$ also involved in the struggle in the early 1970s, said that in those days "there were very very few women who would've made it into the Army, but those of them who did make it into the Army ... would've been treated exactly as [the men]. The fact that they were brass-necked enough to get in there in the first place would have meant that they had the same responsibilities and duties." On the other hand, she also reflected that:

I was to an extent tolerated as a necessary evil and did indeed even have my uses, but it is still essentially a male bastion and while I assumed a "male" role to some extent I never seen any evidence that my male counterparts embraced or took on any of the more traditional female roles. This differs slightly where the male had spent some time in prison but essentially I feel the whole experience did not further the cause of female emancipation.

Interestingly, Mary reported more instances of resistance to her involvement and leadership, as a woman, in republican political activities than in their military activities. Male republicans in Counties Kerry and Galway in the late 1970s gave her a cold welcome when she arrived to coordinate the H-Block campaign, though she asserts this would not have happened in Belfast or County Tyrone. "There was more equality within the military, and I would say that is probably because the soldiers respect [each other]." She also feels there was a difference in her parents' attitude towards her involvement and their attitude towards her brothers' involvement, although they did not try to stop her. Similarly Caral ${ }^{65}$ and Maeve, ${ }^{66}$ involved in a later phase of the conflict, feel that their parents took their involvement and imprisonment harder because they were daughters rather than sons.

Teresa and Mary also indicated tensions in the early 1970s between female volunteers and the older women of Cumann na mBan over 
women's appropriate gender roles. In Teresa's words, "there was a great feelin' within the Cumann na mBan circles of, oh, you kind of thought you were better than them - but it wasn't a case of that, it was just a case of Cumann na mBan had its place and it was great work that they did but it was just that I didn't want to do that, I wanted to do somethin' else, I wanted to have more of an active role than a supportive role." Mary reported that:

In the early '70s when I came to Dublin [on the run] the women's organization would've been quite standoffish from the couple of us women that weren't in [Cumann na mBan] - I think the word "hussy" would've been used, you know? But I think that left, as society itself progressed that stopped. I don't think that was an issue even in the late ' 70 s... It was just that first break had to be made.

She remembers an incident "when this particular [Cumann na mBan] woman was being obnoxious and giving out about being treated properly, and this woman [volunteer] was getting ready to go out for the night clubbing, and the OC [commanding officer] made this woman [volunteer] stand guard all night on a training camp and was told 'that's equality for you, dear'. Still in her finery!" However, Mary did admit that for their own part "we would've been scathing about them [too]. We would talk about them and their bandaids, you know, and their first-aid kits. Yeah, we would've been just as chauvinistic."

Maria was involved in supportive roles in the early days of the Troubles and then very active in the late 1980s to early 1990s. She experienced a real difference in respect between the two periods. "In the early days I would say it didn't matter what you did, it was just 'thanks love', you know? 'Good for you', and like patronizing. But certainly the second time around I felt greatly respected. And I woulda been in charge of a job maybe... and I liked that... I liked knowin' exactly what a job was about, where I was goin'." Part of this, she feels, is due to the impact of male ex-prisoners, many of whom took some women's studies classes in prison and experienced a certain re-education. "I was almost revered at times and I couldn't believe it, you know, that I was gettin' this respect from men, and then we talked about women's studies and all and I thought 'God, so this is what the new men are like!' In sayin' that, mind you, there was still the ones who were still Mr Macho Man, you know? They tended to be the ones that hadn't been to prison and hadn't been educated in that way." Similarly, Niamh felt that in the later phase of the conflict "in me own experience with people who have went to prison and come out, people who went to prison especially would be much more progressive in their attitudes towards feminism, towards equality". Nonetheless, she still 
encountered some sexist attitudes. At one point she was arrested and held for interrogation (before the time she was imprisoned) and afterwards she heard that a male volunteer had said "oh she'll break [and reveal information]", which she believes he would not have said if she were a man. She remembers feeling very angry about the intimation.

Although the interviewees who were active in the 1980s and 1990s generally said they were treated the same way as male volunteers and felt respected by their comrades, like Teresa they all stressed that they were speaking only from their personal experience and it was quite likely that others had had difference experiences. ${ }^{67}$ Like Teresa before them, both Eileen $^{68}$ and Mairead ${ }^{69}$ believe that their male comrades were a little more protective towards them and a little more concerned for their safety, perhaps even subconsciously. Eileen also suggested that "at the height of struggle people maybe were treated a little bit more equally in a sense, because there was so much to do and there was no point in saying well you go off and, you know, make the sandwiches while I - because there was too much stuff for people to do". In accordance with this suggestion and Mary's reported experiences, Mairead also indicated that there has perhaps been greater gender equality within the military side of the republican movement than within the political side in terms of how people were treated and issues addressed. This view also fits with some of Caral's comments. One of the few blatantly sexist incidents Mairead experienced was not in the IRA but in Sinn Féin after her release from prison:

I'm not going to say that there isn't people with sexist views in the movement, there is. I'm not going to say I've never experienced sexism. But it was in a different part of the movement that I experienced sexism - you know, where people just hadn't politicized themselves and were stuck in the past and then you were comin' in and you were young and you were female and, you know, they were just goin' like "yeah stick the kettle on" and you were goin' like [sarcastically] "yeah, dead on, so I will".

Despite significant numbers of women being involved in the IRA, some male paramilitary members have not been comfortable with women being on "active service" and, as well as occasionally refusing to go out on an "operation" with female volunteers, ${ }^{70}$ some seem to have maintained conceptualizations of their masculinity that entail a certain relationship by which they derive status from possessing and using guns and respond to female comrades as constituting a potential threat to their masculinity. Although Teresa asserted that on the whole her experiences within the IRA were of equal treatment, she also reported the odd occasion where a man "would expect to be given a better weapon than a 
woman, and certainly if that wasn't the case they were kind of 'why's she gettin' that and I'm gettin' this?', On the other hand, in her own experience 'the people I was workin' with would say 'well because she knows how to use that and you don't'. Quite a simple answer, you know, and gender wasn't brought into it."

As I have already mentioned, the issue of motherhood is significant. However, it is an area in which the gender-blind approach of the IRA, in terms of treating male and female members in the same way, has in fact had negative outcomes for women. Many active republican women over the course of the Troubles had children during their involvement, including four of my interviewees. The IRA has not had institutionalized childcare facilities for operatives and the organization does not seem to have made any particular effort to facilitate the involvement of women with children. It was expected that a man with children would have a wife to care for them while he was on an operation, and it does not seem that much allowance was made for mothers, aside from giving them more prior notice than men about an operation so that they could organize childcare arrangements themselves. Maria had small children during the first, more auxiliary phase of her involvement in the early 1970s. However, she chose to wait until her youngest was a reasonable age before becoming "active" and undertaking any operations that might have got her killed or imprisoned for a long period of time. Her youngest was 12 when she was imprisoned and was cared for by her older children. Emma $^{71}$ had young children during her active involvement (in the Irish National Liberation Army rather than the IRA) and was reliant on other women to help her to carry out her activities - her sisters cared for the children while she was out or away. She was married but the relationship was strained, and her husband was a fairly absent father as well as (I believe) being involved in the struggle himself. Bernadette ${ }^{72}$ actually gave birth to her first child during her trial, while on bail, and was allowed to keep her baby with her in prison for the first year. After that she was forced to send the child out of jail, to be cared for by a female relative, her mother-in-law. Her husband, also "active", was not in prison at that time but their house was constantly being raided by the security forces and he was not able to care for their child full time. Caral's children were around one and two years old when she was imprisoned, which must have been extremely hard, but she was unwilling to discuss this issue and I am unsure who cared for them.

Cynthia Cockburn cautions that "Even in liberatory national movements women are driven to a double militancy, organizing in and against' the movement to give a contrary spin to its prevailing gender relations. If women in the movement organize in the interests of women as women, and more so if they form anti-militarist and cross-ethnic women's 
projects, they are quickly cast as traitors." ${ }^{173}$ This dual struggle has been part of the experiences of women working within nationalist movements across the globe, and Irish republicanism has been no exception. Caral feels that outside of the armed side of republicanism, where "first and foremost you were a soldier and that was it", in the wider movement "there was a certain amount of denial about, you know, we're gonna build this utopia... Well I never seen that. I seen the same women who were struggling, who were demanding equality within every aspect of their life - and they got it within the movement, but they got it because they fought for it, not because it was the right thing to do." One of the reasons she never joined Sinn Féin (though she has since this interview) was the party's refusal of unequivocal support for abortion rights, which has been controversial within the party and is an example of feministnationalist internal tensions. Caral said "to me it's the contradiction of fightin' a struggle for national liberation, and it's always been a big contradiction for me because yes, me and a fella will certainly take up arms to liberate A, B, C and D, but will the same comrade feel as strong about gettin' equality for women? No, not them at all. And that's a contradiction."

\section{Loyalists}

As I have previously noted, loyalist paramilitary groups have had a clearer sexual division of labour than republican groups. Further, my research suggests that a common pattern for loyalist women was never officially to join a paramilitary organization but to be active in support roles through association with their husbands. When I asked Alison about this she suggested it may simply have been because the men never thought to ask the women to enlist, but did not indicate a strong push from women themselves to join. "I don't know, maybe because no one came and says to me 'do you want to get swore in?' If somebody came and said to me 'do you wanna get swore in?' I probably woulda said 'yeah'. And I think that was the only reason." It never occurred to her to ask to join, but she is clear that if she had been approached, she would have accepted. "Maybe they thought the women just didn't want to, they were quite happy the way they were. They maybe just did not think of approaching them for to do it." Linda, ${ }^{74}$ however, though never directly involved herself, maintained that there were a number of women in the past who wanted a women's military wing established in the UVF but they were not supported by the organization. There have been a few UVF women who engaged in the full range of military activities, but by all accounts they were rare and probably faced a lot of opposition. As noted earlier, access to such women willing to speak to researchers about their past is difficult, 
which I believe to be largely due to the greater community stigma attached to being a female loyalist paramilitary than a male one. Alison maintained that the majority of those women who joined loyalist paramilitary groups, in whatever role, would have done so with the backing and help of husbands but that "there would be some male chauvinist pigs out there within the loyalist side thinkin' that women couldn't do just as good as a job as them 'uns'. She claimed that most loyalist women would not have wanted the same kinds of roles as men had. When I asked why not, she replied, "I don't know. Well, from my experience and different bits and pieces that I would have done, I was just quite happy in exactly what I was doin' because it meant I was still doin' my bit, so I was. I was doin' my bit."

The Ulster Defence Association did in fact have a women's branch in the early years of the Troubles, but this was disbanded as early as 1974 after a number of its members murdered Ann Ogilby, a married Protestant woman who made prison visits to an unmarried male prisoner. Ogilby's murder was a "romper-room" killing: she was beaten to death while her six-year-old daughter was sent out to buy sweets. ${ }^{75}$ Sales notes that this murder provoked widespread revulsion, even among UDA prisoners, and suggests that although punishment of women seen to transgress the gendered rules of society has been tolerated within the Protestant community, as it has within the Catholic community, ${ }^{76}$ "the fact that it was women, acting on their own initiative, who carried out this particularly brutal murder may have contributed to the condemnation". ${ }^{77}$ This illustrates the point that in many cases women who engage in organized violence (or in fact individual violence) are viewed as deviant in a way that men are not; women's violence remains more socially shocking. Nevertheless, women have continued to be involved in the UDA, and in 1980 a Protestant woman claimed to Eileen Fairweather that of 13 people on the UDA's inner council, at that time three were women. ${ }^{78}$ However, one of my interviewees informed me that women currently have no say in the workings of the inner council. ${ }^{79}$

Tracey, my only loyalist interviewee who engaged in more than support activities, explained that when she first joined the UVF there were a number of resistant male members. Because she was female they were "very iffy, but they seen then that I was genuine enough like, I wouldna talked". She noted that "I woulda said that most of the men didn't want women to be involved." When I asked why not, she replied, "I don't know. I don't know - the female's the weaker sex [they think] ... I always seem to be the odd one out." Over time they came to accept her but she gave the impression that this acceptance had to be hard earned through proving that she was trustworthy by not talking when arrested. With some exceptions, men generally did not say things to her face, but a 
male paramilitary friend told her of some men who had made remarks about not wanting her to be involved in operations. "They don't think that's a woman's place. Like I was told one time I should be at home washing dishes. That's the place to keep a woman, chained to the kitchen sink! [She laughs.] Aye, dead on. I says 'get stuffed, wash them yourself!" She reported that "I got an awful stick off men for, as they said, carryin' on the way I was doin'... I was a girl, I should be sittin' knittin', washin' dishes and rearin' [children]." Men seemed to assume that women were more likely to crack under interrogation and give away damning evidence - which, as noted in the section on republican women, was also an experience of Niamh. The week Tracey was in the army barracks being interrogated in relation to the incident she was later convicted for, she refused to admit anything or make a statement until after all the men who had been arrested with her had made statements. She is proud of this, and feels it changed the way the men looked at her and earned her a lot of respect from them. She carries no bitterness towards the men who earlier doubted her, as she feels she proved them wrong.

\section{The sexual appeal of arms and paramilitarism}

An under-discussed aspect of the Northern Ireland conflict, and indeed of other armed conflicts and non-conflict armed societies, is the sexualization of violence and weapons from women's perspective. Although much is made of the sexualization of arms and violence for men, feminists have been more reluctant to address the question of women who are attracted to this form of masculinity, and what this says about constructed femininity. This is a difficult area to assess, and requires extensive further investigation, but certainly one loyalist woman I interviewed raised the issue independently of my questions. Speaking of herself as a teenager, Linda said, "when we'd a went out, me and my chum, it was all paramilitary ones we run about with, it's the power... They're the paramilitaries, you know... I truly believe that power's the biggest aphrodisiac in the world, and that's bein' honest with you. I really do believe that." She feels that this is what drew her to her husband, who is a UVF man. However, through her later involvement in community work she came to change her opinions in many areas and now believes that the attraction of the paramilitaries is one of the social problems facing young people in loyalist communities, alongside alcohol and drugs:

I always hear them sayin' about wee boys gettin' drawn in - I think they're overlookin' the wee girls out there that gets drawn in, and they get drawn in in a big way because they see somebody with a flashy car, jewellery, you know 
what I mean, and they are drawn in in a big way, definitely. It's a power magnet for young girls. They're concentrating on boys joining up, but what about the girls that's goin' out there and sleeping with them... [and then] bein' dumped cos there's another young one'll come along.

Related to this is the story conveyed by a male ex-UVF member about women's behaviour at UVF weapons displays and public meetings - behaviour vehemently denied by female loyalists when I asked them if his assertion was true. The man claimed that at such meetings, which involve paramilitary fundraising and displays of their weaponry, some young women become so overwhelmed and excited that they urinate on themselves and, therefore, are dubbed "pishies". This is not a tale I have heard from anyone else, so it is hard either to substantiate or to disprove, but the mere fact it was repeated is interesting in itself, given what it perhaps suggests about male expectations about female sexuality. Of further interest is the fact that the same man claimed that for women to advance through the ranks within loyalist paramilitaries they have to be sexually promiscuous with male paramilitary members. This, in fact, is something I have heard before. Again, however, some loyalist women I put this to were insulted and denied it. For Joy ${ }^{80}$ a community worker with an unspecified past history of UDA loyalist activity, respect is important. She was irate about this man's comment and told me to tell him to come down to the Shankill Road and say that to her, and she would "send him away with a red face!" Any woman who "went down that road", according to Joy, would lose all respect from others. "Any bitch can lie down with any dog. It takes a woman to stand up and say 'no'." The accusation of promiscuity operates here, again, as a means of social control of women, and specifically as a way to contain the challenge to gender norms presented by militant/combatant women.

\section{Representations of paramilitary women}

In stark contrast to the heroic images of female paramilitary members in republican street art (as well as women in other public, active roles), in the iconography of loyalist political murals in Northern Ireland the images are almost entirely masculine. The Northern Irish Protestant churches are conservative in many areas, including that of gender roles and relations, and Sales points out that "The imagery of the Protestant community is masculine, whether it is bowler-hatted Orange men celebrating Protestantism's triumph at the Battle of the Boyne, the archetypal Protestant worker (the skilled male manual worker), the harsh fundamentalist rhetoric of Ian Paisley or the balaclava-hooded Loyalist 
paramilitaries." 81 An interesting recent exception to this has been the media representation of Gina Adair, whose husband Johnny is a notorious UDA/UFF prisoner with links to drug dealing, extortion, prostitution and neo-Nazism as well as murder. Gina Adair has the reputation of being as "hard" as Johnny; while his nickname is "Mad Dog", hers is "Mad Bitch" - an interesting gendered tag in itself, as well as being a play on the "dog" of his moniker. In early 2003 Gina and her children and associates from the lower Shankill Road in Belfast were among those who fled Northern Ireland as the result of the internal split between the main UDA and Adair's "C" Company. Tabloid newspapers have followed their progress continually since then, apparently relishing the reduced circumstances and loss of power of the Adair family. In the Sunday Mail Gina Adair's situation in 2003 is contrasted with her so-called "heyday", with a photograph taken on the Shankill Road some time ago featuring her in a balaclava, miniskirt and belted UFF jumper, holding a Kalashnikov. ${ }^{82}$

The image of an armed loyalist woman remains, however, much more unusual than that of an armed republican woman. Republicanism has promoted active images of women as "freedom fighters", and female paramilitary members are celebrated in a number of republican street murals in nationalist areas. Their representation in the media is also interesting. In 2003 and 2004 two newspaper articles on the Continuity IRA (CIRA, a still-active "dissident republican" breakaway group from the Provisional IRA) pictured female members. The Andersonstown News carried a front-page photograph of five CIRA members. ${ }^{83}$ Three balaclava-hooded figures, clearly male, are seated with the central figure reading a prepared statement. The men are not visibly armed, though there is a handgun placed on the table in front of the man reading the statement. Two other figures stand behind the men, each holding a handgun. Rather than balaclavas, their faces are partially obscured by scarves tied around their lower faces and large dark sunglasses, topped by berets. These two armed figures appear to be female. In fact, later in the article there is a close-up photograph of the face of one of the armed standing figures, with the caption "Show of Strength: Woman CIRA member at secret location armed with a 9mm Austrian Glock 17." No further comment on the presence of women is made in the article.

The Sunday World tabloid similarly carried a front-page photograph of three CIRA members in another "show of strength" in Belfast. ${ }^{84}$ The central figure is an armed woman, flanked by two armed men, though another photograph later in the article shows a third armed man. The article lists the group as being armed with "at least one automatic rifle, two Uzi sub-machine guns and a pistol". Given what Teresa reported in her interview with me about male republicans sometimes demanding better 
weapons than their female comrades, it is interesting to note that it appears to be the woman in this photograph who is carrying the pistol, rather than a submachine gun or automatic rifle. Again, the men wear balaclavas while the woman wears a scarf and beret. On this occasion the female figure is not even wearing sunglasses and her eyes and forehead are clearly visible. Given the sexualization of "terrorist" women it is interesting to note that this female figure has impeccably manicured eyebrows and made-up eyes, and is clearly very attractive.

Mary told me that in the 1970s when she was a republican on the run in the Irish Republic the British authorities released a photograph of her in the newspapers along with her alleged crimes. She pointed out that the authorities could have used her driving licence or passport photograph, yet chose to use one taken outside a Dublin nightclub. "I was good press. At 21 years of age I was reasonably photogenic - without all these wrinkles!" The headlines referring to her, too, clearly indicate a sexualization of the female "terrorist" in terms of their media representation. I cannot repeat those particular headlines, as that would reveal Mary's real identity, but there are other similar headers noted by Jayne Steel, such as "The Sexy Steps of Terror" (1996), "Bomb Gang Beauty" (1991) and so on. As Steel points out, "A curious thing about the press in the United Kingdom seems to be its expectation and demand that female terrorists be young, beautiful and sexy. Clearly something quite strange, albeit very recognizable, is being suggested here about the proximity between fear and desire in which the signifying potential of women in a predominantly male media becomes an important stake in the propaganda war'." ${ }^{85}$ This phenomenon is in fact by no means restricted to the Northern Ireland conflict. Much was made in the press of the beauty of Leila Khaled, the most famous female Palestinian "terrorist" until the recent intifada and its pattern of female Palestinian suicide bombers. ${ }^{86}$

\section{Conclusions}

This chapter has tried to enhance our understanding of the proliferation and use of small arms and light weapons in the context of armed conflict, by bringing a gendered analysis to bear on certain key issues related to the subject. The most significant findings are summarized here. The chapter has, in particular, illustrated how armed conflict draws in different social actors, by examining women's involvement in republican and loyalist paramilitary groups in the Northern Ireland conflict. An interesting speculative idea is the possibility that women who engage in political violence may sometimes be motivated by concerns about protecting their families and homes, rather than more abstractly political goals (though these con- 
cerns and goals can interlink), and that this sets them apart from men who engage in political violence. This idea is supported to an extent by some of my interviews with loyalist women, but is contradicted to an extent by some of my interviews with republican women. It is possible that this reflects differences between the motivating experiences of republican and loyalist women, as well as underlying ideological differences, but given the difficulty in gaining access to loyalist paramilitary women and the lack of comparison with paramilitary men I would hesitate to argue this too strongly. The proposition nonetheless deserves further investigation both in Northern Ireland and in regard to other armed conflicts. It does not mean, however, that we should fall back into the old easy trap of assuming women are apolitical.

One significant aspect of women's involvement in the proliferation and normalization of guns in many different contexts has been their role in smuggling and concealing weapons. This has certainly been important in the Northern Ireland conflict, where women on both sides of the politico-military divide have had primary responsibility in this area due to gendered expectations of women's and men's differential behaviour and concerns over negative publicity (again stemming from gender ideologies) about the searching of women's bodies, which have provided them with a certain space to pursue their military objectives. Those gender ideologies have even, on occasion, meant that women (particularly women from the Protestant-unionist community) have escaped legal punishment for offences involving the transport of arms, such as in the case of Ann who was told by the judge in her trial to go home and look after her children. Ironically, however, those very same gendered ideas about women's roles and women's bodies have meant the deliberate use of brutal physical searches of "rebellious" political women (particularly women from the Catholicnationalist community), in the form of prison strip-searching, as a way to control and contain them.

Regardless of the participation of women in the transport, concealment and usage of arms during the conflict in Northern Ireland, a masculinist identity associated with the possession and usage of guns is nonetheless visible. Despite this, my research showed that women who have transported or used arms remain most likely to hold the view of their politico-military organizations on disarmament/decommissioning of paramilitary weapons, rather than sharing some kind of anti-masculinist, prodisarmament perspective. That is to say, both republican and loyalist paramilitary women interviewed for this study generally saw the disarmament issue as an ultimately irrelevant political distraction from more important things, though their reasons for this varied according to their respective "sides" of the conflict. In fact, some loyalist women even independently raised the issue of the sexualization of arms and violence and 
the attraction many women in their community have for men who accord with this form of masculinity. If this suggests any lesson for other postconflict contexts, it is that militant women cannot be expected to be automatically any more pro-disarmament than militant men, despite the hyper-masculinity of gun cultures. It also suggests that the increasingly well-recognized problem of the wartime proliferation of small arms and light weapons contributing to a rise in levels of domestic violence (in particular involving weapons), which has happened in Northern Ireland as elsewhere, will not necessarily be independently recognized or acknowledged by militant women, even those concerned with feminist issues.

\section{Notes}

1. Farr, Vanessa (2003) "Gender Awareness in Research and Policy Making”, African Security Review 12(1), pp. 115-116.

2. Enloe, Cynthia (2000) Maneuvers: The International Politics of Militarizing Women's Lives, Berkeley, CA: University of California Press, pp. $\mathrm{x}-\mathrm{xii}$.

3. Farr, Vanessa (2002) "A Gendered Analysis of International Agreements on Small Arms and Light Weapons", in Gender Perspectives on Small Arms and Light Weapons: Regional and International Concerns, Brief 24, Bonn: Bonn International Center for Conversion, p. 18.

4. Grant de Pauw, Linda (1998) Battle Cries and Lullabies: Women in War from Prehistory to the Present, Norman, OK: University of Oklahoma Press, p. 17.

5. Turshen, Meredeth (1998) "Women's War Stories", in Meredeth Turshen and Clotilde Twagiramariya, eds, What Women Do in Wartime: Gender and Conflict in Africa, London: Zed Books, pp. 1-26.

6. Farr, Vanessa (2003) "Men, Women and Guns: Understanding How Gender Ideologies Support Small Arms and Light Weapons Proliferation", in BICC Conversion Survey 2003: Global Disarmament, Demilitarization and Demobilization, Baden-Baden: Nomos Verlagsgesellschaft, pp. 120-133.

7. van Creveld, Martin (2001) Men, Women and War: Do Women Belong in the Front Line?, London: Cassell, p. 227.

8. Sharoni, Simona (2001) "Rethinking Women's Struggles in Israel-Palestine and in the North of Ireland", in Caroline O. N. Moser and Fiona C. Clark, eds, Victims, Perpetrators or Actors? Gender, Armed Conflict and Political Violence, London: Zed Books, p. 86.

9. Lentin, Ronit (1997) “(En)gendering Genocides”, in Ronit Lentin, ed., Gender and Catastrophe, London: Zed Books, p. 12.

10. Farr, note 1 above, p. 116.

11. As Adrian Guelke has noted, outside Northern Ireland "paramilitary" usually designates state security forces lying between the police and the military. However, in Northern Ireland it is used to designate non-governmental organizations that have used or threatened to use political violence. Guelke, Adrian (1999) "Political Violence and the Paramilitaries", in Paul Mitchell and Rick Wilford, eds, Politics in Northern Ireland, Boulder, CO: Westview Press in cooperation with PSAI Press, p. 31. Since this is in such common usage in Northern Ireland, I also refer to the organizations that utilize political violence (both republican and loyalist) as paramilitaries. 
12. The name for Northern Ireland is contested. Legally it is "Northern Ireland" and this is used by the British government. Most unionists use "Northern Ireland" but many also use "Ulster" (though seemingly less so now than in the past). Nationalists tend to use "the north" or "the six counties" for Northern Ireland and "the south" or "the 26 counties" for the Republic of Ireland. (Republicans studiously avoid using "Northern Ireland".)

13. Ruane, Joseph and Jennifer Todd (1996) The Dynamics of Conflict in Northern Ireland: Power, Conflict and Emancipation, Cambridge: Cambridge University Press, p. 1.

14. These figures are taken from the Northern Ireland Statistics website, www.nisra.gov.uk. Crown copyright material is reproduced with the permission of the Controller of HMSO. See key statistics tables, available at www.nisranew.nisra.gov.uk/Census/pdf/ Key\%20Statistics\%20ReportTables.pdf.

15. Ruane and Todd, note 13 above, p. 1.

16. Also known as the Good Friday Agreement or just the Agreement.

17. It is worth noting that female officers in the RUC were not armed until April 1994, after a court case against employment discrimination in this respect was pursued by female officers. Coulter, Colin (1999) Contemporary Northern Irish Society: An Introduction, London: Pluto Press, p. 132. On women in the RUC see Brewer, John D. (1991) "Hercules, Hippolyte and the Amazons - Or Policewomen in the RUC", British Journal of Sociology 42, pp. 231-247; Brewer, John D. and Kathleen Magee (1991) Inside the RUC: Routine Policing in a Divided Society, Oxford: Clarendon Press; Brown, Jennifer (2000) "Discriminatory Experiences of Women Police: A Comparison of Officers Serving in England and Wales, Scotland, Northern Ireland and the Republic of Ireland", International Journal of the Sociology of Law 28, pp. 91-111.

18. Ward, Margaret (1989) Unmanageable Revolutionaries: Women and Irish Nationalism, London: Pluto Press, p. 259.

19. Sales, Rosemary (1997) Women Divided: Gender, Religion and Politics in Northern Ireland, London: Routledge, p. 71.

20. Porter, Elisabeth (1998) "Identity, Locality, Plurality: Women, Nationalism and Northern Ireland", in Rick Wilford and Robert L. Miller, eds, Women, Ethnicity and Nationalism: The Politics of Transition, London: Routledge, p. 44.

21. Yuval-Davis, Nira (1997) Gender \& Nation, London: Sage Publications, p. 98.

22. Interview with "Peter" (not his real name).

23. Brown, Kris and Corinna Hauswedell (2002) Burying the Hatchet: The Decommissioning of Paramilitary Arms in Northern Ireland, Brief 22, Bonn: Bonn International Center for Conversion.

24. Ibid., pp. 19-20.

25. Northern Ireland Office, available at www.nio.gov.uk/decommissioning.

26. On 3 May 2007 the UVF leadership publicly announced that the organization was standing down and that it had put all its weapons "beyond reach", but declined to engage in a formal decommissioning process overseen by the IICD. In November 2007 the UDA also announced that it was standing down its armed wing, the UFF. It, too, has no current intention to decommission weapons, although like the UVF some members of the leadership have met with General de Chastelain of the IICD. The continued tensions within the organization and the ever-present threat of renewed violent internal feuds mean the UDA/UFF situation remains unstable.

27. Report of the Independent International Commission on Decommissioning, 21 October 2003, available at www.nio.gov.uk/iicd_report_21oct03.pdf.

28. Report of the Independent International Commission on Decommissioning, 19 January 2006, available at www.nio.gov.uk/report_of_the_independent_commission_on_ decommissioning_19_january_2006.pdf. 
29. Brown and Hauswedell, note 23 above, pp. 51-52.

30. UNDP (2002) "Small Arms and Light Weapons", Essentials 9, November, p. 4.

31. Brown and Hauswedell, note 23 above, pp. 67 and 4.

32. Ibid., p. 68.

33. Ibid., pp. 65-69.

34. Cukier, Wendy with Alison Kooistra and Mark Anto (2002) "Gendered Perspectives on Small Arms Proliferation and Misuse: Effects and Policies", in Gender Perspectives on Small Arms and Light Weapons: Regional and International Concerns, Brief 24, Bonn: Bonn International Center for Conversion, p. 34.

35. UNDP, note 30 above, p. 4.

36. Brown and Hauswedell, note 23 above, p. 67.

37. UNDP, note 30 above, p. 5.

38. Moser, Caroline (2001) "The Gendered Continuum of Violence and Conflict: An Operational Framework", in Caroline O. N. Moser and Fiona C. Clark, eds, Victims, Perpetrators or Actors? Gender, Armed Conflict and Political Violence, London: Zed Books, pp. $36-37$ and 39.

39. BBC1 Northern Ireland (2003) Spotlight: A Place of Safety, BBC1 Northern Ireland, 18 March, $10.30 \mathrm{pm}$ (documentary). It is possible, however, that similar levels of racial violence occurred before the cease-fires, but were obscured by the overarching conflict.

40. Farr, note 3 above, p. 21; Cukier, note 34 above, p. 26; Kelly, Liz (2000) "Wars Against Women: Sexual Violence, Sexual Politics and the Militarized State", in Susie Jacobs, Ruth Jacobson and Jennifer Marchbank, eds, States of Conflict: Gender, Violence and Resistance, London: Zed Books, pp. 59-60; McWilliams, Monica (1998) "Violence Against Women in Societies Under Stress", in R. Emerson Dobash and Russell P. Dobash, eds, Rethinking Violence Against Women, Thousand Oaks, CA: Sage Publications, pp. 111-140.

41. McWilliams, ibid., p. 132. See also McWilliams, Monica and Joan McKiernan (1993) Bringing It Out in the Open: Domestic Violence in Northern Ireland, Belfast: HMSO; McWilliams, Monica and Lynda Spence (1996) Taking Domestic Violence Seriously: Issues for the Criminal and Civil Justice System, Belfast: HMSO; Montgomery, Pamela and Vivian Bell (1986) Police Response to Wife Assault, Belfast: Northern Ireland Women's Aid Federation; Evason, Eileen (1982) Hidden Violence, Belfast: Farset.

42. McWilliams, note 40 above, pp. 131-132.

43. Brown and Hauswedell, note 23 above, pp. 63-64.

44. See BBC1 Northern Ireland (2003) Spotlight: Loyalists at War, BBC1 Northern Ireland, 28 January, 10.35 pm (documentary); BBC1 Northern Ireland (2003) Panorama: Gangsters at War, BBC1 Northern Ireland, 22 June, 10.15 pm (documentary).

45. Bruce, Steve (1992) The Red Hand: Protestant Paramilitaries in Northern Ireland, Oxford: Oxford University Press, pp. 66-67.

46. Statistics from the Police Service of Northern Ireland website, listing "Casualties as a Result of Paramilitary-Style Attacks 1973-31 January 2009”, available at www.psni. police.uk/ps_attacks_cy.pdf. Statistics for 2008 and 2009 are provisional. Other sets of security-related statistics are available at www.psni.police.uk/index/updates/updates_ statistics/updates_security_situation_and_public_order_statistics.htm.

47. 1998 varied from the pattern, during which loyalists were responsible for 34 paramilitary-style shooting casualties as opposed to 38 on the part of republicans.

48. Laurance, Edward J. and Sarah Meek (1996) The New Field of Micro-Disarmament: Addressing the Proliferation and Buildup of Small Arms and Light Weapons, Brief 7, Bonn: Bonn International Center for Conversion, p. 18.

49. Brown and Hauswedell, note 23 above, p. 66. 
50. Interview with "Alison" (not her real name). Subsequent references to Alison are taken from this interview.

51. For some testimonies of sexual molestation and harassment during interrogation see Calamati, Silvia (2002) “The Trouble We've Seen...” Women's Stories from the North of Ireland, Belfast: Beyond the Pale; Pickering, Sharon (2002) Women, Policing and Resistance in Northern Ireland, Belfast: Beyond the Pale.

52. Interview with "Niamh" (not her real name).

53. Interview with "Maria" (not her real name).

54. See for example Ruddick, Sara (1989) Maternal Thinking: Toward a Politics of Peace, New York: Ballantine Books.

55. For a presentation of this argument see Skjelsbæk, Inger (2001) "Is Femininity Inherently Peaceful? The Construction of Femininity in War", in Inger Skjelsbæk and Dan Smith, eds, Gender, Peace and Conflict, London: Sage Publications, pp. 47-67.

56. Interview with "Tracey" (not her real name).

57. Interview with "Ann" (not her real name).

58. Interview with Alison.

59. Alison, Miranda (2004) "Women as Agents of Political Violence: Gendering Security", Security Dialogue 35(4), p. 462.

60. Bennett, Olivia, Jo Bexley and Kitty Warnock, eds (1995) Arms to Fight, Arms to Protect: Women Speak Out about Conflict, London: Panos Publications, pp. 4-5.

61. Saint-Germain, Michelle (1998) "Women, Democratization, and Public Policy", Policy Sciences 27, p. 274, cited in Miller, Robert L. (1998) "Conclusion", in Rick Wilford and Robert L. Miller, eds, Women, Ethnicity and Nationalism: The Politics of Transition, London: Routledge, p. 199.

62. Yuval-Davis, note 21 above, p. 101

63. Interview with "Teresa" (not her real name). Subsequent references to Teresa are taken from this interview.

64. Interview with "Mary" (not her real name).

65. Interview with "Caral" (not her real name).

66. Interview with "Maeve" (not her real name).

67. The reason for this caution is a little unclear to me, but it may possibly be accounted for by both an awareness that some women were not treated as well by the organization as they themselves were, and a sensitivity to accurate representation on the part of the republican community, engendered by years of being research subjects.

68. Interview with "Eileen" (not her real name).

69. Interview with "Mairead" (not her real name).

70. Interview with Teresa.

71. Interview with "Emma" (not her real name).

72. Interview with "Bernadette" (not her real name).

73. Cockburn, Cynthia (1998) The Space Between Us: Negotiating Gender and National Identities in Conflict, London: Zed Books, p. 42.

74. Interview with "Linda" (not her real name).

75. Fairweather, Eileen, Roisín McDonough and Melanie McFadyean (1984) Only the Rivers Run Free: Northern Ireland: The Women's War, London: Pluto Press, p. 283.

76. Catholic women have suffered political violence from within their own community, often signalling communal concern to maintain boundaries and regulate sexual conduct. A particularly well-known manifestation of this, especially in the early years of the conflict, was the punishment of young Catholic women who had relationships with British soldiers (or supposedly committed other "offences", such as extra-marital affairs and informing on the IRA). Some were tied to lampposts, had their heads shaved and were tarred and feathered. See McCann, Eamonn (1993) War and an Irish Town, 3rd edn, 
London: Pluto Press, p. 153; Fairweather, McDonough and McFadyean, ibid., pp. 247 251; MacDonald, Eileen (1991) Shoot the Women First, London: Fourth Estate.

77. Sales, note 19 above, p. 71.

78. Fairweather, McDonough and McFadyean, note 75 above, p. 304.

79. Interview with "Joy" (not her real name). Subsequent references to Joy are taken from this interview.

80. Ibid.

81. Sales, Rosemary (1997) "Gender and Protestantism in Northern Ireland", in Peter Shirlow and Mark McGovern, eds, Who Are "the People"? Unionism, Protestantism and Loyalism in Northern Ireland, London: Pluto Press, p. 144.

82. Sunday Mail (2003) "Mrs Mad Dog”, Sunday Mail, 9 February, p. 1. The article does not specify when the photograph was taken.

83. Andersonstown News (2003) "Easter Shocker", Andersonstown News, 19 April, pp. 1 and 5. The Andersonstown News is a West Belfast republican paper.

84. Sunday World (2004) "Orange Dis-Order", Sunday World, 11 July, pp. 1 and 4-5.

85. Steel, Jayne (1998) "Vampira: Representations of the Irish Female Terrorist", Irish Studies Review 6(3), p. 274.

86. On this see MacDonald, note 76 above. 


\title{
The gun on the kitchen table: The sexist subtext of private policing in Israel
}

\author{
Rela Mazali
}

Reactivating dulled senses, relearning healthy fears

I felt both children stiffening, their bouncy excitement silenced. Following my daughter's transfixed gaze, I was puzzled. A friend and I were taking our toddlers on their first train ride; a round trip to the next town. Suddenly I saw it. The rifle. It had been there all along. Propped up against the soldier's leg, half a metre away. Neither child had ever seen a real one up close. How should they know it wasn't dangerous, wasn't loaded, at the moment? And, in fact, wasn't it? Now, seeing it, I took a closer look.

Foreigners visiting Israel for the first time are often taken aback by the sheer quantity of rifles and handguns present in the public sphere, nonchalantly slung over shoulders and across hips, often with magazines inserted. They are on buses, on streets, leaning on walls at fast-food stops. International non-government organizations (NGOs) and the United Nations have long recognized that "buildups of light weapons... increase the number of casualties, especially to civilians... [and] contribute to the proliferation of centres of violence within states", ${ }^{1}$ and are hence developing micro-disarmament guidelines while exhorting the "prohibition of firearms in urban public places". ${ }^{2}$ Yet Jewish Israelis tend to dismiss the lethal potential of weapons as something that is there "for our protection" and which consequently doesn't endanger "us". Most Jewish Israelis are desensitized to the public presence of small arms. Many actually learn not to register that there are guns present, just as I failed

Sexed pistols: The gendered impacts of small arms and light weapons, Farr, Myrttinen and Schnabel (eds), United Nations University Press, 2009, ISBN 978-92-808-1175-9 
at first to notice the rifle, and was only awakened to its presence through the fresh, and frightened, reactions of two small children.

For over a decade now I have been studying, writing about and involved in activism against processes of militarization in Israel. Drawing on the rich and complex feminist analysis of the subject of militarization, I have painstakingly rehabilitated some of what I see as a child's healthy fear and suspicion of guns and armed people in and out of uniform. That is why I have noted and been seriously troubled by developments which are all but invisible to many around me. I see them as a relatively recent outcome of the intensive processes of militarization moulding Israeli society and politics for six decades and more. I am referring to the accelerated proliferation of privately owned and operated "security" or "private policing" firms.

\section{Methods, structure and gender-sensitive analysis}

Notably, at the time of this study no anti-gun lobby exists in Israel and no independent civil society organizations, other than (occasionally) the press, are known to be documenting, collecting and publishing data on the licensing, possession or numbers of small arms throughout the country. Neither have any independent sources published in-depth overall assessments of the dimensions and social impacts of private policing in Israel. This chapter, then, offers a first systematic study of the private policing industry in Israel.

The evidence supporting its claims was amassed through a longitudinal study of several hundred texts produced and published over the years 1998-2008, a decade which has emerged in hindsight as a pivotal phase in Israel's progressive privatization of state violence. The first type of texts studied was press reports on the industry over the years in question, including a period of exceptional growth in private policing in Israel from 2000 to 2004. I monitored both Hebrew and English press in Israel and identified relevant items from the foreign press; the study covered both internet and printed publications, and independently owned as well as state-operated organs (such as the police news periodical). In addition, I studied numerous publications and documents placed in the public sphere by government institutions (both national and municipal), public and civil society institutions and business organizations, again spanning the period from 1998 to 2008. In combination, this array of sources - a large collection of news items, investigative reports, official statistics, government documents, parliamentary protocols, business plans and texts of other types - provided concentrated, although sometimes inconsistent, quantitative data, while simultaneously reflecting public perceptions of 
and attitudes towards ubiquitous "security guards", towards the private companies employing them and towards small arms in general in Israel. This corpus also exposed central assumptions and methods of government in Israel in regulating (or perhaps deregulating) the growing field of private policing. ${ }^{3}$ In addition, these textual sources were further enhanced by selected interviews with key informants.

The data amassed through my research were read and interpreted within the context of declarations, research documents and reports of international NGOs addressing the worldwide proliferation of small arms and light weapons, as well as reports and case studies publicized by Israeli NGOs monitoring the police, discrimination and violence against women or breaches of workers' rights in Israel's private policing industry. In addition, the study integrated the work of academics and activists, in particular feminist thinkers - both in Israel and in other regions towards understanding and analysing the gendered implications in Israel of increasingly privatized state violence, linking the process and its effects in terms of employment, public funds and small-arms availability with gender discrimination and violence against women.

Commencing with the quantitative attributes of the industry, the chapter will first show that private policing armament in Israel has significantly raised the number of firearms circulating through streets and homes, distinctly accelerating small-arms proliferation. It will also outline the overall scope and dimensions of the private policing industry active in Israel (to be distinguished from the large-scale Israeli export of "security experts", guards, trainers, surveillance equipment, etc.). I will cite a number of separate and differing indices of these dimensions, including the spurt of unique, exceptional growth in this industry between the years 2000 and 2004. This will provide the backdrop for my claim, later in the chapter, that various, largely insidious, forms of economic gender discrimination are deeply embedded in the process of Israel's privatization of state violence.

The following two sections of the chapter then go on to describe how the spread and growth of private policing have deepened Israeli militarization in unprecedented ways; they will claim that in qualitative terms, the small arms recently introduced through the institution of security guards represent a new phase of proliferation. These, unlike the arms routinely touted through civic space in Israel by tens of thousands of soldiers and reservists, are no longer chiefly "arms in transit" but constitute an intentional, functional component of the civic sphere itself. Rising numbers of guns now stationed in the civilian sphere introduce and maintain an intended presence, denoting a specific array of meanings. I will argue that these, in combination with the increasingly confusing multiplication of "security" agencies, generate a sharp increase in the conflation 
of civic and militarized space, in turn normalizing lethal weapons even further in Israel and extending dangerously indiscriminate policies on the licensing and use of guns.

Finally, addressing the strongly gendered implications of these developments, I will trace ways in which the process of militarization, enhanced by the private policing industry in Israel and the accelerated proliferation of arms it sanctions, has intensified existing gender discrimination and violence against women. This segment will apply gendersensitive questions and criteria to the collected data, in the light of findings by numerous feminist scholars of a pronounced sexism both required and reproduced by processes of militarization and manifested through an interconnecting variety of social structures. Indeed, masculinity in Israeli society has been cast as tough and protective of its mandatory complement - a soft and vulnerable femininity. The chapter will identify the growing role of the private policing industry in the spectrum of interacting cultural and formal institutions serving to maintain and "naturalize" this overarching structure. It will point out ways in which the spread of private policing builds on and reinforces a rigidly gendered division of labour, further circumscribing Israeli women's freedom of movement and employment, keeping them at risk, often fearful and increasing their dependence on the men positioned as dominant "providers" and "protectors". It will clarify new ways in which, as sociologist Nitza Berkovitch has claimed, "the [Israeli] government invests greater effort and resources to enable women to maintain their roles as homemakers... than it does to allow them an opportunity for economic independence and/or equality in the job market". ${ }^{4}$

My discussion will claim the increased skewing, over the years of the study, of an already discriminatory job market. As the industry, heavily financed by public funding, created many thousands of new (albeit largely exploitative) jobs, offered predominantly to men, the public sector, mainly comprised of women, was subjected to concurrent and severe cutbacks, as was the social safety net alleviating poverty in Israel, which is distinctly feminized. In addition, as I will hypothesize, the entrenchment of a culture of sexual harassment through a militarized industry deeply embedded in civic space has further compounded discrimination in the job market and in the allocation of public funds, severely undermining women's capacity for achieving economic and emotional independence.

I will then go on to offer evidence of direct contributions by the private policing industry to the violence against women endemic to Israeli society. "Increased awareness... has not produced any real change in women's reality", Ruth Halperin-Kaddari wrote in a comprehensive 2004 study. "It sometimes seems that both public and government reaction are merely lip service." As evidence, she cited the persistent omission 
"from police or state attorney records" of the data that would allow assessments of "the extent of overall violence against women", querying, "How can any claim about the growing phenomenon of gender-based violence against women be made when the official police record 'shows' that there is no such thing?",5

The current chapter will identify a previously unnoted phenomenon of women's murder by security guards with their legally issued arms. As I will show, while utilizing and deepening the gender divide, the private policing industry also capitalizes on gaping class divisions in Israel, employing a majority of unskilled, untrained guards, many with limited job opportunities. The systematic exploitation and degradation suffered by these people, the vast majority of them men, have repeatedly turned lethal when they come with a gun. Some of the men most badly mistreated by militarized Israeli society have turned to endemic violence against some of this society's poorest and most severely weakened women. Among these victims of the private policing industry I will note a disproportionate number of relatively recent émigrés to Israel from the former Soviet bloc and Ethiopia. I will also touch briefly on the specific risks that private policing and a spreading trend of community policing, in the state-administered Civil Guard, pose for women who are Palestinian citizens of Israel.

Integrating these previously unreported, related and distinctly gendered effects of Israel's growing private policing industry, the discussion will outline a compound sexist subtext: a combination of three phenomena or trends operating in unison to keep women at home and poor and, in turn, reinforcing the processes and practices that shore up Israeli militarization. In its entirety, the study presents and problematizes central perceptions and social mechanisms exacerbated by the local private policing industry. Describing the grave differential implications of this industry's recent growth for Israeli women and men, the study identifies the severe damages it entails for Israeli society at large and the serious risks it continues to pose for human security in Israel.

The dimensions of private policing, the increase in gun licensing

In present-day Israel, people are funnelled through routine security checks when entering almost any public or commercial space: at schools, municipal and government buildings, supermarkets, office buildings, cafés, clinics, train and bus stations, sometimes even on beaches. The vast majority of checks are performed by "security guards" employed by private companies subcontracted by the management of the facility or by 
the municipality. Some of the data I have accumulated on this phenomenon suggest the dimensions of the private policing industry in Israel in terms of financial values and the number of workers involved.

A January 2003 "Branch Business Profile" comprehensively listed the clients of private policing firms in Israel as "factories and large commercial organizations, government offices, public utility services, public companies, malls, halls, educational institutions, small businesses". In October 2003 Peter Lagerquist wrote, "Together with South Africa and the U.S., Israel has one of the highest concentration[s] of security guards in the world: approximately one for every hundred Jewish citizens." ${ }^{.7} \mathrm{Be}$ tween 2000 and 2003 private policing was the fastest-growing segment of Israel's economy, and by May 2003 Dun and Bradstreet ${ }^{8}$ listed the largest single employer in Israel as Hashmira, a private policing company whose workforce had reached 15,000 following a swift 15 per cent rise. Eight thousand of these were security guards. The outbreak of the 2000 Intifada (Palestinian uprising) greatly accelerated the growth of the private policing workforce, with estimates of the rise in manpower over the period between 1999 and 2003 ranging from 20 to 40 per cent. ${ }^{9}$ While "the demand for security guards ... [rose] by several hundred percent", ${ }^{10}$ the rest of Israel's economy showed negative growth, extended recession and fast-climbing unemployment over the same period.

According to a 2003 report, security workers in Israel were employed by approximately 250 companies, whose annual revenue per worker was placed at between 50,000 and 250,000 shekels. ${ }^{11}$ A 2005 assessment placed the number of private policing companies anywhere between several hundred and 1,000 , with the officially licensed companies numbering 530 in 2004. ${ }^{12}$ Between 2000 and 2002, 120 million shekels a year in state funding went to private policing companies to pay guards at educational institutions alone. ${ }^{13}$ In early 2002 half the ownership of Hashmira was purchased by the Danish-based Group 4 Falck for $\$ 30$ million. ${ }^{14}$ In mid2003, according to both journalists and independent researchers, "the security business generate[d] some eight billion Shekels per year", ${ }^{15}$ while the Israeli police force budget for the same year was only 5.63 billion shekels. ${ }^{16}$ In March 2004 a donation of US\$7 million from the US Friendship Fund allowed the deployment of 1,000 new guards on bus lines, ${ }^{17}$ and in 2007 the Ministry of Transport allocated 90 million shekels for security guards. ${ }^{18}$ Virtually utilizing the country as a whole as a "beta site" for high-tech-based security, "exports in counter terrorism-related products and services increased by 15 percent in 2006 and were projected to grow by 20 percent in 2007 , totalling $\$ 1.2$ billion annually". ${ }^{19}$

Estimates of the number of security guards active in 2004 ranged from $46,500,{ }^{20}$ representing a full 2 per cent of the national workforce, ${ }^{21}$ to $90,000^{22}$ or even $100,000,{ }^{23}$ though a drop in bomb attacks caused the 
layoff of thousands of guards in 2005, with their numbers reportedly slipping to somewhere between 44,500 and $43,000 .{ }^{24}$ By way of comparison, however, even this reduced force was significantly larger than the entire Israeli police force, which comprised 27,900 in 2003 and just over 31,000 in $2005 .{ }^{25}$

The long-standing and common presence of military arms in Israeli public space undoubtedly laid foundations for the largely untroubled attitudes of most Jewish Israelis towards the public presence of non-military rifles and handguns. Fully supported by this indifferent, or even receptive, climate and by widespread public preoccupation with "external threats", the private policing boom has significantly affected small-arms proliferation in Israel. They are currently being licensed and acquired in total disregard of the price a society must inevitably pay when "laissezfaire attitudes to weapons... [become] normalized". ${ }^{26}$ Applications for gun licences doubled between 2000 and 2002 and tripled by mid-2004. ${ }^{27}$ In March 2003 considerably increased demands for small arms were ascribed, largely, to the private policing industry, ${ }^{28}$ to whose companies 35,000 guns were reportedly licensed between 2000 and April 2004. ${ }^{29}$ Simultaneously with the increase in demand, various sources noted an easing in licensing criteria by the Ministry of the Interior, ${ }^{30}$ and a 2005 inter-ministerial committee stated that the employees of private policing companies were actually subject to looser licensing requirements than those pertaining to private gun owners. ${ }^{31}$ Officials repeatedly called for increased civilian armament, ${ }^{32}$ despite police sources' admission of a "significant reduction" in the state's capacity to monitor individual gun carriers and particularly security guards. ${ }^{33}$ For example, it was only after the alleged suicide of Arkady Trigonov, a security guard posted at the separation barrier built by Israel in the Occupied West Bank, that police discovered he had neither been issued a licence nor undergone basic weapons training. Executives at the employing company nevertheless maintained that they had been legally authorized to hire him. ${ }^{34}$

According to Interior Ministry data, 58,690 new gun licences were issued in Israel between 2000 and $2004,{ }^{35}$ raising the total of licensed non-military guns by nearly one-fifth (just under 19 per cent), while population growth over this period was only about 7.7 per cent. ${ }^{36}$ Nearly 60 per cent of the new guns introduced into civic space in Israel over this period were licensed to employees of private policing companies. According to the inter-ministerial Committee for the Review of the System of Arms Licensing for Guards convened in 2005, "In the absence of conditions allowing for an orderly flow of firearms between the guards [employed by these companies], the number of firearms in the country has in fact grown beyond need." ${ }^{37}$ In all, though half of all licence applications were still being rejected, the number of licensed guns in Israel re- 
portedly reached an all-time high of about 372,000 by early $2004 .{ }^{38}$ Demonstrating its awareness that the situation was spiralling out of control, the Ministry of the Interior has convened no fewer than five committees on the question of gun licensing over the past decade, whose recommendations nevertheless remain largely unimplemented. ${ }^{39}$

In Israeli schools alone, ${ }^{40}$ the overall number of (recently) armed guards was placed between 3,500 and 6,000 in 2003-2004. ${ }^{41}$ This trend is in shocking contrast with approaches in other conflict or post-conflict areas, where the damages attending the proliferation of guns in supposedly protected, "safe" spaces are being clearly registered and addressed. In some countries, for instance, "Gun Free Zones have been prescribed for schools". ${ }^{42}$ In Israel itself, proliferation in schools is a sharp reversal of an emerging anti-gun trend evident as recently as 1998, when rising violence in the school system ${ }^{43}$ led to the appointment of a parliamentary Sub-Committee for the Prevention of Bringing Arms into Schools. ${ }^{44}$ Gun licensing authorities, which are apparently well aware of the threat posed by arms in schools and civic space, have stated that "Once the security situation has improved we may have to cut back the number of licensed gun carriers again." 45 However, despite repeated cases of students' intimidation, sexual abuse and rape by armed school guards, as well as several accidental shootings, ${ }^{46}$ campaigns against the accelerated militarization of non-combat zones simply dropped out of sight once the Intifada had focused public attention on external threats.

\section{Obvious and less-obvious objectives of private policing}

Private policing, this burgeoning branch of Israel's economy, has come about as an obvious and socially sanctioned response to the rise in suicide bombings by Palestinians targeting Israeli public spaces between 2000 and 2004. While alternative options were not even envisioned or explored, the perceived or real need for these measures was emphatically reinforced by the events of 11 September 2001 in the United States, and the subsequent worldwide preoccupation with terrorism. However, the growth of private policing in Israel is also driven by the trend, both local and worldwide, towards increased privatization and "outsourcing" of government services. Where subcontracted "civilian" employees typically cost Israel's police force 70,000 shekels a year in 2000, policeemployed staff cost up to twice that sum. ${ }^{47}$ Systematic outsourcing, which effectively drives privatization, is slated as a means of achieving government budget objectives. But it can equally be said to privilege "market forces" or "the business community", with potentially severe implications for the public at large. Philip Graham and Allan Luke, describing a 
worldwide push towards "de-territorialization, dispersion and distancing of ownership, commercial, financial, administrative and productive functions", have warned of a "global complex of corporatized police" for which "Allegiance to particular national... labour forces [or publics] has become, at best, a commercial liability." 48

The specific Israeli circumstances of real and repeated attacks against random civilians in public spaces do much to underplay these aspects of a growing private policing sector and, in particular, to hide the identity of its main beneficiaries. Facilitating this trend, authorities and media - in Israel as elsewhere - translate the individual economic insecurity endemic to an increasingly globalized economy into "privatized concerns with public safety such as street crime ... and, of course, terrorism ... [diverting attention from] the dismantling of social safety nets... [and] the kind of collective action that could address the very causes of insecurity". ${ }^{49}$

Feminist sociologist Erella Shadmi, formerly a senior police officer, has described a transition in Israel "from a state police that serves the state, to a market police that serves, first and foremost, economic factors". She has noted the pressures driving Israel's police "towards dismantling and redefining the concept of public order as well as differentiating between police services, according to the receivers of those services... Privatization of certain police services and the use of alternative defense means... and services which aim at defending property." 50

As a case in point, the annual programme of the Department for Security, Safety and Emergency Services in the beach town of Herzlia noted defence of property as a prominent result and an implied justification for its dramatic growth over 2002-2003. While this growth and the expenditure it required were presented to the public as a necessary response to Palestinian attacks, the list of the department's achievements featured a 20 per cent drop in breaking and entry into schools and a 65 per cent drop in breaking into cars, clearly addressed to - and intended to impress - property owners. ${ }^{51}$ In a second town, too, an official cited stakeouts preventing vandalism and burglaries in schools as major components of municipal private policing activity. ${ }^{52}$ In practice, the protection of property is at least as central an objective of private policing in Israel as the prevention of terrorist attacks. ${ }^{53}$ The latter, however, is upfronted as an effective means of maintaining broad public support for a service that is clearly skewed to the advantage of a well-off minority. ${ }^{54}$

In addition, private policing companies both feed and cater to public perceptions to their own advantage. "We provide the client with a subjective sense of security; we manufacture a feeling of security", I was told point blank by a company owner. ${ }^{55}$ The 2005 Committee for the Review of the System of Arms Licensing for Guards stated that "Clients' demands, rather than actual needs, are what dictate the [current] situa- 
tion of excessive armed guarding. The client, whether a business owner or someone holding an event and wishing to give his customers/guests a sense of security, hires armed guards even when there is no need for this. The economy fails to examine alternatives to armed guards... resulting in a guard force that exceeds necessity." 56

Significantly, the swift growth of the private policing industry in Israel has occurred during a period of severe economic crisis and fast-widening gaps between rich and poor. ${ }^{57}$ Economic activity shrank consistently between 2000 and 2003, due to both the peaking violence of the Israeli-Palestinian conflict and the effects of worldwide recession, with Israel's gross national product dropping 0.26 per cent. ${ }^{58}$ Over the years of the Intifada unemployment rose sharply, from an average of 8.8 per cent in 2000 to 10.9 per cent in $2004 .{ }^{59}$ With the advent of relative calm inside Israel (as opposed to the Occupied Territories) and the gradual resumption in 2003 of economic expansion, unemployment slowly dropped again to 9 per cent by 2005. However, a majority of the newly created jobs have been part-time and low-pay employment, while the numbers of long-term unemployed and those despairing altogether of the job market have continued to rise. ${ }^{60}$ Meanwhile, successive governments have implemented repeated and significant cutbacks in social support systems - a move which hit women especially hard. ${ }^{61}$ In all, over this period economic policies in Israel have had "devastating consequences for employment and wages; the pension system; the safety net; the legal protections of wage earners; the education, health and social welfare systems; civil society institutions like the labour unions; the status of the basic institution of parliamentary democracy - the Knesset". ${ }^{62}$ Rather than introducing steps, however unpopular, by means of which to answer the needs of a failing economy and a severe poverty problem, government measures have been driven by an agenda "aimed at downsizing the role of the state, at upfronting the role of big business in political and social affairs, at debilitating the unions, lowering the cost of labour and diluting the social support systems". ${ }^{63}$

Consistent with this agenda, the government itself has been a major beneficiary from the privatization of security services. Economist Linda Efroni has described what she called the "Isra-bluff" of government involvement in determining the labour practices of security companies, practices through which property owners and corporations secure benefits at the expense of the public, and particularly those in a vulnerable economic position. This "bluff", she says, comprised: ${ }^{64}$

a significant increase of the operational budgets of the various [government] ministries in return for a seeming slash in tenured manpower. The cut-backs could then be compensated for by purchasing alternative services from tempo- 
rary manpower companies... forced to meet the requirements of a Finance Ministry tender... [which] precluded paying workers according to their legally stipulated rights... Several private policing companies planned to petition the High Court of Justice against the Ministry for forcing them to break labour laws... But the Finance Ministry exerted enormous pressure... [and] the companies... reneged. Ever since... very specific security companies are repeatedly awarded contracts for tens of millions of Shekels.

This would seem to clarify why, for instance, the business licence of Hashmira was renewed in May 2006, despite repeated court convictions for violating workers' legal rights, when business licensing law requires the revocation of licences following such convictions. ${ }^{65}$ Later that year, major private policing companies actually provided explicit support for Efroni's analysis. Following disclosure by a workers' rights organization that companies were regularly short-changing both their workers and the government, and a consequent declaration by the Finance Ministry of a new monitoring and enforcement regime, security guard companies initiated a campaign blaming the government for forcing them to adopt illegal employment policies. ${ }^{66}$ By December 2007 effective labour activism pushed the High Court of Justice to uphold a government decision requiring "all security firms seeking to renew their licences to present data on both civil suits and criminal cases against them for violating labour laws". ${ }^{67}$ While workers' rights groups have meanwhile achieved additional significant gains, it remains to be seen how all this will play out in future through the salaries and social benefits paid to individual security guards.

As political and security conditions in Israel-Palestine have generated a mushrooming security industry and a rise in demand for security workers, high unemployment rates and the disintegrating welfare system have joined with accelerated privatization to increase employers' power over workers. Concurrently, due to government policies, competition for contracts has grown extremely vicious. ${ }^{68}$

Accordingly, while the private policing sector as a whole has exhibited exceptional growth, most security workers have been paid minimum wage or below and are routinely laid off before earning the social benefits to which Israeli labour law automatically entitles workers after a continuous year of employment. Their exploitation, which has become standard practice, has occurred until very recently with full government support and, by and large, with the support of the labour courts. ${ }^{69}$ Security guards' rights, Larry Derfner wrote, are "violated nearly as a matter of routine by employers who act like they're immune". ${ }^{70}$ Hanna Zohar, director of an important workers' rights group, estimated in 2002 that "about 60 percent of the guards get cheated". ${ }^{71}$ Ariyeh Avitan, deputy 
manager of a private policing firm employing 6,000, stated in December 2004 that every security guard was illegally short-changed 5,000-6,000 shekels a year by employers. ${ }^{72}$ Moreover, regardless of their temporary employment, security workers have tended to come from groups dependent on the social support systems that were forfeited for the growth of the companies they work for. Thus the workers and the public at large benefit to a very limited degree from the huge public investment in private policing in Israel, which meanwhile generates substantial benefits for company and property owners.

\section{The militarization of Israeli civic space - A new phase}

Jews in Israel have been involved in the maintenance of a community at war for over 50 years. In my view, as I have written elsewhere, ${ }^{73}$ much of "Israeli discourse [is] rooted in its culture of war. Within this culture, social priorities and the allocation of resources are dictated by militarized patterns of thought and action. These include the presuppositions that war is imposed upon, rather than chosen by, the Israeli state; that it is unavoidable, much like natural disaster; and that it is a reasonable, acceptable, though unfortunate means of securing political ends." Such presuppositions, and the absence of a sufficiently visible or widespread debate questioning or even exposing them, are crucial to successive governments' ability to secure public consent for their ongoing choice of state violence and war. They also provide the conceptual infrastructure for the casual introduction of growing numbers of armed guards into civic space. Fixing public attention on the threat from the perceived enemy, they facilitate sweeping inattention to the threats posed by the armed guards themselves. The existence of a machinery that maintains presuppositions about what constitutes danger - powerfully bolstered by militarized Israeli education ${ }^{74}$ - explains why the majority of Israeli Jews barely register their inevitable daily encounters with private police, much as they (or we) fail to notice the small arms all around us.

Israel's seemingly open democratic system of government and its supposedly civic sphere in fact demonstrate striking degrees of militarization. Partly insidious, it is masked behind the civilian suits replacing politicians' former uniforms, and obscured by the procedures of democracy legitimizing semi-military rule. A vastly disproportionate percentage of leading Israeli politicians are ex-military men, including past and present prime ministers, cabinet members and mayors. High-ranking officers leaving the military often move straight into leading political roles. Shaul Mofaz, defence minister in 2004, was chief of staff immediately prior to his appointment. Outside electoral politics, ex-officers occupy high-level 
positions in commercial firms, research institutes and universities, and in the non-profit sector - often thought to epitomize civic culture. One telling example is the number of ex-officers welcomed to work in schools. As journalist Orna Coussin reported in 2001, "Over the past 14 years, more than 300 ... officers... have been employed at various schools around the country. Some... studied only for a single year to receive their teaching certificate... [or] were appointed to administrative positions without any formal training at all." 75 Sociologist Henriette Dahan-Kalev told Coussin, "incorporation of military personnel into the schools is related to general trends of violence in Israeli society and the weakness of the education system as an educator toward democracy".

However, the relatively recent phenomenon of armed guards at every public doorway represents a new level in the conflation of civic and military spaces in Israel. A distinct characteristic of accelerated militarization described by feminist writers such as Jacklyn Cock $^{76}$ and Ximena Bunster, ${ }^{77}$ the multiplication of "security" agencies operating in civilian populations, blurs distinctions between the agencies. Allowing players to evade responsibility, this undifferentiation expressly flaunts accountability. In Israel today, it is often difficult to identify the affiliation of a given guard or even to decide whether he (or occasionally she) belongs to one of the differently uniformed state security agencies. "The employees of some private policing companies", Elat Maoz wrote in 2008, discussing the privatization of formerly military checkpoints, "are dressed in a manner surprisingly reminiscent of the Border Police... Recent visits at... checkpoints have revealed that the strange phenomenon of one organization 'impersonating' another is now very widespread and confusing." 78 Moreover, when a guard's affiliation is known, it is not obvious to whom he is answerable. The institution he is guarding? The security company employing him? Local authorities? The police? ${ }^{79}$ An instance of how this lack of accountability plays out was obvious in 2003, when municipal supervisors supposedly monitoring the work of a private police company in a major Israeli city routinely joined the rounds of the company supervisors, giving the company effective control of the supervision. ${ }^{80}$ "Every police district", wrote Haaretz police reporter Roni Singer, "appoints a security officer to act as liaison to these private companies. Police update these officers and private guards via common beeper systems and communication devices." 81 In January 2004 residents complained when security guards at a nearby construction site put up illegal living quarters. The municipality, the building company and the private policing firm all denied responsibility. ${ }^{82}$ In May 2004 a guard stationed at a bank refused to admit a Herzlia resident, allegedly due to his "oriental looks". A bank spokesperson denied responsibility, as this act apparently did not reflect "bank policy". ${ }^{83}$ This incident is consistent with Erella Shadmi's obser- 
vation that guards commonly exercise illegal "authority" to deny individuals freedom of movement, "usually exceptional individuals, like Arabs, homosexuals or anyone who might be defined as a suspect", ${ }^{84}$ serving to bar them from the (often public) spaces they are employed to guard. It demonstrates the increasingly legitimized racism involved in accelerated militarization, and some of its specific implications for Palestinian citizens of Israel.

"In the current situation, the line of authority between private guards and police becomes blurred", said Singer, who was told by Shadmi that "In recent years... most of the country's police are not really uniformed... the 'blue,' real police are only a portion of the whole. There are now public 'police' units, guards in the courts, investigation departments... everywhere. The private security companies are just one more of these sectors ... a process has developed of authority being given to security guards and volunteers to an extent that is illegal." 85 Police officials, for instance, have voiced contradicting claims on questions as fundamental as whether or not security guards are allowed to detain and hold suspects, or to exert force. ${ }^{86}$ However, Singer said "The question of authority does not concern security guards in the field. They detain suspects." ${ }^{87}$ It is becoming increasingly clear that the confusion of unclear identity and authority raises a bureaucratic maze around the agencies authorized by government to deploy organized violence, effectively shielding them from scrutiny and citizens' complaints. For instance, the Israeli Broadcasting Authority illegally collected millions of shekels from citizens in 2003-2004 at roadblocks at which it employed policemen after hours, concentrating particularly on Palestinian communities in Israel. ${ }^{88}$ As the Association of Civil Rights in Israel wrote to the minister of public security in 2008, "There is, at present, no central body charged with collecting complaints regarding abuses of authority [by security guards] or responsible for disciplinary measures against such abuse. There is, in addition, no mechanism ensuring that the Minister is informed of individual complaints ... enabling him to exercise his power of supervision." 89 In this climate, private policing companies seem, at the very least, to enjoy a considerable degree of impunity through obfuscation. While virtually all small-arms research and the resulting international declarations stress the vital importance of enhanced transparency, ${ }^{90}$ the current process of privatization in Israel generates fragmentation and a dispersion of responsibility, effectively precluding accountability. As a result, Israeli civic space becomes increasingly controlled by the agents and symbols of organized violence, while resistance to this process is nullified.

Similar processes have been documented and studied in other parts of the world. Bunster wrote of the "repression... handled by the armed forces, the police and civilians hired by the military" in Argentina. ${ }^{91}$ In 
apartheid South Africa, Cock said "The SADF [South African Defence Force] often acted together with the South African Police (SAP). The activities of the two were indistinguishable to many ... [and] fused in a pattern of indiscriminate violence... during $1986 \ldots$ surrogate forces in the form of vigilantes and municipal constables came to be agents of violence and fear." 92 The violence practised by security agencies inside Israel may be growing similarly indiscriminate. Three chilling instances involved members of the media, which have been a site of some resistance to militarization in Israel. In April 2004 film-maker David Ben-Chitrit was assaulted and seriously injured by security guards at the entrance to the Defense Ministry in Tel Aviv. ${ }^{93}$ In October members of a news crew were beaten by security guards at the same site. ${ }^{94}$ In May 2004 public transport guards attacked an Israeli journalist on a Jerusalem street. ${ }^{95}$

Yet in May 2002 the public rated its overall trust in security guards as 3.3-3.7 out of 5-well above the halfway mark. Over half of restaurant and café customers, one-fifth of Israel's population, had supported onsite guards via the "security fee" added to the bill. One-tenth of the population had paid for extra school guards despite a large majority of parents who thought they should be government funded. ${ }^{96}$ In the town of Herzlia, where I live, the municipal comptroller reported unjustified spending by the local Security Department, ${ }^{97}$ but town residents have added a security fee of 228 shekels a year to municipal taxes without protest. Similar security fees were still being collected in 2006 by a number of municipalities. ${ }^{98}$ The recommendations (unimplemented to date) of the 2005 inter-ministerial committee actually exhorted substantial reductions in the number of security guards to be reinforced by the institution of clear criteria for sites requiring armed protection, ${ }^{99}$ but the de facto public consensus continues to treat guards as a protective factor, there for "our" defence, a logical, unthreatening, effective measure against a faceless external enemy.

The dangerous implications of this process are magnified in view of the growing involvement of private security companies in tasks previously performed by the Israeli military and bearing directly upon the IsraeliPalestinian conflict. One of the major military tasks privatized over the past few years concerns the loaded and highly sensitive construction of the separation barrier being built by Israel in the West Bank. Ruled illegal by the International Court of Justice, ${ }^{100}$ the barrier cuts deep into prime agricultural areas, depriving hundreds of thousands of Palestinians of their lands and livelihood. ${ }^{101}$ Many sites along the route of the barrier have become focal points for extended popular protests, making the area chronically volatile. In July 2005 a 15 -year-old Palestinian youth was shot and killed by one of the civilian security personnel guarding the barrier. ${ }^{102}$ In a distinct instance of the type of dispersed responsibility effec- 
tively precluding clear accountability, in September 2006 construction of the barrier was reportedly being secured by 11 private policing companies subcontracted, in turn, by 20 different construction companies employed by the Ministry of Defense. According to the Kav LaOved workers' rights group, separation barrier guards were subject to severe exploitation and appalling working conditions. ${ }^{103} \mathrm{In}$ another case of the privatization of extremely sensitive, formerly military tasks, security companies have been charged with the operation of depots regulating Palestinians' entry into and exit from Israel. In January 2006, for instance, the handover of the Erez crossing between Israel and the Gaza Strip to a private policing company triggered rioting due to severe inefficiencies. ${ }^{104}$ Regardless, both the construction and the security measures at a planned industrial zone immediately adjacent to this volatile site - on the Palestinian side - were outsourced by the Defense Ministry to private Turkish companies. ${ }^{105}$ By October 200848 major checkpoints through which Palestinians are required to pass regularly for inspection as they travel throughout the Israeli-occupied West Bank were reportedly fully or partly "outsourced" to five private companies. ${ }^{106}$ Moreover, expressly facilitating and preparing for this process, ${ }^{107}$ the legal authority of security guards in both Israel and the Occupied Territories was considerably and disturbingly extended. ${ }^{108}$

I believe that the breakdown of relatively clear boundaries between state security agencies and profitable, privately owned companies has increased the normalization of organized violence, and especially the presence of guns, in Israeli civic culture. UN researchers have clearly established that "small arms and light weapons facilitate the creation of cycles of violence... [which] distort attitudes and behaviour... entail the normalization and glorification of war, weaponry, military force... celebrate armed violence and privilege violent solutions [over] peaceful ones". ${ }^{109}$ As arms and armed men grow more ubiquitous than ever in Israel, and as they become progressively dissociated from easily distinguishable organizations, both the guards themselves and the violent reality they denote are further entrenched as "facts of life", seemingly mundane and unremarkable. Journalist Naomi Klein has described the political economy of this process in her groundbreaking 2007 study:

The rapid expansion of the high-tech security economy created a powerful appetite inside Israel's wealthy and most powerful sectors for abandoning peace in favour of fighting a continual, and continuously expanding, War on Terror... though the benefits of the boom have not been widely shared, they have been so lucrative for a small section of Israelis, particularly the powerful segment that is seamlessly integrated into both the military and the government... that a crucial incentive for peace has been obliterated. ${ }^{110}$ 
Ironically, then, while their function is purportedly to promote security through keeping danger at bay, guards embody and constantly reiterate the danger's very existence, representing it as routine and unexceptional, a basso ostinato accompanying daily life. Their spatial positioning depicts the threat as external, posed to invade "our" public space whose multiple entries they guard, while their physical presence becomes a pedestrian material signifier denoting, and in that sense (re)constructing, an implied "we" in opposition to an ever-present enemy. The omnipresence of guards thus continually reproduces the imagined community of Israeli Jews, perceived to be facing an outside, "existential" threat, imposed upon "us" and beyond "our" control. Guards and their guns carry out the task of demarcating, in practical terms, just who "we" are; which people are considered unthreatening and allowed to move (relatively) freely through "public" space. By the same token, they act routinely to exclude (or at the very least intimidate and harass) those who are not "us" and are therefore suspect. While these include a variety of people identified as "deviant" by guards and/or their employers, they are first and foremost Palestinians - stateless residents of the Occupied Territories but also those who are citizens of Israel. Dalia Sachs, Amalia Sa'ar and Sarai Aharoni wrote, "In the past four years, the Palestinian citizens of Israel have come under increased exposure to... policing practices, as well as public Jewish hostility." ${ }^{11}$ Through identification, harassment and exclusion of a suspicious "them", the massive presence of security guards serves also to designate the imagined community of "the enemy". The growth of private policing in Israel has both implemented and deepened the racism embedded in militarization, while repeatedly denoting the besieged collective and naturalizing the policy choice of war. The complex implied message accordingly reinforces the public mindsets that underpin Israel's militarization.

\section{"The gendered division of violence"}

A core component of militarized mindsets is what feminist scholar Cynthia Enloe has called "the usually elaborate ideology of femininity constructed by military authorities to serve their own institutional interests... [which is just] as important to the maintenance of military life as has been the ideology of manliness". ${ }^{112}$ Feminist geographer Joni Seager has also pointed to the military's "manipulation of gender", which she describes as a "reliance on the construction of both a dominant masculinity and a dependent femininity". ${ }^{113}$ Militarization and militarized ideologies are predicated upon sharp gender role distinctions and a sharply gendered division of labour. Societies that require young men to 
enlist and engage in combat over extended periods achieve their compliance through beliefs about, and images of, manhood, as well as perceptions of a feminized, vulnerable "home front" that men are called on to protect. As small-arms researcher Vanessa Farr has said, "the complexity of... [women's] experiences is boiled down to a single ideology that women are more vulnerable than men, and thus deserving of a kind of protection and security that is decided by men". ${ }^{114}$

In militarized societies, then, keeping women both physically in and conceptually associated with "home" is a vital part of the mechanism that keeps young men enlisting, maintaining public (and particularly parental) consent to their conscription and deployment as fighters. V. Spike Peterson and Anne Sisson Runyan called this "the gendered division of violence in which the reproductive work of child-bearing and child care - life-giving - is reserved for women, while the work of war making and hunting - life-taking - is reserved for men". ${ }^{115}$ Accordingly, in Israel the fields of care and education are strikingly feminized, while both are denigrated and unpaid or low paid, as fits the ongoing cultural project of constructing women as secondary and weak. Israeli women, Orly Lubin wrote, exist in a "cycle of affirmation, enforcement and maintenance of male military rule and violence". ${ }^{116}$ "The local public discourse on "national security'... is totally oblivious to women's interests and knowledge... [as demonstrated in] the complete exclusion of gender-based violence... from discussions of 'safety',, said Sachs, Sa'ar and Aharoni. ${ }^{117}$ Underlying militarization even encompasses many feminist groups in Israel, which, according to Madelaine Adelman, "have tended to reject or ignore militarism and the Occupation as problematic for women's safety at home, perceiving them as irrelevant, not feminist issues, or too divisive for their organization or funding sources". ${ }^{118}$ Thus a process of intensified militarization, further obscured and naturalized through a growing private policing industry, presumably entails developments which reinforce the standard gender divide and have differential practical implications for men and women.

\section{The sexist subtext}

\section{Making women poorer, keeping women home}

A now classic gender-sensitive analysis of 1977 US economic and employment data found that "military spending predominantly buys goods from industries that... disproportionately employ men, largely because these professions tend to be male dominated... This means that women are largely excluded from many jobs that may be created by ... increases 
in defense spending." 119 In addition, "the major industry categories that receive the bulk of military spending... disproportionately employ many highly skilled and often high-wage individuals". ${ }^{120}$ This is a clear instance of how the culture of militarization, feeding a widespread devaluation of women and women's potential, severely constrains their capacity for economic independence through relegating them to poorly paid jobs or unpaid domestic work. ${ }^{121}$ The process effectively enforces women's widespread dependence on "protectors" and "providers" who are rendered more "masculine" merely by virtue of the socially constructed dependence of their female intimates. Men are conversely constructed as more able, more important and deserving, more "task-oriented" and generally more fit to deal with a competitive commercial world than are women. Both reflecting and upholding an ideology that idealizes certain configurations of masculinity towards keeping men and boys battleready, this mechanism also maintains property and control in the hands of a virtually all-male ruling class.

The issue of gender-equal access to employment in Israel's militarized job market is a pressing concern. In Israel, as elsewhere, poverty rates are significantly higher among women than among men. In 200391 per cent of Israeli single parents were women, and their children were among Israel's most poverty-prone groups. ${ }^{122}$ In October 2003 the Israeli Social Security Service assessed a rise in poverty to almost one in five families and almost one in three children. ${ }^{123}$ Over the years 2004-2006 the percentage of families living in poverty was consistently above $20{ }^{124}$ Clearly, then, an inordinate proportion of the adults bearing the brunt of impoverishment were (and are) women, who comprised two-thirds of the lowest income earners in Israel in $2004^{125}$ and headed 97 per cent of the single-parent families receiving state welfare ("income support payments") in 2003. ${ }^{126}$ As put succinctly by Sachs, Sa'ar and Aharoni, "Israeli women's over-representation in poverty makes them structurally vulnerable to the economic recession... The earning power of women across the class-lines is significantly lower than that of men, which implies an initial disadvantage ... when employment becomes scarce." 127

Given the extensive evidence of systematic breaches of labour law by private policing companies, ${ }^{128}$ it seems obvious that these companies also routinely evade the requirements of Israeli equal opportunity legislation - all the more so as the industry has a built-in escape clause: it only recruits people with "prior combat experience". Many, possibly most, of the "wanted" ads for private policing work specify this as a requirement or an advantage. Only a minute fraction of women $(0.9$ per cent in $2001)^{129}$ serve in combat roles in the Israeli army (versus 20 per cent of the men conscripted). ${ }^{130}$ Moreover, as Erella Shadmi explained, women tend to "give up in advance on any attempt to staff positions reserved for 
the male sex due both to the social pressure applied towards keeping women in traditional roles and to [society's] failure to invest in the female work force". ${ }^{131}$

Problematically, since it does not preclude their recruitment, a significant number of the men employed in the private policing industry may not in fact have prior combat experience. In 200375 per cent of security guards were reportedly newcomers to Israel, mainly from the former United Socialist Soviet Republic (USSR) ${ }^{132}$ and Ethiopia. ${ }^{133}$ Security companies apparently require recent emigrants to declare army service in their country of origin but have no requirement that they provide supporting documentation. ${ }^{134}$ Proof of experience is thus arbitrary. Due to gender stereotyping, however, the claim to previous combat experience is automatically and unthinkingly ruled out for immigrant women, and all the more so for women from older age groups comparable to those of many guards. For the most part, then, women have been excluded from the private policing industry en bloc simply because of their gender. While a security official in a town of about 100,000 said that approximately 20 per cent of the security guards subcontracted by the municipality were women, ${ }^{135}$ a city of over 250,000 was reported to employ well below 10 per cent female guards ${ }^{136}$ and in 2005 an official government assessment placed the overall percentage of women guards at 15.4, stating that "the field of guarding and security is a masculine profession". ${ }^{137}$ Nachum Sweid, whose security company employs 250 people, said he rarely employed women guards. ${ }^{138}$

Gender discrimination persists throughout Israel's job market, including the national police force (only 22 per cent were women in 2003). ${ }^{139}$ However, state security organizations are increasingly monitored. In recent years they have collected and publicized gender-disaggregated data on employment and promotion, which are closely followed by feminist organizations and discussed somewhat by government and media. ${ }^{140}$ In contrast, the municipal security officials and company owner interviewed for this study said there was no process of data collection on security workers, and at least one parliamentary document expressly cited the lack of gender-disaggregated data on municipal employees. ${ }^{141}$ Through failing to collect or publicize such data and by invoking "combat experience" as a criterion for employment, private policing firms effectively circumvent equal opportunity law.

Discrimination against women in the Israeli job market has accordingly worsened considerably in correlation with the growth of the largely publicly funded private policing industry, where jobs - predominantly open to men - multiplied by several hundred per cent, ${ }^{142}$ coupled with drastic reductions in the - predominantly female - public sector. ${ }^{143}$ While men's unemployment decreased slightly in the first quarter of 2004, after a 
three-year rise, women's unemployment reached a record peak of 12.1 per cent when some 13,000 teachers and social service workers were laid off. ${ }^{144}$ By the end of 2006, official statistics for unemployment had dropped to 8.4 per cent ( 7.9 for men; 9.0 for women). ${ }^{145}$ However, Commerce and Labour Ministry officials claimed in 2004 that about two-thirds of newly employed workers were under-employed and still searching for vital full-time employment, bringing the true unemployment rate to 16.5 per cent. A majority of the workers suffering increased under-employment and sub-minimum pay were women. ${ }^{146}$

It is important to place this trend within the context of the steady growth, over three to four years of economic crisis, of a single, quasimilitary section of the market, albeit one in which workers are poorly paid and exploited: the "gendered division of violence" both results from and is reinforced by the fact that private security jobs have largely been closed to women, while traditionally feminized sections of the economy have, quite literally, sent working women home. Over this period, only two government ministries were spared the significant, repeated budget cuts imposed by successive governments over the past few years in Israel: the Defense Ministry and the Ministry of Public Security. ${ }^{147}$ It is the latter that subcontracts a large proportion of Israel's security guards (through the police), and its budget has actually doubled over the past decade. ${ }^{148}$ Meanwhile, as "national security" budgets rise, social security payments are repeatedly and severely slashed. As a result, under the guise of "enhancing national security", women - already disproportionately represented among the poor - have been pushed further into poverty. ${ }^{149}$

Within this framework, Palestinian women who are citizens of Israel face both heightened discrimination as "others" and much-increased constraints on the freedom of movement necessary for participation in the workforce. Their mobility is reduced due to the widespread presence and relatively unchecked authority of security guards who designate Palestinian citizens of Israel as "suspect" almost automatically. Among the respondents to a 2005 survey conducted by Sachs, Sa'ar and Aharoni, 13.7 per cent of Palestinian women from Israel reported experiencing some injury in a racist context, while 7.8 per cent had suffered offences by armed forces. ${ }^{150}$ The security industry, then, has forcefully diminished these women's access to work. While women from majority groups in Israel face reduced job opportunities due to unfair hiring practices and budget cuts in the public sector, Palestinian women from Israel, excluded from the outset from "security"-related work, have additionally experienced increased intimidation and harassment, worsening the spatial restrictions that act to keep them home. Thus exacerbating women's impoverishment, private policing has meanwhile bolstered the property of the rich and the mechanisms of its protection. 


\section{"Sexually harassing systems"}

I have already shown that the purported hiring policies of private security companies are a thin disguise for gender discrimination. Because of its privileged position as an unregulated industry, this sector can also provide a cover for additional illegal, sexist practices. In November 2003 an ex-police officer was convicted of extended sexual harassment of a policewoman. The court ruled eight months' suspended sentence and a fine of 2,000 shekels. However, following his dismissal from the police, the officer reportedly opened a private policing company. ${ }^{151}$

That he could sidestep his removal from a position of public trust so easily illustrates that military and militarized organizations, both in Israel and elsewhere, can often be construed as "sexually harassing systems", pivotal in creating and maintaining women's second-class status in society at large. This formulation is one developed by feminist sociologist Orna Sasson-Levy, who wrote, "The [Israeli] army, as a central institution of both the state and patriarchy, constructs the Jewish man who serves in combat roles as the prototype of hegemonic masculinity ... which is identified with 'good citizenship.' This construction of masculinity is used as a major criterion in shaping the differential modes of belonging to the state. Groups... that do not or cannot stand up to this criterion (e.g., women, lower-class, ultra-Orthodox, Israeli Palestinians) are not integrated as full and equal citizens." ${ }^{152}$ Moreover, militarized mindsets are so deeply internalized by most Jewish Israelis that even women's organizations often fail to see harassment in security agencies as systemic, tending to privilege the security sector in their critical discourse. ${ }^{153}$

Nevertheless, in 2002 the Israeli Defense Force conducted an extensive study of sexual harassment. Yohalan, adviser to the chief of staff on women's affairs, found that 80 per cent of women soldiers were exposed to harassing conduct in the course of their military service. ${ }^{154}$ The study identified the attitudes of commanding officers as crucial to women's ability to take action against harassment, but said that only one-third of women respondents considered their commanders honestly committed to stopping such harassment. Notably, this finding followed several years of a declared campaign against sexual harassment throughout the army. As Sasson-Levy has said, "Ignoring sexual harassment or interpreting it as 'just something that happens' and 'part of everyday culture' is women's most prevalent reaction... unless there is a significant discursive and legal support for naming and litigating that harassment." ${ }^{155}$ Despite its awareness-raising campaign, the military was still failing to provide such support in 2002. Given the high percentage of women who had experienced harassment, this meant that army culture was still sanctioning and probably encouraging the practice as if still ignorant of its impact. In 
the police force, a 2000 survey revealed that 92.4 per cent of the women in the force said they were sexually harassed on the job. ${ }^{156}$

Both the military and the police are associated with and comparable to private policing firms, which are often viewed and treated as quasimilitary bodies. Among security workers, and particularly at management level, many are former soldiers or policemen. Presumably, such workers tend to import core components of the organizational culture of the police and army into the private environment, especially given the large overlap between job descriptions in private and state agencies, and the similar access that such organizations allow to the "resource" of state-sanctioned violence. I have no doubt that one of the main aspects of police and army culture brought into such firms is the standard, widespread practice of systematically harassing women. That the pervasive oppression of women goes right through the system is attested to by the fact that the Ministry of Defense, staffed by many ex-military men and closely linked with the military, was the government ministry with the highest rate of sexual harassment in 2000. ${ }^{157}$ But for many, arguably most, women the prevalent atmosphere precludes reporting harassment or filing charges. Victims of sexualized violence are marginalized in Israel, Madelaine Adelman wrote, due to the "nationalist collectivism that demands attention to the body politic as a whole and its vulnerability to external sources of victimization, rather than attention to the health and welfare of individuals". ${ }^{158}$

Nevertheless, despite their stubbornly privileged status, the Israeli army, and even more so the police, have been subject for some years now to apparently rising levels of scrutiny and control, following the success of a broad feminist lobby in achieving the enactment in 1998 of progressive legislation against sexual harassment. ${ }^{159}$ Though the media virtually ignored it, the Yohalan study was discussed by the Knesset (Parliamentary) Committee for the Advancement of Women's Status. Several widely publicized trials of high-ranking officers, including ex-Defense Minister Itzhak Mordechai, indicate that sexual harassment law is being enforced at least to some initial degree within state security forces. ${ }^{160}$ All the same, clearly oblivious to the "growing recognition [elsewhere] of the value of incorporating gender perspectives", ${ }^{161}$ private policing companies have developed no mechanisms at all for enforcing such legislation and appear to be under no pressure to do so; the rare women guards employed by such companies, among the lowest-paid and weakest workers in the economy, are arguably even more hesitant than policewomen or women soldiers to file complaints against harassing superiors. Given that a nationwide survey of crime victims in 2000 found that 96 per cent of harassment victims do not report the crime, ${ }^{162}$ I propose the existence of a high level of vulnerability to sexual harassment, as well as high 
levels of harassment, among the few women employed by private policing firms. An obvious effect of this culture is that women, not only discouraged by sexist recruitment policies but also afraid of the working conditions they would face, are hesitating to apply for positions in the security sector. Self-exclusion should thus be added to the obstacles that face Israel's vulnerable female job-seekers.

While I can offer no direct statistics or case histories to support this hypothesis, the image of security firms as "sexually harassing systems" is so obvious in the context of Israeli culture as to be taken for granted. The exclusively masculine image of the private security sector may wield an impact which surpasses that of the reality in a context in which sexual harassment is one of the central social mechanisms for women's disempowerment. Whether overtly or covertly, patriarchal, militarized societies actively encourage harassment and violence against women, and the endemic fear these instil provides an effective means of controlling not just the victims, but all women in the given society. Therefore, when an entire industry or sector allows, or is widely assumed to allow, extensive sexual harassment, and when this form of violence goes apparently unchecked by those social institutions that could stop it, the implications are farreaching. They reinforce the general culture of violence and join the vectors enforcing inequality and gender discrimination throughout the society in question. This then reinforces the mechanisms working to keep women "home"; to exclude them physically and figuratively from public space, from jobs, from the achievement of voice, status, property and power, and - of vital importance in a country at war - from having any stake in deciding and influencing their own security. Sexual harassment joins impoverishment in upholding the dominance of a violent hypermasculinity that is facilitated by, and reliant on, feminine subservience.

\section{The gun on the kitchen table}

At least nine women were murdered in Israel between 2002 and 2007 by security guards, all of whom were their partners, ex-partners or family members. At present it is quite difficult to compile conclusive information on gender-based violence, including murders, in Israel. As mentioned in the introduction to this chapter, the absence of such categories and data in the records of the police and the judiciary form part and parcel of the systemic violence and discrimination practised against Israeli women. Yahel Ash Kurlander has pointed out that feminist researchers and activists concerned with these topics are forced to rely on media reports. Besides the imprecision of many such reports and their common lack of relevant details, she explained, the media tend automatically to exclude, as "uninteresting", victims who were (or were thought to be) sex workers 
and those who were unregistered migrant workers. ${ }^{163}$ Predictably, then, comparisons of the lists of women murder victims painstakingly compiled and publicized by feminist groups such as L.O. Combat Violence Against Women and activists such as Shevi Barzilai of Isha L'Isha ${ }^{164}$ almost invariably show discrepancies. This committed fact-finding work is nevertheless a vital and primary source of data for the present study. Accordingly, the statistics presented here on women murdered by security guards are necessarily partial and inconclusive.

Of 21 women murdered by intimates in 2006, four (representing almost one-fifth) were reportedly shot, three of them with licensed weapons. One of these, Galina Paladiev, was shot with a handgun licensed to her partner, a security guard. ${ }^{165}$ In the course of 200519 women and girls were murdered by ex-partners, partners or other family members. One of them was shot. The gun was licensed to a security guard. ${ }^{166}$ Seventeen women and girls were reportedly murdered by intimates in Israel in the course of 2004. At least three of them (representing 17.6 per cent) were shot. Two of the three known shooters were security guards. ${ }^{167}$ Twentyfive women and girls were murdered by intimates in Israel in the course of $2003 ; 11$ of them (44 per cent) were shot. ${ }^{168}$ Four of the shooters in 2003 were security guards at the time of the murders. ${ }^{169}$ Twenty-nine women and girls were murdered in Israel by intimates in 2002; five of them (17.2 per cent) were shot. One of the shooters was reportedly a security guard. ${ }^{170}$

It has long been recognized that while violence against women is by no means "unique to Israel... Israel does have the special problem of IDF [Israel Defense Force] weapons". ${ }^{171}$ Notably, the percentage of shootings (35.9) among women's homicides in Israel between 1990 and 1999 has been found to "parallel closely the statistics relative to female homicide in the U.S. military... Researchers found that between 1980 and 1992, thirty-five percent of the deaths were caused by firearms." ${ }^{172} \mathrm{Ma}-$ delaine Adelman has written that "Access to [IDF] weapons was officially noted in a special report on family violence submitted in 1998 to the then minister of public security." 173 As I've shown above, private policing weapons now represent an added factor in Israel, increasing the overall number of readily accessible arms, the degree of their normalization and the lack of clarity as regards accountability for their use or misuse. Sachs, Sa'ar and Aharoni found that no less than 47 per cent of the women killed by intimates between 2000 and early 2005 - as bombings and the consequent security boom were peaking - were shot by guards or security forces. The overall number of women murdered with firearms during this period was well over double the number of women shot over a comparable period of four years preceding the Intifada (38 as opposed to 14). ${ }^{174}$ In addition, 20 per cent of the women interviewed for their 
study "reported that they share a household with a person who is a regular soldier, policeman, security guard or reserve soldier". ${ }^{175}$ A significant percentage of these carry weapons which they regularly take home.

In both 2006 and 2005 security guards alone represented approximately 5 per cent of the perpetrators of women's murders by intimates; in 2005 they also represented 100 per cent of the shooters. In 2004 they represented just under 12 per cent of the perpetrators and two-thirds of the shooters; in 2003 they accounted for 20 per cent of the perpetrators and 36 per cent of the shooters; in 2002 they represented 3 per cent of the perpetrators and 20 per cent of the shooters. In all, over the period from 2002 to 2007, security guards committed nine of the reported 144 murders of women by intimates in Israel, comprising over 6 per cent of these murders.

Various studies have clearly established that the presence of firearms in the home raises the risk of women's murder by intimates, which is globally a far greater threat to women than murder by strangers. ${ }^{176} \mathrm{~A}$ 2003 position paper by the International Action Network on Small Arms ${ }^{177}$ cites "a study of 25 high-income countries, [which found that] high household gun ownership rates were correlated with much increased female homicide rates". The document stressed that legal firearms were found to be the primary weapons used in domestic homicides. As Cukier has noted, "From the perspective of women... distinctions between crime and conflict... between legal and illegal weapons are not particularly meaningful." ${ }^{178}$ In Israel, social anthropologist Naomi Gale has written, referring to the 1990s before the accelerated growth of privately owned and armed security companies, that a majority of men who used small arms to kill women partners were either licensed gun holders or reserve soldiers holding legally issued arms. ${ }^{179}$

The recently rising numbers of guards employed by Israeli private policing firms tend to take their guns home. The inter-ministerial committee on the licensing of firearms, convened in the wake of repeated tragic shootings, stated unequivocally that "In numerous cases the current reality is that the firearm remains with the guard after his shift. The system fails to enforce the demand that the guard hold firearms only within the framework and during the time of his work." ${ }^{180}$ Screened by the police and licensed (though indirectly via the employing company) to carry guns by the Ministry of the Interior, security workers are instructed on safe gun storage in the home. But their implementation of these guidelines is not monitored by the company, the police or the municipality. ${ }^{181}$ Furthermore, I was told that many a guard "does just what any policeman does at home - drops it [the gun] on the kitchen table". ${ }^{182}$ Whether stored according to regulations or not, though, the growing number of guns introduced into homes in Israel due, to a significant degree, to the 
growth of the private policing industry obviously increases the threat of women's murder by intimates.

Naomi Gale proposes that security workers (military, police and employees of private firms) are overrepresented among abusers and killers of women "because arms provide the abuser with a threatening, deterrent force and, even worse, reduce the options for dialogue and alternative solutions". ${ }^{183}$ Corroborating this view, a 2002 US study found that military couples showed a rate of domestic abuse two to five times higher than that of the general population. ${ }^{184}$ Older US studies concluded that domestic violence occurred two to four times more in policemen's families than in the general population. ${ }^{185}$

Following a series of women's killings by legally armed intimates in Israel in the late 1990s, authorities initiated a proposal to confiscate arms from husbands immediately following the first charges of domestic violence filed against them. ${ }^{186}$ A major nationwide women's organization, Na'amat, demonstrated in support. Deputy Police Commander Ido Gutman reflected pervasive attitudes to this campaign when he said, "Let's assume that some 20 women are killed each year by people who hold gun permits. What are we going to do? Stop giving permits? Then we'd have an absurd situation where you'd have unarmed guards at schools and a terrorist could come in and kill a whole classroom."187 And indeed, as suicide attacks provided an incentive for accelerated civilian armament, the anti-gun campaign dissolved, as had the parliamentary subcommittee for preventing arms in schools. By 2002 Na'amat spokesperson Gali Etzion said - commenting on small-arms proliferation - "If somebody wants to guard my kid's kindergarten, I can't say I'm against the idea." 188

Besides reflecting the growing pool of (relatively) easily accessible arms, the data on the killing of women by intimates in Israel in recent years show another distinctive trend. According to statistics collected by L.O. Combat Violence Against Women, ${ }^{189}$ of the women murdered in 2001, 42.86 per cent were newcomers to the country, emigrants from the former Soviet bloc and Ethiopia (or, in one case, a woman who had come to Israel as a migrant worker), 28.57 per cent were Palestinian citizens of Israel and 28.57 per cent were veteran Jewish Israelis. The overall proportion of new immigrants to Israel, Palestinian citizens of Israel and veteran Jewish Israelis in the population at the time was 17 per cent, 17 per cent and 66 per cent, respectively, meaning that the number of women murdered by intimates among both newcomers and Palestinian citizens was clearly disproportionate. This pattern was evident in the killings of women by intimates over the entire decade of $1992-2001 .{ }^{190}$ Of all the women murdered by intimates during this period, 36 per cent were recent immigrants (representing about 2.1 times their proportion in the popula- 
tion) and 22.34 per cent were Palestinian citizens of Israel (representing about 1.3 times their proportion in the general population). More recently, at least five of the 17 women murdered by intimates in 2004 were immigrants from the former USSR, two were immigrants from Ethiopia and two were Palestinian citizens of Israel. Of the 19 women murdered by intimates in 2005, four were from Ethiopia, three were from the former USSR and five were Palestinian women.

Reporting on her extensive research in the United States, ${ }^{191}$ Margaret Hobart discussed the disproportionate number of victims of domestic violence who were immigrants or women of colour. ${ }^{192}$ Higher death rates in these communities, she argued, do not occur "because immigrant communities are more violent... instead ... [they are] likely tied to the inability of immigrant women to access services and information which would serve as protective factors". ${ }^{193}$ Hobart proposes that "the race variable is also correlated with limited English language skills, which have a critical effect on women's ability to obtain help when experiencing domestic violence". ${ }^{194}$ Similarly, in Israel, Palestinian feminist criminologist Nadera Shalhoub Kevorkian has demonstrated that police and public service agencies employ culturally inappropriate models in responding to domestic violence against Palestinian women. ${ }^{195}$ In the United States, Hobart notes, women with limited majority-language skills had no access to culturally appropriate victim services and were also taken less seriously by law enforcement officials and judges. This is also true in Israel, where, by and large, women from the minority groups overrepresented among domestic violence victims have limited proficiency in Hebrew, the standard language of police, courts and welfare services. Despite recognition of the crucial role of culture and language in the non-government crisis centre movement, ${ }^{196}$ the hegemonic culture and language still dominate hotlines, rape crisis centres and safe houses. ${ }^{197}$ Thus both immigrant and Arabic-speaking women are significantly more at risk than veteran Israelis.

Palestinian women in Israel, however, are hindered by more than language and culture in their efforts to seek protection from threatening intimates. They must contend with a hostile law enforcement system that repeatedly abandons women to their threatening families, ${ }^{198}$ and systematic state support for the authority of conservative, oppressive elements within their community. ${ }^{199}$ The manifestations of misogynist patriarchy often ascribed by Israeli Jewish discourse to the backwardness and/or fundamentalism of Israel's Palestinian citizens have in fact been encouraged and supported by Israel's state agencies. ${ }^{200}$ "Preserving women's inferior status is the currency with which the state pays dignitaries, sheikhs and traditional religious leaders", Manar Hasan has written, ${ }^{201}$ in the interests of securing their obedience and acquiescence with state 
policies concerning their communities. The rule of the patriarchal clan among Palestinians in Israel does not, strictly speaking, stem from Palestinian "culture" but has rather developed as a politically motivated construct, consistently nurtured by the state. ${ }^{202}$

Increased risks to women from minority groups in the United States, Hobart wrote, were further compounded by the poverty disproportionately experienced by women from these groups. Limited language skills and poverty combined to lead to greater difficulty in obtaining safe housing and ensuring safe transportation to victim services, adding to the women's inability to attain economic independence from their abusers. Another US survey indicated that rates of "abusive violence" to women in households with annual incomes below $\$ 10,000$ were more than 3.5 times higher than in households with incomes over $\$ 40,000 .^{203}$

Palestinian women from Israel are a systematically impoverished minority ${ }^{204}$ within which unemployment rates are significantly higher than those experienced by Israeli women in general. In 1999 unemployment among female Palestinian citizens of Israel was 11.7 per cent, as opposed to 9.4 per cent of the general female workforce. ${ }^{205}$ Debilitating poverty levels accordingly join the combination of language with state and community oppression in disproportionately endangering women from the Palestinian community in Israel. In addition, while most Palestinian citizens of Israel are excluded from both military service ${ }^{206}$ and private policing jobs, their participation in the armed Civil Guard, an auxiliary of the police force, rose by a record 400 per cent between 2000 and 2004 . By the end of 2004 over 7,000 volunteers from the Palestinian community in Israel were active in the Civil Guard. ${ }^{207}$ This process and the general increase in accessible arms ${ }^{208}$ further enhance the threat of domestic and gendered violence facing Palestinian women in Israel. Thus, unsurprisingly, 43 per cent of the women who turned to the Arabic-language rape crisis centre in Nazareth in the first half of 2004 were assaulted within the home or family. ${ }^{209}$

Among the women of immigrant communities in Israel, unemployment in 1999 was 11.9 per cent, even higher than the rate among Palestinian women, while for recently immigrated women, arriving in Israel during or after 1994, it reached a dramatic 16 per cent. ${ }^{210}$ The importance of examining the implications of these women's poverty becomes clearer when one considers that it is precisely the women of immigrant communities whose intimates - overrepresented among security workers - have recently been armed on a significant scale. "About a year or so ago, most security workers were new immigrants and students," said Attorney Ehud Shiloni in 2003, ${ }^{211}$ "two groups that are very convenient for the employers." As a company manager reported, "most of the guards are Russians because ... they put in long hours and they don't complain". ${ }^{212}$ 
With severely limited job options, immigrant groups represent a large proportion of security workers. Among these groups, many are unfamiliar with labour law and unaware of their rights, or lack the cultural and Hebrew literacy to attain them. A significant proportion of those employed as guards tend to be older men struggling with the standard ageism of the job market. ${ }^{213}$ Obviously, the "qualifications" of being desperate and isolated, more than "combat experience", have topped the list of requirements for becoming a security guard.

As I have suggested elsewhere in my writing on conscripts in Israel, a society consistently choosing members of a specific group (or groups) to endanger themselves in its service is "effectively saying that this category of people is relatively expendable. It's saying that society as a whole (not individual families) can cope with the steady loss of some members of this group. Whether or not this stems from dire necessity ... their possible loss is comparatively bearable for the community." ${ }^{214}$ Security officials openly admit that the main goal of posting guards is deterrence through illusion, as their actual chances of effective response to attacks are very small. ${ }^{215}$ Indeed, at least five guards have been killed to date in futile attempts to use their own bodies to block suicide bombers. ${ }^{216}$ The reality of such expendability, which Saltman has called "the soldier's infinite replaceability", ${ }^{217}$ is obscured in the case of Israel's conscripts by the privileged status of soldiers and the systematic valorization of military service in Israeli culture. However, it is glaringly obvious in the case of security guards. While thought necessary, their work is nevertheless considered "despised [and] dangerous". ${ }^{218}$ Their salaries, working conditions and systematic exploitation reflect the extent to which these men are devalued by society. And, in contrast to most conscripts, they are all too aware of this devaluation. A newly immigrated security worker commented, "It is fear that keeps... [us] docile despite... maltreatment.",219 Many of the immigrant men employed as guards were "accountants, teachers and... professionals" 220 in the countries they left. Struggling to put food on the table in Israel, they have been "reduced to minimum wage, boring, potentially lethal guard work". ${ }^{221}$

Such a situation feeds directly into the "gender dynamics of arms possession... [through which] weapons ... tend to become 'tools of violence' when un- or underemployed... males gain access to them". ${ }^{222}$ A 2003 US study found domestic abusers' lack of a job to be "the strongest social risk factor, increasing the risk of femicide fourfold". ${ }^{223}$ Unemployment compounded by abusers' access to firearms increased the risk to more than five times the norm. While security guards in Israel are obviously not unemployed, it is precisely their under-employment which provides them with guns and by the same token subjects many of them to social and economic degradation under a spectre of unemployment. 
For many immigrant guards, combined degradation, poverty and underemployment may amount to failure in their attempt to realize the normative masculinity into which they were socialized. These are the type of social conditions believed by Chris Dolan "24 to feed a sense of "thwarted" manhood. Failing fully to achieve "masculine" status tends, in turn, to block men from aspiring to civic and non-violent models of masculinity, promoting violence - both domestic and collective - as a channel for achieving self-esteem. Thus in Albania, for instance, domestic abuse increased over the 12 years of transition from communist to post-communist rule, due to "societal upheaval... [that] diminished men's traditional role... and undermined traditional gender roles". ${ }^{225}$ Albanian women viewed violence as a social problem in a society "caught between tradition and modernity... [where] men have become frustrated at their declining ability". 226

These, then, are the economic and cultural factors seriously endangering some of the women whose security-guard intimates currently carry guns. The potential lethality of the combination of social, cultural and economic circumstances in which some new immigrants are caught is evidenced in the fact that, in 2003, three of the five security guards who killed their partners were recent immigrants from the former USSR or Ethiopia; in 2004 at least one of the two security guards who shot and killed women family members was an immigrant (from Ethiopia); and in 2005 and the beginning of 2006 the two men who shot and killed their partners were both immigrants, one from Ethiopia and one from the former USSR. For some of the most deprived women in Israel it is the private policing industry, ostensibly designed to keep danger out, that brings danger and discrimination in - to their families, their homes, their lives.

\section{Conclusion}

Conflict is ongoing in Israel-Palestine, at varying levels of intensity, with no end in sight. The summer of 2006 saw a renewed round of all-out war between Israel and Hizballah in Lebanon, followed, throughout 2007, by a routine of violent Israeli attacks in Gaza and the West Bank. Both the war and the policy of continuing Israeli attacks were supported by a majority of Jewish Israelis despite extensive Hizballah bombings and repeated (though relatively limited) bombardments of Israeli towns and villages around the Gaza Strip. The private policing industry that has thrived on this conflict is already instituted as one of the many "security" agencies whose very existence stems from and requires it. In a cyclic process, the industry both depends on and strengthens the militarization that, endemic to state and society, "makes war seem either natural or de- 
sirable", ${ }^{227}$ thus maintaining popular acquiescence with the decisions of politicians to initiate war. The relative ease with which Israel again moved into war in 2006, with widespread public backing, and the fact that the subsequent investigative probe totally avoided the question of this war's necessity ${ }^{228}$ are only the latest bits of evidence for the depth and breadth of Israeli militarization.

Given this context, its normalization of violence and its implications for practices of masculinity versus femininity, the phenomena above can be understood as a coherent, cohesive text. Women in Israel today are being progressively impoverished due to high security spending and privatization directly related to the spread of private policing. They are facing increased layoffs and heightened exclusion from a "security"-oriented, gender-, class- and race-discriminatory job market. State-supported oppression and sexual harassment reinforce these trends in keeping or pushing more and more women out of jobs, denying them the resources for personal independence, barring them from the public sphere and confining them "at home". But it is also at home that too many women are facing the death threat of firearms given (directly or indirectly) to their partners and intimates by a society that concurrently devalues and exploits these men.

Clearly, most women do not face the full force of impoverishment, harassment and life-threatening violence (or murder), combined, on an everyday basis. Some, though, definitely do. While these tend to be among the most marginalized members of Israeli society, it is their lives at the limits that most clearly illuminate the systemic positioning of all women in Israel. Although their subordinate position is implicit throughout the social fabric of contemporary Israeli society, women's significance as insignificants becomes most visible on the extremes, at the margins. Their vulnerability - invisible because it is in part socially sanctioned - is the enraging image to be held squarely in view and acted on whenever the topic of gun availability is raised.

\section{Acknowledgements}

The author expresses her gratitude to Small Arms Survey, Geneva, for supporting her work on this chapter.

\section{Notes}

1. Laurance, Edward and Sarah Meek (1996) The New Field of Micro-Disarmament: Addressing the Proliferation and Buildup of Small Arms and Light Weapons, Brief 7, Bonn: Bonn International Center for Conversion, p. 5. 
2. Ibid., p. 27.

3. In this context, I wish to clarify that although the current chapter will make mention of some legislature, various cases of litigation and a few legal rulings, it will treat these as reflective of government policies as well as social attitudes and processes. It will avoid the type of strictly legal analysis that would, in my view, divert the chapter towards a more legalistic, technical discussion.

4. Berkovitch, Nitza (2006) "Dual Wage-Earner, One Career: The Israeli Model", Adva Center Information on Equality and Social Justice in Israel, p. 3, available at www. adva.org/UserFiles/File/Nitza\%20Berkovitch\%20in \%20English\%202006.pdf.

5. Halperin-Kaddari, Ruth (2004) Women in Israel: A State of Their Own, Philadelphia, PA: University of Pennsylvania Press, pp. 178 and 197.

6. Snir, Yedidya (2003) "Branch Business Profile: Security Companies", report for MATI Israel Business Development Center and the Small Business Bureau, ISH Consultants, Ministry of Industry and Commerce, Tel Aviv, p. 3, available at www.asakim.org.il/ upload/p52.doc (original in Hebrew, translated by the author).

7. Lagerquist, Peter (2002) "Private Security, Colonial Wars", Eurozine Net Magazine, 23 October, available at www.eurozine.com/article/2002-10-23-lagerquist-en.html.

8. Leibovitch Dar, Sara (2003) "Security Counsel", Haaretz, 30 May.

9. Meletz, Judy (2003) "Who Will Protect the Guards?", Globes, 30 April (in Hebrew); Levy, Shelly (2005) "Background Paper on Features of the Employment of Guards in Israel", presented to Knesset member Juri Shtern, Knesset Center for Research and Information, 10 July, available at www.knesset.gov.il $/ \mathrm{mmm} / \mathrm{doc} \cdot \mathrm{asp} ? \mathrm{doc}=\mathrm{m} 01173 \&$ type $=$ pdf (in Hebrew).

10. Snir, note 6 above, p. 1 .

11. Ibid., p. 7.

12. Levy, note 9 above, p. 4.

13. Leshem, Guy (2002) "One Guard for Every Four Educational Institutions", Yedioth Ahronoth: Hamussaf Leshabat, 1 March (in Hebrew).

14. Lagerquist, Peter and Jonathan Steele (2002) "Group 4 Security Firm Pulls Guards Out of West Bank", The Guardian, 9 October, available at www.guardian.co.uk/israel/ Story $/ 0,2763,807149,00 . \mathrm{html}$.

15. Kav LaOved (2002) "Kav LaOved Activities in Assisting Israeli Security Workers", 12 July, available at www.kavlaoved.org.il/katava_main.asp?news_id=759\&sivug_id=28; Bior, Haim (2004) "Feeling Safer, Businesses Cut Out 14\% of Guard Jobs", Haaretz, 13 September, available at www.haaretz.com/hasen/objects/pages/PrintArticleEn. jhtml?itemNo $=477020$.

16. Arlosoroff, Meirav (2006) "The Economic Police Chief", Marker Week Haaretz, 21 April, p. 11 (in Hebrew). See also Yadid, Orit (2003) "The Safe", Marot Hamishtara 179, available at www.police.gov.il/persumim/kitvey_et/01_179/03_179.asp (in Hebrew).

17. Kra, Baruch (2003) "Seven Million Dollar Donation to Enable New Bus Defense Program", Haaretz, 5 March; Barkat, Amiram (2004) "The Donations - From US Christians and Jews", Haaretz, 5 March (in Hebrew).

18. Melman, Yossi (2007) "Big Security", Haaretz, 12 July (in Hebrew), available at www.haaretz.co.il/hasite/spages/880952.html.

19. Klein, Naomi (2007) The Shock Doctrine: The Rise of Disaster Capitalism, New York: Metropolitan Books, p. 436.

20. Sinai, Ruth and Amnon Barzilai (2004) "Ministry of Commerce: Continued Calm Could Cause Layoff of 15,000 Security Guards", Haaretz, 23 June (in Hebrew).

21. Levy, note 9 above, p. 1.

22. Bior, note 15 above. 
23. Kav LaOved (2003) "Who Will Protect the Protective Legislation? Systematic Violations with State Encouragement", Newsletter, December, available at www.kavlaoved. org.il/word/110104.rtf.

24. Sinai, Ruth (2005) "For the First Time in Eight Years, a Drop in Private Policing Employees", Haaretz, 12 January (in Hebrew); Regev, David and Yehudit Yahav (2005) "The Number of Security Guards Has Fallen by $8.5 \%$ in Recent Months, Because of the Calmer Security Situation", Yedioth Ahronoth, 31 January.

25. Central Bureau of Statistics (2005) "Government Employees by Ministry and the Israel Police", available at http://www1.cbs.gov.il/shnaton56/st10_11.pdf.

26. Farr, Vanessa (2002) "A Gendered Analysis of International Agreements on Small Arms and Light Weapons", in Vanessa Farr and Kiflemariam Gebre-Wold, eds, $A$ Gender Perspective on Small Arms and Light Weapons: Regional and International Concerns, Bonn: Bonn International Center for Conversion, p. 22.

27. Palter, Nurith and Ariye Egozi (2004) "New Record: Climbing Number of Gun Carriers in Israel", Yedioth Ahronoth, 8 April (in Hebrew).

28. Broyda, Haim and Nurith Palter (2003) "An Easing of Restrictions on Distributions of Guns to Public", Yedioth Ahronoth, 6 March (in Hebrew); Mualem, Mazal (2003) "Heavy Demand for Handguns Leading to Weapons Shortage", Haaretz, 26 March; Shavit, Uriya (2003) "Happiness Is a Warm Gun", Haaretz, 20 March.

29. Palter and Egozi, note 27 above.

30. Ibid.; interview with head of Municipal Security Department, 5 May 2004, conducted by Edna Toledano Zaretsky.

31. Private policing companies are authorized to request licences for lists of employees. The employees listed are not required to submit medical reports from their personal physicians nor are they interviewed in person by the ministerial licensing authority. They are often authorized by the employing company to carry a gun prior to official approval of its request to license them. Committee for the Review of the System of Arms Licensing for Guards (2005) "Report of the Committee for the Review of the System of Arms Licensing for Guards", 13 July, p. 16, available at www.moin. gov.il/Apps/PubWebSite/mainmenu.nsf/4DF815EA4AC4E503C2256BA6002EE732/ 95EEB8757FB10F1542257053003C720B/\$FILE/News.pdf (in Hebrew). See also Zelikovich, Moran and Diana Bahur-Nir (2005) "Guards Blasted for Lax Regulations", Ynet, 3 August, available at www.ynetnews.com/articles/0,7340,L-3122014,00.html.

32. Navon, Eran, Arad Nurith and Yossi Yehoshua (2002) "You Can't Give Every Watchman a Gun", Yedioth Ahronoth, 20 January (in Hebrew); Broyda and Palter, note 28 above; Harel, Amos and Baruch Kra (2004) "Sixty Alerts of Bombings Over Holidays; Police Commissioner Calls Civilians to Carry Guns", Haaretz, 7 April (in Hebrew).

33. That is, via the relevant authorities: the Ministry of the Interior, the Health Ministry and the Ministry of Law. See Lis, Yehonatan (2004) "Arms in Israel: More Guards Less Supervision", Haaretz, 8 November (in Hebrew).

34. Haaretz (2004) "Security Firm Execs Arrested after Guard Commits Suicide", Haaretz, 29 September, available at www.haaretz.com/hasen/objects'pages/PrintArticleEn. jhtml?itemNO=483021.

35. Palter and Egozi, note 27 above.

36. Central Bureau of Statistics (2005) "Selected Data (English), Population, by Population Group", available at www.cbs.gov.il $/ \mathrm{lmse} . c g i ? \mathrm{i}=1 \& \mathrm{t} \mathrm{i}=2 \& \mathrm{r}=0 \& \mathrm{f}=3 \& \mathrm{o}=0$.

37. Committee for the Review of the System of Arms Licensing for Guards, note 31 above, p. 13.

38. Palter and Egozi, note 27 above.

39. Committee for the Review of the System of Arms Licensing for Guards, note 31 above, pp. 4 and 14; Association for Civil Rights in Israel (2008) "The Association to the Min- 
ister of Public Security: Supervise the Conduct of Security Guards", 8 September, available at www.acri.org.il/Story.aspx?id=1954 (in Hebrew).

40. The number of schools (including kindergartens) was about 3,770 in 2003; see Ministry of Education website at www.education.gov.il/moe/klali/netunim_sd.htm (in Hebrew).

41. Leshem, note 13 above; Saar, Reli (2003) "Some 40\% of Guards at Schools Aged 5065", Haaretz, 11 September (in Hebrew); Saar, Reli (2004) "No Budget for In-depth Screening of Guards", Haaretz, 3 September (in Hebrew).

42. Cukier, Wendy with Alison Kooistra and Mark Anto (2002) "Gendered Perspectives on Small Arms Proliferation and Misuse: Effects and Policies", in Gender Perspectives on Small Arms and Light Weapons: Regional and International Concerns, Brief 24, Bonn: Bonn International Center for Conversion, p. 32.

43. See, for instance, Benvenisti, Rami, Anat Zeira and Ron Astor (1999) "Violence in the Education System 1998-9: Executive Summary”, Head Scientist's Office, Ministry of Education, available at http://207.232.9.131/scientist/up_load/alimut/executive_ summary.pdf (in Hebrew); State Comptroller and Ombudsman (2000) "Annual Report 51B for 2000 and for Accounts of Fiscal Year 1999 - Educational Research Background Examining the Phenomenon of Violence and Its Forms", available at www. mevaker.gov.il $/$ serve $/$ showHtml.asp? bookid $=156 \&$ id $=2 \&$ frompage $=72 \&$ contentid $=1827 \&$ parentcid $=1822 \&$ direction $=1 \&$ bctype $=1 \&$ frombutton $=0 \&$ startpage $=24 \&$ sw $=1024 \& \mathrm{hw}=$ 698 (in Hebrew).

44. Trabelsi-Hadad, Tamar (1999) "Principals Will Be Authorized to Search Students' Bodies and Bags for Guns", Yedioth Ahronoth, 22 June (in Hebrew).

45. Lis, note 33 above.

46. Trabelsi-Hadad, Tamar (2000) "Some School Guards Endanger Students", Yedioth Ahronoth, 16 May (in Hebrew); Itim News Agency (2003) "Suspected Rape of 12 Year Old Girl by School Guard", Maariv Online, 16 March, available at http://images. maariv.co.il/channels/1/ART/494/431.html (in Hebrew); Rotem, Tamar (2003) "School Guard in Kiryat Malachi Accidentally Shot and Killed by Friend", Haaretz, 1 September (in Hebrew); Singer, Roni (2003) "Guard at Rupin Heard Explosion and Fired His Gun - Thirty Year Old Wounded", Haaretz, 28 October (in Hebrew); Rotem, Tamar (2004) "Six Cases of Accidental Firing Since 2002", Haaretz, 18 January (in Hebrew); Rotem, Tamar (2005) "School Guard Suspected of Molesting Students", Haaretz, 27 February (in Hebrew); Tsomet Hasharon (2004) "Ramat Hasharon: Guard Who Slapped Student at Or Hashahar Back on the Job", Tsomet Hasharon, 1 April (in Hebrew); Haaretz (2004) "School Guard Videotaped Himself Having Sex with Dozens of Children", Haaretz, 2 September (in Hebrew); Azoulay, Yuval (2004) "Police Turn Up New Leads in Ashdod Pedophile Case", Haaretz, 3 September, available at www.haaretz.com/hasen/objects/pages/PrintArticleEn.jhtml?itemNo=473137; Khromchenko, Juli, Eli Ashkenazi, Yuval Azoulay and Ruth Sinai (2004) "Schools Strike for an Hour Today to Protest Violence", Haaretz, 25 October (in Hebrew); Roeh, Anat (2004) "Manslaughter Charges against School Guard Who Shot Technician", Haaretz, 8 November (in Hebrew); interview with head of Municipal Security Department, 2004.

47. Yadid, note 16 above.

48. Graham, Philip and Allan Luke (2003) "Militarizing the Body Politic: New Mediations as Weapons of Mass Instruction", Body \& Society 9(4), pp. 159-160.

49. Saltman, Kenneth J. (2003) "The Strong Arm of the Law", Body \& Society 9(4), p. 55.

50. Shadmi, Erella (2001) "Why Police Conduct in September Towards the 48 Palestinians Was Predictable", Between the Lines. Between the Lines was a monthly magazine published for a few years in Israel (in English), both online and on paper. It now seems to be unavailable online. 
51. Department of Security, Safety and Emergency Services, Municipality of Herzlia (2004) "Introductory File to Herzlia: Work Year 2004", unpublished document (in Hebrew, translated by the author, no page numbers).

52. Interviews with director of Municipal Department of Security, Safety and Emergency Services, 23 May and 29 June 2004.

53. Gorali, Moshe (2004) "The Security Gap", Haaretz, 13 August (in Hebrew).

54. Interview with Erella Shadmi, 29 August 2004.

55. Interview with Nachum Sweid (owner of Amnoor Moked Amon Caesarea security company), 7 July 2004.

56. Committee for the Review of the System of Arms Licensing for Guards, note 31 above, p. 13.

57. Sinai, Ruth (2005) "Report: Only the Top Income Decile Benefited from the Growth in Israel in 2004", Haaretz, 2 January (in Hebrew).

58. Tal, Avraham (2004) "Growth Needs More Support", Haaretz, 30 January (in Hebrew).

59. Bior, Haim (2004) "Men Coming Out of Recession; Women Still Holding Back", Haaretz, 7 July (in Hebrew); Bassok, Moti and Ruth Sinai (2004) "Unemployment Down - But Peaking for Women", Haaretz, 31 May (in Hebrew); Bassok, Moti and Amir Teig (2004) "Unemployment Stuck at 10.7\%", Haaretz, 19 January (in Hebrew); Atad, Amnon (2003) "Temporary Drop in Unemployment", Ynet, 31 August, available at www.ynet.co.il/Ext/Comp/ArticleLayout/CdaArticlePrintPreview/1,2506,L2742016,00.html (in Hebrew); Bassok, Moti (2001) “Unemployment Last Year 8.8 Percent", Haaretz, 15 February (in Hebrew).

60. Swirsky, Shlomo and Etti Konor-Attias (2006) Workers, Employers and the Distribution of Israel's National Income: Labor Report 2005, Tel Aviv: Adva Center, pp. 3, 22-23, 30, available at www.adva.org/E-adva-web_new.pdf.

61. Swirsky, Shlomo, Etti Konor-Attias and Barbara Swirsky (2003) Two Years of Destructive Policies: A Critique of the Budget Proposal for Fiscal 2004 from a Gender Perspective, Tel Aviv: Adva Center, available at www.adva.org/Budget2004GenderEnglish. htm.

62. Ibid.

63. Ibid.

64. Efroni, Linda (2003) "You Scratch My Back, I'll Scratch Yours”, Globes, 28 April (in Hebrew, author translations).

65. Sinai, Ruth (2006) "Hundreds of Employees Sued but 'Hashmira's' Licence Was Renewed by the Government", Haaretz, 29 May (in Hebrew); Committee for the Review of the System of Arms Licensing for Guards, note 31 above.

66. Sinai, Ruth (2006) "All of a Sudden the Finance Ministry Woke Up", Haaretz, 12 July (in Hebrew); Leshem, Guy (2006) "Security Guard Companies Breaking Minimum Wage Law; Blaming the Government", Marker Haaretz, 9 July (in Hebrew).

67. Sinai, Ruth (2007) "Court Deals Security Firms Licensing, Financial Blows", Haaretz, 25 December, available at www.haaretz.com/hasen/spages/937949.html.

68. Caspi, Ariyeh (2003) “The Battle of the Tender", Maariv, 8 July (in Hebrew).

69. Interview with Dana Myrtenbaum, attorney at law, specialist in labour law, 22 December 2004; Sinai, Ruth (2004) "Government Ministries Try to Save at Any Price and Sub-contractors' Employees Paid Sub-minimum Wages", Haaretz, 22 December (in Hebrew); Kav LaOved, note 23 above.

70. Derfner, Larry (2002) "Beneath Contempt: The Exploitation of Israeli Security Guards", Jerusalem Post, 29 November, available at www.kavlaoved.org.il/katava main_heb.asp?news_id=354\&sivug_id=1.

71. Ibid. 
72. Sinai, note 69 above.

73. Mazali, Rela (2003) “'And What About the Girls?': What a Culture of War Genders Out of View”, Nashim: Journal of Jewish Women's Studies and Gender Issues 6, pp. $39-50$.

74. Mazali, Rela (2005) "Conscripted Parenthood”, in Gor Haggith, ed., The Militarization of Education, Tel Aviv: Babel Press, pp. 322-332 (in Hebrew); Mazali, Rela (1998) "Parenting Troops: The Summons to Acquiescence", in Lois Ann Lorentzen and Jennifer Turpin, eds, The Women and War Reader, New York: New York University Press, pp. 272-286; Mazali, Rela (1995) "Raising Boys to Maintain Armies", British Medical Journal 311, 9 September.

75. Coussin, Orna (2001) "Recruiting in the Kindergarten", Haaretz, 30 May, p. 7, available at http://www3.haaretz.co.il/eng/secret/article.asp?mador $=5 \&$ datee $=05 / 30 / 01 \& \mathrm{id}=$ 12033.

76. Cock, Jacklyn (1993) Women \& War in South Africa, Cleveland, OH: Pilgrim Press, p. 9 .

77. Bunster, Ximena (1988) "The Mobilization and Demobilization of Women in Militarized Chile", in Eva Isaksson, ed., Women and the Military System, New York: St Martin's Press, pp. 210-211.

78. Maoz, Elat (2008) "The Privatization of Checkpoints and the Advanced Occupation", Hagada, 10 October (in Hebrew).

79. On analogous obfuscation of the separation between the General Security Service (Shabak) and the police force in Israel see Oren, Amir (2005) "Inside Track: Not Every Policeman Is Really a Policeman", Haaretz, 25 December.

80. Leshem, note 13 above.

81. Singer, Roni (2004) "In Lieu of the Boys in Blue", Haaretz, 13 August, available at www.haaretz.com/hasen/objects/pages/PrintArticleEn.jhtml?itemNo=464088.

82. Cooper, Carmela (2004) "Permanent Lodgings", Maariv Online, 1 January, available at www.images.maariv.co.il/cache/ART619826.html (in Hebrew).

83. Aberjil, Meir (2004) "Complaint Against Hapoalim Bank: Barred From Entering Bank Due to Oriental Looks", Tsomet Hasharon, 6 May (in Hebrew).

84. Singer, note 81 above; interview with Erella Shadmi, 2004.

85. Singer, note 81 above.

86. Ibid.

87. Ibid.

88. Balint, Anat (2004) "Broadcasting Authority Collecting Millions of Shekels From Citizens Under Duress and Against the Law", Haaretz, 30 May (in Hebrew); Balint, Anat (2004) "Collection of Broadcasting Tax at Illegal Roadblocks Continues", Haaretz, 31 May (in Hebrew).

89. Association for Civil Rights in Israel, note 39 above.

90. See for instance Bureau of Political-Military Affairs (2000) "Bamako Declaration on an African Common Position on the Illicit Proliferation, Circulation and Trafficking of Small Arms and Light Weapons", declared at Ministerial Conference on the Illicit Proliferation, Circulation and Trafficking of Small Arms and Light Weapons, Bamako, Mali, 30 November-1 December 2000; UNDP Evaluation Office (2000) "Small Arms and Light Weapons", Essentials 9, October.

91. Bunster, note 77 above.

92. Cock, note 76 above.

93. Singer, Roni (2004) "Ben-Chitrit: After Mauling Me the Guard Said, 'Target Neutralized" ", Haaretz, 29 April (in Hebrew).

94. Walla (2002) "Channel 1 News Crew Beaten Opposite the Defense Ministry", Walla, 4 October, available at: http://news.walla.co.il?w=//607443. 
95. Balint, Anat (2004) “Arabic Language Radio Reporter: Security Guards Attacked Me", Haaretz, 12 May (in Hebrew).

96. Chen, Shoshana (2002) "Who Will Guard the Guards?", Ynet, 24 May, available at www.kavlaoved.org.il/katava_main_heb.asp?news_id+185\&sivug_id=14 (in Hebrew).

97. Yaakov, Nitzhia (2004) "Report by Herzlia Municipal Comptroller: Security Department Squanders Unauthorized, Unmonitored Monies", Tsomet Hasharon, 28 August (in Hebrew).

98. Linder-Gans, Roni (2006) "No Police State”, Marker Haaretz, 22 February (in Hebrew).

99. Committee for the Review of the System of Arms Licensing for Guards, note 31 above, pp. 6, 25-26.

100. International Court of Justice (2004) "Legal Consequences of the Construction of a Wall in the Occupied Palestinian Territories", 9 July, available at http://reliefweb. int/rw/RWB.NSF/db900SID/SZIE-62QPZZ?OpenDocument\&rc=1\&emid=ACOS635PFR.

101. B'tselem (2005) “Separation Barrier: Statistics”, available at www.btselem.org/english/ Separation_Barrier/Statistics.asp.

102. Regular, Arnon (2005) "Palestinian Youth Shot Dead by Separation Fence Guard", Haaretz, 10 July (in Hebrew).

103. Grinberg, Mijal (2006) "No Food or Pay for Overtime: That's How Construction of the Barrier Fence Is Being Guarded", Haaretz, 7 September (in Hebrew).

104. Levy, Gideon (2006) "Privatization Accompanied by Delays and Riots", Haaretz, 24 January (in Hebrew).

105. Regular, Arnon (2006) "Guards from Turkey to Guard the New Industrial Zone at Erez", Haaretz, 4 January (in Hebrew).

106. Maoz, Elat (2008) "The Privatization of Checkpoints and the Advanced Occupation", Hagada, 10 October (in Hebrew).

107. Committee of the Interior and the Environment (2005) "Protocol Number 495", 27 July (in Hebrew).

108. Association for Civil Rights in Israel, note 39 above.

109. UNDP Evaluation Office, note 90 above, p. 5.

110. Klein, note 19 above, pp. 430, 439-440.

111. Sachs, Dalia, Amalia Sa'ar and Sarai Aharoni (2005) The Influence of the Armed Israeli-Palestinian Conflict on Women in Israel, presented to forty-ninth meeting of CSW (Beijing + 10) New York, March, Haifa: Isha l'Isha - Haifa Feminist Center, p. 5.

112. Enloe, Cynthia (2000) Maneuvers: The International Politics of Militarizing Women's Lives, Berkeley, CA: University of California Press, p. xiii (emphasis added).

113. Seager, Joni (2004) "Introduction", in Ryn Gluckman, Rachael Kamel and Betsy Hartmann, eds, Militarized Zones: Gender, Race, Immigration, Environment, American Friends Service Committee, p. 6, available at www.afsc.org/militarized-zones/.

114. Farr, note 26 above, p. 19.

115. Peterson, V. Spike and Anne Sisson Runyan (2003) Global Gender Issues, Boulder, CO: Westview Press, p. 91.

116. Lubin, Orly (2002) " "Gone to Soldiers': Feminism and the Military in Israel”, Journal of Israeli History 21(1/2), special issue on "Women's Time", p. 191.

117. Sachs, Sa'ar and Aharoni, note 111 above, pp. 3-4.

118. Adelman, Madelaine (2003) "The Military, Militarism, and the Militarization of Domestic Violence", Violence Against Women 9(9), p. 1141.

119. Beneria, Lourdes and Rebecca Blank (1989) "Women and the Economics of Military Spending", in Adrienne Harris and Ynestra King, eds, Rocking the Ship of State: Towards a Feminist Peace Politics, Boulder, CO: Westview Press, p. 195. 
120. Ibid.

121. For a similar analysis of South Korean society see Moon, Seungsook (1998) "Gender, Militarization, and Universal Male Conscription in South Korea”, in Lois Ann Lorentzen and Jennifer Turpin, eds, The Women and War Reader, New York: New York University Press, pp. 90-110.

122. Bassok, Moti (2004) "Women in Israel: Longer Lives, Higher Education, Lower Paid", Haaretz, 8 March (in Hebrew); Sinai, Ruth (2002) "U.N. Worried by the Number of Poor Children in Israel", Haaretz, 21 October (in Hebrew).

123. Sinai, Ruth (2004) "Threefold Rise in Number of Poor Families in 14 Years", Haaretz, 29 October (in Hebrew).

124. GPN: Global Labor Market Database: Israel 2007, Tel Aviv: Adva Center, available at www.gpn.org/data/israel/israel-data.pdf; information on equality and social justice in Israel, p. 6.

125. Swirsky and Konor-Attias, note 60 above, p. 19.

126. Swirsky, Barbara (2003) The Safety Net from a Gender Perspective: Income Support Payments, November, Tel Aviv: Adva Center, available at www.adva.org/ incomemaintenanceEnglishsummary.htm.

127. Sachs, Sa'ar and Aharoni, note 111 above, p. 12.

128. Regev, David (2005) "Private Policing Companies to Be Licensed - On the Condition that They Protect Their Workers", Yedioth Ahronoth, 28 March (in Hebrew); Horev, Gil (2005) "Security Guards with No Security", Maariv, 27 March (in Hebrew); Sinai, note 69 above; interview with Dana Myrtenbaum, 2004; Kav LaOved, note 23 above.

129. Wertzberger, Rachel and Dotan Russo (2002) "Selected Data on Women 2002", presented to Committee for the Advancement of Women's Status, 14 July, available at www.knesset.gov.il $/ \mathrm{mmm} /$ doc.asp?doc $=$ m00355\&type $=$ pdf (in Hebrew).

130. Cohen, Stewart (1997) "Towards a New Portrait of the (New) Israeli Soldier", Israeli Affairs 3-4, pp. 77-117.

131. Interview with Erella Shadmi, 29 August 2004.

132. Mozgobiyyeh, Natasha (2003) "New Immigrants Working as Guards, 'We Get Treated Worse than the Sabras'", Yedioth Ahronoth, 27 April (in Hebrew).

133. Swirsky, Barbara and Yosef Kefalea (2005) The Employment Situation of Ethiopian Israelis, Tel Aviv: Adva Center, pp. 14, 33, available at www.adva.org/EthiopianEng.pdf.

134. Interview with security guard at a mall, 25 May 2004.

135. Interview with relevant head of Municipal Security Department, 2004.

136. Interview with head of Municipal Security Department, 2004.

137. Levy, note 9 above, p. 3 .

138. Interview with Nachum Sweid, note 55 above.

139. Bassok, note 122 above.

140. In 2000 the Knesset Committee for the Advancement of Women's Status dedicated at least one session to the glass ceiling barring or slowing policewomen's professional advancement. See Committee for the Advancement of Women's Status (2000) "Protocol Number 40", Protocols/Women's Status/179, 15 February, available at www.knesset. gov.il/protocols/data/html/maamad/2000-02-15.html (in Hebrew). In May 1999 the Association for Civil Rights in Israel petitioned the High Court of Justice against discriminatory hiring by the police. See Gross, Netty C. (1999) "Machismo Gone Mad?", The Jerusalem Report, available at www.jrep.com/Info/10thAnniversary/1999/Article15.html. A joint session of the Knesset Committee on Matters of State Control and the Committee for the Advancement of Women's Status was entirely dedicated to the obstacles barring women's integration into all parts of the army. See Committee for the Advancement of Women's Status (2002) "Protocol Numbers 214, 226", Protocols/ 
Women's Status/5870, 14 October, available at www.knesset.gov.il/protocols/data/html/ maamad/2002-10-14.html (in Hebrew).

141. Interview with director, 2004; interview with Head of Municipal Security Department, 2004; interview with Nachum Sweid, note 55 above; Parliamentary Center for Research and Information (2008) The Proportionate Representation of Various Sectors in Municipal Government, 23 October, available at www.knesset.gov.il $/ \mathrm{mmm} /$ doc.asp? $\mathrm{doc}=\mathrm{m} 02137 \&$ type $=$ pdf (in Hebrew).

142. Lis, note 33 above.

143. In 2006 , for instance, " $71 \%$ of the total employees in Israel's public services (the civil service, education, health, and community services) ... [were] women - some 515,400 employees. Approximately $45 \%$ of all employed women work[ed] in public services. Women comprise[d] two-thirds of the employees in government ministries." Hasson, Yael (2007) "Privatization of Public Services in Israel", paper presented at Women's Employment in the Days of Privatization - Sixth Annual Adva Center Conference on Budget and Gender, p. 34, available at www.adva.org/UserFiles/File/ gender6thkenes2007e.pdf. In 2003 women constituted two-thirds of public service workers, including, for instance, 80 per cent of elementary school teachers and 63 per cent of high school teachers. See Swirsky, Konor-Attias and Swirsky, note 61 above.

144. Bior, note 59 above; Bassok and Sinai, note 59 above; Bior, Haim (2003) "Steady Demand for Workers in August 2003 vs. July - Due to Demand for Guards", Haaretz, 15 September (in Hebrew); Bassok, Moti (2003) "Drop in Unemployment Due to Rise in Number of Guards", Haaretz, 1 September (in Hebrew).

145. GPN, note 124 above.

146. Sinai, Ruth (2004) "Part-time Jobs Working Full-time", Haaretz, 1 November (in Hebrew).

147. Bassok, Moti (2004) "Treasury Caves: Security Budget to Rise by 1.6 Billion Shekels", Haaretz, 5 February (in Hebrew); Swirsky, Shlomo (2004) The Budget of Israel, Tel Aviv: Adva Center/MAPA Publishers, pp. 88-103.

148. Swirsky, ibid., p. 100.

149. Sinai, Ruth (2005) "Drop in Number of Welfare Recipients - Especially Single Mothers", Haaretz, 4 January; Sachs, Sa'ar and Aharoni, note 111 above, pp. 12-13; see also Swirsky, note 126 above.

150. Sachs, Sa'ar and Aharoni, note 111 above, pp. 9, 30.

151. Senior, Eli (2003) "Judge Rejects Plea-bargain, Convicts Police Officer of Sexual Harassment", Ynet, 30 November, available at www.ynet.co.il/articles/1,7340,L2827219,00.html (in Hebrew).

152. Sasson-Levy, Orna (2003) "Feminism and Military Gender Practices: Israeli Women Soldiers in 'Masculine' Roles", Sociological Inquiry 73(3), pp. 440-465.

153. Mazali, note 73 above.

154. Levy, Ina, Sarah Ben-David and Sarit Amram (2003) The Phenomenon of Sexual Harassment in the IDF, Yohalan (Adviser to the Chief of Staff on Women's Affairs), available at www.aka.idf.il/yohalan/main/main.asp?catID=18283 (in Hebrew).

155. Sasson-Levy, note 152 above.

156. Kra, Baruch (2000) "Police Study: Ninety-two Percent of Policewomen Sexually Harassed at Work", Haaretz, 12 November (in Hebrew); Kra, Baruch (2000) "Police Assessment: Conscription of Policewomen Has Increased Sexual Harassment", Haaretz, 12 November (in Hebrew).

157. Rabin, Ethan (2000) "The Ministry of Defense, Centre for Sexual Harassment", Maariv Weekend Supplement, 25 August, available at http://images.maariv.co.il/cache/ cachearchive/25082000/ART65057.html (in Hebrew). 
158. Adelman, note 118 above, p. 1138 (emphasis added).

159. Na'amat (2004) "It Bothers Me", Journal, available at www.naamat.org.il/themes/ default.asp?PageId=7 (in Hebrew). See also Herzog, Hannah (2000) "Women in Israel", Virtual Library, Center for Educational Technology (Matakh), available at http://lib.cet.ac.il/Pages/item.asp?item $=4298 \& k w d=739$ (in Hebrew).

160. Kamir, Orit (2002) Feminism, Rights and the Law, Jerusalem: Ministry of Defense Publishing, pp. 202-204 (in Hebrew).

161. Department for Disarmament Affairs (2003) "Gender Mainstreaming Action Plan: Public Version", April, United Nations, New York, p. 2.

162. Bassok, Moti (2003) "18\% of Households Victims of Property Crimes in 2000", Haaretz, 12 February (in Hebrew).

163. Quoted in Reuveni-Geffen, Orit (2008) "Just Because They Were Women", La'Isha, 28 January, pp. 46-47 (in Hebrew). See also Halperin-Kaddari, note 5 above.

164. I wish to express my sincere esteem and gratitude to both.

165. While the data collection has yet to be completed, to the best of my knowledge to date, none of the 33 women murdered in the course of 2007 was shot by security guards. See L.O. Combat Violence Against Women (2008) "Deaths Due to Domestic Violence in Israel", available at www.no2violence.co.il/Statistics/Statistics011.htm (in Hebrew); Reuveni-Geffen, note 163 above.

166. Two additional women were murdered by boyfriends serving their term of mandatory military duty, although they did not use their firearms as murder weapons. One of them, however, later committed suicide with his military rifle. See L.O. Combat Violence Against Women (2005) "Women and Family Members Murdered in Israel in 2002", available at www.no2violence.co.il/Statistics/Statistics038.htm (in Hebrew); Ratner, David (2005) "Haifa Man Confesses to Stabbing His Wife to Death", Haaretz, 22 February, available at www.haaretz.com/arch/objects/data/logonEng.jhtml; Singer, Roni (2005) "Police Launch Hunt for Partner of Woman Found Dead in Bat Yam", Haaretz, 2 March, available at www.haaretz.com/hasen/pages/arch/ArchArticleEng. jhtml?_DARGS=\%2Farch \%2Fobjects \%2Fdata \%2FArchSearchResultsEng.jhtml; Ratner, David (2005) "Police Find Body of Missing Woman; Abusive Boyfriend Held", Haaretz, 7 March, available at www.haaretz.com/hasen/pages/arch/ArchArticleEng. jhtml?_DARGS=\%2Farch\%2Fobjects \%2Fdata \%2FArchSearchResultsEng.jhtml; Ashkenazi, Eli (2005) "As Police Prepared to Indict Him for Violence, Man Kills Exwife", Haaretz, 11 February, available at www.haaretz.com/hasen/pages/arch/Arch ArticleEng.jhtml?_DARGS=\%2Farch\%2Fobjects\%2Fdata\%2FArchSearchResultsEng. jhtml.

167. The L.O. Combat Violence Against Women website, www.no2violence.co.il, lists 13 women and girls, two of them from the Occupied Territories, which have not been covered in this chapter. However, press reports list six additional women killed by family members. See Lis, Yehonatan (2005) "Jerusalem Man Kills Girlfriend Who Wanted to End Relationship and Shoots Himself", Haaretz, 23 January (in Hebrew); Ashkenazi, Eli (2004) "Shot and Killed His Wife Whom He Suspected of Adultery with a Friend", Haaretz, 1 October (in Hebrew); Hasson, Nir (2005) "Negev Man to Be Charged in 'Honor Killing' Case”, Haaretz, 3 January, available at www.haaretz.com/ hasen/pages/arch/ArchArticleEng.jhtml?_DARGS=\%2Farch\%2Fobjects\%2Fdata \% 2FArchSearchResultsEng.jhtml.

168. The L.O. Combat Violence Against Women website, ibid., lists 22 women, but a report in Haaretz lists three women who are not on the L.O. list. See Chasson, Nir (2004) "Resident of Tel Sheva Aged 40 and His Wife Suspected of Murdering His Second Wife", Haaretz, 1 February (in Hebrew). 
169. A fifth man, who killed his partner with a knife, was a security guard until his layoff just weeks before the murder.

170. The data regarding shooter identities are particularly inconclusive for 2001, in which 28 women and girls were reported murdered by partners or family members. At least five of these girls and women (17.8 per cent) were shot - three of them by family members who were soldiers. See Shahak, Yifat (2002) "Background Document on Violence against Women - Data Update", presented to Committee for the Advancement of Women's Status, 4 November, p. 2 (in Hebrew); L.O. Combat Violence Against Women website, note 167 above; Beno, Goel (2003) "Police Failed to Report, Army Didn't Know", Yedioth Ahronot, 26 August (in Hebrew); Naeh, Bouki and Dudi Nissim (2003) "Security Guard Murders Wife in Front of Son", Yedioth Ahronot, 24 June (in Hebrew); Naeh, Bouki and Dudi Nissim (2003) "Gregory, You're Hurting Me, Don't Do It", Yedioth Ahronot, 27 April (in Hebrew); Nissim, Dudi, Itzik Saban and Danny Abbaba Adino (2003) "Student Murders Girlfriend and Shoots Himself", Yedioth Ahronot, 11 April (in Hebrew).

171. Sered, Susan (2000) What Makes Women Sick? Maternity, Modesty and Militarism in Israeli Society, London: Brandeis University Press/University Press of New England, p. 98.

172. Adelman, note 118 above, p. 1135.

173. Ibid.

174. Sachs, Sa'ar and Aharoni, note 111 above; Sinai, Ruth (2005) "The Murderers in $47 \%$ of Women's Murder by Intimates - Security Guards or Security Personnel", Haaretz, 27 November (in Hebrew).

175. Sachs, Sa'ar and Aharoni, note 111 above, p. 11.

176. Wiebe, Douglas (2003) "Homicide and Suicide Risks Associated with Firearms in the Home: A National Case-Control Study”, Annals of Emergency Medicine 41(6), p. 775; Brock, Karen (2003) When Men Murder Women: An Analysis of 2001 Homicide Data, Violence Policy Center, p. 3, available at www.vpc.org/graphics/WMMW03.pdf; Mathews, S., N. Abrahams, L. J. Martin, L. Vetten, L. van de Merwe and R. Jewkes (2004) “"Every Six Hours a Woman Is Killed by Her Intimate Partner': A National Study of Female Homicide in South Africa", Policy Brief, South African Medical Research Council, Cape Town, pp. 1-4.

177. International Action Network on Small Arms (2003) Women, Gun, Violence and the Home, available at www.iansa.org/women/documents/women_gunviolence_home.pdf.

178. Cukier, note 42 above, p. 30.

179. Gale, Naomi (2003) Violence against Women: A Normal or a Deviant Behaviour?, Tel Aviv: Hakibbutz Hameuchad Publishing, p. 71 (in Hebrew).

180. Committee for the Review of the System of Arms Licensing for Guards, note 31 above, p. 12.

181. Interview with company director, 2004; interview with head of Municipal Security Department, 2004; interview with Nachum Sweid, note 55 above; interview with security guard, 2004.

182. Ibid.

183. Gale, note 179 above, p. 88 (original in Hebrew, author's translation).

184. Prigerson, Holly G., Paul K. Maciejewski and Robert A. Rosenheck (2002) "Population Attributable Fractions of Psychiatric Disorders and Behavioral Outcomes Associated with Combat Experience Among U.S. Men", American Journal of Public Health 92(1), pp. 59-63.

185. L. B. Johnson (1991) "On the Front Lines: Police Stress and Family Well-being", Hearing before Select Committee on Children, Youth, and Families, House of 
Representatives, 102 Congress First Session, 20 May, Washington, DC: US Government Printing Office, pp. 32-48; Neidig, P. H., H. E. Russell and A. F. Seng (1992) "Interspousal Aggression in Law Enforcement Families: A Preliminary Investigation", Police Studies 15(1), pp. 30-38; Straus, M. and R. Gelles (1990) Physical Violence in American Families - Risk Factors and Adaptations to Violence in 8,145 Families, New Brunswick, NJ: Transaction Publishers; Neidig, P. H., A. F. Seng and H. E. Russell (1992) "Interspousal Aggression in Law Enforcement Personnel Attending the FOP Biennial Conference", National FOP Journal, Fall/Winter, pp. 25-28 (all quoted on National Center for Women and Policing website at www.womenandpolicing.org/ violenceFS.asp).

186. Gale, note 179 above, p. 72.

187. Sered, note 171 above, p. 99

188. Quoted in Urbina, Ian (2002) "Up in Arms", Village Voice, 27 November-3 December, available at www.villagevoice.com/issues/0248/urbina.php.

189. L.O. Combat Violence Against Women (2008) "Women Murdered in Israel in 2001", available at www.no2violence.co.il/Statistics/Statistics025.htm.

190. L.O. Combat Violence Against Women (2002) "Women Murdered in Israel by Husbands, Partners and Relatives 1992-2001", available at www.no2violence.co.il/ Statistics/Statistics009.htm.

191. Hobart, Margaret (2002) "Tell the World What Happened to Me": Findings and Recommendations from the Washington State Domestic Violence Fatality Review, Washington State Coalition Against Domestic Violence, available at www.wscadv.org/projects/ FR/02_FR_report.pdf.

192. Among cases covered by the review, African American women and Hispanic women were at least twice as likely to be victims of domestic violence homicide than white women. Hobart, ibid.

193. Ibid., p. 64

194. Ibid., p. 38.

195. Quoted in Gale, note 179 above, p. 111.

196. Ibid., pp. 97-140.

197. Shapiro, Ina (2004) "It's Hard to Talk about Rape in a Foreign Language”, Haaretz, 6 October (in Hebrew)

198. Hasan, Manar (1999) "The Politics of Honor: Patriarchy, the State and the Murder of Women in the Name of Family Honor", in Dafna N. Izraeli, Ariella Friedman, Henriette Dahan-Kalev, Sylvie Fogiel-Bijaoui, Hanna Herzog, Manar Hasan and Hannah Naveh, eds, Sex, Gender, Politics: Women in Israel, Tel Aviv: Hakibbutz Hameuchad Publishing House, pp. 291-297 (in Hebrew).

199. Ettinger, Yair (2004) "Achievement for Arab Feminists: Increased Reporting on Assaults against Women”, Haaretz, 22 November (in Hebrew).

200. Hasan, note 198 above; Kanaaneh, Rhoda Ann (2002) Birthing the Nation: Strategies of Palestinian Women in Israel, Berkeley, CA: University of California Press, pp. 122-125.

201. Hasan, note 198 above, p. 204 (original in Hebrew, author's translation).

202. Lustick, Ian (1980) Arabs in the Jewish State: Israel's Control of a National Minority, Austin, TX: University of Texas Press, p. 121; Rabinowitz, Dan (1997) Overlooking Nazareth: The Ethnography of Exclusion in the Galilee, Cambridge: Cambridge University Press, p. 149.

203. Hobart, note 191 above; Schechter, Susan (2000) "Expanding Solutions for Domestic Violence and Poverty: What Battered Women with Abused Children Need from Their Advocates: Building Comprehensive Solutions to Domestic Violence", Publication \#13, Vision Paper, University of Iowa, available at www.vaw.umn.edu/documents/ expandin/expandin.html\#id2634255. 
204. Kanaaneh, note 200 above, pp. 83-85; Gale, note 179 above, pp. 98-100.

205. Wertzberger, Rachel (2001) "Background Document for International Women's Day: Women in the Israeli Economy - Influence, Participation and Injury", presented to Committee for the Advancement of Women's Status, 4 March, pp. 12-13, available at www.knesset.gov.il $/ \mathrm{mmm} /$ doc. asp? $\mathrm{doc}=\mathrm{m00080} \&$ type $=$ pdf (in Hebrew).

206. That is, with the exception of the men of the Druze community, who are subject to conscription, and male volunteers from the Bedouin and (more rarely) other Palestinian communities in Israel.

207. Ratner, David (2004) "Six Times More Arabs Volunteering for the Civil Guard in the North", Haaretz, 1 November (in Hebrew).

208. Khoury, Jacky (2004) "Two Hundred and Fifty Unlicensed Arms Confiscated in the Galilee", Haaretz, 28 December (in Hebrew).

209. Ettinger, note 199 above,

210. Wertzberger, note 205 above, p. 14.

211. Quoted in Meletz, note 9 above.

212. Derfner, note 70 above.

213. Yoaz, Yuval (2004) "High Court Cancels Age Discrimination in the Public Service", Haaretz, 13 January (in Hebrew); Saar, note 41 above,

214. Mazali, Rela (1999) "Voting with Our Feet: Women (and Children) in Israel Making New Move(ment)", f/m feminist magazine 3; see also Mazali (1995), note 74 above.

215. Interview with director, 2004; interview with Nachum Sweid, note 55 above; Shavit, note 28 above; Navon, Arad and Yehoshua, note 32 above.

216. Haaretz (2003) "Guard Dreamed of Opening His Own Café", Haaretz, 11 September (in Hebrew); Derfner, note 70 above.

217. Saltman, note 49 above, p. 58.

218. Derfner, note 70 above.

219. Ibid.

220. Ibid.

221. Ibid.

222. Gebre-Wold, Kiflemariam (2002) "Security Dilemmas in the Horn of Africa: Reflections from the SALIGAD Project", in Vanessa Farr and Kiflemariam Gebre-Wold, eds, A Gender Perspective on Small Arms and Light Weapons: Regional and International Concerns, Bonn: Bonn International Center for Conversion, p. 82.

223. Johns Hopkins Medical Institutions (2003) public release, 30 June, available at www.hopkinsmedicine.org/press/2003/June/030630.htm.

224. Dolan, Chris (2003) "Collapsing Masculinities and Weak States - A Case Study of Northern Uganda", in Frances Cleaver, ed., Masculinity Matters: Men, Masculinities and Gender Relations in Development, London: Zed Books.

225. UNICEF Albania Media Center (2003) press release, 17 September, available at www.unicef.org/albania/what_we_do/press-12.htm.

226. Ibid.

227. Mann, M. (1987) “The Roots and Contradictions of Modern Militarism", New Left Review 126, March/April, p. 35, quoted in Cock, note 76 above, p. 187.

228. Segev, Tom (2008) “Was Lebanon War Necessary? Report Doesn't Say”, Haaretz, 31 January, available at www.haaretz.com/hasen/spages/949993.html. 
Securing private spaces:

Gendered labour, violence and democratization in South Africa

\author{
Jennifer N. Fish and Pumla Mncayi
}

\title{
The South African case
}

South Africa, one of the most widely studied conflict nations, has been crucially shaped by a militarized enforcement of racial apartheid governance that normalized multiple levels of violence in everyday life. In sharp contrast to the legacy of stark social inequality accompanying apartheid, the dramatic 1994 transition to democracy provided a hopeful model of the potential for peaceful governmental and structural change after nearly 50 years of brutal race- and gender-based violence. Fourteen years after the transition, however, extreme levels of violence and crime pose one of the most serious threats to the actualization of a democracy that truly liberates and ensures the equitable development of all citizens. Notably, South Africa's gun-violence levels are currently the second highest in the world, exceeded only by Columbia. ${ }^{1}$ The presence of small arms throughout South Africa creates a social context where peacetime gun violence severely limits human rights as well as the nation's overall social and economic development. Furthermore, deeply instilled historical race and class divides, as well as entrenched gender inequalities, pervade the nation. At the same time, the increasing presence of weapons, gang conflicts and a culture of fear permeate the social landscape. For these reasons, South Africa provides a critical case study to analyse the impact of small arms in a post-conflict reconstruction period; the particularly gendered nature of peacetime small-arms violence; the exorbitant human and national development costs associated with the proliferation

Sexed pistols: The gendered impacts of small arms and light weapons, Farr, Myrttinen and Schnabel (eds), United Nations University Press, 2009, ISBN 978-92-808-1175-9 
of small arms; and the vastly diverse experience of gun violence in relation to social location differentials, particularly gender, race and class. This chapter explores these interconnected layers of impact at the micro and macro levels of South African society, with a particular focus on the relationship between gender and small arms.

In the process of post-conflict reconstruction, South Africa prioritized gender rights to integrate "non-sexism" and "non-racialism" components of its democratic transformation - illustrating an unusually progressive commitment to redressing the severe social inequalities of the apartheid era. Notably, the process of restructuring South Africa's governance saw the promotion of gender commitments in leadership when the first democratic election resulted in the appointment of women to 29 per cent of parliamentary positions, establishing a revolutionary representation at the public level. ${ }^{3}$ To facilitate the full implementation of gender equity in the nation's restructuring, South Africa created a trilevel "Gender Machinery" that instituted structures to ensure the representation of women's rights throughout all levels of governance. These institutional structures at the forefront of nation-building represented a revolutionary public commitment to gender rights throughout the process of democratization. Yet the private realm, where social relations continue to encompass patriarchal gender inequalities, illustrates a striking dichotomy between public victories and everyday realities for those who continue to be severely marginalized within the new democracy.

The interlocking ways in which women pay the price for gun violence in both household and community spaces represent one of the most powerful examples of the disjuncture between South Africa's public commitment to gender rights and the daily social relations that inflate power differences through the use of weapons. The extremely high levels of crime and small-arms violence manifest themselves in ways that are particularly gendered, posing pervasive barriers to accessing the gender rights that are central to South Africa's democratic transformation. Local experts suggest that 40 per cent of women's deaths are the result of gun violence and 25 per cent of rapes in South Africa are carried out with the use of a gun. ${ }^{4}$ Because women bear the brunt of violence in South Africa, a gendered analysis that centralizes women's experiences and their contributions to ending small-arms and gun-based violence is critical to any evaluation of this context. As we know from the cases throughout this collection, women are integrally connected to small-arms violence in their daily lives. Particularly in South Africa's ongoing transition, women's central leadership in the eradication of violence stemming from small arms and light weapons fosters an increased potential for the realization of human security.

Our data illustrate that gun violence in South Africa must be analysed 
in relation to the wide socio-economic disparities that continue to structure the nation in the post-apartheid context. We expand the international conversation on gender and small arms through an empirical case study of paid domestic labour, where such disparities exist most strikingly between women situated in very diverse race and class positions. Throughout this chapter we shall illustrate how women, across diverse socio-economic backgrounds, both mediate violence because they serve in critical (although invisible) security roles and confront the daily threat of small arms within the domestic sphere - a space that is often outside the purview of those observing the ongoing transition to a more peaceful post-apartheid society. We hold that women's labour in private households illustrates how race, class and gender locations are centrally connected to both gun violence and access to human safety and security in the context of South Africa's ongoing transition.

Our analysis is based on longitudinal field research across wide sectors of South African society. We examine 100 in-depth interviews conducted with community leaders, women workers, employers, parliamentarians and policy-makers from 2001 to 2006. In addition, we draw upon community surveys conducted by the Gender Advocacy Programme $(\mathrm{n}=200)$, focus groups, organizational action research and archival data. Through our combined scholar-activist perspectives on social change in South Africa, this chapter provides analyses that are grounded in the lived realities of women who both experience the daily threat of small arms and offer viable solutions aligned with the overarching human rights priorities of national transformation.

\section{Historical foundations of apartheid violence and gender inequality}

The current context of small-arms violence must be situated within the complex historical social structures established throughout the apartheid era. ${ }^{5}$ Orchestrated processes of state-imposed violence remained central to the enforcement of racial apartheid from 1948 to 1994 . Nearly 75 per cent of the population, labelled as "African" or "black", as well as the 9 per cent mixed-race "coloured" group and the 2 per cent "Indian" group, experienced severe state violence through police structures that utilized small-arms force to contain resistance and mobilization. ${ }^{6}$ Jacklyn Cock $^{7}$ identified the militarization of South African society during apartheid at three distinct levels: economic, political and ideological. Military expenditures, arms production and white male conscription illustrate the interconnected investments of both economic and political resources to sustain the apartheid system. The ideological level of militarization, how- 
ever, created a social context that glorified the South African Defence Force (SADF), while constructing the African National Congress (ANC) as well as black South Africans as violent and criminal. This ideology relied significantly on the manipulation of gender identities, because it promoted the white male as "protector" of vulnerable women and children, while demonizing black men. Simultaneously, apartheid's militarized structure normalized the use of armed force and subsequent violence as a necessary means to assure white minority rule. Furthermore, the ideology of militarization permeated social institutions and everyday life - controlling the geographical movement of marginalized sectors of the population through the "pass laws" while enforcing the rigid structure of work, housing and education according to the stratification of racial privilege. ${ }^{8}$

This systemized separation of society by race materialized in particularly gendered processes. Women's bodies were used as battlegrounds to enforce the racial power structures of apartheid governance. ${ }^{9}$ Activists' 1996 efforts to prioritize the revelation of gender-specific crimes in the Truth and Reconciliation Commission hearings resulted in women's testimonies that revealed the pervasive use of rape as a conscious (and possibly sanctioned) strategy of SADF operations. ${ }^{10}$ Importantly, the gendered violence during apartheid was distinctly connected to women's varying social locations according mainly to race, but also class. White women were not spared from police violence; however, the daily public experience of a militarized state certainly impacted on black and coloured women more severely than on white women. Black women interviewed for this study recalled public rapes, psychological and physical torture, and even murder imposed by police officials as a means of instilling state power and dominance over the majority population. White female anti-apartheid activists, alternatively, described utilizing their race, class and intimate relations with white men to challenge power structures as a means to "barter privilege for justice". ${ }^{11}$

Integrally connected to the physical injustices imposed on women by the SADF, institutionalized structures of violence permeated everyday life and relegated women to particular roles in society based upon both race and gender. Labour, for example, remained highly racialized and feminized. Accordingly, domestic work in private households was one of the few sanctioned sectors of employment for black women. Strategic labour policies demanded black migration from rural to urban areas, which had significant effects on family support structures. Furthermore, male security forces continually mediated black women's ability to move freely through public spaces, which often resulted in daily experiences of harassment, gender-based violence and a variety of threats of violence through the use of intimidation. The following narrative, as portrayed by 
a Xhosa-speaking woman in her recollection of the apartheid era, illustrates the interconnected nature of the structural inequality and gendered police institutions that enhanced power asymmetries and shaped women's everyday experiences through the use of guns:

The divide amongst Blacks was invented and implemented by the apartheid regime. To come to urban areas in search of work, women would leave their homes before dawn, running away from security/police officials, risking their lives in the taxis or having to walk long distances of about three to five kilometres just to get to one of the suburbs to literally look for domestic work, moving from door to door. In some houses, they were experiencing the worst harassment and some were threatened by guns and there was no recourse for them. At others, they were chased by the dogs or "die baas" [the boss] threatening to shoot them saying that they were trespassing. The men and youth were always carrying guns. ${ }^{12}$

When women did attain work in a private household, the intimate nature of the labour itself constructed contexts where black women were particularly vulnerable to both male power and the use of legal weapons to induce fear. Nomsa, a domestic worker formerly employed by a member of the South African Defence Force authority, vividly depicted the severe vulnerability and isolation she experienced as a result of the conditions of her employment:

Now, there is one day I can never forget, when the uprisings were starting in 1976 when my "Baas" [boss, employer] said I must take out his attire as a soldier to iron, his shoes to polish. I started to be scared, the feeling of a cold pain creeping through my back, I did not know what was going on, but something told me that there was something going on. I would not dare ask as no one would share any interesting news with us. Actually we did not even have time for whatever news. By 5 am we were already on the job and I was knocking off only after $10 \mathrm{pm}$. You would not dare think of complaining or protesting. That was it for me, when he brought the "big rifle" and commanded that I polish it because that day he was going "kill the young ones of a kaffir" [derogatory term for a black African]. That made me to shiver even worse, but I could not question the motive. I had to do as I was told. Despite that attitude, I had to go on working under the same conditions, fearing that the next mistake, the rifle would be pointed at me and my little children.

As this narrative illustrates, the household represented an important political space where distinct asymmetries of power based in race, class and gender locations paralleled the overarching structural inequalities constructed by the apartheid regime. With the presence of a weapon in this case one used as a tool of the police state - such power differentials become even more severely pronounced. 
While both sexism and racism remained integral to the enforcement of apartheid rule and the severe oppression of the majority population, women certainly did not passively accept their marginalized roles in society. Rather, the central involvement of women in both the anti-apartheid struggle and the realization of a democracy, which clearly commits the state to promote women's rights, illustrates one of the most successful collective actions to integrate gender rights with transformative social change. In the early phases of apartheid, women played active roles as leaders in the African National Congress, the Federation of South African Women and the trade unions, which were central to collective mobilization. As apartheid violence heightened and the ANC took on an armed struggle beginning in the 1960s, women (predominantly black) joined the armed forces and were jailed for their public demonstrations and participation in organizations dedicated to both anti-racism and a collective women's movement. From the 1970s women (predominantly white) challenged the militarization of society through the Black Sash and the End Conscription Campaign, which was intended to break down masculinized notions of armed violence. ${ }^{13}$ While the prioritization of racial injustices over gender rights characterized this period of activism, these early collective women's movements pivotally established women's voices in the struggle to end apartheid.

Women continued to organize throughout the 1980s and 1990s to realize the transformation of South Africa from apartheid to democracy. Notably, the collective activism that established the Women's National Coalition of more than 100 organizations in 1992 marked a crucial alliance across political, race and class divides. As the realization of a new governance became increasingly more evident, women pushed for central inclusion in public leadership roles, which, after a series of negotiations, resulted in the 1994 national democratic election where, as mentioned, women were appointed to 29 per cent of parliamentary positions, and the structuring of the national Gender Machinery to ensure the ongoing inclusion of gender rights as central to all processes of nation-building. This transition structure marked a significant victory for women's public leadership as well as demonstrating their central agency in the process of political transformation. ${ }^{14}$

As this historical overview illustrates, the realization of a democratic South Africa is directly connected to women's collective activism at a number of critical junctures. The successes of South Africa's foundation of gender activism provide a model for the central role of women in transformative social change. As South Africa continues to emerge as a new democracy, the eradication of the prevailing violence incited by the ongoing circulation of weapons remains one of the greatest challenges. This history of collective activism means that South African women are 
well placed to seize opportunities to change radically the pervasive threat of small arms facing this new democracy today, a role which many play through their close involvement with civil society organizations such as the Gun Control Alliance. ${ }^{15}$ As our data suggest, while women are severely marginalized by the threat of armed violence, they are simultaneously able to foster powerful change through this historical foundation of collective activism, in many cases across social location divides.

\section{The state of small arms and security in post-apartheid} South Africa

The militarized apartheid era reveals how the current democratic state "emerged from the barrel of a gun". ${ }^{16}$ The vast number of both legal and illegal guns in circulation in South Africa today can be linked to state processes of militarization throughout apartheid - which included armed incursions across the borders into neighbouring countries, from which arms continue to flow back into the country today - as well as an active industry of arms production. As the state declared an armed struggle with the African National Congress and the Pan African Congress (PAC) in the 1960s, the use and production of small arms became a central component of maintaining white minority rule. Simultaneously, the ANC established a military arm (Umkhonto we Sizwe or MK) and declared an armed struggle following the 1960 Sharpeville massacre, where police opened fire on 20,000 unarmed protestors against pass laws. When South Africa faced an arms embargo in 1977, its arms production became completely self-sufficient. ${ }^{17}$ Testimonies at the Truth and Reconciliation Commission hearings also identified the apartheid government's distribution of firearms to the Inkatha Freedom Party and the former "homeland" areas to influence public perception and stimulate conflict within the black majority population. The 1980 s marked a period of extreme violence in the armed struggle for liberation. As South Africa entered the phase of political transformation in the early 1990s, the demobilization and integration of the South African National Defence Force (SANDF) symbolized a critical macro movement to a post-conflict society. Yet the residue of a dominant structural ideology of militarization persists to challenge seriously the transition to democracy. Perhaps the most pervasive carryover of this militarized past is the continued circulation of guns, coupled with the reinforcement of a collective consciousness about the power of weapons as a means to influence others and attain power.

Five years after the democratic transition, small-arms experts estimated approximately 4 million legally owned guns in South Africa, in addition to the approximately 4 million illegally attained guns. ${ }^{18}$ In 2003 the 
stockpile of police firearms totalled 262,062, while the SANDF owned 350,636 small arms and private security companies held an estimated 58,981 firearms. ${ }^{19}$ As we see throughout the world in post-conflict regions, the ongoing prevalence and circulation of weapons fuel social instability and crime, while posing a serious threat to human security, even in contexts characterized by peaceful transitions. In South Africa, one of the most severe barriers to the realization of democracy and peace stems from the circulation of illegal weapons - creating an overarching culture of fear, crime and insecurity. As a result, the political violence of South Africa's past has shifted to socio-economic violence in everyday life, the impact of which falls disproportionately on women.

The most extensive research to date in South Africa indicates that the primary sources of illegal firearm circulation are gun-owner loss, misuse and negligence; theft from stockpile sources and registered gun owners; remaining firearms unaccounted for from the militarized apartheid era; porous borders with neighbouring African countries; and a serious growth in gangsterism and vigilante groups that attract the youth. ${ }^{20}$ The presence of stockpiles and the excessive levels of individual ownership create an extremely challenging cycle where the theft of weapons leads to heightened levels of crime throughout the nation. Furthermore, serious shortages in funding and human resources within the South African Police Service fuel the emergence of gangs, vigilante groups and private security companies that utilize firearms both to commit and to confront crime. In addition, many white South Africans possess guns in order to increase their sense of security within a system of rapidly shifting power relations and an economic apartheid that motivates violent crime.

Recognizing the severity of the small-arms situation, South Africa initiated specific steps that connected the proliferation of weapons with serious risks to a rather fragile democracy. In 1995-1998 a series of initiatives, dubbed Operation Rachel, were carried out by the South African government (in collaboration with Mozambique) that ultimately destroyed more than 400 tons of light weapons and 40 million rounds of ammunition. In 2000 the domestic Operation Mouflon succeeded in destroying some 63,000 assault rifles, pistols and machine guns, with an additional 263,000 scheduled for destruction. These operations have been considered some of the most effective and comprehensive arms decommissioning projects in the world. ${ }^{21}$ Parallel to these commitments, at an ideological level South Africa actively participated in the creation of the 2000 Bamako Declaration on an African Common Position on the Illicit Proliferation, Circulation and Trafficking of Small Arms and Light Weapons. ${ }^{22}$ That same year the Firearms Control Act was passed to reduce the number of illegal firearms in circulation and monitor appropriate use of firearms throughout South African society. Collaborative efforts 
to establish community support structures, public campaigns and "gunfree zones", such as schools, workplaces and churches, are ongoing.

In stark contradiction to these significant efforts to reduce the overarching impact of small arms in the post-apartheid context, however, in 1999 the government decided on an investment in five arms deals totalling US $\$ 4.5$ billion. This government purchase in the absence of a military threat was sharply controversial and widely criticized by a broad spectrum of stakeholders. Investigations into the heavily publicized investment also evoked widespread questions about possible corruption, conflicts of interests and compromised transparency within parliament. In the context of South Africa's severe social inequality, the "arms deal" fuelled serious concerns about the government's willingness to address social and economic development. Furthermore, these state actions reified social constructions of militarization that glorify weapons and promote them as an appropriate means to resolve conflict, thus reverting the country back to an ideology similar to that which predominated in the apartheid era. Women parliamentarians ${ }^{23}$ were pivotal in protesting the arms deal by juxtaposing governmental expenditure on arms with the severe HIV/AIDS crisis, unemployment and housing needs. Highlighting these severe socio-economic threats facing South Africa situates the overarching connections between poverty and violence as central explanations for the skewed development and replicated historical inequalities. ${ }^{24}$ This arms expenditure, coupled with the ongoing production of small arms in South Africa, presents one of the greatest challenges to the process of making the necessary ideological shift away from valorized constructions of militarization that glorify weapons and arms to a nonviolent peacetime nation.

\section{Gender and small arms}

The availability of guns makes already existing gender inequalities much more pronounced. In peacetime South Africa, the circulation, proliferation and misuse of small arms are integrally linked to endemic genderbased violence. In the context of national transition, women face gun violence continually in interconnected ways that shape their daily lived experiences. As in other parts of the world, rape, femicide and related violent crimes against women are committed with the use of firearms, both inside the home and in the public sphere. Their ubiquitous presence magnifies power differentials while increasing the lethality of violence. ${ }^{25}$ Among the countries that collect data on rates of femicide, South Africa ranks highest in the world: a woman is killed by her intimate partner every six hours. Within these recorded cases of femicide, 21 per cent are 
committed with legal firearms. ${ }^{26}$ These striking data illustrate the central connection between the proliferation and misuse of small arms in South Africa, the continued failure of gun control measures to protect vulnerable members of society and the disproportionate impact of gun violence on women, who, while in the minority of gun users and owners, continue to suffer the most severe forms of violence inflicted with small arms.

The perpetual gun violence shaping post-apartheid South Africa also manifests itself in other important and particularly gendered conditions. Today, South Africa has been characterized by some as the "rape capital of the world", ${ }^{27}$ with the consistently highest national percentage of reported levels. Analysis of data from 1994 to 1997 demonstrated that rape was one of the few crimes that steadily increased after 1994, by an average of 7 per cent per year. ${ }^{28}$ The South African Police Service reported a total of 52,733 rapes in the 2003/2004 year. It is important to remember that these figures, as with records of sexual and domestic violence globally, do not reflect the real extent of the problem. In South Africa, as elsewhere, a significant proportion of such crimes go unreported each year. Furthermore, the vulnerability of victims substantially increases as firearms become ever more widely available; thus fewer incidents of sexual assault and rape are reported as a result of fear of further, lethal, violence.

The pervasive gun culture - coupled with the gender power differentials on which it relies - structures women's everyday experiences in peacetime South Africa. Yet the ways in which women confront gun violence must be situated within the sharp race and class divides that continue to maintain divisions among women, particularly in the severely unequal socio-economic context of post-apartheid South Africa. While car owners may fear armed hijackings, many poorer women who rely on public transportation, for example, refuse to ride city trains because of the extremely high incidence of rape and assault in this mode of transportation. One woman in this study reported witnessing on more than one occasion the theft of a cellular telephone at gunpoint on a city "taxi" 29 while travelling to work. Fuelled by the frequency of "taxi wars", women repeatedly expressed extreme levels of fear and heightened vulnerability as they commuted from township locations (structured by the apartheid era) in order to get work. Black and coloured women participants in this study are also forced to maintain strict boundaries about staying "out after dark" because of the pervasive threat of gender-based violence, particularly in economically disadvantaged residential areas. These fears severely limit women's ability to move freely through public spaces, a central component of human security. Furthermore, those most vulnerable to South Africa's overarching gun culture are disproportionately black and coloured women, who are also those with the least economic resources. 
For men in South Africa, in the context of severe poverty and experiences of powerlessness, gun ownership can serve to enhance class status as well as social power. Muggah and Berman ${ }^{30}$ argue that this access to small arms confers an "emboldening effect on those who possess them, particularly children and young men". This inflation of power emphasizes the masculine nature of gun ownership, particularly in contexts where severe social marginalization exists, and exacerbates already existing unequal gender relations, especially among the youth. For example, research with boys in South Africa indicated a perception that girls prefer men with guns, whereas girls in the same community linked guns to violence, fear and sexual coercion. ${ }^{31}$ In addition, male gang initiations in South Africa may involve the armed raping of very young girls to uphold masculine constructions of power and identity, enhanced through this emboldening effect of the gun. One young woman in this study stated that certain gang identifiers were widely recognized by girls in her secondary school as a severe threat because of such ritualized practices of raping schoolgirls.

An interview with a former male gang member from one of Cape Town's most violent township areas revealed a central connection between the availability of small arms and the growing gang culture that dominates several areas of the "Cape Flats". According to this participant, guns became more widely available after the 1994 political transformation. As some members acquired weapons, the overarching culture of competition and dominance increased the perceived need for a gun among the majority of male gang members. Not only did guns provide access to economic resources, power and sex, they also became central to gang members' identity constructions. As this account reveals, the association between guns, masculine notions of power, socio-economic status and identity illustrates how prevailing social structures that rely upon the use of weapons continue to marginalize severely both men and women. While women may often be victims of violent crime, when notions of masculinity rely upon gun ownership and misuse, men - particularly black and coloured men from the lowest socio-economic class - are also seriously impacted because they are constrained in these roles. Such limited constructions of masculinity not only place men in physical danger but also limit their access to development as human beings, a central component of human security.

In addition to this high incidence of documented crime in South Africa, the complex relationship between gun violence and gender-based inequality constructs social conditions that severely marginalize women, even if they are not counted as victims in official crime statistics. The presence of small arms permeates South African society, such that women's ability to access their basic democratic rights is drastically compro- 
mised. With the reality of such ominous rates of femicide - coupled with a collective awareness of extremely high levels of gun circulation throughout South Africa - the ability of many women to realize the revolutionary gender rights of the new democracy is seriously threatened. This limited access to democratic protection falls disproportionately on women who are black and poor. Furthermore, institutional structures often fail to provide material support for the impressive gender initiatives at the policy level. South Africa's 2000 implementation of the Domestic Violence Act, for example, was not supported by government funding or human resources to ensure applicants' safety when requesting protective orders - leaving an enormous void in the materialization of gender rights in the new democracy. ${ }^{32}$ As these examples reveal, the prevalence of weapons throughout South Africa stands in sharp contradiction to the goals of human rights central to the process of nation-building.

These social circumstances shape women's ability to move freely within public spaces, to access education and other forms of empowerment and to realize basic democratic rights. Local gender activists illustrate the daily experience of gun proliferation among women:

Day in and day out, women are traumatized directly and indirectly by gun violence. We live in violent communities, under the shadow of guns in our homes and within earshot of gunfire down the street. All too often, it is we [women] that must answer: "Who has been shot now?" And at any time, on any day, it may be our partner or our child that is the perpetrator or the victim of gun violence. $^{33}$

As this analysis illustrates, women's experiences of gun violence are twofold: they are directly impacted by violence in their communities and they are disproportionately affected by personal threats of direct violence, particularly from intimate relations. Because the vast majority of guns in South Africa are owned by men, women are most seriously impacted by the asymmetry of power created by the presence of a weapon in intimate and confrontational situations. In the post-apartheid context of severe gun violence, male/female roles are bifurcated in ways that essentialize women paradoxically as both victims and community-builders, while men are seen as predominantly perpetrators of gun violence. Therefore in South Africa, much as in other post-conflict regions, women face a dialectic challenge because they are both victimized by gun violence and central to rebuilding communities as a result of pervasive small-arms and gender-based conflicts. ${ }^{34}$ A thorough analysis of the private sphere elucidates this duality in women's experience because, as our data suggest, the household is a space of particular vulnerability for women. 


\section{The private nature of gender violence}

While data on gender and armed crime cannot be causally linked to individual or isolated constructs, research conducted by the Gender Advocacy Programme (GAP) points to pervasive patriarchal norms that continue to frame the context of gender-based gun violence within the private household. The prevalence of guns in South Africa severely heightens incidence of domestic violence because ongoing power asymmetries between men and women reflect traditional patterns of patriarchy that prevail in the private household. These patterns suggest that the power of a gun in the household counteracts men's decreased power at the public level, regardless of South Africa's emphasis on women's representation in governance.

To address this enormous gap between public gender rights victories and the prevalence of domestic violence, GAP partnered with Unicity's Safer Cities Programme and the Mannenberg community to create an educational mural on the criminal nature of domestic violence in one of Cape Town's most violent communities with the highest incidence of gun violence and gang-based warfare. A year after the completion of Mannenberg's mural campaign, GAP interviewed a cross-section of 200 residents on commonly held perceptions of gender-based domestic violence. The results (Figure 10.1) illustrate key underlying attitudes and belief systems that remain instilled in patriarchal perceptions about the private nature of domestic violence. ${ }^{35}$

The data illustrate assumptions about the private nature of domestic violence that parallel the private/public divide between the masculine and feminine domains. ${ }^{36}$ In the current South African context, as other studies suggest, the private sphere remains the most challenging aspect

- 98.4 per cent reported witnessing domestic violence within their community, supporting the assumption that domestic violence is widespread and pervasive in South African society

- 61 per cent of males agreed with the statement that "domestic violence is an issue between husband and wife", indicating that men still perceive domestic violence as a private matter

- 33 per cent of men and 24 per cent of women who participated reported having ignored a witnessed act of domestic violence, indicating that men are more likely to consider domestic violence as a "private affair"

Figure 10.1 GAP survey on domestic violence in Mannenberg Township Source: Mathews, Shanaaz (2000) "Domestic Violence Project", Gender Advocacy Programme organizational report. 
of the actualization of gender rights at the public level. ${ }^{37}$ International research demonstrates that more women are shot at home in domestic violence situations than in public settings or at the hands of intruders. ${ }^{38}$ In South Africa, the home is also the most likely place for female homicide. ${ }^{39}$ Furthermore, masculine notions of power in the household are upheld in South Africa's dramatic rates of domestic violence and intimate femicide, reinforced through the power of gun possession. ${ }^{40}$ The Mannenberg study, in conjunction with overarching gender initiatives in South Africa, underscores the central need to involve men in community initiatives to reduce domestic violence.

\section{The geography of small-arms violence in South Africa}

Geo-political divisions from the apartheid era remain central to the nature of small-arms violence in South Africa. The construction of separate residential areas for the black and coloured portions of the population during apartheid created severe socio-economic divides across these racially defined regions. Today, levels of violence are also geographically concentrated within township areas, fuelled by extreme economic crises, a nearly 40 per cent national unemployment level and pervasive gang violence. Several participants in this study associated high levels of unemployment among men in townships with the ongoing proliferation of small arms, suggesting that as men lose their economic power, gun ownership remains one of the few mechanisms to maintain a sense of control. ${ }^{41}$

White residences in South Africa remain extremely representative of the former inequity of economic privilege. Although racial demographics in communities formerly defined as exclusively white are slowly shifting, social relations remain characterized by the distinct geographical separation of the apartheid era. Furthermore, the contrast between white residences and the residences of members of the new black élite and township communities vividly demonstrates the reality that South Africa's political transformation did not engender a similarly democratic redistribution of economic resources. Thus the geography of private residences is integrally linked to class and race relations and notions of security in the context of an extremely violent society.

Participants in this study perceived protection of the private household space as critical to mediating the ongoing threat of gun violence in South Africa. Yet, as the research illustrates, the household is also a space where women experience disproportionately high levels of domestic violence, often involving gun usage. ${ }^{42}$ Ongoing apartheid structures of feminized, racialized labour complicate the private/public distinction, because 
the private household space is also a public labour site for the majority of employed black women in post-apartheid South Africa. This institution therefore constructs particular experiences of small-arms violence for women employed in private households as domestic workers. In addition, it encapsulates the diverse social positions of South African women, who experience the overarching culture of gun violence very differently based upon race and class locations. Within this normalized institution of traditionally feminine labour, we will examine the intersections of apartheid's structural legacy of inequality and the gendered nature of small arms in this post-conflict period of South Africa's national transformation.

\section{Case study: Gendered labour and human security}

\section{The institution of domestic labour}

It is well documented that the gendered experience of small-arms violence varies distinctly based upon differentials of social location - namely race and class. However, no research to date has asked how prolific small arms might impact on the institutionalized employment of women in households, a traditionally "private" space that is also a public work domain for less-privileged women. As global restructuring is specifically characterized by a rapidly growing service industry, ${ }^{43}$ we are seeing a sharp increase in women's domestic and international migration into this sector, which creates another level of vulnerability for women, as domestic workers in the home. ${ }^{44}$ As women enter the workforce, their ongoing responsibility for the maintenance of the household creates a context where the hiring of "other" women becomes one of the few viable options to manage both public and private labour. ${ }^{45}$ Therefore, household spaces are the locations of a sharp socio-economic divide when women who are marginalized by race and class positions manage and sustain daily life for women who have greater access to class privilege, yet remain responsible for the household through traditional division of labour processes that feminize the private space while associating masculine work with the public realm. The socio-economic inequalities that surface in this extremely gendered and racially defined institution are multiplied when domestic workers not only maintain the household but literally secure the private domains of more privileged sectors of society.

In the South African context, paid domestic work remains the largest sector of employment for black women. ${ }^{46}$ Work in domestic service is still extremely gendered, class-based and racialized, with the sector consisting almost completely of economically disadvantaged black women. ${ }^{47}$ Characterized by a colonial labour ideology that relegated black women 
to paid labour in the private households of white employers, today domestic service is arguably "the last bastion of apartheid" in modern South Africa. ${ }^{48}$ Even though it is more than 12 years since the official end of apartheid, the social arrangements embodied in the normalized institution of domestic work illustrate power structures much more aligned with the former regime than with the new human-rights-based democracy. Domestic workers serve a critical role in post-apartheid South Africa because they assuage the tension of national transition by ensuring that daily life for privileged sectors of South African society remains relatively unchanged. ${ }^{49}$ Privileged (predominantly white) households continue to be maintained by domestic workers (predominantly black) who are paid minimal salaries for their (often live-in) services. Although paid domestic labour is central to the regeneration of South African society, it remains largely devalued and invisible: it is rarely problematized or raised as one of the priorities for including the most marginalized women in the project of democratization. Through the lens of domestic labourers, the perception that "not much has changed" since the end of apartheid is pervasive. ${ }^{50}$ Black and coloured domestic workers continue to sustain the households of their (predominantly white) employers through the paid services of cleaning, cooking, childcare, laundry and, we argue, through affording the privileged persons greater access to human security.

\section{Domestic labour and human security}

In South Africa's current transitional phase - characterized by extremely high rates of gun and gender-based violence - domestic workers provide a critical service that is rarely acknowledged as part of the labour contract. In addition to the assumed work of household maintenance, domestic workers literally provide a human barrier against the threat of violence and small arms in the protected private spaces of the privileged sectors of South African society who can afford to hire them. They are in essence live-in human security systems, whose bodies mediate the threat of violence in their employers' private households, thus reifying former race and class divides of the apartheid era that place a higher value on certain lives over others.

The end of apartheid supposedly signalled the end of systematic exploitation of black labour. It has become less socially acceptable in postapartheid South Africa to express publicly the (formerly appropriate) paternalistic views held towards black workers. However, since domestic workers continue to labour under conditions that replicate the systemized racism of apartheid, the attitudes of employers continue to reflect deeply embedded notions of racialized and gendered servitude. In our interviews, employers repeatedly expressed a perception that workers were 
"much better off" living on the premises where they are employed rather than in the violent townships that surround urban centres. This perception ignores the disruption in family structures as a result of women's live-in labour in private households and the fact that women working away from home worry continuously about the safety of those they have left behind, while allowing the privileged classes in South Africa to overlook the reality that their safety is far less precarious than that of the majority of the population.

Economic privilege affords employers a certain "peace of mind" from the threat of the severe proliferation of small arms and violence in South African society. Purchasing domestic labour enables employers to experience enhanced physical and psychological comfort: by hiring a domestic worker, they are also securing the private household space from outside armed criminals. The spatial arrangements at the labour site - where workers often live at the employers' home in an isolated space - illustrate how workers create a human barrier to mediate the threat of small-arms violence from "outside" and the safety of private spaces "inside" the protected domain of employers. For women like Phyllis, an employer of three domestic workers in a wealthy white Cape Town suburb, the employment of staff members ensured her own sense of physical security in her private home.

We've never had a break-in. They know I have a staff member here every day... and she will never let anybody in the gate unless I have instructed her. We've never had a security problem.

Another employer illustrated how the daily presence of a domestic worker contributes to her everyday psychological sense of safety within South Africa's pervasive gun and crime culture:

I just feel more comfortable with her here every day, even if she is not working. We've never been burgled because I think people know that she is here.

Domestic workers commonly identified the responsibility for household security as a central job expectation of their employers, even though it was rarely discussed. This additional role of security provider expected by many employers was a substantial concern for workers because of the severe risk to their own personal safety if they were confronted by a situation in which they would need to "protect the house" from crime. In stark contrast to the comfort experienced by employers whose domestic labourer was taking care of their possessions, for workers their additional security responsibilities created both physical threats and psychological hardship, as these responses illustrate: 
It's dangerous because we are in charge of that house... you answer the door and sometimes people don't give their name and you think maybe you know the people and they come straight to you... They got in and they nearly killed me, they nearly killed me.

They broke into the study, but I thought that morning it was [my employer] walking up and down and then it was the person who was breaking in! So you are not safe, there is no protection, that is it.

The majority of the workers in this study experienced high levels of fear in relation to the direct physical threats associated with securing the private space of their employers. In every instance when workers discussed this threat, they linked it to perpetrators' use of a gun. As a result of the embedded expectations of protecting the household from "outsiders", domestic workers risk their own bodies to mediate the threat of crime enhanced by the power of a gun. In a nation infused with small arms and gun violence, the vulnerability of domestic workers expands beyond the exploitation of their labour alone. They are obliged to put their physical safety and well-being on the line - a critical aspect of their human security is thus compromised.

Workers also spoke of their fear of losing their jobs if they failed to provide protective security services in addition to their household labour responsibilities such as cleaning and childcare. In many instances, the knowledge that they had to protect their employers' home created an ongoing burden. Workers, particularly those in live-in employment situations, were especially traumatized because they had no means of disassociating from their daily labour tasks. They simply could not get away from the pervasive insecurity of their workplace, as this unionactivist domestic worker portrayed:

One night I was so afraid when I'm here alone... they [her employers] went away for the weekend and they just left me here. The alarm went off and I heard somebody when I was sleeping and I peeped through the window and the person was right here by the car. They break in and they took some stuff, washing off the line. They break the car already... Sometimes employers don't believe you.

This participant further described that she had witnessed two other break-ins where the perpetrators were carrying guns. The added expectations of ensuring employers' security significantly extends the work hours and job expectations of women employed in private households. However, current policy initiatives to protect and standardize the labour conditions of paid domestic workers in South Africa fail to acknowledge these added hours of psychological burden as well as the expectations 
that women employed in this sector must provide a round-the-clock presence to dissuade the potential threats of outside armed criminals.

\section{Socio-economic divides and human security}

We assert that the institution of domestic work makes the underlying structures of race, class and gender inequalities in South Africa much more visible, particularly when we examine how access to human security and protection from gun violence are directly related to the divergent social positions of employers and workers. To understand why employers value the security roles fulfilled by domestic workers, we must examine the connections between crime, gun violence and social location. Generational poverty, which is exacerbated by the abuse of drugs and alcohol in communities that have been systematically destroyed for generations, has led to the growth of a skollie (hooligan or criminal) class, predominantly comprising black and coloured men. In privileged, predominantly white sectors of society, an overarching ideology about keeping skollies beyond the reach of private residential spaces guides decisions around protective security measures against the threat of armed criminals. For instance, residential neighbourhoods without public transportation are valued because they are perceived to be more difficult to reach for marginalized sectors of the population who reside in township locations. That this isolation also makes it more difficult, and dangerous, for domestic workers to commute to and from work is rarely considered. Crime is therefore racialized and gendered, in that black male skollies are most commonly associated with crime - both statistically and in the broader public perception - and most likely to use small arms to access privileged sectors of South African society. This social construction motivates a series of protective measures adopted by white South Africans, as well as newly élite black and coloured employers, to mediate the perceived threat of violence. Participants in this study took specific actions to protect themselves from armed crime by maintaining geographically separate residences to distance the threat of small arms; purchasing highly technical security systems; making conscious decisions about daily life to avoid potentially violent circumstances; and hiring domestic workers to serve as gatekeepers to the "outside" world.

Severe economic inequality fuels the use of small-arms crime as a means to access material resources, but for employers of domestic workers, purchasing household labour assures some level of protection against violence in the most vulnerable private household sphere. In South Africa, protection against household theft becomes a central obsession in daily life, particularly for those sectors of the population with relative wealth. The employment of a domestic worker offers an enhanced level 
of psychological comfort in addition to the value of the household labour provided. The South African context illustrates, therefore, how efforts to implement protective measures against the threat of small-arms violence rely upon the often exploited and usually invisible labour of marginalized women.

This dependence upon black women's labour to mediate threats of armed crime illustrates a series of critical complexities in the normalized institution of domestic work in post-apartheid South Africa. Black men, namely skollies, must be kept away from the private households of employers because of their high levels of involvement with armed incidents of crime. Yet black women remain caretakers in the intimate private household spaces that are coveted in privileged sectors of society. In effect, then, black women are hired as domestic workers literally to keep their brothers at "arm's length" from the families they serve. Domestic workers must therefore take on the role of aggressor in keeping crime perpetrators out of the private spaces of privileged sectors of society. At the same time, the lingering nature of domestic service is shaped by the expectation that workers remain docile within a paternalistic employment context that is structured by the passive invisibility of workers, who are most valued when they are literally not seen. By fulfilling employers' security expectations, to a certain degree domestic workers must also uphold former structures of severe racial stratification to secure their own economic survival. As gun violence becomes increasingly prolific in South Africa, the institution of domestic labour poses new threats to women workers, who face increasing risks at multiple junctures in their daily lives.

\section{Vulnerability within the private home}

Research in South Africa demonstrates that the highest levels of violent crime against women are carried out in the private household. According to internal data gathered by the Gun Control Alliance, 54.6 per cent of female homicides take place in the private household, compared to 34.9 per cent of male homicides. These figures demonstrate how severely women are threatened by the proliferation of small arms in South Africa, both in their own domestic spaces and when their daily employment is contained within the private household domain of others. Arguably, when women are employed in a private household their vulnerability to violence and the threat of small arms may be said to double.

While these gender-disaggregated data unquestionably illustrate the severity of gun misuse for women in South Africa, particularly because of the apartheid history, the experiences of women must be analysed in relation to not only gender but also the intersection of gender with race 
and class. Challenging the monolithic construction of women ${ }^{51}$ is central to understanding the relationship between gender and human security in South Africa. As we see in the institution of domestic labour, women's social locations situate very distinctly their risk to small-arms violence: race and class differentials literally determine vulnerability.

Research on gender violence and guns in South Africa illustrates that black and coloured women with fewer economic resources are much more vulnerable to the threat of small arms than white women. Comprehensive analysis of female homicides based on mortuary records illustrated that rates of intimate femicide vary dramatically by race. The rate for coloured women was highest at $18.3 / 100,000$, whereas the rate for African women was $8.9 / 100,000$. White women were least likely to be victims of intimate femicide, with a rate of 2.8/100,000. Shockingly, the seriousness with which perpetrators were punished also varied according to the race of the woman they had murdered. ${ }^{52}$ Because black and coloured women live in the geographic spaces with the highest levels of gun misuse, their experience of gun violence is pervasive in everyday life. As domestic workers transcend these public spaces within South Africa's most marginalized and violent communities, they continue to face the threat of gun violence in the private homes of more privileged sectors of society.

The institution of domestic labour creates a particular vulnerability for workers because, in addition to highly sophisticated security systems, employers often arm their homes with guns for personal protection. Like the peace of mind afforded when domestic workers double as security systems, employers described an enhanced feeling of comfort when they held weapons in the household. For some employers, gun ownership was seen as a "last resort" protective measure. For others, it was the primary means of ensuring their protection. In one instance, a Johannesburg employer described how she slept with a loaded weapon under her pillow; this was the only means of security she trusted. Another employer described how he continually carried a gun on his calf, in both public spaces as well as his private home, where he employed two domestic workers.

For domestic workers, the presence of a weapon in the employment space adds considerably to a predominant sense of insecurity. One respondent in this study said that she felt extremely unsafe knowing that there was a loaded weapon somewhere in her employer's home, which was also her daily workplace and personal accommodation: "Maybe the boss has so many guns and we don't know when he is going to use it." Since employers tend to withhold details of the location of their weapons and rarely train domestic workers in their use, workers' level of fear increases at the same time as unequal power relations in the private household work environment are reinforced. When there is a weapon in the 
home, the vulnerability of women expands to include both the threat of "outside" criminals and a distinct threat from within the workplace. These dual vulnerabilities to the proliferation of guns are distinctly gendered. For example, in every interview with domestic workers, the male employer was associated with both gun ownership and the possible danger of misuse by the "boss" - illustrating how gender power asymmetries are central to the perceived risk and fear of weapons.

Because of the intimate nature of domestic labour, workers are also disproportionately vulnerable to abuse and sexual violation stemming from the presence of a gun within the household labour context. Domestic workers are more likely to become victims of domestic violence, sexual abuse and even femicide because of their intimate/emotional relationship to the private household setting, the low value put on their lives and security, and their isolation, which translates into a complete lack of protection in this space. Research on intimate femicide conducted by the Medical Research Council identifies six factors that distinguish intimate femicide (i.e. the murder of a woman by a family member or partner) from non-intimate femicide (i.e. the murder of a woman by a stranger). The study placed women who "work as domestic workers" in the category of those more likely to be killed by people known to them, and, moreover, found that the murderers of domestic workers were less likely to be convicted. ${ }^{53}$ These data underscore the prevailing social perceptions that continue to devalue women employed in this sector. Furthermore, the institutionalized nature of domestic work complicates the intimate/non-intimate distinction in femicide statistics because women who are in so many regards perceived as outsiders are actually intimately involved in the families of their employers.

Another paradox of this labour institution lies in the fact that domestic workers - who are in many ways dependent upon their employers for economic survival - are also in positions that heighten the vulnerability of these same employers because of the extensive access the workers have to the private sphere of privileged sectors of society. The majority of employers in this study acknowledged a distinct insecurity about their material possessions because of the presence of workers in their private lives. Workers' extensive private knowledge of intimate relations in the households of their employers also illustrates this dialectic of social power and vulnerability. Domestic workers are privy to knowledge about abuse that takes place in the household, which may also increase their vulnerability to violence from the perpetrator. Because they know so much about the movements of their employers, they also could conceivably breach household security by informing criminals of the best time to burgle the house. Employers who spoke of their comfort in the protection they acquired through hiring workers with whom they were very 
familiar also described the extreme vulnerability they felt with the prospect of hiring a new worker. All the same, current employment trends in domestic work show a move towards more casual, part-time labour. Rather than the relationship of live-in servitude that heightened familiarity, normalized in the apartheid era, workers who are employed on a part-time daily basis are less accountable to individual employers. Levels of security enjoyed by employers therefore shift according to the nature of the work relationship and reflect broader patterns of change in the post-apartheid context.

While rates of violence against women in South Africa are generally extremely high, black women face the threat of gun violence in three specific spaces that remain defined by race and class inequalities: the social and economically marginalized communities that contain the highest levels of crime and gun misuse, the systems of public transportation and the isolated domestic sphere which comprises the largest sector of labour for black women. Workers in this study specifically identified commuting by public "taxis" as the most severe threat they face in relation to gun violence. Fighting among taxi drivers, hijackings and armed robberies of taxis were named by workers as specific examples of the way in which guns impacted on their daily lives. That black women are most vulnerable to gun violence when travelling to and from their place of work by foot and on unsafe public transport, while white women are generally privileged enough to drive personal vehicles, is virtually ignored in mainstream media. Importantly, the media fail to convey the overlapping vulnerabilities faced by the majority of the female population in their coverage of crime and weapons misuse. Rather, attention is directed at incidents of crime that impact on privileged communities. Yet the daily experiences that distinctly shape women's lives according to race and class privilege clearly illustrate that a shared experience of small-arms violence fails to exist in South African society.

In a few cases, workers stated that they preferred to live on the premises of their employers to minimize this risk in public transportation. For some women, domestic work is an escape - physically, if not psychologically - from the violence that pervades township life in South Africa in the aftermath of apartheid's structuring of economic and racialized dependency. Workers in this study did acknowledge a sense of escaping daily township violence through their employment in domestic labour. However, their economic circumstances failed to provide adequate means to secure the homes and informal settlements in which their families reside. Added to the psychological burden of domestic work we have described above is many workers' sense of guilt that they have found some measure of safety from the threat of violence as a result of their 
employment in private homes, but can do little or nothing to protect their loved ones who remain in the most violent locations in the country.

\section{Security and emotional labour}

The security role that domestic workers are expected to play is directly linked to the highly gendered emotional labour that is particular to this work performed in the most private social spaces. As we have seen, workers often stated that they were expected to assure employers of the safety and well-being of the household. In some instances, workers described a daily ritual to reinforce the security of their employers, such as double-checking all the gates before bedtime. Given the daily experience of a pervasive gun culture in South Africa, workers further assuage the tension of violence by providing emotional comfort about the security of the private home. Yet this added role is often fulfilled at the expense of workers' own emotional and physical well-being. One participant, Thandi, described how her life was threatened when armed burglars attempted to enter the home in which she was employed. Although the perpetrators did not succeed, Thandi was directly threatened by the power of their weapons and experienced lasting trauma as a result of a daily fear that she would again be confronted by "thieves with guns" attempting to access her employer's home. In her perception, this threat in her daily work environment could easily take her life, yet she was still expected to ensure her employer's comfort and protection from possible harm within South Africa's overarching gun culture.

Another participant, Nomsa, recalled an incident of gun violence that shifted her entire employment experience in a wealthy Cape Town suburb. When her employer did not return home one evening, Nomsa searched the apartment building's secured garage and found her "madam" shot dead outside her car, stripped of all her jewellery and personal belongings. Nomsa reported that her employer had also been raped. The motivation for this crime, in Nomsa's view, was the material resale value of her employer's diamond rings, jewellery and personal belongings. As she recalled this story, Nomsa repeated several times how she had warned her employer about the risk of wearing such valuable pieces of jewellery in an overarching climate of severe economic inequality linked to South Africa's pervasive gun culture.

Since this incident, Nomsa's employment conditions, as the domestic worker for her widowed male employer, have changed dramatically. She described her employer's ongoing extreme fear and the heightened protective measures he installed after the death of his wife to minimize the threat of armed "outsiders" entering their home. Nomsa's workload 
increased when she became responsible for the continued emotional comfort of her widowed employer because she was now the only "woman of the house". Although Nomsa also experienced extreme psychological, emotional and physical discomfort from the killing, she upheld this highly gendered caretaking role by assuaging her employer's daily fear of perceived threats from "outside" armed criminals while accepting that no similar trauma counselling would be offered to her. Nomsa repeatedly expressed the inner complexity this created for her. At the same time, she was very clear that in order to retain her job, she was expected to perform this emotional caretaking labour to uphold her security service role. Yet she was only compensated for the assumed role of household maintenance, illustrating that the emotional and security roles of private household labour go unrecognized in South African society.

\section{Private security systems}

In South Africa, the private security sector continues to comprise the highest level of industry sales growth since the end of apartheid. ${ }^{54}$ This consumer pattern illustrates the immense culture of fear and protection embedded in this "post-conflict" nation. The visual representations of South Africa's crime threats manifest themselves repeatedly in urban spaces, where private security guards protect parking spaces, garages, restaurants and clubs. This almost exclusively male security presence is so much a part of everyday life in South Africa that evening social events in privileged urban areas often include the hiring of a "car guard" for party guests. While these human security systems embody an illusion of control within an overarching environment of social fear, they simultaneously reify, in an explicitly gendered way, the severe threat of gun violence that must be mediated in everyday life in South Africa. The pervasive presence of (predominantly black male) armed security guards in public spaces is mirrored in the fact that private spaces are partly protected by unarmed (predominantly black female) domestic workers.

In many household employment contexts, domestic workers are required to operate highly technical, computerized security systems as part of their daily responsibility to maintain the private household, particularly in the absence of their employers. One worker in our study was even required to lock a secured gate into her employers' bedroom each night to ensure their safety should burglars penetrate the other two levels of protection surrounding the house. Some workers spoke about feeling particularly at risk when entering and leaving the house because they could be identified as a permeable barrier to the wealth contained in the employers' homes. Workers shared fears that because of the prevalence of small arms in South Africa, they felt highly vulnerable to violent crime 
and even stood a high chance of facing death if armed outsiders forced access to the homes they protected. Some workers chose to limit the extent to which they left their employers' households because of this perceived threat to their physical safety at the point of entry to the home, creating a greater level of entrapment in this highly feminized private employment sector.

Many workers felt very uncomfortable with the responsibility to operate sophisticated security systems, particularly because errors could result in a threat to their own well-being and job security, as well as the employer's physical property. Moreover, a stark inequality existed in the level of security domestic workers were expected to provide in their employers' household and the measures available to assure their own safety, particularly during "off-duty" times within their live-in premises. Workers repeatedly pointed out that employers often failed to extend, even in a less sophisticated way, the security system in the main house to the domestic worker's accommodation:

About this burglar alarm system that they put over there by the door and now I have got this remote thing that I must use. If I see someone in the yard at night and I'm getting frightened then I must use this thing so that the alarm can go off... but here [in her accommodation] there is no protection. That door is nothing. They can kick it open and they come in easily. That is why I am so afraid when I am alone here.

This narrative illustrates a crucial component of the perceived, and often actualized, threat to workers in their employers' households. When workers live at the site of their employment, the inequality between worker and employer accommodations is clearly evident in the poor protection extended to workers' private spaces. Ultimately, these spatial arrangements reflect a core underpinning ideology about the value of particular groups: the lives of poor black women are just not worth as much as those of white, or rich, employers. Or, as one worker put it in this study, "if a domestic worker is shot, it is just another black woman down the drain". The institution of domestic work thus materializes the ongoing structures of inequality through the spatially defined divisions between those whose race and class position makes them a target of bandits and those who have nothing that can be taken from them but a life that is not even seen as being worthy of protection.

\section{Trafficking in domestic workers}

Because domestic work remains a primary means of employment for black women in South Africa, human trafficking networks have focused 
on the potential to recruit within this expanding sector. Since guns are often smuggled through the same routes and are frequently used to enforce the movement of individuals through intimidation and enhanced power relations, human trafficking should, we argue, be read as another gendered impact of small-arms proliferation. Throughout South Africa, women migrate from rural to urban areas specifically for employment in the domestic work sector. Recent trends point to an active network of predominantly male-run trafficking systems that recruit girls and young women from severely economically disenfranchised rural communities within South Africa. In Cape Town, girls are solicited from northern rural areas by bribing family members with promises of economic rewards and constructing life in cities as extremely lucrative and glamorous. Without any exposure to urban settings, girls who enter South Africa's cities under the guise of possible employment in "hotel work" are trafficked into the two most exploitative and gendered employment sectors - domestic labour and sex work.

Discussions of these trafficking structures with police officials, former workers, union officials and legal advocates revealed the most egregious violations of human rights within the institution of paid household labour in situations where trafficking agencies specifically recruited domestic workers. Reports illustrated that in some cases workers were locked in their employers' houses to ensure they did not leave or threaten the security protection systems within the home. In other instances, sexual violence from male members of the household became a frequent tactic to enforce power over domestic workers. One participant described being threatened with a gun by her male employer, who attempted to rape her. Keeping her wits, she fled the house and sought the support of the local union of domestic workers.

For many young workers who are victims of trafficking, such positive avenues to access their rights are not available, even though such incidents are terrifyingly common. Police reports in three suburbs outside Cape Town indicated that each day between five and 15 young women and girls arrive at community police headquarters after escaping particularly oppressive domestic work environments. The risks to girls and young women trafficked from rural areas into domestic work are clearly extremely high. The sheer lack of regulated economic opportunities increases the likelihood that such workers will experience violence and severe threat, possibly through the use of small arms, and that their suffering will remain invisible since their daily lives are structured by the highly isolated nature of this labour sector. Escaping from servitude may also not provide a solution, since workers who are displaced in urban centres are often recruited for sex work, a sector where gender-based 
violence creates enormous risks for young females. The vulnerability of poor women in South Africa increases dramatically with the advent of trafficking systems that are built upon the exploitation of young women and girls, often through the threatening power of small arms. Furthermore, this case illustrates that preventing the risks of gun violence for women and girls in South Africa will require breaking down interconnected systems that profit from the exploitation inherent to domestic labour.

\section{Related implications}

As it relies on women leaving their own homes and communities to work elsewhere, the institution of domestic work reflects another form of underpinning inequality, fuelling gender-based gun violence. The majority of domestic workers leave their own families to care for the children of their employers and maintain more privileged households. Their migration impacts on workers' families in substantial ways. Children are often raised without their immediate parents. In fact, workers consistently identified leaving their own families as the greatest difficulty in their work. Essentially, because their mothers have to work far away, a large sector of South Africa's children are either motherless or, because single-parent families are so common, entirely parentless. Coupled with the severe threat of HIV/AIDS, many children in South Africa are extremely vulnerable to both small-arms and gender-based violence as well as the lure to join gangs and take up illicit weapons as a means of survival. As Elizabeth described, the burden domestic work places on family structures can be directly connected to the ongoing violence and small-arms proliferation in South African society:

If we [could] stay with our children it will be better for our children. That is why there is so much crime and the children in jail, doing the wrong things, killing and raping, because they couldn't stay with the mother.

The absence of parents, combined with forced changes in social support systems, creates a ripple effect throughout South African society and perpetuates generational patterns of inequality and violence that were established during the apartheid era. Because over 1 million women are employed in the domestic labour sector of South Africa, the related social implications expand beyond the threat to women employed in private homes alone. Their absence from their own family members means that the number of children who are drawn into perpetrating the high levels of armed violence is alarmingly high. As armed violence becomes 
normalized in the generation now growing to adulthood, the extreme difficulty and length of time required to transform a society inured to violence are clearly demonstrated.

\section{Actions towards change}

Gender-based gun violence in South Africa is deeply rooted in the patriarchal nature of a country emerging from a political era in which both men and women experienced severe discrimination on the basis of race. With this legacy, women in South Africa face a society based on patriarchal domination, in which men's power is often enhanced by the proliferation of small arms. As our study illustrates, these processes of gender inequality impact on women very differently according to race and class positions - creating diverse experiences of gun violence based upon the intersections of social location. Yet, building upon the strong movement of collective action, women in South Africa continue to enact agency at both personal and collective levels to support the realization of human rights and accessible democracy. Women in government persist in their prioritizing of small-arms control as critical to the process of ongoing public reconstruction. For example, Thandi Modise, former chair of the Portfolio Committee on Defence and the Joint Standing Committee on Defence, took a central role in challenging the new government on its continued arms production and trade in the context of severe inequality and gun proliferation. Motivated by a similar desire to alleviate smallarms violence, women developed the "Books Not Bullets" project to break down the militarized normalization of weapons by stopping the distribution of guns in schools for sport activities. ${ }^{55}$ Furthermore, women continue to lead communities at the grassroots level on peacebuilding campaigns, such as the Mannenberg mural project, to eradicate the pervasive impact of gun violence.

The Gun Control Alliance, the nation's largest advocacy group on small-arms concerns, is led by women who effect change at policy, civil society and community levels. As a direct result of women's leadership, this organization has succeeded in changing gun control policy, influencing public decision-makers, persuading the government to destroy surplus weapons and stigmatizing the pervasive use of firearms in South African society. ${ }^{56}$ This organization also models the power of establishing cross-sectoral networks to strengthen positions on South Africa's gun violence and its gendered impact. The model of alliance-building established through the anti-apartheid struggle in the Women's National Coalition strengthens the potential for South African women to collaborate across diverse political perspectives to actualize change in realms 
that directly affect them. One of the current challenges for gender equality in South Africa derives from the continuing divisions of race, class, sex and geographic location that limit the power of a collective women's voice, as we illustrate in the institution of domestic labour. Some progress is being made, as we saw in 2001 when the South African Domestic Service and Allied Workers' Union aligned with the Commission on Gender Equality and the Black Sash to protest the exclusion of domestic workers in critical labour legislation on unemployment insurance. The public submissions and collective agency of this coalition successfully influenced a pivotal policy change at the national level that recognized the value of domestic labour and the essential protection of this critical sector of women's labour. ${ }^{57}$ This approach holds potential for similar crosssectoral alliances around the multiple and intersecting layers of gun violence in contemporary South African society.

These sites of activism, across social location divides, form the basis of a movement to connect the small-arms crisis in South Africa with the public gender rights victories realized in the transition to democracy. To date, South Africa has committed itself to the eradication of violence against women at its highest policy level through the ratification of CEDAW, the Beijing Platform for Action and the Constitution and Bill of Rights, as well as the implementation of the Domestic Violence Act. Collective action on the small-arms crisis in South Africa could still, we believe, be more strongly taken up as an issue of gender rights by emphasizing the multiple and interconnected impacts of gun violence on women. Furthermore, the successful ongoing initiatives to protect women from small-arms violence through education on rights, the creation of safe spaces such as rape crisis centres and the enactment of protective legislation including the Firearms Control Act, as well as ongoing efforts to collect and destroy illicit weapons, need to include women across a variety of race and class positions to implement change most meaningfully. Effective gender campaigns on small arms must establish viable mechanisms to address the differential impacts of gun violence, as exemplified in the institution of domestic work where access to human security is directly related to the relative race and class privilege of female workers and employers. Because they are the largest sector of working women in South Africa, establishing a gender perspective on the nation's smallarms crisis must of necessity include this group of women who experience extremely high rates of gun violence as they transcend the public/private divide.

We also contend that the realization of a "gun-free South Africa" will not be possible unless action on the gendered effects of small-arms violence includes men and an analysis of the lingering constructions that connect masculinity with violence. The mutually reinforcing nature of 
masculinity and femininity limits both men and women from fully realizing their human potential. Men are confined by masculine roles that are grounded in the use of violence and militarization in ways that shape their everyday existence. Interrupting the pervasive small-arms threat to South African society therefore also mandates a deconstruction of notions of social power as best achieved through gun use and other forms of violence, especially gender-based violence. The campaigns to control small arms provide a tangible avenue by which to challenge a core construction of masculinity while improving the ability to access central rights such as human security across all sectors of South Africa's population.

South Africa's Gender Advocacy Programme identifies the need to involve men in grassroots education on domestic violence, femicide and the gendered impact of small arms throughout a series of recent campaigns. GAP's ongoing Domestic Violence Project (DVP) implemented a campaign to empower men and women in communities to lobby for the reduction of domestic violence and small arms. In 1996 the DVP joined forces with five other organizations in the campaign to raise awareness on the issue of violence against women, with femicide being the most pressing form of gender-based violence. The "Every Six Days... Do Something" campaign was developed after the release of 1996 femicide statistics indicating that femicide claims the life of a woman at the hands of an intimate partner every six days in South Africa. ${ }^{58}$ This campaign has since been restructured to reflect the release of 2004 statistics indicating that every six hours a woman is killed by her intimate partner. ${ }^{59}$ In August 2004 GAP partnered with the Commission on Gender Equality (CGE) to initiate the "Men's Summit" in Cape Town. This initiative was founded on an underlying belief that the eradication of gender-based violence requires an inclusive approach to involve both men and women.

These initiatives illustrate viable models to align women and men across divides in ending the severe impact of gun violence that presents such a serious obstacle to the realization of South Africa's new democracy. Social change initiatives centred on strengthening civil society and increased activism hold the potential of transforming individuals' experiences of democracy in their everyday lives through decreased levels of violence and greater access to human security.

\section{Conclusions}

This chapter analysed the central connections between gender, smallarms misuse and human security in South Africa's ongoing transition to democracy. From our longitudinal data, we complicate a monolithic no- 
tion of women's experience of gun violence by situating gender within intersecting race and class positions that remain pivotal to systems of inequality 14 years after the democratic transition. As our case study illustrates, the institution of paid domestic labour constructs very particular conditions in which gender-based violence and small arms threaten women in their everyday lives, even in a peacetime context. Through their assumed roles as human security systems in the homes of more privileged sectors of South African society, domestic workers are especially vulnerable as they protect employers' physical spaces and family structures. The institution of domestic work therefore mediates the tensions of the nation's ongoing transformation and its interconnected levels of violence by reinforcing former race-, gender- and class-based power structures of the apartheid era, thus further stratifying South Africa by levels of risk of small-arms violence. Moreover, when the private sphere becomes a public workspace for women employed as domestic workers, the binary constructions of public/private and intimate/non-intimate that are generally used to conceptualize and document gun violence and crime must be reconsidered.

Our research illustrates that the gendered nature of much of the violence committed with small arms is embedded in unjust social institutions, particularly the exploitation of women's labour in unsafe environments. Breaking the cycle of gun violence therefore calls for policies and processes that restructure institutions in which severe social inequalities continue to stratify South Africa and reify the gender, race and class differentials established in the colonial and apartheid eras. Therefore, social change intended to reduce small-arms proliferation in South Africa must also be connected to redressing South Africa's overarching race, gender and class divides that continue to marginalize the most vulnerable sectors of the population, particularly women employed as domestic workers. Small-arms proliferation in South Africa is a symptom of the underlying structural violence that is disproportionately affecting women. In order to implement transformative change, the distinct experiences of women across race and class divides must be included in both policy and action.

We focused this chapter on the relationship between human security and paid domestic labour in the South African context, which carries a highly particular set of social circumstances as a result of the history of 46 years of systemic apartheid governance. However, we feel it is important to note that this institution, while shaped in South Africa by a particular history of violent, racialized, class-based and gendered oppression, does not operate in isolation from global structures of power that relegate women to the household domain and continue to marginalize this rapidly growing sector of service labour throughout the global economy. 
Certainly, connections can be drawn between gender-based violence throughout the world and the devalued nature of women's social position in the household - as both paid and unpaid labourers. This sector, seen to perform the "dirty work" across societies, is marginalized through global patterns of class, gender and race/ethnic inequalities that threaten domestic workers' physical and psychological well-being. In addition, many women migrate transnationally to gain work in domestic service. In these instances, citizenship rights are most often denied, creating even greater vulnerability through the substantial distances from support systems and workers' associated status as "illegal immigrants" in many national contexts. With the growth of small-arms circulation at a global level, as well as the marked increase in the global trafficking of women, it is likely that the most vulnerable sectors of the world's population will remain at greatest risk. Therefore, as in the South African case, decreasing the threat of small-arms violence for women requires a restructuring of systems of inequality as well as ongoing resocialization that devalorizes the power associated with weapons. As South Africa continues to emerge as a new post-apartheid nation, we suggest that the ultimate measure of the realization of its lauded human-rights-based democracy hinges most crucially upon the alleviation of gun violence and the lingering impacts of social inequalities.

\section{Notes}

1. Small Arms Survey (2003) Development Denied, Geneva: Oxford University Press.

2. Constitution of South Africa, 1994.

3. Britton, Hannah (2005) Women in the South African Parliament: From Resistance to Governance, Urbana, IL: University of Illinois.

4. Personal interview with Margie Keegan, March 2004.

5. Because apartheid history is so extensive and complex, we introduce overarching constructs and pivotal moments that are most directly related to the existing context of small-arms violence and gender inequality. Our intent is not to reduce the multiple and interconnected layers of South Africa's past, but rather to present the historical components most relevant to this research.

6. We use the terms "black" and "coloured" to distinguish the socio-economic differences between these two distinct identity groups. Our intent is not to reify former apartheid divisions through the language of racial classification. Rather, we attempt to offer a more nuanced understanding of the divisions among women based upon race and class. To date, these social categories that distinguish black and coloured groups continue to reflect the realities of South Africa's social landscape, 14 years after the end of apartheid.

7. Cock, Jacklyn (1989) Maids and Madams: Domestic Workers under Apartheid, 2nd edn, London: Women's Press.

8. Wells, Julia (1993) We Now Demand! The History of Women's Resistance to Pass Laws in South Africa, Johannesburg: Witwatersrand University Press. 
9. Cock, Jacklyn (1993) Women and War in South Africa, Cleveland, OH: Pilgrim Press.

10. Goldbatt, Beth and Sheila Meintjes (1998) "South African Women Demand the Truth", in Meredeth Turshen and Clotilde Twagiramariya, eds, What Women Do in Wartime, London: Zed Books.

11. Fine, Michelle (1994) "Working the Hyphens: Reinventing Self and Other in Qualitative Research", in Norman K. Denzin and Yvonna S. Lincoln, eds, Handbook of Qualitative Research, Thousand Oaks, CA: Sage Publications.

12. Personal interview, 2004.

13. Cock, note 7 above.

14. For a comprehensive account of gender and the political process of transformation that details the experiences of women parliamentarians in their first terms of office, see Britton, note 3 above.

15. The Gun Control Alliance was previously Gun Free South Africa; it was renamed in 2004.

16. Lamb, Guy (2000) An Overview of Small Arms Production, Export, Ownership and Proliferation in South Africa, Cape Town: Center for Conflict Resolution, University of Cape Town, p. 1.

17. Ibid.

18. Fleshman, Michael (2001) "Small Arms in Africa: Counting the Cost of Gun Violence", Africa Recovery 15(4), available at www.un.org/ecosocdev/geninfo/afrec/ vol15no4/154arms.htm.

19. Gun Control Alliance (2004) "Southern Africa Regional Research Programme on Small Arms and Light Weapons", organizational document, Gun Control Alliance, Cape Town.

20. Based upon interviews with researchers and experts at the Center for Conflict Resolution, the South African Police Service and the Gun Control Alliance, South Africa, March 2004.

21. Fleshman, note 18 above.

22. Organization of African Unity (2000) "Bamako Declaration on an African Common Position on the Illicit Proliferation, Circulation and Trafficking of Small Arms and Light Weapons", declared at Ministerial Conference on the Illicit Proliferation, Circulation and Trafficking of Small Arms and Light Weapons, Bamako, Mali, 30 November-1 December 2000.

23. Pregs Govendar, ANC parliamentarian and former chair of the Commission on Gender Equality, actually resigned in large part to protest the arms deal. Thandi Modise, former chair of the Portfolio Committee on Defence and the Joint Standing Committee on Defence, also took a strong position on full parliamentary oversight of arms sales. For a more detailed description of women's leadership in the arms deal, see Anderlini, Sanam Naraghi (2004) Negotiating the Transition to Democracy and Reforming the Security Sector: The Vital Contributions of South African Women, Washington, DC: Initiative for Inclusive Security, available at www.huntalternatives.org/pages/7_the_ initiative_for_inclusive_security.cfm.

24. Ibid.

25. Cukier, Wendy with Alison Kooistra and Mark Anto (2002) "Gendered Perspectives on Small Arms Proliferation and Misuse: Effects and Policies", in Gender Perspectives on Small Arms and Light Weapons: Regional and International Concerns, Brief 24, Bonn: Bonn International Center for Conversion.

26. Mathews, Shanaaz, Naeemah Abrahams, Lorna J. Martin, Lisa Vetten, Lize van der Merwe and Rachel Jewkes (2004) Every Six Hours a Woman Is Killed by Her Intimate Partner: A National Study of Female Homicide in South Africa, Tygerberg: Medical Research Council. 
27. Interview and observation data across participant groups in 2001 and 2004 research.

28. Bollen, Sandra, Lillian Artz, Lisa Vetten and Antoinette Louw (1999) Women in Metropolitan South Africa: A Case Study on Impact and Service Delivery, Pretoria: Institute for Security Studies.

29. "Taxis" are minibuses used to carry typically 15 passengers. In South Africa, this mode of transportation is most widely utilized by black and coloured women as opposed to larger city buses. Taxis were repeatedly mentioned as sites of particular vulnerability for women because of the weapons that are carried by passengers and taxi drivers. Incidents of "taxi wars" between competing networks of drivers have also escalated and resulted in armed conflict. This public space illustrates a site of distinct economic divisions; it forces women with less economic privilege to confront gun violence as part of their daily travel.

30. Muggah, Robert and Eric Berman (2001) Humanitarianism under Threat: The Humanitarian Impacts of Small Arms and Light Weapons, Geneva: Small Arms Survey, p. ix.

31. Hillier, Debbie and Brian Wood (2003) "Shattered Lives: The Case for Tough International Arms Control”, organizational report, Amnesty International/Oxfam, available at www.amnestyusa.org/arms_trade/pdfs/arms_report_full.pdf.

32. Vetten, Lisa (2003) "Government Urged to Put Its Money Where Its Mouth Is", amalungelo, August-September, pp. 18-19.

33. Keegan, Margie and Ntutu Mtwana (2004) Women Say "No" to Guns, Cape Town: Gender Advocacy Programme.

34. For detailed case study analyses of women's roles in war and reconstruction, see Turshen, Meredeth and Clotide Twagiramariya (1998) What Women Do in Wartime: Gender and Conflict in Africa, New York: Zed Books; Meintjes, Sheila, Anu Pillay and Meredeth Turshen (2001) The Aftermath: Women in Post-Conflict Transformation, New York: Zed Books.

35. Mathews, Shanaaz (2002) Making the Home a Safer Space: Assessing the Impact of the Domestic Violence Mural in Manenberg, Cape Town: Gender Advocacy Programme.

36. Enloe, Cynthia (1993) The Morning After: Sexual Politics at the End of the Cold War, Berkeley, CA: University of California Press.

37. Britton, note 3 above; Fish, Jennifer N. (2006) Domestic Democracy: At Home in South Africa, New York: Routledge.

38. Hillier and Wood, note 31 above.

39. Gun Control Alliance, note 19 above.

40. Mathews et al., note 26 above.

41. Based on interviews with NGO leaders, parliamentarians and domestic workers.

42. Vetten, note 32 above. See also Mathews, Shanaaz (2004) Building Peace in the Home, Cape Town: Gender Advocacy Programme; Gun Control Alliance, note 19 above.

43. Marchand, Marianne H. and Anne Sisson Runyan (2000) Gender and Global Restructuring: Sightings, Sites and Resistances, London and New York: Routledge; Sassen, Saskia (1998) Globalization and Its Discontents, New York: New Press.

44. Predominant migration patterns are from least developed nations to the so-called "first world". Sharp class divides, however, also construct internal migration patterns in countries like Brazil, Australia, Mexico and South Africa.

45. Chin, Christine (1998) In Service and Servitude: Foreign Female Domestic Workers and the Malaysian Modernity Project, New York: Columbia University Press; Romero, Mary (1993) Maid in the USA, New York: Routledge.

46. Farm labour has been identified as the largest documented sector of employment for women, but because household labour is considered private, official estimates suggest figures lower than actual employment rates. Furthermore, analysis of race in relation to women's work reveals that domestic labour remains the largest sector of employ- 
ment for black women. See Statistics South Africa (www.statssa.gov.za/) for specific labour representations by sector, sex and race.

47. Although "coloured" women assume positions as domestic workers, this distinction is regionally centred in Cape Town and the sector overall is composed predominantly of black women.

48. A common reference shared by interview research participants, 2001 and 2004 .

49. Fish, note 37 above.

50. Domestic worker interview participant, 2001.

51. Mohanty, Chandra, Ann Russo and Lourdes Torres (1991) Third World Women and the Politics of Feminism, Bloomington, IN: Indiana University Press.

52. Mathews et al., note 26 above.

53. Ibid.

54. Statistics South Africa (2000) "October Household Survey", Statistics South Africa, South African National Government, Pretoria.

55. Gun Control Alliance, note 19 above.

56. Anderlini, note 23 above.

57. Fish, note 37 above.

58. Vetten, Lisa (1996) "Man Shoots Wife: Intimate Femicide in Gauteng, South Africa", Crime and Conflict 6, pp. 1-4.

59. Mathews et al., note 26 above. 



\section{Part IV \\ Gender, weapons collection and small-arms control}





\title{
Just a matter of practicality: Mapping the role of women in weapons for development projects in Albania, Cambodia and Mali
}

\author{
Shukuko Koyama
}

This chapter discusses how women make unique contributions to weapons collection programmes. It draws its findings from research on such programmes in Albania, Cambodia and Mali conducted by the UN Institute for Disarmament Research (UNIDIR) between 2002 and 2004. The examples from weapons collection initiatives in the three countries show that women are not only victims or perpetrators, ${ }^{1}$ but also actors contributing to peacebuilding in conflict-affected societies, as feminist scholars and practitioners have increasingly recognized. ${ }^{2}$

Between 2002 and 2004 UNIDIR carried out in-depth field assessments of community-based small-arms disarmament programmes in Albania, Cambodia and Mali. The assessments employed a qualitative research approach known as participatory monitoring and evaluation $(\mathrm{PM} \& \mathrm{E})$. The research project's aim was to assess past and ongoing weapons collection programmes to determine the actual impact that weapons collection has had on local communities. UNIDIR conducted workshops with three social groups - youth, women and men - in each community. The workshops employed several PM\&E techniques (see Appendix 11.1) and discussions were aided by local facilitators. Unfortunately, the research was not initially designed for a systematic gender analysis of the disarmament projects. Workshop facilitators were not instructed to ask gender-focused questions unless participants spontaneously raised gender-related issues in their testimonials.

Using these limited sources, this chapter compiles comparative testimony on gender-related issues extracted from the overall research pro-

Sexed pistols: The gendered impacts of small arms and light weapons, Farr, Myrttinen and Schnabel (eds), United Nations University Press, 2009, ISBN 978-92-808-1175-9 
cess. Given the few records on gendered analysis in the previous research on small-arms disarmament efforts, UNIDIR's research findings are valuable and worth noting even though it was not the researchers' specific aim to gather information on the gendered impacts of the disarmament programmes. This chapter provides empirical examples of women's relevance to small-arms disarmament and shows that the involvement of women in this process is not a matter of political correctness: rather, it is a matter of practical effectiveness.

Small-arms disarmament takes several forms. For instance, small arms and light weapons possessed by armed forces are often integrated into the military aspects of peace process implementation, i.e. disarmament, demobilization and reintegration of ex-combatants (DDR). These processes are often carried out by armed forces from either the international community, such as UN peacekeepers (e.g. Guatemala, Mozambique), the multilateral and bilateral assistance agencies (e.g. Afghanistan) and/ or national governments (e.g. Angola). Weapons collection may also be carried out on a voluntary basis, which often takes place in the postDDR period (e.g. El Salvador). ${ }^{3}$ Among the voluntary approaches to weapons collection, so-called "weapons for development" (WfD) programmes are attracting increasing attention from donors and implementing agencies. ${ }^{4}$ The aim of these initiatives is to collect weapons from a community in exchange for development commodities and services that benefit the whole community. Incentives often include social infrastructure such as roads, bridges, schools and healthcare centres as well as wells, cereal banks and mills. Providing these incentives to the community, weapons for development programmes differ from other microdisarmament strategies such as "buy-backs", which provide incentives, often in the form of cash, to individual ex-combatants and civilians to hand over their weapons.

Involving communities has become a popular management style among international agencies. However, unlike in the fields of the environment and health and development, there is a lack of gender analysis of post-conflict disarmament. Women's capacities and usefulness in small-arms disarmament are not fully understood or examined, and their participation is therefore not institutionalized as one of the policy tools of the international assistance community, despite growing efforts to mainstream gender in disarmament and peacebuilding activities among the relevant agencies. ${ }^{5}$ As a result, there is still a long way to go before a gender-aware approach to micro-disarmament is developed and implemented. One has to understand from this that community-based disarmament does not automatically provide for, or even take into account, the whole community's needs. For example, social groups such as women, young adults and illiterates have different needs, roles and responsibil- 
ities in the community. Despite gender-mainstreaming policies aimed at the international community, gendered disarmament is a long way from becoming operational at the field level. In practice, as the OECD recognizes, gender issues are often misunderstood by policy-makers and implementing agencies, ${ }^{6}$ and are conceived as "solely concerning the number of women participants or the development of marginal side initiatives for women within mainstream programmes". ${ }^{7}$ It is time for implementing agencies to recognize and understand gender relations in the community and to develop them with more appropriate and effective programming. This chapter outlines some of the reasons why.

Evidence from the field shows that women have the potential to execute small-arms disarmament in a more comprehensive manner than is currently understood by "specialists" in practical disarmament. In the Central African Republic, for instance, women collected weapons informally, following the flight of mutineers. ${ }^{8}$ They then turned in the collected weapons to the UNDP voluntary weapons collection programmes in exchange for vocational training. ${ }^{9}$ Failure to recognize women's capacity can lead to poor project management and performance. As the UNIDIR WfD project records, women are not being empowered in such areas as disarmament; however, they are already powerful participants in peacebuilding. It is the international community that needs to be empowered to work with women. The international assistance community must therefore become well aware of women's actual capabilities and the gaps between needs and assistance, and start to equip assistance policies with tools to utilize women's capacities as much as possible.

\section{Tools matter: Distilling gendered findings by using participatory methods}

\section{Participatory monitoring and evaluation in disarmament research}

Participatory methods, long tested in these fields, have the potential to facilitate communication with and among the actual beneficiaries of disarmament projects. Recently, qualitative research has been conducted to study the impact of small arms and light weapons on security, mainly using participatory rural appraisal (PRA) techniques. ${ }^{10}$ Mine action organizations also use participatory research methods in their mine-awareness programmes. The Child-to-Child Trust, the UN Children's Fund (UNICEF) and the International Committee of the Red Cross (ICRC) are examples of other organizations that use these methods. ${ }^{11}$

UNIDIR has recognized that the existing "consultants-and-clipboards" evaluation approach has not fully involved the most salient stakeholders 
- women, children, the elders, youth and other local community members at the grassroots level. It therefore pioneered the PM\&E methodology in the micro-disarmament field by applying the methods to its WfD research. PM\&E techniques are integrated into an empirical project cycle, serving as alternative monitoring and evaluation tools. The techniques can be applied to assess the whole weapons collection project process, including overall goal setting, project design, preparatory appraisal, implementation, monitoring, and evaluation of effectiveness, relevancy and sustainability of the project. UNIDIR's WfD project, for instance, applied PM\&E techniques to assess all project cycle stages, ranging from project appraisal, design, implementation and monitoring to evaluation. By doing so, PM\&E is anticipated to "allow for the beneficiaries of programmes to make assessments of the effectiveness of existing projects". ${ }^{12}$ Needless to say, the current PM\&E tools in disarmament research are far from perfect. The tools must be refined and improved further, drawing upon existing experiences, failures and lessons learnt. Yet the tools are useful to gather more nuanced, gendered findings.

\section{Unexpected positive outcomes of the methods}

There were a few unexpected positive outcomes of the participatory workshops. Given the sensitive nature of the workshop theme, i.e. weapons, the UNIDIR team initially assumed that local community members would be afraid of the authorities and would not share critical opinions about the WfD projects. On the contrary, however, the community members turned out to be candid even in front of their local authorities. Moreover, such open sharing of views provided the first opportunity in Albania and Cambodia for direct discussion of the WfD projects between the authorities and local communities.

Participatory methods do not automatically guarantee that women's views are expressed. There were also challenges in implementing the workshops. In particular, it was difficult to get access to female participants. For example, in the rural village of Lere in Mali, only five women came to workshops because the UNIDIR team did not offer the necessary logistics to provide transport for the female villagers, some of whom lived as far as $20 \mathrm{~km}$ away from the community centre where the workshop took place. By contrast, male participants had their own means of transportation, such as motorbikes; thus, in the same community, the workshop had about 25 male participants.

The two most difficult social groups to get access to were young women and female ex-combatants. After school, young women and girls were often confined to their houses by their families, helping their parents or taking care of small children of their own. In some communities the local 
people did not want to mix young women and girls with young men and boys in the same workshop group. ${ }^{13}$ In some communities, particularly in rural areas, male community members did not want external people, especially male, to speak to the women. Thus it is crucial to staff the research team with both genders, in order to improve access to female community members.

Furthermore, the female combatants in Mali were excluded from all workshop groups. When the UNIDIR team asked a group of women to include female ex-combatants, the participants rejected the request by saying that they did not want to sit next to combatants. When the team turned to a group of men with the same request, it was again rejected, as the men, who were mostly ex-combatants, did not want women in their workshop. As a result, the UNIDIR team did not manage to involve female ex-combatants in their field research.

Considering women's participation, the issue of when to hold workshops cannot be overlooked. International organizations and community councils often organize formal meetings to discuss weapons collection projects during "office hours" - the worst possible time for women to participate. When the UNIDIR team conducted research in the field, women were often too occupied with their housework during daytime to participate in workshops at the time suggested by the research team. Only for an hour or two immediately after lunch and before preparation for dinner could they spare some time to attend a workshop. This was particularly the case for housewives in rural areas. Thus the UNIDIR research team adapted their research schedule to women's time commitments, rather than setting up meetings during "office hours".

\section{Overview of the research areas}

Seven hundred thousand weapons were said to have been looted in Albania during the political turmoil in 1997. Huge numbers of weapons circulated in society. But what sort of gun incidents did people in Albania actually experience? When the UNIDIR team visited Albania in 2003, six years after the chaos, people still remembered those days vividly, although they felt that "those incidents sound very odd now, as if all this happened in a bad dream". ${ }^{14}$ Individual testimonies showed how the looted weapons had threatened their very lives.

During 1997 Albania went into a panic after the collapse of a pyramid investment scheme. The economy collapsed, the government stopped functioning and law enforcement was non-existent. People felt insecure and began to arm themselves with looted weapons to defend themselves. Some women told us that they also bought arms in a market and kept 
them to protect themselves and their families. ${ }^{15}$ Reflecting on those days, a middle-aged male participant noted, "There was no enemy that we had to fight. But we armed ourselves for our security." 16

In the 1980s the northern regions of Mali in particular experienced severe drought, causing large-scale population displacements, especially among the nomadic Tuareg population. The social and economic deprivation of the north was followed by civil strife, as people in the north felt that their problems were caused by the centralization of governance. Armed cattle rustling became much more ubiquitous. In a region where hunger had become chronic, "guns became people's means for livelihood". ${ }^{17}$ People started to resort to weapons to settle disputes by force. Women told the UNIDIR team that, as a result of fear, they suffered health problems such as miscarriages.

In contrast to Albania and Mali, Cambodian society experienced a large-scale violent conflict in two decades of war throughout the 1970s and 1980s. After about a decade of relative peace, the Cambodian people still have to overcome suffering caused by hidden ammunition and uncleared landmines. They must also rebuild their livelihoods after returning from where they had been displaced. Unlike the women in Albania and Mali, especially those Cambodian women from areas controlled by the Khmer Rouge directly experienced war. They carried weapons and ammunition to their men, who were fighting at the front lines. While women in Albania and Mali did not possess technical knowledge of weapons, in Cambodia it was women rather than men who were better educated in the types of weapons collected.

In all case study countries, lethality among men rose during the time of arms proliferation. Young men were especially prone to becoming victims of firearms, because street fights involved firearms. Women and young girls and boys at the UNIDIR workshops also reported that some male family members became more coercive when they were armed. ${ }^{18}$

It was not only direct physical damage that was caused by available weapons in Albania, Cambodia and Mali. Proliferating arms imposed serious social constraints, especially on women and girls. Their freedom of movement was curtailed and their sense of fear accumulated, causing enormous stress. Girls became more confined to home than any other social group in the community. In a rural village in Albania, for example, a school was the only place for most of the girls to socialize and "have fun", according to a 12-year-old schoolgirl we interviewed. But their parents did not allow them to go outside because they feared their daughters would be kidnapped by traffickers and/or raped at gunpoint on their way to school.

Moreover, arms proliferation was detrimental to community development. Especially in rural areas, the limitation of women's mobility af- 
fected community development. In these communities, women are usually "water collectors" and a major workforce in agricultural activities. Before weapons collection started, women in the rural villages could not go out to collect water or work in farming and cattle rearing. Fearing being shot, they had to stay home and could not work, which led to food shortages in the community. Women also lost access to health and education services due to the rampant violence outside their homes. To give an example, in Gramsh, Albania, a young woman in her last month of pregnancy was shot and killed by accident on her way to a hospital. This scared other women so much that they were afraid to go out on the street. As a result, livelihoods deteriorated further in communities that already suffered from poverty and violent conflict.

\section{Weapons for development projects in Albania, Cambodia and Mali}

General components of a weapons for development project

A "weapons for development" project usually consists of the following stages: a public awareness campaign; identification of incentives for disarmament through community meetings; weapons collection, storage and destruction; and the provision of development projects. These stages are not necessarily sequential, depending on how implementing agencies design projects.

\section{Albania}

In 1997 the first weapons for development programme was implemented in Albania (Table 11.1). Financed by several EU countries, the United Nations and the UNDP, together with the Albanian government, carried out the Gramsh Pilot Project (GPP). This pilot was succeeded by the Weapons in Exchange for Development (WED) programme, which was implemented in Gramsh, Elbasan and Diber between 2000 and 2002. Between 2002 and 2004 the UNDP launched the Small Arms and Light Weapons Control (SALWC) project in Tirana, Kukes, Shkodra, Lezna and Vhlora. Under that scheme, communities collected weapons and incentives were given to those communities which collected the largest amount of arms.

\section{Public awareness-raising}

After the looting of government stockpiles, it was the women who started to take action to end the violent turmoil within communities. Staying at 
Table 11.1 Roles of women and men in weapons for development projects in Albania

\begin{tabular}{|c|c|c|}
\hline & Women & Men \\
\hline $\begin{array}{l}\text { Public awareness } \\
\text { campaign }\end{array}$ & $\begin{array}{l}\text { Persuaded family } \\
\text { members to hand } \\
\text { over weapons }\end{array}$ & $\begin{array}{l}\text { Information exchange } \\
\text { on arms law and } \\
\text { WfD projects with } \\
\text { neighbours }\end{array}$ \\
\hline $\begin{array}{l}\text { Identifying incentives } \\
\text { through community } \\
\text { meetings }\end{array}$ & Not included & $\begin{array}{l}\text { Attended community } \\
\text { meetings }\end{array}$ \\
\hline Weapons collection & $\begin{array}{l}\text { Brought weapons to } \\
\text { police }\end{array}$ & $\begin{array}{l}\text { Brought weapons to } \\
\text { police }\end{array}$ \\
\hline Weapons storage & (Local authorities) & (Local authorities) \\
\hline Weapons destruction & $\begin{array}{l}\text { Few attended "Flame } \\
\text { of Peace" events }\end{array}$ & $\begin{array}{l}\text { Participated in "Flame } \\
\text { of Peace" events }\end{array}$ \\
\hline $\begin{array}{l}\text { Provision of } \\
\text { development projects }\end{array}$ & (Contractors) & (Contractors) \\
\hline
\end{tabular}

home and witnessing incidents involving weapons before official weapons collection activities began, women became a strong force in alerting society to the danger of weapons, and consequently in mobilizing community members to hand them over. With few job opportunities at home, many men of working age from both rural and urban communities resided abroad as migrant workers. Being responsible for family issues - including safety - during their husbands' absence, women, especially mothers, have become sensitive about weapons kept at home. Before the start of disarmament activities, they witnessed increasing incidents of violence in their neighbourhoods and own houses. A housewife in Gramsh said: "I was more afraid of keeping weapons at home than someone with weapons breaking in the house and attacking me." ${ }^{19}$ Mothers had seen their children playing with guns hidden by their male family members at home. They had heard of neighbours' children shooting their mothers by accident. A housewife from the same community in Gramsh explained why they started to give up their weapons:

We [housewives in the village] handed in weapons of our own will. We had heard news [about trouble] involving guns in the neighbourhood. We wanted to bring an end to these incidents. ${ }^{20}$

Women were recognized for their role as mobilizers for disarmament and peacebuilding by the entire community, including youth, men, elders and community chiefs. Men, youth and women stated that women contributed greatly to raising sensitivity about the need for weapons collection. A middle-aged male, a village head, told us that in his community: 
Women took very responsible roles because of their children. Fathers were away abroad, so they felt responsible for their children. Sensitization [of the danger of weapons and to hand over weapons] was done by teachers and mothers. $^{21}$

High-school students in a border village in Albania stated that their mothers were very sensitive to weapons issues and most active in sensitization; their fathers were not active, being scared of Serbians coming across the border from the former Yugoslavia to attack the community. In the same community, men acknowledged women's role in sensitization, since "they talked to us about the problem of having weapons at home". 22

The toughest obstacle for women was to make men listen to them. A housewife from a rural village told us that she regarded the weapons collection project as a success because "Men started listening to women. For the first time, women were listened to." ${ }^{33}$ Thus women showed their strong capability to influence social attitudes towards weapons. Their role in the sensitization greatly contributed to developing momentum for subsequent weapons collection initiatives.

\section{Identifying incentives through community meetings}

The identification and design of community-based development projects were carried out by the UNDP and local authorities. Development projects included the rehabilitation of roads, water-supply systems, a cultural centre and the provision of bridges and electricity lines. Through a number of community meetings, the UNDP tried to consult as widely as possible in order to identify development projects that would meet the entire community's needs.

Despite the efforts of the UNDP, however, the consultation did not reach women. In a village bordering with Montenegro in Shkodra, for example, all female participants in our interviews did not know that a development project in exchange for weapons collection had taken place in their village. They said they had not been informed about such a project by either their male family members or a development agency. As a housewife in Gramsh said, "We did not know about the project. If the village chief made a decision on the project, he certainly did not ask us." ${ }^{24}$ It seems that in Albania, meetings, especially with external agencies such as the UN organizations, are regarded as "official", and "official" events are intended for men only. This perception of the nature of "meetings" repeatedly appeared during workshop discussions in testimonials by all social group members. This shows that a community meeting might exclude women automatically, unless a meeting organizer takes particular action to involve women. ${ }^{25}$ 
Not only in the official setting but also at the household level, women could not participate in decision-making regarding these projects. Although men and women discussed the projects at home, it was men, including teachers and village leaders, who actually made decisions. As an elderly male participant in Shkodra noted, "Women were good at convincing us to hand over weapons. But they did not take part in making decisions about projects." ${ }^{26}$ According to male participants, it was men who were in charge of making final decisions at home, and only when a husband was absent did his wife or mother make decisions on his behalf.

\section{Weapons collection}

The GPP collected 5,981 weapons. ${ }^{27}$ Of those, 2,931 weapons were collected prior to the project's start in anticipation of the project. The WED project collected 23,079 weapons. ${ }^{28}$ The SALWC project collected 6,453 weapons in exchange for development initiatives in the project areas. ${ }^{29}$

The majority of those who brought weapons to collection points were men. However, some women also collected weapons from where their male family members and sometimes they themselves had hidden them, and brought them to collection points. Direct participation in weapons collection seemed to send a strong message to local community members - especially women - that the weapons-dominant society would soon be overcome. In a village in Shkodra, women vividly remembered the day of weapons collection. A housewife in the village said: "It was such a good day. We walked to the school with weapons [to hand over]. We felt happy and victorious." 30

\section{Weapons storage and destruction}

In the case of Albania, the collected weapons were stored in police facilities and the military was in charge of weapons destruction. However, as some researchers found out, ${ }^{31}$ there was no independent monitoring of the police's weapons collection activities and the military's destruction activities.

At the UNIDIR workshops, the participants confirmed the lack of third-party monitoring and verification during the weapons storage and destruction period. None of the women and men who participated in the workshops could tell what exactly happened to the weapons after collection. Reflecting the lack of local community participation in weapons storage and destruction, none of the workshop groups (except the men's group in Elbasan) rated this stage of the project as "good" in the threestar game exercise (see Appendix 11.1).

\section{Provision of development projects}

According to the workshop participants, none of the companies employed labourers from the local communities. In Albania neither men 
nor women were involved in the implementation of development projects. Unlike in Cambodia, where local community members were paid in return for their physical labour as construction workers on incentive projects, the provision of development projects did not become an incomegenerating opportunity for local community members. Instead, private companies contracted by the UNDP carried out the construction of development projects.

When a community started a weapons collection initiative, and before weapons for development projects arrived in the community, the community members, both women and men, did not relate weapons collection to the provision of development assistance. To educate them, the UNDP paid for TV commercials and programmes about the Albanian government's Amnesty Law in order to encourage citizens to hand over weapons. However, the awareness campaign on weapons for development projects seems not to have reached such extensive audiences as previous public awareness campaigns. Gramsh is the first community where pilot WfD projects took place in Albania. Here a development project was a reward for getting rid of weapons, and people emphasized that the collection of weapons itself was the goal, not a means to obtain development projects. Most of the participants in Gramsh regarded the projects as a success "because people handed in weapons". ${ }^{32}$

As weapons for development projects spread to other regions, however, things began to change. After the initial stage of the projects passed, women were rarely invited to community meetings to discuss the projects and, according to female participants, had little communication with their community chiefs. A project assessment by the UN Development Fund for Women (UNIFEM) concurs with their observations. According to UNIFEM, the UNDP office did not consider targeting women as a priority. ${ }^{33}$ Yet the UNIFEM assessment reports that women's active involvement in further awareness-raising about weapons collections has not improved. ${ }^{34}$

The exclusion of women in the process of the WfD projects seemed to send a wrong message about weapons collection to communities and affect project performance negatively. The development projects became the purpose of collecting weapons. Not always, but quite often, a WfD project became a bargaining chip. A housewife articulated this shift in her testimonial:

If we get something in return, we will hand over weapons. We will go and buy weapons from a black market, and then hand in the weapons to get incentives. ${ }^{35}$

A middle-aged woman told us that the villagers were keen on giving up weapons in exchange for roads, a healthcare centre and a kindergarten. 
Then an older woman cut in and said: "We don't want guns at all anyway. We are tired of them." 36

After attending awareness-raising meetings and communicating with community chiefs over weapons for development projects, men became more aware of the link between weapons collection and the provision of development projects. By contrast, it seems that the momentum in disarmament work to achieve peace and development, gathered at the initial stage, is now lost among most of the female participants.

\section{Cambodia}

Since 2000, the European Union's Assistance on Curbing Small Arms and Light Weapons in Cambodia (EU-ASAC) has carried out weapons collection projects as part of its overall security-building assistance in Cambodia. While EU-ASAC has implemented projects in central and southern Cambodia, the Japan Assistance Team for Small Arms Management in Cambodia (JSAC) started its own weapons collection projects in northern Cambodia in 2003. Both the programmes have shifted an emphasis from weapons collection activities themselves (Table 11.2) to more holistic approaches, such as institutional reform and capacity-building of law enforcement bodies (in particular the police) in the case of EU-ASAC and peacebuilding and development in the case of the JSAC.

Table 11.2 Roles of women and men in weapons for development projects in Cambodia

\begin{tabular}{|c|c|c|}
\hline & Women & Men \\
\hline $\begin{array}{l}\text { Public awareness } \\
\text { campaign }\end{array}$ & $\begin{array}{l}\text { Sensitized family and } \\
\text { community members }\end{array}$ & $\begin{array}{l}\text { Reported to authorities } \\
\text { those who were in } \\
\text { possession of } \\
\text { weapons }\end{array}$ \\
\hline $\begin{array}{l}\text { Identifying incentives } \\
\text { through community } \\
\text { meetings }\end{array}$ & $\begin{array}{l}\text { Widows attended } \\
\text { community meetings }\end{array}$ & $\begin{array}{l}\text { Attended community } \\
\text { meetings }\end{array}$ \\
\hline Weapons collection & $\begin{array}{l}\text { Provided food and cash } \\
\text { to support weapons } \\
\text { search groups }\end{array}$ & $\begin{array}{l}\text { Formed weapons search } \\
\text { groups, searched for } \\
\text { weapons in jungles }\end{array}$ \\
\hline Weapons storage & (Local authorities) & (Local authorities) \\
\hline Weapons destruction & $\begin{array}{l}\text { Participated in "Flame } \\
\text { of Peace" events }\end{array}$ & $\begin{array}{l}\text { Participated in "Flame } \\
\text { of Peace" events }\end{array}$ \\
\hline $\begin{array}{l}\text { Provision of } \\
\text { development } \\
\text { projects }\end{array}$ & $\begin{array}{l}\text { Provided labour forces } \\
\text { to construct schools } \\
\text { and water pumps }\end{array}$ & $\begin{array}{l}\text { Provided labour forces } \\
\text { to construct schools } \\
\text { and water pumps }\end{array}$ \\
\hline
\end{tabular}




\section{Public awareness-raising}

It was difficult for the people to feel confident about the peace process and decide to hand over their weapons to the authorities. In order to overcome the constraints, together with local authorities and NGOs EUASAC repeatedly organized workshops in communities to encourage voluntary weapons handover. The workshops were not only meant for village chiefs. Community chiefs mobilized the villagers to participate in the meetings, and both male and female groups told the UNIDIR research team that there was wide community participation. Young mothers, however, could not attend the meetings as, in their opinion, their children were too small to attend community discussions.

\section{Identifying incentives through community meetings}

Both women and men said that decisions over the selection of development projects were made by consensus, and the final decision was made by community leaders. In the communities visited by the UNIDIR team, both groups typically preferred incentives such as the provision of a medical centre, schools, wells, roads and toilets.

When we questioned them more precisely, women claimed that they would have preferred the supply of medicine to the construction of a healthcare centre, because they could not afford to pay for medical services at the centre. The provision of a school was highly valued by men and women in a rural village. A women's group in a rural village was particularly grateful for an adult literacy programme, which took place at the school. Almost all the adults could not write or read, since they were deprived of opportunities to go to school due to the chronic violent conflict during the 1970s and 1980s. While women in the village appreciated that their children could go to school, they also valued the adult literacy programmes that helped them to achieve a better position in society.

\section{Weapons collection}

In addition to weapons possessed by households, large numbers of weapons were hidden in jungles by former warring parties. To find and collect them, the communities decided to organize groups of village men to go to the jungle and look for weapons. Participation in such groups was voluntary, and little allowance was provided for those who did the work, so material incentives to join the groups were low. Women took on the task of persuading their male family members to participate in weapons collections. They not only persuaded their husbands and brothers to join in, but while their male family members engaged in weapons collection, women also provided food for them during the weapons search. 
Weapons storage and destruction

Men and women have different impressions of the degree of community participation in weapons destruction ceremonies. According to men in a border village, for example, many villagers including men, women and local authorities participated in the event and could see that the weapons were actually destroyed. On the other hand, women in the same village reported that the destruction ceremony was for high-ranking people such as local authorities and community chiefs, and not many villagers participated.

The reason for these contradicting observations is twofold. First, the weapons destruction event took place not in the village but in a town centre, which takes at least one hour by motorbike from their village. Most of the women, as well as some men, could not afford the time and money to reach the town centre. ${ }^{37}$ Second, the female participants told us that the public event was official, so women, especially young mothers, felt they should not attend. They explained that they had been afraid that their small children would make a noise during the ceremony and disturb the event. Given that most of the women in the village were carers of small children, this means that few women were available for the public event.

\section{Provision of development projects}

Women contributed to infrastructure construction by providing caregiving work in the household while their husbands were working at construction sites. Some women also participated in the construction work. However, their labour contribution is not valued as much as that of men, as reported by both male and female community members at the UNIDIR assessment workshops. While men were paid for their construction work, women did not receive a salary for their labour. According to the male participants, this was because men engaged in tougher jobs, i.e. major construction works, than women, who were doing "small works" such as carrying cement. Both male and female participants pointed out that the fee was too small for the workload.

Besides the monetary benefits, the male participants acknowledged that through the construction work they obtained skills which could be used for future construction and maintenance of infrastructure in their communities. This was an unintended benefit of the development projects, giving male villagers a chance to obtain new vocational training. By contrast, women did not benefit in such a way.

\section{Mali}

Although not reported on as much as Albania and Cambodia, Mali has also seen weapons for development initiatives. Coopération Technique 
Table 11.3 Roles of women and men in weapons for development projects in Mali

\begin{tabular}{|c|c|c|}
\hline & Women & Men \\
\hline $\begin{array}{l}\text { Public awareness } \\
\text { campaign }\end{array}$ & $\begin{array}{l}\text { Persuaded community and } \\
\text { family members to } \\
\text { surrender weapons }\end{array}$ & $\begin{array}{l}\text { Exchanged information } \\
\text { on arms law and } \\
\text { WfD projects with } \\
\text { neighbours }\end{array}$ \\
\hline $\begin{array}{l}\text { Identifying incentives } \\
\text { through community } \\
\text { meetings }\end{array}$ & $\begin{array}{l}\text { Discussed incentives with } \\
\text { male family members at } \\
\text { household level }\end{array}$ & $\begin{array}{l}\text { Attended community } \\
\text { meetings }\end{array}$ \\
\hline Weapons collection & $\begin{array}{l}\text { Some said to have brought } \\
\text { weapons to collection sites }\end{array}$ & $\begin{array}{l}\text { Brought weapons to } \\
\text { collection sites }\end{array}$ \\
\hline Weapons storage & Did not participate & $\begin{array}{l}\text { Monitored if weapons } \\
\text { were safely stored }\end{array}$ \\
\hline Weapons destruction & $\begin{array}{l}\text { Attended destruction events } \\
\text { (Lere) }\end{array}$ & $\begin{array}{l}\text { Attended destruction } \\
\text { events (Lere) }\end{array}$ \\
\hline $\begin{array}{l}\text { Provision of } \\
\text { development } \\
\text { projects }\end{array}$ & (Contractors) & (Contractors) \\
\hline
\end{tabular}

Belge (CTB) has implemented weapons for development projects in the Timbuktu region, providing television antennas, water pumps and other social infrastructure. The town of Gao has experienced two different types of weapons collection: collection targeted at ex-combatants as part of a DDR process, and a more community-based weapons collection. The collection initially took place under the guidance of the UNDP, and was then taken over by CAR-Nord (Consolidation des Acquis de la Réinsertion des ex-combattants), which now leads the community-based weapons collection programme (Table 11.3).

\section{Public awareness-raising}

In Mali, women were actively involved in the peace process as peacemakers at the grassroots level and played a prominent role in creating momentum in society to hand over weapons. In the early 1990s a peace process was initiated by the Malian government and civil society. Numerous community meetings took place to discuss local leaders' initiatives. Several women's associations were created by prominent female figures in communities. These NGOs sensitized communities on disarmament and peace through radio and by facilitating inter-communal meetings to discuss reconciliation. They also visited cantonment areas and persuaded demobilized soldiers not to return to fighting. At the household level, women as sisters, wives, mothers and grandmothers talked their male family members into giving up their weapons. A woman elder told us that she had threatened her grandsons by telling them that she would go 
naked in public unless they handed over their weapons. In Mali, women are respected for their "motherhood-ness" and are a symbol of peace. This threat of self-stigmatization by the elder woman thus sent a powerful message to her male family members. Through tenacious persuasion at home, women made their male relatives accept the peace process as a better alternative to war.

\section{Identifying incentives through community meetings}

Weapons for development projects identified incentives through meetings with local commissions on disarmament. Commission members were selected from among local community members. The majority of the committees were composed of men, often prominent figures in the communities. Women told us that they trusted their village chiefs and believed their opinions were being taken into account regarding the selection of projects. But they did not actually know whether their requests were presented at official meetings, since they did not participate in them.

\section{Weapons collection}

Weapons collection in Mali was mostly done by men. However, community members told the UNIDIR team a few anecdotes about women bringing weapons hidden by their male family members to collection sites, which were often at the residences of community chiefs and local commission members.

\section{Weapons storage and destruction}

The momentum of the process was marked by a symbolic weapons destruction event: "Flamme de la Paix (Flame of Peace)" in Timbuktu, 1994. Women we interviewed in Gao, however, complained that it was too far and too expensive for them to travel to Timbuktu, about $400 \mathrm{~km}$ away from Gao, to participate in the event. They complained that they missed an opportunity to feel they had actually contributed to disarming communities and bringing peace to society. In contrast, men and women of a rural village, Lere, expressed their satisfaction in their own Flamme de la Paix event. The event was organized by local commission members in the village, so that the villagers, both men and women, could participate and see for themselves that the collected weapons were destroyed.

\section{Provision of development projects}

Neither men nor women directly participated in constructing development infrastructure. Men in rural communities, however, believed that some development projects contributed to women's further involvement in awareness-raising activities. For example, according to them, the provision of grinding mills freed their women's time to visit their neighbours 
and persuade them to give up their weapons. This view was confirmed by the female participants at the workshop. Women, by contrast, acknowledged the community leaders' role in the provision of development projects, but not the role of men.

\section{How do weapons for development projects affect men and women differently?}

\section{They have different goals}

A weapons collection programme typically involves the provision of micro-scale incentives such as animals, dikes for irrigation, bridges, roads, schools and boreholes. Men and women chose differently when offered this range of incentives in exchange for disarmament. When asked what development projects should be adopted, men tended to choose social infrastructure such as roads and bridges as appropriate incentives. They stated that such projects should aim to enhance commerce and economics at the regional level, and thereby improve people's standard of living. Men defined successful weapons collection as reducing the number of weapons in circulation. When asked how to evaluate the success of weapons collection projects, men focused on such material factors as the number of weapons collected and destroyed, and a reduction in gun-related crime and injuries.

By contrast, women prioritized development projects with more direct and immediate impacts on their daily lives. The starkest contrast between men and women regarding their needs is that while men tend to want the physical provision of social infrastructure, women were more interested in the actual services that were supposed to be provided after the construction of such infrastructure: for example, the building of a clinic was not as important to them as the subsequent provision of affordable healthcare. Women emphasized that the ultimate purpose of collecting weapons is peacebuilding in the community; they stressed the need to address the root causes of violent conflict such as poverty. They expressed the aim of weapons collection as being the promotion of reconciliation among the various ethnic factions in the community, so that the free movement of people could resume. Moreover, they attributed men's urge to hold weapons to a lack of opportunities, and thus emphasized the importance of job creation, especially for young men, as a means of peacebuilding. In comparison with men's preferences for development projects, women appreciated smaller-scale development assistance with less immediately tangible results, such as provision of a television antenna and education programmes. 


\section{Do women feel safer after weapons collection?}

It became clear that women and men have different perceptions on security after weapons collection. During the workshops, men attributed their reasons for possessing weapons to their sense of physical insecurity, i.e. intimidation by armed governmental officials, robbers and enemies. Men explained that they wanted to hand over weapons because they wanted to reduce "useless killings and injuries, to avoid their children following their experiences of suffering such as being conscripted to fight". ${ }^{38}$ To men, security threats are external. Men handed over their weapons when they felt secure and confident enough in the government. In other words, men started feeling secure even before weapons collection began.

By contrast, women seem to perceive their family and neighbours as sources of insecurity. Women also report that insecurity still persists at local and domestic levels after weapons collection took place. Before weapons collection, keeping guns at home was a hazard to their family members, especially children. Human rights and health NGO workers in Albania, Cambodia and Mali told the research team that drunken husbands often use guns to intimidate their wives and children. Even after most of the guns were collected, gendered and sexual violence such as rapes and domestic violence still persists, although fewer guns are used. ${ }^{39}$

In a rural village in Cambodia there are no police stations, and this worries women. A women's group in the village mentioned the lack of police patrols as problematic. Water wells, bridges and roads projects put forward by men were provided in the community. However, in none of the projects was infrastructure such as police stations, patrols and streetlights provided or at least considered in the planning stage. Weapons collection does not necessarily improve subjective perceptions of security among women.

\section{Community participation does not guarantee women's participation}

In making the project process "bottom-up" or "participatory", participants were invited from the community, including village committee members, community chiefs, elders and some men. They discussed which type of development projects should be provided. In all cases, however, women's contributions were inadequately recognized. Once formal weapons collection projects had started, the profile of women declined further, and their representation in community meetings was correspondingly lessened. The reason for the decline in their participation varies. Women were either not invited or unable to attend official meetings to discuss the projects. They were also often simply not informed well enough of the projects by their husbands, although a growing number of implement- 
ing agencies invited local beneficiaries to meetings to discuss current weapons collection projects.

Many weapons collection programmes are said to be taking a participatory approach, inviting women to community meetings. However, in most cases women are included only in the sense that they are perceived as victims and given an awareness-building lecture on the dangers of weapons. Ironically, they are the ones who are most familiar with the actual risks of having weapons. When women did turn up to community meetings, they were mostly widows, single women or wives whose husbands were out of the country. Young women with small children did not attend meetings at all, because they were afraid that their children would be too noisy in such "formal and official meetings". ${ }^{40}$ In other words, when women participated they did so on behalf of their husbands and/or brothers, not representing themselves. The meeting space was not friendly to them or able to address their needs. As a result, after a project started women became confined to the "domestic", "private" space in society again, and gained little in terms of entry to community decisionmaking on security.

Absence of women's participation affects decision-making over which projects are to be provided in exchange for weapons. In Cambodia, for example, women would have preferred small paths going through their neighbourhood rather than roads reaching their village from a regional capital. This is because women use these paths to collect water and daily commodities on foot. However, such paths have not been paved yet because the paving is on the priority agenda at the community level. In Gramsh, Albania, after community consultation, protection walls against corrosion were provided in exchange for the weapons collected. However, a 13-year-old girl said: "I want more electricity. When I do homework at home in the afternoon, the light goes off. So I cannot prepare well for the next day." ${ }^{41}$ A park was built near Gramsh town centre, too, but it was not used much by the girls: "Our parents tell us not to go there, because it is too far and too dangerous to go." 42 The park is one hour away on foot from the village, too far for girls and small boys to visit after school.

Community consultation quite often does not reach women at all - village women in Shkodra did not know a road was constructed in exchange for collected weapons. Overall, in Albania, Cambodia and Mali the consultation process itself, and the development projects implemented, favour men and give them clear priority over both processes and projects that should include and benefit women.

Field interviews show there is a danger in sending the wrong message if a sensitization programme does not reach the right audience. Making a weapons collection project inclusive and participatory is not a matter of 
political correctness, but is crucial in order to prevent the project from becoming a bargaining tool for the communities instead of an incentive to disarm. The choice of development projects must be carefully negotiated and well explained; otherwise it is possible to misinterpret the provision of projects as means by which community élites can maintain the status quo by gaining rewards but not giving up weapons. The concept behind weapons for development projects is to provide community development by transforming a weapons-prolific society into a less-militarized one. Public awareness campaigns must speak to the whole community, including women, in order for the projects to convey the correct message. Otherwise, a weapons collection programme can become counterproductive, adding value to weapons instead of reducing it.

\section{Unrecognized contributions of women}

As mentioned earlier, in Cambodia men formed a group to search for weapons hidden in the jungle. The village men also provided labour during the construction of such development projects as schools and wells. Having been involved in actual weapons collection activities, men seemed to project designers to be better at taking part in technical issues of weapons collection, such as the timing and location of collections, and identifying trustworthy government actors for surrendering such weapons. They also undertook the physical collection and surrender of these weapons to the authorities. What is invisible is that domestic duties as well as childcare are undertaken by women while men are outside, engaging in weapons collection and construction work. This work was not mentioned by men's and youth's groups, and often even overlooked by women's groups.

The scant recognition of their contributions and potential abilities creates frustration among women. In Cambodia, for example, rurally based women were eager to acknowledge women's peacebuilding capacities, such as mediating and resolving conflict in their households and communities. When community members have arguments at home, women are encouraged to talk among themselves. In cases of rape, they would encourage a victim to talk to other women to relieve herself of the burden. They argued for the need to include women in weapons collection, because they believe they can trigger changes within the community. They felt that there is a need to increase women's participation in designing and planning projects on domestic violence, so that other women could provide victim consolation and consultation. In the Cambodian community, women are currently organizing "problem-solving groups" to discuss domestic violence, rapes etc. However, there is no external assistance to support these activities so far. 


\section{Involving women beyond their role as mothers}

One way to make sure of women's substantive (not only symbolic) participation would be to incorporate participatory techniques into weapons collection programmes. The participatory approach is useful because it can directly access actual beneficiaries' assessment of weapons collection projects; it is able to prevent prominent figures in a community from speaking on behalf of other community members, while at the same time maintaining their dignity; and it enables researchers to undertake assessment of overall impacts of disarmament interventions on a community holistically, measuring the social impacts of weapons collection. Thus inviting local "representatives" to a meeting is not enough to sustain women's relevance to weapons collection projects. It is better to involve women directly in such a meeting, incorporating their views as they express them rather than having someone else "represent" their views. Implementing agencies need to pay particular attention to ensuring that women participate in such meetings by themselves, and also take part in decision-making.

"Women" does not refer to a homogeneous social group. It is not enough to treat women as a single analytical unit. When women are involved, it is important to pay attention to differences between and among them. In communities as well as among implementing agencies, women are often simply identified as mothers. Focusing only on their motherhood can, however, fail to attend to women's needs.

This was exactly the case in Mali. Women are generally narrowly defined as wives and mothers. However, if they are unmarried, or generally do not fit in the social strata, they might be excluded from consideration, even by fellow women. An illustrative example is the case of female excombatants. During its field research, the UNIDIR team came upon a few female ex-combatants in communities in Mali. When the research team asked to involve them in an ex-combatants' discussion group, the male members of the group refused, because "they were women". ${ }^{43}$ Likewise, when women were asked to integrate the female ex-combatants into their discussion group, they too declined, because "Those women were fighters, not civilians." 44

\section{Conclusions}

Involving both men and women in design, implementation, monitoring and evaluation during a project cycle is key for the achievement of effective projects. In particular, women should directly participate in decisionmaking throughout a project process. Integrating PM\&E techniques into 
a project cycle can be an effective way to encourage and promote women's participation in decision-making about weapons collection and other small-arms disarmament projects.

In a post-conflict society where not enough social resources are available, it is a waste not to involve women as active participants. As discussed in the chapter, women have various roles in weapons collection. While a gender-aware approach is still not recognized in micro-disarmament practice, in light of the different impacts on weapons collection of women's and men's different roles and access to power in a community, failing to recognize difference can lead to poor programme management and performance. As discussed above, women's role as mobilizers is well recognized by communities. However, less well recognized is the fact that women also contribute to weapons collection and social infrastructure construction. The international assistance community needs to grasp women's actual capacity and potential in the implementation of weapons collection projects. In order to make micro-disarmament more effective, it is crucial to devise policies that utilize this capacity and potential as much as possible. In this sense, gendered programming of weapons collection is not a matter of political correctness, but a matter of practicality.

\section{Appendix 11.1: Methodology}

$\mathrm{PM} \& \mathrm{E}$ involves interactive discussion and visual aids such as flow-charts and pictures. PM\&E workshops can be held both indoors and outdoors. Any community member, literate or illiterate, rich or poor, man or woman, can participate. Unlike conventional research, there are no standardized questionnaires or surveys to fill in, and community members can arrange time for a workshop more flexibly according to their own daily schedules (Table 11.4).

\section{$P M \& E$ tools used by the UNIDIR research team}

Prior to the field research, the UNIDIR research team spent three months refining existing PM\&E techniques to be appropriate for evaluating weapons collection projects. The programme manager extensively consulted materials by the World Bank, which has applied the techniques to evaluate development projects. ${ }^{45}$

The UNIDIR team used five PM\&E techniques during the field research. Firstly, in order to review how the local community members regarded overall goals of weapons collection, the UNIDIR team used a technique called "force-field analysis". Using the technique, facilitators for a workshop asked which changes took place before and which after 
WFD PROJECTS IN ALBANIA, CAMBODIA AND MALI 351

Table 11.4 Differences between conventional monitoring and evaluation and $\mathrm{PM} \& \mathrm{E}$

\begin{tabular}{|c|c|c|}
\hline & $\begin{array}{l}\text { Conventional monitoring and } \\
\text { evaluation }\end{array}$ & $\begin{array}{l}\text { Participatory monitoring and } \\
\text { evaluation (PM\&E) }\end{array}$ \\
\hline Who & External experts & $\begin{array}{l}\text { Stakeholders include community } \\
\text { members and project staff, as well } \\
\text { as outside facilitators }\end{array}$ \\
\hline What & $\begin{array}{l}\text { Predetermined indicators } \\
\text { to measure inputs and } \\
\text { outputs of a project }\end{array}$ & $\begin{array}{l}\text { Indicators identified by stakeholders } \\
\text { to measure a project process as } \\
\text { well as outputs and/or outcomes }\end{array}$ \\
\hline How & $\begin{array}{l}\text { Using structured research } \\
\text { techniques such as } \\
\text { questionnaires and surveys }\end{array}$ & $\begin{array}{l}\text { Using qualitative and quantitative } \\
\text { research methods, partly created } \\
\text { by stakeholders themselves }\end{array}$ \\
\hline Why & $\begin{array}{l}\text { To make projects and staff } \\
\text { accountable to donor } \\
\text { agencies }\end{array}$ & $\begin{array}{l}\text { To assess actual impacts on } \\
\text { stakeholders and empower } \\
\text { stakeholders to take action }\end{array}$ \\
\hline
\end{tabular}

the implementation of a weapons collection programme. Two contrasting pictures of "before" and "now" situations were presented to the participants. Participants identified steps and resources needed to move from the "before" to the "now" situation.

After comparing the previous and current situations, the participants were then asked to discuss how decisions were made during a weapons collection process. This technique enabled participants to understand and evaluate the decision-making process in a community's weapons collection project. To identify who made actual decisions, participants were given small cards that represented different actors in the community, i.e. community leaders, external agents and community members (men, women, youth and elders), and were asked to compare these actors to one another and discuss who did and did not take initiatives in the weapons collection project.

Thirdly, focus group discussion was used to assess the overall project's implementation in the form of casual and unstructured discussion without a questionnaire. The purpose of the group discussion was to evaluate how the weapons collection project was implemented, with more emphasis on the appraisal and implementation stages of the project.

The fourth technique is called "community calendar". Participants were asked to list all the activities undertaken during the weapons collection project in chronological order, indicating when weapons were collected most and the reasons why. This technique is useful in order to understand the community's experiences about how the weapons collection project was executed.

The last technique used in the workshop was the so-called "three-star 
game". This exercise used three stars; the biggest star representing a rating of "excellent", the middle-size one "fairly excellent" and the smallest "good". This was meant to evaluate performance in weapons collection, unlike usual three-star games with rankings of "excellent, good and bad". The reason for this was that the participants were reluctant to be critical or offensive to people who were involved in weapons collection. At the workshop, the participants were asked to list all the activities and agencies in the weapons collection project, and to place stars on the activities and agencies in accordance with their performance. This exercise enabled the participants to understand which activities and agencies were preferred by communities, based on their relevance, effectiveness and sustainability. The participants were also able to identify which agencies and activities should be involved in future weapons collection projects. There were several guiding questions for each workshop session, but no structured questionnaires; this was done to enhance interaction between facilitators and participants.

\section{Implementing the research methods}

In each of the three case study countries the research team spent approximately one month. The team visited three case study locations: urban, rural and bordering communities in each country. In Albania the UNIDIR team chose Gramsh as an urban community, a village in Elbasan as a rural community and a village in Shkodra as a bordering community. For Cambodia the team chose a village in Snoul as rural, a village in Angkor Thom as rural and Pailin as the urban/bordering community. In Mali the team visited Lere, a rural village; Gao, an urban community; and Menaka, a bordering community.

The research team consisted of two international researchers from UNIDIR $^{46}$ as well as two to three translators and six to 18 facilitators who were all locally recruited. ${ }^{47}$ The translators and facilitators were trained in communication skills and PM\&E research tools prior to each workshop. The training session lasted one to two hours daily.

In each community, workshops were conducted with three social groups: men, women and youth. The average duration of stay in a community was four days, and a workshop was held daily for one or two hours. In all case study countries, workshops were usually held in the afternoon because the women and youth participants found it easiest to attend at that time. The number of participants in each workshop group ranged between five and 50 .

The research team consisted of three major groups - local facilitators, translators and international researchers. The local facilitators performed the important role of communicating directly with community members. 
For each social group, two facilitators were allocated: one as a main facilitator and another as a note-taker. Workshops were conducted, and notes taken, in the local language(s). Translators then translated all the notes from the local languages to English for use by the international researchers. The role of the international researchers was to train the translators and facilitators, monitor the workshop process and occasionally supervise the facilitation.

\section{Notes}

1. See, for example, Turshen, Meredeth and Clotilde Twagiramariya, eds (1998) What Women Do in Wartime: Gender and Conflict in Africa, London: Zed Books; Moser, Caroline and Fiona C. Clark, eds (2001) Victims, Perpetrators or Actors? Gender, Armed Conflict and Political Violence, New York: Zed Books; Rehn, Elisabeth and Ellen Johnson Sirleaf (2002) Women, War and Peace: The Independent Experts' Assessment on the Impact of Armed Conflict on Women and Women's Role in Peace-Building, New York: UN Development Fund for Women.

2. Hill, Felicity (2003) "Women's Contribution to Conflict Prevention, Early Warning and Disarmament", Disarmament Forum 4/2003, UN Institute for Disarmament Research, Geneva, pp. 18-24.

3. Faltas, Sami, Glenn McDonald and Camilla Waszink (2001) "Removing Small Arms from Society: A Review of Weapons Collection and Destruction Programmes", Occasional Paper No. 2, Small Arms Survey, Geneva.

4. Different organizations describe such initiatives differently depending on the incentives used. They are known variously as weapons for development (WfD), weapons in exchange for incentives (WEI), weapons in exchange for development (WED), weapons in competition for development (WCD) and weapons reduction and development for peace (WDP).

5. See, for example, the UN Department of Disarmament Affairs (DDA) Gender Action Plan, available at http://disarmament.un.org/gender.htm; United Nations (2002) "S/PV.4589: A Statement before the 4589th Meeting of the Security Council", UN Department of Peacekeeping Operations, New York, 25 July.

6. OECD/DAC (2004) "Conflict, Peace Building, Disarmament, Security", Gender Equality Tipsheet, available at www.oecd.org/dataoecd/3/26/1896536.pdf.

7. Ibid., p. 2.

8. International Alert and Women Waging Peace (2004) Inclusive Security, Sustainable Peace: A Toolkit for Advocacy and Action: Security Issues, London and Washington, DC: International Alert/Women Waging Peace, p. 20.

9. Ibid.

10. Banerjee, Dipanker and Robert Muggah (2002) Small Arms and Human Insecurity: Reviewing Participatory Research in South Asia, Geneva and Colombo: Small Arms Survey/Regional Centre for Strategic Studies.

11. Willett, Susan, ed. (2003) Participatory Monitoring of Humanitarian Mine Action: Giving Voice to Citizens of Nicaragua, Mozambique and Cambodia, Geneva: UN Institute for Disarmament Research, p. 7.

12. Ibid.

13. For future similar exercises, it is recommended to hold separate workshops for young women and men. 
14. An elderly man, Gramsh, Albania, 21 October 2003.

15. Gramsh, Albania, 21 October 2003.

16. Gramsh, Albania, 21 October 2003.

17. A local administrator, Menaka, Mali, 22 March 2003.

18. In Cambodia workshop participants and a local human rights NGO told the UNIDIR team that prior to weapons collection the major cause of domestic violence by husbands against wives was a combination of alcohol and firearms. In Albania the UNIDIR team was informed of some cases where wives used firearms to protect themselves from their husbands. In both Albania and Cambodia domestic violence has been a serious security problem even after weapons collection. However, the security sector agencies in these countries have not considered the issue as a priority, nor do international aid agencies provide appropriate assistance to address the issue.

19. Gramsh, Albania, 21 October 2003.

20. Gramsh, Albania, 21 October 2003.

21. Gramsh, Albania, 21 October 2003.

22. An elderly man, Shkodra, Albania, 29 October 2003.

23. A middle-aged housewife, Elbasan, Albania, 25 October 2003.

24. Gramsh, Albania, 22 October 2003.

25. The UNIDIR team found it difficult to secure female participants for its own workshops, too. The team requested local NGOs and prominent figures such as community chiefs to inform women of the UNIDIR workshops in advance.

26. Shkodra, Albania, 30 October 2003.

27. European Union (1999) Décision du Conseil 1999/320/PESC concernant une contribution de l'Union européenne à la collecte et à la destruction des armes en Albanie, Brussels: European Union.

28. UN Development Programme Albania (2002) Small Arms and Light Weapons Control, Annual Report 2002, Tirana: UNDP.

29. The Small Arms and Light Weapons Control Programme, UNDP Albania, available at www.salwc.undp.org.al/?background.

30. Shkodra, Albania, 30 October 2003.

31. Bonn International Center for Conversion and South Eastern Europe Clearinghouse for the Control of Small Arms and Light Weapons (2003) "You Have Removed the Devil from Our House": An Assessment of the UNDP Small Arms and Light Weapons Control (SALWC) Project in Albania, Bonn: Bonn International Center for Conversion.

32. A female participant, Gramsh, Albania, 22 October 2003.

33. Farr, Vanessa, Flora Macula and Bjarney Fridrikdottir (2003) "An Assessment of Women's Role in the 'Weapons in Exchange for Development' Programme, Albania", unpublished paper, p. 5.

34. Ibid., p. 6.

35. Shkodra, Albania, 30 October 2003.

36. Shkodra, Albania, 30 October 2003.

37. Motorbikes and taxis are the only transportation in the region. Villagers must pay them in cash. However, the border village's economy is hardly a currency economy, and the villagers do not usually have enough cash. Therefore, at the destruction time, it was virtually impossible for most of the villagers to use these transport services in order to participate in the event in the town centre.

38. A middle-aged man, Angkor Thom, Cambodia, 3 May 2004.

39. It is difficult, however, to obtain quantitative data on the usage of guns in domestic violence, and even on domestic violence in general, because few criminal data in these countries are gender-disaggregated.

40. Female participants, Snoul, Cambodia, 25 April 2004. 
41. Gramsh, Albania, 21 October 2003.

42. A schoolgirl, Gramsh, Albania, 21 October 2003.

43. Gao, Mali, 17 March 2003.

44. Gao, Mali, 18 March 2003.

45. In particular, the following was consulted during the development of the research methods: Rietberger-McCracken, Jennifer and Deepa Narayan (1997) Participatory Tools and Techniques: A Resource Kit for Participation and Social Assessment, Washington, DC: World Bank.

46. The project manager was male and the project assistant was female.

47. For Albania the research team consisted of two UNIDIR researchers, one male Albanian coordinator from a local NGO, two Albanian translators (a male and a female) and 18 local facilitators (nine male and nine female). The team in Cambodia consisted of two UNIDIR researchers, two Cambodian coordinators from local NGOs (a male and a female), two male Cambodian translators and 18 local facilitators (nine male and nine female). In Mali the team consisted of two UNIDIR researchers, three Malian coordinators (one male and one female from local NGOs, and one male from the National Commission for the Fight Against the Proliferation of Small Arms) and six male local facilitators. 


\section{Poems against bullets? The role of Somali women in social gun control}

Katrin Kinzelbach and Zeinab Mohamed Hassan

This chapter is based on field research conducted in 2003, and thus focuses on a particular phase of the conflict. Since the time of writing, the Intergovernmental Authority on Development (IGAD) succeeded in 2004, after several failed attempts, to broker an agreement on a Transitional Federal Government (TFG). Internationally, this development raised moderate hopes for a new beginning and an end to the violence in southern Somalia. The TFG, however, remained weak. In June 2006 the Union of Islamic Courts took charge of Mogadishu and much of southern Somalia; in December 2006 it was ousted by an Ethiopian military offensive with the support of the United States. Armed resistance continued to challenge the TFG and led to massive new displacements. In 2007 the African Union deployed a peacekeeping mission with Ugandan and Burundian troops. The situation remained highly volatile and violent. In June 2008 an agreement was signed between the TFG and opposition groups in Djibouti. However, the militant insurgent group alShabab was not party to it. The TFG remains dependent on outside support and is seen as increasingly week, ineffective and illegitimate. Piracy affects Somalia's shores and the humanitarian crisis continues to escalate. In the northwest of Somalia, Somaliland remains a de facto independent state with rising hopes for recognition. It will hold its next presidential elections in March 2009, but suffered a serious security setback when it was hit by multiple suicide attacks in October 2008.

In September 1994 fighting broke out in Hargeisa, the capital of the de

Sexed pistols: The gendered impacts of small arms and light weapons, Farr, Myrttinen and Schnabel (eds), United Nations University Press, 2009, ISBN 978-92-808-1175-9 
facto, although unrecognized, state of Somaliland. As a consequence, the city of Hargeisa was divided into two parts, each controlled by a different subclan. A group of women raised their voices in protest and went between the fighting factions, marching through the dry riverbed that marked the front line. With their bodies in the line of fire, they started singing:

Hadaba Deeqay dagaalkanu muxuu ahaa?

Degelba degelkuu ku xigay daabcad kula kacyey,

Shisheeye haduu is dilo waaba kala durkaa,

Marada labadeeda dacal buu dab ii qabsaday.

$\cdots$

Oh, Deeqa, I am truly at loss

About the real intention of this war.

Unrelated people can drift apart,

But my own people are fighting one another.

Neighbours are fierce at each other's throat,

My plight has no match.

On both ends have my cloth caught fire.

Knowing nothing of swimming,

I was taken away by a current.

From the bitter da'ar tree [aloe]

I carried a fatal poison.

Why do people from this bank

Despise people on the other?

Why must weary orphans flee again?

Must grieving mothers suffer afresh?

Out of desperation, I rejected

Hargeisa and my own people

Only to flee just as hastily from newly visited Berbera.

Deeqa, I am truly at a loss. ${ }^{1}$

The shooting stopped. Realizing that their defenceless women almost got killed, some of the fighting men even started crying.

Poetry sung by Somali women with howling voices to end fighting and support indigenous micro-disarmament initiatives is a main source of information used in this chapter to illuminate the gender dimension of small-arms proliferation in Somalia. Somali oral culture is not a unique phenomenon. Oral literature has significant importance across the African continent. It allows individuals to comment on power relations in society and can be an agent of change: directing, provoking, preventing, overturning and recasting perceptions of social reality. Oral poets are not only commentators; often they are directly involved in power relations, 
choosing either to support or to subvert those in power. ${ }^{2}$ Open confrontation between the sexes is discouraged in Somali culture, but the poetic word provides women with a socially acceptable strategy of confrontation. John William Johnson explains that work poetry (usually recited by women when performing their customary tasks such as churning milk, weaving mats or pounding grain) and the modern popular song are the voices of the politically disenfranchised. Seemingly innocent in function, they catch the powerful off guard. ${ }^{3}$ Oral poetry is therefore an indispensable source of information for understanding Somali socio-political reality, including, we argue in this chapter, the impact of guns and violence on daily life.

Although there are some studies about small arms and light weapons in the Horn of Africa, and in Somalia in particular, we still have little knowledge about the full gender dimension of the problem. The existing explorations and surveys are based exclusively or disproportionately on the knowledge and views of men. Researchers on Somalia assume that men control the arms trade and arsenals, and cite cultural impediments as reasons for avoiding the involvement of women in research, or simply do not recognize or try to understand the gendered implications of the questions they ask or the situations they analyse. This chapter asks some of the missing gender questions. We look at the role of both men and women in the sanctioning of violence and its control, the small-arms trade, victimization, armed groups and peacebuilding.

Our findings suggest that men are the primary direct victims of smallarms violence in Somalia, that women suffer most from indirect impacts of small-arms proliferation, that men and women are involved in the trade, control and use of small arms, and that, contrary to the assumptions of both local and international researchers, Somali women have a lot to say about guns and their impact on society. This demonstrates that the incorporation of a gender dimension into research on small-arms proliferation leads to a more nuanced understanding of the complexity of its impacts. An improved understanding can aid local activists and help international agencies improve the design of violence reduction programmes.

\section{Research methodology}

The chapter draws on insights gained through personal involvement in the peace movement in Somaliland, and experience with technical assistance projects on small-arms control, demobilization, disarmament and reintegration on behalf of GTZ (German Technical Cooperation Agency) and the UN Development Programme (UNDP). ${ }^{4}$ We cite oral poetry and provide an analysis of the political, social and cultural context 
in which the songs are sung. We assume that women all over Somalia have composed poetry to comment on the civil war. Unfortunately, the security situation did not allow us to collect poems from all regions of Somalia, and the analysis thus relies primarily on poems composed in Somaliland.

Furthermore, we review information provided in existing studies from a gender perspective and analyse a unique set of quantitative data made available by GTZ, collected through the registration of security personnel and armed forces across Somalia in 2000-2003. For this chapter, the latter set of data were disaggregated by gender, providing the first gender-sensitive quantitative analysis of small-arms proliferation and its impacts in Somalia. ${ }^{5}$ The aim of combining a quantitative analysis with the ideas expressed in oral poetry as an alternative source that is rooted in traditional practices is to generate new insights that are relevant to the work on gender and small arms, while recognizing and upholding the efforts of Somali women to speak the messages they wish to communicate.

\section{The proliferation of small arms and light weapons in Somalia}

Strategically located in the Horn of Africa, Somalia had geo-political importance during the Cold War and reportedly received military assistance from various countries at different times, including the United States, the Soviet Union, Italy, Romania, East Germany, Iraq, Iran, Libya, South Africa, Saudi Arabia and China. ${ }^{6}$ It is estimated that the Soviet Union delivered some US\$260 million in arms to Somalia from 1973 to 1977. During the Ogaden war with Ethiopia (1977-1978), military assistance was provided by Egypt, Saudi Arabia and Iran. After the Ogaden war, the United States and Western European allies took over. Between 1978 and 1982 , US $\$ 380$ million was provided by Italy. The United States delivered arms to a total worth of US $\$ 154$ million between 1981 and $1991 .^{7}$ When Somalia was about to sign a peace accord with Ethiopia in 1987, an estimated 16 per cent of its imports were in the form of arms. ${ }^{8}$ As a consequence, Somalia had one of the most heavily armed armies in Africa.

In opposition to the military regime of Siad Barre, the Somali National Movement (SNM) was formed in April 1981 in London. In a struggle to overthrow the military regime, and with the help of Ethiopia, the SNM distributed weapons to sympathizers and auxiliary forces. A number of militias with varying clan loyalties were created. ${ }^{9}$ After the fall of Siad Barre's regime and the disbanding of the Somali Army in 1991, some 40,000 weapons were abandoned and channelled into clan militias. ${ }^{10}$ Since 1991 caches of arms and ammunition have been built up from 
open and black markets, including from the demobilization process in Ethiopia. A UN Panel of Experts determined in 2003 that the arms market in Somalia is supplied by both external and internal sources. Arms, ammunition and cash have become completely fungible. ${ }^{11}$ The final report issued by this panel in 2006 confirms the continuation of the illegal arms trade and states that business cartels, associated businesses and local administrations have created a very powerful cross-clan web of economic vested interests, which works to maintain a status quo that ensures the preservation of these highly lucrative interests. ${ }^{12}$

The level of insecurity in Somalia varies significantly by region and over time. In 2003 the situation looked as follows. The administration of Somaliland had instituted relative peace and stability in northwest Somalia since 1997. Puntland (in the northeast) sought autonomy within a united Somalia and was also relatively stable. The central and southern parts of the country remained volatile, with Mogadishu being controlled by warlords and an estimated 15,000 freelance militia members. ${ }^{13}$ But even in the relatively stable areas, weapons remained easily obtainable. Their low market price indicates the extent of their proliferation. In 2003 an assault rifle AK-47, for example, cost between US\$120 and US\$250. AK-47 bullets cost only US $\$ 0.20-0.30$ per round. ${ }^{14}$ Virtually every family owned guns, and it was not very costly to equip a small militia group.

\section{Data environment}

Given the complete destruction of statistical data that may have existed locally before the state's collapse, and given the rudimentary capacity of local authorities, internationally funded research is the only source for data on small arms in Somalia. In addition to the above-mentioned reports by the UN Panel of Experts, there exist a small number of relevant studies.

Based on interviews conducted in March/April 1998, the Berlin Information-center for Transatlantic Security published a first study on the role and diffusion of small arms in Somaliland, concluding that small arms "no longer determine the dynamics of daily life" but that the "specific dangers lie in the potential of these weapons for armed conflict and individual violence". ${ }^{15}$ In the first quarter of 2001 the Bonn International Center for Conversion, in cooperation with the Somaliland Life and Peace Institute, conducted an exploratory study in Hargeisa and Berbera as part of a regional project on small arms and light weapons in IGAD. ${ }^{16}$ The study highlights that small arms are contained through clan-based control, and that more research is needed to gather detailed information on the extent and nature of small-arms proliferation in Somaliland. 
In 2003 the Hargeisa-based Academy for Peace and Development (APD), a Somali institute for action-oriented development research and member of the War-torn Societies Project (WSP), conducted a smallarms baseline assessment with technical advice from the Small Arms Survey and financial support from the UNDP. Using clustered random sampling, a total of 699 structured questionnaires were analysed. Respondents were male heads of households residing in Somaliland, their age ranging from 17 to 88 years. The study constitutes the only quantitative baseline assessment available on small-arms proliferation in Somaliland. ${ }^{17}$

Also in 2003, the Center for Research and Dialogue conducted a UNICEF-sponsored study entitled "The Impact of Small Arms on Children \& Youth in Central and South Somalia". Five hundred children aged 14 to 18 years were interviewed; 80 per cent of respondents were male, 20 per cent female. ${ }^{18}$ A "Protection Study" published by UNICEF in 2003 further includes useful data on the level of violence as perceived by communities.

None of the small-arms studies provides gender-disaggregated data or gender-sensitive analysis. Although the UNICEF studies included female respondents, not all data have been disaggregated. The APD researchers (all male) decided that the structured questionnaires would be administered only to males by male enumerators because women were assumed to engage in armed conflict rarely, and not to own guns or have interesting opinions on the subject. Furthermore, the researchers deemed visits by strangers soliciting female respondents to be culturally inappropriate. ${ }^{19}$ Neither international researchers who participated in the survey on behalf of the Small Arms Survey nor the UNDP, which funded the research, countered this decision.

Contextual statistics used in this chapter are drawn from the 2002 UNDP/World Bank Watching Brief on Somalia, which provides basic demographic and socio-economic data. This multisectoral nationwide household survey is, in fact, the first of its kind in Somalia over the last two decades. Concerned about reactions by locals, the Watching Brief team decided that it would be too sensitive to ask about guns in a general household survey. ${ }^{20}$ Unfortunately, the study results also fall short of tracing the socio-economic impact of armed violence.

In societies where small-arms proliferation is pervasive, all research ought to be sensitive to the impact of gun violence, and clear categories are needed to trace this impact, for example in the sector of health. Watching Brief data on the distribution of deaths by stated causes show that sickness rather than violence is the most frequent cause of death in Somalia (about 61 per cent). Other sources indicate that the direct impact of gun violence on health is nonetheless significant, especially in the 
south of Somalia: Mark Snelling of the ICRC reports that of more than 46,000 patients admitted to Keysaney Hospital in Mogadishu between 1992 and 2003, half had gunshot wounds. ${ }^{21}$ There is, of course, a difference between death and injury, but it is implausible that the trends differ significantly.

Research on small arms as well as gender-sensitive research in maledominated societies is certainly sensitive and difficult to undertake. But neither the omission of sensitive issues such as the impacts of prolific small arms nor the omission of women subjects from research is a solution, because results obtained in this way run the risk of simplifying, if not defying, reality. Constituting 48.5 per cent of the population and heading 12.6 per cent of Somalia's households, ${ }^{22}$ it is evident that women have an important perspective on the impact of small arms on daily life in Somalia. It is further worth pointing out that Somali women received military training under the 20 years of Siad Barre's military regime. This means that Somali women not only live in a society where weapons are widely available - they also know how to use them.

Although this chapter can build on previous research, there is unfortunately a significant level of uncertainty in the evidence we have found so far, and gender-disaggregated data on small-arms proliferation are missing entirely. In this research environment, GTZ's registration of armed forces across Somalia in 2000-2003 constitutes a unique source of quantitative information. Small-arms-related questions were included in a comprehensive, structured questionnaire to which 7,231 men and 879 women responded. In Somaliland, respondents were identified using the government payroll for police, custodial corps and the military. In Mogadishu, Baidoa, Kismayo, Belet Weyne, Galkayo and Bossasso, militia groups willing to cooperate were registered. GTZ's data are unpublished but were made available for this chapter, including technical assistance to disaggregate the data by gender. ${ }^{23}$

\section{Oral poetry: Social commentary of the marginalized}

Somali women are not only regularly excluded from surveys conducted by international researchers. Beyond their immediate family circles, they have largely been excluded from any decision-making processes and denied both political authority and economic autonomy. In this restrictive context in which they are not expected to have views - let alone to express them - Somali women use poetry to comment on social problems. As we show in this chapter, they have a lot to say about the issue of small-arms proliferation and misuse. The subversive power of their en- 
gagement strategy, given women's extremely subordinate status in the society, is vividly demonstrated in a Somali proverb that says: "Three qualities that are considered a virtue for men are considered a vice for women: bravery, generosity and eloquence." 24

Their defiance of dominant gender expectations by employing not merely eloquence but the sophistication of poetry requires bravery, and constitutes a forceful indication of women's creativity in expressing their entitlement to empowerment. With their songs, Somali women resist being reduced to silence.

Somalia has often been called a nation of poets, although it continues to have one of the lowest literacy rates in the world. The adult female literacy rate for rural and nomadic areas is as low as 6.7 per cent. ${ }^{25}$ Among illiterate pastoralists, great importance is attached to the spoken word, which is kept alive in the collective history through a vibrant oral heritage. Lidwien Kapteijns explains the role of poetry in war and peacemaking by highlighting that the Somali value system ascribes to male elders the qualities required for political authority. An alternative option for social and economic establishment, especially for young adult men, is to assume wealth through raiding and warfare. It is the task of orators to weigh up the dangers and opportunities each of these actions presents. ${ }^{26}$

Unlike individual crime, clan-based warfare and raiding require social consensus, and debates precede the taking up of arms. In this context, poetry has been used to advocate for war or to forge peace. Although women were often consulted in private, they were not typically included in any form of public debate and decision-making. Female poetry was traditionally not recited in the context of political discourses, but primarily used to communicate from one generation of women to the next. It captures female interpretations and valuations of events, their consciousness of the past and their stories. It captures the female experience. During the Somali liberation struggle, however, women started to use their poems to engage in political processes. There are examples of women who used their poetic skills to support the fighting, such as a poem composed when Abdullahi Essa Mohamoud, prime minister of the first independent government, participated in the UN General Assembly to voice the cause of the Somali nation:

Since you are leaving oh Abdullahi Permit me to recommend you that, If we are not slain by bomb or Other lethal weapons,

Our fighting will never stop

Till the final victory! ${ }^{27}$ 
In contrast, a poem composed at the time of independence by Kadija Muse Mattan, a prominent woman who supported political parties morally, politically and materially, is the earliest disarmament poem of which we are aware:

I warn you, Somalis

Disarm yourselves

Leave each other in peace!

Your women mourn every spring, while the vultures feast

On their flesh

I warn you, Somalis

Leave each other in peace! ${ }^{28}$

After the struggle for independence, it was the outbreak of clan-based militia wars that prompted women to use their poems for political purposes. Mark Bradbury reports that this political engagement was acknowledged at the Borama Conference of 1993, at which women were given a greater opportunity than usual to recite poems. ${ }^{29}$

\section{Social sanctioning of violence and small-arms control}

Achievements in disarmament and small-arms control in Somalia have thus far been largely limited to locally driven processes, with clans and communities taking responsibility for the collection and control of weapons. The UN Security Council issued an arms embargo in 1992 (Resolution 733/1992), but this embargo remains unenforced. Arms control at the state level is essentially non-existent, due either to the absence of state institutions or to their limited capacities. Even today, the main source for arms control in Somalia is an informal code of customary law that sets standards for social behaviour: the xeer. The xeer is an oral tradition with the force of law, passed on from generation to generation. It forbids the carrying of weapons in settlements. The act of pointing a gun at someone is as severe as having actually shot the person ( $d i l)$.

In 1998 the Somalia Delegation of the International Red Cross/Red Crescent published an overview on those customary norms that regulate Somali behaviour in warfare, define an immunity code and describe the rules for fighting with honour. ${ }^{30}$ One of the most relevant of these, for this study, is the law of bloodshed (xeerka dhiigga), which deals with cases in which someone is killed or wounded. When a man is killed, 100 camels have to be paid; a woman - depending on her marital status and the number of children she has raised - is worth up to 50 camels. Unlike 
men, whose status increases with age, women lose status after their childbearing years. There is also a law, biri-ma-geydo ("spared from the spear"), that protects vulnerable groups such as women, children, the aged and the sick, as well as men of religion, peace delegates, traditional leaders, guests, travellers, the unarmed and neutral, the war-wounded and other protected persons (magan), for example men who sojourn with their mothers' people where their own clan lineage is in the minority.

Many of the norms collected by the Red Cross are anecdotal, and are presented with an analysis of local cultural practices. One of the arguments put forth is that Somali culture has contributed to the promotion of violence: a man who was engaged in killing and looting was usually admired and praised, while a peace advocate was scorned and dismissed as being weak and worthless. In a culture of raids and camel looting, men brace themselves for their attacks, and weaponry is emblematic of manliness. To substantiate this analysis in the Red Cross study, a short poem is cited in which the poet woos his beloved by bragging about the wealth he secured through raids:

O daughter of Diriye, our saddles are kept [ready] outside;

We are people who have benefited by attacks and raids;

[So] just travel hither; I will take you to a home full of fermented camel milk.

In their own songs, women express agreement with this ideal of masculinity, and thus contribute to the social sanctioning of violence. Two traditional lullabies sung by mothers to their newborns capture the predominantly held gender expectations, namely that men should fight and women should marry, work and be quiet.

Lullaby for a son

War Bilow, tolkay biirayow hoowaa.

Hooyo, tolkaa caawa duulayaa...

Bile, you have increased [the number of] your patriliny

Son, your kin are setting out to fight tonight.

Son, they are fighting right now.

Son, your kin are setting out to fight tonight.

Son, won't you go and get some looted animals [yourself] ${ }^{31}$

Lullaby for a daughter

Hooyo, gunnadi habeen guurtay gagaabsi gabadh baaleh... 
Daughter, the wealth that comes by night [the bride wealth]

Belongs to the girl who is quiet.

Saado, Saado hoowa

In a place where there is no girl

No camels will be milked

And no bride wealth received.

There is a marriageable young man in the house,

And men pass by our dwelling.

Lest the bride wealth camels must be returned,

Don't weep so loudly! ${ }^{32}$

The traditional norms not only offer protection but also promote notions of femininity and masculinity, which can hamper the establishment of a holistic human security that includes gender equality. Men have a superior social status to women and are expected to assume powerful roles in religion, economics and politics. Women are expected to give birth to many children, preferably boys, and do domestic work. Childbearing is highly valued and closely linked to the ideal of strengthening the clan. This ideology is also reflected in the reconciliation practice of exchanging virginal maidens after mutual claims for compensation between two clans have been settled. The saying "Where blood has been spilled, birth fluids should also be spilled" refers to the expectation that the maidens bear their new husbands sons to compensate the lineage for the men lost in war. ${ }^{33}$

The xeer does not recognize women as independent legal persons they are protected by the xeer and obliged to uphold it, but when women bring cases before the traditional councils they are usually represented by men: fathers, husbands, brothers, sons, cousins. Women are thought to be vulnerable and dependent, while men are called upon to act as protectors. Men take part in wars, and if necessary are expected to die for the sake of the clan. Today, the regulatory provisions of the xeer are still perceived to be binding, but warfare with modern weapons in the context of a failed state undermines the logic of this traditional justice system. Bryden and Steiner point out that calculations of livestock as compensation became meaningless as casualties mounted to the hundreds of thousands. ${ }^{34}$ Especially in the southern parts of Somalia, it is evident that traditional norms and conflict resolution mechanisms have not served to control the fighting of warlords and their militias. One explanation for the traditional clan-based system's failure to institute peace and order in regions other than Somaliland is that it was significantly weakened during the time of Italian colonial rule. Somaliland, on the other hand, was a British protectorate, and the policy adopted towards traditional social order was less intrusive. Other explanations for the difference in conflict dynamics in the south and the north include the clan structure being far 
less homogeneous in the south, making a clan-based solution more complicated. Because of the Juba and Shabelle Rivers, there is valuable arable land in the south. There is much less arable land in the north and grazing land falls under communal ownership, with land disputes being less common than in the south. Also, in the south there is no group that can establish military supremacy, unlike in the north where the Isaaq clan effectively won the war. ${ }^{35}$

Despite the inability of the xeer to control and end the horrendous militia war in the centre and south, traditional norms still offer the best available protection against armed violence. Due to the lack of central government and general lawlessness in most parts of the country, policing and gun control are non-existent. Even the administration of Somaliland, which governs in a context of relative peace and stability, has hardly any capacity for arms control. The badly equipped and minimally trained police force is not in a position to control arms. With the support of the UNDP, it started to register its own weapons and build basic armouries. Controlling civilian-held arms is, for the moment, unthinkable. At present there is no legal provision to mandate the police to control arms.

Under the leadership of the National Advisory Council on the Control of Firearms (NACCOF), established in 2003 with support from the UNDP, discussions started on an arms control law for Somaliland. Although an essential step in the context of strengthening modern state structures, its potential effect can only be limited. According to the UNDP/World Bank Watching Brief for Somalia, only 28.7 per cent of all Somalis report that the judiciary is available to them as a justice system. In rural and nomadic settings the figure is even smaller: 25.6 per cent. In contrast, 96.7 per cent of all Somalis report that clan and community elders are available to them; 98.4 per cent think these elders provide them with a functional justice system. ${ }^{36}$ Security, however, is not effectively upheld by this system: 94.1 per cent of the respondents to the APD study expressed the view that increased control of firearms would improve security. ${ }^{37}$ GTZ data confirm this finding, and also reveal that Somali men and women share similar views on the issue of gun control. A large majority of more than 90 per cent think that improved control of firearms would increase security, as Table 12.1 illustrates.

While these results might be encouraging, it is nonetheless a matter of some doubt whether people in Somaliland would indeed be ready to accept tighter control, especially since the formal authorities do not necessarily have the capacity or the popular trust for instituting adequate security. A further impediment for control and individual or clan-based disarmament is the positive value many Somalis ascribe to guns. This is demonstrated by the fact that guns are sometimes included in the dowry (yarad) given by the husband's family to the family of the prospective 
Table 12.1 Somali views on control of firearms

\begin{tabular}{lrrrr}
\hline $\begin{array}{l}\text { Do you think that improving } \\
\text { the control of firearms in } \\
\text { your country/region would } \\
\text { increase security? }\end{array}$ & $\begin{array}{l}\text { Frequency, } \\
\text { male } \\
\text { respondents }\end{array}$ & $\begin{array}{l}\text { \% } \\
\text { (men) }\end{array}$ & $\begin{array}{l}\text { Frequency, } \\
\text { female } \\
\text { respondents }\end{array}$ & $\begin{array}{l}\text { \% } \\
\text { (women) }\end{array}$ \\
\hline Yes & 6,740 & 93.2 & 800 & 91.1 \\
No & 168 & 2.3 & 23 & 2.6 \\
Don't know & 81 & 1.1 & 5 & 0.6 \\
Makes no difference & 93 & 1.3 & 4 & 0.5 \\
Refused to answer & 148 & 2.1 & 46 & 5.2 \\
Total & 7,230 & 100 & 878 & 100 \\
\hline
\end{tabular}

wife. ${ }^{38}$ Mohamoud Jama Omar reports that a gun is seen as a sign of prestige, power and authority. A suitor who pays a dowry in camels is popular, but he who can also offer a gun is believed to make a better husband. ${ }^{39}$

Cynthia Enloe argues that a gun can be militarized or non-militarized: what matters is the use to which it is put and the meaning with which it is invested. ${ }^{40}$ Guns are not only instruments to inflict pain in Somalia, and not all gun usage is usefully thought of as militarized. Firearms used for herding and protecting livestock have helped Somali nomads and pastoralists prosper in peaceful times. However, since livestock are also an insignia of power, one can nonetheless argue that both militarized and non-militarized gun usage in Somalia are linked to the establishment of power, most predominantly male power. Both militarized and nonmilitarized gun usage in Somalia boost ideals of masculinity. As is demonstrated by the following story, guns are, conversely, also used to defend traditional values of femininity:

The only free hospital in the Somali capital, Mogadishu, has closed after medical workers went on strike because of threats from gunmen... The gunmen were sent to the hospital three weeks ago by the family of a woman whose womb was removed during a life-saving operation... The hospital workers say that they will carry on with their strike until the militiamen are withdrawn from the building. But the woman's family is insisting that the militiamen will continue to occupy the hospital until they are compensated for the removal of her womb. The family is demanding 50 camels, which is the traditional Somali compensation offered for the death of a woman. The woman's family say she is as good as dead because she can no longer bear children. ${ }^{41}$

Although many Somalis oppose such actions, it is nonetheless noteworthy that guns are being used to combat any views or actions that challenge traditional definitions of femininity. 
To summarize, it can be said that a gun and warrior culture sanctions the widespread possession of small arms in Somalia; that control is largely limited to traditional, clan-based structures which enforce the xeer with varying degrees of success; that gun violence is, in some cases, linked to conceptions of femininity and masculinity; and that the level of threat experienced by Somali men and women is very high.

\section{The small-arms trade}

The APD's decision not to include women in its small-arms baseline assessment reflects the widely held perception that Somali women do not engage in the trade and use of small arms. This perception is not supported in scholarly research, however: Bryden and Steiner had already pointed out in 1998 that women have not only provided spiritual support and food to the militia as well as care for the wounded, but that they also sold jewellery or collected funds to contribute to the war effort. ${ }^{42}$ At least a portion of the proceeds from such fundraising efforts has been used to fund stockpiles of guns and ammunition. This is not a new phenomenon - women sold their jewellery to fund the Somali struggle for independence from colonial rule. In post-independence Somalia, Hawo Jibril sang about women's contribution to the war effort:

Sisters, you sold your jewellery

Depriving yourselves,

Enriching the struggle.

Sisters, you stayed as one,

United, even when your brothers

Divided and deceived our nation.

Sisters, you joined the fight

Remember the beautiful one

Hawa - stabbed through the heart.

But, sisters, we were forgotten!

We did not taste the fruits of success

Even the lowest positions

Were not offered

And our degrees were cast aside as dirt.

Sisters, was this what we struggled for $?^{43}$

The main message of this poem is that the contribution of Somali women to the independence struggle was accepted when times were dark, but 
overlooked when access to post-war privileges was determined. History repeated itself, because many of the female supporters of the struggle against Siad Barre's regime also shared this fate. Implicitly, the poem carries another message - it confirms that women did indeed play a willing role in the armed struggle, including in trade to help finance it.

The same continues to be true today. At a UNDP-sponsored workshop of Somali women, held at the Hargeisa-based women's umbrella organization NAGAAD in September 2003, participants emphasized the role of women in the small-arms trade. ${ }^{44}$ However, the existing literature on this trade in Somalia is silent about the actual and potential role of women. For example, the UN Panel of Experts makes no reference to women in the sections on funding of the arms trade and trafficking. This omission constitutes a potentially significant information gap in the otherwise very detailed report. While the overall financial and logistical contribution of women to the arms trade may be small, it could still be significant because of the specific nature of the Somali trade. As pointed out by the UN experts themselves:

In the face of these continuous and flagrant violations it should be stated that the vast majority of the numerous cases investigated involved relatively small amounts of arms and ammunition. Somalia's general poverty and the limited and sporadic clashes between the factions require little more. ${ }^{45}$

How, then, does the trafficking of small arms and ammunition get organized in Somalia, where numerous clan militias control relatively small parts of the country? We have no hard data on the role of women in this process, but indications exist that they do play a part. One such indication is drawn from the protection that women enjoy according to the customary norms of the xeer. Women are often the only ones who can move between adversary groups, ${ }^{46}$ a freedom they have used to considerable advantage - for purposes of peace and of war. Like women in other countries, Somali women make choices about either supporting or subverting gun culture and militarization. As a mirror image of bellicose masculinity, whose opposite they have to embody in order to give that form of masculinity meaning, women are perceived to be non-belligerent, and thus not a legitimate target for search and assault. Their presumed passivity makes them ideal traffickers. The assumption that women are not a threat during war is linked to their exclusion from participation in political affairs during peaceful times, which shapes expectations about their behaviour in war.

When investigating the role of women in the small-arms trade in Somalia, it is helpful to look at their involvement in other trade networks. 
Mark Bradbury reports that Somali women in Ethiopian refugee camps established extensive and diverse trading networks that involved sending ghee to Djibouti and the Gulf, cloth from Djibouti to Mogadishu and Somali shillings from Mogadishu to the refugee camps. ${ }^{47}$ Moreover, Amina Warsame's research indicates that Somali women have established trade networks that reach as far as Ethiopia, Djibouti, Saudi Arabia and the Arab Emirates. ${ }^{48}$ These women-owned networks provide an ideal cover for the smuggling of arms and ammunition precisely because women so skilfully manoeuvre within the spaces open to them while exploiting and subverting stereotypes of appropriate feminine behaviour. In this way their actions remain invisible, unnoticed - and above reproach. An interview with a gunwoman held in Merca in 1996, recorded by Bryden and Steiner, indicates that Somalis are not the only ones who are fooled by the assumed innocence of female arms traders:

I was pregnant but I continued to fight until the end. We travelled during the night to bring the bullets to our troops. We passed the UNOSOM [UN Operation in Somalia] checkpoints looking as if we had children on our shoulders. ${ }^{49}$

Men dominate the gun markets, for example in Mogadishu, Galcaio and Burao. Women tend not to sell in public. But the roles that Somali women have played during the war are multifaceted and more complex than what foreigners see or even, in fact, what the local gender expectations allow. When asking the workshop participants at NAGAAD why women bought and sold arms, they cited income generation as a main reason for female involvement in the trade. They also, intriguingly, explained that women have access to weapons because they are in charge of gun storage at home. In peaceful times, Somali women are responsible for hiding any weapon owned by the family so that no child or unauthorized person can misuse it. In this context, training women on gun safety measures can be expected to make a significant contribution to accident prevention in Somalia. If the clan decides to go to war, a woman will hand out the weapons. But if her husband demands the gun when there is no collective decision to take up arms and he is hot-tempered, she will both refuse and raise alarm to her neighbours. Being expected to oppose their hot-tempered husbands, Somali women are given a critical social responsibility for gun control, and often put themselves at risk.

Information on fundraising efforts, the extent of women's trade networks and their role in gun storage and indigenous gun control suggests that involvement of Somali women in the small-arms trade is very probable. The motivations for trading could be divided into two main categories: women's involvement in the small-arms trade is linked either to 
their active support for armament or to their search for income opportunities. While men are likely to dominate decisions on the first aspect, all indications point towards women playing a significant role in trading decision-making because they rely on and exploit small arms for incomegeneration purposes.

\section{Victims of small-arms violence}

While women obviously do have some power over and interest in small arms, they also have other roles that derive from the threats of small arms. In many of the poems composed during the unstable years of the early 1990s, when the initial euphoria around Somaliland's independence was muted by the renewed outbreak of fighting, Somali women speak about the pain caused by violence. Tying white bands around their heads as a sign of mourning, and singing their highly emotive songs, women reminded men of the suffering. Saado Abdi Amare composed a song that was sung by around 300 women: wives, sisters and in-laws of the fighters in Burao. The song was so powerfully effective that it convinced the fighting factions to stop firing.

Dahir

Waatii aad dahiroow wax badan dibadada taagnayde,

Wakaa dugaagii idin cunay duurka xulayaaye,

Dagalkii xuma iyo hubkii qaraxayay dib uga qiirooda,

Dhibaartada hubku leeyahayn ku dulmarayaye

$\cdots$

Dahir, You have been standing outside too long

Your people have been beaten by wild beasts,

I am shocked by the terrible war and the exploding weapons.

I will explain to you the catastrophe caused by these arms.

It is bitterness and sorrow that is left behind

Dead bodies are lying everywhere in the aftermath of war.

The vultures are feasting on the dead bodies

Old men's death is the advantage of war.

Burials and wailing women are the advantages of war.

Widows with white dresses are the advantages of war

Distressed orphans are the advantages of war. ${ }^{50}$

The emotional power of this poem is linked to the personal experience of loss. It bleakly alludes to the continued struggle for life after communities and individuals are weakened, both by sorrow and by the practical 
impacts of losing husbands, fathers, brothers and sons. It focuses on the victims of armed violence but it is not an expression of weakness. Instead it directly addresses militiamen, accusing them of having placed themselves outside the bonds of humanity. The poet states that they have lost all cultural values, including any perspective on why the war is being fought at all, as a result of their refusal to see their own humanity and the humanity of those in whose lives their own lives are enmeshed. Implicitly the poet says men are the direct victims of gun violence, whereas women are left behind as widows who feel bitterness and sorrow, walking between dead bodies and vultures, wailing over burials and dealing with the long-term consequences of a moment's violent action, such as looking after distressed orphans. A testimony collected by Shukri Harir in 1988 confirms that men are particularly threatened because of their gender. She records the sad fate of Asha Yusuf, who testified that the menfolk in her group, including her husband, were slaughtered and even the babies were checked to determine their sex, with four baby boys being killed. ${ }^{51}$

Saado Abdi Amare's poem does not simply mourn about the horrifying suffering experienced by the Somali people. It emphasizes that people's belligerent actions, their refusal to remain inside the human family where they have to consider and face up to the effects of their actions, and their technologically advanced weapons are the cause of the misery. Through the portrayal of widespread suffering and her relentless reiteration of the uselessness and waste of war, she calls for a change of action from those who establish their power through violence. As in many other poems, her message is not limited to reflection or description, and it is not a helpless wringing of hands. She does not shy away from naming the problem and its devastating consequences, shaming the perpetrators and appealing to them to change.

The impact of powerful and prolific weapons figures prominently in her poem. They are explicitly named as the cause of the catastrophe. Given the poet's direct confrontation with active fighting when this poem was composed and sung, this emphasis is hardly surprising. But her focus is the consequence of armed violence, rather than the weapons themselves, because she sees the weapons are merely an instrument through which to express violence. In another of her poems, Saado Abdi Amare elaborates further on the societal consequences of armed violence. She had been an active SNM member, but upon her return from Ethiopia in 1991 she and other women sold their weapons to be able to support their families. Now unarmed, she found herself confronted by young militias, looting her at checkpoints. In response to this violation she raised her voice, singing a poem that is both a confrontation and a warning: 
Dayday

Dhulkii burburay beerka kuma hayow,

Markay buuruhu ruxmaeenbeerka kuma hayow,

Ololkii samada u baxay beerka kuma hayow

Xornimo waataa bidhantee ma beegsadow,

Sidii uu noo bobilaa dayday ula baxow

Dakoo bismilaahi yidhi keligii bahanow,

Banka yomal shaxar baa inoo balane,

Malinta bacadka weyn baa inoo balana,

Ilahay baaqi yahay baa inoo balana.

...

\section{The Armed Youth}

You mindless ones, who forgot our destroyed land

Did you forget when the mountains were shaken by the shells

The flames that went up to the sky

Did you forget?

Did you forget the dawning freedom?

You are still thinking of ways how to loot us again

You, who are needy when all others are thanking God

We will meet again in a second world

When God will ask you all about your deeds in this world

We will meet again on a heated day.

You are mindless of your berkas [water reservoirs]

When they were blown up with mines

You are mindless of the plains where all our people were forced to live.

You forget the children conceived through rape

You do not remember how a child got lost when running away in fright

You do not recall the rain and the cold of a cruel night.

You forget the dawning freedom?

You are still thinking of ways to loot us again

You, who are needy when all others are thanking God

We will meet again in a second world

When God will ask you all about your deeds in this world

We will meet again on a heated day.

You, who forget your weeping mother,

You, who do not remember those men who were run over by armoured troop carriers,

You, who do not recall the misery we have witnessed,

You, who forget how our enemy forces looted our property

You don't enjoy the dawning freedom

You are still thinking of ways to loot us again 
You, who are needy when all others are thanking God

We will meet again in a second world

When God will ask you all about your deeds in this world

We will meet again on a heated day. ${ }^{52}$

Although threatened by guns, Saado Abdi Amare does not perceive of herself as either powerless or a victim. In fact she, as a powerful orator, is a vengeful carrier of communal memory who sees the armed youth as victims: they are ignorant of the past so they cannot recognize the achievements and potential of the present. Their forgetfulness is indicative of a breakdown of morality. Unlike her and those she speaks for, they neither remember the pain of the past nor understand the motivations of those who fought before. They have become addicted to mindless violence and cannot recognize the treasures of the "dawning freedom". Apart from the direct effects of the reckless violence they commit with their powerful weapons, she is concerned to name the longer-term consequences of their behaviour, which are so massive and multifaceted that she can only see them being addressed by God on a Judgment Day which must surely come to pass. The theme of accusing gun bearers of inhumane acts recurs. Accusing individuals of having placed themselves outside of humanity is a very strong indictment in a society whose social structure is based on reciprocity and expressions of communality.

Today, the consequences named in these poems are vivid: large numbers of women struggle to care for their families, assuming many responsibilities that were traditionally held by men. In addition, women care for physically or psychologically harmed ex-combatants, many of whom place a heavy burden on their families, live in desperate conditions and display violent characteristics. Post-traumatic stress disorder (PTSD) is known to increase the inclination towards violence, making the availability of arms even more threatening to public and domestic safety. A Vivo/ GTZ study conducted in 2002 studied 612 households with 4,854 persons in Hargeisa (identified through random sampling). This study points out that the incidence of PTSD is particularly high among ex-combatants: about one-sixth of those who fought actively developed a very severe form of mental disorder later in their lives. In contrast: 4.2 per cent of the civilian war survivors and 1 per cent of the persons not exposed to war suffered from a severe mental disorder at the time of the study. ${ }^{53} \mathrm{~A}$ study conducted by the APD in April 2002 complements this picture; 775 respondents were interviewed in Hargeisa, Berbera, Borama and Burau, including 424 former combatants (presumably all male, although the report is unclear), 177 war widows and 174 youths in prison. The study confirms a high prevalence of PTSD among former combatants, with 52.4 
per cent having experienced traumatic events and 45 per cent still reexperiencing these events including through dreams, flashbacks and physical reactions; 83 per cent reported at least one incident in which they thought they were about to die. Fifty-six per cent of the war widows report having had an active role in the war, for example by cooking and taking care of the wounded. About 50 per cent of them presented at least three symptoms of PTSD. Fifty-six per cent of the widows rate the loss of their husbands as their worst war experience; 17 per cent named the witnessing of killings and 3 per cent rape as their worst experience. Being injured or threatened by guns does not appear among the responses. ${ }^{54}$ These data show that both men and women suffer from the consequences of armed violence. Apart from the threat to life, women also suffer from the prolific spread of arms and the lack of protection in other, often less tangible, ways - including losing their husbands and witnessing killings or sexual violence.

Clan alliance is linked to the issue of gender, and constitutes a second determining factor in patterns of victimization. Clan identity is patrilinear, for both men and women. In addition to her primary clan identity, a woman usually has a strong relationship with her mother's clan, and after marriage will develop a third strong clan identity related to her husband and children. Gardner and Warsame argue that women are not only valued as bridges between clans; their multiple and potentially conflicting loyalties also put them at the centre of war-induced suffering. ${ }^{55}$ In her poetry, Faduma Halane, who works as an educator, touches upon her ambiguous and even paradoxical alliance with the different clans of her family. She composed a disarmament poem in 1991 while witnessing two clan militias fight in Burao. When her husband, her brother, her son and all the other men in Burao took up arms, she appealed to them with the following words:

Waa hooyo laba will leh,

Oo midiba beel raacay,

Oo beelaha dhex cararaysa,

Oo basaasd lagusheegay,

Baaqeedu waxa weeye,

Kii aan dhalow hubka dhig,

Kii aan u dhaxow hubka dhig,

Kii ila dhashow hubka dhig,

Beelaha Somalilandow hubka dhiga.

$\cdots$

This is a mother of two boys

Each joined his own clan

And she runs from one clan to the other. 


\section{Both call her spy}

She is calling out aloud to all:

"Please put down your guns"

She begs us all to heed

My son, please put down your gun.

My husband, please put down your gun.

My brother, please put down your gun.

Somaliland clans, put down your guns.

This is a homeless mother drifting aimlessly,

The sound of different guns have defeated her

She is roaming around in distress.

She calls to all to stop the artillery shells.

Her plea to all is this:

My son, please put down your gun.

My husband, please put down your gun.

My brother, please put down your gun.

Somaliland clans, please

Put down your guns. ${ }^{56}$

Clearly, Faduma Halane does not feel safe in her own families. Tragically, because she moves freely between them as a mediator, as women historically have been able to do, she is now labelled a traitor by both sons' clans: "Both call her spy." Women get torn between the clan identity of their husbands, sons, fathers and brothers. Speculations are nurtured over a women's dominant clan identity. Many Somali women share this experience, because clan-exogamous marriages were very common before the war. As a result of this experience, it seems that women today increasingly prefer their daughters to marry within their own clan. While this might protect them from the identity crisis and clan-based violence experienced by their mothers during the war, young women lose protection from spouse-related domestic violence in marriages within the same lineage: men are protective of their female relatives when assaults involve other clans, but will usually not seek retribution within their own clan. ${ }^{57}$ Furthermore, when they marry within their lineage, women's movement between clans is of necessity restricted, so they lose an important function as intermediaries who can resolve conflict when it builds up between rival clans. Instead of being seen as a valuable gobetween with influence in the various private spheres of the family, women's relative freedom becomes a source of suspicion. Their already limited access to political space in traditional cultures is eroded. The widespread violence during the war has thus had a significant impact on 
Table 12.2 Perceptions on levels of family violence

\begin{tabular}{lccccc}
\hline $\begin{array}{l}\text { How common is } \\
\text { violence in the family } \\
\text { in your community? }\end{array}$ & $\begin{array}{l}\text { Common } \\
(\%)\end{array}$ & $\begin{array}{l}\text { Moderate } \\
(\%)\end{array}$ & $\begin{array}{l}\text { Rare } \\
(\%)\end{array}$ & $\begin{array}{l}\text { Never } \\
(\%)\end{array}$ & $\begin{array}{l}\text { No response } \\
(\%)\end{array}$ \\
\hline Adults & 21.6 & 27.0 & 27.7 & 19.0 & 4.7 \\
Children & 28.2 & 23.0 & 27.1 & 16.1 & 5.2 \\
\hline
\end{tabular}

family structures, leading to new threats and restrictions not only for women but also for men. For example, there have been cases where wives shot their husbands in a reaction to adultery or polygamy. The UNICEF child protection study indicates that both children and adults perceive the level of family violence in their community to be quite high. The data are based on interviews with 686 people in 123 community locations across Somalia (Table 12.2). ${ }^{58}$

The gendered implications are difficult to interpret because the data are not disaggregated; still, it is significant to note that approximately 50 per cent of the respondents rated violence in the family to be common to moderate. The Watching Brief data confirm this trend: 62.5 per cent of the respondents identified domestic violence as a security problem only wild animals and armed groups were more commonly named as a security problem (66.7 per cent and 80.7 per cent respectively). ${ }^{59}$ Often violence within a family is directed against women, and it is known to become more lethal in the presence of guns.

Other data reveal that Somalis are ambivalent about the impact guns have on security -60.8 per cent of respondents to the APD study thought that people keep firearms for personal protection. The GTZ data confirm that both men and women identify personal protection as the primary motivation to keep firearms (named 5,509 times by men, 541 times by women). Community protection was rated the second most important motivation for gun ownership (named 2,468 times by men, 304 times by women). Political security rated third (named 1,642 times by men, 175 times by women). But less threatening reasons were also given: 1,030 men and 110 women said they owned guns because they are an intrinsically valuable possession; 774 men cited hunting as a reason for possessing small arms, as did 78 women. Paradoxically, despite their assertion that they keep firearms for their own protection, 73 per cent of the same respondents surveyed by APD thought that having a gun is dangerous to their families. To shed more light on this important issue, we tabulated data collected by GTZ and compared the responses given by men and women who own arms with those who do not (Table 12.3).

The data reveal that a very large majority of armed and unarmed men and women in Somalia think that having a gun is dangerous to their fam- 
Table 12.3 Security aspects of gun ownership

Many people feel that

having a gun helps to

protect their families.

Other people believe that

having a gun is dangerous

to their families. Which

Armed

opinion do you agree with?

men

(\%) $\begin{array}{ll}\text { Armed } \\ \text { women }\end{array}$

(\%) $\begin{aligned} & \text { Unarmed } \\ & \text { men }\end{aligned}$

men

(\%) women

Dangerous

Protective

4,173

85

97

91.5

5,986

741

100

106

100

6,185

96.8
3.2

663

93.8

Total

100

707

100 
ilies. Comparing responses from unarmed men and women with those from armed men and women, we found that more unarmed men and women see guns as dangerous rather than protective. While the difference between armed and unarmed women is minimal (only 2.3 per cent), the divergence between armed and unarmed men is more significant: 11.8 per cent. One reason could be that unarmed men are particularly vulnerable because they are easy and socially acceptable targets for militia attacks. Given that guns are a sign of wealth in Somalia, another reason could be that unarmed men claim they do not want guns because they consider them dangerous when in fact they would acquire a gun if they had the means to do so. It is therefore difficult to predict if the unarmed will attempt to acquire weapons or continue to refrain.

\section{The composition of armed groups}

Somali women who are directly involved in combat are a minority, although it is uncertain if they are an insignificant one. Among the 879 women registered by GTZ, only 155 report having had combat experience; that is 17.6 per cent, compared to 71.3 per cent of the men. Information on female combatants is scarce, but from the GTZ data we can deduce that most are not armed. More than 86 per cent of the women registered by GTZ reported being unarmed. In contrast, 57 per cent of the men claimed to own automatic rifles, and only 32 per cent of them were unarmed. It seems that the recruitment of Somali women is guided by their expected, i.e. peaceable or passive, gender role. Rather than being involved in combat, they are required to assume support roles. Who these women supporters and combatants are and how many of them exist are not clear. In terms of age, the GTZ data provide us with a comparison of men and women with combat experience (Table 12.4).

Significant difference in the age structures of male and female combatants is not evident, but the data show that combat experience is not restricted to a narrow age group - active involvement in combat is an experience that all living Somali generations share. Most men and women among the oldest age group presumably fought during the strug-

Table 12.4 Age of Somalis with combat experience

\begin{tabular}{lccccc}
\hline & $\begin{array}{l}\text { Under } 18 \\
(\%)\end{array}$ & $\begin{array}{l}18-25 \\
(\%)\end{array}$ & $\begin{array}{l}25-35 \\
(\%)\end{array}$ & $\begin{array}{l}35-45 \\
(\%)\end{array}$ & $\begin{array}{l}\text { Over 45 } \\
(\%)\end{array}$ \\
\hline Male & 0.8 & 18.0 & 32.8 & 25.3 & 23.0 \\
Female & 0.0 & 20.0 & 34.8 & 31.3 & 13.9 \\
\hline
\end{tabular}


gle for independence. The fact that they agreed to register in 2000-2003 as combatants demonstrates that the experience of combat was a lasting one for their identity. On the other hand it can be assumed that expectations of reintegration benefits were a strong motivation for registration, possibly overriding their actual affiliation with today's armed groups. It can further be noted that no female respondent under the age of 18 had combat experience. According to the child protection study conducted by UNICEF, no specific evidence of girls' involvement in militia activities exists. Neither duty bearers nor advisory group members reported knowing militia girls. Assessors only interviewed boys because they did not meet girls who associated with militia groups. ${ }^{60}$ This is in contrast to boys, who reportedly begin to participate in hostilities at an average age of 12.4 years. Additional information included in the same UNICEF study indicates, however, that girls do carry out assistance functions for the militias, such as carrying equipment and guns, cooking, cleaning, spying, helping at checkpoints, fighting and acting as machine-gun assistants. ${ }^{61}$ Although the data are limited to a small number of respondents, they suggest nonetheless that some girls may carry out the same assistance activities as boys, including carrying guns ( 25 boys, 13 girls), fighting with the militia ( 24 boys, 10 girls) and acting as machine-gun assistants (17 boys, 12 girls). This finding contradicts the statement made in the same study on the lack of evidence on female child soldiers. Another source confirms the involvement of girls in the militias. The following statement by a member of the Somali National Front is recorded in a workshop report issued by Geneva Call: "Some children do not have a choice; it can be a way to survive. There is no food, no education. Boys can join at ten, girls at fifteen." 62 It can be concluded that expectations about gender roles may obscure our ability to understand the true complexity of people's affiliation with armed groups.

\section{Drivers of peacebuilding}

Disarmament and reintegration efforts during the 1990s have largely been limited to the northeast of Somalia. Due to the lack of international recognition of the de facto state of Somaliland (and consequently the shortage of reconstruction and development assistance), disarmament and reintegration have primarily been a locally driven process. Following a political deal negotiated in Borama in 2003, traditional and religious leaders put pressure on the government to absorb large numbers of armed militias into its security forces, following a quota system designed to satisfy every clan. One of the conditions for joining the new armed forces of Somaliland was to have a gun. The distinction between those 
who are armed and those who are not was therefore not only important during the war, but has also made a significant difference with regards to post-war social reward and reintegration schemes. By the time the new Somaliland armed forces were constituted, many women had already sold their guns and very few joined the army or had access to reintegration programmes.

Women who supported the struggle against Siad Barre's regime continue to be proud about their contribution, but the male-dominated society, as women's poetry shows, does not pay much tribute to their work nor provide assistance to the women who suffered because of their affiliation with the armed groups. Some of the women were caught and raped while carrying food, ammunition, drugs and other supplies to the front line. Female fighters even run the risk of being stigmatized as prostitutes because they spent time together with men outside their families. Anecdotal evidence also suggests that male fighters disliked fighting together with women at the front line. Being a woman and carrying a gun means crossing the boundaries of what society acknowledges as womanly - no matter what the reality of women's lives in this war-torn context may be, ideals of femininity and guns clearly do not go together in Somalia.

The Borama peace deal not only neglected the women who had been associated with the armed forces. Other women received support; for example significant numbers of widows are now on the payroll of the government's armed forces. While an arrangement was agreed upon to provide social security to the families of deceased ex-combatants, an estimated 70 per cent of the budget available to the Somaliland authorities is now spent on security forces, with little remaining for investment in reconstruction and social services. ${ }^{63}$ Since 2000 the Somaliland authorities have shown an interest in diminishing the exaggerated number of security personnel and requested international agencies to fund and implement a force reduction and reintegration programme, and some progress has been made towards the better recognition of women's contributions and needs. Initially the reduction and reintegration processes focused primarily on male combatants, with less attention being given to female excombatants, wives of veterans, female followers of the militias and war widows. Out of the 666 ex-combatants identified for reintegration in 2000 , only three were women. Later it was understood that war widows remained on the payroll of the army and were therefore eligible for reduction from the armed forces payroll. In addition, it was decided to include women carers of traumatized men within the scope of the programme. That more women participated in the programme after 2000 can be attributed to a partnership between GTZ and UNIFEM, and the introduction of gender-sensitive programming. Also an external evaluation conducted by Agrisystems and the WSP on behalf of the 
European Commission highlighted the need for more gender sensitivity, and recommended discarding the assumption that support to male beneficiaries would benefit female relatives. ${ }^{64}$

Somaliland's women played a significant role in arms collection following the deal negotiated at Borama, and their poems have been a key advocacy tool for disarmament. They have also devoted enormous amounts of energy to peace and development efforts. In early 1994 Dhudi Axmed Jamane, a member of the local NGO SOWDA (Somali Women's Development Association), composed a forceful appeal for peace. The poet explicitly addresses men and directly confronts them as those responsible for the fighting. She speaks to them not only as a peace activist, but also as a woman activist:

Ragoow Nabadbaan Rabnaa

Dhamaan ina ragoow

Rag iyo dumar baynunahay

Rafaad baa noo dhamoo,

Ruclo iyo ord baa nadilay,

Anaga rubadaa na maqan,

Adigoo kaare riixayiyo,

Rasaasta canabnayiyo,

Anagoo nabad raadis ah,

Baleeg labadeena ruux,

Miyay isku raadyihiin,

Kursigu waa ruux gudhee,

Miyuu kala riiqmayaa,

Ragoow nabadbaan rabnaa.

Men, we want peace

You men! Listen, all of you!

The society is comprised of all, men and women.

We, women, have suffered all the woes,

We are fed up with running for our lives.

Also we are about to die.

You men, you are enjoying your roaring tanks

With your guns cocked to fire at us,

While we are looking for peace.

See! How different the two of us are!

The seat of State suffices only one person.

It will never accommodate all of you!

Oh, men, we want peace. 
How often did politicians betray all of us?

When we were tired with broken limbs,

They always fired their guns at us,

They have deployed their tanks again,

Countless bodies are lying in the woods,

The numbers of the dead are soaring high.

Whenever we rise up against them, they change their tactics.

How often do they visit America

To confer in deceit with Congress?

Sometimes they lie and claim to represent the fifth Ethiopian province,

All these lies bring woe to us women.

Oh men, we want peace!

Hey you! With two shirts!

He who has been causing misery and shame,

He who enjoys the woes of others,

God is the Almighty, and

$\mathrm{He}$ is watching all of your moves.

The guns planted at the airport plateau of Hargeisa?

Where are they aiming at?

Are they to burn the masses?

Oh men, we want peace!

Men include my father,

and the brother from my own mother,

The one whose breast I shared,

The one to whom I have given birth,

He, who has been feeding on my blood,

My child, my love, my sight.

Men include my darling husband,

For whom I have borne children.

Have they joined together and turned all the fire on me?

Let me share my fatal fate:

When I heard the guns,

I thought it was all joke,

Until I was hit on the side of my head.

Where can I hide my child?

Where can I seek refuge?

I weep from a bleeding heart!

Oh men, we want peace.

Ragoow nabadbaan rabnaa. ${ }^{65}$ 
The poem's eloquence and rhetorical power are impressive, as are the issues covered: women's vulnerability, the experience of family breakdown, disillusionment with politicians and all men who are in positions of authority, and an unequivocal moral judgement about the fighting. Dhudi Axmed Jamane accuses men of bellicose attitudes and condemns the fighting as morally wrong. Again, this is a poet who does not shy away from naming and shaming individuals ("Men include my father, and the brother from my own mother"). She also demands political empowerment to overcome women's marginality and voicelessness, and emphasizes that men should listen to the views of women, who are part of the community and therefore have a right to help decide its fate. At Borama, shortly before this poem was created, women appealed to traditional ideals of masculinity and femininity and requested men to reassume their function as protectors of women and children. Although their interventions were filled with references to traditional gender roles, their poems and speeches also challenged them. The following excerpt from a speech delivered at the Borama Conference belongs, for example, to that subtle discourse because it utters resistance to men's actions:

Men had been our shelter

But they have thrown us outside.

We are now buffeted by winds and rain,

Being thrown here and there.

You have made us flee from Mogadishu;

You have made us flee from Burao;

You have made us flee from Berbera,

We will not allow you to move us from Hargeisa.

Maantse ogolaan mayno in aanu hargeisa ka qaxno. ${ }^{66}$

Through their poems, Somali women not only express their views on socio-political issues, but also declare their self-esteem and pride in their role as the people's conscience, which has never been passive or subservient. At Borama, women demanded political rights, including representation in Somaliland's parliament. This was denied, and the struggle for emancipation and inclusion continues.

Today, women and men remember that the only woman with political power in Somali oral history is Queen Arraweelo. The legend claims that she castrated all men, except one boy. This boy killed her, bringing men back to power in Somalia. It is clear that men continue to feel threatened by any sign that women will gain access to political power. In reality, however, male dominance is more tenuous than ever before: many lost farms and livestock during the war; today they are unable to provide for their families, cannot meet social expectations and have lost their sense 
of worth as men. This may be one reason why the idea of women's political empowerment is so threatening in Somalia today.

Given that Somalis have a long tradition of valuing small arms as insignia and instruments of power, it is yet to be seen if women's eagerness to engage in politics and decision-making, as well as the identity crisis among men, will increase or alter the demand for small arms in Somalia.

\section{Conclusion}

Somalia is the classical example of a failed state, and yet we find that the absence of national law and enforcement agencies does not equate with the absence of social norms and controls. They exist, and need to be studied as they offer a key to understanding the role and impact of guns and existing traditional forms of gun control on people's lives.

All effective small-arms reduction programmes require sound analysis of the situation in which they are expected to run. In many countries, statistical data on small arms are scarce and, if available, can easily disguise reality, in particular the gender dimension of the gun problem. Our exploration of poetry recited by Somali women demonstrates that in this situation, where forms of data on women's perceptions on small arms are scarce, other indicators and methods may provide a more useful means by which to examine the roles played by women in the social sanctioning of both gun violence and gun control. Where surveying women is difficult, for example due to security restrictions or cultural opposition to their independent participation, it is paramount that alternative methodologies be found to include them in any examination of the nature and extent of small-arms proliferation. In the case of interventions that focus on the impact of small arms, rather than on the number in circulation, there is a particular need to be grounded in the cultural context and, most importantly, to understand decision-making processes in whatever manner these are expressed at the community level.

In Somalia, as our analysis shows, debates about small arms that take place within communities instrumentalize and question conceptions of femininity and masculinity. This finding demonstrates that gender-blind small-arms research neglects both an important aspect of the problem and already existing avenues for its solution. Gender is a key determinant for small-arms use and victimization: as in many other countries, Somali men are the primary bearers and victims of small arms, whereas women suffer most commonly from indirect results of armed violence. Our study highlights the fact that Somali women are not passive victims but actors who make decisions on whether to sanction or oppose violence and gun culture. The experience of a gruesome clan-based militia war in 
the context of a failed state has turned many Somali women into advocates for peace and non-violent conflict resolution. Somali men have listened and will continue to listen when women try to keep them from unpacking guns stored at home, or when they demand a cessation of hostilities by singing songs. The effectiveness of their peace and disarmament poems should offer a lesson to aid agencies that it is essential to attend to customary forms of debate when researching, planning and implementing violence reduction programmes.

\section{Notes}

1. Saado Abdi Amare, one of the women peacemakers, composed this poem in response to the outbreak of violence. Translated by Salebaan Dahir Afqarshe. A shorter version and slightly different translation can be found in Gardner, Judith and Judy El Bushra, eds (2004) Somalia: The Untold Story. The War Through the Eyes of Somali Women, London and Sterling, VA: CIIR/Pluto Press, p. 139.

2. See the extensive study published by Furniss, Graham and Liz Gunner, eds (1995) Power, Marginality and African Oral Literature, Cambridge: Cambridge University Press.

3. Johnson, John William (1995) "Power, Marginality and Somali Oral Poetry: Case Studies in the Dynamics of a Tradition", in Furniss and Gunner, ibid., p. 121.

4. The views expressed in this publication are those of the authors and do not necessarily represent those of GTZ or the UNDP.

5. We would like to thank Shomari Rashid Brown and Birgitt Hotz of GTZ who provided much-appreciated support.

6. Bradbury, Mark (1994) The Somali Conflict: Prospects for Peace, Oxfam Research Paper No. 9, Oxford: Oxfam, p. 10.

7. All values are in 1993 US dollars. See UN Security Council (2003) Report of the Panel of Experts on Somalia Pursuant to Security Council Resolution 1425/2002, S/2003/223, New York: UN Secretariat, p. 13, available at http://daccessdds.un.org/doc/UNDOC/ GEN/N03/259/25/IMG/N0325925.pdf?OpenElement.

8. Bradbury, note 6 above, p. 10.

9. Omar, Mohamoud Jamar (2002) "Management and Control of Small Arms: The Somaliland Experience", in Kiflemariam Gebre-Wold and Isabelle Masson, eds, Small Arms in the Horn of Africa, Brief 23, Bonn: Bonn International Center for Conversion, p. 18.

10. Adibe, Clement and J. W. Potgieter (1995) Managing Arms in a Peace Process: Somalia, UNIDIR/95/30, New York and Geneva: UNIDIR, pp. 156-157.

11. UN Security Council, note 7 above, p. 7.

12. UN Security Council (2006) Report of the Monitoring Group on Somalia Pursuant to Security Council Resolution 1630 (2005), S/2006/229, New York: UN Secretariat, p. 7, available at http://daccessdds.un.org/doc/UNDOC/GEN/N06/305/15/PDF/N0630515.pdf? OpenElement.

13. UN Security Council, note 7 above, p. 15.

14. Ibid., p. 16.

15. Forberg, Ekkehard and Ulf Terlinden (1999) Small Arms in Somaliland: Their Role and Diffusion, Berlin: BITS, p. 10.

16. Gebre-Wold, Kiflemariam and Isabelle Masson, eds (2002) Small Arms in the Horn of Africa, Brief 23, Bonn: Bonn International Center for Conversion. 
17. Academy for Peace and Development (2003) "Survey on Small Arms in Somaliland", unpublished report available from APD Hargeisa and UNDP Somalia, p. 4. An almost identical version of the report was published in 2004 by the Centre for Creative Solutions and Hussein Abdilahi Bulhan (former APD director), available at www.so.undp. org/pdf/SALW\%20survey.pdf.

18. Center for Research and Dialogue (2003) The Impact of Small Arms on Children \& Youth in Central and South Somalia, Mogadishu: CRD.

19. Academy for Peace and Development, note 17 above.

20. Personal communication by Watching Brief team at UNDP Somalia, 21 July 2004. See UNDP and World Bank (2003) Socio-Economic Survey, 2002: Somalia Watching Brief, Nairobi: UNDP/World Bank.

21. Snelling, Mark (2003) "Eyewitness: On Somalia's Surgical Frontline”, BBC News Online World Edition/Africa, 7 February, available at http://news.bbc.co.uk/1/hi/ world/africa/2733255.stm.

22. UNDP and World Bank, note 20 above, pp. 56, 61.

23. For more information, contact the regional GTZ/IS office in Nairobi.

24. Hassan, Dahabo Farah, Amina H. Adan and Amina Mohamoud Warsame (1995) "Somalia, Poetry as Resistance against Colonialism and Patriarchy", in Saskia Wieringa, ed., Subversive Women, Women's Movements in Africa, Asia, Latin America and the Caribbean, London: Zed Books, p. 174.

25. UNDP and World Bank, note 20 above, p. 13.

26. Kapteijns, Lidwien (1991) "Women and the Somali Pastoral Tradition: Corporate Kinship and Capitalist Transformation in Northern Somalia", African Studies Center Working Paper No. 153, Boston University, Boston, MA, p. 6.

27. Hassan, Adan and Warsame, note 24 above, pp. 171-172.

28. Ibid., p. 179.

29. Bradbury, Mark ([1997] 2001) Somaliland - CIIR Country Report, 3rd edn, London: CIIR, p. 39.

30. Somalia Delegation of the International Committee of the Red Cross (1998) Spared from the Spear: Traditional Somali Behavior in Warfare, ICRC/SRCS T.98 59/002 6/98, Nairobi: ICRC, pp. 20-21.

31. Kapteijns, Lidwien (1993) "Women and the Crisis of Communal Identity: The Cultural Construction of Gender in Somali History", African Studies Center Working Paper No. 173, Boston University, Boston, MA, p. 6.

32. Ibid., p. 7.

33. Somalia Delegation of the ICRC, note 30 above, p. 60.

34. Bryden, Matt and Martina I. Steiner (1998) Somalia Between Peace and War: Somali Women on the Eve of the 21st Century, African Women for Peace Study Series, Nairobi: UNIFEM, pp. 51-52.

35. Bradbury, note 6 above, p. 67.

36. UNDP and World Bank, note 20 above, pp. 106-107.

37. Academy for Peace and Development, note 17 above, p. 15.

38. Ibrahim, Rhoda (2004) "Women's Role in the Pastoral Economy", in Gardner and El Bushra, note 1 above, p. 26; Musse Ahmed, Sadia (2004) "Traditions of Marriage and the Household", in Gardner and El Bushra, note 1 above, p. 55.

39. Omar, note 9 above, p. 20.

40. Enloe, Cynthia (2002) Maneuvers: The International Politics of Militarizing Women's Lives, Berkeley, CA: University of California Press, pp. 3-4.

41. Hassan, Mohamed Olad (2004) "Militiamen Shut Somalia Hospital", BBC News Online World Edition/Africa, 17 May, available at http://news.bbc.co.uk/2/hi/africa/ 3720619.stm. 
42. Bryden and Steiner, note 34 above, p. 44.

43. Hassan, Adan and Warsame, note 24 above, pp. 171-172. The Somali original of this poem was archived on audiocassette by the Women's Documentation Unit of the Somali Academy of Arts and Culture, but unfortunately got lost in the destruction of Mogadishu.

44. Thirty women participated from the Awdal, Northwest, Sahil and Togdher regions of Somaliland.

45. UN Security Council, note 7 above, p. 14.

46. Somalia Delegation of the ICRC, note 30 above, p. 59.

47. Bradbury, note 6 above, p. 71.

48. Warsame, Amina Mohamoud (2004) "Crisis or Opportunity? Somali Women Traders and the War", in Gardner and El Bushra, note 1 above, p. 125.

49. Bryden and Steiner, note 34 above, pp. 45-48.

50. Translated by Salebaan Dahir Afqarshe.

51. Harir, Shukri (2004) "Testimony", in Gardner and El Bushra, note 1 above, p. 92.

52. Translated by Salebaan Dahir Afqarshe.

53. Vivo and GTZ (2002) War-trauma, Khat Abuse and Psychosis: Mental Health in the Demobilization and Reintegration Program in Somaliland, EC Delegation in Nairobi, p. 32, available at www.delken.cec.eu.int/en/list_of_publications.htm.

54. Academy for Peace and Development (2002) "Presentation to Psychosocial Support Project Workshop, Nairobi", unpublished study commissioned by UNDP Somalia, pp. $11-12$.

55. Gardner, Judith and Amina Mohamoud Warsame (2004) "Women, Clan Identity and Peace-building", in Gardner and El Bushra, note 1 above, pp. 160-162.

56. Translated by Salebaan Dahir Afqarshe.

57. Musse Ahmed, note 38 above, pp. 52-53.

58. UNICEF (2003) From Perception to Reality: A Study on Child Protection in Somalia, Nairobi: UNICEF, Ch. 3, Table 2.

59. UNDP and World Bank, note 20 above, p. 50.

60. UNICEF, note 58 above, Ch. 4, section 4.2.1.

61. Ibid., Ch. 4, Table 9.

62. Mazurana, Dyan (2004) Women in Armed Opposition Groups Speak on War, Protection and Obligations under International Humanitarian and Human Rights Law, Geneva: Geneva Call/PSIO, p. 51, available at www.genevacall.org/resources/testi-publications/ gc-29aug04-long.pdf.

63. Agrisystems and War-torn Societies Project (2002) Somalia N.W. Demobilization and Re-integration Programme: Evaluation Report, Nairobi: Delegation of the EC in Kenya, p. 26, available at www.delken.cec.eu.int/en/list_of_publications.htm.

64. Ibid., p. 51.

65. Translated by Salebaan Dahir Afqarshe.

66. Speech originally delivered by Zeinab Mohamed Hassan, and frequently reiterated by women participants at the Borama Conference. Translated by Zeinab Mohamed Hassan. 


\section{Missing men, lost boys and widowed women: Gender perspectives on small-arms proliferation and disarmament in Karamoja, Uganda}

Christina M. Yeung

Weapons collection programmes have become a critical activity of postconflict reconstruction; a product of the merging of development and security policy in the post-Cold War era. However, while the discourse on the impact of small arms in developing countries centres on human security, disarmament activities favour the creation of strong states by returning the monopoly on the use of force to the state irrespective of statesociety relations or local norms on gun possession and use. The logic of weapons collection programmes is thus incongruous: there is a gap between the object to be secured (i.e. individuals) and the actual means of achieving a subjective state of security. Moreover, previous policy and practice have favoured the international and national levels of analysis developing a standard model of micro-disarmament - to the detriment of the particular local context of the programmes. By ignoring local culture and traditions, such programmes are by and large unaware of the impact of gender differences. The effects of such an approach will be discussed by examining a case study of the 2001-2002 weapons collection programme in Karamoja, Uganda. In addition, this chapter will explore the difficulties of reconciling the creation of a strong central state with the needs of pastoralist communities in East Africa.

The first part of this chapter will examine the gendered effects of weapons proliferation in Karamoja, a pastoralist region in northeastern Uganda. I will discuss how the demand for small arms is underpinned by gender ideologies, and in turn how gender identities and relations are shaped and impacted by violence and the use of firearms. Particular at-

Sexed pistols: The gendered impacts of small arms and light weapons, Farr, Myrttinen and Schnabel (eds), United Nations University Press, 2009, ISBN 978-92-808-1175-9 
tention will be paid to the experiences of male youths and women, both married and unmarried. The second part of this chapter will discuss the 2001-2002 weapons collection programme in Karamoja. In this section, I analyse which social groups were targeted for and benefited from the exercise, explicitly clarifying whether certain social groups were marginalized or ignored in the process, and what impacts this had on the distribution of in-kind benefits linked to the programme, such as maize meal, ox ploughs and iron sheeting. I will also explore how successful the weapons collection programme was at fully disarming households, to what extent women were involved in the decision to disarm or retain firearms and whether the experience and perception of (in)security of men and women differed as a result of the decommissioning of weapons. My research asks whether and how practical disarmament influenced the demand factors for small arms in this region, for example cultural notions of masculinity and femininity, and explores how changes might have affected the gendered socio-economic deprivation in the Karamoja cluster. Finally, I question whether the weapons collection programme made any positive or negative contributions to the long-term development and security situation of the women and men of the region, and ask what policy implications can be drawn from this case study.

The data for this chapter originate from primary and secondary sources (both published and unpublished), as well as over 70 semi-structured interviews conducted with a variety of informants in Uganda and Kenya. The categories of interviewees included kraal leaders; ngikaracuna (male youth); ngikasikou (elders); ngaberu (women); ngapesur (female youth); urban élite; community and political leaders; civil servants; representatives of civil society organizations; members of the security and intelligence organizations; journalists; and diplomats. ${ }^{1}$ Group interviews were also conducted in Jie and Bokora counties, involving between 10 and 40 participants in a semi-structured forum, comprising homogeneous or mixed groups of ngikaracuna, ngikasikou and ngaberu. Separate womenonly group interviews proved to be fruitful, as sensitive topics such as sexual violence and gender relations could not be discussed easily in the presence of men. Women were also keen to express their opinions on small-arms issues and security, topics on which they are rarely consulted. ${ }^{2}$

\section{Karamoja, Uganda - Background}

The subregion of Karamoja lies in northeastern Uganda, bordering Sudan to the north, Kenya to the east, the Ugandan districts of Mbale and Kapchorwa to the south and Kumi, Katakwi, Lira and Kitgum to the west. Karamoja covers a semi-arid area of $27,000 \mathrm{~km}^{2}$, approximately 
the size of Belgium. It is divided into five administrative districts: Abim, Kaabong, Moroto, Kotido and Nakapiripirit. ${ }^{3}$ The districts are further divided into counties, which roughly correspond to the main sections of the Karamojong tribe and other pastoralist groups of the region: Dodoth, Jie, Labwor, Bokora, Matheniko, Pian, Chekwii and Pokot. Approximately 1 million people live in the subregion and share a similar language and lifestyle, although there are minority groups, some of whom practise subsistence farming to a greater extent, such as the Labwor, while others such as the Ik and Teuso are hunter-gatherers in the mountains. ${ }^{4}$

The majority of residents in Karamoja lead an agro-pastoralist lifestyle. The frequency of drought and limited annual rainfall have encouraged a transhumance existence in order to cope with the periodic scarcity of natural resources such as water and pasture land. While the Karamojong engage in some basic subsistence agriculture of crops such as millet and sorghum, the main focus of their spiritual, economic and social life revolves around the breeding and keeping of cattle. This particular way of life has created conflict with past governments, as attempts to settle and "civilize" the Karamojong have been resisted. Beginning with the British colonial administration, state policies towards the pastoralists have varied from neglect and containment, by closing off the subregion to other districts in Uganda, to "modernization" by the introduction of cotton as a cash crop by Idi Amin and the more modest development efforts of the present government through the creation of the Karamoja Development Agency. However, Karamoja remains a relatively under-serviced, underdeveloped zone of Uganda, beset by general insecurity and marked by several layers of conflict. ${ }^{5}$

A lack of presence of the government and the proximity to rebel movements in northern Uganda and southern Sudan have facilitated criminal activity such as arms smuggling, commercial cattle raiding and banditry on the roads. These activities are primarily motivated by economic demands, but unfortunately have resulted in a very negative stereotype of the Karamojong among other Ugandans. The levels of conflict in the region are threefold: firstly, inter-tribal clashes between the various pastoralist groups in Karamoja such as the Bokora, Matheniko, Dodoth and Jie; secondly, raiding of their predominantly agriculturalist neighbours in Uganda such as the Acholi, Sabiny, Langi and Itesot, and mutual clashes with other pastoralist tribes in neighbouring countries such as the Turkana and Pokot of Kenya and the Toposi and Didinga of Sudan; and finally, conflict with the state, especially when the Uganda People's Defence Force (UPDF) responds to cattle raids or is forced to implement government policy such as the disarmament programme. ${ }^{6}$ The conflicts in Karamoja are widely misunderstood; the violence is generally not politically motivated or targeted towards the state, 
unlike the Lord's Resistance Army (LRA). Nor is the violence sustained, but rather it seems to pursue a pattern of large sporadic clashes, mostly between sections of the Karamojong or against neighbours, followed by a response by the state which usually takes the form of overwhelming use of force.

Weapons and a warrior culture have a long history in the Karamoja subregion. Until about the 1950s the weapons tended to be sticks, spears and bows and arrows; however, as firearms were acquired in the 1970s by various neighbouring tribes, home-made guns (amatida) and then modern weapons such as the AK-47, G3, SMG (submachine gun), SLR (self-loading rifle), LMG (light machine gun) and pistols became commonplace. One anthropologist, Sandra Gray, has argued that the weapons themselves are not the cause of violence in Karamoja, but reinforce a process of division already under way among the clans due to ecological degradation and colonial and post-colonial policies. ${ }^{7}$ While the history of arms acquisition and their effect on the nature of cattle raiding are well documented in the literature on Karamoja, there is very little discussion about why there has been an evolution towards more brutality during the conflicts, such as raping, pillaging, killing of women and children and attacking internally displaced person (IDP) camps. As the use of force with increased firepower is often asymmetric and unnecessary, I hypothesize that the increasing brutality is due to a crisis of masculinity among the Karamojong youth, or ngikaracuna, compounded by the social and economic breakdown of traditional institutions of authority and social structures. As will be demonstrated, the women of Karamoja are at the heart of this crisis.

\section{The agency of women in the Karamoja conflict}

Karamojong society is highly stratified and the division of labour and responsibilities still falls largely along traditional notions of gender roles. Women are excluded from the age-set system of men. Although they have their own initiation into womenhood called akiwor, they technically belong to the generation and clan of their husband. While the akiwor bestows upon the older women a certain status, a right to meet with other women and perform ceremonies, it does not confer the same socioeconomic powers of decision-making as the council of initiated (male) elders, or akiriket. ${ }^{8}$ Traditionally, the akiriket had the responsibility of deliberating and settling issues regarding grazing grounds, enemies, raids, bride wealth, political alliances, etc. ${ }^{9}$ Uninitiated men would implement the decisions of the akiriket, and in doing so could gain distinction and social advancement through bravery in battle or raids. For younger men, 
often perceived as "irresponsible, disrespectful, impatient, arrogant and fun lovers", especially those who are unmarried and have not fathered a child,${ }^{10}$ combat or raiding activities gave youths a means by which they could participate in the political life of the clan.

Although Karamojong women do not have formal access to traditional decision-making institutions, through their social roles as unmarried girls, wives, mothers and elder women they play an ambiguous and often ignored part in the conflict dynamics of the region. Their influence is regularly demonstrated in the subtle ways in which they encourage/discourage men to raid, and during infrequent occurrences such as peace crusades. In the past, women have been accused of encouraging and inciting men to raid and take revenge, especially in times of great hunger or following a devastating raid by enemies. ${ }^{11}$ The women would help initiate the raid by hinting that the children were without milk (indicating the need for cows) or, in extreme cases, wives would attempt to inspire their husbands to raid by beating their children to portray poor household welfare. ${ }^{12}$ More explicit and popular methods of encouraging cattle raiding among older generations of women include taunting and humiliating the men, or insulting their manhood by accusing them of not providing for the family. ${ }^{13}$ However, in my field interviews and in more recent literature it appears that these techniques are used less frequently today, as women are often left to fend for themselves and their children, especially during bouts of famine. One Dodoth woman remarked: "Men do not feel for the cries of their children." ${ }^{14}$ Recent periods of extreme scarcity and food insecurity have strained the communal nature of Karamojong society.

In customary tradition, the elder women of the village and mothers of raiders would wear the arapet skin to indicate when they were ready to send their sons to raid. The women would also bless the ngikaracuna before the raid by smearing the youth with animal blood and making the ngikaracuna pass through their legs. As they sang and danced, the women also performed the ceremony of awatun; they "sprinkled water in specifically made gourds as they [the men] make symbolic first steps into the journey ahead". ${ }^{15}$ While women are not perpetrators of the raids themselves, they can, and by means of such ceremonies do, play a supporting role. One female commentator noted, "The women do not fire AK-47 rifles. However they have an important cultural role in cattle rustling. The weapon they hold is their tongue."16 Besides verbal encouragement, wives and mothers assist their husbands and sons in supporting roles by boiling sorghum (preparing food) for the often long raiding excursions. ${ }^{17}$ Although the women deny any involvement in the smuggling or trade in small arms, ${ }^{18}$ women sell ammunition to the ngikaracuna that they have collected as payment for alcohol they have brewed and sold. A 20-litre 
jerry can of ebutia (local brew), for example, might be bartered for 20-50 bullets. ${ }^{19}$ The UPDF has until recently assumed that women were not involved in the weapons trade, but it has begun to search women in an effort to stem arms trafficking in the region. ${ }^{20}$

Traditionally, upon their return from a successful raid the women would sing and dance songs of praise for the brave warriors, and the youth were given new names describing their role in the battle, such as Giraale ("you killed a man who had scarifications", i.e. one who had killed previously). ${ }^{21}$ The distinction in battle and subsequent exaltation of the ngikaracuna by elder women appear to have great significance for the youth, especially those unmarried, as bravery in battle is traditionally a desirable attribute for a husband. Perpetrators of botched raids return home under the cover of darkness to avoid the shame of failure. In fact, honourable conduct in battle is so highly valued that security officers note the most dangerous group of ngikaracuna are the unpredictable youth between the ages of 15 and 24 (generally unmarried). These are typically the armed thugs who ambush cars and buses on the roads in frustration after returning from an unsuccessful raid. ${ }^{22}$

The role of women in the conflicts of Karamoja is somewhat ambiguous; besides encouraging raids in various ways, the women are also highly active in peace activities. Women, like uninitiated men, cannot sit at the council of initiated elders, akiriket. However, initiatives by the local government and the Organization for African Unity-Interafrican Bureau for Animal Resources (OAU-IBAR) have attempted to build upon traditional women's initiatives such as the alokita a ngaberu, where groups of women gather to compose songs containing messages of social importance to the community. This occurred during the 2001-2002 disarmament programme. Through their roles as wives and mothers, women also participate in conflict mitigation and resolution. During peace negotiations, two mothers from opposing communities exchange babies and breastfeed them as a symbolic alliance between the two communities. ${ }^{23}$ Or women can be chosen as messengers between clans, as they occasionally marry into different clans and are not directly perpetrating raids. They also can choose to go on peace crusades of their own, sharing milk and tobacco with enemy communities as peace offerings. These offerings are rarely refused, as it is believed that to reject a woman's peace initiative is to invite a curse. ${ }^{24}$ Older, well-respected women also have the power to curse younger generations. Many ngikaracuna no longer ask for the blessings of women before raids, as they fear that a raid which is not sanctioned will encounter major obstacles. ${ }^{25}$ Lately, some women have performed innovative roles in the provision of security. When the vigilante system of community-based security was pioneered in the early 1990 s, women were mobilized as intelligence gatherers, given their ability 
to move about without causing suspicion due to the necessity of performing domestic chores, such as fetching water and firewood. ${ }^{26}$ More recently, a few individual women have become involved practically in defence, by joining the Anti-Stock Theft Unit (ASTU) militia. These women are reportedly supported by their communities in their roles as providers of security, but face numerous obstacles to these roles, such as sexual harassment by their superiors and limited promotion opportunities because of their lower levels of education in comparison to their male peers. ${ }^{27}$

\section{The gendered effects of small-arms proliferation}

These days, there is increasing ambiguity among the young women about what makes a desirable husband. As in many other African pastoralist societies, the payment of bride wealth by the groom in heads of cattle is a critical feature in the institution of marriage in Karamojong culture. As has been noted by one study, "Although these gifts are supposed to be tokens of appreciation to the women's parents, often they have been regarded as a price or value for the woman." ${ }^{28}$ Thus the customary norm is that women do not participate in formal decision-making; because of the high bride price, the women are considered the property of men, who are generally richer, more educated and own other assets as well. This has the effect that women are under pressure to produce children, to increase the resources of the husband's clan. These children belong to the husband's clan and in case of divorce must be left with the father's family. ${ }^{29}$ Although divorces do occur, they are rare, as the bride wealth would have to be returned. The bride's family would discourage the divorce unless it appeared that another man was willing to refund the bride wealth. In fact, it is much easier for a man to demand a divorce than a woman, as divorce is perceived as a loss of face to the man, even in cases of extreme beatings. ${ }^{30}$ Grace Loumo, the coordinator of KAWOGO, a women's NGO in Karamoja, observed: "The women lack the awareness that they have rights." 31

Traditionally, the "bride price" would vary between 20 and 160 cattle (depending on the community and clan). ${ }^{32}$ Friends and members of the groom's family would contribute to the payment, and relatives and friends of the bride would then share the bride wealth. In this way, affiliation ties were multiplied and strengthened, contributing to an important social network which could be called upon in times of need, such as poor harvest or famine. Unlike other tribes, where an exchange of livestock has more of a symbolic value, in Karamoja the bride wealth forms a part of a survival strategy for living in a harsh environment. Weapons are in- 
creasingly being included as part of the bride wealth in Karamoja and with neighbouring tribes; the inclusion of guns in this most sacred of cultural institutions indicates that "arms' bearing has acquired a significant role in the spiritual and material culture of the pastoral nomads of Eastern Africa". ${ }^{33}$

These days, a groom's parents and family do not always meet the marriage obligation, leaving the young man to his own devices. As a result, several options exist; the youth could marry on "credit" with the intention of paying later, or "half marry" the woman, where he pays eloto/ekichul, one to three cows for the birth of each child, to the wife's family (as the child belongs to the clan of the father) ${ }^{34}$ However, in both of these options the man could lose his wife and children to another suitor who is willing to pay the bride wealth promptly. ${ }^{35}$ Alternatively, the groom could replace the payment of cows with other animals, such as goats and sheep. However, these arrangements for marriage are not as desirable and, where possible, all efforts are made to pay the bride wealth in cattle. Due to the importance of meeting the demanded bride wealth, some ngikaracuna, especially those from poorer families, will mount armed raids with their friends to acquire the necessary cattle. ${ }^{36}$ If they do not already possess weapons, guns will be "rented" from friends, relatives or other members of the community. In some cases the debt will be repaid in cattle or through participation in further raids. ${ }^{37}$

Many reports have pointed to the high bride wealth (relative to other communities) as causing conflict both within families and between communities. ${ }^{38}$ Besides raising the necessary cattle for bride wealth, raiding is a means of achieving recognition of adulthood for young men; it is also considered a responsibility to replenish the family/father's herd; or as one author remarked, the karacuna becomes "a virile protector of the tribe and family". ${ }^{39}$ However, there is a tension in the acquisition of status, for the karacuna, like other youth, wishes to assert his independence from his father. Through raiding, the young men are able to accumulate wealth and cattle of their own, in order to fulfil their own needs for marriage and economic self-sustenance. Sometimes a youth will choose the life of a professional raider rather than tend to the cattle of his father's herd. Lokui, a notorious raider in Jie county, explains: "We use the gun to defend ourselves and some get rich... I'm willing to stop, yes, but I want to marry and have money to buy things just like you and the other people in town." 40

Many elders claim gun possession has made the youth more arrogant and aggressive. ${ }^{41}$ They lament the lack of respect from the younger generations of men for their decision-making authority on important matters of raiding, grazing, conflict resolution with other tribes, etc. At the heart of the matter, weapons have accelerated and rendered the process of 
acquiring status and wealth (in the form of cattle) unpredictable in Karamoja society. Charles Ocan, a researcher on pastoralism, explains:

Once again there is ardent conflict between the elders and the war-leaders. There is total disrespect of the will and power of elders in favour of the will and power of weapons. Possession of weapons and a retainer army is now the major determinant of authority. Age is virtually a very insignificant factor... The accumulation by the new leaders, the war-lords, is largely through cattle raids. However, the instability of cattle ownership makes their wealth risky and their position fluid. ${ }^{42}$

Ocan hypothesizes further that "because cattle have become so fluid and risky to possess, people turn cattle wealth to 'women wealth' by marrying several as a kind of cattle security". ${ }^{43}$ The uncertainty of individual cattle ownership appears to afford some Karamojong men the ability to enter into multiple marriages, while reducing the likelihood of others to marry at all. Research by scholars on other related pastoralist societies seems to reinforce this finding. In her study of the Turkana and Pokot in Kenya, Vigdis Broch-Due observed that the priority of some men was to marry additional wives rather than save up for the bride wealth of their sons. ${ }^{44}$ By delaying his sons' weddings as long as possible and marrying off his daughters, the father is able to accumulate bride wealth and can thus achieve his polygamous ambitions. ${ }^{45}$ The number of wives varies, although six co-wives for a rich man is not unusual and one study even recorded a case in which a man had 24 wives. ${ }^{46}$ This practice puts increasing strain on father-son relations and has been noted as a cause of the rising number of cases of parricide reported in Karamoja. ${ }^{47}$

It is interesting to note that although bride wealth and cattle ownership may cause disputes leading to fractured homesteads and premature division of family herds, out of the different social groups I interviewed only the ngikaracuna advocated for smaller bride wealth. ${ }^{48}$ As demonstrated above, senior men have an interest in higher bride wealth as it eases competition with younger men for wives. Perhaps surprisingly, the women and elders were virulently against any change in the custom. They made references to the traditional function of the bride wealth as a kind of social safety net, which is shared among their kin and friends: "Paying the bride price is the responsibility of the whole family and community. It is the equivalent of education; it benefits everyone." 49 Women, in particular, mentioned that large numbers of cattle were essential to feed their family. (It has been estimated that six head of cattle per person are needed to satisfy alimentary needs. ${ }^{50}$ ) Despite being one of the most vulnerable groups during a raid, the women refuted any link between high bride wealth and the need for the ngikaracuna to raid. 
Young men in Karamoja, obviously, felt quite differently. Many complained of few other economic options than to use a gun for cattle rustling. Very few boys, especially in rural areas, are educated: 91 per cent of male children of primary school age do not attend school. ${ }^{51}$ The young men are disempowered economically and socially, with little hope for the future. Similar to the cases of South Africa, Timor-Leste and Papua New Guinea covered in this book, unemployed and redundant youth are increasingly the users of illegal weapons for criminal purposes. Some businessmen and warlords have capitalized on the lack of job opportunities to employ the young men as thugs and raiders. ${ }^{52}$ As a consequence, commercialized armed cattle rustling has provided many ngikaracuna with the means to enjoy luxuries they see in the towns, such as Western goods, clothing, ornaments and bottled or locally brewed beer. ${ }^{53}$ The allure of owning non-traditional luxuries - and the status they confer - has the distorting effect that the weapon, which is actually owned by the family (or group of brothers), brings benefits to the individual karacuna who uses it and claims ownership of the gun. In an effort "to show off his generosity and sophistication... and to celebrate a kind of soldierly camaraderie", the young man will share his purchases with his fellow warriors and the women he may be courting. "These forms of exchange... not only exclude older men from the social content of the transactions, but also eliminate their wives and children in the settled communities from the benefit of customary exchange relationships which they enjoyed before the arrival of AK-47s." 54 The firearms have afforded male youths an immediate means of self-affirmation and an external display of their masculinity which bypass customary routes to manhood in Karamojong society, such as the age-set initiation, marriage and ownership of cattle. In recent years these cultural markers of male prestige have become more difficult to achieve for a variety of complex socio-economic reasons.

Many young, uneducated women are looking for other ways, besides cattle keeping, in which a man might be able to provide for his family. To avoid the likelihood of becoming a widow, these young women are increasingly refusing to marry warriors from their clan, instead choosing to marry (educated) urban businessmen. ${ }^{55}$ And few of the women I interviewed spoke positively of the practice of encouraging men to raid, so prevalent in anthropological accounts of the Karamojong. Instead, women lamented about becoming widows and the ensuing problems:

If there is a woman who supports raids, it can only be because she has not suffered from the consequences of raids. I would say categorically that women should campaign for an end to war and conflict; because at the end of the day, they are the ones who are rendered destitute. Men have the privilege of being able to die out there during the raids, but we have to die here at home slowly 
and painfully. I have lost all the men around me to raids. First it was my husband, then my son and finally my son-in-law. At my age, that means that I am a destitute, because in this society, if there is no man in your life, you are nobody. ${ }^{56}$

Despite the custom of wife inheritance by a male relative of the husband, one woman in Jie county noted:

The widows are not looked after properly. Sometimes the community doesn't help. There are no programmes from the government. Sometimes the women are left with the children, but no support, especially if the widow has no male children. $^{57}$

Some women have even been widowed multiple times. Within three years, one woman from Nabilatuk subcounty was widowed four times; her husbands were all brothers. The cousin of her last husband recently inherited her; she has asked her family not to demand a dowry in order to avoid being condemned as a witch. ${ }^{58}$ Thus greater incidence of mortality due to firearms injuries has translated practically into an increasingly widowed society, with a statistically skewed male-to-female population ratio.

As a direct result, in recent years female-headed households have become commonplace in the northeastern region due to violent cattle rustling and related activities. According to data from the Ugandan Child Health and Development Centre, these households are more likely to suffer poverty than male-headed households due to the fact that women have lower literacy levels, less likelihood of owning land and fewer means of income generation than men. ${ }^{59}$ Another growing trend of concern is the increasing number of orphans. ${ }^{60}$ At the last count, in 1994, there were almost 26,000 orphans in the Karamoja region. ${ }^{61}$ Christine Lacun, a member of the Kaabong Women's Group, noted: "Many of the women and children are finding their way out of Karamoja to Mbale and even as far as Jinja and... Kampala. Children hide underneath the seats of buses headed for Kampala. Many of them are now street children." 62 Others, especially girls, have been trafficked as cheap labourers or sex slaves in neighbouring districts. ${ }^{63}$ Those children who stay in Karamoja are obliged to begin working at an early age as a result of becoming the head of the household. According to Anna Regina, the Kotido district planner: "The orphans are forced to become shepherds under difficult circumstances. During raids, the raiders tie them to trees. Some are forced by raiders to drive the raided cattle for long distances and later abandoned. Some get lost and others are killed." 64

Even for women who are not widowed, the strain of constant insecurity 
due to armed violence is an extra burden on their ability to perform normal household functions. Karamojong women are already weighted with many responsibilities. In general, the division of labour between men and women is split between tending the cattle and looking after the home and garden, although men are increasingly helping out with agricultural chores such as ploughing and harvesting. ${ }^{65}$ Some of women's duties include raising and feeding children; looking after the homestead; preparing meals; brewing and distilling; fetching water, firewood and household materials such as grass for the huts and sticks for fencing; building homesteads; and planting, weeding and harvesting the garden. The chores that require leaving the safety of the homestead, such as fetching water up to $10 \mathrm{~km}$ away, are particularly dangerous. As a result, the women tend to travel in groups of between five and 50 individuals, depending on the anticipated distance they have to cover. ${ }^{66}$ They have also curtailed activities such as foraging for wild greens and planting in the more fertile borderlands between tribes, which has severely impacted on their family nutrition. Intensifying usage of natural resources located in proximity to the homesteads has in many cases depleted water sources, rendered agricultural land unproductive (due to lack of alternation) and caused unnecessary deforestation of tracts of land.

While rape used to be frowned upon ${ }^{67}$ the sheer number of testimonials from interviews I conducted seemed to indicate that rape and assault of women by government soldiers and armed men from enemy tribes, during raids and also in non-raid situations, have become widespread practices. ${ }^{68}$ There have also been reports of women who contracted "slim" (HIV/AIDS) from husbands who raped other women while raiding. ${ }^{69}$ As a result of sexual violation, many of the women suffer from sexually transmitted diseases (STDs), damage to their reproductive organs, chronic pelvic pain and psycho-traumatization. As access to and a lack of health facilities are particular problems in violent conflict areas, serious reproductive health complications develop, such as "perineal tears, obstructed labour with tears in the birth canal" and infertility. ${ }^{70}$ In addition to the trauma of health complications, a Karamojong woman who is raped is implicitly held responsible for her suffering and subjected to certain ceremonies conducted in cases of adultery before she can return to her partner. ${ }^{71}$ If she is no longer able to bear children, she might also suffer the humiliation of being divorced by her husband or face other ridicule in a society that values fecundity.

In general, women and children are particularly affected by the interrupted service delivery of non-governmental organization (NGO) and governmental health, education and development programmes due to armed conflict. Over 30 years of uncontrolled proliferation of small arms in Karamoja (and government mismanagement) have taken their toll and 
are clearly evident in development indicators of the region. According to the Ugandan government's own statistics, only 27 per cent of the population have access to health services in Moroto district, and a mere 10 per cent in Kotido district. ${ }^{72}$ Both the infant mortality rate $(137 / 1,000)$ and the maternal mortality rate $(500 / 100,000)$ are much worse than the national averages. ${ }^{73}$ Literacy rates for men stand at 12 per cent and are only 6 per cent for women. ${ }^{74}$ It is believed that of the children who are enrolled for primary school (but do not necessarily attend), up to onequarter may do so solely to benefit from the World Food Programme's feeding programme. The government acknowledges that many children do not attend school due to the long distances from the homestead to school (up to $10 \mathrm{~km}$ ) and insecurity as a result of frequent cattle raids. ${ }^{75}$ Furthermore, many women I interviewed complained that in order to access a hospital with surgery facilities they would have to cross enemy territory, where they risked being killed.

One district official noted that "During periods of insecurity, development activities are another area relegated to a low priority; projects are delayed or disrupted, and planning becomes crisis-oriented or nonexistent." Moreover, "Unstable settings also affect the willingness (or not) of government and donors to invest in the health and well-being of women, adolescents and children." 76 Furthermore, the district administration has difficulty attracting and retaining educated and well-trained professionals due to the hardship and danger of working in areas of armed conflict. As a result of frequent road ambushes, service providers have the additional inconvenience and financial burden of budgeting for armed escorts. The district planner of Kotido explains: "Within Jie, there is no insecurity, but to move to the next county of Dodoth, one has to budget for escorts. This situation applies to everyone: Government, NGOs, and individuals. Even if you are carrying armed personnel, you may still be attacked and killed." 77

\section{Disarmament in Karamoja, 2001-2002}

The increasing use of small arms by the ngikaracuna, in conjunction with increasingly frequent and brutal cattle rustling, has degraded the personal security of the most vulnerable social groups (women and children) in Karamoja. Unfortunately, other tribes in neighbouring districts have also experienced the effects of armed raiding by the Karamojong. While cross-border raiding has been a regular occurrence over the past 25 years, in March 2000 particularly destructive attacks perpetrated by armed Karamojong internally displaced approximately 56,000 people in Lira, Soroti, Kumi and Katakwi districts. ${ }^{78}$ Almost one-third of the pop- 
ulation of Katakwi district sought refuge in 53 IDP camps. ${ }^{79}$ The raids caused much furore in the media and among the general public.

The same month, Captain Michael Mukula, member of parliament (MP) for Soroti municipality, introduced a private member's motion on behalf of parliamentarians from the affected districts, committing the government to disarm the Karamojong. The motion also called on the government to develop the northeast, but placed its emphasis on immediate steps to remove armed Karamojong from the neighbouring districts, as well as setting up armed militias and deploying troops along the border areas of Kapchorwa, Mbale, Kumi, Katakwi, Lira, Apac, Gulu and Kitgum. ${ }^{80}$ This containment of Karamoja was eerily reminiscent of British colonial policy, which attempted to create a cordon sanitaire around the region. ${ }^{81}$ The parliamentary debate was heated, and the gendered nature of armed violence in Karamoja and its neighbours received particular, and frank, attention:

Capt. Michael Mukula (MP Soroti Municipality, Soroti): In the African culture, it is a taboo for a man to rape another man...

Mr. Benedict Mutyaba (MP Makindye East): Mr. Speaker ... may I also inform him that it is a taboo in African culture for a man to rape a woman?

Capt. Mukula: Mr. Speaker, I thank my Colleague for the information, but that is exactly what the Karimojong are doing; they are raping women and men equally. I was coming to it. ${ }^{82}$

Mr. Adome Lokwii (MP Jie County, Kotido): This is a situation where people have been conceived, born, lived and are dying in that kind of militarized situation... we must devise means to make the Karimojong know that they can still survive without a gun, without a cow and so forth. ${ }^{83}$

Although the resolution on disarmament in Karamoja was passed on 14 March $2000,{ }^{84}$ the actual programme did not get under way until well after the presidential and parliamentary elections in mid-2001. In midSeptember a particularly bloody attack on Ngariam IDP camp in Katakwi district reignited the debate regarding disarmament. Inter-ethnic conflict between the Karamojong and their neighbours threatened to spiral out of control. In response, President Museveni launched a weapons collection programme in Karamoja on 2 December 2001.

\section{Phase I - Voluntary disarmament}

As early as October 2001, the women in Karamoja were organizing themselves and lobbied to meet with the president to voice their developmental concerns. They told him they felt marginalized and wanted improvements in infrastructure, education, security and legal counsel. ${ }^{85}$ 
The meeting was successful, and unique in that it brought the concerns of the grassroots right up to the president. Later, during the voluntary phase of the disarmament programme, the president used this strategy of meeting with various social groups - ngaberu (women), ngikasikou (elders) and ngikaracuna - to address their specific demands and concerns in order to encourage disarmament. President Museveni appealed to the women of Karamojong to take a leading role in the weapons collection programme, as it was the only way to "peace, unity and development". 86 Many women responded by attending meetings and lobbying their husbands and sons individually at home. Almost all the women I spoke with claimed to have been very positive about disarmament before the initiation of the second or forceful phase of disarmament. Polls conducted before the weapons collection programme in 2000 revealed that the ngaberu and ngikasikou overwhelmingly supported the decommissioning of weapons ( 88 per cent), while 82 per cent of ngapesur (young women) supported the initiative. ${ }^{87}$ The reasons for advocating for the surrender of arms varied. Some women were weary of the effects on their family, the indiscriminate attacks on women and children during cattle raids, the loss of life and cattle and ensuing poverty; they felt that the weapons were now doing more harm than good. Others were concerned about gun violence within their communities, especially due to drunken behaviour among men. ${ }^{88}$ One woman told me she wanted greater security; she wanted to be free to go to neighbouring districts for household needs. ${ }^{89}$

While most of the women took a very active and risky role in the first phase, a few told me that, as they themselves were not handling the guns, they did not think that the weapons collection programme was relevant to them. They were not involved in the deliberations regarding disarmament. This opinion was, however, rarely expressed. The majority of women I spoke with claimed that the decision to disarm was taken at the family level and usually at least one gun was kept for insurance purposes. On the other hand, one man told me that the men of his village threatened the women with violence when the women told them to hand in their firearms. ${ }^{90}$ Attacks on women did in fact become a common occurrence later on; when the raiding recommenced and many families lost their cattle, wives and mothers were blamed for convincing their husbands and sons to surrender their weapons.

Many women had actually been the ones to turn in the weapons to the army and the civil-military operation centres (CMOCs). ${ }^{91}$ Some men feared being arrested (although a general amnesty had been declared for the voluntary phase); others felt that women were less likely to be interrogated about the origin of the gun, other weapons at home or the poor state of many of the firearms surrendered. ${ }^{92}$

As individuals and through women's NGOs, women were also active in 
advocating for peace, despite the poor financing of their activities and the lack of facilitation to meet as a regional collective. ${ }^{93}$ They composed and sang songs about disarmament that became well known, building on the local tradition of peace crusades and peace choirs. In Moroto women's groups mounted a play about the dangers of small arms, which was performed within their communities.

\section{Disarmament for development incentives}

The response to disarmament incentives and other efforts to mobilize the community, which were led by the local leaders and civil society organizations, was initially described as "excellent" by the government. ${ }^{94}$ By 2 January 2002, the original deadline of the voluntary phase, 6,452 weapons of an estimated 40,000 had been collected. ${ }^{95}$ The deadline of Phase I was then extended to 15 February 2002, as the response to the voluntary strategy had been so productive that the government had difficulty in delivering the promised incentives for the surrender of weapons. Several incentives had been promised to each person surrendering a weapon: a certificate for the weapon relinquished, a one kilo bag of maize meal and an ox plough. For the local leaders who successfully mobilized their communities to comply, 20 iron sheets were also pledged. ${ }^{96}$ These items were recommended as appropriate rewards by an earlier parliamentary task force after, as was claimed, adequate discussion with the communities. Few of the villagers I interviewed, however, felt that they had been consulted. Suggestions by community-based organizations (CBOs) for non-discriminatory communal incentives, such as cattle dips or boreholes, were ignored.

In general, people were disappointed with the exchange scheme for weapons. Opinions regarding the rewards were mixed. Many found that the ox ploughs were not useful and came too late in the agricultural season, or could not be used because all their cattle had been rustled. A majority of people interviewed felt the rewards did not suit their needs and they would have preferred cows or money to buy cattle. Others found the items helpful when they were given to them. However, not everyone who surrendered a gun got one of the incentives: in the end, the majority did not receive anything. ${ }^{97}$ The government ran out of money to supply the maize meal and ox ploughs. And certainly, the methods of distribution of the rewards were not transparent; at the village level, many people suspected that corruption at the district level was preventing fair and equitable distribution. By the end of the original deadline of Phase I, the non-delivery of goods was affecting the motivation to turn in weapons voluntarily, and the extended deadline of 15 February yielded only another 1,224 guns. ${ }^{98}$ 


\section{Phase II - Forceful disarmament}

By the end of February, the government's stance and language had changed quite dramatically. Major Shaban Bantariza, the government spokesman, told the UN news agency IRIN that "the army had decided to move in and forcibly disarm the Karamojong because they had largely ignored the call to surrender their guns under the voluntary disarmament programme launched by President Yoweri Museveni". ${ }^{99}$ The minister of state for Karamoja further warned: "We have persuaded you [Karamojong] to return the guns for the last two months, and now we have washed our hands. It is time for the army to act - you know the consequences." 100 While the official disarmament strategy by this time had changed to one of force, civil society, local and national NGOs and the Uganda Human Right Commission (UHRC) were continuing a strategy of engagement and dialogue with the army to try to minimize the risk of human rights violations. The UPDF leadership was largely cooperative and open to attempting to deal with indiscipline within the lower ranks of soldiers who were implementing the second phase of the weapons collection programme.

Nonetheless, during the subsequent months serious concerns were raised by the media and civil society about the indiscriminate methods of disarmament used by the army despite human rights sensitization by the UHRC. ${ }^{101}$ During Phase II, in Jie county where I conducted many of my group interviews it was not uncommon for the men of a village to have been beaten, arrested and taken to the army barracks until weapons were surrendered. ${ }^{102}$ And despite the fact that women, children and the elderly were not the primary users of weapons, they were not spared beatings either when the army came to search for firearms in the villages. ${ }^{103}$ Many women reported being raped and assaulted during the military operations, including one pregnant woman who subsequently lost the baby, and another who was beaten and later gave birth to a stillborn child. ${ }^{104}$ One village testified that they had been displaced 20 miles after the army burned down their shop and huts. The villagers claimed to have stayed in the bush for two months, during which time many children died in the crossfire of raids or from disease. ${ }^{105}$ Few of the people that I interviewed at the village level had heard of the civil-military operation centres, where human rights abuses could be reported, as the CMOCs were located only in the administrative town centres of Kotido, Moroto and Namalu. Those who did use the CMOCs complained that often they were only staffed by army officers, and not a single centre had a female representative, despite the fact that local women's organizations had requested them during initial community consultations. ${ }^{106}$ Furthermore, there were no provisions to ensure privacy, especially for those reporting abuse of a sexual nature. ${ }^{107}$ 


\section{Disarmament and the provision of security}

In other areas, such as Nakapiripirit district, the weapons collection programme was conducted with significantly fewer incidents of human rights abuses, although by May 2002 the disarmament exercise was yielding significantly less results in the entire region. ${ }^{108}$ In part this slowness was due to the problems of the incentives and the inability of the government to ensure the basic security of communities in Karamoja. While the army was attempting to recruit, train and deploy local defence units (LDUs) or militias of armed local volunteers, a major military offensive, Operation Iron Fist, was launched in March 2002 against the rebel Lord's Resistance Army in northern Uganda. This had the negative effect of severely reducing the military's presence and capacity in Karamoja to deal adequately with increasing incidents of internal and international cattle raiding. ${ }^{109}$ Furthermore, the different clans perceived the weapons collection programme to be unevenly implemented, and mutual distrust resulted in the rearmament of various communities. By this time women felt that there was very little they could say to their menfolk about rearmament and disarmament, as many women had been beaten as punishment for having advocated the surrender of weapons during Phase I. ${ }^{110}$ Months after the 2001-2002 programme ended, even the government acknowledged that the levels of small-arms proliferation in Karamoja afterwards were greater than before the disarmament programme. ${ }^{111}$ As a result, it can be argued that the programme failed to improve the strategic environment for socio-economic development of the communities and of the women in particular, who defined security for themselves as freedom of movement, increased access to education for their families and assistance to deal with stress such as famine and drought. The silencing of women, who had initially shown such willingness to influence the men to disarm, is probably the most invisible of the impacts of the failed weapons collections initiative. However, it is among the most serious, as it has undermined their hard-won progress in participating politically in community decisions, and renewed stereotypical masculinist views that women are too ignorant to be trusted with important issues such as decisions on security.

The weapons collection programme also did little to improve the lot of men, who defined their security interests primarily in terms of peace and their ability to keep cattle. ${ }^{112}$ Because of the predominant ideal of masculinity in Karamoja, which is fundamentally tied to notions about men as protectors, disarmament was experienced as a kind of emasculation. It undermined both social status and the militarized sexual identity which is held as an ideal: that of a heterosexual adult male who is a brave and successful warrior; one who is able to protect his many wives, children and cattle. Some men were taunted by their peers for surrendering their 
weapons to the government. It was claimed that in doing so they had become "as powerless as women". ${ }^{113}$ This logic stressed that a man had no right to give away the (potential) wealth and means of protecting his family. The ultimate humiliation for many men was their inability to protect their family from beatings, rape and loss of cattle, and the banning of their traditional cloth, the suka, especially throughout the period of the forced disarmament. By giving in their weapons and returning the monopoly of the use of force to the state, the men of Karamoja were supposed to place their security in the hands of the state. However, the poor planning and implementation of the militia initiative and the unfortunate coincidence of the disarmament exercise with Operation Iron Fist, which reduced the army's effectiveness in dealing with increased raiding, means that the state failed to meet expectations that it could protect the lives and property of the Karamojong. Paradoxically, this issue had been raised earlier during the debate on the parliamentary motion for disarmament. The MP for Agago county, Kitgum, Owiny Dollo, one of the co-sponsors of the motion, commented:

Although this motion is called Karamoja Disarmament motion, it is in fact an indictment of the Government. It is in fact questioning the justification for having Government, given that the principle, if not the sole reason, why there is Government is the protection of life and property of its citizenry. ${ }^{114}$

In the words of the then minister of state for internal affairs, Kiyingi Namusoke, the weapons collection programme mandated by the resolution passed in parliament was to be "comprehensive", based on concerns for development and security. ${ }^{115}$ In the end, however, there was an apparent lack of will on the part of the government to carry it through in a systematic and sustainable manner: at first, the government delayed the launching of the disarmament programme, citing the slow and complex nature of the demands for security and development, such as increased border control, assurance of food security and the provision of water sources and dams, until this position was politically untenable due to the large-scale raids by ngikaracuna in districts neighbouring Karamoja. Then, when it was finally implemented, there was no serious attempt to link long-term socio-economic development with the disarmament programme. Of critical importance is the fact that the programme was severely compromised by limited funding, and was tainted by corruption. ${ }^{116}$ In practice, incentives such as ox ploughs and iron sheets were given to leaders, not those who needed the rewards for income generation and sustenance. And the provision of maize flour proved to be a short-term solution and not a means of supporting a family - unlike a gun. Furthermore, there were no attempts to provide alternative livelihoods for the primary users of weapons, the ngikaracuna. ${ }^{117}$ They would 
have preferred incentives that were not linked to agriculture (primarily a woman's domain) and which could lead to sustainable means of generating wealth, such as mining, brick-making etc. Moreover, the disarmament and security policies did little to reward those who put their faith in the government by joining the local defence units. Even today, these militiamen have no legal status, are not provided with food or transportation and often are paid as much as five months in arrears. ${ }^{118}$ Many within the LDUs were involuntarily drafted and sent to fight the Lord's Resistance Army outside Karamoja; some of these men have deserted and returned home. It is no wonder, then, that they command little respect within their communities or that, being armed, angry and ostracized, they have increasingly taken to lives of crime.

\section{Conclusions and policy recommendations}

The case of Karamoja offers some surprising results about the utility and limitations of weapons collection programmes which have not been discussed elsewhere in the micro-disarmament literature. The fact that the negative impacts of poorly designed and implemented weapons collections can be highly gendered and actually exacerbate power imbalances between women, men and children in ways that make the lives of the most vulnerable even less secure has been entirely overlooked. Yet it is important to ask why, in this instance, the disarmament programme as an independent activity did not automatically improve the security situation for various members of the society, nor for the community as a whole. In fact, the reduction in the number of weapons in circulation proved to be reversible and the disarmament programme actually worsened the precarious strategic balance between the clans. A more appropriate strategy would have initially included negotiated arms control among the clans, coupled with the introduction of militias and the sustained presence of the UPDF in border areas, followed by the development of alternative income-generating activities for the users of weapons (primarily the ngikarakuna). Only after these elements were in place should long-term disarmament have been attempted. Furthermore, the emphasis of the programme should have extended beyond the decommissioning of weapons to a more sustainable preventive approach to smallarms proliferation by means of a slow process of changing attitudes towards weapons possession and use. In essence, the weapons collection programme lacked a conception of how to "disarm" the minds of the young men of Karamoja; and it actively undermined women's influence as disarmament agents. As a result, the worsened socio-economic welfare of the Karamojong has reinforced the notion among the ngikaracuna that 
the only way to survive is to be armed, and women have fallen silent on the matter of restricting the number of weapons in their society. Obviously, this has deleterious effects on any attempt to develop alternative ideals of masculinity, and must have broader implications for women's ability to assert their right to full participation in all aspects of community decisions. When the 2001-2002 collection programme failed, many Karamojong, especially the youth, refused any discussion of a resumption of disarmament.

In September 2004 the Ugandan government relaunched the disarmament programme, using many of the same incentives. However, due to poor community response and resistance by the ngikaracuna, the UPDF has largely reverted to a strategy of seizing weapons through a "cordon and search" approach using overwhelming and disproportionate force. An escalation of incidents in Kotido district in late 2006, including the killing of 21 UPDF soldiers and their battalion commander, and shots fired on a government plane and helicopter by Karamojong warriors, resulted in the massacre of 74 civilians in Lopuyo and the bombing of Turkana communities in Nakapelmoni in which 10 Kenyans died. Besides the casualties, some 16 homesteads and granaries were burnt down by the UPDF and 1,145 local residents were displaced by the fighting. ${ }^{119}$

Earlier in the year, an investigative team comprised of representatives from the police, military intelligence, government and human rights agencies found that gross human rights violations had occurred during the recent forceful disarmament operation. These and other allegations include the rape of women, the defilement of children, torture, looting, the destruction of property and several incidents where villagers were rounded up and men were forcibly kept at the army barracks until a gun was surrendered or a bribe of 250,000 Ush was paid. ${ }^{120}$ A UPDF military disciplinary committee has recently prosecuted and sentenced a few soldiers for misconduct, failure to protect war material and other offences to enforce the military code of conduct while implementing the disarmament exercise, and in response to allegations of gross human rights violations. ${ }^{121}$

Although the military campaign to rid the region of small arms resulted in the seizure of 4,501 weapons between January and October 2006, this has come at a very high price. ${ }^{122}$ Many Karamojong families have endured great strain and even break-up. In some cases husbands have gone into hiding to avoid surrendering their weapons, leaving the wives with the difficult choice of either revealing the whereabouts of the guns and their husbands or suffering harassment by soldiers for information. Lina Longeti, a member of the Teso-Karamoja Women's Initiative for Peace (TEKWIP), noted that a great many women have become internally displaced due to "human rights abuse during the disarmament exer- 
cise" or suffered domestic violence for disclosing information about the family's weapons. Another peace volunteer in Moroto district, Veronika Ayumei, suggested that "The exercise is purely military and the people who should have helped it succeed (such as women) are being victimized." 123

This case study suggests that we are still a long way away from microdisarmament initiatives that are truly situated in a demand-side logic. During the conception of the 2001-2002 Karamoja programme, like many other disarmament programmes, there was little attempt to address the material and security needs of the various stakeholders in a sustained manner, including both the gun users and the more vulnerable sections of society, such as rural women and orphans. Nor did the Ugandan policymakers - or donors and other members of the international community ask who was to be rendered more secure by the confiscation of the weapons. As a result, the recent micro-disarmament programmes in Karamoja have been unable to address the emerging socio-economic order that has developed in the conflict situation. The primary motive of the government in disarming the pastoralists is not to improve the human security conditions in Karamoja and neighbouring districts, but rather to avert an internal political crisis by enacting a highly visible, short-term, reactive activity.

In conclusion, the experience of micro-disarmament in Karamoja offers essential lessons on how the international community should rethink small-arms issues. It raises substantial questions, such as who is the referent object to be secured by peacebuilding initiatives such as disarmament? What impact do these programmes have on civil-military, state-society and interpersonal, particularly gender, relations? Do weapons collection programmes actually contribute to an amelioration of the human security and peacebuilding efforts in the affected communities?

The case of Karamoja suggests that there are still contradictions in donor funding priorities when it comes to security initiatives. No normative framework exists to guide donors on questions about who should have the right to bear arms (i.e. non-state actors, community-based security systems) and under what conditions (i.e. when the state is unable to provide security to its citizens, as part of arms control measures, etc.). Finally, state-centric security interventions such as micro-disarmament programmes need to be harmonized with wider trends in overseas development policy. Donors favoured a peaceful disarmament approach to small-arms proliferation in Karamoja, but they did not want to provide project funding for a programme which involved non-state military forces. Their supplementary aid to the Ugandan national budget was conditional on the provision that defence-related expenditures were cut (over a period of time) in favour of poverty-reduction priorities. As a 
result, in practice the government of Uganda does not have the manpower or financial resources to protect its citizens simultaneously in both northern Uganda and the Karamoja region. ${ }^{124}$ In 2002 the Ugandan government chose to prioritize the political threat of the LRA, to the detriment of resolving the worsening social and economic violence in Karamoja and surrounding districts. Greater consideration of these contradictions in funding and a better-researched conception of small-arms initiatives that is actually grounded in an analysis of demand would go a long way towards improving the results of such initiatives. The beneficiaries will be not only the local stakeholders and the state, but also donors and other international actors who are interested in supporting this type of security sector reform and the development benefits it is hoped to promote.

Notes

1. Interviews were held in English, Akaramojong and Kiswahili; non-English interviews were translated.

2. I am grateful for the generous assistance and insight of John Bosco Akore, Nathan Byamukama, Margaret Lomonyang, Darlington Lorika, George Odongo, Dr Simon Simonse, the staff of the Centre for Basic Research and Isis-Women's International Cross Cultural Exchange (Isis-WICCE) in Kampala for their support during my field research in Uganda.

3. President Museveni has provisionally accepted the creation of a new district in the region, Pokot district, primarily inhabited by a tribe of the same name. Etengu, Nathan (2007) "Pokot Get Conditions for New District", New Vision, 14 October.

4. Kestelyn, Iseult (2002) "Peace and Development in Karamoja: Analysis of the Local Women's Organizations", Pax Christi, unpublished study.

5. The districts of Kotido and Moroto have the lowest human development index (Moroto 0.18 , Kotido 0.182 , national average 2.8 ) and poverty index ratings in Uganda. See Kagoro, Asingura (2002) "The Disarmament Program in Uganda with Special Focus on the Karamoja Case: Approaches, Methods and Outcomes", unpublished study, p. 14.

6. The 2001-2002 weapons collection programme in Karamoja was the seventh unsuccessful bid to disarm the Karamojong since the 1950s. All previous efforts have been forceful, causing significant harm to state-society relations. The current National Resistance Movement (NRM) government last attempted disarmament of the Karamojong in 1986-1987. Since then there has been a de facto tolerance of small arms in Karamoja due to the "external threats" faced by the pastoralists.

7. Gray, Sandra (2000) "We Were Running, Running: Ecological Politics, Local History, and the Evolution of Karimojong Violence", University of Kansas, Lawrence, unpublished study; Gray, Sandra, Paul Leslie and Helen Alinga Akol (2002) "Uncertain Disaster: Environmental Instability, Colonial Policy and the Resilience of East African Pastoralist Systems", in W. R. Leonard and M. H. Crawford, eds, The Last of the Nomadic Herders, Cambridge: Cambridge University Press.

8. Gomes, Nathalie (2003) "Women, Peace Building, Security and Development in the Karimojong Cluster", paper presented at Conference on Controlling Demand for 
Small Arms: The Search for Strategies in the Horn of Africa and the Balkans, The Hague, Netherlands, 8-10 December, p. 88.

9. Novelli, Bruno (1988) "Aspects of Karimojong Ethnosociology", Museum Combonianum, Vol. 44, Verona: Novastampa, p. 62.

10. Dolan, Chris (2003) "Collapsing Masculinities and Weak States - A Case Study of Northern Uganda", in Frances Cleaver, ed., Masculinities Matter!, London: Zed Books. Dolan's chapter discusses a northern Ugandan normative model of masculinity, particularly in Gulu and Kitgum districts, but I feel that much of the model is also very representative of Karamojong ideals of masculinity.

11. Gomes, note 8 above, p. 86 .

12. Katakwi Urafiki Foundation (2003) Baseline Survey on the Social and Economic Effects of the Karamojong Conflict on both Karamoja and the Teso Regions, Kampala: Kaufo, p. 27.

13. Odhiambo, Michael Ochieng (2000) Karamoja Conflict Study: A Report to Oxfam GB in Uganda, Kampala: Oxfam GB, p. 32.

14. Lochhead, Alison (1990) Gender and Development in Dodoth County, Karamoja, Uganda, Oxford: Oxfam, p. 31.

15. Luganda, Patrick (2003) "Grace Loumo Spearheads the Karamojong Women's Peace Drive", New Vision, 14 October.

16. Ibid.

17. Interview with women from Kamor parish, Panyagara subcounty, 20 October 2003.

18. Action for Development of Local Communities (2001) Arms Trafficking in the Border Regions of Uganda: A Case Study of Uganda North, Northeastern and Eastern, Kampala: ADOL. Women's lack of involvement seems to be confirmed by this report, which states that most smuggling is done by businessmen and ngikaracuna.

19. Interview with women from Kamor parish, Panyagara subcounty, 20 October 2003.

20. Mafabi, David (2007) "UPDF Soldiers Recover 4 Guns From K'jong Women", The Monitor, 28 May.

21. Novelli, note 9 above, p. 100.

22. Personal communication from UNDP security officer, 15 October 2003; interview with Edward Obin, ADOL, 20 October 2003.

23. WVU, WVK and POKATUSA (2002) Peacebuilding Project Annual Report, Moroto: POKATUSA, pp. 10-12.

24. Kestelyn, note 4 above, p. 9.

25. Gomes, note 8 above, p. 89.

26. The vigilante system was the precursor to other versions of community-based security, including the Anti-Stock Theft Unit and the local defence units. Interview with Sam Abura Pirir, MP for Matheniko county, Kampala, 4 December 2003.

27. Interview with Rose Lochiam, MP for Moroto district, Kampala, 3 December 2003.

28. Law \& Advocacy for Women - Uganda (2000) Project Report on the Domestic Violence Study, Kampala: LAW-U, p. 6.

29. Dolan, note 10 above, p. 2.

30. Lochhead, note 14 above, p. 12.

31. Interview with Grace Loumo, coordinator of Kaabong Women's Group Organization (KAWOGO), Moroto town, 23 November 2003. In Uganda, at the time of the research there was no specific provision protecting women against domestic violence, including marital rape, although the constitution makes mention of "special provisions for the protection of women as a marginalized group" and accords them "full and equal dignity of the person with men, equal opportunities in political, social and economic activities, and equal rights within the family between men and women in 
marriage, during marriage and after its dissolution". Law \& Advocacy for Women Uganda, note 28 above, p. 12 .

32. Gomes, note 8 above, p. 87.

33. Mburu, Nene (2002) "The Proliferation of Guns and Rustling in Karamoja and Turkana Districts: The Case for Appropriate Disarmament Strategies", Journal of Peace, Conflict and Development 2(2), p. 10. See also Mirzeler, Mustafa and Crawford Young (2000) "Pastoral Politics in the Northeast Periphery in Uganda: AK-47 as Change Agent", Journal of Modern African Studies 38(3), p. 421.

34. de Koning, Ruben (2003) "What Warriors Want: Young Male Perspectives on Armed Violence, Peace and Development in Najie, Karamoja", paper presented at Conference on Controlling Demand for Small Arms: The Search for Strategies in the Horn of Africa and the Balkans, The Hague, Netherlands, 8-10 December, p. 96; Mirzeler and Young, ibid., p. 421.

35. de Koning, ibid.,p. 96; Lochhead, note 14 above, p. 8.

36. Lochhead, ibid.

37. Gomes, note 8 above, p. 87.

38. Katakwi Urafiki Foundation, note 12 above, p. 35

39. de Koning, note 34 above, p. 97.

40. Ibid., p. 99.

41. Katakwi Urafiki Foundation, note 12 above, p. 33.

42. Ocan, Charles Emunyu (1994) "Pastoral Crisis and Social Change in Karamoja", in M. Mamdani and J. Oloka-Onyango, eds, Uganda: Studies in Living Conditions and Popular Movements and Constitutionalism, Kampala: JEP Books, p. 140.

43. Ocan, Charles Emunyu (1992) Pastoral Crisis in Northeastern Uganda: The Changing Significance of Cattle Raids, Kampala: Centre for Basic Research, p. 31.

44. Broch-Due, Vigdis (1999) "Remembered Cattle, Forgotten People: The Morality of Exchange and the Exclusion of the Turkana Poor", in David M. Anderson and Vigdis Broch-Due, eds, The Poor Are Not Us: Poverty and Pastoralism in Eastern Africa, Oxford: James Currey, pp. 50-88.

45. One interviewee noted that cases of parricide are not unheard of, due to the frustration of young men who want to marry but receive no support from their father, as he continues to marry other women himself. Interview with an anonymous source, Moroto town, 22 November 2003.

46. Lochhead, note 14 above, p. 10. Fifty-nine per cent of women in Karamoja live in polygamous unions, the highest incidence in the country, according to the 2006 Demographic and Health Survey conducted by the Uganda Bureau of Statistics. Musamali, Gereson and Fred Ouma (2007) "North Leads in Polygamy - Health Survey", New Vision, 16 August.

47. Gomes, note 8 above, p. 87.

48. Interview with women from Kamor parish, Panyagara subcounty, 20 October 2003; interview with villagers from Nakongumutu-Loposa parish, Panyagara subcounty, 18 October 2003; interview with villagers from Rupa parish, Rupa subcounty, 25 November 2003.

49. Interview with women from Kamor parish, Panyagara subcounty, 20 October 2003.

50. Novelli, note 9 above, p. 101.

51. This figure rises to 94 per cent for girls. Wamai, Gimono and Tom Barton (1994) "Women, Adolescent and Children in the Context of Insecurity: An Extract from the Uganda National Situation Analysis", paper presented at National Conference on Strategies for Peace and Sustainable Development in Karamoja and Neighbouring Districts, Makerere University, Kampala, 18-22 July.

52. Association for World Education-Uganda National Chapter (2000) Summarized Re- 
port of the Research Findings on the Transformation of Cattle Rustling and Conflicts in North-Eastern Uganda, Mbale: AWE-UNC, p. 13; Katakwi Urafiki Foundation, note 12 above, p. 27.

53. de Koning, note 34 above, p. 96; Mirzeler and Young, note 33 above, p. 421.

54. Mirzeler and Young, ibid., p. 422.

55. Interview with George Odongo, BAY-YPP, 13 October 2003; interview with Darlington Lorika, ADOL, 15 October 2003. These marriages tend to be less polygamous and conducted in the (Catholic) church, thus ensuring a legal status by which the wife is entitled to an inheritance. Kestelyn, note 4 above, p. 13.

56. From an elderly woman, Komuria parish, Kaabong, Kotido district. See Odhiambo, note 13 above, p. 32.

57. Interview in Lokadeli parish, Jie county, 21 October 2003.

58. Onyang, Sylvester (2002) "Anecdotal Introduction to Karamoja Conflict", in Syed A. H. Abidi, ed., Living Beyond Conflict: For Peace and Tolerance, Kampala: ABETO, p. 139.

59. Wamai and Barton, note 51 above,

60. Association for World Education-Uganda National Chapter, note 52 above, p. 14.

61. Ibid.

62. Luganda, note 15 above.

63. Omoding, John (2006) "Uganda: Police Round Up K'jong Girls", New Vision, 6 November.

64. Action for Development of Local Communities (2000) Conflict's Children: The Human Cost of Small Arms in Kitgum and Kotido, Uganda, Oxford: Oxfam, p. 22.

65. Interviews with women in Lokadeli parish, Rengen subcounty; Kamor parish, Panyagara subcounty; Nakongumutu-Loposa parish, Panyagara subcounty; Rupa parish, Rupa subcounty. Hereafter cited as interviews with women.

66. Interviews with women.

67. Lochhead, note 14 above, p. 14.

68. Cases of male rape during inter-Karamojong raids have not been reported, although a few cases perpetrated by Karamojong raiders in neighbouring districts do exist.

69. Interview with Madelena Adyaka, Moroto town, 20 November 2003.

70. Isis-WICCE (2002) "Medical Intervention Study of War Affected Teso Region, Uganda", Isis-WICCE, Kampala, p. 38. This study examines the effects of Karamojong raids and rebel conflict on the health of men and women in the Teso region, but the authors believe that women raped in the Karamoja region also suffer from similar health complications.

71. Lochhead, note 14 above, p. 15.

72. Karamoja Data Centre (2003) "Kotido District Information Guide", Office of the Prime Minister, Government of Uganda, Kampala, p. 21; Karamoja Data Centre (2003) "Moroto District Information Guide", Office of the Prime Minister, Government of Uganda, Kampala, p. 7.

73. These statistics are only for Moroto district.

74. Karamoja Data Centre, note 72 above, "Kotido District Information Guide", p. 5.

75. Ibid., p. 25.

76. Wamai and Barton, note 51 above,

77. Action for Development of Local Communities, note 64 above, p. 26.

78. These areas are also affected by incursions by the Lord's Resistance Army, a rebel group operating out of northern Uganda; however, the IDPs were attributed to Karamojong attacks. At the time, Karamoja was suffering from famine and two years of drought. See OCHA (2000) "Karamojong Neighbours Recovering", UN OCHA Humanitarian Update Uganda 2(4). 
79. Isis-WICCE (2002) Documentation of Teso Women's Experiences of Armed Conflict: 1987-2001, Kampala: Isis-WICCE.

80. Parliament of Uganda (2000) Motion on Karimojong Disarmament, 6th Parliament, 4th Session, 2nd Meeting, 9 March.

81. Cisterino, Fr Mario (1979) "Karamoja: The Human Zoo", postgraduate diploma thesis, University of Wales, Swansea.

82. Parliament of Uganda, note 80 above, 9158.

83. Ibid., 9170

84. The resolution passed with amendments to the motion and was supported by MPs from Karamoja.

85. Interview with Margaret Lomonyang, member of Riamiriam (a women's umbrella group in Moroto and Nakapiripirit districts), Moroto town, 24 November 2003.

86. New Vision (2001) "Museveni Appeals to K'jong on Guns", New Vision, 17 December.

87. Among the ngikaracuna, pro-disarmament opinion fell to only 32 per cent, with 58 per cent of warriors claiming that they would resist disarmament. A full breakdown by clan and social groups is available in Action for Development of Local Communities in conjunction with USAID (2000) Research and Workshop Report on Feasible, Participatory, Peaceful and Sustainable Disarmament of the Karamojong, Kampala: ADOL, p. 11.

88. Although domestic violence is acknowledged to be very common, none of the women spoke of domestic violence with a gun. It is apparently still a taboo to threaten or use a weapon on a member of your own clan and family. Interview with women and a dispensary nurse in Moroto district, 25 November 2003.

89. Interview with an anonymous source, Lokadeli parish, 21 October 2003.

90. Interview with an anonymous source, Nakongumutu-Loposa parish, 18 October 2003.

91. The CMOCs were innovations in partnerships between the UPDF army, civil society organizations, religious leaders, the Uganda Human Rights Commission and DANIDA's Human Rights and Democratization Program. They had a mandate to report on the progress of the disarmament programme and record human rights abuses. Women had asked for a women's desk in the CMOCs, but this never materialized. Interview with Margaret Lomonyang, Moroto, 21 November 2003; interview with Jessica Nkunke, Kampala, 24 October 2003.

92. Interview with an anonymous source, 15 October 2003.

93. Interview with Rose Lochiam, 3 December 2003.

94. IRIN (2002) "Uganda: Focus on Karamoja Disarmament”, IRIN, 10 January.

95. Ibid.; personal communication from Third Division, UPDF.

96. Interview with John-Bosco Akore, KAPEPS, Kampala, 11 October 2003.

97. Interview with an anonymous source, Moroto, 25 November 2003.

98. IRIN (2002) "Uganda: Army to Begin Forcible Disarmament of Karamojong", IRIN, 25 February.

99. Ibid.

100. Ibid.

101. OCHA (2002) “Karamoja Remains Volatile”, UN OCHA Humanitarian Update Uganda $4(4 / 5)$

102. Interviews in Kamor parish, 20 October 2003.

103. Interviews with women.

104. Interviews in Lokadeli parish, 21 October 2003.

105. Interviews in Kamor parish, 20 October 2003.

106. Interview with Margaret Lomonyang, Moroto town, 24 November 2003.

107. Kestelyn, note 4 above, p. 8.

108. By 4 May 2002, 9,291 guns had been recovered in the three districts of Karamoja dur- 
ing the entire weapons collection programme. Personal communication with a UPDF source.

109. Interview with an anonymous source, 15 October 2003.

110. Interview with Hon. Christine Nakway, MP for Kotido district, Kampala, 28 November 2003.

111. Ibid.; personal communication with a UPDF source. The most recent attempt at disarmament, restarted in 2004, has also failed to rid the region of small arms. The minister of state for primary education, Hon. Peter Lokeris, acknowledged that there was a renewed inflow of illegal guns into the region despite efforts to disarm the pastoralists. Mugerwa, Yasiin (2007) "Disarmament Crisis Over Rising Gun Trade in Karamoja Region", The Monitor, 30 December; Lucheli, Isaiah (2007) "Cattle Rustling Persists Even After Disarmament", The East African, 28 January; Mafabi, David (2008) "Uganda, Sudan in Talks Over Arms Trafficking", The Monitor, 15 January.

112. These definitions of security by men and women are based on findings from my field research.

113. Interview with Grace Loumo, KAWOGO, Moroto town, 23 November 2003; interview with Sammy Okene Ayaru, USAID, Moroto town, 22 November 2003.

114. Parliament of Uganda, note 80 above, 9161.

115. Parliament of Uganda (2001) Debate on the Report of the Minister of State for Internal Affairs on Katakwi Internally Displaced Persons, 7th Parliament, 1st Session, 2nd Meeting, 14 August, p. 357.

116. Major donor countries were solicited by the president, but hesitated to fund directly a programme that would involve militia forces. Those donors who did contribute to the disarmament exercise did so indirectly by funding the CMOCs or making token contributions to the initiative's programme. In the end, the disarmament exercise was funded from the national budget. Interviews with anonymous sources, Kampala, 30 September 2003, 7 November 2003, 4 December 2003; and Moroto town, 22 November 2003.

117. Etengu, Nathan (2007) "Army Kills 5 K'jong Warriors”, New Vision, 24 October.

118. Interviews with LDUs and UPDF soldiers in Lokadeli parish, 21 October 2003, Rupa parish, 25 November 2003.

119. Etengu, Nathan (2006) "Kotido Recalls Horror", New Vision, 11 November.

120. New Vision (2006) "Angry in Karamoja", New Vision, 10 November; IRIN News (2007) "Uganda: Government Efforts to End Abuses in Karamoja Inadequate HRW", IRIN News, 11 September; Mugerwa, Yasiin (2007) "Karamojong MPs Want Government to Certify Disarmed Warriors", The Monitor, 16 April; Muhumuza, Rodney (2006) "Govt Report Pins UPDF on Raping Karamojong", The Monitor, 22 October; Musiga, Anne (2007) "UNDP Suspends Karamoja Projects", New Vision, 28 June.

121. Etengu, Nathan (2007) "Army Fires 4 in Moroto", New Vision, 19 December; Mafabi, David (2007) "Army Dismisses Three Soldiers", The Monitor, 18 December.

122. Muhumuza, Rodney (2006) "Karamoja - Army Vows to Fight Fire with Fire", The Monitor, 9 November. A further 1,500 guns were collected between January and September 2007, according to the UPDF. See IRIN News (2007) "Uganda: Optimism in Karamoja Despite Lingering Security Concerns", IRIN News, 20 September.

123. Emasu, Alice (2006) "K'jong Women Bear the Brunt of Disarmament", New Vision, 6 November.

124. With improvements in the conflict situation with the LRA, the Ugandan government has recently promised more resources to improving the security situation in Karamoja. However, it remains to be seen if this will be a sustainable commitment. Etengu, Nathan (2007) "Government to Recruit 4,000 ASTU Forces", New Vision, 31 July; Mafabi, David (2007) "Police Beef Up Karamoja Security", The Monitor, 21 December. 

Conclusion 



\section{Conclusions: Recommendations for further research and activism}

Vanessa Farr, Henri Myrttinen and Albrecht Schnabel

Despite the passing of Security Council Resolution 1325 (2000) and its call to include women in all aspects of peace and security, women's initiatives towards peacebuilding and violence prevention, undertaken either autonomously or in support of efforts initiated by men, are often invisible beyond the immediate community they touch; men's attraction to and misuse of small arms remain under-remarked and insufficiently addressed in arms control interventions; and community arms control efforts as a whole continue to receive little respect or support in official circles.

The research carried out for this book, together with the authors' workshop organized as an integral part of the project, has highlighted a range of issues and problems related to identifying, understanding and responding to the gendered impacts of small arms. By bringing these diverse studies together, we hope to contribute to the development of a more nuanced set of approaches to the dangers presented by prolific and readily accessible small arms. We believe that our multidisciplinary approach is unique in the field of what could be termed "small-arms studies". While much of the existent literature focuses on technical or quantitative aspects of SALW-linked violence, such as public health impacts, our approach was of a more qualitative nature. Both approaches, quantitative and qualitative, are necessary for dealing with this complex issue.

As part of their task, researchers were asked to identify methodological challenges arising out of their work and to formulate recommendations for future gender-aware small-arms work with respect to policy

Sexed pistols: The gendered impacts of small arms and light weapons, Farr, Myrttinen and Schnabel (eds), United Nations University Press, 2009, ISBN 978-92-808-1175-9 
formulation, policy implementation and research needs. We will conclude the book by summarizing these and listing some recommended further reading.

\section{Methodological challenges}

As this research area is fairly new, the group as a whole recognized several methodological challenges.

First, in gendered research on small arms, feminist theories and methodologies offer very useful approaches to research design and implementation, as well as insights into how to process the data, describe the findings and develop policy. They intend to challenge the existing exclusion of gendered perspectives and activism on small arms, but, more than that, they aim to support the broader political claim that women and marginalized men have the right to participate in this and all other aspects of security-related decision-making globally. The importance of using feminist approaches to advance these goals was frequently remarked upon in the methodological discussions of the author team. We also understand that feminist theories offer the best means to address other issues of difference that are of concern to us, such as race, ethnicity, class, age, ability and location (rural/urban).

Second, there is a lack of sex- and age-differentiated data on small arms. Much of the official data on small arms and light weapons are not disaggregated by gender, and women have been inadequately consulted when research is planned and data are collected. Young people are also a neglected constituency when it comes to understanding and combating the problem better, even though young men in particular represent a significant number of those who are attracted to the ownership and use of firearms and the power they confer. This poses difficulties for researchers as they attempt to measure and assess the different impacts of small arms on women and men, girls and boys. In our view, alternative ways have to be found to describe in detail communities affected by readily available small arms. Where possible, the contributors to this book collected gender-disaggregated data themselves. They employed interdisciplinary research methodologies to identify indicators other than exclusively looking at numbers of people killed by guns or numbers of weapons collected. Qualitative data were collected by diverse methods, including interviews, focus groups, oral accounts of experiences and art, as well as each researcher's personal observations.

Third, it is important to consider issues of difference between the people being researched and the researcher. When conducting their research, writers asked questions. Are those interviewed going to be safe 
if they talk to me? Will they benefit from these interviews? Are women and men differently informed about debates on small arms in this context, and is this difference recognized in the corridors of power? To reflect on such issues, researchers included local voices, stories and experiences; and through our active engagement with the development of public policy, which will hopefully improve the design and implementation of future weapons collection processes, we hope to facilitate the greater involvement of informed citizens in the important political discussions that are currently under way on the subject of small-arms control. The research team hope that, rather than serving merely as subjects, the women and men we interviewed will be in some way empowered by the research processes in which they participated, and that being part of this study will help them to do more to achieve social change and curb smallarms violence in their communities.

Fourth, the research challenged several conventional dichotomies. Many of the contributors highlight their struggle with contradictions and speak of the ambiguities that arose in the course of undertaking this research. Such dichotomies demonstrate the need to explore stereotypes and question readily accepted concepts and definitions on women's and men's, girls' and boys' attitudes to small arms in their societies. Dichotomies include weapons in public spaces/private spaces; the perceptions of small arms as protection/threat; and the role of women as peacemakers/ fighters or inciters of violence.

\section{Masculinities and femininities}

There are many different ways of "becoming a woman/man" and expressing "masculinity/femininity" in any socio-cultural environment and historical context. It is important, therefore, to be subtle when looking at how prolific small arms impact on the changing social construction of male and female roles. Issues related to masculinities and femininities include such challenges as the stigma borne by women associated with armed groups (for example, female ex-combatants are often seen as too "manly" and therefore unmarriageable, or as "spoiled goods" who have been sexually active, even if this is due to the fact that they have been subjected to sexual violence), and the problem that all men are assumed to endorse positive perceptions of guns, which may make it difficult or impossible for them to organize and participate in defining new images of successful masculinity that do not rely on violence. Such exclusionary stereotypes make it more difficult to find, and celebrate, alternative understandings and expressions of masculinity and femininity that contribute to the success of peacebuilding and other human security initiatives. 


\section{Multiple roles}

Women and men play a myriad of roles in peace, conflict and postconflict situations, and these roles are often in flux and run contradictory to social expectations about appropriate masculine and feminine behaviour. These realities have to be kept in mind when discussing small-arms misuse, violence, conflict, power and security. There are many women active in disarmament work, but women are also combatants and gun users. While women are all too frequently victimized when guns proliferate, in many societies it is men, especially young men, who are disproportionately affected by small-arms violence. These uncomfortable truths come about because women and men occupy multiple roles - as activists, violators and victims - often at the same time.

During the transition from conflict to peace, opportunities may arise for unequal gender relations to be transformed, giving women new opportunities for fuller participation in political, social and cultural affairs. It is important to facilitate these opportunities by questioning the habit of stereotyping and compartmentalizing women and men according to perceptions of appropriate male and female characteristics. Gender roles are a social construct and can, like all cultural structures, evolve in a more equitable direction. While researchers in this project describe the roles that women and men are currently playing with regard to small arms, they also attempt to understand the roots of these roles and, in exposing them, suggest that, even in relation to violence, gender roles are adaptable and capable of change over time.

\section{Sites of difference}

The case studies presented here discuss broader problems than the exclusion of women from disarmament processes and analysis, including the marginalization of other groups. Sex-role stereotyping is not the only source of exclusion from security decision-making, but cultural influences, class, location, age and ability are also important determinants of how individuals relate to both small arms and disarmament processes. Sometimes men and women of a certain class or ethnicity will have more in common with each other than with people of the same sex who are from different social groupings. Thus, when discussing the issue of small arms, the implications of gender difference cannot be examined in isolation from other social categories. In the preparation for this research, for instance, the difficult challenge of how to work with marginalized men was repeatedly raised. 


\section{Key policy recommendations}

Over the course of the past few years, following the first UN Summit on Small Arms and Light Weapons held in 2001 in New York, there has been an increasing understanding that gender perspectives need to be incorporated into small-arms policy work, programming and research in order to achieve sustainable human security.

An important policy framework for this work was laid down with the passing of UN Security Council Resolution 1325 in 2000. Other recent examples of an increased awareness of the importance of incorporating gender into small-arms and human security policy, programming and research have included UN Security Council Resolution 1612, the Nairobi Protocol for the Prevention, Control and Reduction of Small Arms and Light Weapons in the Great Lakes Region and the Horn of Africa of 2004, the OECD Development Assistance Committee guidelines on disarmament, the Geneva Declaration on Armed Violence and Development in 2006, the UN Integrated Disarmament, Demobilization and Reintegration Standards (IDDRS) in 2006 and the SEESAC (South Eastern and Eastern Europe Clearinghouse for the Control of Small Arms and Light Weapons) initiative. The implementation of the Programme of Action to Prevent, Combat, and Eradicate the Illicit Trade in Small Arms and Light Weapons in All Its Aspects, which was decided upon at the UN SALW Conference in New York in 2001, though recognizing the gendered impacts of SALW, has unfortunately turned out to be a rather technical and legalistic exercise.

These initiatives give a clear mandate to national governments, international agencies and local NGOs that carry out disarmament work to incorporate gender perspectives in security-related decisions and the implementation of disarmament, demobilization and reintegration (DDR) and security sector reform (SSR) processes. To be able to ensure an effective, gender-sensitive implementation of these policy documents, they may need to be revisited and reflected upon based on experiences gained in the field since their inception, including the experiences from such cases as Haiti, Sierra Leone and Timor-Leste reflected upon in this book.

In order better to encapsulate the complexity of the gender, security and small-arms nexus, it can be useful to reframe the small-arms problem as a human security issue. This creates space to undertake activism and research from broader perspectives, including development, human rights, health and humanitarianism. The respective local contexts in which these issues are addressed need to be taken into account. Often, recourse to traditional justice methods can be an effective and culturally appropriate method for addressing the issues, but it needs to be kept in 
mind that traditional justice methods can often be problematic in terms of providing equitable access to traditionally marginalized groups, including women, children, ethnic and sexual minorities and those in a socio-economically disadvantageous position. These complexities were explored in the cases of Somalia and Uganda, as well as to an extent for Papua New Guinea.

Much current national policy does not adequately address cases where gun owners are perpetrators of domestic violence. There is thus often a need to update national legislation to ensure the incorporation of a gender perspective in small-arms legislation. Further, guns in private homes can increase the lethality of insecure environments, as discussed here especially in the case studies from Israel and South Africa. This is particularly true in situations of domestic abuse, but is also the case in armed robberies or other altercations in the home, which are often more likely to result in death or injury if a gun is available.

An audit on national legislation on gun laws should be conducted to explore areas for potential improvement based on the UN Programme of Action on small arms using gendered perspectives - the implementation of which, as mentioned earlier, has tended to be rather legalistic and technical to date. The security sector and the judiciary should be better trained to respond effectively and sensitively to all forms of violence against women.

In many conflict zones, growing numbers of small arms in the hands of security agencies are assumed by both government and the public to be a protective factor, targeting enemies. However, these small arms often pose real risks to civilians - in particular to women and children through their exacerbation of both domestic and indiscriminate violence. Examples discussed in this book include the DR Congo, Papua New Guinea, Timor-Leste and Uganda. It is vital to involve local authorities and organizations in conflict zones in disseminating pertinent information and organizing towards arms reduction in the civic sphere.

\section{Policy implementation}

It is important to involve meaningfully both women and men in the development of disarmament policy and its implementation that will directly or indirectly affect their lives. For example, in the planning of a disarmament process it is important to consider whether both men and women were consulted in threat assessment surveys, and identify incentives for weapons collections programmes, as discussed here for Albania, Cambodia, Mali and Uganda. Based on this information, public awareness strategies must be identified that would actually resonate with the 
people being disarmed. Externally imposed solutions to reduce violence may be less effective when they counter or ignore already existing local practices. Therefore, the implementation of community-based solutions should be prioritized by tapping into local knowledge, resources and effective traditions, bearing in mind, however, that these may reflect highly gendered structures of power.

As the case studies of this book have shown, many cultures link guns with expressions of "masculinity". The media, childhood toys and the militarization of society all contribute to prioritizing this association. Alternative masculine behaviours that do not uphold violence are less obviously explored and frequently appear to be less validated. Other social inequalities, such as those exemplified in class and race difference, are also exacerbated when small arms are prevalent. As the cases of Haiti, Northern Ireland and Somalia show, there is also a need to look closer at women's agency in conflict situations.

While men are often killed by strangers with guns, women are more at risk of armed violence from intimate partners or other men known to them. The presence of a gun in the home increases the likelihood that domestic violence will result in death. However, in many countries national legislation does not address this issue. Civil society research, advocacy and campaigning, with a focus on the gender-specific impacts of reducing gun violence, can make significant contributions to new national gun control laws. The complexities surrounding advocacy and campaigning are reflected upon in several chapters in this book.

\section{Weapons collection programmes}

Historically, post-conflict weapons collection programmes and disarmament projects have not taken the interests of men and women into account equally. As a result, the success of such projects may have been compromised. As shown by the case studies from Somalia and Uganda, women can play a significant role in encouraging men in their families and mobilizing communities through peace movements to give up their weapons, but this is not a simple, linear process.

Weapons collection programmes implemented by international agencies or foreign governments often do not carefully consider local realities, traditions or concerns. This negligence may end up alienating the communities who are the intended beneficiaries of such programmes.

As discussed by Kinzelbach and Hassan, Koyama and Yeung, when communities are offered development aid incentives in return for giving up their weapons, women (if they are consulted at all) may request very different projects than men. Evidence was offered that men tend to request large-scale, prestigious projects such as major new roads. Women, 
by contrast, tend to ask for projects that will have a direct impact on alleviating their workload and reducing their poverty. There is even some evidence that women will hand in weapons for no other reward than that of having proactively contributed to making their personal and community spaces safer, which raises important questions for those who believe weapons cannot be collected without material incentives.

Disarmament, demobilization and reintegration and security sector reform processes

UN Security Council Resolution 1325 and other UN initiatives such as the Department for Disarmament Affairs' Gender Action Plan promote and commit member states to include gender considerations in postconflict DDR and other disarmament exercises. However, the findings of this research project are that gender concerns have been blatantly ignored in the planning and execution of such processes.

Increasingly, conflicts include both female and male combatants. Often armed groups have recruited women as fighters, sometimes by force. Evidence shows that leaders often either do not give females their own arms or prevent them from keeping arms after peace accords are signed. As a result, many female ex-combatants and other women associated with fighting forces are not included in disarmament programmes, as witnessed in Sierra Leone and Timor-Leste. Even if they are still armed, DDR processes have primarily addressed male combatants. Women and girls are forced to self-demobilize and reintegrate as best as they can, often with devastating impacts on themselves and their children.

The contributors to this project confirm that women and men have different needs in DDR processes. For example, whereas both women and men may have been combatants and suffered separation from their families and other forms of trauma, there are situations where women have only played a role in supporting male fighters, by being forced to do domestic work or enslaved into sexual servitude. However, DDR processes are not adequately addressing these differences in the way women and men experience conflict - and are therefore not as effective as they hope to be in promoting peace and social change through the reintegration of ex-fighters into society.

Since the passing of UN Security Council Resolution 1325 there have been numerous experiences with incorporating gender perspectives into DDR and SSR programming, some of which are documented in this book. These experiences need to be evaluated, with lessons learned and best practices documented and incorporated into future programmes. An important tool in this respect is the DCAF/UN-INSTRAW Toolkit on Gender and SSR published in 2008. ${ }^{1}$ 


\section{Future research priorities}

Research into issues of gender and small arms is to date still limited. Further research is urgently needed on various questions linked to this complex issue, such as the alienation of young men and women from employment opportunities, the glorification of gun possession and the impact of interventions to end gun violence against women. Sustained institutional and funding support for such research has not, to date, been forthcoming.

All organizations, researchers and relevant actors collecting data should gender-disaggregate them and also use gender as a category of analysis in processing data. This will make their research, findings and resulting recommendations more convincing, broader and likelier to facilitate the advancement of more effective means to control weapons. In addition, the development of indicators to measure the impacts of gender difference in the uptake and use of small arms is a useful contribution to both academic analysis and policy development.

Action-oriented research that gives emphasis to qualitative approaches should be prioritized, and non-academic input should also be valued. This can involve the education of men and women from violence-affected communities, who can then undertake research and advocacy work on gender and small arms themselves. When outside researchers are employed, "parachute research" where an expert "drops in" on a community should be avoided. Instead, networks to appreciate the depth of issues and develop local and national capacity to present solutions to problems should be strengthened. Only then will we be able to feed meaningful research into effective policy to reduce small-arms violence globally.

As this book has shown, activist work within NGOs at the local and international levels is challenging the silencing of women's and men's gendered experiences of small-arms violence. We conclude that recognizing and boosting women-centred NGOs at the local level could have a significant impact on the success of gun control and management efforts instituted by governments and other agencies concerned with disarmament, and thus play an important role in the processes of long-term peacebuilding. The full impact of small arms on the lives of women, girls, men and boys can only be lessened if researchers and activists take the following steps.

- Demand that strict controls on firearms are enforced by local, national and regional authorities.

- Demand that laws underpinning discrimination and violence against women be repealed.

- Insist on collecting gender- and age-disaggregated data on firearm inju- 
ries and firearm ownership and use, and on the importance of analysing these data through a gender lens.

- Try to understand the diversity of women's, men's and children's attitudes towards small arms. If they support gun control measures, how do they demonstrate this support? If they support gun ownership, how do they express this? How is gun ownership naturalized in a society so that decreasing numbers of people resist their presence? Do men, women and children participate differently in this naturalization process?

- Carefully ascertain the perspectives and insights of women and children when conducting field research on small-arms proliferation and misuse.

- Ask standard questions about the supply side of small weapons from a different perspective, by ascertaining whether, for example, gunrunners also smuggle women and children to do exploitative and illegal work; or whether women are involved in running munitions and weapons, and if so why and for what profit?

- Pay attention to community perspectives on activities related to smallarms misuse.

- Ask whether men, women and children are differently affected by small-arms proliferation in the aftermath of conflicts. This means discovering what each group thinks would make them secure, how they understand any mechanisms that are in place to protect civilians and demobilized soldiers from easily available guns, and whether a culture of firearm ownership for self-protection has begun to arise and, if so, how each group understands this phenomenon.

- Analyse resistance to being drawn into arms ownership and misuse. Which social actors say no to guns? Why? How can they be supported and protected?

Such questions would help to determine the extent to which a society has adapted itself to living with violent conflict, from which can be ascertained people's sense of whether peace and non-violence are possible and desirable. Such questions also offer a means to identify activities that arise at the grassroots (such as peace groups or volunteer organizations to counsel victims of gun violence), which are frequently overlooked as peacebuilding initiatives but have significant potential with proper support.

The rhetoric of "gender mainstreaming" has permeated international agreements in recent years, but practical strategies for ensuring that the needs of women and men receive equal attention have been more difficult to implement. The pervasiveness of small arms and light weapons, their ease of use and their lethal impact on everyone from combatants to innocent passers-by make this problem an ideal platform from which to institute gender-aware policy, research and activism. It is imperative 
that a shift in approach to the small-arms problem avoids the omissions of past disarmament research. There is a serious need to gather data on how different social actors perceive small arms, and the tools exist with which to analyse the effects of gender ideologies on attitudes to, and the misuse of, these arms. As a research community, we possess excellent theoretical frameworks that show us how to take gender into account, have developed techniques that facilitate gender-aware research and are increasingly able to produce a gender-disaggregated pool of data on the effects of small-arms misuse.

\section{Conclusion}

As the case studies of this book have shown, addressing the gendered impacts of small arms and light weapons is a complex undertaking. Clearly, a greater commitment to gathering gender-disaggregated data on the effects of pervasive small arms is essential, as is an understanding that such data need to be analysed by gender specialists. Without this work, there is little chance of overcoming the silence about who bears the real costs of small-arms proliferation or of changing the social structures that support and perpetuate men's violence against women. However, gathering such data continues to pose a significant challenge (especially in recent war zones in the developing world), when the collection of firearmrelated violence data is frequently haphazard, and the data are handcollated for the purposes of regional rather than national statistics and otherwise unsystematic. Queries about firearms-related violence are often met with hostility and men's violence against women remains a taboo subject in many societies, thus limiting the accuracy of available figures. As a result, any indication of the sex of perpetrators or their victims, along with information about the circumstances in which attacks take place, may only be gleaned through reading between the lines of case notes.

What this lack of information suggests is that civil society organizations involved in gun control should make a particular effort to develop awareness-raising and training models through which to institute a new culture of data collection and analysis. They must emphasize the importance of collecting information on the sex of both the victims and the perpetrators of firearm-related violence. International organizations, governments and local authorities must be lobbied to make the institution of such data-collection practices standard and seek out expert assistance in examining them, because recording and analysing these figures is arguably the most important first step in challenging the indifference and denial that currently attend cases of gender-based violence. 
We need to provide a clear picture of the particular suffering women face when guns are pervasive, when people believe a man without a weapon is not a man, and when crimes are mostly reported, judged and punished by men. It is only when we are properly informed about the effects of pervasive small arms that we will be in a position to convince opinion leaders, policy-makers and the general public that easily available guns are dangerous to women, compromising their options and freedom of choice and denying them the right to lead a safe and full life, and that women have the right to participate fully in all efforts to control arms. We also need to develop a far better understanding of the ways in which dangerous images of masculinity are upheld in violent societies. The findings of research on demand must reinforce ongoing activism to encourage positive, peaceful expressions of male identity: this is a cornerstone of controlling and managing small arms.

\section{Note}

1. Bastick, Megan and Kristin Valasek, eds (2008) Gender \& Security Sector Reform Toolkit, Geneva: DCAF/OSCE/ODIHR/UN-INSTRAW, available at www.dcaf.ch/gendersecurity-sector-reform/gssr-toolkit.cfm. 


\section{Selected recommended reading}

\section{SALW and disarmament}

Bamako Declaration on an African Common Position on the Illicit Proliferation: Circulation and Trafficking of Small Arms and Light Weapons, 1 December 2000;

www.globalpolicy.org/security/smallarms/regional/bamako.htm.

Cukier, Wendy (2001) "Gender and Small Arms", presentation at a workshop on Gender Perspectives on Disarmament, United Nations, New York, 14 March;

www.guncontrol.ca/Content/gender.pdf.

Department for Disarmament Affairs (2001) Gender Perspectives on Small Arms, Briefing Note 3, New York: United Nations, March; http://disarmament2.un.org/gender/note3.htm

Department for Disarmament Affairs (2002) Gender Mainstreaming Action Plan, New York: United Nations, December; http://disarmament.un.org:8080/gender/gmap.pdf.

Farr, Vanessa A. and Kiflemariam Gebre-Wold, eds (2002) Gender Perspectives on Small Arms and Light Weapons, Brief 24, Bonn: Bonn International Center for Conversion, July; www.bicc.de/publications/briefs/brief24/content.html.

Farr, Vanessa A. (2003) "Men, Women and Guns: Understanding How Gender Ideologies Support Small Arms and Light Weapons Proliferation", in BICC Conversion Survey 2003: Global Disarmament, 
Demilitarization and Demobilization, Baden-Baden: Nomos Verlagsgesellschaft, pp. 120-133;

www.bicc.de/publications/survey/2003/content.html.

Farr, Vanessa A. (2003) "Triple Jeopardy: Women, Guns and Violence", in Putting People First: Human Security Perspectives on Small Arms Availability and Misuse, Geneva: Centre for Humanitarian Dialogue;

www.hdcentre.org/Programmes/smallarms/publications.htm\# Putting \%20People\%20First.

Farr, Vanessa A. (2004) “'The New War Zone': The Ubiquitous Presence of Guns and Light Weapons Has Changed the Definitions of 'War,' 'Victim,' and 'Perpetrator',', in The Women's Review of Books: Special Issue on Women, War and Peace, February, p. 16; www.wellesley.edu/WomensReview/archive/2004/02/highlt.html.

Nairobi Declaration on the Problem of the Proliferation of Illicit Small Arms and Light Weapons in the Great Lakes Region and the Horn of Africa, Great Lakes Region and the Horn of Africa Conference on the Proliferation of Small Arms, Nairobi, 15 March 2000;

www.ploughshares.ca/CONTENT/BUILD\%20PEACE/ NairobiDeclar00.html.

Report of the United Nations Conference on the Illicit Trade in Small Arms and Light Weapons in All its Aspects, A/CONF.192/15, New York: United Nations, July 2001; www.smallarmssurvey.org/resources/2001_un_conf.htm.

UN Institute for Disarmament Research (2003) "Women, Men, Peace and Security", in Disarmament Forum 4, Geneva: UNIDIR; www.unidir.org/gender/.

Violence Policy Center (2003) "When Men Murder Women: An Analysis of 2001 Homicide Data - Females Murdered by Males in Single Victim/Single Offender Incidents", Violence Policy Center, Washington, DC;

www.vpc.org/graphics/WMMW03.pdf.

Weiss, Taya (2004) Guns In The Borderlands: Reducing The Demand For Small Arms, ISS Monograph Series 95, Pretoria: Institute for Security Studies, January;

www.iss.org.za/pubs/Monographs/No95/Contents.html.

\section{Armed conflict}

Farr, Vanessa A., Andrew Dawes and Zareena Parker (2003) Youth Violence Prevention and Peace Education Programmes in South Africa: A Preliminary Investigation of Programme Design and Evaluation 
Practices, Cape Town: Children's Institute, University of Cape Town, July;

http://web.uct.ac.za/depts/ci/pubs/pdf/trauma/resrep/violence_prev.pdf.

Farr, Vanessa A. (2002) Gendering Demilitarization as a Peacebuilding Tool, BICC Paper 20, Bonn: Bonn International Center for Conversion, June;

www.bicc.de/publications/papers/paper20/content.html.

Giles, Wenona, Malathi de Alwis, Edith Klein and Neluka Silva, eds, with Maja Korac, Djurdja Knezevic and Zarana Papic, advisory eds (2003) Beyond Fears and Tears - Feminists under Fire: Exchanges across War Zones, Toronto: Between the Lines;

http://www.wellesley.edu/WomensReview/archive/2004/02/highlt.html.

IASC Working Group (1999) "Mainstreaming Gender in the Humanitarian Response to Emergencies", Background Paper for IASC XXXVI Meeting, Rome, 22-23 April;

www.reliefweb.int/ocha_ol/pub/iasc/IASC\%20gender.htm.

International Alert (2001) Gender Considerations for Disarmament, Conflict Transformation and the Establishment of Human Security, London: International Alert;

www.international-alert.org/women/women/Publications/Protection_ of_civilians.pdf.

Kent, Vanessa and Angela McIntyre (2004) From Protection to Empowerment: Civilians as Stakeholders in the Democratic Republic of the Congo, ISS Paper 84, Pretoria: Institute for Security Studies, February; www.iss.org.za/pubs/papers/84/Paper84.htm.

Lindsey, Charlotte (2000) "Women and War", International Review of the Red Cross 839, 30 September, pp. 561-579;

http://www.icrc.org/Web/eng/siteeng0.nsf/iwpList179/

5BD0956E8C9593CFC1256B66005EFEE9.

Mazurana, Dyan and Khristopher Carlson (2004) From Combat to Community: Women and Girls of Sierra Leone, Policy Commission and Women Waging Peace/Hunt Alternatives Fund, January; www.womenwagingpeace.net/content/articles/ SierraLeoneFullCaseStudy.pdf.

McKay, Susan and Dyan Mazurana (2000) Girls in Militaries, Paramilitaries, and Armed Opposition Groups, Ottawa: Government of Canada; www.waraffectedchildren.gc.ca/girls-en.asp.

McKay, Susan and Dyan Mazurana (2004) Where Are The Girls? Girls in Fighting Forces in Northern Uganda, Sierra Leone and Mozambique, Montreal: Rights \& Democracy, March; www.ichrdd.ca/english/commdoc/publications/women/Girls/ execsummary.html. 
Muggah, Robert with Martin Griffiths (2002) Reconsidering the Tools of War: Small Arms and Humanitarian Action, Humanitarian Practice Network (HPN) Paper 39, London: Overseas Development Institute, July;

www.smallarmssurvey.org/copublications/HPNNetworkPaper. 2002.pdf.

Ogunsanya, Kemi and Kwezi Mngqibisa (2000) A Gender Perspective for Conflict Management, ACCORD Occasional Paper 4, Durban: African Centre for the Constructive Resolution of Disputes; www.womenwagingpeace.net/content/articles/OccasionalPaper.pdf.

Rehn, Elisabeth and Ellen Johnson Sirleaf (2002) Women, War and Peace: The Independent Experts' Assessment on the Impact of Armed Conflict on Women and Women's Role in Peace-building, New York: UNIFEM; www.unifem.org/index.php?f_page_pid-149.

United Nations (1995) "Beijing Platform for Action, Critical Area of Concern, Women and Armed Conflict, Strategic Objectives", in Fourth World Conference on Women A/CONF.177/20, 4-15 September, paras 131-149;

www.un.org/documents/ga/conf177/plateng/aconf177-20-tocen.htm.

United Nations (2000) United Nations Security Council Resolution 1325: Women, Peace and Security, S/RES/1325, 31 October;

www.un.org/events/res_1325e.pdf.

Peacekeeping, disarmament, demobilization and reintegration, and security sector reform

Brett, Rachel (2002) Girl Soldiers: Challenging the Assumptions, Geneva: Quaker UN Office;

www.geneva.quno.info/pdf/Girl_Soldiers.doc.pdf.

Cape Town Annotated Principles and Best Practice on the Prevention of Recruitment of Children into the Armed Forces and Demobilization and Social Reintegration of Child Soldiers in Africa, adopted by the participants in the Symposium on the Prevention of Recruitment of Children into the Armed Forces and Demobilization and Social Reintegration of Child Soldiers in Africa, organized by UNICEF in cooperation with the NGO Subgroup of the NGO Working Group on the Convention on the Rights of the Child, Cape Town, 30 April 1997; www.mdrp.org/capetownprinc.pdf.

Bastick, Megan and Kristin Valasek, eds (2008) Gender and Security Sector Reform Toolkit, Geneva: DCAF, OSCE/ODIHR and UNINSTRAW. 
Department of Peacekeeping Operations Lessons Learned Unit (1999) Disarmament, Demobilization and Reintegration of Ex-Combatants in a Peacekeeping Environment: Principles and Guidelines, New York: United Nations;

www.un.org/Depts/dpko/lessons/DD\&R.pdf.

Department of Peacekeeping Operations Lessons Learned Unit (2000) Mainstreaming a Gender Perspective in Multidimensional Peace Operations, New York: United Nations, July;

www.un.org/Depts/dpko/lessons/Gender Mainstreaming.pdf.

Department of Peacekeeping Operations (2003) "Gender Mainstreaming", in Handbook on United Nations Multidimensional Peacekeeping Operations, New York: United Nations, December;

www.womenwarpeace.org/issues/peacekeeping/dpko_handbook_ gender.pdf.

de Watteville, Nathalie (2002) Addressing Gender Issues in Demobilization and Reintegration Programs, Africa Region Working Paper Series 33, Washington, DC: World Bank, August; www.worldbank.org/afr/findings/english/find227.pdf.

DFID/DFAIT (2002) Gender and Peacekeeping Training Course; www.genderandpeacekeeping.org.

Farr, Vanessa A. (2002) Gendering Demilitarization as a Peacebuilding Tool, Paper 20, Bonn: Bonn International Center for Conversion, June; www.bicc.de/publications/papers/paper20/paper20.pdf.

Farr, Vanessa A. (2003) Gender-aware Disarmament, Demobilization and Reintegration (DDR): A Checklist, New York: UNIFEM; www.womenwarpeace.org/issues/ddrenglish.pdf (English), www.womenwarpeace.org/issues/ddrfrench.pdf (French).

Farr, Vanessa A. (2003) "The Importance of a Gender Perspective to Successful Disarmament, Demobilization and Reintegration Processes", in Disarmament Forum 4, Geneva: UNIDIR, pp. 25-35; www.unidir.org/pdf/Gender/5\%20Farr.pdf.

Higate, Paul (2003) "Peacekeeping and Gendered Relations", in Peace and Conflict Monitor, Costa Rica: University for Peace, July; www.monitor.upeace.org/archive.cfm?id_article $=47$.

Higate, Paul (2004) Gender and Peacekeeping Case Studies: The Democratic Republic of the Congo and Sierra Leone, ISS Monograph 91, Pretoria: Institute for Security Studies, March; www.iss.org.za/pubs/Monographs/No91/Contents.html.

International Alert (2001) Gender Mainstreaming in Peace Support Operations: Moving Beyond Rhetoric to Practice, London: International Alert, October;

www.international-alert.org/women/women/publications/pso.pdf. 
Kearns, Yvonne E. (2002) The Voices of Girl Child Soldiers, Geneva: Quaker UN Office; www.geneva.quno.info/pdf/WUNO child soldiers report.pdf.

Laurance, Edward J. and Sarah Meek (1996) The New Field of MicroDisarmament: Addressing the Proliferation and Buildup of Small Arms and Light Weapons, Brief 7, Bonn: Bonn International Center for Conversion, September; www.bicc.de/publications/briefs/brief07/brief7.pdf.

Pearson Peacekeeping Centre (2001) Human Rights and Gender Issues in Peacekeeping: Report of the VIII Seminar of the Challenges Series, Cornwallis: Pearson Peacekeeping Centre;

www.peaceoperations.org/en/conference_reports/Human_Rights.pdf.

UN Development Programme (2002) Small Arms and Light Weapons, Essentials 9, UNDP Practice Area, Crisis Prevention and Recovery Synthesis of Lessons Learned, New York: UNDP, November; www.undp.org/bcpr/smallarms/docs/essentials.pdf.

UNIFEM (2004) Getting It Right, Doing It Right: Gender and Disarmament, Demobilization and Reintegration, New York: UNIFEM, October; www.womenwarpeace.org/issues/ddr/gettingitright.pdf.

UN Transitional Assistance Group (2000) Windhoek Declaration: The Namibia Plan of Action on "Mainstreaming a Gender Perspective in Multidimensional Peace Support Operations", Windhoek, 31 May; www.reliefweb.int/library/GHARkit/FilesFeb2001/windhoek_ declaration.htm.

\section{Gender and research}

Farr, Vanessa A. (2003) "Gender Awareness in Research and Policy Making”, African Security Review 12(1), pp. 115-118; www.iss.co.za/Pubs/ASR/12No1/CFarr.html.

Reimann, Cordula (2004) "Gender in Problem-solving Workshops: A Wolf in Sheep's Clothing?”, Working Paper 3/2004, swisspeace, Berne, November; www.swisspeace.org/publications/wp/WP_ReimannNov04.pdf.

Shrader, Elizabeth (2001) "Methodologies to Measure the Gender Dimensions of Crime and Violence", Policy Research Working Paper 2648, Gender Unit, Latin America and Caribbean Region, World Bank, Washington, DC, July; www-wds.worldbank.org/servlet/WDS_IBank_Servlet?pcont= details\&eid=000094946_01080704010310.

Sikoska, Tatjana and Juliet Solomon (2004) "Introducing Gender in Conflict and Conflict Prevention: Conceptual and Policy Implications", 
in David Carment and Albrecht Schnabel, eds, Conflict Prevention from Rhetoric to Reality: Opportunities and Innovations, Lanham, MD: Lexington Books, pp. 63-77;

www.un-instraw.org/en/docs/gacp/gender_and_conflict.pdf.

\section{Public health impacts of SALW}

Li, Quan and Ming Wen (2005) "The Immediate and Lingering Effects of Armed Conflict on Adult Mortality: A Time-Series Cross-National Analysis", Journal of Peace Research 42(4), pp. 471-492.

Murray, C. J. L., G. King, A. D. Lopez, N. Tomijima and E. G. Krug (2002) "Armed Conflict as a Public Health Problem", British Medical Journal 324, pp. 346-349.

Nasir, Khurram, Adnan Hyder and M. Shahbaz (2004) "Injuries Among Afghan Refugees: Review of Evidence", Prehospital and Disaster Medicine 19(2), pp. 169-173.

Plümper, Thomas and Eric Neumayer (2006) "The Unequal Burden of War: The Effect of Armed Conflict on the Gender Gap in Life Expectancy", International Organization 60, pp. 723-754.

Reza, A., J. A. Mercy and E. Krug (2001) "Epidemiology of Violent Deaths in the World", Injury Prevention 7(2), pp. 104-111.

Vervimp, Philip (2006) "Machetes and Firearms: The Organization of Massacres in Rwanda", Journal of Peace Research 43(1), pp. 5-22.

\section{Useful links}

Bonn International Center for Conversion: www.bicc.de.

Centre for Humanitarian Dialogue: http://www.hdcentre.org/.

Geneva Centre for the Democratic Control of Armed Forces: www.dcaf.ch/.

Human Rights Watch, Women and Armed Conflict: www.hrw.org/ women/conflict.html.

International Action Network on Small Arms: www.iansa.org/.

International Alert, Women Building Peace: www.international-alert.org/ women/new2.html.

International Committee of the Red Cross, Women and War: www. icrc.org/web/eng/siteeng0.nsf/iwpList2/Focus:Women_and_war?

OpenDocument.

PeaceWomen: www.peacewomen.org.

South Eastern and Eastern Europe Clearinghouse for the Control of Small Arms and Light Weapons (SEESAC): www.seesac.org/. swisspeace: www.swisspeace.org/.

The Men's Bibliography: www.xyonline.net/nesbiblio/\#fairuse. 
UN Department for Disarmament Affairs, Gender and Disarmament: http://disarmament2.un.org:8080/gender.htm.

UNIFEM: www.WomenWarPeace.org.

UN Integrated DDR Standards (IDDRS): www.unddr.org/iddrs/.

Women's Human Rights Net, War and Armed Conflicts: www. whrnet.org/docs/issue-warconflict.html. 


\section{Index}

"f" refers to figures; " $t$ " table; " $n$ " notes.

AAP. See American Academy of Pediatrics (AAP)

ABRI. See Angkatan Bersenjata Republik Indonesia (ABRI)

AC75. See Association of Ex-Combatants 1975 [East Timor] (AC75)

acquired immune deficiency syndrome

(AIDS), 32. See also human immunodeficiency virus (HIV)

HIV/AIDS prevention, 77

Papua New Guinea, 147, 164

South Africa, 298, 317

Uganda, 401

ADF. See Angolan Defence Force (ADF) ADFL. See Alliance des Forces

Démocratiques pour la Libération du Congo (ADFL)

Afghanistan, 20, 30, 330

African National Congress [South Africa] (ANC), 293, 295-96

African Women's Anti-War Coalition, 38

AK-47. See Avtomat Kalashnikova 1947 (AK-47)

Albania

arms exports to Rwanda, 92

domestic abuse, 276

Gramsh Pilot Project (GPP), 335, 338 guns and masculinity, 30

incentives identified by community meetings, 337-38

provision of development projects, 338-40

public awareness-raising, 335-37

Small Arms and Light Weapons Control (SALWC), 335, 338, 354n28-29

weapons collection programmes, 336-40, $346-47,352$

weapons for development (WfD), 335, 339-40

Weapons in Exchange for Development (WED), 335, 338

Alliance des Forces Démocratiques pour la Libération du Congo (ADFL), 82

American Academy of Pediatrics (AAP), 30-31

Amnesty International (AI)

DRC and rape of women and girls, 90 gun ownership and male identity, 30 guns and violence against women,

$$
41-42
$$

Timor-Leste, 181, 198, 200

Angkatan Bersenjata Republik Indonesia (ABRI), 178-79, 181, 183, 191-92

Angolan Defence Force (ADF), 89 
Anti-Stock Theft Unit [Uganda] (ASTU), 396

Armée du Peuple Congolaise (APC), 92

Assistance Scheme for Law Enforcement and Legal Agencies (ASLLEA), 170

Association of Ex-Combatants 1975 [East Timor] (AC75), 195

Australia

armouries for PNG, 150

arms trade with PNG, 148

Australian Broadcasting Corporation, 153

Australian Women's Services Network, 24

Australia-Papua New Guinea Defence Cooperation Program, 152 capacity-building projects in PNG, 165

Coalition for Gun Control, 39

Defence Cooperation Program, 169

domestic violence, 40

domestic violence laws, 24

Enhanced Cooperation Program (ECP), 169

Federal Police into PNG, 169

F-FDTL, training and arming of, 196

firearms laws, stronger, 26

gun licences, prohibitions on issuing, 25

gun-lobby groups in, 35

Indonesia, 179

International Force for East Timor, 180

intimate-partner homicides, 21

media content and media exposure regulation, 31

sexual harassment charges against soldiers, 201

women's group and standards for gun control, 40

Austria, 39, 238

Avitan, Ariyeh, 256-57

Avtomat Kalashnikova 1947 [Soviet-made assault rifle] (AK-47)

Papua New Guinea, 161-62

Sierra Leone, 53, 58, 70

Somalia, 360

Timor-Leste, 181

Uganda, 393-94, 399

Ayumei, Veronika, 411

Bamako Declaration on an African Common Position on the Illicit Proliferation, Circulation and
Trafficking of Small Arms and Light

Weapons [South Africa], 297, 433

Barre, Siad, 359, 362, 370, 382

Barzilai, Shevi, 270

Beijing Platform for Action, 111, 119, 436

Belfast Agreement [Northern Ireland], 214, $217,221-22$

Belgium, 52

Ben-Chitrit, David, 260

Berkovitch, Nitza, 249-50

Berman, Eric, 300

Black Sash, 41, 295, 319

Borama peace deal [Somalia], 381-83, 385

Bradbury, Mark, 364, 371

Brazil, 21, 41

Brigade Mobil [Indonesian paramilitary police] (Brimob), 180

Broch-Due, Vigdis, 398

Brown, Kris, 219-20, 222-23,

Bryden, Matt, 366, 369, 371

Bunster, Ximena, 258-59

CADET. See Canadian Assistance to Demobilization in East Timor (CADET)

Cambodia

domestic violence, 22

European Union (EU), 340

incentives identified by community meetings, 341

Japan Assistance Team for Small Arms Management in Cambodia (JSAC), 340 provision of development projects, 342 public awareness-raising, 341

weapons collection programmes, 340-41, 346-48, 352

weapons storage and destruction, 342

Canada

abused women and gun violence, 24

anti-violence campaigns and media literacy, 31

Canadian National Firearms Association, 32-33

Coalition for Gun Control, 39

domestic violence, 24-25, 39

female murders by their intimate partners, 21

femicide, 21,24

firearms, Anglophone vs. Francophone views on, 38

firearms, gender split in attitudes over, 37 
firearms laws and decrease in femicide, $26-27$

firearms legislation, 39

gun control, resistance to, 34

gun control and women politicians, 39

gun-lobby groups in, 35

gun ownership levels by men, 18

"Lioness Method of Rape Prevention", 32-33

"Montreal Massacre" of female engineering students, 39

right to bear arms, rejected concept, 28

US culture of violence $v s$., 31, 34

violence against women, domestic, 25 , 39

Canadian Assistance to Demobilization in East Timor (CADET), 194

Centre for Humanitarian Dialogue (CHD), 95,439

child soldiers

in Africa, 436

girl, 438

in Sierra Leone, 53-56, 68-69, 76

in Somalia, 381

Civil Defence Forces [Sierra Leone] (CDF), 53,66

civil-military operation centre (CMOC), 404, 406

Coalition for Gun Control [Canada], 39

Cock, Jacklyn, 258, 260, 292,

Cockburn, Cynthia, 233-34

Colombia, 21

Comissão de Acolhimento, Verdade e Reconciliação do Timor-Leste (CAVR), 199

Commission on Gender Equality [South Africa] (CGE), 319-20

Committee for the Popular Defence of the Democratic Republic of Timor-Leste (CPD-RDTL), 195

community-based organization (CBO)

Papua New Guinea, 170

Uganda, 405

Congo. See Democratic Republic of the Congo (DRC)

Conseil national pour la défense de la démocratie - Forces pour la défense de la démocratie [DRC] (CNDD-FDD), 92

Conselho Nacional de Reconstruçao Timorense (National Congress for the
Reconstruction of East Timor)

(CNRT), 191

Consolidation des Acquis de la Réinsertion des ex-combattants [Mali] (CAR-Nord), 343

Continuity IRA (CIRA), 238

Control Arms Campaign, 41-42

"Convention of Belem Do Para", 110

Convention on the Elimination of

Discrimination against Women

(CEDAW), 111, 319

Coopération Technique Belge (CTB), 342-43

corruption

Haiti, 111, 122-23

Papua New Guinea, 146-47, 166

Sierra Leone, 51, 72

South Africa, 298

Timor-Leste, 192, 197

Uganda, 405, 408

culture of violence

Bowling for Columbine documentary, 31

Brazil, violence against women in, 41

gun culture and, 7, 30

interpersonal violence and, 34

Israel, 269

laws and attitudes to killing, 34

Sierra Leone, 8, 61, 65

small arms and, 53

Timor-Leste, 188

violent media's contribution to, 31

Cumann na mBan [Northern Ireland], 215, 224, 229-31

Dahan-Kalev, Henriette, 258

de Chastelain, General John, 217

decommissioning of weapons

DRC, 95

Northern Ireland, 213-14, 216-20, 240

security perceptions of men $v s$. women, 16

South Africa, 297

Uganda, 391, 404, 409

Defence for Children International Sierra Leone (DCI-SL), 54

Democratic Liberation Forces of Rwanda (Interahamwe) (FDLR), 84, 89

Democratic Republic of the Congo (DRC) arms embargo on, 91, 93-95

Batwa people ("Pygmies"), genocide and systematic rape of, 90-91, 100

Bemba, Jean-Pierre, 84, 90 
Democratic Republic of the Congo (DRC) (cont.)

Democratic Liberation Forces of Rwanda (FDLR), 84, 89

embargo violation, 83, 86, 94

Ertürk, Yakin, 96

Geneva Conventions, 86, 90

Global and All-Inclusive Agreement, 83, 93

Hague Convention, 86, 90

human rights violations, 88,92

Integrated Regional Information Networks (IRIN), 90

International Alert, 85, 96

International Committee of the Red Cross (ICRC), 86

International Criminal Court (ICC), 86-87, 90-91, 100

legal framework, 84-88

Médecins Sans Frontières (MSF), 88-89, 95

mutilation, 9, 86, 95

Nkunda, General Laurent, 84

non-governmental organization (NGO), 82, 89, 91, 97

rape, Amnesty International report, 90

rape, gang, 88, 95-96

rape, Human Rights Watch report, 88-89, 95-96

rape, systematic, $81-82,88-91$

rape and Decree of 1940, 85

rape and ICTY Anto Furundzija case, 87

rape and ICTY Delalic case, 87

rape and ICTY Tadic case, $87-88$

rape as a system of war, $81-82,86,95-97$

rape by military commanders, 89

rape under domestic laws, 82, 84-86

"sexual exploitation" and MONUC

troops, 98

sexual slavery, 9, 87, 91

sexual violence, 84, 89-90, 97-98

sexual violence, prohibition of, 86-87

small arms and light weapons (SALW), 92

small arms in, 91-93

systemic rape, MONUC and protection of women from, 97-98

systemic rape as a system of war, $81-82$, 88-91

UN arms embargo, 83, 91-95, 99

UN Panel of Experts, 92-93
UN Secretary-General, 98

UN Security Council Resolution 1325, 5, 16,76

US Agency for International

Development (USAID), 88-90, 95

violence against women, 96-97

weapons collection programmes, 38

Derfner, Larry, 256

disarmament, demobilization and reintegration (DDR)

Haiti, 110

Sierra Leone, 70-73

Timor-Leste, 193

disarmament and reintegration (D\&R), 118, 136-37, 381

Dolan, Chris, 276

domestic violence

Albania, Cambodia and Mali, 346, 348, Australia, 24, 40

Cambodia, 22

Canada, 24-25, 39

Colombia, 21

Haiti, 109, 119-21

international human rights law, 28

Israel, 272-73

Northern Ireland, 221, 223, 241

in Norway and Denmark, 22

in PNG, 162-63, 167

policy and legislation on, 19

in private domain, 4

Somalia, 377-78

South Africa, 21, 24, 41, 299, 301-2, 303, $311,319-20$

Timor-Leste, 188, 198, 200-201

Uganda, 411

United States, 21-22, 25-26, 34-35

WHO report, 21

women victims of, 21

Domestic Violence Act [South Africa], 41, 301, 319

Domestic Violence Project [South Africa] (DVP), 320

Draft Framework Convention on International Arms Transfers, 99

East Timor. See Timor-Leste

Economic Community of West African States Monitoring Group (ECOMOG), 70

Efroni, Linda, 255-56

England. See United Kingdom 
Enhanced Cooperation Program [Papua New Guinea] (ECP), 169

Enloe, Cynthia, 211, 262, 368

Etzion, Gali, 272

EU Assistance on Curbing Small Arms and Light Weapons in Cambodia (EU-ASAC), 340

European Union (EU), 340

Fairweather, Eileen, 235

Falintil-Forças de Defesa de Timor-Leste (F-FDTL), 181, 184, 193-94, 196-98, 202

Falintil Reinsertion Assistance Program (FRAP), 194

family violence

Israel, 270

Papua New Guinea, 147

Somalia, 378

female combatants

Mali, 333

Northern Ireland, 12, 212-13

Sierra Leone, 70-71, 76, 78

Somalia, 380

female identity. See also identity of young people; male identity

Haiti, 132, 137-38

in Northern Ireland, 220, 239-40

Sierra Leone, 69

Somalia, 376-77, 381

femicide

Canada, 21, 26-27

Finland, 26

Israel, 275

South Africa, 298, 301, 303, 310-11, 320

Switzerland, 26

Timor-Leste, 184

Finland, 26, 31

Firearms Control Act, 297, 319

Forças Armadas de Libertação Nacional de Timor-Leste (Falintil), 178-79, 181-83, 185, 187, 189-91, 193-96, 198, 205

Force Armée Congolaise (FAC), 83, 89

Force de résistance patriotique en Ituri (FRPI), 91

Forces Armées de la République Démocratique du Congo (FARDC), 84, 89, 97-98

Forces Armées d'Haiti (FADH), 129

Forces Armées pour le Congo (FAPC), 92
Forces for the Defence of Democracy

[Burundi] (FDD), 89

formed police unit (FPU), 180

Frente Revolucinária de Timor-Leste Independente (Fretilin), 179, 186

Gale, Naomi, 271-72

gang rape

DRC, 88, 95-96

Haiti, 113, 116, 121, 126, 129, 131-34, 136-37

Papua New Guinea, 10, 153, 163

Sierra Leone, 57

Timor-Leste, 198

Gebre-Wold, Kiflemariam, 433, 435, 437

gender, attitudes and regulation of small arms. See also notions of masculinity

American Academy of Pediatrics (AAP), 30-31

Canadian National Firearms Association, 32-33

cinematic heroes and gun use, 31-32

Control Arms Campaign, 41-42

Domestic Violence Act [South Africa], 41, 301, 319

firearms, licensing and registration, 25-27 firearms, regulated civilian possession, 28-29

gender and attitudes to small arms and regulation, 36-38

gender and demand for small arms, 29-36

gender and effects of small arms, 19-27

gender and political processes, 38-42

gun control in Canada, 34-36

media and role of guns in society, 34-35

National Rifle Association [USA] (NRA), 31-33, 35

regulation of civilian possession of small arms, 27-29

sexual violence, 21

small arms and light weapons (SALW), 43

UN Commission on Crime Prevention and Criminal Justice, 25, 28

UN Conference on the Illicit Trade in Firearms in All Its Aspects, 28, 434

Universal Declaration of Human Rights, Article 3, 28

US female sexual abuse and homicides, 22-23 
gender, attitudes and regulation of small arms (cont.)

US notion of "right to keep and bear arms," 27-28, 32

US resistance to gun control, 35-36

video games, effects of violent, 30-31, 156, 191

women victims of small-arms by intimate partners, 18-19

Women Waging Peace, 38, 435

Gender Advocacy Programme [South Africa] (GAP), 302, 320

gender-based violence

DRC, 98

gang violence and, 6

Haiti, 110, 112

Israel, 250, 263, 269

Papua New Guinea, 10, 143, 147, 163

political interest and rates of, 4

as responsibility of governments and international agencies, 16

South Africa, 14, 290, 293, 299, 305, 317, 320

Timor-Leste, 200

women's space and, 11

gendered impacts of prolific small arms

domestic sphere, militarizing, 11-14

domestic violence, 4

firearms-related injuries, 5

gender, small arms and violence in fragmented societies, 9-11

gender, weapons and small-arms control, $14-16$

gender and small arms and sexualized violence, $8-9$

gender-based violence, 4

gender ideologies shaping behaviour of men and women, 4

gender roles, 5, 11

Geneva Declaration on Armed Violence and Development, 5, 16

proliferation and misuse of small arms, preventing, 4

Security Council Resolution 1325, 5

Security Council Resolution 1612, 5

sexual violence, $9-10$

small arms and light weapons (SALW), $3-7,10,13$

social hierarchies, unequal, 4

social stereotypes shaped by support for violence, 5 gender identity

gender analysis $v$ s., 77

shapes violence and firearm use, 16

Gender Machinery [South Africa], 291, 295

gender roles

Haiti, 111-12

Israel, 13, 276

Northern Ireland, 12, 227-28, 231, 237

small arms, gendered impacts on prolific, 5,11

Somalia, 381, 385

Timor-Leste, 11, 186, 188

Uganda, 393

Geneva Conventions

of 1949,86

Additional Protocols I and II, 86

Convention IV, 86

DRC and systematic rape, 90

on the laws of war on independence, 86

rape is prohibited in international conflict, 86

sexual violence as a war crime, 86

sexual violence as serious violation, 86

Geneva Declaration on Armed Violence and Development, 5, 16, 425

German Technical Cooperation Agency (GTZ)

DRC, 90

Somalia, 358-59, 362, 367, 375, 378, 380, 382

Germany, 359

Government of Papua New Guinea (GoPNG), 165

Graham, Philip, 253

Gramsh Pilot Project [Albania] (GPP), 335, 338

Grant de Pauw, Linda, 212

Gray, Sandra, 393

Great Britain. See United Kingdom

Gun Control Alliance [South Africa]

(GCA), 41, 296, 309, 318

Gun Control Network, 39-40

gun culture

culture of violence, 7,30

gendered nature of, 42

male identity and, 7, 30

in media reinforce notions of heroes with guns, 43

Northern Ireland, 241

Papua New Guinea, 10, 144, 148, 150, 160, 167-70 
Somalia, 370, 386

South Africa, 299, 313

United States, 31-32, 34

Gun Free South Africa, 39, 41

Hague Convention, 86, 90

Haiti

Aristide, President, 109, 113, 117

armed groups, typology of, 112-16

armed violence, gendered aspects, 117-19

armed violence and women, 130

bandes de zenglendo, 113, 134-35

brigades de quartier, 113, 116, 127, 129-30

brigades de vigilance, 113, 116, 127, 130

corruption, 111, 122-23

disarmament, demobilization and reintegration (DDR), 110

domestic violence, 109, 119-21

D\&R program, 138-39

Enloe, Cynthia, 125

female armed violence, characteristics of, $127-31$

firearms as a symbol of power, 135-36

food aid, management of, 124-25

Forces Armées d'Haiti (FADH), 129

gang rape and armed violence, 131-34

gender-based violence, 110,112

gender roles, 111-12

groupes de bandits, 113, 128-29, 134-35

Haitian National Police (HNP), 116, 119

identity, female, 132, 137-38

insecurity from violence and guns, 110 ,

$120-21,125-26,138$

International Crisis Group, 120

juvenile armed violence, characteristics of, 134-37

juvenile delinquency, 109, 119, 136

legislation to eliminate violence against women, 111, 121

legislation to protect and empower women, 111

Magloire, Danièle, 120-21

Manigat, Senator Mirlande, 122

matrifocal household, 127, 137-38

Milices populaires, 127-30

Muggah, Robert, 119-20

Organisations Politiques (OPs), 113, 119, 127, 129

political life, exclusion of women from, $122-24$ power from guns and acts of violence, $117,121,135-36$

rape, $111,113,116,121-22,128-29$.

131-34, 136-38

rape, gang, $113,116,121,126,129,131-37$

security for women, 120, 124-26

sexual violence against women, 120-21,

124, 132-33, 138

small arms and light weapons (SALW), 130

Tickner, Ann, 122, 126

UN Security Council Resolution 1325, 5 , $16,76,111$

UN Stabilization Mission in Haiti

(MINUSTAH), 10, 110-11, 113, 117, 129,138

vagabonds (delinquents), 113, 133-34, 136

violence against women, 9, 110-12,

119-26, 131, 133

violence reduction, gendered approach to, $130-31$

woman as victims of violence, reasons for, 121-22

women associated with small-calibre

arms, 118-19

women in political process, obstacles to, 123-24

women's motivation and weapons used, 127-28

women's rights violations, 121

young people and disarmament and reintegration (D\&R), 136-37

Haitian National Police (HNP), 116, 119

Halane, Faduma, 376-77

Halperin-Kaddari, Ruth, 249

Harir, Shukri, 373

Hasan, Manar, 273-74

Hauswedell, Corinna, 219-20, 222-23

Hobart, Margaret, 273-74

human immunodeficiency virus (HIV). See also acquired immune deficiency syndrome (AIDS)

Papua New Guinea, 147, 164

Sierra Leone, 77

South Africa, 298, 317

Uganda, 401

Human Rights Watch (HRW)

DRC and rape, 88-89, 95-96

PNG, beatings, rape and torture in, 167

Women and Armed Conflict, 439

Hurbon, Laënnec, 110 
identity of young people. See also female identity; male identity; specific country

Haiti, 137

Somalia, 381

South Africa, 300

Independent International Commission on Decommissioning [Northern Ireland] (IICD), 217-19

Independent Monitoring Commission [Northern Ireland], 218

insecurity of society

Albania, Cambodia and Mali, 346

Haiti, 110, 120-21, 125-26, 138

Israel, 13, 254

Northern Ireland, 223, 226

PNG, 144, 148, 161, 168

SALW and, 3

Somalia, 360

South Africa, 297, 307, 310-11

Timor-Leste, 11, 184-85, 189, 203

Uganda, 392, 394, 400, 402

Integrated Regional Information Networks (IRIN), 90

Inter-American Convention on the

Prevention, Punishment and

Eradication of Violence against Women, 110-11

Intergovernmental Authority on Development (IGAD), 356, 360

internally displaced person (IDP)

Timor-Leste, 177, 184, 201

Uganda, 393, 403

International Action Network on Small Arms (IANSA), 41, 439

Israel, 271

International Alert, 85, 96

International Alliance of Women (IAW), 41

International Committee of the Red Cross (ICRC), 20

DRC, 86

Somalia, 362

"Women and War", 435, 439

International Criminal Court (ICC)

DRC, 86-87, 90-91, 100

International Criminal Tribunal for Rwanda (ICTR), 87

International Criminal Tribunal for the Former Yugoslavia (ICTY), 87

International Crisis Group, 120

International Force for East Timor

(INTERFET), 180-81, 183, 185
International Organization for Migration (IOM), 194

International Stabilization Force [East Timor] (ISF), 177, 180-81, 184

Iraq, 30, 359

Irish Republican Army (IRA), 12, 214-16, 217t8.1, 218-20, 225, 227-30, 232-33, $237-38$

Israel and private policing Adelman, Madelaine, 263, 268, 270

Avitan, Ariyeh, 256-57

Barzilai, Shevi, 270

Ben-Chitrit, David, 260

Berkovitch, Nitza, 249-50

Bunster, Ximena, 258-59

civic space, militarization of, 257-62

Cock, Jacklyn, 258, 260

Committee for the Review of the System of Arms Licensing for Guards, 252 254-55

Derfner, Larry, 256

domestic violence, $272-73$

domestic violence and thwarted

masculine identity, 275-76

family violence, 270

Gale, Naomi, 271-72

gender roles, 13, 276

Graham, Philip, 253

gun on the kitchen table, 269-76

guns licensed in Israel, 252-53

insecurity of society, 13, 254

International Action Network on Small Arms (IANSA), 271

Israel Defense Force (IDF), 270

Israeli Defense Force survey of sexual harassment, 267

Israeli police force, 251-53, 265, 268, 274

Klein, Naomi, 261, 435

Lagerquist, Peter, 251

L.O. Combat Violence Against Women, 270,272

"making women poorer, keeping women home", 263-66

Maoz, Elat, 258

micro-disarmament, 246

militarized mindsets and systemic harassment by security agencies, 267

Mothers Against Military Might, 39

non-governmental organization (NGO), 246, 248 
private policing, obvious and less-obvious objectives of, 253-57

private policing and increased gun licensing, 250-53

security guard levels, 251

security guards, exploitation of, 256 security guards as recent émigrés from

Soviet bloc and Ethiopia, 250, 265, 272

sexist subtext, 263-76

sexual harassment, 249, 267-69, 277

"sexually harassing systems", 267-69

Shadmi, Erella, 254, 258-59, 264

Shiloni, Ehud, 274-75

Singer, Roni, 258-59

small arms and light weapons (SALW),

248, 261

small-arms proliferation, 12, 248, 252, 272

UN Children's Fund (UNICEF), 289

unemployment, 251, 255-56, 265-66, 274-75

violence, gendered division of, 262-63

violence against women, 12, 248-50,

269-70, 272

women's impoverishment and security spending, 277

women's poverty and threat of domestic violence, 274-75

Zohar, Hanna, 256

Israel Defense Force (IDF), 270

Jamane, Dhudi Axmed, 383-85

Japan

gun control, 34

gun culture vs. US, 34

International Organization for Migration

(IOM), 194

Japanese Imperial Army in Indonesia, 192

PKF component in Timor-Leste, 194

Japan Assistance Team for Small Arms

Management in Cambodia (JSAC), 340

Johnson, John William, 358

Johnson, Senator Janice, 42

Kaabong Women's Group Organization [Uganda] (KAWOGO), 396, 400

Kapteijns, Lidwien, 363

Kashmir, 20, 81

Kepolisian Negara Republik Indonesia (POLRI), 196

Khaled, Leila, 239
Klein, Naomi, 261, 435

Kup Women for Peace [Papua New Guinea] (KWP), 168

Kurlander, Yahel Ash, 269

Lacun, Christine, 400

Lagerquist, Peter, 251

Laurance, Edward J., 223

Lebanon, 39, 276

legislation

firearms, 7, 25-26, 33, 35, 37, 39, 42

for firearms regulation [PNG], 147-48

on guns in home and domestic violence resulting in death, 427

incorporating a gender perspective in small-arms legislation, 426

Israeli equal opportunity, 264

nation legislation on gun laws, 426

for ownership, import, export, display and use of firearms, ammunition, explosives and offensive weapons [Timor-Leste], 185

to procure weapons for private sales and transfers [PNG], 148

to protect and empower women, 111

protect women from small-arms violence [South Africa], 319

to reduce risk to women from gun violence, 33

to regulate production and proliferation of small arms [PNG], 170

against sexual harassment [Israel], 268

for small-arms trade [PNG], 143

Lentin, Ronit, 212

light machine gun (LMG), 157, 393

limited preferential voting (LPV), 162

LMG. See light machine gun (LMG)

local defence unit (LDU), 407, 409

L.O. Combat Violence Against Women

[Israel], 270, 272

Lord's Resistance Army [Uganda] (LRA), 393, 407, 409, 412

Loumo, Grace, 396

Loyalist Volunteer Force (LVF), 218

Luke, Allan, 253

male identity. See also female identity; identity of young people

culture of violence and guns, 7, 30

gun ownership and, 30

Northern Ireland, 220 
male identity (cont.)

notions of masculinity, 30

peaceful expressions of, 432

small arms are linked to, 30

Somalia, 376-77, 381, 386

South Africa, 300

in Uganda, 407-8, 432

Mali

development projects provisions, 344-45

female combatants, 333

incentives identified by community meetings, 344

provision of development projects, 344-45

public awareness-raising, 343-44

weapons collection programmes, 39 , 343-44, 346-47, 349, 352

weapons for development (WfD), 342-45

weapons storage and destruction, 344

WED and incentives, 344

Maoz, Elat, 258

martial arts group (MAG), 189, 196, 205

Mattan, Kadija Muse, 364

McWilliams, Monica, 222

Médecins Sans Frontières (MSF), 88-89, 95

Meek, Sarah, 223

member of parliament (MP), 403, 408

micro-disarmament

Albania, Cambodia and Mali, 329-30, 332, 350, 357, 438

DRC, 38

Israel, 246

Uganda, 16, 390, 409, 411, 438

militarized masculinity

Papua New Guinea, 143, 147

Sierra Leone, 67-69

Timor-Leste, 191-92, 197

Million Mom March [United States], 33, 39, 41

Minority Rights Group (MRG), 90

Mission de l'Organisation des Nations Unies au Congo (MONUC)

arms embargo monitoring and enforcement, 94-95, 99

rape, protection of women from, 97-98

rape by, reports of systematic, 90

UN Security Council authorized mission, 83-84

Moser, Caroline, 221

Mouvement de Libération du Congo (MLC), 83, 89-90
Muggah, Robert, 300

Mukula, Captain Michael, 403

Museveni, President Yoweri, 403-4, 406

mutilation

DRC, 9, 86, 95

Sierra Leone, 62

Timor-Leste, 199

National Advisory Council on the Control of Firearms [Somaliland] (NACCOF), 367

National Capital District [Papua New Guinea] (NCD), 154, 156

National Organization of Women [USA] (NOW), 41

National Rifle Association [USA] (NRA), 31-33, 35

New Guinea. See Papua New Guinea non-governmental organization (NGO)

Albania, Cambodia and Mali, 341, 343, 346

Defence for Children International Sierra Leone (DCI-SL), 54

DRC, 82, 89, 91, 97

EUASAC, 341

Israel, 246, 248

KAWOGO, 396

Kup Women for Peace (KWP), 168

local, 425, 429

Papua New Guinea, 144, 168

peace role, 42

Sierra Leone, 73-74

Somalia, 383, 396

South African NGO Coalition, 41

SOWDA (Somali Women's Development Association), 383

Timor-Leste, 177, 186-87, 201

Uganda, 401-2, 404-6

Working Group on the Convention on the Rights of the Child, 436

Northern Ireland

Belfast Agreement, 214, 217, 221-22

British military, 214, 224, 226-27

conflict, 213-16

Cumann na mBan, 215, 224, 229-31

decommissioning of weapons, 213-14, 216-20, 240

disarmament/decommissioning of paramilitary weapons, 216-20

domestic violence, 221, 223, 241

female combatants, 12, 212-13 
female paramilitary members, heroic images of, 237

gender relations in paramilitary organizations, 229-36

gender roles, 12, 227-28, 231, 237

gun culture, hyper-masculinity of, 241

Hauswedell, Corinna, 219-20, 222-23

identity, female, 220, 239-40

identity, male, 220

Independent International Commission

on Decommissioning (IICD), 217-19

Independent Monitoring Commission, 218

insecurity of society, 223, 226

Irish Republican Army (IRA), 12, 214-16, 217t8.1, 218-20, 225, 227-30, 232-33, 237-38

Loyalists, 234-36

Loyalist Volunteer Force (LVF), 218

Northern Ireland Assembly, 214, 216, 218

Operation Banner, 218

paramilitary women, representations of, 237-39

patriarchal social systems and

"traditional" gender roles, 12

prostitution, 223, 238

racism and racist violence, 221

rape and sexual harassment of female soldiers, 229

Republicans, 229-34

Royal Ulster Constabulary (RUC), 214, 226, 242

Sales, Rosemary, 215, 235, 237

sexual appeal of arms and paramilitarism, 236-37

sexualization of arms and violence for men, 236

sexual violence against women, 224

shootings, paramilitary-style, 222-23

Sinn Féin, 218, 232, 234

small arms and light weapons (SALW), 211-13, 216-24, 239, 241

Steel, Jayne, 239

submachine gun (SMG), 239

Ulster Volunteer Force (UVF), 222, 225-27, 234-37

van Creveld, Martin, 212

violence, new forms of, 220-24

violence against women, 221

women, concealment and transport of weapons, 225-26 women and paramilitary activity, 228-29 women militant, media's portrayal,

238-39

women's role in the concealment and transport of arms, 224-29

Yuval-Davis, Nira, 215-16, 229

Northern Ireland Assembly, 214, 216, 218

notions of masculinity

cultural norms can be a strong antidote to, 43

culture of violence and, 30

cultures with the link to guns, 34

as demand factor for small-arms, 391

firearms ownership and use, 36

gun culture and, 7

gun manufacturers exploit, 32

gun ownership and women as victims of

violent crime, 300

male identity and, 30

men in role of protector and defender, 30

resistance to gun control and, 35

roles that guns play in male culture, 29

small-arms demand and, 29

Operation Iron Fist [Uganda], 407-8

oral poetry in Somalia, 15, 358-59, 362-64

Organisations Politiques [Haiti] (OPs), 113, 119, 127, 129

Organização Populer da Mulher Timorense (OPMT), 191

Organization for African UnityInterAfrican Bureau for Animal Resources (OAU-IBAR), 395

Organisation for Economic Co-operation and Development (OECD)

Albania, Cambodia and Mali, 331

Development Assistance Committee guidelines on disarmament, 425

Pacific Islands Forum (PIF), 170

Pan African Congress (PAC), 296

Papua New Guinea (PNG)

acquired immune deficiency syndrome (AIDS), 147, 164

arms, stockpiles of, 161

Australia and capacity building, 165

Avtomat Kalashnikova 1947 (AK-47), 161-62

child abuse, 147, 165

community-based initiatives against tribal fighting and gun culture, 167-69 
Papua New Guinea (PNG) (cont.)

corruption, 146-47, 166

Defence Cooperation Program, 152, 169

domestic violence, 162-63, 167

Enhanced Cooperation Program (ECP), 169

family violence, 147

Firearms (Amendment) Act, 147, 149

firearms use, principle contexts, 153-62

gender-based violence, 10, 143, 147, 163

Government of Papua New Guinea

(GoPNG), 165

gun culture, 10, 144, 148, 150, 160, 167-70

high-powered weapons, 147, 149-50,

151t6.1, 152, 155, 157-58, 162, 168, 170

human immunodeficiency virus (HIV),

147, 164

insecurity of society, 144, 148, 161, 168

Inter-Group Fighting Act, 156

Kup Women for Peace (KWP), 168

Law Reform Commission, 162

leakage from legal stocks, 150, 152

legislation for firearms regulation, 147-48

male beliefs about women and power, 146-47

Meier, Sister Gaudentia, 163-64

militarized masculinity, 143, 147

Morauta, Sir Mekere, 161-62

National Capital District (NCD), 154, 156

NCD victimization survey, 156-57

non-governmental organization (NGO), 144, 168

Papua New Guinea Defence Force (PNGDF), 149-50, 152, 162

People's Democratic Movement (PDM), 162

policing strategies, reactive, 166-67

political élite and gun-related incidents, 150,152

prostitution, 147, 163, 165

rape, $147,153-54,157,159,163-65$, 167-68

rape, gang, 10, 153, 163

raskol gangs, 147, 153, 155-56, 166, 168

raskolism (gangsterism), 10, 145, 153-56,

Royal Papua New Guinea Constabulary

(RPNGC), 149, 162, 167

self-loading rifle (SLR), 157-58

sexual assault, 147, 153-54, 163

sexual violence against women, 163-64, 167 small arms and light weapons (SALW), 143, 149

Small Arms Survey, 150, 154, 156

Southern Highlands Province (SHP), 154, 163

tribal fighting, 10, 145, 149, 152, 156-61, 163, 169

UN Children's Fund (UNICEF), 165

UN Interregional Crime and Justice Research Institute, 153

victimization of females, 153-54, 156

violence, election-related, 161-62

violence, gender of, 162-65

violence and conflict, state response to, 165-67

weapons trade and availability, 148-50

Papua New Guinea Defence Force (PNGDF), 149-50, 152, 162

participatory monitoring and evaluation (PM\&E)

Albania, Cambodia and Mali, 329, 332, 349-52

participatory rural appraisal (PRA), 331

patriarchal

authority and abuse of small arms, 67

clan among Palestinians in Israel, 274

domination and men's power enhanced

by proliferation of small arms, 318

gender inequalities in social relations, 291

hierarchies, traditional, 64, 68

institutions condoning psychological,

physical and symbolic violence, 112

Israeli army as central institution of state, 267

Israeli Jewish discourse as misogynist and, 273

militarized societies encouraging harassment and violence against women, 269

militarized structures of violence, 68

norms and gender-based gun violence within private households, 302

patterns of asymmetrical power between men and women, 302

perceptions about private nature of domestic violence, 302

social systems and traditional gender roles, 12

society, 131, 318

systems of authority, militarized, 69 
Timorese society, with complex malefemale roles, 186 peacekeeping forces (PKF)

International Force for East Timor (INTERFET), 180, 185, 196, 201

UN Mission of Support in East Timor (UNMISET), 180

People's Democratic Movement [Papua New Guinea] (PDM), 162

Philippines, 28

PKF. See peacekeeping forces (PKF)

Poland, 31

Policía Nacional de Timor-Leste (PNTL), 181, 184, 193-94, 196-98, 201-2

Porter, Elisabeth, 215

post-traumatic stress disorder (PTSD), $375-76$

prostitution

DRC, 86

Northern Ireland, 223, 238

Papua New Guinea, 147, 163, 165

Sierra Leone, 74-75

Timor-Leste, 201

Rassemblement des Congolais pour la Démocratie (RCD), 83-84, 89, 95-96

RCD-Mouvement de Libération (RCD-ML), 89

Recovery, Employment and Stability Programme for Ex-Combatants and Communities in East Timor (RESPECT), 194, 203

Regina, Anna, 400

República Democrática de Timor-Leste (RDTL), 178, 182, 185, 195, 205

Revolutionary United Front [Sierra Leone] (RUF), 8, 51-69, 72-73, 75-76

ritual arts group (RAG), 189, 196

"The Role of Men and Boys in Achieving Gender Equality" (UN), 111

Royal Papua New Guinea Constabulary (RPNGC), 149, 162, 167

Royal Ulster Constabulary (RUC), 214, 226, 242

Rwanda

armies, $82-83$

arms embargo, violation of, 83

arms embargo by UN Security Council, 92, 94

arms for DRC, 89, 92 arms for groups committing grave human rights violations, 92

arms imports from Albania and Bosnia, 92

conflict, 81

Democratic Liberation Forces of Rwanda (FDLR), 84, 89

DRC, assistance to, 83

General Nkunda and arms from, 84 genocide, $82,84,439$

Hutu, 89

International Criminal Tribunal for Rwanda (ICTR), 87

Saado Abdi Amare, 372-75

Saint-Germain, Michelle, 228

Sales, Rosemary, 215, 235, 237

Sasson-Levy, Orna, 267

Scotland

feudal rivalry, 222

Gun Control Network, 40

hand gun ban after murder of school children, 40

security sector reform (SSR)

disarmament, demobilization and reintegration and, 425, 428

Papua New Guinea, 169

Timor-Leste, 11

Uganda, 412

self-loading rifle (SLR), 157-58, 393

sexual assault armed, 20-21

in industrialized countries, 21

PNG, 147, 153-54, 163

Sierra Leone, 57, 62-63, 73

South Africa, 21, 299

sexually transmitted disease (STD), 164, 401 sexual slavery

DRC, 9, 87, 91

Sierra-Leone, 57-58

Timor-Leste, 179-80, 199-200

sexual violence

Albania, Cambodia and Mali, 346

DRC, 84, 89-90, 97-98

gender, attitudes and regulation of small arms, 21

gendered impacts of prolific small arms, 9-10

Geneva Conventions, 86

Haiti, 120-21, 124, 132-33, 138

PNG, 10, 163-64, 167 
sexual violence (cont.)

Sierra Leone, 57, 72

Somalia, 376

South Africa, 315-16

Timor-Leste, 188, 198, 201-2

Uganda, 391

Shadmi, Erella, 254, 258-59, 264

Sharoni, Simona, 212

Shiloni, Ehud, 274-75

Sierra Leone

Avtomat Kalashnikova 1947 (AK-47), 53, 58,70

"bush marriages", 57-58

child combatants, demobilization, 69-70

child recruitment and illicit drugs, 60

child soldiers, 53-56, 68-69, 76

Civil Defence Forces (CDF), 53, 66

corruption, 51,72

culture of violence, $8,61,65$

disarmament, demobilization and reintegration (DDR), 70-73

female combatants, 70-71, 76, 78

female resistance and solidarity, 65-67

girl combatants: under-reported and misunderstood, 53-54

girl ex-combatants and marginalization in aftermath of conflict, 69-75

girls, recruitment of, 55-56

girl's initiation into small arms use and armed conflict, 55-61

girls in RUF, multiple roles of, 56-58

girls in RUF: drifting between

victimization and violence perpetration, 61-65

girl's struggle to survive: duality of structure and agency, 67-69 human immunodeficiency virus (HIV), 77 marginalization and survival in post-war, 73-75

militarized masculinity, 67-69

non-governmental organization (NGO), $54,73-74$

patriarchal hierarchies, traditional, 64, 68 power from guns and acts of violence, 63-65, 68-69, 76

prostitution, 74-75

Revolutionary United Front (RUF), 8, $51-69,72-73,75-76$

sexual assault, 57, 62, 65, 73

sexual services to the men and boys, 57

sexual slavery, $57-58$ sexual violence, 57,72

small arms and civil war, 51-53

small arms and light weapons (SALW), 52

small-arms proliferation, 51,53

UN arms embargo, 52

UN Convention on the Rights of the

Child, 77, 436

unemployment, 74

UN Mission to Sierra Leone

(UNAMSIL), 70

victimization of girls by acts of murder,

torture and rape, 54, 61, 63, 65, 70, 76

Women in Development (WID), 78

Singer, Roni, 258-59

Sinn Féin, 218, 232, 234

small arms and light weapons (SALW)

Albania, 335-36, 338

Albania, Cambodia and Mali, 330-31, 335

Cambodia, 340

DRC, 92

gender, attitudes and regulation of small arms, 43

gendered impacts of prolific small arms, $3-7,10,13$

Haiti, 130

Israel, 248, 261

New Guinea, 143, 149

Northern Ireland, 211-13, 216-24, 239, 241

Sierra Leone, 52

Somalia, 358-60

South Africa, 291, 297

Timor-Leste, 178, 181-85, 196, 198-99, 202, 204-5

Small Arms and Light Weapons Control project [Albania] (SALWC), 335, 338

small-arms proliferation

Israel, 12, 248, 252, 272

Papua New Guinea, 143

Sierra Leone, 51, 53

Somalia, 357-62, 386

South Africa, 316-17, 321

Uganda, 15, 390, 396-402, 407, 411

Small Arms Survey

Israel, 277

PNG, 150, 154, 156

Somalia, 361

small-arms violence

Haiti, 9, 109-42

Somalia, $372-80$ 
South Africa, 290-92, 303-4, 306, 309-10, $312,319,321-22$

Timor-Leste, 9, 177-208

Snowdrop Petition, 39

Somalia

Academy for Peace and Development (APD), 361, 369, 378

Amare, Saado Abdi, 372-75

armed groups, composition of, 380-81

Barre, Siad, 362, 370, 382

Borama peace deal, 381-83, 385

Bradbury, Mark, 364, 371

Bryden, Matt, 366, 369, 371

child soldiers, 381

clan alliance and gender victimization, 376

clan-based militia war, 386-87

data environment, 360-62

domestic violence, 377-78

elders provide functional justice system, 367

family violence, 378

female combatants, 380

gender roles, 381, 385

German Technical Cooperation Agency (GTZ), 358-59, 362, 367, 375, 378, 380, 382

gun culture, 370, 386

guns defend traditional views of women, 368-69

identity, female, 376-77, 381

identity, male, 368, 376-77, 381, 386

Intergovernmental Authority on

Development (IGAD), 356, 360

Jamane, Dhudi Axmed, 383-85

law of bloodshed (xeerka dhiigga), 364-65

National Advisory Council on the Control of Firearms (NACCOF), 367

non-governmental organization (NGO), 383, 396

oral poetry, $15,358-59,362-64$

peacebuilding, drivers of, 381-86

post-traumatic stress disorder (PTSD), $375-76$

rape, $374,376,382$

sexual violence, 376

small arms and light weapons (SALW), $358-60$

small arms and light weapons, proliferation of, 359-90 small-arms trade, 369-72

small-arms violence, $372-80$

social sanctioning of violence and smallarms control, 364-69

Somalia Delegation of the International Red Cross/Red Crescent, 364-65

Somali National Movement (SNM), 359, 373

Somali Women's Development Association (SOWDA), 383

"Survey on Small Arms in Somaliland" (APD), 361, 369, 378

UN Children's Fund (UNICEF), 361, 378, 381

UN Development Fund for Women (UNIFEM), 382

UN Panel of Experts, 360, 370

victimization, 358, 376, 386

Watching Brief, 361, 367, 378

women and trafficking of small arms and ammunition, 370-72

women's umbrella organization in Somaliland (NAGAAD), 370-71 $x e e r$ and women, 366

Somali National Movement (SNM), 359, 373

Somali Women's Development Association (SOWDA), 383

South Africa acquired immune deficiency syndrome (AIDS), 298, 317

actions towards change, $318-20$

African National Congress (ANC), 293, 295-96

apartheid violence and gender inequality, historical foundations of, 292-96 arms trade to DRC, 94

arms trade to Sierra Leone, 52

arms trade to Somalia, 359

arms trade to Uganda, 92

Bamako Declaration on an African Common Position on the Illicit Proliferation, Circulation and Trafficking of Small Arms and Light Weapons, 297, 433

Black Sash, 41, 295, 319

"Books Not Bullets" project, 318

case study: gendered labour and human security, 304-18

Child Accident Prevention Foundation of South Africa, 41 
South Africa (cont.)

Commission on Gender Equality (CGE), 319-20

corruption, 298

decommissioning of weapons, 297

Disabled People of South Africa, 41

domestic labour, institution of, 304-5

domestic labour and human security, 305-8

domestic violence, $21,24,41,299,301-2$, 303, 311, 319-20

Domestic Violence Act, 41, 301, 319

domestic workers, trafficking in, 315-17

"Every Six Days... Do Something" campaign, 320

femicide, 298, 301, 303, 310-11, 320

Firearms Control Act, 297, 319

gangs, 297, 317

Gender Advocacy Programme (GAP), 302,320

gender and small arms, 298-301

gender-based violence, 14, 290, 293, 299 , $305,317,320$

Gender Machinery, 291, 295

gender violence, private nature of, 302-3

Gun Control Alliance (GCA), 41, 296, 309, 318

gun culture, 299, 313

Gun Free, 39, 41, 298, 319

human immunodeficiency virus (HIV), 298, 317

Human Rights Institute of South Africa, 41

human rights violations, 316

human security, 291, 297, 299-300, 304-21

implications, related, $317-18$

insecurity of society, $297,307,310-11$

legislation for exclusion of domestic workers from unemployment insurance, 319

legislation protecting women from smallarms violence, 319

Mannenberg mural project, 302, 318

"Men's Summit" in Cape Town, 320

poverty and violence, 298

private household space, 13-14, 292-94, 302-11, 314

private security companies, 297

private security systems, 314-15

Quaker Peace Centre, 41 rape, 291, 293, 298-99, 313, 316, 319

"rape capital of the world", 299

raskolism (gangsterism), 10, 297

security and emotional labour, 313-14

sexual assault, 21, 299

sexual violence against women, 315-16

shootings of women, non-fatal, 24

small-arms and gender-based violence, high rates of, 14

small arms and light weapons (SALW), 291, 297

small arms and security in post-apartheid, 296-98

small-arms proliferation, 316-17, 321

small-arms violence, 290-92, 303-4, 306, 309-10, 312, 319, 321-22

socio-economic divides and human security, 308-9

South African Association of Youth Clubs, 41

South African Defence Force (SADF), 260, 293-94

South African National Defence Force (SANDF), 296-97

South African NGO Coalition, 41

Truth and Reconciliation Commission, 293, 296

Umkhonto we Sizwe (MK), 296

UN arms embargo, 296

unemployment, 298, 303, 319

Unicity's Safer Cities Programme, 302

vigilante groups, 297

violence against women, 312, 319-20

vulnerability within the private home, 309-13

Women's National Coalition, 295, 318 young men, economically and socially disempowered, 399

South African Defence Force (SADF), 260, 293-94

South African National Defence Force (SANDF), 296-97

Southern Highlands Province [Papua New Guinea] (SHP), 154, 163

Steel, Jayne, 239

Steiner, 366, 369, 371

submachine gun (SMG), 239, 393

Sudan

arms smuggling into Uganda, 392

commercial cattle raiding and banditry, 392 
Didinga tribe, 392

DRC, alliance with, 83

sexual abuse as intimidation strategies in conflicts, 20

Women's Peacebuilding in, 120

Sudanese People's Liberation Army (SPLA), 92

Tentara Nasional Indonesia (TNI), 178-81, 183, 191-92

Teso-Karamoja Women's Initiative for Peace (TEKWIP), 410

Timor-Leste

Amnesty International (AI), 181, 198, 200

Angkatan Bersenjata Republik Indonesia (ABRI), 178-79, 181, 183, 191-92

Comissão de Acolhimento, Verdade e Reconciliação do Timor-Leste (CAVR), 199

corruption, 192, 197

culture of violence, 188

DDR process, post-conflict, 193-97

domestic violence, 188, 198, 200-201

Falintil-DDR process and build-up of new security forces, 193-94

Falintil-Forças de Defesa de Timor-Leste (F-FDTL), 181, 184, 193-94, 196-98, 202

Falintil Reinsertion Assistance Program (FRAP), 194

formed police unit (FPU), 180

gang rape, 198

gang violence and political instability, 11 gender, social construction of, 186-93 gender-based violence, 200

gender ideologies in society, 186-88 gender ideologies within the pro-

Indonesian militia groups, 191-93

gender mainstreaming and new security forces, 197-99

gender politics within the Falintil, 190-91

gender roles, 11, 186, 188

insecurity of society, $11,184-85,189$, 203

integration of ex-combatants into the new security forces, 194-96

internally displaced person (IDP), 177, 184, 201

International Force for East Timor

(INTERFET), 180-81, 183, 185
International Stabilization Force (ISF), $177,180-81,184$

legislation for ownership, import, export, display and use of firearms,

ammunition, explosives and offensive

weapons, 185

masculinity and violence, $188-90$

militarized masculinity, 191-92, 197

Policía Nacional de Timor-Leste (PNTL), 181, 184, 193-94, 196-98, 201-2

post-conflict violence and SALW, 183-85

power from guns and acts of violence,

183-84, 186, 197, 202, 204

rape, $179-80,184,188,198-201$

raskols, 185

Reinado, Major Alfredo, 180-81, 184, 187, 195

República Democrática de Timor-Leste (RDTL), 178, 182, 185, 195, 205

security sector problems, 196-97

sexualized violence during and after conflict, 199-201

sexual slavery, 179-80, 199-200

sexual violence, male-to-male, 188

sexual violence against women, 188, 198, 201-2

small arms and domestic and indiscriminate violence, 426

small arms and light weapons (SALW), 178, 181-85, 196, 198-99, 202, 204-5

small-arms violence, 9, 177-208

Tentara Nasional Indonesia (TNI), 178-81, 183, 191-92

unemployment, 189

UN Mission of Support in East Timor (UNMISET), 180, 187, 203

UN Police (UNPOL), 180, 184-85, 198, 201

UN Security Council Resolution 1325, 195, 203

UN Transitional Administration in East Timor (UNTAET), 180, 182, 184-85, 187, 193-96, 200, 202-3

violence against women, 183

violence and socially constructed meanings of SALW, 182-83

women in the new security forces, 197-99

Transitional Federal Government [Somalia] (TFG), 356

Truth and Reconciliation Commission [South Africa], 293, 296 
Uganda

acquired immune deficiency syndrome

(AIDS), 401

African Union peacekeeping mission, 356

Anti-Stock Theft Unit (ASTU), 396

arms embargo violations in DRC, 83, 91-92, 94

arms from North Korea, 92

arms from Russia and Ukraine, 92

arms from South Africa, 92

arms smuggling, 392

Avtomat Kalashnikova 1947 (AK-47), 393-94, 399

bride wealth and cattle ownership, 397-98

Broch-Due, Vigdis, 398

cattle raiding, 392-94, 407

corruption, 405, 408

decommissioning of weapons, 391, 404, 409

disarmament incentives, 405, 407-10

domestic violence, 411

DRC, assistance from, 83

gender roles, 393

guns and "bride price", 396-97

guns for cattle rustling, 334, 394, 399-400, 402

home-made guns (amatida), 393

human immunodeficiency virus (HIV), 401

human rights violations, 406, 410

human trafficking, 400

identity, male, 407-8, 432

insecurity of society, 392, 394, 400, 402

inter-ethnic conflict between Karamojong and neighbours, 403

internally displaced person (IDP), 393, 403

International Crisis Group, 120

inter-tribal clashes, 392

Kaabong Women's Group Organization

(KAWOGO), 396, 400

karacuna (virile protector of the tribe and family), 397, 399

Karamoja, disarmament in, 402-9

Karamoja, voluntary disarmament, 403-5

Karamoja conflict, the agency of women in, 393-96

Lord's Resistance Army (LRA), 393, 407, 409, 412

Loumo, Grace, 396

micro-disarmament, 16, 390, 409, 411, 438
Mukula, Captain Michael, 403

Museveni, President Yoweri, 403-4, 406

ngaberu (women), 391, 395, 404

ngapesur (female youth), 391, 404

ngikaracuna (male youth), 391, 393-95,

397-99, 402, 404, 408-10

ngikasikou (elders), 391, 404

non-governmental organization (NGO), 401-2, 404-6

Operation Iron Fist, 407-8

Organization for African UnityInterAfrican Bureau for Animal

Resources (OAU-IBAR), 395

rape, 401, 403, 406, 408, 410

security sector reform (SSR), 412

sexual violence, 391

small arms and domestic and

indiscriminate violence, 426

small-arms collection programmes, 6, 15

small-arms proliferation, 15, 390,

396-402, 407, 411

Teso-Karamoja Women's Initiative for Peace (TEKWIP), 410

Uganda Human Rights Commission (UHRC), 406

Uganda People's Defence Force (UPDF), 92, 392, 395, 406, 409-10

urban élite, 391

weapons and acquisition of wealth and status, 397-98

weapons and a warrior culture, 393

weapons collection programmes, 6 ,

14-16, 390-91, 403-4, 406-9, 426

woman's role in raids, smuggling and small-arms trade, 394-95

women as intelligence gatherers, 395-96

Uganda Human Rights Commission (UHRC), 406

Uganda People's Defence Force (UPDF), 92, 392, 395, 406, 409-10

Ulster Defence Association (UDA), 222-23, 235, 237-38

Ulster Freedom Fighters (UFF), 222-23, 238

Ulster Volunteer Force (UVF), 222, 225-27, 234-37

Umkhonto we Sizwe [South Africa] (MK), 296

UN arms embargo

DRC, 83, 91-95, 99

Sierra Leone, 52 
Somalia, 364

South Africa, 296

UN Children's Fund (UNICEF)

Albania, Cambodia and Mali, 331

Israel, 289

Papua New Guinea, 165

Somalia, 361, 378, 381

UN Conference on the Illicit Trade in Firearms in All Its Aspects, 28, 434

UN Convention on the Rights of the Child, 77,436

UN Declaration on the Elimination of Violence against Women, 110

UN Development Fund for Women (UNIFEM)

Albania, Cambodia and Mali, 339

Somalia, 382

UN Development Programme (UNDP)

Northern Ireland, 219

Somalia, 358

Timor-Leste, 194

UN Educational, Scientific and Cultural Organization (UNESCO), 31

unemployment

Israel, 251, 255-56, 265-66, 274-75

Sierra Leone, 74

South Africa, 298, 303, 319

Timor-Leste, 189

UN Human Rights Commission on Violence against Women, 96

União Democrática Timorense (UDT), 179

UN Integrated Mission in Timor-Leste (UNMIT), 180, 184

UN Interregional Crime and Justice Research Institute (UNICRI), 153

Union of Congolese Peoples (UPC), 89, 91-92

United Kingdom, See also Northern Ireland domestic violence, 40

family feuds, 222

firearms legislation, strengthening, 26

gun violence and murder of women, 40

Northern Ireland and, 213-14, 221, 239

Northern Ireland conflict and casualties, 213

small arms, regulation of, 39

Snowdrop Petition and Gun Control Network, 39

women's groups and campaign to ban handguns, 40
United States (US)

American Academy of Pediatrics, 30-31

American gun lobby, 28

arms supplier to African states, largest, 91

arms supplier to Haiti, 120

arms supplier to Sierra Leone, 52

arms supplier to Somalia, 359

culture of violence and Bowling for

Columbine documentary, 31

culture of violence vs. Canada, 31, 34

domestic violence, 21-22, 25-26, 34-35, 273

female sexual abuse and homicides, 22-23

femicide rates, 22

firearm ownership among women, 33

firearms and masculinity in television and film, 31-32, 35

firearms controls relaxed, 29

gender split and Brady Bill, 37

gun control, resistance to, 35-36

gun culture, 32

gun laws, relaxed, 36-37

gun lobby, 28, 35

gun makers and notions of femininity,

32-33

gun makers and notions of masculinity, 32

gunplay in American movies, "mythic"

constructions of, 32

gun-related violence, 35

Marlboro Man, 32

men and gun ownership levels, 18

methods of violence exported to

Indonesia and Central America, 199

Million Mom March, 33, 39, 41

National Rifle Association (NRA), 31-33, 35

"right to keep and bear arms" vs. Second Amendment, 27-28, 32

security guard levels, 251

sexual assault, 21

spousal homicides by men, 21-22

terrorism, preoccupation with, 253

victim services $v s$. law enforcement

officials and judges, 273

violence against women, 25-26, 28, 274

violence restraining order, 26

violent entertainment and murder rate of young blacks, 30

Women Against Guns, 40-41

women and stricter gun laws, 37 
United States (US) (cont.)

women from minority groups at higher risk, 274

women killed with small arms per day, 21

UN Mission of Support in East Timor (UNMISET), 180, 187, 203

UN Mission to Sierra Leone (UNAMSIL), 70

UN Office in Timor-Leste (UNOTIL), 180, 193

UN Operation in Somalia (UNOSOM), 371

UN Panel of Experts

DRC, 92-93

Somalia, 360, 370

UN Police (UNPOL)

Timor-Leste, 180, 184-85, 198, 201

UN Secretary-General

Democratic Republic of the Congo (DRC), 98

UN Small Arms Expert Panel, 42

UN Stabilization Mission in Haiti (MINUSTAH), 10, 110-11, 113, 117, 129, 138

UN Transitional Administration in East Timor (UNTAET), 180, 182, 184-85, 187, 193-96, 200, 202-3

US Agency for International Development (USAID), 88

DRC, 88-90, 95

Timor-Leste, 194

van Creveld, Martin, 212

violence against women

Amnesty International (AI), 41-42

in Brazil, 41

in Canada, 25, 39

Control Arms Campaign and safety of women, 42

as a crime, 7

DRC, 96-97

firearm regulation, 25

Haiti, 9, 110-12, 119-22, 124-26, 131, 133

Inter-American Convention on the

Prevention, Punishment and

Eradication of Violence against

Women [Haiti], 110-11

Israel, 12, 248-50, 269-70, 272

legislation shapes values and norms, 33

L.O. Combat Violence Against Women [Israel], 270, 272
Northern Ireland, 221

Papua New Guinea, 144, 147, 153, 160, 163-64, 167, 426, 429, 431

patriarchal militarized societies and, 269

small-arms and, 19, 27

South Africa, 312, 319-20

Timor-Leste, 183

UN Declaration on the Elimination of

Violence against Women, 110

UN Human Rights Commission on

Violence against Women, 96

in United States, 25-26, 28

Waffen-Weg [Austria], 39

Ward, Margaret, 215

War-torn Societies Project (WSP), 361, 382

Watching Brief, 361, 367, 378

weapons collection programmes

Albania, 336-40, 346-47, 352

Albania, Cambodia and Mali, 6, 329-33, 335, 345-52

Cambodia, 340-41, 346-48, 352

components of, 335

DRC, 38

El Salvador, 330

Liberia, 38

Mali, 39, 343-44, 346-47, 349, 352

SALW in the domestic sphere and, 6

Uganda, 6, 14-16, 390-91, 403-4, 406-9, 426

UNIDIR's WfD project and PM\&E

techniques, 332

voluntary, 330

women take lead in disarmament and, 38

weapons for development (WfD)

Albania, 335, 339-40

Albania, Cambodia and Mali, 14, 330-32, 335-45, 339, 348

Mali, 342-44

Weapons in Exchange for Development programme (WED), 335, 338

Windhoek Declaration, 16, 438

Women Against Guns [US], 40-41

Women in Development (WID), 78

Women's International League for Peace and Freedom (WILFP), 41

Women's National Coalition [South Africa], 295,318

women's umbrella organization in Somaliland (NAGAAD), 370-71 
Women Waging Peace, 38, 435

World Health Organization (WHO), 21, 88

Yugoslavia

International Criminal Tribunal for the Former Yugoslavia (ICTY), 87 sexual abuse as intimidation strategy in conflict, 20

women's role and weapons at home, 337

Yuval-Davis, Nira, 215-16, 229

Zohar, Hanna, 256 
